LBL-2299

UC-2 General, Miscellaneous, and Progress Reports

TID-4500-R6I

\title{
INORGANIC MATERIALS RESEARCH DIVISION ANNUAL REPORT, 1973
}

April 1974

Lowrence Berkeley Loboratory University of Colifornio Berkeley, Colifornio 
Work done under

U.S. Atomic Energy Commission

Contract No. W-7405-eng-48

Printed in the United States of America

Available from

Nationa! Technical Information Service

U.S. Department of Commerce

5285 Port Royal Road

Springfield, Virginia 22151

Price: Printed Copy \$7.60; Microfiche \$1.45 
I. CHEMISTRY

A. Inorganic Chenistry

Wiltiam L. Jolly, Principal Inveatigator

1. Estimation of Atomic Charges by an Electronegativity Equalization

Procedure Calibratted with Core Binding Energies

2. Reactions of the Heptasulfur Imide Anion . . . . . . .

3. The Reaction of Hydrogen with Copper (I) in Liquid Ammonia-Amide

4. The Reaction of Potassium Germi with Boron Trimethy $\ldots \ldots \ldots 4$

5. Research Plans for Calendar Year $1974 \ldots \ldots \ldots$

6. 1973 Publications and Reports ................ 5

Robert E. Connick, Principal Investigator

1. Oxygen-17 NR Studies of the Rate of Water Exchange from Partially

Complexed Nickel Ion . . . . . . . . . 7

2. The Exchange Lifetime of Water Molecules in the Second Coordination Sphere of Chrumic Ion . . . . . . . . . . . . . 7

3. Computer Simulation of jolvent Exchange with the First Coordination Sphere of Metal Ions .............. 7

4. Research Plans for Calendar Year $1974 \ldots \ldots$. . . . . . . . 7

5. 1973 Publications and Reports .................. 8

Neil Bartlett, Principal Investigitor

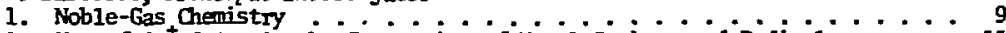

2. Use of $\mathrm{O}_{2}^{+}$Salts in the Generation of Novel Cations and Radicals . . . II

3. High Oxidation States of the Heavy Elements ............ 12

4. Research P1ans for Calendar Year 1974 ............... 12

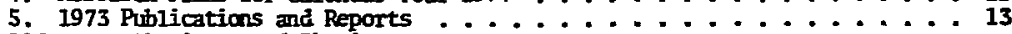

B. Solid iste Chemistry and Physics

Borman B. Pinillips, Frincipal Irvestigator

I. Heat Capacity of the Kondo-Superconfuctor $(\mathrm{La}, \mathrm{Ce}) \mathrm{Al}_{2} \ldots \ldots$. . . . . 15

2. Heat Exacity of the Singlet-Ground-State Systems PrCu2,

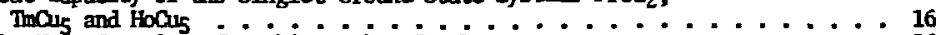

3. The Heat Capacity of Terbium Ethyi Suiphate $\ldots \ldots \ldots \ldots \ldots$ i6

4. The Low-Temperatire Heat Capacity of Natrolite $\ldots \ldots \ldots$

5. Hagnetic Field Dependence of the Low-Temperature Heat Capacity

of Neodyium ..................... 17

6. Research Plans for Calendar Year $1974 \ldots \ldots \ldots \ldots$

7. 1973 Publications and Reports ................. I8

George Jura, Frincipal Investigator

1. Heat Capacities of Hetals Under High Pressure ............. Ig

2. Optical Studies of Solids Under High Pressure ............ 19

3. Heat Capacity of Bismuth at High Pressure ............... 21

4. Research Plans for Calendar Year $1974 \ldots . . . . . . . . . .22$

Gabor A. Somorjai, Imineipal Investigator

1. Low Energy Electron Diffraction (LEFD) Studies of Surfaces . . . . . . 23

2. Auger Electron Spectroscopy of Surfaces ............... 24

3. Catalysis by Single Crystal Sirfaces . . . . . . . . . . . 25

4. Mblecular bean Seattering from Surfaces $\ldots \ldots \ldots$

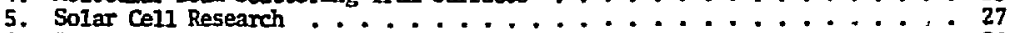

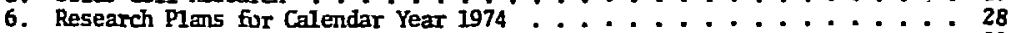

7. 1973 publications and Reports . . . . . . . . . . 29

Lee F. Doraghey, Prineipal Inveatrigator

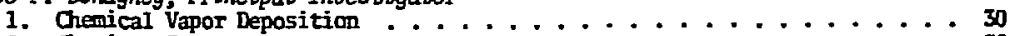

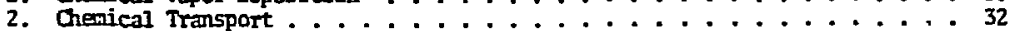

3. Crystallization . . . . . . . . . . . . . 33

4. Sputter Deposition . . . . . . . . . . . . . 33

5. Solid-State Eectrochenistry $: \ldots 33$

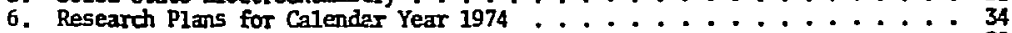

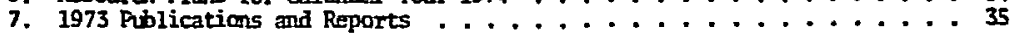


C. Electrochenistry

Chartes V. Tobias, Princifal Investigaton

1. Fundamental Studies of Ionic Mase Transport . . . . . . . . . . . . . 36

2. Electrolysis at High Current Densities . . . . . . . . . . . . 37

3. Electrochemistry in Nonaqueous Solvents . . . . . . . . . . . 40

4. Research Plans for Calendar Year $1974 \ldots . . . . . . . . . . . . .440$

5. 1973 Publications and Reports . . . . . . . . . . . . . . . . 40

Rolf $H$. Muller, Principal Investigator

1. Optical Studies of Interfacial Phenomena . . . . . . . . . . . . . 42

2. Hydrogen Econany ................................ 45

3. Research Plars for Calendar Year $1974 \ldots . . . . . . . . . . .45$

4. 1973 Publications and Reports . . . . . . . . . . . . . . . 46

Join Reumon, Erincipal Investigator

1. Current Distribution on a Rotating sphere Below the Limiting Current .. . . 47

2. The Short-Time Response of a Disk Electrode . . . . . . . . . 47

3. Measurement of the Transient Response of a Disk Electrode . . . . . . . . 48

4. Transient Convective Diffusion to a Disk Electrode ......... 49

5. Rotating Ring-Disk Electrodes . . . . . . . . . . . . . . . . 49

6. Mass Transfer to a Piane Below a Rotating Disk . . . . . . . . . . . 50

7. Mass Transfer to a Rotating Disk Electrate in the Region of Transition to Turbulent Flow ................ 50

8. Mass Transfer in Porous Electrodes .................. 50

9. Steady State Current Distribution on a Rotating Disk Below the Limiting Current for a Redox Reaction . . . . . . . . . . . . . 51

10. The Removal of lead Ions from very Dilute Solutions Using a Pcrous

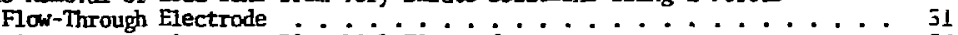

11. Admittance Coupling on a Ring-Disk Electrode $\ldots \ldots \ldots$

12. Research Plans for Calendar Year $1974 \ldots . . . . . . . . . . .53$

13. 1973 Publications and Reports . . . . . . . . . . . . . . 53

D. Physical Chemistry

Lec Brewer, Prineipal Investigator

1. Thermodynamic Properties of Third and Fourth Group Transition Metals with Piatinum Group Metals ................ 55

2. Application of the Regular Solution Theory to Betailic Solutions . . . . 55

3. Thermodynamic Evaluation and Compilation of Metal Alloy Systens . . . . . 55

4. The Matrix Spectra of $\mathrm{Ca}$ with $\mathrm{O}, \mathrm{O}_{2}$, and $\mathrm{N}_{2} \mathrm{O} \ldots \ldots . . \ldots 5$

5. Research Plans for Calendar Year $1974 \ldots . . \ldots$. . . . . . . . 55

6. 1973 Publications and Reports . . . . . . . . . . . . 56

Charies B. Barris, Principal Investigator

1. Exrited Triplet States in Molecules and Molecular Crystals . . . . . . . 57

2. Optical Detection of Coherence in Molecular Excited Localized and Delocalized Bond States ................. 57

3. Exciton-Trap Interactions in the Coherent and Incoherent Limits . . . . . . 58

4. The Decay of Localized States into Delocalized Band States . . . . . . . . 59

5. The Theory of 0ptically Detected Spin Coherence in Excited Triplet

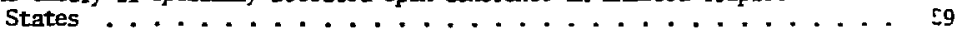

6. The Theory of Optically Detected Spin Coherence in Non-Stationary

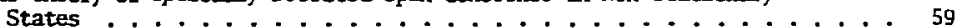

7. Optically Detected Carr-Purceli Trains and Coherent Averaging Theory : . . 59

8. Opticaily Detected Spin Locking and Its Applications to Kinetic Phenonena .................... 60

9. Optically Detected Adiabatic Demagnetization in Excited Triplet States in Zero-Field and the Ayplication to Kinetic Phenomena . . . . . 60

10. Cptically Detected Rotary Echo Trains in Excited Triplet States . . . . . 60

11. Dicosecond Spectroscopy: Coherence in Vibrational Relaxation . . . . . . . 60

12. Energy and Electron Transfer in Photosynthetic Bacterial Systems . . . . 6I

13. Research P1ans for Calendar Year 1574............... 61

14. 1973 Publications and Reports . . . . . . . . . . . . . . 62 
Alexander Dines, Principal Investigator

1. Nuclear Magnetic Double Resonance Spectrometer . . . . . . . . . . 63

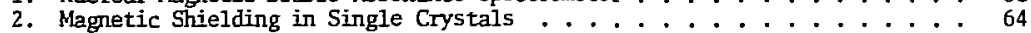

3. Dynanics of Nuclear Magnetic Double Resonance : . . . . . . 67

4. Long-Lived Nuclear Spin Transients in Solids . . . . . . . . . 68

5. Spin Thermodynamies in Time-Dependent Fields . . . . . . . . . . . . 69

6. Research Plans for Calendar Year $1974 \ldots \ldots$. . . . . . . . . . 70

7. 1973 Publications and Reports ................ 71

Ronald R. Herm, Principal Investigator

1. Crossed Beams Chenistry: Alkaline Earth Atom Reactions . . . . . . . . 72

2. Photodissociation of $\mathrm{NaBr}$, NaJ, and $\mathrm{KI}$ Vapors and Collisional Quenching of $\mathrm{Na}^{\star}\left(3^{2} \mathrm{P}\right), \mathrm{K}^{\star}\left(4^{2} \mathrm{P}\right)$, and $\mathrm{K}^{\star}\left(5^{2} \mathrm{P}\right)$ by foreign Gases . . . . 73

3. Energy Dependence of Sensitized Fluorescence: $\mathrm{Hg}^{\star}+\mathrm{TI}+\mathrm{Hg}+\mathrm{T}^{\star} \ldots \ldots 74$

4. Collision Dynamics Involving Metal Atons . . . . . . . . . . . 76

5. Research Plans for Calendar Year $1974 \ldots \ldots$. . . . . . . . . . 76

6. 1973 Publications and Repc rts . . . . . . . . . . . . . 76

Ilarola S. Johnston. Principal Inveatigator

1. Experimental Studies . . . . . . . . . . . . . . . 78

2. Theoretical Studies .......................... 80

3. Research Plans for Calendar Year 1974 . . . . . . . . . . . . . . . 83

4. 1973 Pwilications and Reports . . . . . . . . . . . . . 83

Bruce $B$. Mahon, Frincipal Invesizigetor

1. Dymamics of the $\mathrm{O}^{+}-\mathrm{H}_{2}$ Reaction: Reactive Scattering at Relative Energies above $15 \mathrm{eV}$. 2 Reaccilon: Reactivescattering at Relative Energies

2. Analytical Treatment of the Sequential Inpulse Model for Chemical Reastion .................... 86

3. Dynamics of the $\mathrm{C}^{+}-\mathrm{H}_{2}$ Reaction . . . . . . . . . . 86

4. Large Angle Inelastic Scattering of $\mathrm{Na}^{+}$by $\mathrm{D}_{2} \ldots \ldots 7$

5. Dynamics of the $\mathrm{N}^{+}-\mathrm{H}_{2}$ Reaction at Low Energies . . . . . . . . 88

6 . Research Plans for Calendar Year $1974 \ldots . . . . . . . . . .88$

7. 1973 Publications and Reports . . . . . . . . . . . 88

Filliam H. Uiller, Principal Investigator

1. Improved Classical Path Approximation for the Boltzmann Density Matrix . . . . . . . . . . . .

2. Potential Cirves and Inelastic Crass Sections for Low-Energy

3. Partial Averaging in Classical S-Matrix Theory: vibrational Excitation of $\mathrm{H}_{2}$ by $\mathrm{He}$.................... 91

4. Penning and Associative Imization of Triplet Metastable Helium Atoms . . 92

5. Research Plans for Calendar Year $1974 \ldots \ldots . \ldots 3$

6. 1973 Publications and Reports . . . . . . . . . . . . . 93

Rolitie J. Syers, Frincipal Investigator

1. Molecular Field Effects in Electron Paramagnetic Resonance Spectroscopy ...................... 95

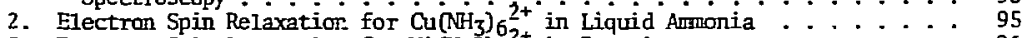

3. Electron Spin Relaxation for $\left.\mathrm{Ni}^{\left(\mathrm{H}_{2} \mathrm{C}\right.}\right)_{6}{ }^{2+}$ in Solution ......... 96

4. Electron-Electron Double Resonance for Two Radicals in Solution . . . . 99

5. Electron Paramggnetic Resonance Spectra of Radical Anions in . . . . . . 98

6. Research PIans for Calendar Year $1974 \ldots . . \ldots$. . . . . . . . . 98

7. 1973 Plolication. . . . . . . . . . . . . . . . 98

Kenneth 3 . Fitzer, Erincipal Investigator

1. Solutions of Electrolytes . . . . . . . . . . . . . . . 99

2. Muclear Spin Species Effects in the Heat Capacity of $\dot{\mathrm{CH}}_{4} \ldots \ldots . . . .299$

3. Anomalous Internal Notions in Molecules .............. 99

4. Research Plans for Calendar Year $1974 \ldots \ldots$. . . . . . . . . 100

5. 1973 Publications and Reports . . . . . . . . . . . . 100 
E. Nuclear Science

Donald R. Olander, Principal Inveatigator

1. Isotope Exchange of Water Vapor on Pyrolytic Graphite . ......... 102

2. The Oxidation of Anmonia by $\mathrm{O}_{2}$ on Polycrystalline Platinum by

Modulated Molecular Bean Mass Spectrometry . . . . . . . . . . . . . . . 102

3. The Themal Accomodation Coefficients of Helium and Xenon on $\mathrm{HO}_{2}$

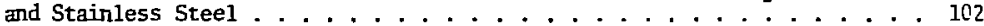

4. Diffusion of ianthanum іл Molten Uraniurn . . . . . . . . . . . . . . . 103

5. Oxygen Redistribution in Ceramic Nuclear Fuels ............ 103

6. The Conservation Equations Governing Porosity and Actiride Redistribution in Mixed Oxide Fuels ................. 104

7. The Kinetics of Actinide Redistribution by Vapor Migration in Mixed Oxide Fuels (I), By Cracks . . . . . . . . . . . . . . . 104

8. The Kinetics of Actinide Redistribution by Vapor Migration in Mixed oxide Fuels (II). By Pores . . . . . . . . . . . . . 105

9. The Shape of the Doppler-Broadened Spectral Lines Produced by Light-Atom Bontatdnent of Metals . ................. 105

10. Reseatch Plans for Calendar Yea $1974 \ldots \ldots$. . . . . . . . . . 105

11. 1973 Publications and Reports . . . . . . . . . . . . . . . 105

II . METALLURGY

A. Crystal Imperfections

Jack Habhburn, Principal Investigator

1. Transmission Electron Microscope Investigation of the Growth of Copper Precipitate Colonies in Silicon . . . . . . . . . . . . . 109

2. Determination of Loup Type in $\mathrm{As}^{+}$Iroplanted Silicon . . . . . . . . . . . 109

3. Memory Switching Effects in As-Te-I Chalcogenide Glass . . . . . . . . 109

4. Computer Simulation of Frank Loop Contrast in Field Ion Images . . . . . . 110

5. On the Annealing of Stacking Fault Tetrahedra and Frank Dislocation Loops in Sirver ................... 110

6. On the Nature of the Long-Tern Degradation of "Cadmiun Sulfide" Solar Cells ....................... . . 111

7. Electron Microscope Stidies of Microerosion in Mgo Single Crystals . . . . 111

8. Research Plans for Calendar Year 1974 . . . . . . . . . . . . . . 111

9. 1973 Publications and Reports . . . . . . . . . . . . . . . . . 112

B. Theoretical Metallurgy

John W. Horrio, Jr., Principal Investigator

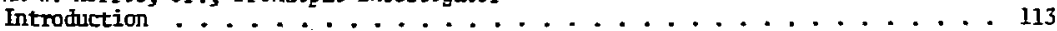

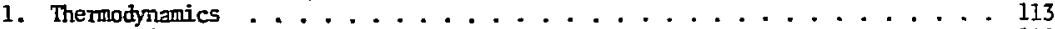

2. Correlation of Microstructure to Processing . . . . . . . . . . . . . 116

3. Correlation of Mechanical Properties to Microstructure . . . . . . . . 117

4. Alloy Design . . . . . . . . . . . . . . . . 130

5. Research Plans for Calendar Year 1974 . . . . . . . . . . . . . 137

6. 1973 Publications and Reports . . . . . . . . . 137

C. Microstructure, Properties and Alloy Design

Gareth Thomas, Principal Investigator

Synopses of Research Programs on Structure, Properties, and Design of

Materials . . . . . . . . . . . . . . . . . . 139

1. Design of Experimental Strong, Tough, Econorical Structural Steels . . . . . 139

2. The Stress-Induced Martensite-Austenite Interface in $\mathrm{Fe}-15 \mathrm{Ni}-15 \mathrm{Cr}$ Single Crystals ..................... 146

3. On Structural Interpretation of Short Range Order . . . . . . . . . . 147

4. Lattice Imaging of Ordered Alloys . . . . . . . . . . . . . . . 147

5. The Metastable Phase $\mathrm{Ni}_{2} \mathrm{Mo}$ and the Initial Stages of Ordering in Ni-Nb Alloys . . . . . . . . . . . . . . . . . 148

6. Loss of Coherency in Spinodaliy Decomposed Lu-Ni-Fe Alloys . . . . . . . . 149

7. Research in Progress .................. . . 149

8. Research Plans for Calendar Year 1974 . . . . . . . . . . . . . . . . . 151

D. High Voltage Electron Microscopy

Gareth Thomas, Principal Imvestigaton

1. Current Research Programs . . . . . . . . . . . . . . . . . 152

2. Research Plars fnr Calendar year $1974 \ldots \ldots$. . . . . . . . . . . 158

3. 1973 Publications and Reports . . . . . . . . . . . . . . . 158 
E. Alloy Design

I'ictor F. Zackay and Earl R. Porker, Principal Investigators

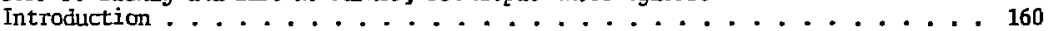

1. Design of Interstitial-Free Cryogenic Alioys $\ldots \ldots$

2. Influence of Microstructure on Fatigue Crack Fropagation in a Cryogenic Alloy ......................... 162

3. Microstructural Variables and Fractire Toughess of High Strength C-Mo and C-Mo-Ni Steels . . . . . . . . . . . . . 163

4. Influence of Heat Treatment on the Fatigue Crack Growth Rates in a Secondary Hardening Stee1 ............ 165

5. Structure and Elevated Temperature Properties of Non-Carbon-Containing Ferritic Alloys Strengthened by a laves Phase . . . . . . . . . . 167

6. Investigation of Bainitic Hardenability in Steels by the use of a Rapid Magnetometric Technique . . . . . . . . . . . . . 169

7. An Isothermal Study of Bainitic and Martensitic Transformations in Some Low Alloy Steels . . . . . . . . . . . . 171

8. Research Plans for Calendar Year $1974 \ldots \ldots 173$

9. 1973 Publications and Reports . . . . . . . . . . . . . 173

F. High Field Surerconductivity

Hilton R. Fickas, Frincipal Investigctor

Introduction ........................... 175

1. Present Status of IMRD Powder Rolied Supercorducting Tape . . . . . . 175

2. Research P1ans for Calendar Year $1974 \ldots \ldots$. . . . . . . . . . 176

3. 1973 Publications and Reports . . . . . . . . . . . . . . 177

G. Powder Metallurgy

Milton R. Pickus, Principal Investigator

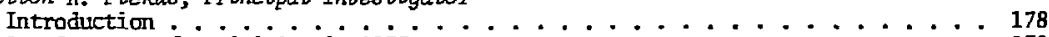

1. Sumary of Activities in $1973 \ldots \ldots \ldots$

2. Research Plans for Calendar Year $1974 \ldots \ldots$. . . . . . . . . . 178

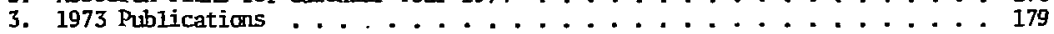

H. Advanced Materials
Robert $B$. Bragg, Prineipal Investigator

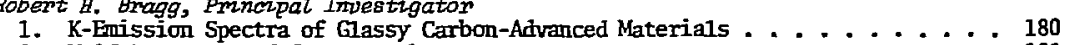

2. Void Structure of Glassy Carbon ....................... 181

3. Charge Transpart in Giassy Carbon ................. 181

4. Electronic Properties of Unidirectionaliy Solidified Eutectics . . . . . 182

5. Small-Angle Scattering by Pyrolytic Graphite . . . . . . . . . . . . . 182

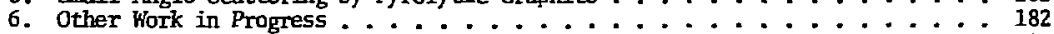

7. Research Plans for Calendar Year $1974 \ldots \ldots$. . . . . . . . . . 183

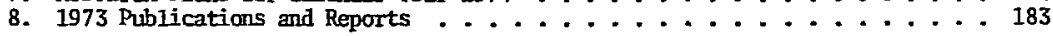

III. CFRAMIC SCIENCE

A. High Temperature Reactions

Alan W. Searcy, Principal Investigator

1. The Variation with Temperature of the Congruent Vaporization

Composition of Gallium Sesquisulfide $\left(\mathrm{Ga}_{2} \mathrm{~S}_{3}\right) \ldots \ldots . \ldots . . . \ldots 187$

2. Kinetics of Dissociative Vaporization Reactions .......... . 188

3. Thermodynamics of Decorposition of Strontiun Sulfate and Barium $\ldots \ldots$. . . . . . . . . . . . . . . . . . . . .

4. Magnetic Monent of the Sej Molectile $\ldots \ldots$

5. The Kinetics of Decamposition of Barium Carbonate $\ldots \ldots \ldots$

6. Research Plans for Calendrr Year $1974 \ldots \ldots$. . . . . . . . . . . . . . . . . .

7. 1973 Publications and Reports . . . . . . . . . . . . 191

B. Microstructure and Mechanical Behavior of Ceramic Materiais: Giass- and

Ceramic-Metal Systems

Joseph A. Pasर, Principal Investigator

1. Diffusion and Phase Relationship Studies in the Silica-Alumina System . . . 192

2. Permeation of Silicates in Magnesia and Forsterite Compacts. . . . . . 193

3. Phase Distribution in Solid-Liquid-Vapor Systens . . . . . . . . . 193

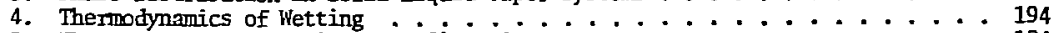

5. Thermodynamies of Solid State Sintering . . . . . . . . . . 194

6. Kinetics of Intermediate and Final Stages of solid state Sintering . . . . 194

7. Kinetics and Thermodynamics of Liquid Phase Sintering . . . . . . 195

8. Polycrystalline Spinel from Powders Przpared by Freeze Drying Teclorique . . 196

9. Effect of Fabrication on Polycrystalline MgO Microstructure . . . . . 196 
10. Impact Fracture of Brittle Transparent Materials . . . . . . . . . 197

11. Creep of Lithium Fluoride Single Crystals at Elevated Temperatures . . . 197

12. Time-Dependence of Mechanical Behavior of MgO Single Crystals . . . . . 198

13. Interfacial Reactions and lietting Behavior of Glass-Iron Systems . . . . . 199

14. Effect of Composition on Glass-Metal Interfact Reactions and Adherence . . 199

15. Metal-Glass Interfaces . . . . . . . . . . . . . . . I99

16. Research Plans for Calendar Year 1974 . . . . . . . . . . . . . . . . 200

17. 1973 Publications and Reports . . . . . . . . . . . . . . . . 200

C. Relation of Microstructure to Properties in Ceramics

Richand M. Fulrath, Principal Investigator

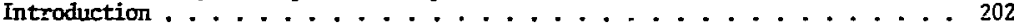

1. Relation of Processing Parameters to the Properties of Lithium

Ferrite . . . . . . . . . . . . 202

2. A liquid Phase Densification Technique for the Lead Zirconate Titanate

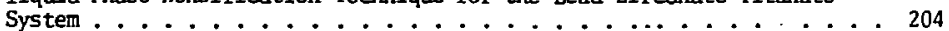

3. Liquid Phase Sintering in Seleıted Systems .............. 206

4. Solid State Sintering Studies . . . . . . . . . . . . . 208

5. Permeation of Helium in Polycrystalline $\mathrm{Al}_{2} \mathrm{O}_{3} \ldots \ldots \ldots$. . . . . . 211

6. Research Plans for Calendar Year 1974 .... . . . . . . . . . . 211

7. 1973 Publications and Reports . . . . . . . . . . . . . 212

IV. SOLID STATE PHYSICS

A. Theoretical Solid State Physics

Mavin L. Cohen, Frincipal Investigator

Introduction ....................... 215

1. Seniconductors and Insulators. . . . . . . . . . . . 215

2. Amorphous Materials ............... 215

3. New Theoretical Methods for Solid State Studies . . . . . . . . . . 216

4. Crystal Structure ...................... 216

5. Metals, Superconductivity and X-Ray Scattering . . . . . . . . . 217

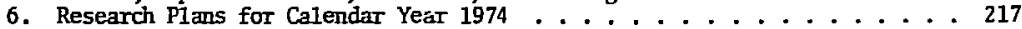

7. 1973 Publications and Reports . . . . . . . . . . . . . . 217

B. Far Infrared Properties of Solids

Pall L. Richords, Principal Investigator

1. Far Infrared Photoconductivity of Ultrapure Germanium . . . . . . . 220

2. Balloon-Based Measurements of the Cosmic Background Radiarion ..... 220

3. Surface Magnetic Resonance in $\mathrm{MnF}_{2} \ldots \ldots . . \ldots . . . . .222$

4. Far Infrared Nenlinear Spectroscopy in $\mathrm{LiNbO}_{3} \ldots \ldots . \ldots . . \ldots 223$

5. Instrumentation for fourier spectroscopy . . . . . . . . . . . . 224

6. Far Infrared Spectra of $\mathrm{Mn}^{3+}$ in $\mathrm{Al}_{2} \mathrm{O}_{3} \ldots \ldots \ldots . . . \ldots . . . .224$

7. Superconfucting Tumel Jumction Bolometers . . . . . . . . . 225

8. Research Plans for Calendar Year 1974 . . . . . . . . . . . . . . 225

9. 1973 Publications and Reports . . . . . . . ....... 226

C. Superconductivity

Gene T. Rochlin, Principal Investigator

1. Pair-Quasiparticle Interference Current in Superconducting TumeI

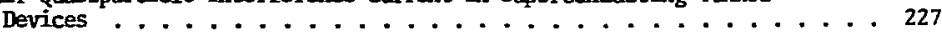

2. Tumel Juncticns with Flworocarbon Barriers . . . . . . . . . 227

3. Metal Oxide Tumel Barriers . . . . . . . . . . . . . . . 228

4. Research Plans for Calendar Year $1974 \ldots . . \ldots . . . . . . .228$

5. 1973 Publications and Reports ... . . . . . . . . . . . . . 228

John Clarke, Principal Investigator

1. $1 / \mathrm{f}$ Noise in Diniusive systems ....................... 230

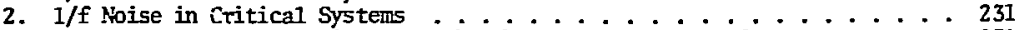

3. Relaxation of Quasiparticle Branch Imbaiance in Siperconductors . . . . 231

4. Electron Focusing in Bismuth: A New Method of Measuring the Diameizi of a Fenmi Surface .................... 232

5. Determination of BCS Parameter $\mathrm{N}(\mathrm{O}) \mathrm{V}$ in "Nomal" Metais $\ldots \ldots \ldots 233$

6. Superconducting Tunnel Junction Bolometers . . . . . . . . . . 234

7. Stable Sensitive Superconducting Devices . . . . . . . . . . . . . 234

8. Research Plans for Calendar Year $1974 \ldots . . . . . . . . . . .234$

9. 1973 Publications and Reports . . . . . . . . . . . . 235 
D. Experimental Solid State Physics and Qumtum Electronics

1. Ron Shen, Principal Investigator

1. Tunable Far Infrared Generation by Optical Mixing . . . . . . . . 237

2. Optical-Field Induced Ordering in the Isotropic Phase of a

Nematic Liquid Crystal .................... 238

3. Experimental Study of Transient Self-Focusing . . . . . . . 239

4. Luminescence at High Exciton Densities in CdSe . . . . . . . 239

5. Dispersion of Nonlinear Optical Susceptibilities $x^{(2)}(2 \omega)$ of

III-V Seniconductors . . . . . . . . . . . . . . 240

6. Resomant Raman Scattering in Cuzo ................. 240

7. Absorption, Photoluminescence, and Resonant Raman Scattering in

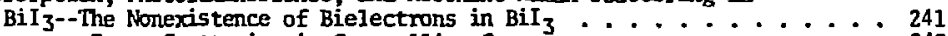

8. Resonant Raman Scattering in Crystalline Se . . . . . . . 242

9. Wavelength-Modulation Spectroscopy of Solids . . . . . . 242

10. Rayleigh-Hing Scattering in a Liquid Crystalline Material . . . . . 243

11. Theoretical Problens . . . . . . . . . . . . . . 243

12. Research Plans for Calendar Year $1974 \ldots \ldots . \ldots 244$

13. 1973 Publications and Reports ................. 244

APPENDICES

MRD STAFF FOR $1973 \ldots \ldots \ldots \ldots$

VISITING SCIENTISTS $\ldots . . \ldots . \ldots 255$

DEGRES AULARDED IN $1973 \ldots \ldots \ldots$

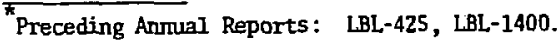




\title{
GENERAL INTRODUCTION
}

\author{
Leo Brewes, Diviaion Head \\ Victor E. Zackor, Associate Head \\ Rolf $\mathrm{B}$. Muller, Asaistont to Division Bead
}

1973 has been a year with on increase in productivity for the division with $24 \mathrm{Ph} . \mathrm{D}$., 4 Doctor of Engineering and 16 Master of Science degrees being awarded to our students. Joumal articles and book chapters published numbered 190, including 14 articles based on vork supported by other agencies such as DOT, NSF, EPA, and NASA. Support from these other agencies continues to be a significant fraction of our total this year amounting to approximately $15 \%$ of the total budget for the division. Postdoctorals and sabbatical visitors were at an all-time high of 52 for 1973, while our graduate student population remains at about 180 - the same level as in the previous 5 or 6 years.

Principal Investigators in the Inorganic Materials Research Division continue to be involved in the University Canpus Administrotion.

Professor Joseph Pask is an Assistant Dean of the College of Engineering, Professor Rollie Myers is Assistant Dean of the College of Chemistry, and Professor Alan Searcy was Acting Chaiman of the Materials Science and Engineering Department fral Jamiary to June.

Awards and honors were received by a number of the division's investigators in 1973:

Professor Neil Bartlett--Elected Fellow of the Royal Society.

Professor Harold Johnston--1974 American Chemical Society Award

Frofessor Bruce Mahan-Miller Research Fellowship

Professor J. W. Morris, Jr.,--Robert Lansing Hardy Gold Nedal by the Metallurgical Society of ATRE.

Professor Earl Parker--Gave the first ASM Western Lecture at the 1973 Hestern Metal and Tool Exposition and Conference.
Professor Gareth Thomas-Was keynote speaker at the Thind International Conference on High Voltage Electron Microscopy, Oxford University, England, August 26-30, 1973 .

Several investigators were on sabbatical leave during 1973:

Professor Garles Harris--Fall Quarter in Berkeley.

Professor John Nenman--Fall Quarter at the University of Wisconsin.

Professor Joseph Pask--Winter Quarter extended visits to several laboratories and attended an International Conference on Sintering in Yugoslavia.

Professor Yuen-Ron Shen--University of Paris at Orsay (February through July).

Professor Charles Tobias--Winter and Spring Quarters in Berkeley.

Professor Victor Zackay--Fall Quarter in Berkeley.

The Seventh Annual MRD Program Review meeting was held on February 1 and 2, 1973. In addition to representatives from the U.S. Atomic Energy Commission Division of Physical Research, and from other laboratories, universities and industrial organizations, the formal reviewers were:

Professor C. S. Barrett, University of Denver.

Professor Eneritus J. Ghipman, Massachusetts Institute of Technology.

Professor N. Nachtrieb, The University of Chicago.

Dr. E. Raidy, Oregon Graduate Center for Research.

Professor 0 . Sherby, Stanford Iniversity .

Professor J. Shyne, Stanford University.

Professor W. Sneltzer, MoMaster University.

Professor W. Heltner, University of Forida. 


\section{A INORGANIC CHEMISTRY}

HLILian L. solly, Frinoipal Investigator

1. ESTMATION OF ATOAIC COARGES BY AN ELECTRONECATIVITY EQUALIZATION PPDCEDURE CALIBRATED WITH CORE BINDING ENEPGIES*

Hillian L. Jolly and Winfield B. Perry

The favorito and most mractical mothod for quantitatively describing electron distribution in a molecule is the essigment of partial charges to the atons. A wide variety of theoretical and emirival methods have been used for evaluating atamic charges, end most of these have served advantageously in the correlation of atonic charge related properties. There is need for a simple method for calculating atomic charges which not only has theoretical justification but also can be related to on experimental measurement that depends fairiy directly on atcoinc charges, We believe thit such a method is now possible in the form of the technique of electronegativity equalization calibrated with $X$-ray photoelectron spectroscopic core binding energies.

The concept of atomic electronegativity equalization has been developed into the concept of the equalization of the electronegativities of bonding orbitals. We define orbital electronegativity as a quantity proportional to the derivative of the energy of an atom with respect to the charge in a particular atomic orbital. It is assumed

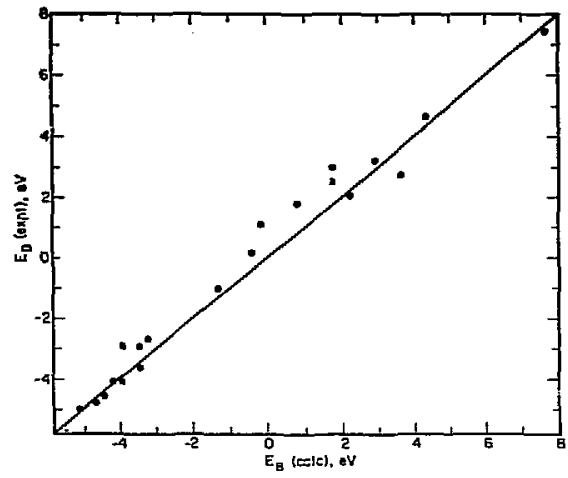

Fig. 1. Plot of $E_{B}$ (calcd) for nitrogen is electrons. (XBL 732-5824) that the orbital charge may have either an integral or nonintegral value and that the energy moy be expressed as quadratic function of the orbital charge. According to the assumptions of the method, the energy is minimized when the orbital electronegativities nf each bond are equal.

The calculation involves four emirical parameters (onily tho of which are needed for most molecules), which have been evaluated by application of the potential model equation for calculating core binding energies to 126 experinental is binding energies for 66 gaseous compounds. The method yields standard deviations in the binding energies of carbon, nitrogen, oxygen, and fluorine of 10.69 , $\pm 0.53, \pm 0.74$, ard $\pm 0.36 \mathrm{eV}$, respectively. To iliustrate the porier of the nethod in correlating core binding energies, we show in Fig. 1 a plot of experimental $E_{B}$ 's vs calculated $E_{B}$ 's for gaseous nitrogen compounds.

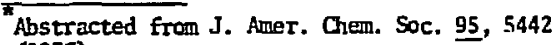
(1973).

\section{REACTIONS OF THE HEPTASULFUR DMIDE ANION*}

Marshall H. Mendelsom and Willian L Jolly

Various $\mathrm{N}$-substituted dorivatives of heptasulfur imide have been prepared by reaction of the imide with strong Lewis acids and with strongly electr nhilic reagents. A much wider range of derivatives is potentially available from reactions of the deprotonated imide, $S_{7} N^{2}$. Gisen et al. were the first to report the use of $S_{7} \bar{N}$ in the synthesis of alkyl derivatives. They concluded, partly because they were unable to ieprotonate S7NH quantitatively, that the treatment of S7NH with bases causes an irreversible ring-cleavage reaction in addition to deprotonation. They also suggested that the $S_{7} N^{2}$ ion is in equilibrium with an open chain isomer. In this paper, we describe a method for the quantitative deprotonation of $\mathrm{S}_{7} \mathrm{NH}$, present data which help clarify the nature of the ring-cleavage and isomerization, and report the symthesis of several new organo derivatives of $\mathrm{S}_{7} \mathrm{NH}$.

Heptasulfur inide can be completely deprotonated by treatment of its solution in tetrahydrofuran with powdered $\mathrm{KOH}$ at $-62^{\circ} \mathrm{C}$ for 15 min; the resulting solution of $\mathrm{K}^{+} \mathrm{S}_{7} \mathrm{~N}^{-}$ 
reacts with $\mathrm{CH}_{3} \mathrm{I}$ to give an essentially quantitative yield of the $\mathrm{N}$-methyl derivative of heptasulfur imide. Extended treatment of a $\mathrm{K}^{+} \mathrm{S}_{\mathrm{N}}$ solution with $\mathrm{KOH}$ causes irreversible decomposition. In solution, the $\mathrm{S}_{7} \mathrm{~N}^{-}$ion undergoes spontaneous isomerization, probably to an open chain form; at terperatures above about $-40^{\circ} \mathrm{C}$, the rate of isomerization is sufficient to permit equilibrium between the tho forms to be readily achieved. The compounds benzyl heptasulfurimidoformate, ethyl heptasulfurimidoformate, and heptasilfurimidotrimethylsilane are formed by the action of the ring form of $\mathrm{S}_{7} \mathrm{~N}$ on the corresponding chloro conpounds.

Abstracted from J. Inorg. Nucl. Chem. 35, 95 (1973).

\section{THE REACTION OF HYDROGEN WITH COPPER (I) IN LIQUUD ANDNIA-ARIDEE SOLUTIONS*}

Kesneth A. Strom and William L. Jolly

Only a few reactions of molecular hydrogen have been studied in liquid anmonia. The amide-catalyzed para-ortho conversion and isotope exchange reactions have been found to be first order in amide concentration and first order in hydrogen concentration. The reaction

$$
\mathrm{e}_{\mathrm{am}}^{-}+\mathrm{NH}_{3}=\mathrm{NH}_{2}^{-}+1 / 2 \mathrm{H}_{2}
$$

has been found to be reversibie. Hydrogenation of trans 1,2-diphenylethylene and diphenylacetylene in the presence of potassitm amide and a reduced iron oxide catalyst has been reported.

We now wish to report the reaction of hydrogen with copper(I) amide complex [probably $\mathrm{Cu}\left(\mathrm{NH}_{2}\right)_{2}^{-}$] in the presence of excess potassium edinde or cesium amide to form thermally unstable or ange-red solids with the approximate compositions $\mathrm{K}_{2} \mathrm{Cu}_{3} \mathrm{H}_{5} \cdot \mathrm{xNH}_{3}$ and $\mathrm{CsCuH}_{2} \cdot \mathrm{xNH}_{3}$. The compounds have been characterized by elemental analysis, $\mathrm{X}$-ray powder diffractometry, and, in the case of the potassium compound, Ranan spectroscopy and magnetic measurements.

The preparation of the ternary hydrides can be represented by the equations

$$
5 \mathrm{H}_{2}+2 \mathrm{~K}^{+}+3 \mathrm{Cu}\left(\mathrm{NH}_{2}\right)_{2}^{-}+\mathrm{K}_{2} \mathrm{Cu}_{3} \mathrm{H}_{5}+5 \mathrm{NH}_{3}+\mathrm{NH}_{2}^{-}
$$

and

$$
2 \mathrm{H}_{2}+\mathrm{Cs}^{+}+\mathrm{Cu}\left(\mathrm{NH}_{2}\right)_{2}^{-}+\mathrm{CsCuH}_{2}+2 \mathrm{NH}_{3} .
$$

The mechanism probably imolves either the intermediate formation of hydride ion from the reaction of hydrogen with amide, or a concerted reaction involving a $\mathrm{Cu}^{+}-\mathrm{H}_{2}-\mathrm{NH}_{2}$ complex. Examples of both types of mechanism are known.

Abstracted from $J$. Inorg. Nucl. Chen. 35,
3445 (1973).

4. THE REACTION OF POTASSILM GERML WITH BORON TRMETHYL*

Esther R, de Staricco, Chris Riddle, and William L. Jolly

Potassium germyltrihydroborate, $\mathrm{KCeH}_{3} \mathrm{BH}_{3}$, was prepared and cha zcterized in this laboratory. Tho other germylborates,

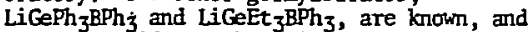
there is evidence that similar species, $\mathrm{KGeH}_{3} \mathrm{BX}_{3}$, are the initial products of reaction between potassien gernml, $\mathrm{KGeH}_{3}$, and several $\mathrm{BX}_{3}$ compounds $\left.\mathrm{X}=\mathrm{I}, \mathrm{CI}, \mathrm{CK}\right)$. In this note we describe the reaction between $\mathrm{KCeH}_{3}$ and boron trimethyl to form the adduct $\mathrm{KGeH}_{3} \mathrm{Bll}_{3}$.

The potassium gernyl solutions reacted with boron trimethyl at $0^{\circ} \mathrm{C}$ to produce ciear colorless solutions which became straw-colored after several hours. Generally a trace of germane, equivalent to ca $1 \%$ of the germanium, was the only volatile product. When more than an equimolar amount of Bilez was used, the excess Bilez was recovered. Hydrolysis of the final reaction mixture gave hydrogen, germane, and digermane. The data taken as a whole are consistent with the initial formation of the germyltrimethylborate ion:

$$
\mathrm{CeH}_{3}^{-}+\mathrm{BNe}_{3}+\mathrm{GeH}_{3} \mathrm{BHle}_{3}^{-} \text {. }
$$

In a mater of minutes, this species undergoes disproportionation:

$$
2 \mathrm{GeH}_{3} \mathrm{Ble}_{3}^{-} \rightarrow \mathrm{HFie}_{3}^{-}+\mathrm{Ge}_{2} \mathrm{H}_{5} \mathrm{Ble}_{3}^{-} \text {. }
$$

The latter reaction is analogous to the disproportionation of $\mathrm{CeH}_{3} \mathrm{BH}_{3}:{ }^{1}$

$$
2 \mathrm{CeH}_{3} \mathrm{BH}_{3}^{-} \stackrel{\mathrm{B}_{2} \mathrm{H}_{6}}{\longrightarrow} \mathrm{Ei}_{4}^{-}+\mathrm{Ce}_{2} \mathrm{H}_{5} \mathrm{BH}_{3}^{-} \text {. }
$$

\footnotetext{
Abstracted from J. Inorg. Nucl. Chem. 35, 297 (1973).
} 
1. D. S. Rustad and W. L. Jolly, Irarg. Chem, 7, 213 (1968).

\section{RESEARCH PLANS FOR CALEMAR YEAR 1974}

Wiliian L. Jolly

\section{a. X-Ray Photoelectron Spectroscopy}

The following projects are nearing completion, and the results should be publisleed in 1974: (a) a study of static relaxation in germane and the estimation of relaxation energy differences from Auger and core binding energies of germanium compounds, (b) determination of the electron distribution in methoxy (methyl) carbenepentacarbonylchromium(0) by X-ray photoelectron spectroscopy, (c) the correlation of core electron binding energies with charge distributions for compounds of carbon, silicon, and germanium, (d) a study of core electron binding energies of thiazyl fluoride and other sulfurr compounds, (e) a study of charge distribution in a variety of nickel coordination compourts, (f) a study of the valence MO levels in some volatile compounds of silicon and germanium, and ( $g$ ) an extension of the electronegativity equalization method for estimating atomic charges to compounds containing any elements from the periodic table.

We plan to study a variety of oxyfluoride carmounds such as $\mathrm{POF}_{3}, \mathrm{SO}_{2} \mathrm{~F}_{2}, \mathrm{SOF}_{2}$, etc., to determine the importance of hyperconjugation or "no-bond" resonance in such compounds. He have begun, and will continue, a study of the series of compounds $\mathrm{M}_{3}$, $\mathrm{PMe}_{3} \mathrm{BH}_{3}, \mathrm{PNe}_{3} \mathrm{CH}_{2}, \mathrm{PNl}_{3} \mathrm{NH}$, and $\mathrm{PNe}_{3} \mathrm{O}$. It will be of interest to determine whether it is necessary to include phosphorus d orbitals in the bonding to account for the charge distributions in these molecules.

We shali continue to work on the problen of studying high-temperature vapor species. It is hoped that a nesi spectrometer, incorporating the capability of studying such species, will be built in a year or so.

\section{b. Boron Hydride Chemistry}

We are completing a study of the quencining Ilow reactor in the synthesis of $\mathrm{BH}_{3} \mathrm{OH}^{-}$and $\mathrm{OO}^{\prime \prime} \mathrm{O}^{-}$; the results should be published in 1574. Wie plan to investigate the possible application of $\mathrm{BH}_{3} \mathrm{OH}^{-}$as a stereospecific or selective reducing agent in organic and inorgaric synthesis. The reduction of octyl halides (to octane) and substituted cyclohexanones (to the corresponding alcohols) will be studied.

\section{c. Germanium Chemistry}

We plan to study the kinetics and mechanism of the decamposition of aqueous solutions of $\mathrm{GeH}_{3} \mathrm{CO}_{2} \mathrm{~K}$ and $\mathrm{CeH}_{3} \mathrm{CO}_{2} \mathrm{H}$. It will be of interest to compare the data for the decarbonylation. and decarboxylation reactions with data for the corresponding reactions of the carbon analogs, $\mathrm{CH}_{3} \mathrm{CO}_{2} \mathrm{~K}$ and $\mathrm{CH}_{3} \mathrm{CO}_{2} \mathrm{H}$. Preliminary work indicates that the decomposition reaction in basic solution is first order in $\mathrm{GeH}_{3} \mathrm{CO}_{2}^{-}$ and that in strongly basic solution the decarboxylation reaction is accompanied by a side reaction involving the formation of $\mathrm{H}_{2}$.

We plan to conplete a study of the preparation and characterization of organic esters of $\mathrm{GeH}_{3} \mathrm{CO}_{2} \mathrm{H}$. These studies should give insight to the fundamental differences between the chemistries of the Group IV elements.

\section{d. Liquid Ammonia Chemistry}

Having recently completed a study of the kinetics of the hydrolysis of $\mathrm{BH}_{4}^{-}$in aqueous solutions, we plan to investigate the corresponding ammonolysis reaction in liquid ammonia. Even the stoichicmetry of the $\mathrm{NH}_{4}{ }^{+}+\mathrm{BH}_{4}{ }^{-}$reaction in liquid ammonia is unknown; useful synthetic as well as mechanistic information should be obtained. The work will require measurements on highpressure ammonia solutions at room temperature and above.

\section{1973 PUBLICATIONS AND REPORTS}

William L. Jolly and Associates

Journals and books

1. M. H. Mendelsohn and W. L. Jolly, Reactions of the Heptasulfur Imide Anion, J. Inorg. Nuc1. Chem. 35, 95 (1973) (LBL-820).

2. E. Staricco, C. Riddle, and W. L. Jolly, The Reaction of Potassium Germyl with Boror. Trimethyl, J. Inorg. Nucl. Chem. 35, 297 (1973) (LBL-826) .

*3. W. L. Jolly, Sodium and Potassium Proniucts and Production, in Encyclopaedia Britannica, 1973 ed.

*4. W. L. Jolly, I:ydrogen and Its Compounds, in Encyclopaedia Britannica, $1973 \mathrm{ed}$. 
5. K. A. Strom and W. L. Jolly, The Reaction of Hydrogen with Copper(I) in Liquid AntmoniaAmide Solutions, J. Inorg. Niucl. Chem. 35, 3445 (1973) (LBL-1439).

*o. W. L. Jolly, book review: "Preparative Methods in Solid State Chemistry," P. Hagennuller, ed., Synth. Inorg, and Metalorg. Chem. 3, 319 (1973).

7. W. L. Jolly and W. B. Perry, Estimation of Atonic Giarges by an Electronegativity Fqualization Procedure Calibrated with Core Binding Energies, J. An. Chem. Soc. 95, 5442 (1973) (LBL-1492).

\section{Papers presented}

1. X-Ray Photoelectron Spectroscopy, three ACS local section talks in Kingsport, Oak Ridge, and Nashville, Tem., March 5-7, 1973.

2. W. L. Jolly, "A Comparison of the Chemistries of Carbon and Genneriưn" and X-Ray Photoelectron Spectroscopy," two talks presented at Indiana University, Bloomington, Indiana, March 8-9, 1973.

3. W. L. Jolly, Applications of X-Ray Photoelectron Spectroscopy in Inorganic Chemistry, du Pont Experimental Station, Wilmington, Delaware, June 11, 1973.

4. W. L. Jolly, X-Ray Photoelectron Spectroscopy and the Estimation of Atomic Charges, Arizona State University, Tenlpe, Arizona, Sept. 21, 1973.

5. W. I. Jolly, "Atomic Charges and X-Ray Photoelection Spectroscopy" and "Thermodynamic Aspects of X-Ray Photoelectron Spectroscopy," du Pont Lectureship, Ceorgia Institute of Technology, Atlanta, Georgia, Nov. 29-30, 1973.

\section{LBL reports}

1. o. Pont, X-Ray Photoelectron Spectroscopy of Some Nickel and Iron Conpounds (M.S. thesis), LBL-1829, June 1973.
2. W. L. Jo1ly, The Application of X-Ray Fhotoelectron Spectroscopy to Inorganic Chemistry, submitted to Coordination Chemistry Reviews (ĹBL-1878, July 1973).

3. L. O. Pont, A. R. Siedie, M. S. Lazarus, and W. L. Jolly, X-Ray Photoelectron Spectroscopy of Some Nickel Compounds, Inorg. Chem., in press (LBL-1897, Aug. 1973).

4. J. W. Reed, H. H. Ho, and W. L. Jolly, Chemical Symthesis with a Quenched Flow Reactor. Hydroxytrihydroborate and Peroxynitrite, submitted to J. Am. Chem. Sac. as a Commmication (LBL-2206, Aug. 1973).

5. W. B. Perry and W. L. Jolly, Static Relaxation in Germane and the Estimation of Relaxation Energy Differences from Auger and Core Binding Energies of Germanium Compoumds, submitted to Chem. Phys. Letters (LBL-2216, Aug. 1973).

6. W. B. Perry, T. F. Schaaf, W. L. Jolly, L. J. Todd, and D. L. Cronin, Determination of the Electron Distribution in a Trassition Metal Carbene Complex by $X$-Ray Photoelectron Spectroscopy, submitted as Note to Inorg. Chem. (LBL-2237, Sept. 1973).

7. W, B. Perry and W. L. Jolly, The Correlation of Core Electron Binding Energies with Charge Distributions for Compounds of Carbon, Silicon and Cermanium, submitted to Inorg. Chem. (LBL-2238, Sept. 1973) .

8. K. A. Strom and W. L. Jolly, The Synthesis and Characterization of Methyl 2-Germaacetate and Ethyl 2-Germaacetate, submitted J. Organometallic Chemistry (LBL-2223, Sept. 1973).

9. W. L. Jolly, M. S. Lazarus, and 0. Giemser, Core Electron Binding Energies of Thiazyl Fluoride and other $\mathrm{Su}$. Ir Compounds, submitted to Zeitschrift für anorganische und allegemeine Chenie (LBL-2503, Nov. 1973).

\footnotetext{
Work not sypporteà by A.E.C.
} 
Robert E. Connick, Principal Investigator

1. OXYGEN-I7 NMR STUDIES OF THE RATE OF WATER EXOHANGF FROA PARTIALLY COPPLEXED NICKEL ION

\section{Thomas V. Rowland}

Nickel ion, when complexed by tridentate iminodiacetate ion (IDA) has three coordination positions occupied by waters, with two of the waters equivalent. Observation of the broadening of the oxygen-17 nuclear magnetic resonance of the bulk water shows that the rates of exchange of the two waters differ measurably, i.e., ca. fivefold. A least-squares fit of the data will be made to deternine the rate and WR parameters with as high arcuracy as possible. The previously observed line broadening maar $0^{\circ} \mathrm{C}$ has been found to be due to unexpected $\mathrm{F}^{\mathrm{H}}$ changes in the solutions. An investigation using the nickel bisiminodiacetate complex, where all six coordination positions are complexed by IDA, has been started to deteruine whether there is appreciable water exchange at the positions normally occupied by the carboxylate anms of the InA. The preliminary results indicate very little exchange with water.

2. THE EXCHANGE LIFETTME OF IYATER MOLECTILS IN THE SECOND COORDINATION SPHERE OF CHRAIIC ION

\section{William L. Ear1}

MR studies of the exchange lifetimes of solvent molecules in paramagnetic solutions nomally measure the lifetime of solvent in the first coordination sphere. It is also of interest to know about the dynamic behavior of solvent molecules beyond the first sphere. Olson, Konazawa, and Taube [J. Chem. Phys. 51, 289 (1969)] have used the transverse relaxation times of 170 in solutions of $C_{T}$ (III) and V(II) to set a limit on the lifetime of water molecules in the second sphere. The present work will measure the lifetime of water molecules in the second coordination sphere of $\operatorname{Cr}$ (III) using a combination of the transverse and longitudinal relaxation times. Our preliminary measurements indicate that the iifetime of water molecules in the second sphere of $\operatorname{Cr}$ (III) is $3 \times 10^{-10} \mathrm{sec}$. In order to refine this measurement we are employing. nonlinear least-squares fits of the absorption spectra and the paver saturation curves. We are also attempting to measure the 1ongitudinal relaxation times by another method, i.e., pulsed $M: \mathbb{R}$ techniques.

3. CO.PUTER SIMULATION OF SOLVENT EXCHANGE WITH THE FIRST COORDINATION SPHERE OF MIETAL IONS

\section{Robert E. Connick}

The computer calculations initiated last year on the modeling of the exchange of a bulk solvent molecule with a solvent molecule in the first coordination sphere of a metal ion have been continued and extended. Currently we are working in two dimensions with an 18-step potential well designed to correspond approximately to a charge-dipole attraction. Results at low activation energies indicate no unique geometry for the activated complex but rather many different geometries. At high activation energies the computer time necessary for finding even a single event becomes prohibitive. Therefore we are attempting to hold the "exchanging" particle in a ring at about the distance it would occupy in the activated complex, while the system equilibrates. The "exchanging" particle is then released and followed forward and backward in time to see if it does in fact exchange. The work is being done in collaboration with Dr. Berni Alder of the Lawrence Livermore Laboratory.

\section{RESEARCH PLANS FOR CALENTAR YEAR 1974}

Robert E. Connick

The work on rates of water exchange of rickel cormplexed by iminodiacetate ion and exchange from the second coordination sphere of chromic ion will be completed. Further studies of water exchange rates will be undertaken on one or more of the following problems: The water exchange of cupric ion and the dynamic Jahn-Teller effect; the very fast water exchampe of ions such as effect of ligand's on water excha: e rates of other partially complexed metal ion species; the effect of complexing on second coordination sphere rates of exchange. The work on computer modeling of exchange reactions will be extended to three dimensions, and the effect on the $\mathbf{r}^{\mathbf{s}^{2}}$ e of exchange of potential depth, potential 
shape, and radius ratio will be determined. The nature of the configuration of the activated complex will be investigated. The applicability of the computer results to actual exchange reactions in solution will be looked at carefully.
5. 1973 PUBLICATIONS AND REPORTS

Robert E. Connick and Associates Jownal

1. Edward E. Genser and Robert E. Connick, Exchange of Iodide Ion with Triiodide Ion Studied by Nuclear Magnetic Resonance, J. Chem. Phys. 58, 990 (1973) (LBL-869). 
Neil Bartlett, Principal Investigator

\section{NOBLE-GAS OHEISTRY}

a. Krypton Chemistry

Douglas E. McKee and Neil Bartlett

The high cost of the cyclotron time for $\mathrm{KrF}_{2}$ synthesis led, early this year, to a suspension of the program of $\mathrm{KrF}_{2}$ chemistry started last year. However, the extraordinaty oxidizing power of $\mathrm{KrF}^{+}$first utilized by us in the synthesis of the novel $\mathrm{XeOF}_{5}{ }^{+}$species has been exploited further by others. The projected synthesis of $\mathrm{BrF}_{6}{ }^{+}$ utilizing cationic krypton fluoride species, mentioned in our research plans for 1973, has been achieved by R. J. Gillespie and his co-workers (Inorg. Chem., in press).

b. Argon Fixation

Kevin Leary and Neil Bartlett

The matter of AuF $_{6}$ synthesis (see gold fluorides) has assumed priority in our attack on the argon fixation problem.

\section{c. Xenon Chemistry}

Christopher J. Adams, Boris Ženna, Aachim W. Roland, and Neil Bartlett

(i) Crystallographic Studies (in collaboration with D. H. Templeton, A. Zalkin, B. G. DeBoer, F. J. Hollander, and D. L. Ward of the Niclear Chenistry Division): Single-crysttal studies of the salts $\mathrm{XeF}^{+} \mathrm{AsF}_{6}{ }^{-}, \mathrm{Xe}_{2} \mathrm{~F}_{3}{ }^{+} \mathrm{AsF}_{6}{ }^{-}$, and $\mathrm{XeF}_{5}{ }^{+} \mathrm{AsF}_{6}$ have been completed. The essential features of the structures are shown in Fig. 1. The geometry of the $\mathrm{XeF}^{+} \mathrm{AsF}_{6}{ }^{-}$unit is remarkably like that of $\mathrm{XeF}^{+} \mathrm{RuF}_{6}{ }^{-}$, although the packing of these units in the crystal is different. for each case. As in the case of $\mathrm{XeF}^{+} \mathrm{RuF}_{6}{ }^{-}$ discussed in an earlier report (1971) the major canonical form, in the resonance hybrid description of XeFAsF $\mathrm{F}_{6}$, must be $\mathrm{XeF}^{+} \mathrm{AsF}_{6}{ }_{-}$. The comparison of $\mathrm{XeF}^{+} \mathrm{AsF}_{6}{ }^{-}$and $\mathrm{XeF}^{+} \mathrm{RuF}_{6}$ is of particular interest because of the widely held view that the bonding within the $\mathbb{N F}_{6}{ }^{-}$transition metal species is fundamentally different from that in nontransition element species. It is evident from these structures that not only are the two anions very similar in size and shape (they are distorted in their interaction with the cation) but their interactions with the $\mathrm{XeF}^{+}$species are similar. Evidently the nature of the $\mathrm{F}$ ligand in $\mathrm{KuF}_{6}{ }^{-}$is very like that in $\mathrm{AsF}_{6}{ }^{-}$. This suggests essentially the same bonding model for each anionic species.

The $\mathrm{Xe}_{2} \mathrm{~F}_{3}{ }^{+}$ion is a $\mathrm{F}^{-}$bridged $\mathrm{Xe}$ (II) relative of the $\mathrm{Xe}_{2} \mathrm{~F}_{11}{ }^{+}$ion which was reported last year. The shape and dimensions of the $\mathrm{Xe}_{2} \mathrm{~F}_{3}{ }^{+}$are consistent with $(\mathrm{F}-\mathrm{Xe})^{+} \mathrm{F}^{-}(\mathrm{Xe}-\mathrm{F})^{+}$ as the major canonical form. The $\mathrm{XeF}_{5}$ species seen in $\mathrm{XeF}_{5}{ }^{+} \mathrm{AsF}_{6}{ }^{-}$is not significantly different from $\mathrm{XeF}_{5}{ }^{+}$in other salts which we have studied, but the packing of
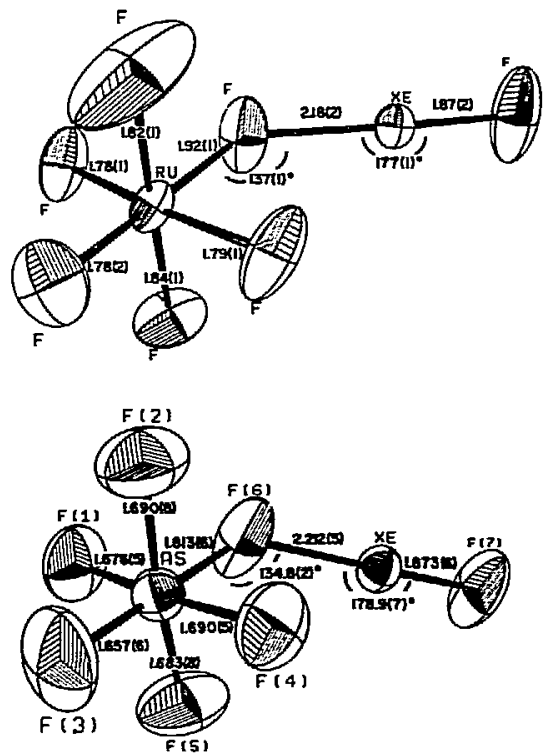

Fig. 1(a). The structural units of $[\mathrm{XeF}]\left[\mathrm{AsF}_{6}\right]$ and $[\mathrm{XeF}]\left[\mathrm{RuF}_{6}\right]$.

(XBL 7311-6807)

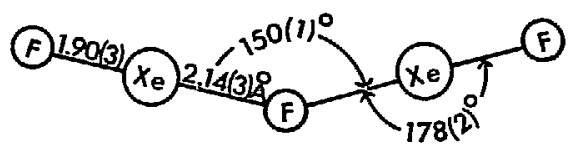

Fig. 1(0). The structural unit of $\left[\mathrm{Xe}_{2} \mathrm{~F}_{3}^{+}\right]$. (XBL 738-1120) 


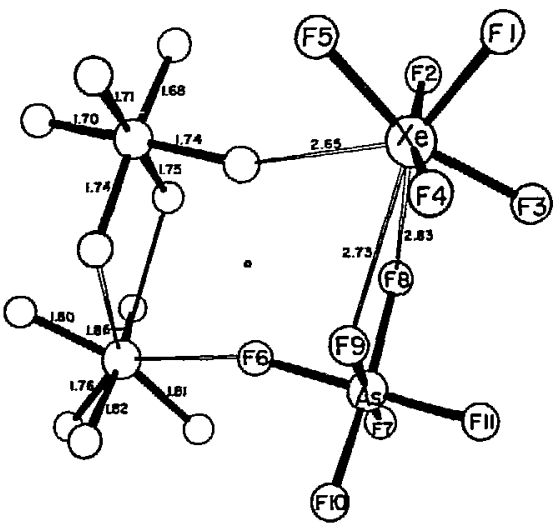

Fig. I(c). The structural mit in $\left[\mathrm{XeF}_{5}\right]\left[\mathrm{ASF}_{6}\right]$.

(WDL 724-665)

the ions differs from that of $\mathrm{XeF}_{5}{ }^{+} \mathrm{MF}_{6}{ }^{-}$ $M=O s, I r, P t, R u, R h)$. Curiously, $\mathrm{XeF}_{5}{ }^{+}$ AuF $_{6}^{-}$(C. J. Adams) is isostructural with $\mathrm{XeF}_{5} \mathrm{AsF}_{6}^{-}$, and the $\left(\mathrm{XeF}_{5} \mathrm{MF}_{6}\right)_{2}$ structural uit for these compounds is almost identical with the rings seen in the $\left(\mathrm{XeF}_{5}{ }^{+}\right)_{2} \mathrm{PdF}_{6}{ }^{2-}$ structure reported last year.

(ii) A Raman Study of $\mathrm{XeF}_{6}$ and Its Complexes (C. J. Adams): The X-ray crystallographic data reported here and earlier have been utilized in assigning the Raman spectra of complexes of $\mathrm{XeF}_{6}$ with Lewis acids $\left(\mathrm{BF}_{3}, \mathrm{PdF}_{4}, \mathrm{PF}_{5}, \mathrm{AsF}_{5}, \mathrm{RuF}_{5}\right.$, $\mathrm{P}^{2} \mathrm{~F}_{5}$, and $\mathrm{AuF}_{5}$ ) which contain $\mathrm{XeF}_{5}^{+}$or $\mathrm{Xe}_{2} \mathrm{Fi1}^{\prime}$ cations.

A full vibrational analysis has been made for the square-pyramidal $\mathrm{XeF}_{5}{ }^{+}$cation. The axial $X e-F$ stretching fundamental and force constant are momalously low in comparison with $\mathrm{IF}_{5}$ (see table), but are well in Iine with values for other xenon fluorides.

The $\mathrm{Xe}_{2} \mathrm{~F}_{11}{ }^{+}$cation, defined crystallographically in the sait $\mathrm{Xe}_{2} \mathrm{~F}_{11}{ }^{+} \mathrm{AuF}_{6}{ }^{-}$and reported last year, behaves as two $\mathrm{XeF}_{5}{ }^{+}$ species joined by a bridging fluoride ion. The stretching force constant of the bridging $X_{e}-F$ band is ca. 0.8 mdyne $A^{-1}$.

The Raman fingerprints obtained for $\mathrm{XeF}_{5}{ }^{+}$ and $X_{2} F_{11}{ }^{+}$in this work, and derived for $\left(\mathrm{XeF}_{5}{ }^{+} \mathrm{F}^{-}\right)_{\mathrm{X}}(\mathrm{x}=4,6)$ and molecular $\mathrm{XeF}_{6}$ from earlier studies of solid and gaseous xenon hexafluoride ${ }^{5}$ have been used to investigate the structure of xenon hexafluoride in ionizing and non-ionizing solvents. In $\mathrm{HF}$, xenon hexaflucride, wich in concentrated solution is present as $\left[\mathrm{XeF}_{5}{ }^{+} \mathrm{F}^{-}\right]_{\mathrm{X}}$, progressively ionizes on dilution to give $\mathrm{Xe}_{2} \mathrm{~F}_{11}{ }^{+}$and $\mathrm{XeF}_{5}{ }^{+}$. On the other hand, in $\mathrm{WF}_{6},\left[\mathrm{XeF}_{5}{ }^{+} \mathrm{F}^{-}\right]_{\mathrm{X}}$ is in equilibrium with molecular $\mathrm{XeF}_{6}$. The Spectra of the latter indicate that it is an essentially octahedral molecule which is perturbed by a second-order Jahn-Teller effect.

1. A. G. Robiette, R. H. Bradley and P. N. Brier, Cheml. Common. 1567 (1971). 2. N. Bartlett, M. Gernis, D. D. Gibler, B. K. Morrell, and A. Zalkin, Inorg. Chem. 12,1717 (1973)

3. X. o. Christe, E. C. Curtis, C. J. Schack, and D. Pilipovich, Inorg. Chem. 11, 1679 (i972).

4. K. Leary, D. H. Templeton, A. Zalkin, and N. Bartlett, Inorg. Chem. 12, 1726 (1973). 5. E. L. Gasner and H. H. Claasen, Inorg. Chen. 6, 1937 (1967); H. H. Claasen, G. L. Goodman, and H. Kim, J. Chem. Phys. 56, 5042 (1973).

\begin{tabular}{|c|c|c|}
\hline & $\mathrm{IF}_{5}(\mathrm{~g})$ & (in $\mathrm{XeF}_{5}^{+}{ }^{+} \mathrm{RuF}_{6}{ }^{-}$) \\
\hline$M-F_{a x}(R), A$ & $1.844(25)^{I}$ & $1.793(8)^{2}$ \\
\hline$M-F_{e q}(r), A$ & $1.869(5)$ & $1.845(9)$ \\
\hline$<F_{\text {ax }}-M-F_{\text {bas }}(B), A$ & $81.9(1)$ & $79.0(17)$ \\
\hline$f_{R}$, mange $A^{-1}$ & $4.82^{3}$ & $4.25 \pm 0.2$ \\
\hline$E_{T}$, matyme $A^{-1}$ & 3.82 & $3.95 \div 0.2$ \\
\hline
\end{tabular}


(iii) Xenon Difluoride Conplexes of. PdF and $\mathrm{PtF}_{5}$ and $A$ Nove1 Synthesis of Xenon Tetrafluoride (B. Zemva): At 140-150" Tiquid xenon difiugride oxidizes paramagnetic palladiun trifluoride (black) to yield yellow dianagnetic Pd(IV) complexes:

$$
(2 \mathrm{X}+1) \mathrm{XeF}_{2}+2 \mathrm{PdF}_{3}+2\left(\mathrm{XeF}_{2}\right)_{\mathrm{X}} \cdot \mathrm{PdF}_{4}+\mathrm{Xe} .
$$

Removal of xenon difluoride under vacum at $0^{\circ} \mathrm{C}$ yields sequentially the compounds $4 \mathrm{XeF}_{2} \cdot \mathrm{PdF}_{4} ; 3 \mathrm{XeF}_{2} \cdot \mathrm{PdF}_{4}, 2 \mathrm{XeF}_{2} \cdot \mathrm{PdF}_{4}$, and finally $\mathrm{XeF}_{2} \cdot \mathrm{PdF}_{4}$ which is stable with respect to dissociation at $0^{\circ}$. Infrared and Raman spectra of this compound indicate that it is the salt $\left.\left(\mathrm{XeF}^{+}\right)_{x}\left(\mathrm{PdF}_{5}\right)^{-}\right)_{x}$ the anion of which may be a tetraner Iike the $\left(\mathrm{RhF}_{\mathrm{S}}\right)_{4}$ described last year. This 1:1 compound loses $X_{e} F_{2}$ under vacunal at $160^{\circ}$ and falls to the compound $\mathrm{XeF}_{2} \cdot 2 \mathrm{PdF}_{4}$. The $X$-ray powder photographs and vibrational spectra of this compound are almost identical with those of $\mathrm{XePt}_{2} \mathrm{~F}_{10}$ reported 1 by Jha and Bartlett in 1963. The vibrational evidence suggests that these compounds are the salts ( $\left.\mathrm{XeF}^{+}\right)_{\mathrm{X}}\left(\mathrm{Pd}_{2} \mathrm{Fg}_{9}^{-}\right)_{\mathrm{X}}$. (It is possible that the anion is a $P d_{8} F_{36}{ }^{4-}$ F-bridged cage species.)

Efforts to remove $\mathrm{XeF}_{2}$ from $\mathrm{XeF}_{2} \cdot 2 \mathrm{PdF}_{4}$ to yield $\mathrm{PdF}_{4}$ resulted in reduction of the $\mathrm{Pd}(\mathrm{IV})$ to $\mathrm{PdF}_{3}$ and simultaneous oxidation of the xenon difluoride to xenon tetrafluoride. The latter was uncontaminated by $\mathrm{XeF}_{2}$, the change being cleanly:

$$
\mathrm{XeF}_{2} \cdot 2 \mathrm{PdF}_{4}+\mathrm{XeF}_{4}+2 \mathrm{PdF}_{3}
$$

The sum of Eqs. (1) and (2) amounts to the effective conversion of two moles of $\mathrm{XeF}_{2}$ to one mole of $\mathrm{XeF}_{4}$ and one mole of $\mathrm{Xe}$ (a pseudo-disproportionation) by the agency of tho moles of palladiun trifluoride.

A similar sturty of the $\mathrm{XeF}_{2}+\mathrm{PtF}_{4}$ system showed that liquid xenon difluoride at - $130^{\circ}$ oxidized $\mathrm{PtF}_{4}$ to $\mathrm{Pt}(\mathrm{V})$ and yielded the known complexes $\mathrm{Xe}_{2} \mathrm{~F}_{3}{ }^{+} \mathrm{PtF}_{6}{ }^{-}$and $\mathrm{XeF}^{+} \mathrm{PtF}_{6}{ }^{-}$.

$$
5 \mathrm{XeF}_{2}+2 \mathrm{PtF}_{4}+2 \mathrm{Xe}_{2} \mathrm{~F}_{3}^{+} \mathrm{PtF}_{6}^{-}+\mathrm{Xe} .
$$

The $\mathrm{Xe}_{2} \mathrm{~F}_{3}{ }^{+} \mathrm{PtF}_{6}{ }^{-}$salt went to $\mathrm{XeF}^{+} \mathrm{PtF}_{6}{ }^{-}$under vacum at $70^{\circ}$. At $140^{\circ}$ the $\operatorname{XeF}^{+} \mathrm{PtF}_{6}$ salt decomposed to yield $\mathrm{XeF}_{2} \cdot 2 \mathrm{P}^{2} \mathrm{~F}_{4}$ (which proved to be identical with the material prepared by Jha and Bartlett ${ }^{1}$, and the only xenon fluoride evolved was $\mathrm{XeF}_{4}$. The decomposition was:

$$
2 \mathrm{XeF}^{+} \mathrm{PtF}_{6}^{-}+\mathrm{XeF}_{4}+\mathrm{XeF}_{2} \cdot 2 \mathrm{PtF}_{4}
$$

Hitherto $\mathrm{XeF}_{4}$ has been difficult to prepare in high purity and all syntheses have involved fluorinations in bambs. These reactions provide a convenient route to high-quality material via the difluoride. The latter con be made in pyrex vessels and is relatively safe to handie.

1. N. Bartlett and N. K. Jha, in Noble Gas Compounds, edited by H. H. Hymar thiversity of Chicago Press, Clicago, 1963), p. 23.

(iv) Xenon Compounds Involving SF5 groups (A. IV, Roland): An improved synthesis of $5 F$ Br was developed to make available macroscopic quantities of high-purity material for the attermted generation of $\mathrm{Xe}\left(\mathrm{SFS}_{\mathrm{S}}\right)_{2}$ and related compounds. Unfortunately all attempts to use $\mathrm{SF}_{5} \mathrm{Br}$, as a route to these compounds, failed. Surprisingly the high-purity compound proved to be relatively inert to cold pure sater and ureactive towards mercary--observations which are contrary to those previously reported for this campound. A full vibrational analysis has been made of the compound.

\section{USE OF $\mathrm{O}^{+}$SALTS IN THE GENERATION OF NOVEL CATIONS AND RADICALS}

\section{T. J. Richardson and Neil Bartlett}

The recent development in these 1aboratories 1 of comvenient high-yield syntheses of high-purity dioxygenyl salts has made these powerfully oxidizing reagents readily available.

We have long sought to oxidize organic aromatic systems with the powerfully oxidizing hexafluorides and although aronatic cation species have been indicated as reaction intermediates, the great lability of the transition metal hexaflurides and their anions has always led to carbon-carbon bond cleavage as a consequence of fluorination reactions involving the hexafluorospecies. The kinetic stability of species such as $\mathrm{ASF}_{6}{ }^{-}$and $\mathrm{SbF}_{6}{ }^{-}$avoids this difficulty. Hence the salts $\mathrm{O}_{2}^{+} \mathrm{AsF}_{6}{ }^{-}$and $\mathrm{O}_{2}{ }^{+} \mathrm{SbF}_{6}{ }^{-}$offered excellent prospects for the synthesis of $\mathrm{C}_{6} \mathrm{~F}_{6}{ }^{+}$by the generalized reaction:

$$
\mathrm{C}_{6} \mathrm{~F}_{6}+\mathrm{O}_{2}^{+} \mathrm{A}^{-}+\mathrm{C}_{6} \mathrm{~F}_{6}^{+} \mathrm{A}^{-}+\mathrm{O}_{2} \text {. }
$$


(The electron affinity of $\mathrm{O}_{2}^{+}$is $12.2 \mathrm{eV}$, whereas the ionization potential of $\mathrm{C}_{6} \mathrm{~F}_{6}$ is $10 \mathrm{eV}$.)

This conversion has been realized for the $\mathrm{AsF}_{6}{ }^{-}, \mathrm{SbF}_{6}{ }^{-}$, and $\mathrm{Sb}_{2} \mathrm{~F}_{11}{ }^{-}$cases. The salts are yellow or yellow-orange and are paramagnetic. Their synthesis is carried out in liquid tungsten hexafluoride which serves as diluent for the $C_{6} F_{6}$ and heat sink (the reactions are moderately exothermic and the salts are thermally unstable). The best-characterized salt is $\mathrm{C}_{6} \mathrm{~F}_{6}{ }^{+} \mathrm{AsF}_{6}{ }^{-}$. It is a yellow-orange paramagnetic solid, m.p. 69.1 (with decarp.). E.p.r. spectra of the solid show a very intense broad signal centered at $\mathrm{g}=2.006$. This is in agreement with a value given for a $\mathrm{C}_{6} \mathrm{~F}_{6}{ }^{+}$species detected previously in $\mathrm{SbF}_{5}$ solution. The salt interacts with NO(I $=9.5 \mathrm{eV})$ in accord with the equation

$$
\mathrm{NO}+\mathrm{C}_{6} \mathrm{~F}_{6}{ }^{+} \mathrm{AsF}_{6}+\mathrm{NO}^{+} \mathrm{AsF}_{6}{ }^{-}+\mathrm{C}_{6} \mathrm{~F}_{6} \text {. }
$$

Single crystals of the conpound have been grown from liquid hydrogen fluoride, and Weissenberg photographs show them to be rhombohedral, space group $\mathrm{R3}^{-}$, the hexagonal wit cell having the dimensions
$\mathrm{g}=10.55$
(1), $C=7.66$
(1), $v=738 \mathrm{~A}^{3}, 0=2.53 \mathrm{~g} \mathrm{~cm}^{-3}, z=3$.

The symmetry indicates either that the $\mathrm{C}_{6} \mathrm{~F}_{6}{ }^{+}$ possesses a threefold axis or that the ion placement is somewhat disordered. The cation should exhibit a Jahn-Teller distortion.

A study of the chemical properties of this interesting ion will be undertaken.

1. D. E. McKee and N. Bartlett, Dioxygenyl Salts $\mathrm{O}_{2}{ }^{+} \mathrm{SbF}_{6}^{-}$and $\mathrm{O}_{2}{ }^{+} \mathrm{Sb}_{2} \mathrm{~F}_{11}{ }^{-}$and Their Convenient Laboratory Syntheses, Inorg. Chem. 12, 2738 (1973).

\section{HIGH OXIDATINN STATES OF THE HEAVY EIEEENTS}

Kevin Leary, Boris Zemva, Thomas C. Parsons, and Neil Bartlett

(i) Gold Chemistry (Kevin Leary): attempts to obtain macroscopic quantities of $\mathrm{AuF}_{5}$ by the more conventional procedures of highpressure synthesis, or acid displacement from AuF $_{6}{ }^{-}$salts, have been fruitless.

The observed chemistry demonstrates the powerful oxidizing nature of non-anionic Au(V). Thus destruction of the $0_{2}^{+}$salt, $\mathrm{O}_{2}{ }^{+} \mathrm{AuF}_{6}{ }^{-}$, in iodine pentafluoride proceeds according to the equation

$3 \mathrm{IF}_{5}+40_{2} \mathrm{AuF}_{6} 25^{\circ} 40_{2}+3 \mathrm{IF}_{6}^{+} \mathrm{AuF}_{6}^{-}+\mathrm{AuF}_{3}$.

Clearly, free AuF5 is capable of oxidizing $\mathrm{IF}_{5}$ to $\mathrm{IF}_{7}$ at room temperature. This oxidizing capability rivals that of $\mathrm{KrF}_{2}$.

The range of known $\mathrm{AuF}_{6}{ }^{-}$salts has been expanded to include $\mathrm{KAuF}_{6}$ and $\mathrm{NOAuF}_{6}$. The latter is isomorphous with $\mathrm{O}_{2}{ }^{+} \mathrm{AuF}_{6}{ }^{-}$, but the unit cell is slightly larger a finding in harmony with earlier results, which indicate that $\mathrm{NO}^{+}$is approximately $2 \mathrm{~A}^{3}$ more voluminous than $\mathrm{O}_{2}^{+}$). A magnetic study of $0_{2}^{+} \mathrm{AuF}_{6}{ }^{-}$indicates Curie-Weiss behavior with $\theta=-3.0^{\circ}$ and $\mu_{\text {eff }}=1.66$ B.M. A Mössbauer study of several AuF $_{6}{ }^{-}$salts has been published. 1 Experiments involving the electrolysis of AuF $_{6}{ }^{-}$salts 25 a source of AuF $_{6}$ are plamned.

1. G. Kaindl, K. Leary, and N. Bartlett, Nossbauer Study of Quinquevalent frold Compounds, J. Chetn. Phys., 59, 5050 (1973).

(ii) Nepturium and Related Chemistry (B. Zemva, in collaboration with Thamas $C$. Parsons): Efforts to prepare $\mathrm{NpOF}_{5}$ by direct fluorination and oxyfluorination of $\mathrm{NpO}_{2}$ have suggested novel species (indicated by infrared spectroscopy) but have not so far given acceptable evidence for the oxide pentafluoride. Low-temperature synthes is may be essentiai for species such as $\mathrm{NpOF}_{5}$ and the new work will take this approach.

\section{RESEARGH PLANS FOK CALENDAR YEAR 1974}

Neìl Rartlett

Noble-Gas and Related Chemistry. The spontaneous fixation of krypton (by AuF $_{6}$ or some other agency) continues to be a major concern as does the synthesis of an $\mathrm{ArF}^{+}$salt.

The $\mathrm{XeOF}_{5}^{+}$species has still not been properly characterized structurally. Solution $19 \mathrm{~F}$ NR studies and crystallographic studies are planned. Attenpts will also be made to isolate the parent base $\mathrm{XeOF}_{6}$.

Electrochemical and other approaches will be explored as a route to AuF6, which is 
considered to be the most promising oxidative species for argon fixation and $\mathrm{ArF}^{+}$preservation.

The exploitation of $\mathrm{XeF}_{2}$ in oxide systems (including water) as a powerful oxidative reagent for the generation of novel oxide and oxyhalide species remains to be properly explored. Species such as $\mathrm{IrO}_{4}, \mathrm{OsO}_{2} \mathrm{~F}_{4}$ and $\mathrm{OBrF}_{5}$ will be sought.

Charge Ambilation Syntheses. The exploitation of $\mathrm{O}_{2}$, $\mathrm{XeF}^{+}$and $\mathrm{KT}^{+}$salts as powerful oxidizers offers the prospect of high-oxidation-state soecies previously unobtainable by purely themical means. The $\mathrm{O}_{2}{ }^{+}$cation is particularly attractive (as has been demonstrated this year with $\mathrm{C}_{6} \mathrm{~F}_{6}{ }^{+}$ synthesis) in the generatior of species which are themselves chemically unsaturated. Both $\mathrm{O}_{2}^{+}$and $\mathrm{KrF}^{+}$offer the prospect of charge annhilation syntheses of the type $\mathrm{O}_{2}^{+}\left(\mathrm{KrF}^{+}\right)+\mathrm{A}^{-}+\mathrm{O}_{2}\left(\mathrm{Kr}+1 / 2 \mathrm{~F}_{2}\right)+\mathrm{A}_{\text {. }}$ In this fashion we can hope to generate species $A$ at low temperature. Thus even species of low thermodynamic stability such as $\mathrm{SbF}_{6}$. radical, $\mathrm{NpOF}_{5}$, or $\mathrm{NpF}_{7}$ molecules can hopefully be generated and preserved.

\section{1973 PUBLICATIONS AND REPNRTS}

\section{Neil Bartlett and Associates}

\section{Journals and books}

1. D. E. Mckee, C. J. Adans, A. Zalkin, and N. Bartlett, Cations $\mathrm{Kr}_{\mathrm{r}}^{+}$, $\mathrm{XeOF}_{3}^{+}$, and $\mathrm{XeOF}_{5}{ }^{+}$and oxidizing Properties of $\mathrm{KrF}^{+}$; J. Chem. Soc. Chem. Commm. 26 (1973) (LBL-1163).

2. K. Leary, A. Zalkin, and N. Bartlett, Crystal Structure of $\left[\mathrm{Xe}_{2} \mathrm{~F}_{11}\right]^{+}$[AuF $\left._{6}\right]^{-}$, J. Chem. Soc. Chem. Commm. 131 (1973) (LBL-1189) .

3. D. E. Alckee, A. Zalkin, and N. Bartlett,

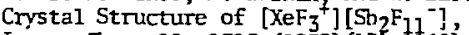
Inorg. Chem. 12, 1713 (1973) (LBL-1160).

4. N. Bartlett, M. Cennis, D. D. Gibler, B. K. Mortell, and A. Zalkin, CrystaI Structures of $\left[\mathrm{XeF}^{+}\right]$[ $\left.\mathrm{RuF}_{6}{ }^{-}\right]$and $\left[\mathrm{XeF}_{5}{ }^{+}\right]$ $\left[\mathrm{RuF}_{6}{ }^{-}\right]$, Inorg. Chem, 12, 1717 (1973) (LBL-850) .

5. D. E. Mckee, C. J. Adams, and N. Bartlett, Preparation and Raman Spectra of Salts [ $\left[\mathrm{XeF}_{3}^{+}\right]\left[\mathrm{SbF}_{6}^{-}\right],\left[\mathrm{XeF}_{3}^{+}\right]\left[\mathrm{Sb}_{2} \mathrm{~F}_{11}{ }^{-}\right]$, $\left[\mathrm{XeOF}_{3}{ }^{+}\right]\left[\mathrm{SbF}_{6}^{-}\right]$, and $\left[\mathrm{XeOF}_{3}^{+}\right]\left[\mathrm{Sb}_{2} \mathrm{~F}_{11}{ }^{-}\right]$; Inorg. Chem. 12, 1722 (1973) (LBL-1425).
6. K. Leary, D. H. Templeton, A. Zalkin, and $N_{\text {. Bartlett, Crystal Structure of }}$ $\left[\mathrm{XeF}_{5}{ }^{*}\right]_{2}\left[\mathrm{PdF}_{6}{ }^{2-j}\right.$, Inorg. Chem. 12, 1726 (1973) (LBL-1171):

7. N. Bartlett and F, O. Sladkey, The Chemistry of Kryptom, Xenon and Radon, in Comprehensive Inorganic Chemistry, Vol. 1, 213 (1973) (JCRL-19658).

8. D. E. McKee and N, Bartlett, Dioxygeny1 Salts $\mathrm{O}_{2}^{+} \mathrm{SbF}_{6}{ }^{-}$and $\mathrm{O}_{2}{ }^{4} \mathrm{Sb}_{2} \mathrm{~F}_{11}{ }^{-}$and Their Convenient Laboratory Syntheses, Inorg. Chem. 12, 2738 (1973) (LBL-1494).

9. B. K. Morre11, A. Zalkin, A. Tressaud, and N. Bartlett, Crystal Structure of Fhodium Pentafluoride, Inorg. Chen. 12, 2640 (1973) (LBL-1154) .

10. G. Kaindl, K. Leary, and N. Bartlett, Mössbauer Study of quinquevalent Gold Compounds, J. Chem. Phys. 59, 5050 (1973) (LBL-1841).

\section{Invited lectures}

1. N. Bartlett, "Concerning the Bonding in Noble-Gas Compounds," The Departmental Colloquium, Purdue Üiversity, Feb. 17, 1973.

2. N. Bartlett, "Bonding in Noble-Gas and Related Compounds," Joint Inorganic-Organie Seminar, U.C.L.A., March 1, 1973.

3. N. Bartlett, Twentieth Gilbert Newton Lewis Memorial Lecture, "Structure and Bonding in Noble-Gas Compounds,"

U. C. Berkeley, Oct. 23, 1973.

4. N. BartIett, "Chemistry of the Noble Gases," Noble Gases Syrmosium, Las Vegas, Sept. 24-28, 1973.

\section{Papers presented}

1. C. J. Adans and N. Bartlett, "Tautomersion in Xenon Hexafluoride--A Reman Study of $\mathrm{XeF}_{6}$ and Its Complexes," presented at The Fluorine Symposium, Salt Lake City, Utah, July 13, 1973 and at The Dalton Symosium of The Chenical Society, University of East Anglia, Sept. 24-27, 1973 (LBL-1859 Abs.).

The following papers were presented at The Seventh International Sympsium on Fluorine Chemistry, Santa Cruz, California, July $15-20,1973$.

2. T. Richardson, * D. E. Mckee, and N. Bartlett, "Approaches to Novel Cations and Radicals." 
3. K. Leary* and N. Bartiett, "AuF 5 Complexes".

4. N. Bartlett*, B. Żemva, and A. Tressaud, "Concerning the Crystal Structures of Platinum Metal Tetrafluorides (Ru, Rh, Pd, Ir, and $F t)$ and their $\left(\mathrm{NF}_{4}+y^{-}\right)_{x}$

Derivatives."

\section{Speaker.}

LBL reports

1. K. Leary, A. Zalkin, and N. Bartlett, The Crystal Structure of $\mathrm{Xe}_{2} \mathrm{~F}_{11}{ }^{+} \mathrm{AuF}_{6}{ }^{-}$and the Raman Spectrum of $\mathrm{Xe}_{2} \mathrm{~F}_{1}+, \mathrm{LBL}-1426$, Jan. 1973.
2. N. Bartlett, B. G. LeBoer, F. J. Hollander, F. O. Sladky, D. H. Templeton, and $\mathrm{A}$. Zaikin, Crystal Structures of $\left[\mathrm{Xe}_{2} \mathrm{~F}_{3}{ }^{+}\right]$ $\left[\mathrm{AsF}_{6}{ }^{-}\right]$and $\left[\mathrm{XeF}_{5}\right]\left[\mathrm{AsF}_{6}{ }^{-}\right], \mathrm{LBL}-1170$, Sept. 1973.

3. N. Bartlett, Krypton, LBL-1862, July 1973.

4. Donald D. Gibler (Ph.D. thesis), Perfluoro Cations of the Non-Netallic Elements, LBL-1157, April 1975.

5. Douglas Edward McKee (Ph.D. thesis), Preparative and Structural Studies Involving Noble-Gas and Related Compor uds, LBL-1814, May 1973.

6. Christopher J. Adams, The Raman Spectra of Solid Xenon Tetrafluoride and Its Adduct with Xenon Difluoride, LBL-1888, Aug. 1973. 


\section{B. SOLID STATE CHEMISTRY AND PHYSICS}

Formen E. Philiips, Principal Investigator

\section{HEAT CAPACITY OF THE KONDO-SUPERCONUUCTOR (La, Ce ) Al2*}

Samue1 D. Bader and Norman E. Phillips

It has been known for some time that magnetic impurities have a dramatic effect on properties of the superconducting state, and recently it has been recognized that the type of behavior should depend on the nature of the magnetic impurity. If there is a Kondo effect associated with the impurity the breaking of the Cooper pairs should be temperature dependent. In that case "reentrant" behavior --the existence of upper and lower critical temperatures-has been predicted. The system $(\mathrm{La}, \mathrm{Ce}) \mathrm{Al}_{2}$ has been identified as belonging to this category--some evidence for a kondo effect in the normal state has been reported and reentrant behavior observed. 1 Calorimetric measurements on this system were undertaken in this laboratory to (1) verify the nomalstate Kondo effect, (2) study the transition at the lower critical temperature, $T_{c 1}$, and (3) stury the development of spin compensation in the superconducting state.

Measurements were made on three alloys: 0.906 at. $5 \mathrm{CeAl}_{2}$ in $\mathrm{LaAl}_{2}$, for which superconductivity is completely suppressed; a 0.64 at so sanple, for which reentrant behavior has been observed; and a 0.193 at. sample which shows only a single transition. Measurements on pure $\mathrm{IaAl}_{2}$ were also made. The normal-state data for all sarples cotld be represented by the sum of electronic and lattice contributions that were independent of concentration, and a magnetic contribution that was proportional to concentration. In 10w magnetic fields (necessary to suppress superconductivity in all except the 0.906 at. 5 sample) the magnetic heat capacity is very similar to that observed 2 in CuFe and CuCr, as shown in Fig. 1. This fact and the proportionality to comcentration confinis the identification of these alloys as Kondo systens.

The slight anomaly at $\mathrm{T}_{\mathrm{cl}}$ in zero magnetic field for the 0.64 at. sample is also apparent in Fig. 1. The size of this anomaly is reasonably consistent with the existence of bulk superconductivity, estimates of the Landau-Ginsberg parameter, and measurements ${ }^{3}$ of the upper critical field. At $\mathrm{T}_{\mathrm{C} 2}$ (as determined magnetically) no structure in the zero-field heat car zcity is observed. A certain amount of broadening of the transition is of course expected (and observed at $T_{C 1}$ ) but the data suggest that

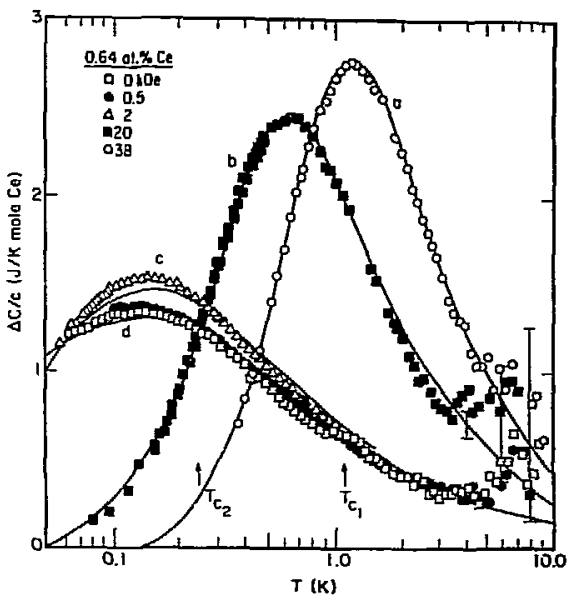

Fig. 1. The heat capacity of 0.64 at. 8 $\mathrm{CeAl}_{2}$ in $\mathrm{LaAl}_{2}$. Curve d represents zerofield experimental data and also theoretical data for other Kondo systems (see Ref. 2).

(XBL 7311-6628)

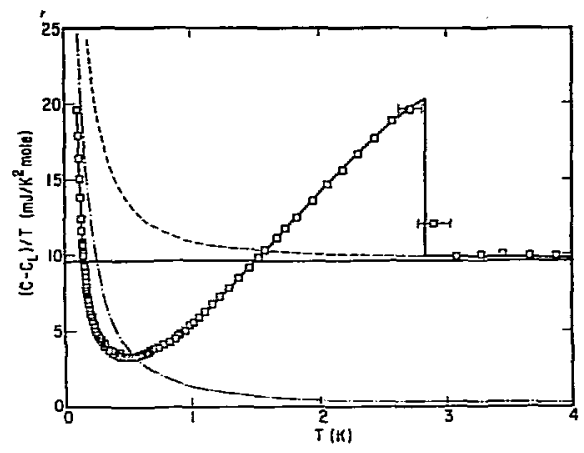

Fig. 2. The heat capacity of 0.193 at. $\mathrm{CeAl}_{2}$ in $\mathrm{LaAl}_{2}$. The dot-dash and dash curves represent tine nomal-state magnetic and total normal-state heat capacities.

(XBL 7311-6624) 
the transition is probably of higher order than second. Additional measurements on a more highly homogenized sample are planned to clarify this point.

The zero-field data for the 0.193 at .8 sample is compared with the nomal-state magnetic heat capacity in Fig. 2. It is clear that the magnetic ordering in the superconducting state is substantially depressed relative to that in the normal state. Qualitatively this can be understood as reflecting a conpetition between two types of order--Cooper pairs, and spin compensation in the Kondo sense.

This work done in collaboration with M. Brian Maple.

1. For references to theoretical and earlior experimental work see M. Brian Maple, in Magnetism, Vol. V, edited by Harry Suhl (Academic Press, New York and London, 1973).

2. B. B. Triplett and N. E. Phillips, Phys. Rev. Letters 27, 1001 (1971).

3. G. Riblet and K. Winzer, Solid State Comm. 11, 175 (1972); K. Winzer, Z. Physik 265, 139 (1973).

2. HEAT CAPACITY OF THE SINGLET-GROND-STATE SYSTEIS PTOL2, TIOH

Gary P. Schwartz, Marilyn Wun, and Norman E. Phillips

Heat capacity and magnetic susceptibility data on PrCu 2 have been interpreted as showing cooperative muclear ordering via the hyperfine interaction in a singlet-groundstate system. ${ }^{1}$ Earlier measurements in this laboratory ${ }^{2}$ showed some differences in behavior that cast doubt on that interpretation. To test the possibility that deviations from stoichiometry or inhomogeneity of the sample contributed to the differences, a second sample was prepared and measured. The results were sinilar to those obtained with the first sample. The heat capacity of $\mathrm{LaCu}_{2}$ was also measured te provide an estimate of the lattici heat capacity. As shown in Fig. 1, the $6^{\circ} \mathrm{K}$ anomaly in the heat capacity is much sharper on the highteriperature side than a Schottky anomaly. Furthermore, the measurements on $\mathrm{LaCu}_{2}$ suggest that the anomalous contribution to the heat capacity extends to above $20^{\circ} \mathrm{K}$. For both these reasons it appears that the electronic transitions are more complicated than was originally assumed.

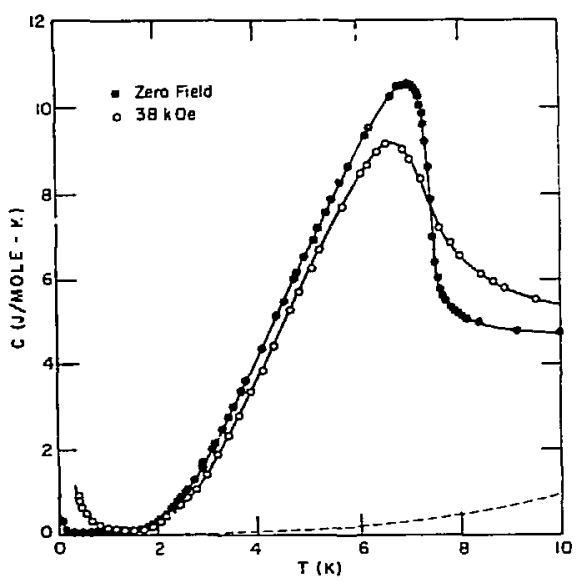

Fig. 1. The heat capacity of $\mathrm{PTCu}_{2}$. The dashed curve represents the lattice heat capacity.

(XBL 741-5467)

Heat capacity measurements on $\mathrm{TmCu}_{5}$ and HoCus have also been made. In both cases hyperfine and electronic contributions are approximately separable. Analysis of these data is in progress.

1. K. Andres, E. Bucher, J. P. Maita, and A. S. Cooper, Phys. Rev. Letters 28, 1652 (1972).

2. IRRD Annual Report for 1973, LBL-1400, April 1973, p. 19.

\section{THE HEAT CAPACITY OF TERBILM ETHYL SULPHATE*}

Marilyn Wun and Norman E. Phillips

Terbium ethyl sulphate is a singlet-groundstate systern in which an anomaly in the magnetic susceptibility occurs near $0.2^{\prime} \kappa .1$ As shown in Fig. 1, the heat capacity indicates a cooperative transition ai $0.24^{\circ} \mathrm{K}$. This temperature is of the der of magnitude of the expected dipole-dipole interaction, suggesting that this is the driving force for moment formation rather than the more usual exchange interaction. 


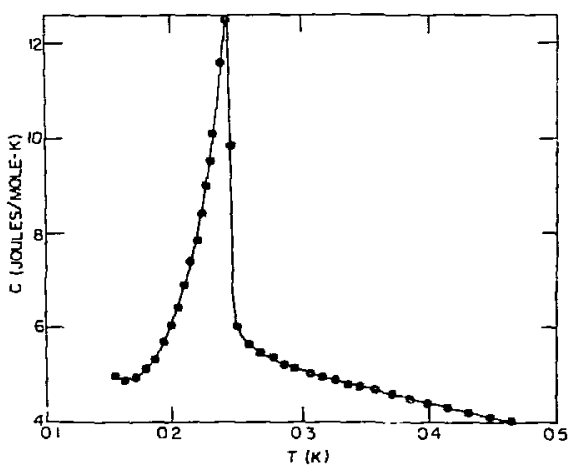

Fig. 1. The heat capacity of terbium ethyl sulphate.

(XBL 741-5466)

This work done in collaboration with

T. E. Katila.

1. T. E. Katila, private commication.

\section{THE LOW-TEMPERATURE HEAT CAPACITY OF NATROLITE}

Samuel D. Bader, Gerald D. Fong, and Norman E. Phillips

It has been suggested that the anomalous 10w-tenperature heat capacity of amorphous dielectrics may be associated with voids, in which case similar ancmalies might be observed in zeolites. 1 To test this possibility, the heat capacity of Indian Natrolite, which is obtainable as natural large single crystals, was measured. The sanmle studied did extibit an anonalously large heat capacity, but messurements in magnetic fields showed that it was largely, if not entirely, magnetic in origin. Any linear term in the heat capacity of this sample is an order of magnitude smaller thar those observed in severai amorphous materials.

1. C. Kittel, private commuication.

5. MAGNETIC FIELD DEPENDENCE OF THE LONTE.PERATURE HEAT CAPACITY OF NEODYMILM

William E. Fogle and Norman E. Phillips

The heat capacity or $\beta$-cerium showed a large, weakly field-dependent, temperatureproportional term that dominated the heat capacity to temperztules of the order of $0.1^{\circ} \mathrm{K}$, belolv which it was masked by the hyperfine heat capacity of impurities. To see whether similar heat capacities might be found in other rare earth metals, we have measured the heat capacity of a neodynium sample enriched to $99.8 \%$ in eveneven isotopes. Resilts obtained in several magnetic fields are shown in Fig. 1. The hyperfine heat capacity becomes increasingly important below $0.2^{\circ} \mathrm{K}$, but it is clear that there is a large linear term. In magnitude, the linear term is similar to that observed in cerium, but its field dependence is much greater. The data obtained so far do not extend to high enough fields to estimate a high-field limit, but it appears that that linit is of the order of magnitude of typical transition-metal electronic heat capacities, suggesting that most of the zerofield linear term is magnetic in origin.

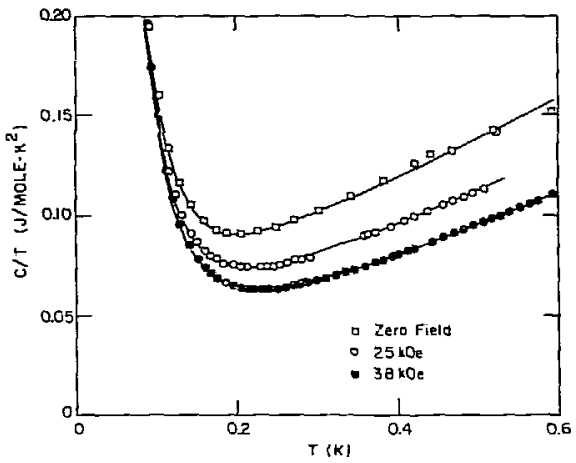

Fig. 1. The heat capacity of neodymiun.

(XBL 741-5465)

\section{RESEAROH PLANS FOR CALENDAR YEAR 1974}

Norman E. Phillips

Calorimetric investigations on dilute magnetic alloys will be continued. The actual choice of systems is still not settled, but possibilities inciude further measurements on the ( $\mathrm{LaCe}) \mathrm{Al}_{2}$ system; on the 
(LaGd)Al2 systsm, which is also superconducting but appears to involve a different kind of spin ordering; and on rare earths in noble metals. The latter class of materials is of interest from several points of view, including the possible identification of alloys with low Kapitza resistence to $\mathrm{He}$. Sorne of these measurements will be made by Mr. W. E. Fogle, and will probably make use of techniques for higher magnetic fields and lower temperatures that he is developing.

A new student, Mr. Brent Krusor, has taken uq the measurements on liquid ${ }^{4} \mathrm{He}$ and is continuing the design of modifications to the apparatus that will pernit measurements to lower temperatures.

Drs. E. W. Hornung and G. Brodale will continue to develop apparatus for measurements in the $\mathrm{mk}$ ragion. It is planned to redesign the dilution refrigerator and add a demagnetization stage.

\section{1973 PUBLICATIONS AND REPORTS}

Norman E. Phillips and Associates

\section{Journals}

1. W. R. Gardiner, J. K. Hoffer, and

N. E. Phillips, Thernodynamic Properties of ${ }^{4}$ He. The hop Phase at Low Densities.
Phys. Rev. A , 1029 (1973) (LBL-1123).

2. N. E. Phillips, T. L. Thorp, and

B. B. Triplett, Inplications of New Data on the Heat Capacity of Tungsten, for the Powdered Cerium Magnesium Nitrate Temperature Scale. Phys, letters 43A, 285 (1973) (LBL-1453).

3. D. B. Mclihan, J. P. Remeika, S. D. Bader, B. B. Triplett and N. E. Phillips, Heat Capacity of Metallic $\mathrm{V}_{2} \mathrm{O}_{3}$ at High Pressure, Phys. Rev. B 7, 3079 (19\%3) (LBL-1467).

4. S. D. Bader, N. E. Phillips, and D. B. Mclihan, Heat Capacity and Resistivity of Metallic Sns at High Pressure, Phys. Rev. B $\underline{7}, 4686$ (1973) (LBL-1194).

*5. D. Avenel, M. P. Berglund, R. G. Gylling, N. E. Phillips, A. Vetleseter, and M. Vuorio, Improved Themal Contact at Uitralow Temperatures between $3 \mathrm{He}$ and Metals Containing Magnetic Impurities, Pnys. Rev. Letters 31, 76 (1973).

6. B. B. Triplett, N. E. Phillips, T. L. Thorp, D. A. Shirley, and W. D. Brewer, Critical Field for Superconductivity and Low-Temperature Normal-State Heat Capacity of Tungsten, J. Low Tentp. Phys. 12, 499 (1973) (LBL-1497).

\footnotetext{
Supported by the National Science Foundation.
} 
George Jura, Principal Investigator

1. HEAT CAPACITIES OF METALS UNDER HICH PRESSURE

George Jura and Tang-hua Chen

A real test for the pulse method for the detemination of the heat capacity under pressure are the metals, aluminum and copper; and they are equally difficult. The reason for the difficulty lies in their low specific resistance. Aluminum is chosen over copper because there is some idea as to the variation of the heat capacity of aluminum as a

function of pressure. The variation is estimated from the change in Debye tenperature as a function of resistance. The Debye was detemined from the variation in resistivity as a furiction of temperature. Some credence can be placed in these values, since they connect well with the heat capacity data obtained from shock experiments.

Ten different currents were used at each pressure. The heat capacities were determined at 5-kbar intervals from 30 to 100 khars.

The heat capacity decreased between $4 \%$ and $5 \%$ in this pressure interval, in good agreement with the data obtained from the resistivity data.

\section{OPTICAL STUDIES OF SOLIDS UNDER HIGH} PRESSURE

\section{Raymond F. Gliems}

Crystalline 1,2,4,5 tetrachloro benzene (TCB) has been used as a model in calculations of ope-dimensional electronic energy processes. 1 The crystal structure of TCB is monoclinic $(321 / a)$ with lattice constants $a_{0}=9.725 \AA, b_{0}=10.602 \AA, c_{0}=3.850 \AA, \beta=103.28^{\circ}$ with a bimolecular unit cell.2 The molecular arrangement within the crystal is similar to tnat of naphthalene, with the molecules lying in two sets of parailel planes. The perpendicular distance between parallel planes can be taken as a "nearest neighbor" distance $k$ disregarding a small angular factor. At low temperature $\left(150^{\circ} \mathrm{K}\right)$ there is a phase transition to a triclinic polymorph with only about a 58 change in tive lattice constants and even less change in $\alpha$ and $\gamma$.

It was thought that the effects of hydrostatic or uniaxial compression on a crystal of TCB would shed light on the form of interaction among neighboring TCB molecules. The a priori assumption was made by Decius 3 that the out-of-plane normal modes would interact via an induced dipole-indueed dipole potential of the form $V^{\prime}=a / R^{3}$, where a is a constant including both induced dipole moments of neighboring molecules for a given nomal mode and angular factors.

An infrared absorption experiment was performed at from one atmosphere to a nominal load of about 40,000 atmospheres. Infrared light was chosen, in part, because of the

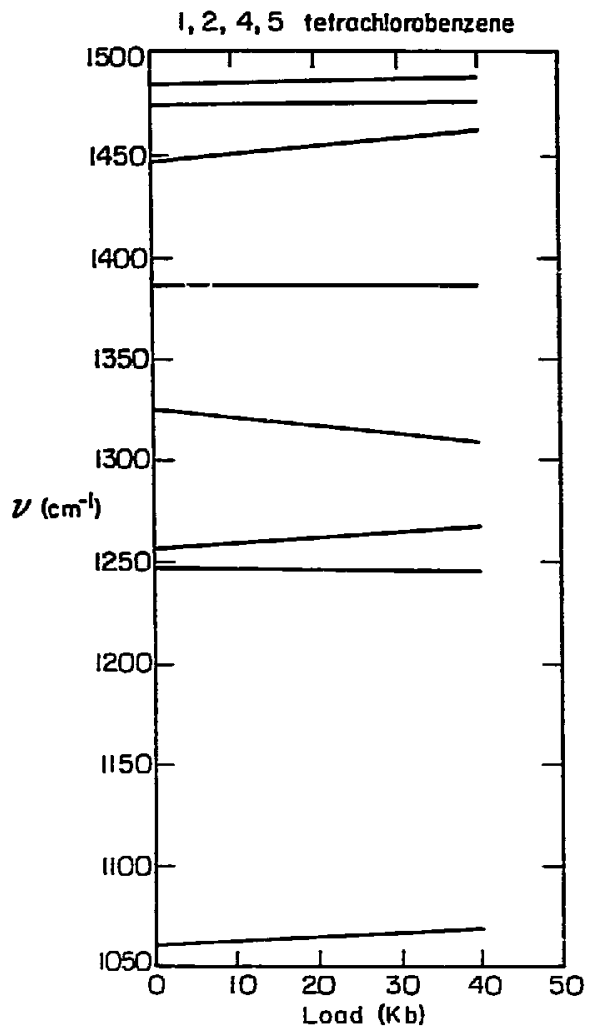

Fig. 1. 1,2,4,5 tetrachloro benzene energy level diagram. 
simplicity of vibrational wave functions. Crystalline TCB was cleaved perpendicular to a long crystal axis into samples about 0.075 min thick. The aligrment of the sample was such that the out-of-plane normal modes would be excited by the incident light. A highpressure Drickamer ce $11^{4}$ modified for infrared measurements ${ }^{5}$ was used in the experiments. The results for the frequency region 1000 to $1500 \mathrm{~cm}^{-1}$ are shown systematically in Fig. 1.

The cormlexity of the energy level diagram and the uncertainty of spectral assignment precluded imnediate accurate determination of interaction terns for this crystal. Therefore a system having only one out-ofplane normal vibration was next imvestigated.

At one atmosphere pressure and room temperature, $\mathrm{BaO}_{3}$ has the aragonite structure with a vertical distance, $R$, between nearest neighbor carbonate ions $=3.275 \mathrm{~A}$.

The infrared spectrum of a*0.075-mm-thick polycrystalline sample of Witherite $\left(\mathrm{BaCO}_{3}\right)$ was measured from a pressure of one atmosphere to a nominal laad of 40,000 atmospheres. The results are shown in Fig. 2. The out-of-plane vibration $v_{2}$ has a fundamental frequency which decreases from $860 \mathrm{~cm}^{-1}$ at one atmosphere to about $850 \mathrm{~cm}^{-1}$ near 40,000 atmospheres. There is mich complex structure to this broad ajsorption band, so the corresponding absorption maximum was measured at ail pressures. Both the symmetric stretch $v_{1}$ and degenerate bend $v_{4}$ increase in frequency from one atmosphere to 40,000 atimospheres (see Table I).

Table I.

$$
\begin{array}{lr}
\Delta v_{1} / \Delta \mathrm{P} & 2.5 \times 10^{-4} \mathrm{~cm}^{-1} / \mathrm{atm} \\
\Delta v_{2} / \Delta \mathrm{P} & -1.7 \times 10^{-4} \mathrm{~cm}^{-1} / \mathrm{atm} \\
\Delta v_{4} / \Delta \mathrm{P} & 1.2 \times 10^{-4} \mathrm{~cm}^{-1} / \mathrm{atm}
\end{array}
$$

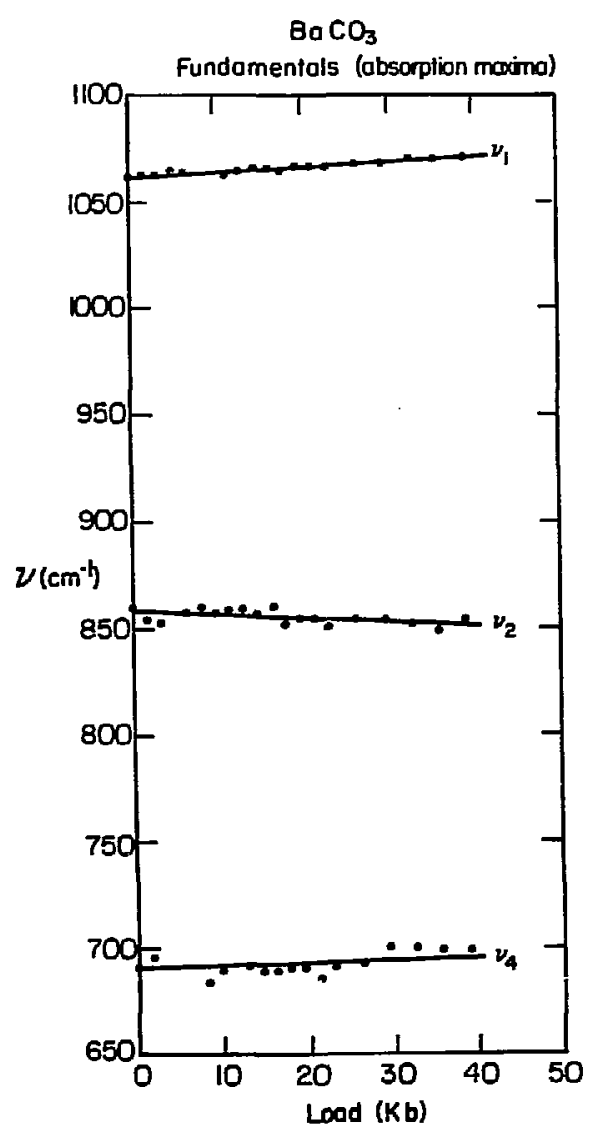

Fig. 2. $\mathrm{BaCO}_{3}$ energy level diagram [furdamentals (ubsorption maxima)].

(XBL 741-5435)

compressibility data.

The signs of these frequency shifts inmly positive interaction constants for the 1 wo in-plane vibrations measured and a regutive interaction term for the out-of-plane mode. These facts definitely justify Decius ' 3 choice of a dipole-dipole type of interaction among nearest neighbors in $\mathrm{BaCO}_{3}$. More quantitative calculations on an exact value for the transition dipole mment of carbonate ion in $\mathrm{BaCO}_{3}$ and other carbonates will be made pending the acuuisition of more complete

\section{compessibility data.}

1. M. D. Fayer and C. B. Harris, private communication.

2. Wyckoff, Structure of Crystals, Vol. 6 ,

3. J. C. Decius, J. Chem. Phys. 23, 1290 (1955).

4. E. Fishman and H. G. Drickamer, Anal. Chem. 28, 804 (1956).

5. C. K. Wu, Ph.D. dissertation, University of California (1971). p. 348 . 


\section{HEAT CAPACITY OF BISMUTH AT HIGH PRESSURE}

\section{George Jura and Berardo Jurado}

Very extensive measurements have been completed on the heat capacity of bismuth as a function of pressure at room temperature using the short (1-msec) constant-current pulsing technique developed in this laboratory.

There has been an improvement in the method of recording the pulses as well as on the analysis. For the data on bismuth a borrowed Fabritek 1070 minicomputer digitizer with a 9-bit resolution and a 20-usec-per point sampling interval was used. The additive feature permitted the collection of many pulses to increase the resolution. A total of 8 pulses for each current increased the resolution to 12 bits (one part in 4096) and a total of 10 currents was taken for each pressure. Data were taken every 1.5 kbars from $\mathrm{J}$ to 100 kbars.

The data were transferred onto magnetic tape for a permment record and subsequent analysis in the Laboratory's CDC 7600 . This method of data acquisition is mich swerior to the one of taking oscilloscope pictures, both in the time saved as well as in the accuracy of the measurements.

The basic equation for the heat capacity that takes into consideration the heat losses due to conduction can be written in the following form:

$$
C_{p} \rho d E(t)=I^{2} R^{\prime} \rho E(t) d t-K \int[E(t)-E(0)] d t \text {, }
$$

where $E(t)$ is the e.m.f. drop across the sample, $R^{r}$ is the themal coefficient of the resistance, $I$ is the current, $C_{p}$ is the heat capacity at constant pressure, and $\mathrm{K}$ is the heat leakage constant. In the limiting case as $\tau \rightarrow 0$ it becomes

$$
c_{p}=\frac{I^{2} R^{\prime} E(0)}{(d E / d t)_{0}}=I^{3} R_{0} R^{\prime} /(d E / d t)_{0} .
$$

Equation (2) can be used satisfactorily for metals like Fe for which there is a linear region beyond the first $100 \mu \mathrm{sec}$ of the pulse where there are rise time effects, and one needs only to measure the linitirıg slope. For $B i$ the pulse is curved, thus. making the detemination of the initial slope difficult. The parameter that determinn:s the amount of curvature in the traces is the time constant $t_{1 / 2}$ (the time at which the heat losses are one half of the total heat imput) which can be shown to be proportional to the ratio $C_{p} / K$. $K$ depends mainly on the gecmetry of the system, the surface of the wire, and the themal condurtivity of the pressure medium. A great deal of the curvature. in $B i$ is die to a lower heat capacity per unit volume with respect to Fe (smaller by a factor of 3) mo le restrictione by the size of the pres: e cell on the use of a wire of greater diame cer which would reduce the surface to volune ratio.

The integrations needed in Eq. (1) in order to solve for $C_{0}$ and $K$ are performed numerically either directly on the data or on smoothed data through the use of polynomial fits. The results are essentially the same.

The following is a table of $C_{p}$ and $K$. values as a function of current for $\mathrm{Bi}$ at 50 kbars:

$\begin{array}{ccc}\underset{I}{\mathrm{~A})} & \begin{array}{c}\mathrm{C}_{\mathrm{p}}\left(\times 10^{5}\right) \\ (\mathrm{J} / \mathrm{deg})\end{array} & \begin{array}{c}K\left(\times 10^{2}\right) \\ (\mathrm{J} / \mathrm{deg}-\mathrm{sec})\end{array} \\ 4.484 & 4.21 & 2.4 \\ 4.582 & 4.14 & 2.5 \\ 4.682 & 4.11 & 2.5 \\ 4.778 & 4.09 & 2.6 \\ 4.887 & 4.04 & 2.7 \\ 4.985 & 3.98 & 2.8 \\ \mathbf{5 . 0 6 1} & 3.93 & 2.9 \\ \mathbf{5 . 1 7 6} & 3.95 & 2.8 \\ \mathbf{5 . 2 7 2} & 3.85 & 3.0 \\ \mathbf{5 . 3 6 9} & 3.86 & 3.0\end{array}$

There is a small current dependence of $C_{p}$ and $K$ which cannot be accounted for at the present. Whenever possible the same set of currents were used.

A great deal of interest in $\mathrm{Bi}$ comes from the number of solid polymorphic transitions (see phase diagram, Fig. 1). There are a total of five known solid phases, four of which exist at room temperature in the 0-100 kbar interval. They can be easily detected by large discontinuities of the electrical resistance with pressure. There are also two postulated phase transitions at 45 and 65 kbars observed by P. W. Bridgman through volune changes but which have not been observed by many other investigators either in a volume change change or a discontimuity in the resistance. It was expected that $C_{p}$ could show discontinuities at those pressures if those transitions were real as well as in the other well-knowm transitions.

The experimental results are shown in Figs. 2 and 3 . First, one can observe no changes in any of the physical properties of $\mathrm{Bi}$ at 45 and 65 kbar. Thus within the experimental uncertainties there are no indications 
of intermediate phases in the 30-90 kbar pressure region. There are huge discontinuities at all the other known phase transitions $(25.4,27$, and 88 kbars $)$.

Secondly, there are huge increases in $C_{p}$ in going from phase I to phase III and from phase III to phase V. Due to the

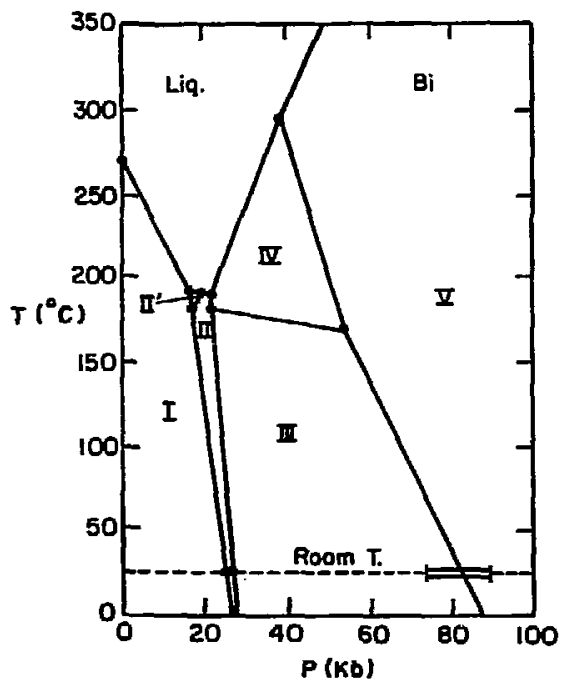

Fig. 1. Phase diagram of Bi.

(XBL 741-5436)

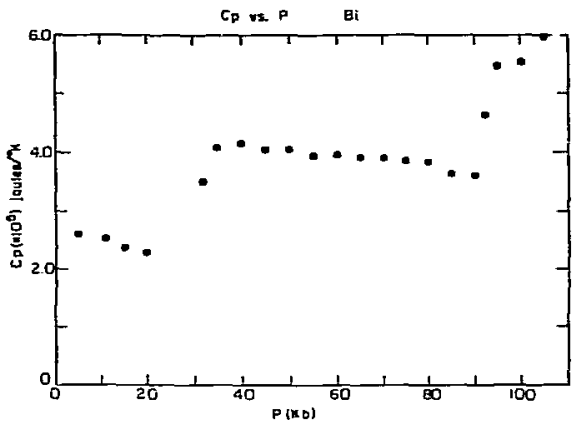

Fig. 2. $C_{p} v s . P$ (Bismuth sample). (XBL 741-5437)

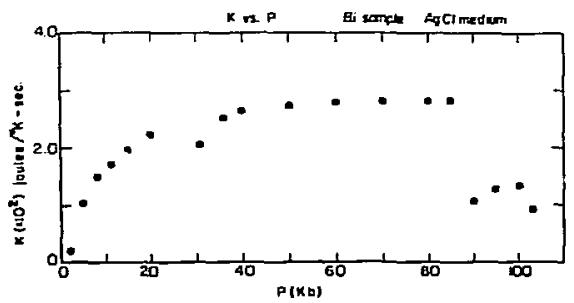

Fig. 3. K vs $P$ (Bismuth sample)

(XBL 741-5438)

narrowness of phase III, $R^{\prime}$ measurements are difficult to make and are not available now, so there are no $C_{p}$ points in that phase.

$K$ increases to about 90 kbars where it drops abruptly. The initial increase of $K$ can be explained entirely in terms of a better contact between the sample wire and the AgCl pressure medium as well as an increase of the thermal conductivity of the $\mathrm{AgCl}$ with pressure. The drop at $90 \mathrm{kbar}$ is consistent with a known phase transition of AgCl at that pressure.

The reason for the very large increase in $c_{p}$, if true, are not as yet known. They could be due to some type of hidden systematic error within tire experiment that has not been discovered. However, if real, they are hard to explain since with a Debye temperature of about $100^{\circ} \mathrm{K} \mathrm{Bi}$ is is already at the classical limit of the lattice heat capacity in phase $I$. The increase could be due to an unusually large electronic contribution to the heat capacity at room temperature of an unprecedented nature.

More measurements need to be done as a function temperature as well as pressure to test the hypothesis of a large electronic heat capacity contribution.

\section{RESEAROH PLANS FOR CALENDAR YEAR 1974 George Jura}

He will continue in the development of a method for determining the specific heats of metals and alloys under high pressures. Also continuat im and extension of high pressure optical experirents with applications to polymers and organic materials. 
Gabor A. Somorjai, Principal Investigator

1. LOW ENERGY ELECTRON DIFFRACTION (LEED) STUDIES OF SURFACES

a. Low Energy Electron Diffraction and Work Function Studies of Adsorbed Organic Layers on the (100) and (III) Crystal Surfaces of Platinum

John L. Gland and Gabor A. Somorjai

The adsorption of a group of organic compounds has been studied on the platinis (100) and (111) single-crystal surfaces. Low energy electron diffraction has been used to determine surface structures. Work function change measurements have been made to df termine the charge redistribution which occurs on adsorption. The molecules which have been studied are acetylene, aniline, benzene, bipheny1, n-butylbenzene, $t$-ubtybenzene, cyanobenzene, $1,3-$ cyclohexadiene, cyclohexane, cyclohexene, cyclopentane, cyclopentene, 2,6dimethylpyridine, 3,5-dimethylpyridine, ethylene, n-hexane, isoquinoline, mesitylene, 2-methylnaphthalene, napthalene, nitrobenzene, piperidine, propylene, pyridine, pyrrole, quinoline, styrene, toluene, m-xylene. Al1 molecules studied adsorb on both the Pt(111) and Pt(100)-(5x1) surfaces. AII molecules studied act as electron donors to the metal surface. The adsorbed layers are more ordered on the hexagonally symetric Pt(111) surface than on the squere symetric Pt(100) surface. Unsaturated molecules generaliy adsorb on the Pt(111) and Pt(100) surface by forming $\pi$-bonds with the metal surface.

b. Iow Energy Electron Diffraction and Hork Function Change Studies of Paraffins Adsorbed an Platinum Single Crystal Surfaces

Lawrence E. Firment and Gabor A. Sonorjai

Low energy electron diffraction studies with simultaneous measurements of the change in the plantinum work fumction were made during adsorption of hydrocarbons on the $\mathrm{Pt}(111)$ and $\mathrm{Pt}(100)$ surfaces. The adsorption of the simplest hydrocartons, the normal paraffins $C_{n} H_{2 n+2}$, for $n=2-7$ was examined. Of these, onIy $n$-heptane produced an ordered surface structure on Pt(1i1), at room temperature. The work function change on adsorption was also largest for $n$-heptane: - 1.3 volts on Pt (111), -1.0 volts on Pt(100). The shorter pararfins caursed proportionately smaller changes in work function. The paraffins $C_{2}-C_{5}$ were readily displaced from the surface by background gases, notably Co. These data indicate that the binding energy of these molecules to the Pt surfaces increases gradually with carbon chain length.

c. Application of Low Energy Electron Diffraction theory to Surface Structurie Analysis of Platinim and of Adsorbed Layers

Larry Kesmodel and Gabor A. Somorjai

The primary goal of 10w energy electron diffraction (LEED) has been the development of a surface crystallography similar to the X-ray method for bulk crystallography. The need for a workable surface cr/stailography is evident in the field of chemisorption where quantitative information generally requires an accurate knowledge of surface atomic geometry. The standard analysis in LEED is the measurement of the intensity of the electrons scattered elastically from the crystal surface as a function of incident beam energy at a given diffraction spot. Unfortunately, these data camnot be directly inverted to give details of surface crystal structure. Instead one must rely on comparisons between experimental results and calculations based on models of the crystal structure and the diffraction process: In recent years the quantum-mechanical scattering theory relevant to LEED has been developed to sufficient accuracy to give good agreement between theory and experiment for a mimer of clean metal surfaces. Mreover, within the past year several chemisorbed overiayer systems have been successfully analyzed by various researchers and bonding lengths have been determined.

We are using a multiple-scattering theory of LEED to investigate the surface structure of clean platinum surfaces and adsorbed gas overlayers. The theoretical work centers on development of fast and accurate perturbation methods for computing the scattering intensities, since comventional "exact" methods are prohibitively long, especially when applied to complex overlayer systems.

d. Development of Rapid Mecsurement of LEED Intensity Data for Surface Crystallography

Thomes Kaminska, Larry L. Kesmodel and Gabor A. Somorjai

Work has continued on the development of improved photographic and scarming techniques to produce intensity vs. electron energy curres 
of low-energy electrons diffracted from clean and gas-covered crystal surfaces. Spots produced on a phosphor screen by diffracted electrons are photographed as a function of energy with an aerial Tri-X film, S0-265. The film is machine-processed in duPont XPD to achieve an ASA speed rating of about 8000 . The film density is determined with a computer-controlled stepping scamer which puts the density data on magnetic tape for further processing. Computer prograns are being developed to integrate and plot the density data in I vs. eV curves for comparison with theoretical calculations. The technique will allow rapid analysis of complex crystal surfaces such a: those that are reconstructed or adsorbed gas overlayers.

e. Low Energy Electron Diffraction Studies of Vanadium Crystal Surfaces

Clifford Hegerle, FTederick J. Szalkowski, and Gabor A. Somorjai.

The intensities of LEFD beams diffracted from single-crystal surfaces depend on the mean vibrational anplitudes of the atoms from wich the incident electrons are scattered. Intensity vs. tempereture corves for the (00) diffraction beams were obtained for the clean $v(100)$, the $v(100) \cdot c(2 \times 2) S$, and the $v(100)-(1 \times 1)$ 's surfaces. These data were obtained at several incident beam energies, and extrapolation to $0 \mathrm{eV}$ incident beam energy permitted the calculation of a surface mean-squane vibrational amplitude, and a surface Debye temperature, for each surface studied.

Both IEED and AES studies were carried out on the (100) face of vonadium metal. It was found that the essentially clean metal surface displays a $(1 \times 1)$ iiffraction pattern indicating a surface structure identical with the corresponding plane in the bulk, but that sulfur segregates to the surface upon heating and transforis the surface into a $c(2 \times 2)$

structure. Room temperature gas adsorption studies on the $V(100)-(1 \times 1)$ sirface indicate that oxygen diffuses into the lattice and produces a disordered structure while carbon monoxide adsorbs upon the surface in a (1x1) ar tay. Oxygen adsorption on the V(100)$c(2 \times 2)$ surface produced a complex structure in which no oxygen was observed within the probed surface layer. This structure has been interpreted in terms of additional sulfur segregating to the solid-gas interface under the influence of the altered surface corditions (i.e., oxygen idsorption) with the subsequent desorption of the origen as this occirs. f. Low Energy Electron Diffraction Studies from Tron Single Crystal Surfaces

Clifford A. Megerle and Gabor A. Somorjai

A series of LEED Auger studies were carried out on iron single-crystal samples in order to develop a treatment to facilitate the preparation of a clean iron surface. It was discovered that sulfur was the most tenaciously held contaminant, and that heating an Fe(100) sarmle in flowing hydrogen at atmospheric pressure resulted in the rempval of all of the sulfur from the crystal. Ihring these studies, the following sulfur structures were observed; Fe(100) (disordered)S, $\mathrm{Fe}(100) \mathrm{c}(2 \times 2) \mathrm{S}, \mathrm{Fe}(100)(\sqrt{5} \times \sqrt{5}) \mathrm{R} 26.5^{\circ} \mathrm{s}$, and Fe(111) (disordered)S.

\section{AUGER ELECTRON SPECTROSCOPY OF SURFACES}

a. Auger Electron Spectroscopy Investigation of Chemical Shifts in the Varadium Compounds and the Oxidation of Vanadiums

Frederick J. Szalkowski and Gabor A. Somprjai

Characteristic Loss measurements were performed on vanadium metal and $\mathrm{V}_{2} \mathrm{O}_{3}$ for the primary bean energy range of 100 to $700 \mathrm{eV}$. Mechanisms which are consistent with all of the observations reported on vanaitiun to date have been proposed for the observed peaks. The somewhat inexpected and interesting phenomenon that a multiple interband transition loss may occur with a probability greater than that of a single interband transition loss is pointed out and is instrumental in explaining the observed data.

AES chemical shift studies were carried out on $\mathrm{v}_{2} \mathrm{O}_{4}, \mathrm{v}_{2} \mathrm{O}_{3}, \mathrm{vo}, \mathrm{VN}, \mathrm{vc}, \mathrm{v}_{2} \mathrm{~S}_{3}$, and VSi . The shift' of the totally inner shell $\mathrm{L}_{3} \mathrm{~N}_{2} \mathrm{~N}_{2}, 3$ transition and the single valence band $L_{-3}{ }_{3}, 3$ transition were measured relative to their energies in metallic vanadium. The $\mathrm{I}_{3} \mathrm{M}_{2}, 3_{2}, 3$ transition displayed a systematic shift wishich could be associated with the successive transfer of the 45 and $3 d$ valence band electrons to the anion, and the observed shifts were correlated with the Philips-Van Vechten ionicity scale. Correlation of the chemical shift data and the $O / V$ peak intensity ratio for the known varadium oxides enables one to unambiguously determine the chemical canposition of the compound formed by oxidizing vanadium metal under different temperature and pressure conditions. In addition to the "normal" vanadiun oxides, the production of the $\mathrm{V}_{3} \mathrm{O}_{5}$ Magneli phase was observed auring this set of experiments. The $\mathrm{M}_{2,3} \mathrm{VV}$ double valence 
band transition was also observed and its behavior upon oxidation indicates that at least one 45 electron is involved in this transition as opposed to the case of the $L \$ 7, V$ transition which appears to overwhelis igly involve the $3 d$ valence band.

b. Augei Electron Spectroscopy Studies of the Surface Composition of Binary A1loys as a Function of Bulk composition and Temperature (Surface Phase Iiagrams)

Steven Overbury and Gabor A. Somorjai

The surface composition of binary systems that obey regular solution theory may be very different from the bulk composition as predicted by surface thermodynamics. In addition the surface composition is also temperature deperdent. Since the nature of surface cherical reactions depend on the surface composition, it is of inmortance to determine the composition as a function of temperature and bulk composition (surface phase diagrams) by Auger electron spectroscopy. The Au-Ag system is being studied. The concentration gradient between the surface and the bulk is determined along with the effect of segregated impurities or adsorbed gases at the surface on the surface composition. These studies will be extended to complex binary alloy systems (Au-Hf, Au-Zr, and $\mathrm{Au}-\mathrm{Ta}$ ) where the surface composition may again be different from that in the bulk. The formation of surface compounds with unique physical-chemical properties is likely.

\section{CATALYSIS BY SINGLE CRYSTAL SURFACES}

a. The Influence of Step Density on the Reactivity and chemisorption if n-heptane on a Series of low and tigh $\mathrm{M}$, 1er Index Platinum Crystals and Polycr talline Platinum

Kenneth Baron, Donald H. Blakely, and Gabor A. Somorjai

The reactions of $n$-heptane, in the presence of hydrogen, on platinum in the form of single crystals (high and low Miller index) and polycrystalline foil, has been studied using the techniques of Aurger electron spectroscopy, quadrupole mass spectronetry, and low energy electron diffraction (LEED). The specific activities for the dehydrocyclization reaction to form toluene, the hydrogenolysis reaction to form saturated hydrocarbons, and the isomerization reactions to form methylhexanes and dimethylpentaies have been obtained. The atomic surface structures detectable after these reactions by LFFH have been tabulated. The hydrogenolysis and isomerization reactions are favored on the single crystals with high step density, which form disordered carbonaceous layers. The dehydrocyclization reaction is most extensive on the stepped surface, which is most favorable to the formation of a $(\sqrt{3} \times \sqrt{3})-R 30^{0}$ carbonaceurs ordered structure. The chemisorption and reactivity of n-heptane on these surfaces has been compared with the data of other workers.

b. Studies of the Chemisorptive and Catalytic Activities of Iridium, Platinu, and Gold Single-Crystal Surfaces Using Low Energy Electron Diffraction, Auger Electron Spectroscopy, and Mass Spectrometry

Michael Chesters and Gabor A. Somorjai

Iridium, platinum, and gold possess siurilar bulk and surface crystal structures but display varying catalytic activity with particular contrast between platinum and the relatively inactive gold. Studies have been initiated on both the low-index and the high-index (stepped) surfaces of these metals to identify the relative importance of crystal surface structure and electronic structure in catalysis.

Preliminary IEED results show that the stepped gold surface AuS $[6(111) \times(100)]$ is stable in vacum us to $800^{\circ} \mathrm{C}$ while its activity in chemisorption of naphthalene, monitored by Auger electron spectroscopy, is some two orders of magnitude lower than the corresponding platinum surface.

c. Studies of the Isomerization of NeoPentane and the Dehydrogenation of cyclohexane on Stepped Platinum Crystal Surfaces

Donald W. Blakely and Gabor A. Somorjai

The reaction rates of these tro inportant catalytic reactions are being measured on various stepped platimum surfaces, using a mass-spectrometer defector at a total presstire of $10^{-5}-10^{-4}$ Torr. The suriace structure sensicivity of these reactions is explored. The active $6(1 i 1) \times(100)$ stepped surface is studied by Auger spectroscoppy ami LEED to explore the structural and conpositional factors controlling the reproducibility of its catalytic activity. 
d. The Hydrogenolysis of Cyclopropane on Plat Inum Stepped Single Crystals at Atmospheric Pressure

Danie1 R. Kahn, Eugene E. Petersen and Gabor A. Somorjai

A review of the arrent literature in surface chemistry and heterogeneous catalysis has revealed that there is a gap between chenisorption and surface reaction studies performed in ultrahigh vacum $\left(10^{-4}\right.$ to $10^{-9}$ Torr) on single-crystal surfaces and those carried out at 1 atmosphere on highly dispersed supported catalysts. Although the low-pressure work is of fundamental importance to catalysis, a direct correspondence between these studies and more $\therefore$ mventional catalytic experiments is id scured by a number of factors, not the least of which is the enompous difference in total pressure--some $10^{7}$ to $10^{12}$ orders of magnitude. Hence there is a need to measure the activity of single-crystal surfaces at high and $10 \mathrm{w}$ pressure. Furthermore, it has been shown that single-crystal surfaces would serve as ideal models for highly dispersed supported metal catalysts.

An apparatus was therefore constructed to stuidy catalytic reactions on one or more platimm single crystals in situ both at 1 atm total pressure and in ultrahigh vacum. The main feature of the design is a novel movable bellows-cup mechanism by which the catalyst can be encased in a small volume for the high-pressure experiments. A gas chromatographic sampling technique is employed to monitor the formation of products in the high-pressure system.

Using this apparatur, the cyclopropane hydrogenolysis has been investigated at 1 atm pressure on a platimu stepped single crystal (Pt(S) - [6(111) $\times(100)]$ having a total surface area of $0.76 \mathrm{~cm}^{2}$. Initial specific reaction rates were reproducible to about $10 \%$, and to within a factor of 2 were identical to published values for this reaction on highly dispersed supported platinum catalysts. The activation energy for the urpoisoned catalyst was found to be $12.2 \mathrm{kcal} / \mathrm{mol}$, while that for the partially deactivated catalyst was $10.5 \mathrm{kcal} / \mathrm{mol}$. The order of the reaction with respect to cyclopropane was satermined to be $0.8 \pm 0.2$. The conditions of ln-Irogen nretreatment were found to be important factors in determining the inttial shape of the reaction rate curve.

This work has shown that it is possible to measure zates of reaction on a single platinum crystal heving a surface area of $1 \mathrm{~cm}^{2}$ at atmospheric pressure using a themal conductivity detector of a gas chromatograph. Studies of this type appear to be riell suited to discover the relarionsinip between the morphology of the catalyst surface and its * heterogeneous catalytic activity.

Partially funded by the U. S. Army.

\section{MoleCILAR BEAM SCATTERING FROM SURFACES ${ }^{\dagger}$ \\ a. The $\mathrm{H}_{2}-\mathrm{D}_{2}$ Exchange Reaction on Stepped and (III) Surfaces of Platinum Crystals}

Steven L. Bernasek and Gabor A. Somorjai

The $\mathrm{H}_{2}-\mathrm{D}_{2}$ isotope exchange reaction was studied on the $\mathrm{Pt}$ (997) and $\mathrm{Pt}$ (111) singlecrystal surfaces. It was found that the exchange takes place readily on the high-index surface but not at all on the (111) surface under the same conditions. Detailed investigations of the kinetics of the exchange reaction on the (997) surface have indicated a two-branch mechanism. One branch appears to be surface-diffusioncontrolled with subsequent dissociation of the hydrogenic moleculle at surface steps, while the other branch is direct step-aided dissociation.

b. Energy Accommodation of Gases on Scattering from Clean and Gas-Covered Platinum Surfaces

Steven L. Bernasek and Gabor A. Somorjai

The angular distributions of several monatomic and diatomic gases scattered from clean and C0-covered $P t(111)$ single-crystal surfaces have been studied. From the clean surface, the scattering distributions are specularly directed, while from the cocovered surface the distribution is cosine. The efficient energy transfer indicated by the scattering distributions from the COcovered surface is attributed to lowfrequency bending modes of the $\mathrm{com}$ molecules on the surface. The increased surface residence time resulting from this efficient energy transfer could be responsible for higher sticking probabilities and increased reaction rates for adsorption-limited reactions.

c. Molecular Beam-Surface Energy Exchange Studies

Stephen B. Brumbach and Gabor A. Somorjai

An apparatus has been assembled to study the energy exchange between particles in a 
molecular beam and a solid surface. The purpose of these experiments is to study the translational energy accommodation between an incident atom or molecule at a particular temperature and a solid surface at some different temperature, and also to study the kinetic energy of the products of chemical reactions formed on the solid surface.

In order to measure the translational kinetic energy of the particles scattered from the surface, a variat-a-speed chopper is placed between the surface and a quadrupole mass spectrometer detector. The phase lag in the resulting ac signal contains information about the time of flight, and hence velocity, of the scattered particles.

TPartially funded by NSF.

\section{SOLAR CELL RESEARCH ${ }^{\ddagger}$}

Wigbert J. Siekhaus and Gabor A. Somorjai

Photovoltaic conversion of sumlight into electricity in solar cells is feasible but presently uneconomical. Efricient and stable solar cells are manufactured today fram highpurity silicon single crystals sliced into thin $(0.3 \mathrm{~mm})$ rectangular wafers of approximately $10 \mathrm{~cm}^{2}$ area $\left(\sim 2 \times 10^{-2}\right.$ watt average output). Five thousand of these cells must be intercomected to provide $1 \mathrm{kw}$. our research is aimed at developing a polycrystalline silicon solar cell with suitable electrical properties that will make photovoltaic energy conversion economical. 1) We are studying the various methods to deposit their layers of solar cell material with sufficient crystallinity over a large area $\left(m^{2}\right)$. The catalysis of condensation and recrystallization of silicon doped with suitable impurities is investigated to produce the thin silicon layers at low temperatures. 2) Electran spectroscopy, low energy electron diffraction and electron microscopy are utilized to investigate the surface and grain boundary structure of the thin films and their effect on the electrical properties. We have dedicated to this solar cell research: an ultrahigh vacunm system equipped wi th LEED, a high-resolution electron spectraneter, an ion sputtering gun, and a device to break materials under ultrahigh vacurm conditions; a high-vacum system with three electron-beam gun evaporators modified for silicon deposition work; and electronic instrumentation to measure electrical properties of solar cell films produced in the laboratory. The following experiments are planned or being performed in the laboratory. a. Identification of Impurities Segregated on Grain Boundaries and Their Effect on Electronic Surface States

Wigbert J. Siekhaus and Gabor A. Somorjai

The review by $\mathrm{Mbinch}^{1}$ and more recent work by Rowe and $\mathrm{Tbaci}^{2}$ show clearly that the large conrentration of surface states which are trays and reconbination centers for photoelections can be filled or decreased by orders of magnitude by exposure to various adsorbates. Polycrystalline samples of electronic and metallurgical grade silion (either before or after they have been diffused to form $\mathrm{m}$ junctions) will be broken along grain boundaries under ultrahigh vacum conditions. Impurities on the grain boundaries will be identified (qualitatively and quantitatively) using Auger electron spectroscopy. Single-crystal silicon samples with low-Miller-index surfaces will be exposed under ultrahigh vacum conditions to various adsorbed impurities. The effect of irmurities on surface states will be studied using high resolution electron loss spectroscopy and phtoelectron spectroscopy.

Development work on a monochmonatic He-light source (20 and $40 \mathrm{eV}$ ) has begun in cooperation with the nuclear chemistry group.

1. Winfried Mönch On the Physics of Clean Silicon Surfaces, XIII Advances in Solid State Physics, Pergamon Press, March 1973. 2. J. E. Rowe and H. Ibach, Surface-State Transitions of Silicon in Electron Energy Loss Spectra, Phys. Rev. Letters, 9 July 1973, Vol. 31, No. 2 .

b. Deposition and Characterization of Silican Films for Solar Cell Use

Chin-An Chang, Tom Kaminski and Wigbert J. Siekhaus

Production of Si polycrystalline thin films can be achieved using techniques such as chemical vapor deposition (CVD), evaporation, sputtering, etc. The CVD method will be the main technique used in this laboratory for the near future. For the epitaxial gIC th of $\mathrm{Si}$ films using the $\mathrm{CD}$ technique, silane gas, $\mathrm{SiH}_{4}$, has been widely used. $\mathrm{SiH}_{4}$ decomposes on a heated substrate at $\sim 1100^{\circ} \mathrm{C}$ and silicon is deposited. The substrate temperature necessary for the thermal decomposition of silane can be significantly lavered by a codeposition of silane with another gas, diborane, $\mathrm{B}_{2} \mathrm{H}_{6}$. The lowest temperatures of decomposition that were achieved were $300-600^{\circ} \mathrm{C}$. I The Si thin filns produced this way, however, have very lows 
photovoltaic efficiencies because of their polycrystalline structure. To improve the film qualities, we plan to combine CVD with the ultrathin alloy-zone-crystallization (UTAZC) technique. 2 In the UTAZC technique an extremely thin alloy 1ayer is deposited on the substrate prior to sublimation or evaporation of $\mathrm{Si}$. The grain size of the $\mathrm{Si}$ film thus deposited was formd to increase to $300 \mu$, compared with the usual 5- $\mu$ size achieved at a substrate temperature of $1100^{\circ} \mathrm{C}$. The combined use of the CVD and UTAZC techriques could therefore produce single crystal-1ike Si films at lower substrate temperatures. This would allow the use of Al as the substrate meterial for a good electrical contact with the Si films deposited.

Systematic studies will be carried out to find the best catalyst for lower temerature CVD of silane, and the best alloy film for the UTAZC purpose. Also, cheaper starting material such as $\mathrm{SiCl}_{4}$ will be tested for CVD of Si. The Si films produced will be characterized by electrical measurents (resistivity, photoconduc tivity, carrier mobility and lifetime) by their grain structure and surface properties. Pichaud and Drechsler ${ }^{3}$ have shown increased surface self-diffusion and surface recrystallization of tungsten under the influence of adsorbed nickel. If such a surface alloy can be maintained dring deposition of silicon, large grain silicon films can be formed at a temperature low corpared with the conventional recrystallization temperature; i.e., the adsorbed species auts as a crystallization catalyst.

In the planned experiment the surface recrystallization temperature will be measured as a function of the adsorbed element. Elements will be chosen that have low bulk solubility in silicon. LEED will be used to define the recrystallization temperature.

d. Measurement of Solar Cell and Semionfluctor Hectrical Characteristics

Tom Kaminska and Wighert J. Siekhaus

Facilities for measuring seniconductor and solar cell electrical parameters are being established to compliment crystallization catalysis and polycrystalline solar cell studies being confucted by the group. The measurements will serve a dual purpose: they will allow quality determination of materials produced and a detailed study of polycrystal. line solar cell operation.

Van der Patw methods 4 will be used to det-rmine sample bulk resistivity and carrier concentrations and a photoconductivity measurement similar to that of Stevenson and
Keyes 5 will determine minority carrier lifetime. The cells will be successively anodized and etched, and electrical measurements made at each step to generate a depth profile of carrier concentration and lifetimes. This will be compared with a doping concentration profile determined by ion sputtering and Auger analysis.

Surface lifetimes, surface state density, and surface state energy levels, and their variation with adsorbed gases and ingurities will be studied using conductivity and temperature ${ }^{6}$ methods in conjunction with ultraviolet photoelectron spectroscopy to determine how electronic surface states at grain boundaries affect polycrystalline solar cell resistance. With this information in hand we should be able to increase polycrystalline solar cell power output.

$\ddagger$ Supported by NSF-RANN.

1. L. H. Hall and K. M. Koliwad, J. Electrochem. Soc. 120, 1438 (1973); F. C. Eversteyn and B. H. Put, ibid. 120, 106 (1973); and references therein.

2. J, D. Filby and S. Nielsen, J. Electrochem. Soc. 112, 957 (1965).

3. M. Pichaud, M. Drechsler, Surface Selfdiffusion of Tungsten under the Influence of Adsorbed Nickel, Surface Sci. 36(3), 813-16 (1973).

4. L. J. Van der Paww, A Method of Measuring Specific Resistivity and Hall Effect of Discs af Arbitrary Shape, Phillips Res. Repts. 13, ㄴo. 1,1 (1958).

5. D. T. Stevenson and R. J. Reyes, Measurement of Carrier Lifetime in Germanium and Silicon, J. Appl. Phys. 26, 190 (1955). 6. P. M. Brown and P. V. Gray, Density of $\mathrm{SiO}_{2}-\mathrm{Si}$ Interface States, Appl. Phys. Letters $\underline{8}, 31$ (1966).

\section{RESEARCH PLANS FOR CALENTIAR YEAR 1974}

Gabor A. Somorjai

WW energy electron diffraction studies of molealar crystals surfaces are initiated. The surface structures of ice, naphtalene and phemantrene that are grown epitaxially on metal surfaces at low temperatures $\left(-100^{\circ} \mathrm{K}\right)$ will be studied. Surface studies of high molecular weight, low vapor pressure organic solids (polymers) will be carried out.

Catalysis studies on alloy surfaces are initiated to investigate the reactivity of hydrocarbons as a function of alloy surface compositions. Gold and platinum alloys, 
gold-iridiun and gold-hafniumi alloys are being used. The purpose of these investigations is to develop an alloy catalyst with catalytic premerties identical to that of platinum for the various hydrocarbon surface reactions. Catalysis of $\mathrm{N}_{2}$ and No molecule reactions on iron crystal surfaces will be investigated. The catalytic hydrogenation of carbon and the catalytic dissociation of water will be studied.

The electronic surface states of silicon and platinum will be studied by electron loss and UV photoelectron spectroscopy. The effect of gas adsorption on the surface electranic properties will be studied by these techniques.

The research on solar cells has been initiated and is outlined in detail in the previous section, 5 .

\section{1973 PUBLICATIONS AND REPORTS}

Gabor A. Somorjai and Associates

Joumals and book chapter

1. G. A. Sonorjai, Low Energy Electron Diffraction and Auger Electron Spectroscopy Studies of the Structure of Adsorbed Gases on Solid Surfaces. Surface Sci. 34, 156 (1973) (LBL-878) .

2. M. R. Martin and G. A. Somorjai, Determination of the Surface Geometry for the Aluminum (110) and (111) Surfaces by Comparison of Low-Energy-Electron-Diffraction Calculations with Experiment, Phys. Rev. B 7, 3607 (1973) (LBL-1151 Rev.).

3. J. L. Glend and G. A. Somorjai, LFED and irork Function Studies of Benzene, Naphthalene and Pyridine Adsorbed on $\mathrm{Pt}(111)$ and $\mathrm{Pt}(100)$ Single Crystal Surfaces, Surface Sci. 38, 157 (1973) (LBL-1422).

4. S. L. Bernasek, W. J. Siekhaus, and G. A. Somorjai, Molecular Beam Study of Hydrogen-Deuterium Exchange on Low and High Miller Index Platinum Single Crystal Surfaces Phys. Rev. Letters 30, 1202 (1973) (LBL-1809)

5. R. W. Joyner and G. A. Samorjai, Reces. Trends in the Application of Low Energy Electron Diffraction, in Suriace and Defect Properties of Solids 2, 1 (1973), The Chemical Society Publ.

6. S. Berglund and G. A. Somorjai, Auger Electron Spectroscopy Study of the Surface Composition of the Lead-Indiun System, J. Chem. Phys . 59,5537 (1973) (LDL-1867).

\section{LBL reports}

1. P. A, Bertrand and G. A. Sumorjai, Estimation of Surface Free Energies of Metals, LBL-1466, Feb. 1973.

2. K. Baron, D. W. Blakely, and G. A. Somorjai, LEED Studies of the Surface Structures of Adsorbed Hydrocarbons (n-Heptane, Toluene, Benzene, Ethylene, and Cyclohexane) on Stepped (High Miller Index) Platinum Surfaces, LBL-1813, May 1973 (to be published іл Surface 3cience).

3. J. Wasilczyk, Measurentant of Intensities of LEED Beams from Platinum Surfaces and from Adsorbed Overlayers (M.S. thesis), LBL-1807, June 1973.

4. J. L. Gland and G. A. Somorjai, LEED and Work Function Change Studies of the Adsorption of Substituted Aromatic Molecules on the (111) and (100) Crystal Faces of Platinlm, LBL-1815, July 1973 (to be published in Surface Science).

5. G. P. Sarnoriai and S. B. Brumbach, The Interacti $\pi_{i}$ of iblecular Beans with Solid Surfaces, LBL-2:12, Aug. 1973.

6. Daniel R. Kahn, The Hydrogenalys is of Cyclopropane on Platinum Stepped Single Crystals at Atmospheric Pressure (Ph.D. thesis), LBL-1891, Sept. 1973.

\section{F. J. Szalkowski, Auger Electron} Spectroscopy Analysis of Vanadium and Vanadium Compound Surfaces (Ph.D. thesis), LBL-888, Dct. 1973.

8. G. A. Somorjai, The Structure and Tnemodynamics of Clean Surfaces-Principles, LBL-2257, Oct. 1973.

9. J. L. Gland, Low Energy Electron Diffraction and Work Function Studies of Adsorbed Organic Layers on the (100) and (111) Crysta1 Surface of Platinum (Ph.D. thesis), LBI-1816, Sept. 1973.

10. F. J. Szalkæwski and G. A. Somorjai, Allb-1 Electron Spectroscopy Shifts in some Vanadium Conpounds, submitted to J. Chem. Phys. North American kackwell Science Center Reportj Decenber 1973.

11. F. J. Szalkowski, P. A. Bertrand, and G. A. Somorjai, Characteristic Energy Loss Spectra of Vanadium and of $\mathrm{V}_{2} \mathrm{O}_{3}$, submitted to Phys, Rev. (North American Rockwell Science Center Report) December 1973. 
Lee F. Donaghey, Principal Investigator

\section{GEAIICAL VAPOR DEPOSITION}

a. Thernodynamics of Phase Equilibria for Chemical Vapor Deposition of GaAs $1-x^{P} x^{n}$

Saleem A. Shaikh and Lee F. Nonaghey

The themodynamics of nhase equilibria in the Ga-As-P-Cl-H system was studied for reactor condition allowing the chemical vapor deposition of $\mathrm{CaAs}_{1}-\mathrm{x}_{\mathrm{x}}$ solid solutions from $\mathrm{Ga}_{2}$ ( ) $\mathrm{AsH}_{3}, \mathrm{PH}_{3}, \mathrm{HCl}$, and $\mathrm{H}_{2}$ source chemicals. The properties of reaction equilibria and the predominant chenical species were deduced for each zone of the reactor. Analytical procedures were deduced for calculating multi-componetit phase equilibria in tems of reduced variables. The composition of the GaAs $1-\mathrm{x}_{\mathrm{x}}$ alloy was calculated as a fre: :tion of temperature and the arsine-phosphine ratio. These calculations provide a basis for efficient III-V compound reactor design and operation. The results of experinental studies provide confirmation of the phase equilibria for alloy compositions near $x=0.4$.

Abstracted fron LBL-2241.

b. Reactor Designs for the Chenical Vapor Deposition of Epitaxial GaAs $]-x \mathrm{P}^{*}$

Saleem A. Shaikh and Lee F. Donaghey

Research and commercial reactor desipns for the chemical vapor deposition of GaAs $1-x p_{x}$ alloys were revievied wi th regard to source chemicals and cherical reaction schemes. The open-flow reactors revietied are shown schenatically in Fig. 1. Reactor design criteria and limitations vere deduced for open-flow reactors utilizing liquid and vapor source chemicals. Commercial reactor designs were examined for properties of reactent flow and substrate orientation. The jesign and operating properties of a cold-wall reactor utilizing trimethyl gallium as a source chemical is compared to hot-wall reactor properties.
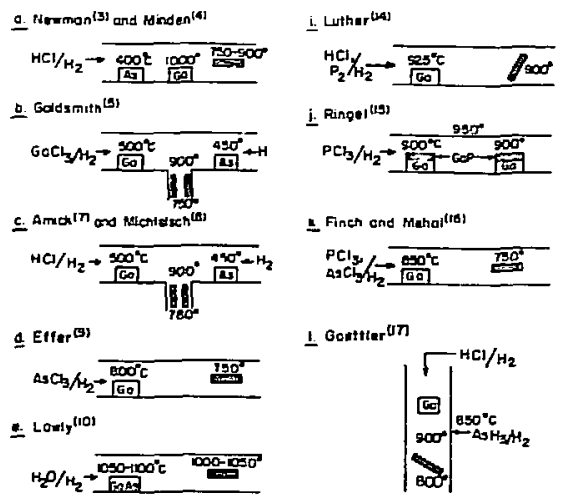

E Finch and Mahail(1s)

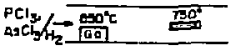

1. Gontieron

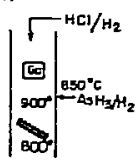

1 Autenstinin (1)

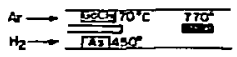

요. $\operatorname{Bon}^{(10)}$

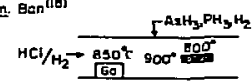

g. Tierientar

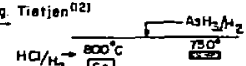

n. Menaba(由)

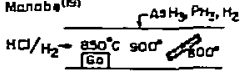

shotis)

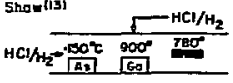

․ㅡ Busichereon

$\mathrm{PCh}_{3} \mathrm{~A}_{2}=6 \mathrm{60}$

Fig. 1. Open flow reactors for the chemical vapor deposition of GaAs, GaP, and GaAs $1-x^{P}$ so id solutions. Refer to LBL- 2518

fur references.

(XBL 729-6985)

* Abstracted from LBL-2518.

c. Kinetics of Gafs-GaP-HCI Reactions

Ronald H. Bissinger and Lee F. Donaghey

The kinetics of gas-solid reactions for etching and deposition are of significant importance in the processing of corpound semiconductor devices. The surface morphology of sites for epitaxial srorth can be optinized by controlled etching with $\mathrm{HCl}$. The kinetics and morphological properties of the raAs-HCl and $\mathrm{GaP}^{\mathrm{H}} \mathrm{HCl}$ reactions are curren $+1 \mathrm{y}$ under study to characterize the mixed-diffusioncontrolled and surface-reaction-controlled kinetic regimes and to allow prediction of etching rates and morphological consequences under various reaction conditions. 
Two methods are presently under investigation for measurement of reaction kinetics. The first method involves themogravimetry, at reduced pressure in order to minimize the gas phase diffusional resistance. The second method utilizes a rotating surface which, through establishing a uniform boundary layer, permits the estimation of diffusional contributions to the measured reaction rate. The goals of the progran are to establish the reaction kinetics and to optimize conditions for processing substrate crystals for electro-optical device applications.

\section{d. Chemical vapor Deposition of Compounds in the Ti-Si-C System}

Charles W. Manke and lee F. Donaghey

The themodynamics of altemative vaporsolid reactions are being studied to develop reaction schemes for the chemical vapor deposition of protective coatings in the Ti-Si-C system at reduced temperature. Chemical vapor deposition is appealing as a process for depositing protective coatings onto low-cost alloys. Deposition onto hardened steels has disadvantages at high temperature, however, as structural properties of the steel substrate are degraded and often the deposited layer exhibits a low impact strength. These factors point to the need for low-temperature chemical vapor depositions. This study will concentrate on phases in the Ti-Si-C system and volatile transport agents. Phases such as TiC have application as self-lubricating coatings at very $10 \mathrm{w}$ temperat ure. A possible limitation of lowtemperature reactions is slow reaction kinetics.

1. H. Gass and H. E. Hintermam, in Chenical Vapor Deposition, 4th International Conference, edited by J. M. Blocher and G. Wakefield (The Electrochemical Society, Princeton, N. J., 1975).

e. Tank-Mixing Nethods for Producing TimeVarying Reactive Gas Nixtures

\section{Lee F. Donaghey and Saleen A. Shaikh}

Tank-mixing methods are under study to provide simple means for producing controlled time-varying reactive gas mixtures for epitaxial reactors. The transient output concentrations of single and multiple mixingtank systems with series and parallel flow were simulated for discrete changes in the input concentration, input flow rate, or tank volumes. A series arrangement of mixing tanks and the output concentration produced (o)
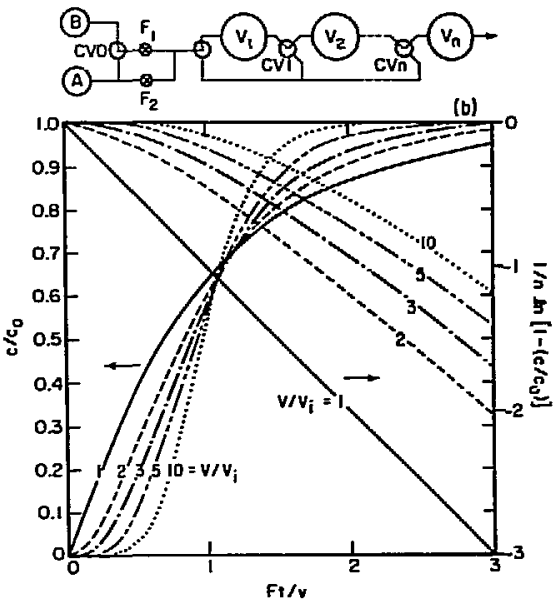

Fig. 1. Initial transient output concentration from a series of $n$ mixing tanks with volumes $v_{i}=V / n$ : (a) schematic of flow system, and (b) time dependence of $c / c_{0}$ and $n^{-1} \ln \left(1-c / c_{0}\right)$.

(XBL 7311-6716)

by a step input change is shown in Fig. 1. A simle tank-mixing system is proposed for composition grading of ternary compoundalloy epitaxial layers on binary substrates. The system proposed requires changes in both gas composition and mixing tank volume.

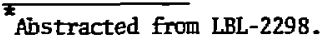

f. Characterization of III-V Compound Substrate and Epitaxial Layers by Bivergent X-ray Bean Diffraction ${ }^{\star}$

Lee F. Doraghey and Ronald H. Bissinger

The divergent $x$-ray bean diffraction method was studied for characterizing the lattice perfection in GaAs substrates and of composition variation and grath defects in epitaxial GaAs $1-P_{x}$ layers. Reflections from the $\{711\},\{620\},\{551\}$, and (400) planes predominate in pseudo-Kossel backreflection patterns obtained fram samples with (100) surface orientations, as is 


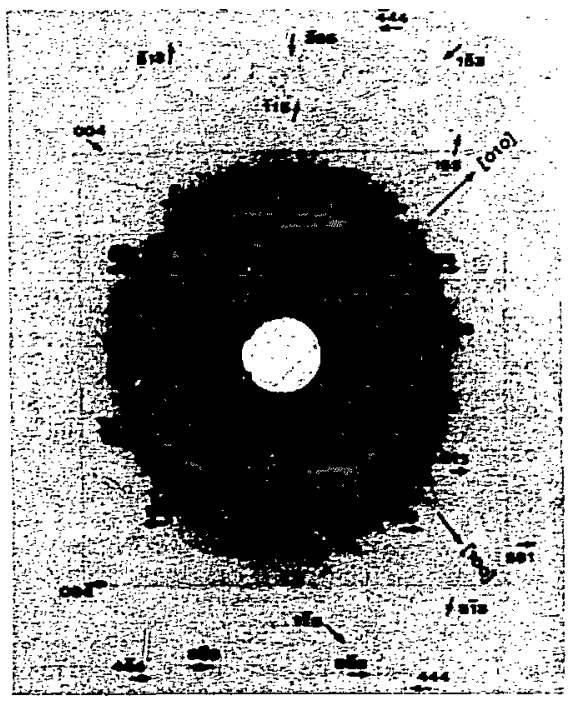

Fig. 1. Pseudo-Kossel back-reflection pattem from (100) GaAs.

(XRB 737-4370)

shom in Fig. 1. The selectivity of pseudoKossel line displacements was assessed as a function of lattice parameter and anisotropic strain distortion. Lattice parameter variations in epitaxial layers are accurately measurable frum $\{551 \hat{j},\{444\}$, and $\{422\}$ plane reflections, wile (400) line displacements can be used to measure lattice strain.

\footnotetext{
Abstracted from LBL-1872.
}

\section{CHEMICAL TRANSPORT}

a. An Aralysis of Mruti-component, Chemical Transport Crystal Growth*

Rajani B. Agnihotri and Lee F. Donaghey

The chemical transport of binary compounds in closed containers is under study to assess the contribution to chenical transport crystal growth of variable transport properties under conditions of multi-component, gas phase, diffusion-controlled kinetics. The analytical approach utilized is the integration of the Stefan-Hfaxwell transport equations for multi-camonent gaseous diffusion. The diffusion flux is calculated by a self-consistent solution of diffusive transport and phase equilibria at ends of the transport path. The general analysis allows the prediction of interdiffusion contributions to the transport flux for crystal growth.

\footnotetext{
Abstracted from LBL,-2254.

b. Chenical Transport Analysis of $\mathrm{nnS}_{\mathrm{S}}$ Crystal Growth*
}

Rajani B. Agnihotri and Lee F. Donaghey

Crystal growth of $\mathrm{znS}$ by the closed-tube chemical transport method with iodine as a transport agent was explored by numerical simulation. An analysis of diffusioncontrolled kinetics based on integration of the Steran-Maxwell equations for multicomponent diffusion was utilized to calculate the transport flux as a function of transport agent concentration and temperature gradient along the transport path. The product flux was found to increase approximately linearly with temperature gradient along the transport path for fixed initial iodine concentration, but to tend to a saturation value as the initial iodine concentration is increased for a fixed temperature gradient. The analysis provides a basis for the crystal growth of $\mathrm{ZnS}$ by chemical transport.

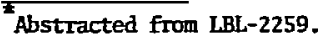

c. Phase Equilibria and Transport Processes for Inqurity Introduction into Compound Semiconductors

Steven R. Styer and Lee F. Donaghey

Phase equilibria between compound semicontuctors and electrically active inpurities are under study toward the design of processes for impurity introduction by closed and openflow methods. Previously determined equilibria in the $\mathrm{Zn}-\mathrm{Ga}-\mathrm{As}$ system will be modeled and extended. The phase equilibria in the Cd-Ga-As systen will then be predicted and confirmed by spectroscopic metheds. Diffusion data will then be combined with optimal equilibrium conditions to design transport processes for the controlled introduction of electronic inmurities. 


\section{CRYSTALLIZATION}

a. Application of Velocity-Selective FreezePushing to the Separation and Characterization of Particulate Natter in Air Pollution Samples:

T. Thomas Shih and Lee F. Donaghey

A new method for sampling and characterizing airborne solid particulate matter in air pollution samples was irvestigated. The method utilizes the phenomenon of velocityselective freeze-pushing of particulate matter during controlled solidification of organic liquids. Selective separation of particles is achieved by differences in their interfacial physical properties relative to the organic liquid or solid. The theoretical basis of this phenomenon was explored to develop a separation factor, $k^{*}$, which characterizes the effectiveness of the freeze-pushing phenomenon. The separation of particulate minerals with $\mathrm{H}_{2} \mathrm{O}$ was explored quantitatively using the zone chromatographic separation technique. The experimental separation of graphite and hematite particles with thymol was investigated toward dedwring conditions leading to optimum separation.

$\overline{{ }_{\text {Abstracted from }} \mathrm{LBL}-2243 .}$

b. Congruent Saturating Solvents for Gamet Crystal Growth

Pei Shiun Ghen and Lee F. Donaghiey

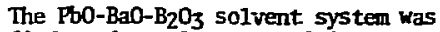
stulied to determine compositions alloring congruent saturation of rare-earthsubstituted magnetic garnets. Because the solvents $\mathrm{BaO}=\mathrm{B}_{2} \mathrm{O}_{3}$ and $\mathrm{PbO}$ have different affinities for rare earth and iron oxides, respectively, it should be possible to detemine solvent mixtures such that solutions in equilibriun with a given compound have component ratios which are the same as those in the compound itself. The problem is complicated by limited stability ranges for complex crystal structures such as the rareearth-stbstituted iron gamets. Congruently safurating solvents would nevertheless allow significant increases in crystal yield fiom the growth solution and improve crystalline perfection through reducing interfacial instabilities caused by constitutional supercooling.

Experimental studies were conmucted to explore phase equilibria in the pseudotermary system, $\left(\mathrm{Eu}_{x} \mathrm{Er}_{1-\mathrm{x}}\right)_{3}\left[\mathrm{Ga}_{y} \mathrm{Fe}_{1-\mathrm{y}}\right]_{5} \mathrm{O}_{12-}$ $\mathrm{PbO}-\mathrm{BaO}_{\mathrm{B}} \mathrm{O}_{3}$. Liquid Dhase epitaxial
Crystallization of the garnet phase was carried out on axially rotating, gadoliniumgallium garnet substrates. Compositions of the epitaxial layers were determined by electron microprobe analysis. The study showed that the gamet phase is the stable solid over a wide range of solvent compositions, and that congruency of saturation is only weakly dependent on the ratios of oxide components of the garnet phase.

\section{SPUTTER DEPOSITION \\ a. Reactive Sputter Deposition of TiO $x$}

Kenneth G. Geraghty and Lee F. Donaghey

The reactive sputter deposition of titanium oxides is under investigation utilizing rf sputtering of a titanium target in an argon plasma containing controlled, partial pressures of oxygen. TiO $x$ thin films with $1<x<2$ were deposited on quartz and glass stbstrates. Amorphous films were deposited at rom temperature with deposition rates decreasing with oxidation of the target. Selected film properties are under study to determine the effect of sputter deposition parameters such as the $\mathrm{O}_{2}$ partial pressure in the plasma. These studies will permit prediction of the stoichiometry and film properties as a function of reactive sputtering conditions.

b. Computer Simmlation of Sputtering

Pravin Mandhr and Lee F. Donaghey

The sputter yield from single crystals is urder study utilizing numerical methods. The sputtering of $\mathrm{Cu}$ with $\mathrm{Ne}^{+}$was simulated as a function of incident ion energy and direction, using interatumic potential fumctions derived from band structure considerations. The repulsive potential function giving agreement with experimental data was deteruined in the ion energy range from 0.5 to $1 \mathrm{keV}$. The sputtering mechanisms and energetics for different mecinarisms will provide information toward predicting the dependence of yield on sputter conditions.

\section{SOLID-STATE ELECTROCHBISTRY}

a. Oxygen Transfer Kinetics Betwean $\mathrm{Ga}-\mathrm{Ga}_{2} \mathrm{O}_{3}$ Electrodes and the Solid Hiectrolyte CalciaStabilized Zirconiax

Lee F. Dant.ghey and Raymond Pong

The ki letics of oxygen transfer between 
Ga-Ga2 $\mathrm{O}_{3}$ cornposite electrodes and the solid electrolyte calcia-stabilized zirconia, $\mathrm{ZrO}_{2}(\mathrm{CaO})$, were studied with the symmetric galvanic cell,

$$
\mathrm{W} / \mathrm{Ga}-\mathrm{Ga}_{2} \mathrm{O}_{3} / \mathrm{Ca}_{0.15} \mathrm{Zr}_{0.85} \mathrm{O}_{1.85} / \mathrm{Ga}-\mathrm{Ga}_{2} \mathrm{O}_{3} / \mathrm{H},
$$

over the temperature range from 800 to $900^{\circ} \mathrm{C}$. Chronopotentiometric studies were conducted using current densities from 0.3 to $130 \mu \mathrm{\mu} / \mathrm{cm}^{2}$ to obtain overpotentials for Faradaic oxidation and reduction reactions at the $\mathrm{Ga}-\mathrm{Ga}_{2} \mathrm{O}_{3} / \mathrm{ZrO}_{2}$ (CaO) interface (see Fig. 1). A linear dependence of the overpotential on current density was obtained, corresponding to a local electrode resistance of $3.8 \mathrm{ohm}$ per $\mathrm{cm}^{2}$ of electrode-electrolyte interface at $800^{\circ} \mathrm{C}$. The data are in agreement with a solution-diffusion mechanism of oxygen transport through liquid $\mathrm{Ga}$ in the electrode between the $\mathrm{ZrO}_{2}(\mathrm{CaO})$ electrolyte and $\mathrm{Ga}_{2} \mathrm{O}_{3}$ particles. The electrode kinetics for oxygen transfer with this electrade are faster than for other metal-metal oxide electrodes.

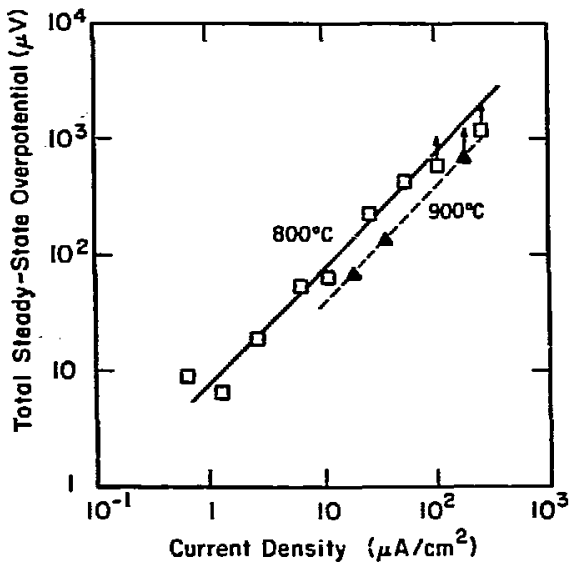

Fig. 1. Total steady-state overpotential as a function of current density for the cell

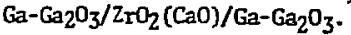

(XBL 737-1573)

Abstracted from LBL-1892. b. Thenmochemical Properties of Cormound Semiconductor Alloys Solutions

Timothy J. Anderson and Lee F. Donaghey

Thermochemical properties of cormound seniconductor alloys are under study by solid state galvanic cell techniques. The research shail be directed toward developing improved solution models which enable the prediction of liquid-solid phase equilibria. Currently, solution models and lattice thermodynamics are being examined to reduce apparent deficiencies and account for ionic bonding contributions. The results will be directed toward devising liquid phase epitaxial processes for electio-optical device fabrication.

\section{c. Activities in the Ga-In-Sb System}

Raymond Pong and lee Donaghey

The thermodynamic properties of liquid compound-seniconductor alloys are under study by solid state galvanic cell techniques. Component activities of the Ga-In liquid alloys were measured with calcia-stabilized zirconia (CSZ) electrolytes. The gallium activities in the Ga-Sb system were measured with yttria-doped thoria (YDT). The experimental investigations are being extended to the Ga-In-Sb ternary.

Through refinents in soild state electrochenical cell design and the use of YDT electrolytes, accurate measurements of gallium activities in Ga-Sb liquid alloys were performed. The measurements indicate a large negative deviation from ideality that is not consistent with current solution models. Similar deviations from ideality are found in the In-Sb system. An extended quasi-chenical treatment is currently being explored, considering multipair-wise interactions in the liquid.

\section{RESEARCH PLANS FOR CALERMAR YEAR 1974}

\section{Lee F. Donaghey}

Studies of the chenical vapor deposition and etching kinetics of conpound semiconductors will be directed toward alloy solid solutions utilizing thermogravimetry to monitor reaction rates. Altemative reaction s'stems for the deposition of phases in the Ti-Si-C system will be studied toward the development of $10 \mathrm{w}$-temperature reaction processes.

Models for phase equilibria required in 
the processing of compound seniconductor photovoltaic and electroluminescent devices will be explored and confinmed using hightermerature electrowotive force, and optical absorption measurements. This information will be applied in the design of processes for heterostructure.

Transients during reactive sputtering deposition of titanium conpounds will be studicd by capacizance-"-?ltage and optical absorption measurcient. . Factors affecting sputter yield of non-stoichiometric compounds produced during reactive sputtering will be studied.

\section{1975 IUBLICATINTS AND REPORTS}

Lee F. Donaghey and issociates

Book contribution

1. "Introduction to Chapter 1: Fundamentals" (with MeD. Robinson), in Chemical Vapor Deposition, Fourth intemational Conference, (The Electrochemical Society, Princeton, New Jersey, Princeton, New Jersey, 1973), pp. 3-4.

\section{Paper presented}

1. L. F. Doraghey, 'Developments in Materials Coating Techniques," Am. Inst. of Chem. Engr. 74th National Mleeting, New Orleans, March 15, 1973.

2. L. F. Donaghey, "Chemical Transport Analysis of CdS and Ans with Iodine," IVth International Conference on Chemical Vapor Deposition, Oct. 8, 1973.

\section{LBL reports}

1. L. F. Donaghey and R. H. Bissinger, III-V Compound Substrate and Epitaxial layer Characterization by Divergent X-ray Beam Diffraction. Accepted for publication in J. Electronic Materials (LBL-1872; (July 1973).
2. L. F. Donaghey and R. Pong, Oxygen Transfer Kinetics Between $\mathrm{Ga}-\mathrm{Ga}_{2} \mathrm{O}_{3}$ Flectrodes and the Solid Electrolyte Calcia-Stabilized Zirconia. To be published in J. Electrochenical Society (LBL-1892, Aug. 1973).

3. L. F. Donaghey and L. Wright, High Temperature Electrical Conductivity of Nonstoichiometrie Gadolinium-Gallium Garjet Single Crystals. Submitted to J. Phys, Chem. Solids (LBL-2244, Oct. 1973).

4. R. B. Agnihotri and L. F. Donaghey, An Analysis of Multi-component, Chemical Transport Crystal Growth. Submitted to $J$. of Crystal Growth (LBL-2254, Dct. 1973).

5. R. B. Agnihotri and L. F. Donaghey, Chemical Transport Analysis of ZnS Crystal Growth. Submitted to J. of Crystal Growth (IBL-2259), Oct. 1973).

5. S. A. Shaikh and L. F. Denaghey, Thermodynamics of Phase Equilibria for Chemical Vapor Depositior of $\mathrm{GaAs}_{1-\mathrm{x}} \mathrm{P}_{\mathrm{X}}$. Stbmitted to I $G$ EC Process Design and Development (IBL-2241, Oct. 1973).

7. T. T. Shih and L. F. Donaghey, Application of Velocity-Selective Freeze-Pushing to the Separation and Characterization of Airborme Solid Particulate Matter in Air Pollution Samples. Submitted for presentation at the March 10-13, 1974 National CIChE Meeting in Tulsa, Oklahoma, for publication in the Conference Proceedings. (LBL-2243, Dec. 1973).

8. L. F. Donaghey and S. A. Shaikh, TankMixing Methods for Producing Time-Varying Reactive Gas Mixtures (LBL-2298, Nov. 19).

9. S. A. Shaikh and L. F. Donaghey, Reactor Designs for the Chemical Vapor Deposition of Epitaxial GaAs $1-x P_{x}$. Submitted to $3 r d$ International Conference on Reaction Engineering, August 27-29, 1974, for Dublication in the Conference Proceedings. (LBL-2518, Dec. 1973). 


\section{ELECTROCHEMISTRY}

Charles W, Tobras, Principal Investigator

1. FUNDAMENTAL STUDIES OF IONIC MASS TRANSPORT

a. Distribution of Ionic Mass Transport Rates in a Flow Channel

Uziel Landau and Charles W. Tobias

Experiments to obtain current distribution and maximum mass transport rates to a segmented electrode embedded in the wall of a flow channel 1 were continued. The parameters investigated were: solution concentration and temperature (corresponding to Se numbers of $-500-1700$ ), rate of current and potential application, surface morphology and flow rate (u to Reynolds number of 120,000 ).

Since the mass transfer rates increase considerably with increasing surface roughmess, especially at high flow rates, special care wes taken to obtain values for transport to smooth surfaces with wellpolished electrodes. In addition, many

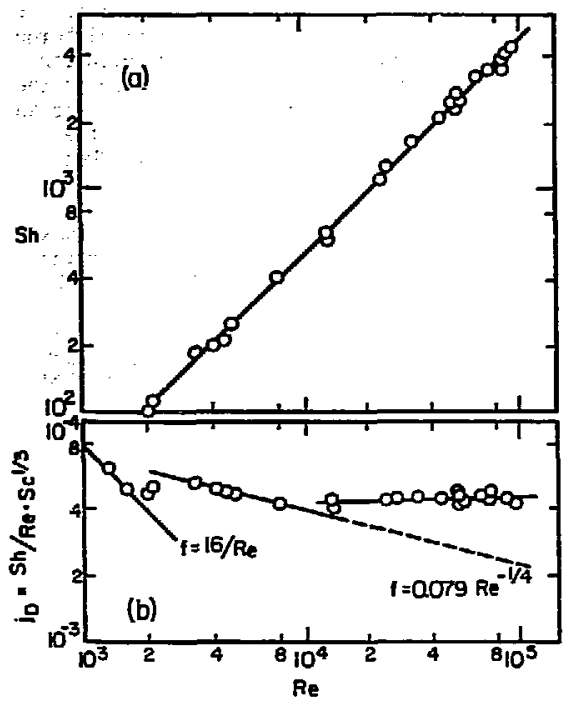

Fig. 1. Mass transport dependence on flow rate.

(a) Sh vs. Re

(b) $j_{D}=S t \cdot S e^{2 / 3}$ vs. Re.

(XBL 741-5468) experiments were conducted with very low copper concentrations $(\sim 0.006 \mathrm{M})$, thus minimizing the amount of deposit. Figure 1 presents part of the experimental results for mass transport to a smooth electrode. The values in Fig. 1(a) agree with some of the existing correlations. Figure $1(b)$ shows that the Chilton-Colburn analogy for the $j$ factor holds up to flow rates of $R_{e}=10,000$. Transport rates obtained from average measurements over the entire electrode were higher than the true values obtained from local current density measurements. This effect becomes more significant at lower flow rates, where the entrance region, in which mass transport is higher, comprises a larger portion of the total electrode. The observed unsteady-state transition times were longer than those predicted by nunerical solution developed by Selman. 2

1. Uziel Landau and Charles W. Tobias, Flow Circuit for Ionic Mass Transfer Studies at High Flow Rates, IMRD Armual Report for 1970, UCRL-20500, April 1971, p. 39. 2. Jan Robert Selman, Measurement and Interpretation of Limiting Currents, UCRL-20557, June 1971.

b. The Effect of Flow of Electrolyte on Surface Morphology in the Electrodeposition of Hetals

Eric J. Carlson, Uziel Landau, and Charles W. Tobias

Mass transfer studies in the flow chanmel described previously ${ }^{1}$ enploying electrodeposition of copper revealed changes in surface characteristics indicating that inrestigation of the interaction of fluid mechanics and mass transfer on the morphology of the deposit would be of value.

The roughness of the deposit depends on the ratio of applied current to the maximm cirrent allowed by convective diffusion, and migration. Depositing the same amount of copper at different fluid velocities, changes in surface morphology were evaluated by using surfanalysis and micrographic examination. Figure 1 illustrates that by increasing the flow rate while maintaining the same deposition rate a smoother surface is obtained.

Initial surface imperfectims are magnified during diffusion-linited depusition. 


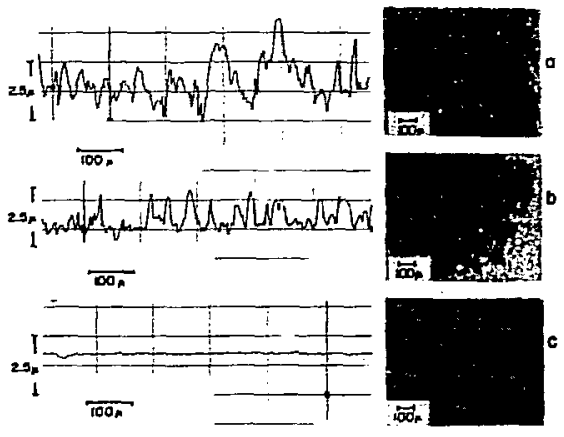

Fig. 1. Deposit roughness at constant current and different flow rates. Profile traces at left from surf-analyzer. (a) $\operatorname{Re}=10,000, i / i_{1}, c . \sim 0.5 . \quad i$ - current density, $i_{1}$.c. - iffiting current density (note changes in magnification on different figures). Total charge passed in all three cases: 1 amperehour. (XBB 741-12)

As shown in Fig. 2, when scratches and protrusions are introduced on the surface of the substrate electrode, enharced preferential deposition on crests is obtained. of special interest is the wakeshaped deposit revealing the highly turbulent region following and preceding a protrusion. Preferential deposition on crests was also studied on unifomly roughened electrodes by using sand-type roughness and machined grooves.

1. Uzie1 Landau and Charles W. Tobias, Flow Circuit for Ionic Mlass Transfer Studies at High Flow Rates, IMRD Amual Report for 1970, UCRL-20500, Apri1 1971, p. 39.

\section{ELECTROLYSIS AT HIGH CURRENT DENSITIES}

a. Mass Transfer at Closely Spaced Electrodes

Rawl E. Pcosta, Rolf H. Muller, and Charles H. Tobias

The study of rates of mass and momentum transfer in flow chamels with very small spacings ( 0.05 and $0.02 \mathrm{~cm}$ ) was brought to conclusim. In addition to the optically smooth chamel reported earlier artificialiy roughened electrode surfaces were also
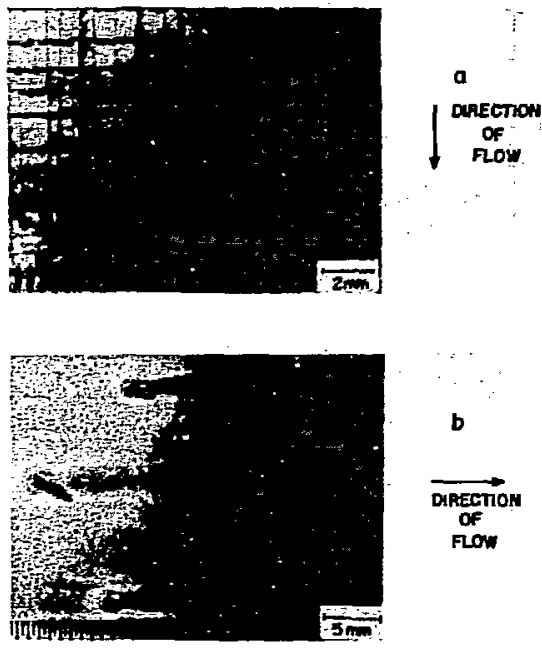

b

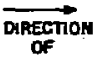

Fon

Fig. 2. Preferential deposition aromd protrusions at high flow rates $(0-20,000)$. (a) Deposition om ridges alongs_ue grooved surface.

$$
\varepsilon \sim 20 \mu, \delta \sim 0.4 \mathrm{~mm}, \varepsilon_{f} \sim 100 \mu
$$

(b) Deposition on and aroumd cylindrical protrusions.

$$
E \sim 1 \mathrm{~mm}, \delta \sim 0.4 \mathrm{mml} .
$$

(Scale: $2 \mathrm{div} / \mathrm{mm}$ )

E - original protrusion height

6 - hydrodynamic boundary layer thickaess

$E_{f}$ - protrusion height after deposition.

(XBB 741-11)

investigated. Of the roughness patterns, three were of the random type, obtained by sandblasting the walls of the chamel, using different abrasive grades; the fourth type of roughness was produced by 'v"'. grooves ruming perpendicular to the fllow direction. The value of the mass transfer coefficients measured are shown in the form of the $j_{0}$ factor in Fig. 1 .

As indicated earlier, 1 operation at high flow rates when using ciosely spaced electrodes is characterized by very large expenditures in punping power. Hence, under 


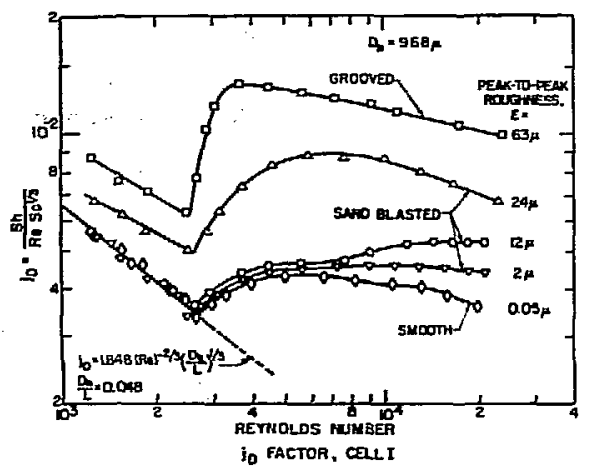

Fig: 1. Mass transfer coefficient for flow chamel with $\mathrm{D}_{\mathrm{h}}=0.096 \mathrm{~cm}$. (XBL 7311-6623)

certain conditions it may be of considerable importance to operate at flow rates where the ratio of the mass transfer to the friction factor coefficient, $j_{D} /(f / 2)$, gives a maximm adventage. The value of this ratio as a fumction of the Reynolds number for the roughness values used is shom in Fig. 2. The decisive role played by the size and type of roughness elements is clear from this figure.

At the highest flow rate employed (74 :meters/sec), with the smallest electrode separation, the equivalent mass transfer

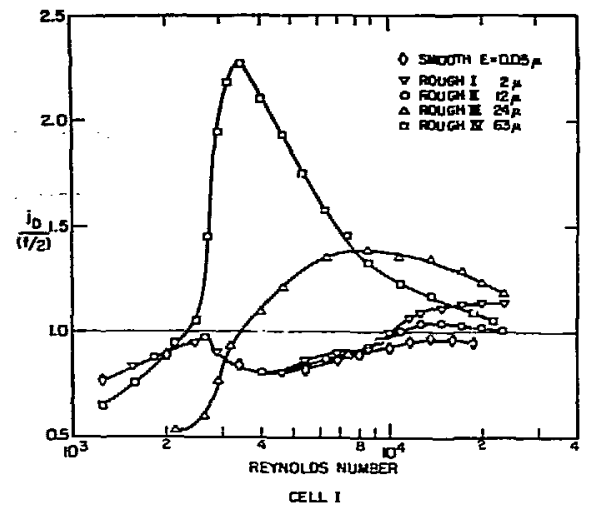

Fig. 2. Ratio of mass to momentum transfer for flow channel with $\mathrm{n}_{\mathrm{h}}=0.0 \% 6 \mathrm{~cm}$.

(XBL 7311-6617) boundary layer thickness was $2 \times 10^{-5} \mathrm{~cm}$. Although this allows very high chargetransfer rates with high current efficiency, the high cost of pumping of electrolyte renders applications, other than in electrochemical machining, unlikely.

1. Raul E. Acosta, Rolf H. Muller, and Charles W. Tobias, Electrolysis at High Current Densities: Mass Transfer at Closely Spaced Electrodes, IMRD Annual Report for 1972, LBL-1400, April 1973.

b. Periodic Phenomena in the Anodic. Dissolution of Copper

John F. Cooper, Rolf $\mathrm{H}$. Muller, and Charles W. Tobias

Earlier studies of anode potential osciliations diring the galvanostatic dissolution of copper have been carried out under welldefined hydrodynamic conditions only up to $36 \mathrm{Avcm}^{2} .1$ In order to further investigate the osciliations at higher current densities, a stagnation point flow cell has been constructed. In this system, a jet of electrolyte is allowed to inminge perpendicularly on a stationary, 0.16 -cm-diameter copper disk electrode. The advantages of the system include: (1) hydrodynamic conditions may be accurately characterized; (2) the electrode surface is uniformly accessible to the electrolyte from the stanipoint of mass transport; and (3) the solution flow rate just outside the diffusion boundary layer is sufficiently high to prevent excessive heating of the electrolyte at high current levels.

A different form of oscillations occurs above $70 \mathrm{~A} / \mathrm{cm}^{2}$, with amplitudes of about 50 volts, as show in Fig. 1. Above $150 \mathrm{~A} / \mathrm{cml}^{2}$, only a few potential oscillations occur, with period lengths of about $10^{-3} \mathrm{sec}$, before continuous oxygen evolution begins and the oscillations cease. Near this upper cirrent density limit, the potential falls from peak to trough levels within $10^{-5} \mathrm{sec}$.

The rapidity of potential decay led to considerations of possible dielectric breakdown in the thin $\left(10^{-5} \mathrm{~cm}\right)$ cuprous oxide surface layer formed during the highpotential phase of the oscillation cycle. Cuprows oxide is known to undergo a transition from a high- to low-resistivity state uon the application of a critical field strength, 2 and similar "resistance-switching" transfonmations occur in a variety of metal oxides. 3 Samples for dielectric breakdown 
studies were prepared by intermpting dissolution firring the high-fotential phase. Potential steps of 1 to 20 volts were applied to the dried, film-covered electrodes by means of point contacts of copper or graphite. The resistance between the point contact and the anode metal substrate was found to drop fran $10^{8}$ olmis to a few ohms after a potential-dependent time lag characteristic of resistance-switching transitions. 3

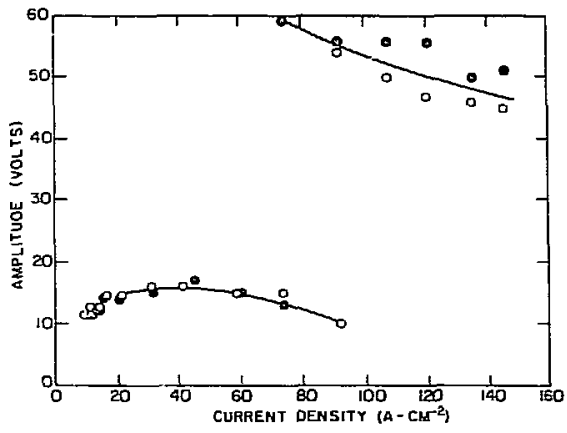

Fig. 1. Variation of oscillation amplitude with current density. Galvanostatic dissolution of 0.16 -cm-diameter copper electrodes in $2 \mathrm{M} \mathrm{NaClO}_{3}$ under conditions of stagnation point flow. Solution flow rate: (o) $93 \mathrm{~cm} / \mathrm{sec}$; (x) $193 \mathrm{~cm} / \mathrm{sec}$.

(XBL 741-5469)

1. J. Cooper, R. H. Nuller, and

C. W. Tobias, "Periodic Phenomena in Copper Dissolution at Constant Current," presented at 138th National Meeting of the Electrochemical Saciety, Atlantic City, Oct. 4-9, 1970.

2. E. L. Cook, J. App1. Phys, 41, 551 (1970).

3. N. Kein, Adv. Elect. and Electran Phys. 26, 309 (1969).

c. Current Distribution in Electrochemical Machining

James B. Riggs, Walter T. Giba, Rolf H. Atuller and Charles W. Tobias

The most serious linitation in a broader utility of electrochemical machining lies in the entpirical development of too1 (cathede) shape to produce the desired metal removal in the workpiece (anode). our understanding of rate-limiting factors in high-current electrolysis that we have gained in the recent past is now being employed in developing a mathematical model to predict tool and workpiece reometries in electrochemical machining. "This model is based upon a numerical solution of the Laplace equation with realistic boundary conditions to represent polarization at anode and cathode surfaces. Also, variations in the conductivity of the electrolyte due to changes in temperature and composition (including gas content) is being included in the made?.

The validity of the theoretical malysis will be tested experimentally with a small technical EOM machine, obtained from surplus, 1 that has been refurnished and instrumented. Suitable test shapes will be developed for this purpose. A preliminary tool design for the experimental determination of spacial frequency transfer fumctions is illustrated in Fig. 1 together with the workpiece.

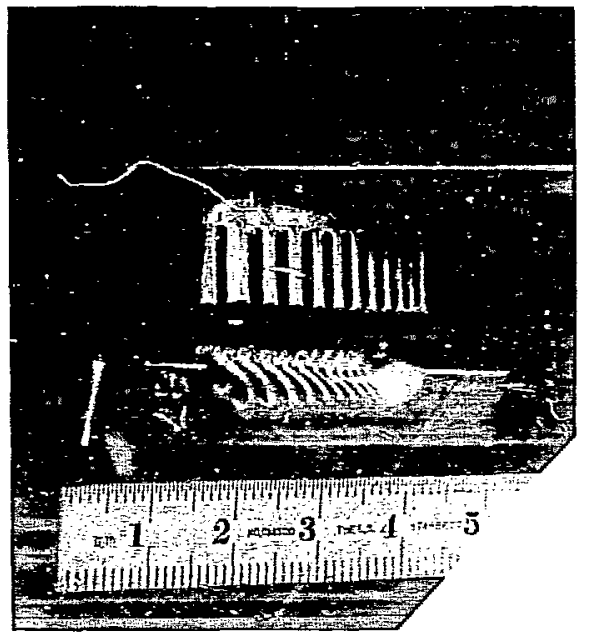

Fig. 1. Shape reproduction in electrochenical machining. Experimental tool and workpiece to quantitatively determine the reproduction. of shape details.

(XBB 742-650)

1. LBL, Livenwore. 


\section{ELECTROCHPIISTRY IN AONALUEOUS SOLVENIS}

a. Studies on the Practical Feasibility of the Electroreduction of Potassium

Oscar Chacon and Charles $W$. Tobias

The feasibility of depositing the alkali metals from solutions of their salts in propylene carbonate (PC) has been demonstrated in this laboratory. 1,2 This provides an attractive altemative for the primary recovery or refining of potassium metal.

Two obstacles have to be eliminated before the quantitative criteria for the practical electroreduction of potassium can be further characterized. First, potassium is not stable in vacum-distilled PC. Experiments have shown that this instability may be explained by the reaction of potassium with propyleme glycols (PG) which canrot be adequately remored from the crude solvent by distillation. A gas chromatographic method was developed to evaluate the concentration of PG in PC and a method of purification was perfected involving treatment by molecular sieve and absorption on alumina which reduces the comcentration of PG belcw $5 \mathrm{ppm}$ (limit of detection). To combat the high reactivity of potassium with moisture and oxygen, our 17 year old vacunm-dry required substantial reconditioning. A helium purifier is under construction.

1. Jacob Jome and Charles W. Tobias, IMRD Annual Report for 1972, LBL-1400, April 1973. 2. Jacob Jorne (Ph.D. dissertation), Electrochemical Behavior of Alkali Metais in Propylene Carbonate, LBL-1111, Sept. 1972.

\section{RESEARCH PLANS FOR CAIENMAR YEAR 1974}

Charles W. Tobias

a. Fundamental Studies of Ionic Mass Transport

This program is aimed at the development of quantitative methods for the prediction of mass transport rates to and from electrolyte electrode interfaces, and at the exploration of novel ways in which such transport rates may be enhanced to improve the econory of electrolysis and galvanic cell processes. Experimental techniquies involve measurement of distribution of limiting currents on surfaces, direct optical observation of boundary layers by Mach Zehnder interferometry (see section under R. H. Muller), and analysis of surface topology of metal deposits using optical and scanning electron microscopy and surf-analysis (for "roughness" of extended surfaces). Primary emphasis is placed on extended planar electrodes in comimel flow up to $\operatorname{Re}=120,000$. A study will be initiated of the initiation and propagation of surface inperfections in quasi-steachy-state metal deposition and the nucleation and growth mechanics of bubbles in electrolytic gas evolution. These phenomena are common ieatures of essentially all electrolytic synthesis and energy conversion processes.

\section{b. Electrolysis at High Curtent Densities}

Investigations aimed at the elucidation of the role of transport processes at very high current densities $\left(\mathrm{P} 100 \mathrm{~A}_{\mathrm{cm}^{2}}\right)^{2}$ will be extended to consideration of the conbined effects of hydrodynaric-flow, anodic surface films and cathode geometry on resulting arode geometry, and surface finish in electrochemical machining processes. A new experimental effort will be initiated for the study of the reverse process: high rate electroforming by rapid electrodeposition of metals. The potential gain inherent in the omission of a significant number of extractive metallurgical and metal-forming steps justifies a serious reevaluation of this relatively old process technolesy.

\section{c. Electrochemistry in Nonaqueous Solvents}

The successful use of lithium as a reversible galvanic electrode in propylene carbonate has long been established; the solvent and scme of its analogues are among the more promising organic solvent media for use in high-energy-density battery applications. Earlier work in this laboratory on the thermodynamics and kinetics of the reduction and oxidation of alkali metals in propylene carbonate provides good promise for the development of economically attractive processes for their primary recovery and refining. Investigations will be continued on solvent purification ana stability with respect to the alkali metals. Emphasis will be placed on the practical recovery of potassiurt metal using $\mathrm{KAICl}_{4}$ solute, but the use of other anions, such as $\mathrm{SbF}_{6}{ }^{-}$, will also be explored.

\section{1973 PUBLICATIONS AND REPORTS}

Charles W. Tobias and Associates

\section{Jomrals}

1. C. W. Tobias, hew Birections in Electrochenical Engineering, J. Electrochers. Soc. $120,65 C$ (1973). 
2. K. Kojima and C. W. Tobias, SolutionSide Transport Processes in the Electro poiishing of Copper in Phosphoric Acid, J. Electro them. Sac. 120, 1026 (1973) (1BL-1106).

3. K. Kojima and C. W. Tobias, Interpretation of Impedance Properties of the Arode Surface Film in the Electropolishing of Copper in Phosphoric Acid, J. Electrochem. Soc. 120, 1202 (1973) (LBL-1129).

\section{Reports}

1. C. W. Tobias, E. Cairns, H. J. Korp, D. G. Wilson, C. Zener, and K. H. Weil, Ar Evaluation of Aicemative Power Sources for Low Enission Automobiles, National Acadenty of Sciences, April 1973.

2. F. Silvester and C. W. Tobias, Electrochanistry in Nonaqueous Solvents: Electroreduction of Calcium, LBL-2580, Dec. 1973.

\section{Papers presented and invited lectures*}

1. Charles W. Tobias, Mass Transport Processes in Electrochemical Machining, keynote address, First Intemational Conference on Eilectromachining, Leicester University, Great Britain, Mlarch 26 and 27, 1973. Extended Abstracts published by Society for Electrochemistry - E.C.M. coordinating Committee, March 1973.)

2. J, Jome and C. W. Tobias, Elect:ode Kinetics of the Alkali Metals and Their Amalgams in $\mathrm{AlCl}_{3}$-Propylene Carbonate Solutions (Extended Abstract No. 277), 143rd meeting, The Electrochemical Society, Chicago, Illinois, May 13-18, 1973.

3. J. Jorne and C. W. Tobias, Thernodynamic Properties of the Alkali Metals in $\mathrm{AICI}_{3}$-Propylene Carbonate Solutions (Extended Abstract No. 288), 143rd meeting of The Electrochemical Society, Chicago, Illinois, Nay 13-18, 1973.

4. $:$ se and C. W. Tobias, Electroredus $s$ of the Alkali iletals at Ambient Temperature, (Extended Abstract No. 295) 144th meeting of The Electrachenical Society, Boston, Mass., Oct. 7-11, 1973.

5. J. Jome and C. W. Tolizas, Electrochemical Behavior of the mikali Metals in Propylene Carbonate, AICHE - C.S.Ch.E. joint meeting, Vencouver, B.C., Sept. 9-12, 1973.

6. C. W. Tobias, Electrolysis at High
Current Densities-Electromachining, invited lectures given at: University of Southamptcn, Great Britain (March 30); Fritz Haber Institute, Berlin (April 6); Lniversity of Belgrad, Yugoslavia (April 9); Yugoslav Academry of Sciences, Zagreb (April 11); Federal Institute of Techmology, Lausame, Switzerland (Apri1 16); Federal Institute of Technology, Zurich (April 17); Tel Aviv University, Israel (April 25); Negev Institute of Arid Zone Research (April 29); National Metallurgical Laboratory, Jamshedpur, India (Aug. 31); National Aeronautical Laboratory, Bangalore, India (Sept. 5).

7. C. W. Tobias, Research in Electrochemical Engineering at Berkeley, invited lectures given at: Croatian Chernical Society, Split, Yugoslavia, (April 14); Technion, Israel (May 2); Arya Mehr University, Iran (May 17); Indian Irstituve of Technology, New Delhi, (Alig. 29); Indian Institute of Science, Bangalore (Sept. 7); Indian Institute of Technology, Meadras (Sept. 1); Indian Institute of Technology, Bombay (Sept. 18).

8. C. W. Tobias, Electrochemical Behavior of Alkali Metals in Propylene Carbonate, invited lectures given at: Iniversity of Ber1in (April 6); Federal Institute of Technology, Zurich (Apri1 18); National Aeronautical Laboratory, Bangalore, India (Sept. 7).

9. C. W. Tobias, Prospects for Electrochemical Energy Contersion and Storage, invited lectures given at: Institure of Petroleum Engineers, Abadan, Iran (May 16); Central blecirochemical Research Institute, Karaikudi, India (Sept. 15).

10. C. W. Tobias, Fumdamentals of Electrochemical Engineering, invited lectures (five each) given at: Abadan Institute of Technology, Abadan, Iran (May 7-15); Central Electrochemical Research Institute, Karaikudi, India (Sept. 10-i5).

\footnotetext{
In the period Jan. 1-June 30, 1973, C. Tobias was on sabbatical leave. Visits universities and govenumental research laboratories were sponsored in Israel (April 19-May 4) by the Negev Institute for Arid Zone Research and in Iran (May 4-18) by the Abadan Institute of Technology. From Aug. 28-Sept. $19 \mathrm{C}$. 14 . Tobias served as an Exchange Scientist, spansored jointly by the National Science Foundation and the Council for Scientific and Industrial Research of India.
} 
Rolf H. Muller, Principal Investigator

1. OPTICAL STUDIES OF INTERFACIAL PHENOMENA

a. Interferometry of Mass Transfer Borndary Layers

Frank R. McLarnon, Rolf H. Muller, and Charles W. Tobias

Light-deflection has been shown previously to lead to serious errors in the derivation of concentration profiles from interferograms of boundary layers, unless appropriate corrections are made. 1 In order to check the computed effect of ' " sse errors experimentally, we have invest-giated the convectionless galvanostatic electrodeposition of $\mathrm{Cu}$ from a stagnant layer of $0.1 \mathrm{M} \mathrm{CuSO}_{4}$ at 5 and $10 \mathrm{~mA} / \mathrm{cm}^{2}$. The theoretically expected concentration profiles under these conditions are well known,?

During these tests it was four. that even after considering light-deflection effects, the observed interference fringes still appeared displaced nommal to the electrode surface. Reflection by the slightly rounded edge of the electrode surface (unavoidable effect of polishing technique) has now been found to ise the source of this displacement. The reflection also gives rise to spurious fringe sl山its near the electrode/electrolyte interface that are not due to a refractiveindex gradient. Figure 1 shows interferograns of the electrode/electrolyte interface with different choices of the plane of focus in the absence of refractiveindex gradients. It can be seen that the position of the interface is best reproduced by the focusing as in Fig. 1D, while the focusing best suited to accolnt for light deflection (Fig. 1B) results in significant errors. ( $x$ is the distance from the plane where light enters the cell and is measured in the direction of light propagation.) By considering light reflection from the electrode edge, we are now able to quantitatively account for both the apparent displacement of the interface and the spurious shift of

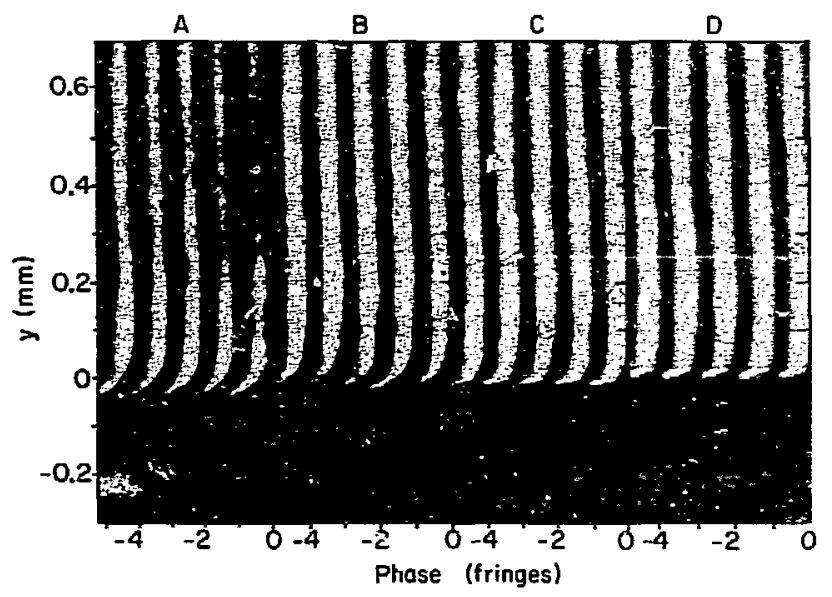

Fig. 1. rffect of iight reflection on interferograms of a $\mathrm{Cu} / 0.1 \mathrm{M} \mathrm{CuSO}_{4}$ interface without a boundary layer present. Abscissa: interferogram phase, ordinate: vertical distance from true interfacial location. A: plane of focus at $x=-0.5 \mathrm{~mm}$, B: plane of focus at $x=0$ (plane of light entrance into cell, employed in boundary layer observations), $C$ : plare of focus at $x=0.5 \mathrm{~mm}, \mathrm{D}:$ plane of forus at $x=1.0 \mathrm{~mm}$. 
the interference fringes in the absence of concentration gradients.

If a determination of the true location of the interface by the above considerations is incorporated in the light-deflection analysis of interferograms, excellent agreement between observed and predicted interference fringes (in the absence of convection) is obtained (Fig. 2).

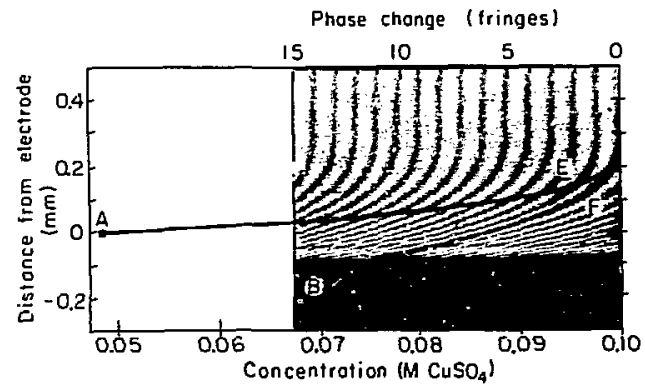

Fig. 2. Comparison of experimentally observed interferogran with interference fringe $\mathrm{BF}$ computed from theoretically expected ${ }^{2}$ concentration profile $\mathrm{AE}$ under consideration of light deflection in the boundary layer and reflection from the electrode edge.

(XBB 7311-6546)

An iterative techrique, based on an aralytic solution of the equation ${ }^{1}$ describing light deflection in a refractive-index field, has been developed to calculate the concentration profile from an experimental interferogram. Compared to the previously used trial and error technique, 3 a simpler mathematical function three instead of four free parameters) is used for the concentration profile. Thus, a better fit of experimental data and use of an autonatic (rather than manual) iteration process have been made possible. The example shown in Fig. 3A demonstrates that good agreenent between concentration profiles derived from interferograms with profiles expected on the basis of the Sand equation ${ }^{2}$ is obtain. for convectionless boundary layers. The similarity between convectionless and convection boundary layers, shown in Fig. 3B, suggests that the technique is also suitable for the analysis of convective transport.

The above advancements allow the application of interferometry to the study of boundary layers in large-scale electrode systems.

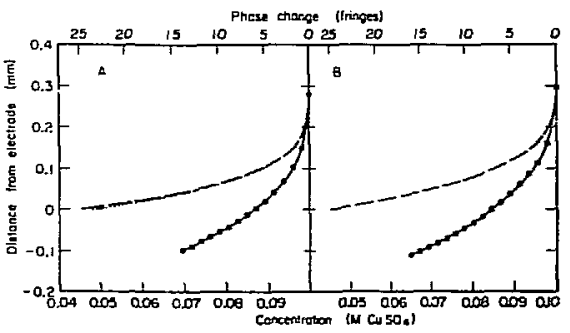

Fig. 3. Interferograns and concentration profiles in the presence and absence of convection.

$I=10 \mathrm{~mA} / \mathrm{cm}^{2}, 10 \mathrm{sec}$ after current switchon.

-**Experimental interferograms

--- Concentration profiles derived from the interferograms

- Interference fringe computed from the derived concentration profile

... Theoretical ${ }^{2}$ concentratioil profile corresponding to experimental conditions

$A=$ Convectionless boundary layer

$B=$ Forced convection $R e=1000,2.0 \mathrm{~cm}$ (1.4 hydraulic diameters) downstream from electrode leading edge.

(XBL 739-4133)

1. K. W. Beach, R. H. Muller, and C. W. Tobias, J. Opt. Soc. Am. 63, 559 (1973). 2. H. J. S. Sand, Phil. $\overline{\mathrm{Lag}}$. (6) 1,45 (1901) .

3. K. W. Beach, Ph.D. thesis, UCRL-20324, June 1971.

\section{b. Automatic Ellinsometer}

H. Jörg Mathieu* and Rolf H. Muller

our newly built self-compensating e1lipsometer that employs Faraday-cell rotators has been denonstrated to provide a combination of speed of response and resolution superior to that of any similar instrment now in use. These performance chiracteristics have been achieved through the use of novel Faraday solenoids, modulation with high frequency and large amplitude, and refinements in circuitry. 1 We have shown why a previously built instrument has not been able to provide the desired capabilities .

Hethods to quantitatively determine the dymamic response of automatic ellipsometers of different designs to variations in the optıcal properties of a secimen surface 
have been developed and appJied to our new ellipsometer. The use of rosating mirrors has been introduced for these tests in order to generate well-defined, fast optical changes in the properties of a reflecting surface. Thus, the response of our ellipsometer to step-wise changes of different magnitude, as well as sinusoidal changes of different amplitude and frequency (Fig. 1) has been characterized. 3

Solid anodic layers formed during the dissolution of copper at moderately high current densities have been observed with the automatic ellipsometer in newly built cells for use of stagnant or flowing electrolyte. The results show that the onset of filn formation occurs only after an induction period during which saturated solutions of reaction products accumulate at the interface.

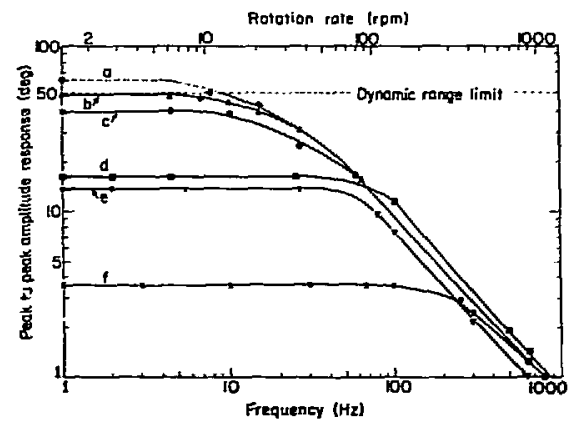

Fig. 1. Response of ellipsoneter polarizer and analyzer azimuth rotation to sinusiodal signals of different anplitude and frequency div to variations in the properties of $a$ specimen.

[XBL 737-3436]

After an initial formation of a compact $\mathrm{Cu}_{2} \mathrm{O}$ layer, 200-800 A thick, the films become increasingly porous, particularly at higher current densities and flow velocities (Fig. 2). These observations are in agreement with independent results on the mechanism of anodic metal dissolution (we Cooper, Tobias, and Muller, p. 38 ).

Two additional computer programs for the interpretation of ellipsometer measurements have been prepared. One considers the effect of two layers of different optical constants and thickness, the other considers an inhomogeneous filla with continuously varying optical constants, modelled by multiple films of equal thickness and monotonically changing optical properties. ${ }^{4}$

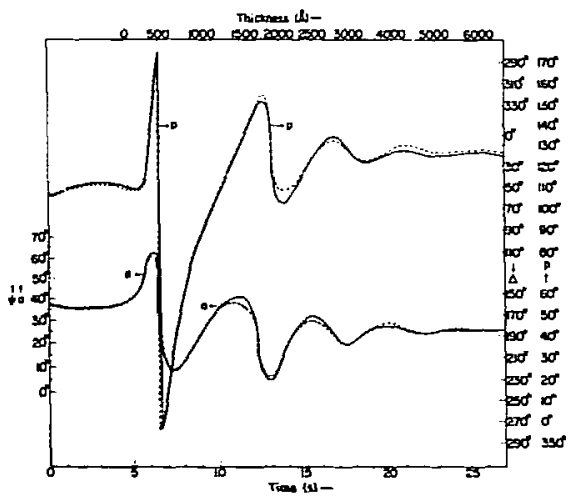

Fig. 2. E1lipsometry of surface layer in the anodic dissolution of $\mathrm{Cu}$ in stagnant $2 \mathrm{M}$ $\mathrm{NaClO}_{3}$ at $112 \mathrm{~mA} / \mathrm{cm}^{2}$,

- measured analyzer and polarizer azimuths $a$ and $p$.

-.--conputation under consideration of presence of mass transport layer (1501) and variable porosity 0-2500 A, 0 \% 2500-6000 A, 25\%.

(XBL 7311-4511)

\footnotetext{
Supported by Deutsche Forschungsgemeinschaft.

1. Abstract of LBL-1478.

2. Abstract of LBL-1835.

3. Abstract of LBL-1857

4. Abstract of :BL-2517
}

\section{c. Optical Interference in Thin Films}

Charles R. Brown, Michael L. Sand, and Rolf H. Nuller

The observation of interference colors is an often used tool for the study of transparent thin liquid films on metal surfaces. However, the derivation of film thickness from such observations is conplicated by the phase change in reflection from the substrate surface. He have previously couputed generalized series of interference colors for the precise dexivation of film thicknesses and have now tested them experimentally for the widest experimentally accessible range of phase changes. Thickness profiles for tapered solid films of $\mathrm{ZnS}$ and cryolite on $A], C r$, and Si substrates have been derived 
by th'o different step-height measureme'lts, ellipsometry and interference spectroscopy. Comparison with film profiles derived from visually observed interference colors has in general shown : stisfactory agreement (Fig. 1). It has also been found that colors of lower saturation than previously assumed can still be observed in practice but the distinction of different hues is not as sharp as expected.

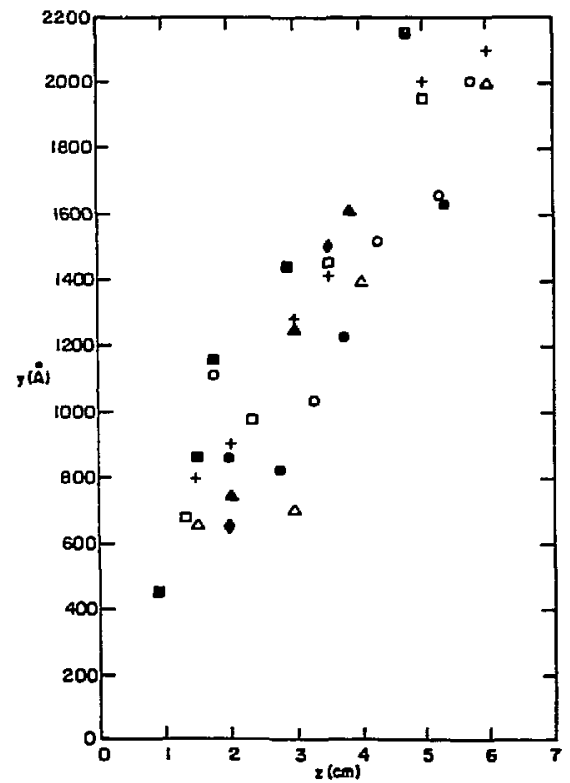

Fig. 1. Profile of $\mathrm{znS}$ film on aluminm substrate, determined by different techniques:

Interference microscope step-height

- Profilameter step-height

$\triangle$ Spectrophotometer, $\lambda$-scan, s-polarization

$\Delta$ Spectrophotcmeter, z-scan, s-polarization

A Spectrophotometer, z-scan, p-polarization

+ Ellipsoneter

Interference colors, s-polarization Interference colors, p-polarization.

(XBL 7310-5433) d. Laser Velocimetry

Calvin $T$. Chew and Rolf $H$ Mullet

Combined forced and natural convection offers effective means to speed up mass transport at electrodes and thus significantly increase the output of electrochemical reactors, but little information is available on the fiow fields existing under these conditions. Laser velocimetry is being developed to provide direct evidence of three-dimensional flow pattems existing in such boundary layers.

\section{HYDROGEN ECONOA:*}

\section{Rolf $\mathrm{H}$. Muller}

A recent review of the prospects for a hydrogen economy has confinmed that water electrolysis is at present still the only feasible route to make hydrogen without the use of cartonaceous materials and discharge of $\mathrm{CO}_{2}$ to the atmosphere. Indesirable features of electrolytic hydrogen production are low energy efficiency and high capital cost. New technical developments require an improved understanding of the detailed mechanism of electrolytic gas evolution.

$\overline{\text { Abstract of LBL }}-2232$.

\section{RESEARCH PLANS FOR CALENDAR YEAR 1974}

\section{Rolf H. Muller}

Convective transport in electrolysis will be systematically analyzed by interfercmetry. of particular interest are the combined effect of forced and natural convection and the deliberate disturbing of boundary layers. Both of these phenomena offer promising mechanisms for substantially increasing the output of electrolytic reactors.

The dynamics of the formation of reacted surface layers (oxides and halides) on electrodes contmonly encountered in primary and secondary (storage) batteries will be investigated by automatic ellipsometry. The details of these processes determine the efficiency with which battery materials are used. Electrochemically generated thin films are also critical elements in many corrosion processes.

Factors responsible for the stability of 
thin liquid elertminte films on metal surfaces will be irvestigated. The existance of such firss is essential for the functioning of fuel-ceil electrodes: and appears to play an important part in ma.y corrosion processes.

Laser velocimetry will be developed for detemining the velocity distribution in mass transfer brundary layers under forced and natural convection, in order to characterize flow conditions for effective transport.

A mathematical model to predict tool and workpiece geonetries in electrochemical machining will be developed. This model is to incorporate $a \geq 1$ of the understanding of high rate anodic metal dissolution that we have gained in the recent nast and thus contribute to alleviating the single most serious limitation of the present practice of electrochemical mad.iring. (See Part 2c of C. W. Tobias' section.)

An analysis of the periodic removal of solid surface layers in the high rate anodic metal dissolution will be concluded (see Part 2b of C. W. Tobias' section).

\section{1973 PUBLICATIONS AND REPORTS}

Rolf H. Mullet and Associates

\section{Journals and books}

1. Rolf H. Puller, editor, Optical Techniques in Electrochemistry, Vol. 9 of Advances in Electrochemistry and Electrochemical Engineering, edited by P. Delahay and C. W. Tobias (Wiley-Interscience, New York, 1973).

\section{Rolf H. Bullet, Principles of} Elilipsometry, in above, pp. 167-226.

\section{Rolf H. Mullet, Double-Bean Interferonetry} for Electrochemical Studies, in ahove, pp. 281-368.

4. K. W. Beach, R. H. Nuller and C. W. Tobias, Light-Deflection Effects in the Interfermetry of One-dimensional Refractiveindex Fields, J. Opt. Soc. Am. 53, 559-66 (1973)

\section{LRL reports}

1. H. Jorg Mathieu, Computer Prograns for El1ipsometry, LBL-1470, May 1973.

2. H. J. Mathiel, D. E. McClure and R. H. Miller, Self-Compensating Ellipsometer Manual, LBL-1478, July 1973.
3. H. J. Mathieu and R. H. Nuller, Faraday Solenoids for Automatic Ellipsometers, LBL-1836, Aug. 1973.

4. Rolf H. Auller, Electrochemical Aspects of the Hydrogen Economy, Symposium Stumiary, LBL-2232, Nov. 1973.

5. R. H. Nuller and H. J. Mathieu,

Performance Tests for Automatic Elipsometers, LBL-1857, Sept 1973.

6. H. J. Mathiceu, D. E. MeClure, and

R. H. Mul]er, Fast Compensating Elitipsometer, LBL-2256, December 1973.

7. F. R. McLarnon, R. H. Muller, and C. W. Tobias, Light-Deflection Errors in the Interferometry of Electrochemical Mass Transfer Boundary Layers, LBL-224n, Dec. 1973.

3. Charles R. Brown (M. S. thesis), Interferometry of Solid Thin Films, LBL-2264, Dec. 1973.

9. H. J. Nathieu, Computer Programs for Ellipsometry II, LBL-2517, Dec. 1973.

\section{Papers presented}

1. Rolf H. Muller, Periodic Phenomena During EOM, invited lecture, International Conference on Electrochemical Machining, Univ. of Leicester, England, March 26-27, 1973.

2. Rolf H. Muller, Periodic Phenomena in the Anodic Dissolution of Metals at High Rates, Bell Telephone Laboratories, Murray Hill, N. J., March 23, 1973.

3. Rolf H. Buller, Optical Studies of HighRate Anodic Metal Dissolution, Swiss Federal Institute of Technology, Zurich, Switzerland, Apri1 6, 1973.

4. Rolf H. Muller, Opticai Techniques in Electrochemical Research, Swiss Aluminum Ltd., Research Laboratories, Neuhausen, Switzerland, April 11, 1973.

5. Rolf H. Nutler, Symosium Summary on Electrochemistry, Intemational Symposium and Workshop on the Hydrogen Economy, Cornell University, August 20-23, 1973.

6. H. J. Nathieu, Autonatic Ellipsometers, IBI Research Laboratories, San Jose, Calif., March 13, 1973.

7. H. J. Mathieu, K. K. Reinhartz, and H. Rickert, The Mechanism of the Electrochemical Degradation of CdS-Cu $S_{2}$ Solar Cells, 10th IEEE Photovoltaic Specialists Conference, Palo Alto, Calif., Nov. 13-15, 1973. 
John Newman, Principal Investigator

1. CURRENT DISTRIBUTION ON A RUTATING SRHERE BELOW THE LINITING CURRENT

\section{KemaI Nisancioğlu and John Newman}

The current distribution on a rotating spherical electrode is calculated at appreciable fractions of the limiting current. Numerical results are given for Tafel kinetics (Fig. 1) and for high rotation speeds 'ig. 2). The current distribution depends only on the specified current leve. and becomes uniform when this level is set beluw $68 \%$ of the limiting current at high rotation speeds even if concentration polarization is present. Furthermore, since the primary distribution is uniform for the sphere, the potential distribution in the solution near the electrode surface is also expected to be uniform whenever the current distribution is uniform. These conclusions suggest the rotating sphere as a viable tool in high-rate metal deposition and dissolution studies and in potentiostatic applications.2 In general, the results disclose a mmber of complementary aspects of the spherical electrode when compared with the disk electrode

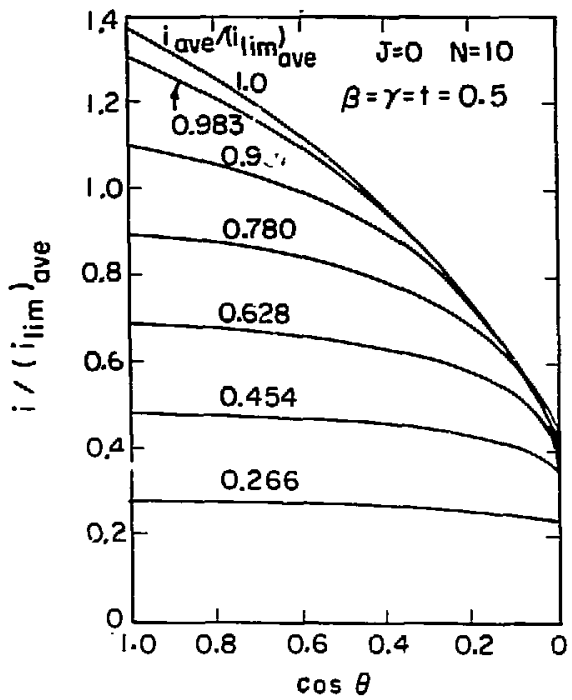

Fig. 1. Current distribution for Tafel kinetics.

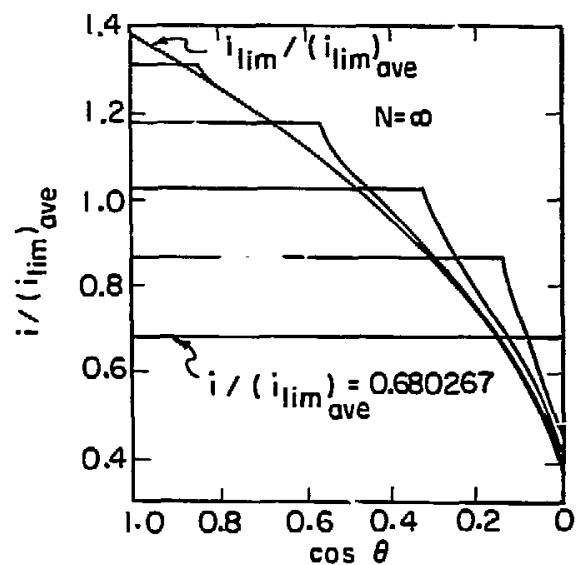

Fig. 2. Current distribution at high rotation speeds.

(NBL 735-3n19)

in electroanalytical applications. 1,2

1. Kemal Nişanciöglu and Jolm Newman, Current Distribution on a Rotating Sphere below the Limiting Current, LBL-1837; Joumal of the Electrochenical Society, to be published.

2. Kemal Nustafa Nişancioğlu, Current Distribution and Mass Transfer in Rotating Electrode Syst,ans, (Ph.D. thesis), LBL-1880, Sept. 1973.

\section{THE SHORT-TTME RESPONSE OF A DISK} ELECTRODE

Kemal Nişancioğlu and John Newman

A theoretical study of the transient behavior of a disk-electrode in the presence of faradaic and capacitive effects has recently been reported. 1,2 Those results are readily applicable to describe the longtime response of the disk and determine the relaxation time of the overpotential after a step change in the current or potential. However, a large number of terms need to be included in the series to express the shorttime behavior adequately. Hence, an asymptotic solution valid at short tines has been sought for the problen, 3 
Shortly after the cell current is switched on, the current distribution on the surface is given by the primary distribution 4,5 everywhere except at a small region near the edge of the disk. Since the primary current density is infinite at the edge, the doublelayer capacity is charged more rapidiy in this region than at other parts of the disk, so that the current density is reduced to a finite value. A similar situation is encountered for farge values of the exchange current density.

A singular-perturbation problem is formulated to treat the edge region of a disk electrode at short times and for large exchange-current densities. 3 Results are obtained for short times by exprering the potential in tepms of an integral equacion at the surface. ${ }^{\prime}$ Re: . ts for large exchangecurrent densities are calculated in a more straight forward fashion by a numerical solution of Laplace's equation for the edge region. Previous series solutions for the transient response 1,2 and the secondary distribution 6 approach present results asymptotically.

1. K. Nişancioğlu and J. Newman, The Transient Response of a Disk Electrode, J. Electrochem. Soc. 120, 1339-1346 (1973) .

2. K. Nisancioglu and J. Newman, The Transient Response of a Disk Electrode with Controlled Potential, ibid, , 120, 1356-1358 (1973).

3. K. Nişancioğlu and I. Newman, The ShortTime Response of a Disk Electrode LBL-1896, Sept. 1973.

4. J. Newman, Resistance for Flow of Cirrent to a bisk, J. Electrochem. Soc. 113, 501-502 (1966).

5. J. Newruan, Ohmic Potential Measured by Interrupter Techniques, ibid., 117, 507-508 (1970) .

6. J. Newman, Current Distribution on a Rotating Disk below the Limiting Current, ibid. , 113, 1235-1241 (1966).

7. KémâT Mus tafa Nişancioğlu, Current Distribution and Mass Transfer in Rotating Electrode Systems (Ph.D. thes is), LBL-1880, Sept. 1973.

\section{MEASUREEENT OF THE TRANSIENT RESPONSE OF A DISK ELECTRONE}

Kemal Nișancioğlu and John Newman

Previous theoretical results ${ }^{1,2}$ for the transient response of a disk electrode suggest that if the current is interrupted, the electrode potential and the potential in the solution decay, respectively, according to the time constants

$$
\tau_{e}=\frac{r_{0} C}{k J} .
$$

and

$$
\tau_{s}=\frac{1}{4.12+J} \frac{\tau_{0} C}{k},
$$

where $r_{p}$ is une radius of the disk, $C$ the double-layer capacity, $k$ conductivity of the solution, and

$$
J=i_{o} r_{o}\left(\alpha_{a}+\alpha_{c}\right) F / R T r
$$

the dimensionless exchange-current density fcr linear kinetics.2 The difference in magnitudes of these time constants may be significant if $J$ is small and should therefore be detected with ease. The time constants can be measured separately by a double-probe reference electrode system placed in the solution near the disk electrode and connected appropriately to a dual-beam oscillos $\mathrm{CO}_{1}$ 'e (see Fig. 1). The double-layer capacity ian then be calculated by writing

$$
\frac{1}{\tau_{s}}-\frac{1}{\tau_{e}}=\frac{4.12 K}{r_{o} C} \text {, }
$$

which is independent of $\bar{J}$.

A preliminary experiment has been conducted to measure the double-1ayer capacity on stationary copper and mercury disk electrodes. $\frac{3}{3}$ The design of the latter is

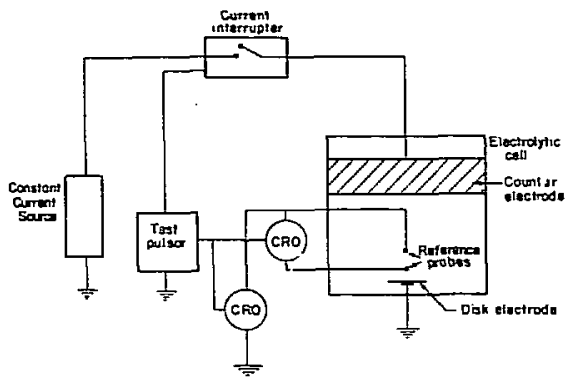

Fig. 1. Electronic circuit.

XBL 739-1885) 
shown in Fig. 2. The solution used was $0.01 \mathrm{~N} \mathrm{KC7}$. Reference electrodes were calomel electrodes. The measured time constants were genera?ly much smaller than those calculated from Eqs. 1 and 2 assuning small $J$ values. Furthermor, the time constant from the single-probe measurement was very close to the double-probe result, indicating that impurities in the solution could not be removed adequately, and hence the value of $\mathrm{J}$ was probably large. Calculated capacities thus were not reproducible, but nonetheless fluctuated within the correct order of magnitude as compared to published results for mercury and copper surfaces. Possible ways of improving the method have been suggested. 3

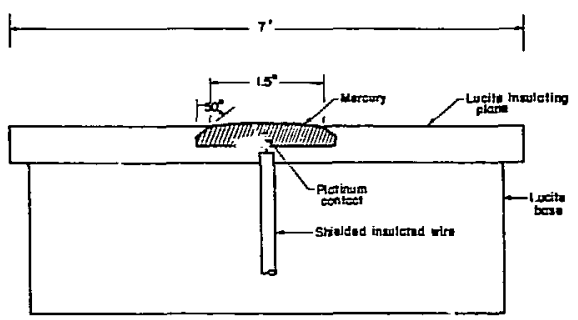

Fig. 2. Mercury-disk electrode (approximate dimensions). (XBL 739-1887)

1. J. Newman, Ohmic ?ctential Measured by Interrupter Techniques, J, Electroche⿰u. Soc. $117,507-508(1970)$.

$\frac{1}{2 .} K$. Nisancioğlu and $J$. Newman, The Transient Response of a Disk Electrode, ibid., $120,1339-1346 \quad$ (1973).

3. Kemal Mustafa Nişancioğlu, Current

Distribution and Mass Transfer in Rotating Electrode Systems (Ph.D. thesis), LBL-1880, Sept. 1973.

\section{TRANSIENT CONVECTTVE DIFFUSION TO A DISK ELECTRODE}

Kemal Nişancioğlu and John Newnan

Analytic solutions are obtained at large times for the transient convective diffusion equation for the disk in the absence of radial concentration gradients considering a step change in the concentration and a step change in the flux at the surface. I The a solutions are shown to match available results for short times, 2,3 with the suggestion that the series for short times and long times cam be enployed interchangeably for nonsteady-state calculations.

The results are exiended to investigate the effect of double-layer charging on transient mass transfer in the presence of a highly reversible electrode reaction. ${ }^{4}$ The effect is shown to be small under the present assumptions, which state in addizion to those mentioned above that the supporting electrolyte only contributes to the doublelayer charge on the solution side, and possible variations in its concentration due to migration are ignored.

A method is proposed to calculate the transient behavior of a disk in the presence of radial convection as well as faradaic and non-faradaic effects at the electrode surface. 4 The fommlation can be extended, if needed, to apply at moderate times by adding more terms to the regular perturbation expansions. The numerical method, even tilough straightforward, seems to require lengthy computations.

1. K. Nişancioğlu and J. Newman, Transient Convective Diffusion to a Disk Electrode, LBL-1881, July 1973.

2. Jan Robert Selman, Measurement and Interpretation of Limiting Currents (Ph.D. thesis) UCRL-20r,57, June 1971. 3. V. S. Krylov and V. N. Babak, NonsteadyState Diffusion tr the Surface of a Rotating Disc, Soviet Electrochem. 7, 626-632 (1971) [Elektrokhimiya 7, 649-654 (1971j]. 4. Kemal Mustafá Nişencioğlu, Current Distribution and Mass Transfer in Rotating Electrode Systems, (Ph.D. thesis), LBL-1880, Sept. 1973.

\section{ROTATING RING-DISK ELECTROUES}

Pete Pierini and John Newman

Rotating ring-disk electrodes are now being used more frequently in research gipiications. Data have been taken for a ferro-ferri cyanide redox reaction. 1 The limiting current was computed and measured with excellent agreement. However, data were present for operating conditions below the limiting current, but no camputations were attempted. We are presently making these computations utilizing methods 
presented in Newman ${ }^{2}$ for potential distribution and mass transfer which have not yet had such a test of validity. The redox kinetic expression 3 is being used and we will obtain parameters for the ferro-ferri cyanide reaction which are not presently available. Finally an explanation of anomalous limiting currents measured on the ring with the disk operating at a net zero current will be made.

1. W. H. Smyrl and N. Newman, Ring-Disk and Sectioned Disk Electrodes, J. Elec'rochem. Soc. 119, 212-219 (1972). 2. J. Newmar, The Fundamental Prirciples of Current Distribution and Mass Trans zort in Electrochemical Cells, in Electromalytical Chemistry, edited by Allen J. Bard (Marcel Dekker, New Yo.'- 1973), Vol. 6, pp. 187-352. 3. J. Newman, Electrochemical Systems (Prentice-Hali, Englewood Cliffs, N.J., 1973), 432 pp.

\section{MASS TRANSFER to A PLANE BELON A ROTATING DISK}

\section{Robert V. Homsy and John Newman}

The rate of mass transfer to a plane below a rotating disk has been measured experimental$1 y$ by the electrodeposition of copper from an aqueous solution of copper sulfate and excess sulfuric acid at the limiting current. Early experiments were beset with natural convection effects caused by concentration stratification within the solution. This effect was considerably reduced by operating at lawer concentration of copper sulfate $(0.01 \mathrm{M})$ and the addition of glycerol (6 M) to the solution. The local mass transfer rate, which is proportional to the thickness of the copper deposit, agrees well with that predicted theoretically. 1 However, at the center of the electrode, the rate appears to be larger than expected, possibly the to lingering natural convection effects or error in the alignment of the electrode below the rotating disk.

The arrent distribution on the plane below the rotating disk was calculated theoretically at various fractions of the limiting current. 2 Nhmerical results show that the current density on the plane becomes more nonumiform as the limiting current is approached.

1. R. V. Homsy and J. Newman, Mass Transfer to a Plane belsw a Rotating Disk at High Schmidt Numbers, AIChE J. 19, 929-933 (1973). 2. R. V. Homsy and J. Newhan, Current Distribution on a Plane below a Rotating Disk, LBL-1887, Aug. 1973.

7. MASS TRANSFER TO A ROTATING DISK ELECTRODE IN THE REGION OF IRANSITION TO TURBULENT FLOW

\section{Charles Mohr and John Newman}

Visual $^{1}$ and electrochenical ${ }^{2}$ evidence has been presented suggesting that in the region if transition from laminar to
turbulent flow $\left(1.5 \times 10^{5}<\operatorname{Re}<3.5 \times 20^{5}\right)$ on a rotating disk, the flow is characterized by a periodic vortex structure, the exact cature of wich is unknown. Since mass transfer to a disk has been well described in the laminar and turbulent ${ }^{3}$ regimes, it i-uld seem desirable to obtain a correlation de,cribing mass transfer in this intermediate region. An experiment is now in progress to measure this by depositing copper, at the limiting current, on a large rapicily rotating disk and examining the deposit. Preliminary results show no trace of the wavy surface predicted in Ref. 1 and although insufficient data have been gathered to formulate a correlation, the mass trausfer rate in this region seems to increase snoothly to that predicted for the turbulent region at its outer edge.

1. N. Gregory et al., Phil. Trans. Roy. Soc. A248, 155 (1955).

2. D. T. Chin and M. Litt, Flow Instability on a Rotating Disk, J. Fluid Mech. 54, 613 (1972).

3. B. Ellison and i. Cornet, J. Elec. Chem. Soc. 118, 68 (1971).

\section{MASS TRANSFER IN POROUS ELECTPODES}

Peter Appel and John Newman

Experiments were conducted in an electrochemical cell packed with uniform spherical stainless steel pellets to measure mass transfer coefficients at low Reynolds numbers. A redox reaction was employed (ferri-ferro cyanide), and measirements were made at the limiting current. Results show that the low Reynolds number asymptste is that predicted by an analysis 1 employing the Graetz solution for a model picturing the bed as a collection of straight cylindrical pores. At higher Reynolds numbers, the results lie between predictions based on 
the correlations of Wilson et al. ${ }^{2}$ and Bird et al. 3

1. John Newmen, private commmication.

2. E. J. Wilson and C. J. Geankoplis, Ind.

Eng. Chem. Fumdamentals 5, 9 (1966).

3. R. B. Bird, W. E. Stêwart, and

E. N. Lightfoot, Transport Phenamena

(Wiley and Sons, New YCrk, 1960), pp. 411 and 679 .

9. STLADY STATE CURRERT DIETRIBUTION ON A ROTATING DISK BELON THE LIMITING CURRENT FOR A REDOX REACTION

Peter Appel and John Newinan

Rednx reactjons on a rotating disk differ fram deposition reactions in that the presence of the product species at the surface enters into the kinetics and tends to drive the reaction in the opposite direction. Numerical calculations ${ }^{1}$ made for simplified kinetic expressions show that at corrent densities below the limiting current, the current distribution is more nonuriform than for the corresponding case with a deposition reaction, as calculated by Newman. ${ }^{2}$ This effect is most pronounced at low current densities.

1. Peter Appe1, Ph.D. thesis, IBL-2280 (in progress).

2. J. Newman, J. Electrochem. Soc. 113, 1235 (1966).

10. THE REMOVAL OF LEAD IONS FRM VERY DILUTE SOLITIONS USING A POROUS FLOW-THROUGH ELECTRODE

James Trainham and John Newman

It has been shown by Bennion and Newman ${ }^{1}$ that a fixed rorous flow-through carbon electrode device can be used to remove copper ions from dilute solutions. Also, they 1 have suggested that this method should work well for other metal systems such as: $\mathrm{Ag}, \mathrm{Au}$, $\mathrm{Cd}, \mathrm{Hg}$, and $\mathrm{Pb}$.

Here a similar study for the removal of lead in excess supporting electrolyte consisting of sulfuric acid and sodium sulfate is considered. The industrial inportance of the $\mathrm{Pb}-\mathrm{PbSO}_{4}$ systern stems not from the economic recovery of lead as a marketable product, but from an industria? waste problem. Lead sulfate is produced as a by-product in the flue gases during rossting of lead sulfide ores, by the aqueous oxidation of galena in zinc electrolytic plant trailings, and in lead acid storage hattery production. Though $\mathrm{PbSO}_{4}$ is quite insoluble in most industrial waste streams, it still exists in ver dilute concentrations, approxinately $5 \mathrm{mg} / \mathrm{liter}$; this concentration is high enough to be toxic to animal anc plant Iife. The environmental Protection Agency (EPA) maximum linit on the discharge of lead into streans is approximately $0.1 \mathrm{mg} / 1$ iter. To date the methods employed by industry to meet the EPA requirements are iradequate.

Design Problem. The design problem is to reduce a lead ion feed concentration from $1.45 \mathrm{mg} /$ itter to a dilute product concentration of $0.05 \mathrm{mg} / 1$ iter. The electrochenical reaction is: $\mathrm{Pb}^{+2}+2 \mathrm{e}^{-}+\mathrm{Pb}$.

When designing an electrochenical system, the ohmic potential drop is of primary importance if unwanted side reactions are to be avoided. In this case the evolution of hydrogen, $\mathrm{ir}^{+}+\mathrm{e}^{-} \rightarrow 1 / 2 \mathrm{H}$ is an unwented side reaction: For a porrus electrode with a higi matrix conductivity, the potential of the matrix phase $\Phi_{1}$ can be considered constant across the electrode. The ohmic potential drop in the solution phase sets the size of electrode. The standard electrode potential of lead is $U^{\theta}=-0.126 \mathrm{~V}$. The hydrogen electrode at $\mathrm{pH}=0$ is at a potential of $0 \mathrm{~V}$. Thus, hydrogen will be evolved first before any lead is deposited, unless there is a sufficient hydrogen overpotential on the cathode material. With this restriction the maximum allowable potential drop was taken to be $0.1 \mathrm{~V}$.

The electrode can now be designed using the equations in (1) and the data found in Table I. The results are given in Table II.

Economic Analysis. The cost per pound of lead recovered (\$/lb) as well as the cost per thousand gallons ( $\xi / \mathrm{kgal}$ ) of lead solution processed for the electrode design above is shown in Table III. The cost of lead ${ }^{2}$ is $18 \$ / 1 b$. Comparison with the results in Table III shows the process will lose $13 \$$ for every pound of lead recovered. Though the process is not profitable, it is an effective form of pollution abatement. At this time 10 data are available on other competitive processes.

Experimental. The same porous electrode cell built by Bennion ${ }^{1}$ for the copper process was used. The cathodic reaciion 
was: $\quad P b^{2+}+2 e^{-}+P b$ and the counter

electrode reaction was: $\mathrm{Cu} \rightarrow \mathrm{Cu}^{2+}+2 e^{-}$.

Unlike Benrion, ${ }^{1}$ limiting cursent curves were not obtained, the experiments being plagued by hydrogen evolution. This problem shouid be alleviated with snall modifications in the cell design. Suggestions are: (1) the heads of the cell should be made hemispherical with a gas release valve at the top of the head, and (2) lead spheres shouid be used in place of carbon for the matrix material.

The experiments were not a total loss, however, and gave some very encouraging results. For a feed concentration of $4.32 \mathrm{mg} /$ liter 15 gallons of solution was processed. Dilute product concentrations were found to be 1.45 and $0.55 \mathrm{mg} / \mathrm{liter}$, yielding a separation factor of 3 and 8 respectively, the separation increasing with decreased flow rate.

Table I. Design parameters.

\begin{tabular}{lc}
\hline & \\
\hline & \\
Feed concentration, mg/liter & 1.45 \\
Product concentration, mg/liter & 0.05 \\
Allowable potential variation, $\mathrm{V}$ & 0.1 \\
Solution conductivit/, mho/gn & 0.8 \\
Specific electrode area, cm 1 & 25 \\
Molecular weight of lead, $\mathrm{g} / \mathrm{mol}$ & 207.19 \\
Valence of lead ions & 2 \\
Diffucion coefficient of lead ions, $\mathrm{cm}^{2} / \mathrm{sec}$ & $4.0 \times 10^{-6}$ \\
Void fraction & 0.3 \\
Density of lead, g/cm 3 & 11.4 \\
Density of solution, $\mathrm{g} / \mathrm{cm}^{3}$ & 1.28 \\
Particle shape factor & 0.86 \\
Kinematic viscosity, $\mathrm{cm}^{2} / \mathrm{sec}$ & 0.016 \\
\hline
\end{tabular}

Table II. Design results.

\begin{tabular}{lc}
\hline \hline Electrode thickness, con & 60 \\
Time to plug electrode, days & 377 \\
Superficial velocity, cm/sec & 0.64 \\
Reynolds mmber & 1.88 \\
Mass transfer coefficient, col/sec & $1.45 \times 10^{-3}$ \\
\hline
\end{tabular}

Table III. Economic evaluation.

\begin{tabular}{lll}
\hline & $\frac{\$ / \mathrm{kgal}}{\$ / 1 \mathrm{~b}}$ \\
\hline Electrode capital cost & 0.2222 & 0.1836 \\
Operating labor & 0.0218 & 0.0180 \\
Electrical energy & 0.0021 & 0.0018 \\
Pumping energy & $\frac{0.132}{0.38}$ & $\frac{0.109}{0.31}$ \\
\hline
\end{tabular}


1. D. N. Bennion and J. Newman, Electrochenical Removai of Copner Ions from Very Dilute Solutions, J. App1. Electrochem. 2, 113-122 (1972).

2. N. A., "Commodity Index," Wa11 Street Jouma1, Dec. 1973.

\section{ADMITTANCE COUPLING ON A RING-DISK} ELECTRODE

Joseph J. Miksis, Jr. and John Newman

A theoretical analysis was made for a ring disk system exhibiting constant disk and ring potential, $\Phi_{\mathrm{d}}$ and $\Phi_{\mathrm{T}}$, respectively, to determine that if

$$
I_{d}=Y_{d}^{d}{ }_{d}+Y_{d}^{T} \phi_{r}
$$

and

$$
I_{I}=Y_{r}^{d} \phi_{d}+Y_{I}^{T} \phi_{r}
$$

where $I_{d}$ : $I_{r}$ are the average currents on the disk and ring, respectively, $Y_{i}{ }^{1}$ the adnittance on surface $i$ due to potential $\phi_{i}$ on surface $i, Y_{i}{ }^{j}$ the admittance on surface $i$ due to potential $\Phi_{j}$ on surface $j$, then

$$
Y_{r}^{d}=Y_{d}^{T}
$$

Previous experimental results ${ }^{1}$ indicated this coupsing relationship to exist.

A conputer program was made to test the velidity of $\mathrm{Eq}$. (3) for systems of various disk and ring radii. The current density as a fimction of radius was also determined.

Analysis showed that only primary current distributions need be considered for Eq. (3) to be valid.

1. C. Gabrielli et al, Étude de la Repartition du Potentiel a la Surface d'ure Électrode a Disque-Anneau, J. de Chimie Physique 69, 739 (1972).

\section{RESEARCH FLANS FOR CALENGAR YEAR 1974}

John Newman

Mass transfer for turbulent flow between rctating concentric cylinders separated by a very thin gap will be measured using the ferri-ferro cyanide redox reaction in an atterpt to improve upon existing ccrnolations for such systems. Mleasurements of mass transfer rates to a rotating disk in transitional flow will be continued. A sturty of electro-osmosis and transport in ion-exchange membranes will be begun.

\section{1973 PUBLICATIONS AND REPQRTS}

John Newman and Associates

Journals and books

1. J. Newman, Electrochcrical Systems (Prentice-Hall, inglewood Cliffs, N.J.), 1973.

2. J. Newman, Fundamental Principles of Current Distribution and Mass Transport in Electrochemical Cells, Electroanalytical Chem., edited by Allen J. Bard, 6, 187-352 (1973) (UCRL-20547).

3. W. Tiedenann, D. Benrion, and J. Newman, Error in Measurenents of Electrode Kinetics Caused by Nonumiform Ohmic-Potential Drop to a Disk Electrode, J. Electrochem. Soc. $120,256-268$ (1973) (LBL-890).

4. T. Chapman and J. Newman, Restricted Diffusion in Binary Solutions, AIChE J. 19, 343-348 (1973) (LBL-1142).

5. K. Nisancioğlu and J. Newman, Diffusion in Aqueous Nitric Acid Solutions, AIChE J. 19, 797-802 (1973) (LBL-1428).

6. J. Newman, Analysis of Porous Electrodes with Sparingly Soluble Reactants, II. Variable Solution Properties, Convection and Complexing, J. Electrochem. Soc. 120, 906913 (1973).

7. R. Honsy and J. Newman, Mass Transfer to a Plane below a Rotating Disk at High Schmidt Numbers, AIChE J. 19, 929 (1973) (LBL-1420).

8. C. Mohr and M. Williams, Diffusion of Gas into a Non-Newtonian Failing Film, AIChE J. 19, 1047 (1973).

9. K. Nişancioğlu and J. Nerman, Transient Response of: a Disk Electrode, J. Electrochem. Soc. 120, 1339-1346 (1973) (IBL-1109).

10. K. Nisancioğlu and J. Newrar, Transient Response of a Disk Electrode with Controlled Potential, J. Electrochem. Soc. 120, 13561358 (1973) (LBL-1173) . 
11. J. Newrnan and J. E. Harrar, Potential Distribution in Axisynnetric Mercrry Pool Electrolysis Cells at the Limiting Current, J. Electrochem. Soc. 120, 1041-1044 (1973) (LBL-1155) .

12. J. Newman, Separation Processes Based Primarily on Action in a Field, Chemical Engineer's Handbook, 5th Edition, edited by R. H. Perry and C. H. Chilton McGraw-Hill, New York, 1973), pp. 17-49 to 17-58.

13. C. Mohr and J. Newman, Mass Transfer in Cylindrical Couetie Flow, Electrochimica Acta, 18, 761 (1973) (LBL-1141).

14. N. Vahdat and J. Newman, Corrosion of Iron Rotating Disks, J. Electrochem. Soc. 120,1682 (1973) (LBL-896).

\section{Papers presented}

1. J. Newman, Electrochemical Reactors. Annual Review Symposium of the United States Atomic Energy Cormission. Incrganic Materials Research Division, Lawrence Berkeley Laboratory, Berkeley, Feb. 1, 1973.

2. J. Newman, Electrochemical Removal of Lead from Process Streams, lecture at Globe-Lnion, Inc., Milwaukee, Wisconsin, Feb. 9, 1973.

\section{J. Newman, Flow-through Porous Electrodes} with Applications to Water-pollution Abatement, invited lecture at Texas Tech University, Lubbock, Texas, March 22, 1973.

4. J. Newman, The Transient Response of a Disk Electrode (with Kenal Nisancioglu, Newman giving address). An invited address at the symposium on Engineering Analysis of Electrochemical Systems at the Chicago meeting of the Electrochemical Society, May 1973.

5. J. Newman, Electrochemical Concentrating and Purifying from Dilute Copper Solutions (with Robert S. Wenger and Douglas N. Bennion, the Iatter presenting tile paper). Symposium on Engineering Analysis of Electrochemical Systems at the Chicago meeting of the Electrochemical Society, May 1973.

6. J. Newman, Mass Transfer of Minor Conponents in a Propagating Crack (with fililiam $H$. Sinyrl, who presented the paper). Symposium on Engineering Analysis of Electre henical Systems at the Chicago meeting of the Electrochemical Society, May, 1973.

7. J. Netman, Corrosion of Rotating Iron Disks, lecture at the Iniversity of Illinois, Urbana; May 18, 1973.

8. J. Newman, Current Distribution on a Rotating Spherical Electrode Below the

Limiting Current, lecture at Atgonne National Laboratory, Argonne, Illinois, Oct. 12, 1973.

9. J. Newman, Removal of Metal Ions from Electrolytic Solutions Using Flav-Through Porous Electrodes, invited lecture at the Chicago Section of the Electrochemical Society, Nov. 8, 1973.

10. J. Newinan, Renoval of Metal Ions from Electrolytic Solutions Using Flow-Through Porous Electrodes, invited lecture before the Chenical Engineering Department, Northwestem University, Evanston, I1linois, Nov. 9,1973 .

\section{LBL reports}

1. R. Homsy and J. Newman, Current Distribution on a Plane BeJ on a Rotating Disk, LBL-1887, Aug. 1973.

2. R. Homsy and J. Newman, An Asymmtotic Solution for the Warburg Impedance of a Rotating Disk Electrode, LBL-2209, Aug. 1973.

3. K. Nişancioğ1u, Current Distribution and Mass Transfer in Rotating Electrode Systems (Ph.D. thesis), LBL-1880, Sept. 1973.

4. K, Nişancioğlu and J. Newman, Current Distribution on a Rotating Sphere Below the Limiting Current, LBL-1837, June 1973.

5. K. Nişancioğlu and J. Newman, Transient Convective Diffusion to a Disk Electrode, LBL-1881, July 1973.

6. K. Nişancioğlu and J. Newmar, The ShortTime Response of a Disk Electrode, LBL-1896, Sept. 1973.

\section{Translations}

1. C. Gabrielli et al., Study of the Potential Distribution on the Surface of a Ring-Disk Electrode, J. de Chimie Physique 69, 739 (1972), translated by Charles Mohr, UCRL-Trans-1498, May 1973. 


\section{PHYSICAL CHEMISTRY}

Leo Brewer, Principal Inveatigator

1. THERIXDYPJAMIC PROPERTIES OF THIRD AND FOURTH GROUP TRANSITION METALS WITH PLATIML! GROUP METALS

John P. Stiga and Gary B. Bullard

The variation of Gibbs energy of dilution with concentration is expected to show unusual behavior for strongly interacting solutions of third and fourth group transition metals with platinum group metals at compositions corresponding to full utilization of low-energy orbitals. Some information can be obtained by determination of the constant boiling compasitions of these alloy solutions. As the volatilities are very low, electron beam heating is being used to produce sufficiently high rates of vaporization. These results are being supplemented by data obtained from hightemperature-solid-electrolyte cells.

2. APPLICATION OF THE REGULAR SOLUTION THEORY TO AETALLIC SOLUTIONS

John P. Stige

A modification of the regular solution theory that uses promotion energies to obtain cohesive energies is being tested for metallic solutions that do not have strong interactions due to electron transfer. The relation of volume expansion to internal pressure difference and excess partial molai entropy of solution is also being examined.

\section{THEPAOINYNAMIC EVALUATION AND CONPILATION OF METAL ALIOY SYSTEMS}

Leo Brewer, Ralph R. Hultgren, and Johm Chipnan

The following compilations were completed and published in 1973. (1) Ralph R. Hultgren, Pramod D. Desai, Donald T. Hawkins, Molly Gleiser, Kenneth K. Kelley, and Donald D. Wagman, Vol. 2, Selected Values of the Thermodynamic Properties of the Elements American Society for lletals, Metals Park, Ohio, 1973) 636 pp.

(2) Ralph R. Hult tgren, Pramod D. Desai, Donald T. Hawkins, Molly Gleiser, and Kenneth K. Kelley, Vol. 2, Selected Values of the Thermodynamic Properties of Binary A1loys (American Society for Metals, Metals Park, Ohio, 1973) 1435 pp.
(3) Donald T. Hawkins and Raiph R. Hultgren, Constitution of Binary Alloys in Metals Handhook, Vol. 8, iletallography, Structures, and Phase Diagrams, edited by T. Lyulan, 8th ed., (American Society for Netals, Hetals Park, Ohio, 1973) (sumported by ASM), pp. 251-376.

(4) Leo Brewer and Shih-Ger Chang, Constitution of Ternary Alloys, ibid., pp. 377-434 (supported by ASM).

The following compilations are still in progress: (1) Compilation of themadynamic properties of molybdenum and its compounds. (Supported by International Atomic Energy Agency.) (2) Calculation of the thermodynamic properties and phase diagrans of the alloy systems of the lanthanide and actinide elements. (3) Calcilation of solubilities of intermetallic compounds in iron and prediction of behavior of all the metallic elements when dissolved in iron.

4. THE MATRIX SPECIRA OF Ca WITH $0, \mathrm{O}_{2}$, AND $\mathrm{N}_{2} \mathrm{O}^{+}$

Walter D. Duley

The spectra of species formed upon cocondensation of calcium vapor with $\mathrm{O}_{2} \mathrm{O}_{2}$, and $\mathrm{N}_{2} \mathrm{O}$ in rare gas matrices at liquid hydrogen temperatures have indicated an unusually complex system with a number of species. Variation of concentrations and isotopic substitutions are being used to identify the species.

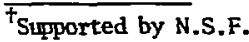

\section{RESEARCH PLANS FOR CALENDAR YEAR 1974}

Leo Brever

Hork will continue on the characterization of the Gibbs energy of dilution as a function cî́ concentration for strongly interacting transition metal alloys in an effort to improve the cinaracterization of the Gibbs energy of transition metal alloys. Conpilation activities will continue on $\mathrm{No}, \mathrm{Fe}$, and the lanthanides and actinides with the objective of providing thermodymamic data that vill allow prediction of the metallurgical and chemical behavior of these metals. loork will continue on the characterization of the matrix spectra of $\mathrm{CaO}_{x}$ species with 
possible extension to $\mathrm{MgO}$ species. It is hoped that manuscripts on the thermodynamic properties of TiO gas, the transition probability of the Swan bands of $\mathrm{C}_{2}$, and the ground electronic state of $\mathrm{CaO}$ will be completed.

\section{1973 PLBLICATIONS AND REPORTS}

Leo Brewer and Associates

\section{Joumals and books}

1. Leo Brewer, Transition Metal Alloys-A Chemist's View, 18th Annual Conference on Magnetism and Magnetic Materials--1972, Denver, Proceedings of AIP Conference (AIP, 1973), No. 10, Pt. 1, pp. 1-16 (LBL,-1424).

2. Leo Brewer and Paul R. Hengert, Transition Metal Alloys of Extraordinary Stability; An Example of Generalized Lewis-Acid-Base Interactions in Metallic Systems, Met. Trans. 4, 83-104 (1973) (L.BL-807).

3. Leo Brewer and Shih-Cer Chang, Constitution of Ternary Alloys, Hetals Handhook, Vol. 8, Metallography, Structure, and Phase Diagrams, edited by T. Lyman, 8th ed. (Americar Society for Netals, Metals Park, (hio, 1973), pp. 377-434.

4. Donald T. Hawkins and Ralph R. Hul tgren, Constitution of Binary Alloys, Metals Handbook, Vo1. 8, Metallography, Stru ttures, and Phase Diagrams, edited by T. Lyman, 8th ed. (American Society for Metals, Metals Park, Chio, 1973), pp. 251-376.

5. Raiph R. Hultgren, Pranod D. Desai, Donald T. Hawkins, Mbily Geiser, Kenmeth $K$.
Kelley, and Donald D. Wagman, Vol. 1, Selected Values of the Thernodynamic Properties of the Elements, (American Society for Netals, Metals Park, Ohio, 1973) $636 \mathrm{pp}$.

6. Ralph R. Hultgren, Pramod D. Desai, Donald T. Hawkins, Noily Gleiser, and Korneth K. Kelley, Vol. 2, Selected Values of the Thermodynamic Properties of Binary Alloys (American Society for Metals, Metals Park, Ohio, 1973) 1435 pp.

LBL reports

1. K. A. Gingerich, Mass Spectrometric Evidence for the Very High Stability of Gaseous ThIr and ThPt and Hethod of Calculating Dissociation Energies of Diatouric Intermetallic Compounds with Multiple Bonds, LBL-2203, July 1973.

2. Chin-An Chang, Emipirical Calculations of the Force Constants, Dissociation Energies and Bond Lengths of Diatomic Molecules, LBL-2252, Nov. 1973.

\section{Papers presented}

1. Leo Brewer, 'Relationships between Electronic Configurations, Thermodynamic Properties and Crystal Structures of Superconducting Transition Metal Phases," Gatlinburg Conference on Superconductivity and Lattice Instability, Gatlinburg, Tenn., Sept. 10-12, 1973 (LRI,-1898 Abs.).

2. Leo Brewer, Prediction of Transition Metal Phase Diagrams, presented at U.S.-Japan Seminar on "Thermodynamics and Phase Relations of Nuclear Materials" at Ames Laboratory, Iowa State University, July 9, 1973 (LBL-2234 Abs. and LBL-2234). 
Charles B. Harmis, Principal Investipator

1. EXCITED TRIPLET STATES IN MOLECUILS AND MOLECULAR CRYSTAJS

\section{Charles B. Harris}

Using new techniques recently developed in these laboratories which utilize simultaneous cptical and microwave numping (Phosphorescence-Hicrowave-Double-Resonance Spectroscopy), we are studying molecular properties of excited triplet states and the dymanics of excited state energy transfer (excitons) in molecular crystals. In oversimplified terms, luminescence from excited triplet states of "isolated" molecules or mobile electronic states, excitons, is monitored while a microwave field changes the orientation of the electron snin in the triplet state. This causes a change in the intensity or polarization of the emission and forms the basis for a technique capable of detecting as fer as $10^{4}$ molecules in excited states. Nany features of triplet states can be studied by analyzing the microwave transitions and the triplet phosphorescence. These include electron distributions, nuclear-electron interactions, excited state orbital symetries, molecular distortions in excited states and, finally, the rates, routes, and mechanisms of inter- and intramolecular energy transfer. In addition tie are investigating relatively unexplored but very inportant aspects of excited states involving molecular processes that occur on a time scale of $10^{-9}$ to $10^{-12}$ seconds. These are aII fundamental in nature and include such things as the primary mechanism in energy migration, radiationless relaxation phenomena, and electron transfer between molecules. A variety of mecharisms have been postulated and theoretically developed for these processes: however. because of the extraordinarily short time scale of the processes feri have been studied. Using Picosecond $\left(10^{-13}\right)$ Laser Spectroscopy certain key aspects of the above phenomena are being experimentally investigated in our laboratory. In effect, a picosecond laser pulse is used to generate molecules in excited states and then it is used to follow spectroscopically the time development of the system under investigation. Since it is possible to obtain the complete spectra of molecules in $\sim 3 \times 10^{-13}$ second using picosecond techniques, the primary events and time-dependent changes associated with excited states, such as energy transfer, radiatimless transitions, and the coherence associated with oscillating electric dinolar states in molecules can be systematically investigated.

\section{OPTICAL DETECTION OF COHERENCE IV MOLECULAR EXCITED LOCALIZED AND DELOCALIZED BATD STATES}

\section{Charles B. Harris}

Although coherent phenomena in an ensumble of two-level systems can chserved by monitoring a macroscopic oscillating magnetic dipole as in conventional magnetic resonance or a macroscopic oscillating electric dipole as in superradiant cmission from crystals or gases, coherent information about the timedependent density matrix describing the ensemble carnot be generally obtained by monitoring properties associated with the population of orly one of the tho levels coupled to the oscillating cipole. As a result, in doubla resonance experinents where optical properties such as emission or absorption of light to a third level are used to measure the coherent properties of two other leve15, the coherent phenomena in many cases are not directly observable via a modulation of emission or absorption of light at the oscillating dipolar frequency. Several methods have been developed that are capable of measuring any state of the coherence of an ensenble by double resonance experiments, regardless of the properties of a single level whose population is being monitored. Although the methods are applicable to any optical-optical double resonance experiment involving two electric dipole transitions, the techniqie has been applied in the context of optically detected magnetic resonance in molecular excited triplet states. The technique is limited oniy by the sensitivity of photon detection and can be used to monitor as few as 104 molecules. The optical detection of electron spin echoes, spin-locking, ratary tho trains, and adiabatic demagnetization in excited electronic states has been accomplished and applied to a variety of problems and phenoriena associated with the solid state. These techniques have been applied to systems which provice partial information on coherent phenomena in "one-dimensional" molecular solids having, as their lowest excited states, delocalized triplet bands anu localized triplet "molemilar" states. Many of the experiments which have been developed utilize zero-field optically detected magnetic resonance in the excited 
triplet states. A series of selected experiments and its associated theoretical interpretation denonstrating coherent migration of electronic energy at $10 \mathrm{w}$ temperatures has been carried out in the context of general considerations of transport problens.

(Partially funded by NSF)

\section{EXCITON-TRAP INTERACTIONS IN THE COHERENT AND INCOHERENT LIMITS}

\section{Michne1 D. Fayer and Charles B. Harris}

At liquid the temperature, phosphorescent emission from organic molecular crystris in general cones from low-energy traps in the lattice, although in some molecules, such as 1,2,4,5-tetrachlorobenzene and 1,4-dibramonaphthalene, exciton emission is aiso observed. The intensity of trap emission is highly temperature dependent in certain temperature regions. This temperature dependence is found to be explicable in tems of a theoretical franework wich includes the method of energy transport in the crystal and the magnitude and sigi of the intermolecular interactions which give rise to the exciton bands in the crystal.

Initially the problem was considered for an ensemble consisting of one-dimensional exciton bands and traps of only one energy. The trap intensity is given by $I_{\text {trap }}(T)=$

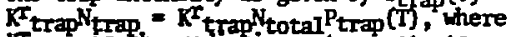
$\boldsymbol{M}_{\text {trap }}$ is the radiative rate constants, $N_{t r a p}$ is the trap population, and $N_{\text {total }}$ is the total excited state population of the system. Since an excitation mst either be in the exciton bands or in the traps, the trap population is equal to the total population times $P_{t}(T)$, the probability that an excitation is in a trap. The numer of energy levels in a one-dimensional exciton band is equal to the number of identical molecules in the linear chain forming the exciton. "These energy levels are labeled by the quantum numer, $k$, and the energy as a finction of $k$ is given by $E(k)=2 \beta \cos k a$, where $B$ is the nearest neighbor intermolecular interaction matrix element and $a$ is the lattice spacing in the direction of the interactions. Using this energy relationship, the partition function 2 for the system can be written as

$$
z=1+e^{-\Delta / k T}+\sum_{k=\pi / n a}^{(n-1) \pi / n a} 2 e^{-[\Delta-2 \beta(1-\cos k a)] / k T}
$$

The zero of energy is taken at the energy of the trap. The trap depth $\Delta$ is the difference in energy between the trap energy and the energy of the $k=0$ level of the exciton band. This is the depth which is measured spectroscopically since only the $k=0$ level of the origin absorbs or emits light. The first term in $z$ is the Boltzmann factor for the trap level, the second term is for the non-degenerate $k=0$ level of the band. The summation is over the remainder of the exciton states which are doubly degenerate. The trap probability $P_{\text {trap }}=1 / z$, and therefore the intensity of trap emission $I_{\text {trap }} \times 1 / z$.

If a sample of known trap concentration is prepared and the trap depth $\Delta$ is measured spectroscopically, then $B$ can be fit to the temperature dependence of the trap emission. As depicted in Fig. 1, two cases arise depending upon the sign of $B$. If $B$ is negative the exciton band spans an energy range from $\Delta$, the $k=0$ energy, to $\Delta+4 \beta$, $k=t / a$. If $B$ is positive the band is inverted and it spans an energy range from $\Delta$ to $\Delta-4 B$. Thus the sign of $B$ in addition to the magnitude of $\beta$ determines the tenperature dependence of the trap intensity. The above description gives excellent agreement with experiment for crystals of $1,2,4,5-$ tetrachlorobenzens which have one-dinensional excitons and traps of a single energy. In order for this description to work, the system must reach equilibrium within the 1 msec lifetimes of the excited states. This implies that excitations must be able

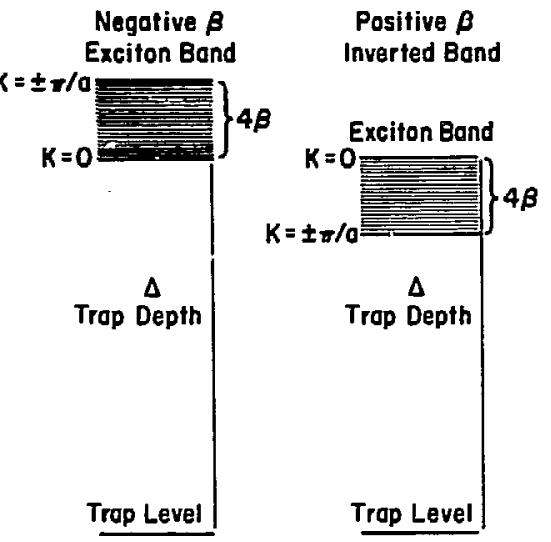

Fig. 1. Trap level and exciton band for systems containing regular and inverted exciton bands.

(XBL 7210-5704) 
to migrate to many trap sites in less than the lifetime. The traps in the 1,2,4,5tetrachlorobenzene samples are of such low concentration that it is possible to distinguish between the two possible modes of exciton transport, coherent migration or random walk hopping. The coupled differential equations have been solved in the coherent limit and in the diffusion limit when the ensemble of localized trap states and delocalized band states are not in Boltzmann equilibrium. Furthermore, the full partition function has been calculated and evaluated in the temperature regime where Boltzmann statistics are applicable. The agreement between experiment and theory in this region was confirmed by a series of experiments utilizing isotopic (d) localization. (Partially funded by NSF)

\section{THE DECAY OF LOCALIZED STATES IRITO DELOCALIZED BAND STATES}

Michael D. Fayer and Charles B. Harris

We have developed a technique for measuring the decay of localized excited triplet states into the delocalized band states of a solid, utilizing the optical detection of electron spin coherence. Specifically, the tecimique employs the optical detection of electron spin locking for the measurement of kinetic phenomera in the presence of fluctuating triplet spin sublevel populations. Experimental data have been obtained which yield the temperature dependence of the phonon-assisted promotion of a localized isotopic site to an energy equal to that associated with the energies of the host exciton band. Ir addition, the data have been analyzed in terus of a kinetic model which relates the incalized states' rate of promotion and radiationless decay into the exciton band states to explicit features of the exciton and phonon band structure anci radiationless relaxation theory.

(Partially funded by NSF)

5. THE THEORY OF OPTICALLY DETECTED SPIN COHERENCE IN EXCITED IRIPLET STATES

Willian G. Breiland, Henry H. Brenner, and Charles B. Harris

The explicit theoretical basis for optically derected double-resonance experiments has been developed using all the available and well-known tools such as the geometrical representation of Schrödinger's equation, the generalized interaction representation, density matrices, and coherent averaging theory. This development has been applied to optically detected Fourier transform spectroscopy, optically detected spin echoes, Carr-Purcell echo trains, spin locking, and other types of experiments.

6. THE THEORY OF OPTICALLY DETECTED SPIN COHERENCE IN NON-STATIONARY STATES

William G. Breiland, Michael D. Fayer, and Charles B. Harris

The theoretical aspects of optically detected spin coherence have been developed to include the effects of feeding and decay into a two-level system. The limiting cases of slow feeding and decay have yielded expressions for optically detected free induction decay, transient nutation, spin echoes, and Fourier transform spectroscopy in an ensemble which is kinetically evolving to a new steady state inder the influence of an applied coherent radiation field. The espects of feeding and decay promise to provide an interesting way of establishing a coherent state that lasts as long as a rf or optical field is applied to the system. The possible alplications of this long-term spin-coherent state are presently being investigated and being extended to include coherence in lasers in which the creation of a super-radiant state is controlled by the radiation field itself.

\section{OPTICALLY DETECTED CARR-PURCELL TRAINS} AND COHERENT AVERAGING THEORY

Henry C. Brenner and Charles B. Harris

The application of a series of phaseshifted (Gieiboon-Gill technique) CarrPurcell optically detectes spin echoes in conjunction with coherent averaging theory den:loped by Waugh annl co-workers has betal used to partially average the effects of electron-nuclear hyperfine interactions, molecular torsions due to low-energy phonons in crystals, and nuclear spin diffusion on the electros spin $T_{2}$ relaxation time of excited triplet states in zero field. 
8. OPTICALLY DETECTED SPIN WOCKTMG AND ITS APPLICATIONS TO KINETIC PHENONENA.

Charles B. Harris and Horst Schuch

The use of spin locking to completely remove relaxation processes $\left(T_{2}\right)$ in excited triplet states has been arcomplished. In effect we have been able to observe the lifetime-broadened zera-field electron spin transition, the lifetime being that associated with radiative decay or radiationless relaxation of the excited triplet state to the ground state. This allows one to we spin locking as a direct kinetic probe of phencmena (cf. Fayer end harris) that cause a change in the Larmor frequency, $\Delta w$, larger than the applied spin lock field, $\mathrm{rH}_{1}$.

(Partially funded by NSF)

9. OPTICALLY DETECTED ADIABATIC DEMAGNETIZATION IN EXCITED TRIPLET STATES IN ZERO-FIELD AND THE APPLICATION TO KINETIC PHENOMENA

Henry C. Brenner, John C. Brock, and Charles B. Harris

Using the technique of adiabatic demagratization in the rotating frame (ADRF), electron spins in triplet excited states have been "ordered" in the local fields associated with their particular environments.

Preliminary results indicate that this ordered state can be readily obtianed, and is in the case of spin locking it is essentially lifetime Iimited, the lifetime being that associated with the fluctuating local field, be it the radiative decay of the excited state or other fluctuations of the local field. The results of these preiininary experiments have demonstrated the fiasibility of using the ordered state as a kinetic probe of many phemamena, such as excited state energy migration, spin lattice relaxation in the excited state spectral diffusion in the excited state, optically purped nuclear polarization, and others. (Partially funded by NSF)

10. OPTICALLY DETECTED ROTARY ECHO TRATNS IN EXCITED TRIPLET STATES

\section{Charles B. Harris and Ronald L. Schlupp}

The rotary echo train pulse sequence has been examined as 5 method for observing the dynamics of phenomena correlated to electron spins in optically excited states for times longer than the electron spin relaxation time, $T_{2}$. Comprehensive experiments were performed on the $3_{7 \pi}^{*}$ state of $h_{2}$ tetrachlorobenzene in a variety of host lattices. Although $T_{2}$ was foumd to increase significantly, the excited-state lifetimelimited broadening was not obtained suggesting that other methods--spin locking or adiabatic demagnetization in the rotating frame--are better for the investigation of kinetic phenomena in excited states. (Partially funded by NSF)

11. PICOSECOND SPECTROSCOPY: COHERENCE IN VIBRATIONAL RELAXATICN

Charles B. Harris, Allan M. Nishimura, and Robert $M$. Shelby

The techrique of picosecord spectrascopy offers the possibility of imvestigating the coherent dynamical properties of certain systems on time scales of from a few picoseconds to tens of nanoseconds. This is made feasible through the utilization of ultra-short pulses of high-intensity coherent light from a mode-locked solid state laser to initiate a process of interest and then to spectroscopically moritor the evolution of the system in time. In this manner it has been shown in other laboratories that it is possible to record the entire spectrum of a sample and its time devendence with a single laser shot. We have constructed mode-locked ruby and Nd glass lasers, and are using single-pulse selection techniques and laser amplification to investigate the coherence associated with vibrational relaxation in molecular liquids. In the phencmenon of stimulated Raman emission, light is used to generate a frequency equal to the difference between the laser frequency and that of some molecular vibration. Because of the coherence of the emitted light, molecules are left all vibrating in phase. It has been shown in other laboratories that it is possible to detect the subsequent presence of this vibrational coherence by observing the coherent anti-Stokes Raman scattering of a delayed probe pulse of light. Using a two-photen optical analog of the conventional nuclear spin echo experiment, we are attempting to investigate the mechanisms leading to the decay of coherence in liquids. The results of these imvestigations should provide new knowledge of vibrational relaxation in 1iquids and of the dynamical structure of the liquid phase, and introduce a method which we plan to extend to the study of solids. 
12. ENERGY AND ELECTRON TRANSFER IN PHOTOSYNTHETIC BACTERIAL SYSTBMS*

Robyn Goodfellow, Charles B. Harris, Allan M. Nishimura, Kenm:sth Sauer, and Robert M. Shelby

A mode-locked ruby laser has been used to probe absorbance changes associated with the primary processes of photosynthesis on a time scale ranging from 20 picoseconds to several nanoseconds. Preliminary results from a recent experiment designed to probe for absorbance changes at $793 \mathrm{~nm}$ in reaction centers from the photosynthetic bacterium Rps. spheroides indicate that there may be a bleaching of P800 at 0.5 nanosecond after excitation with $793 \mathrm{ng}$ light.

Collaborative with Professor Kenneth Sauer, LBL-Biodynamics.

\section{RESEARCH PLANS FOR CALENDAR YEAR 1974}

\section{Charles B. Harris}

\section{a. Dynamics in Solids}

The udy of dynamical processes such as energy transfer in molecular crystals will be extended using thie techniques of laser spectroscop:. In particular, a nitrogenpumped tunable dye laser will be used to populate specific energies of localized and delocalized states, and the techniques developed in 1973 will be hybridized with high-resolution laser techniques to study directly adjitional properties of excited triplet states and exciton bands, ineluding bimolecular exciton-exciton anihilation.

\section{b. Phonon Interactions in Solids}

The specifies of phonon interactions in molecular excited states will be investigated, utilizing the new optical detection techniques developed in this laboratr.ty. Electron spin relaxation rates in excited triplet states will be monitored with optically detected microisve pilse tecluniques while the molecular crystal is sujected to coutrolled heat pulses.

The specifics of the phonon interaction in the molecular crystal will be mapped by varying the phonon distribution of the heat pulse. This will be accomplished by varying the voltage and the electrical pulse duration applied to the resistive element of the heater. The resistive elements are being fabricated by metal evaporation onto a quartz substrate on which the crystal is placed.

In addition, laser techniques will be employed to investigate the coherence of phonon states in solids, particularly the $\mathrm{q}=0$ wavevector states.

\section{c. Molecular Fxcited States on Surfaces}

The recent advances in phosphorescence double resonance spectroscopy (PMDR) made in these and other laboratories have provided a great deal of new information about excited states in the bulk crystal as well as in dilute guest-host $\pi^{-}$-tres. The sensitivity of this method allows one to exanine details of the excited state which have previously been inaccessible. We plan to apply these methods to investigate the nature of monolayers of organic molecules in excited states on the surface of a clean metal or semiconductor. These studies will yield information on how the metal or semiconductor affects spin-orbit coupling, lifetimes, intersystem crossing, and the gecmetry of the excited state of the molecule on the surface and hence give detailed information on the surface states thenselves. It should also be possible to study surface energy migration and to investigate the time evolution of an ensenble of surface excited states wijich have been "prepared" coherently. The information thus gained would be useful in helping to understand the mechanisms of surface catalysis and to understand surface states in general.

Correlated with the experiments will be an attempt to understand the theory of surface states when the molecules deposited on the surface are within $10 \mathrm{~A}$. Naturally, the theoretical developnent must be guided by the experiments.

\section{d. Picasecond Laser Technology}

Additional techniques in picosecond laser tectnology and their application to coherent phenomena will be extended to solids if the initial experiments in liquids look promising.

\section{e. Photosynthesis*}

An attempt to understand the first three steps in photosynthesis (excitation absomtion by antemna pignents, transfer of energy to the reacting center, and the formation of the supposed charge-transfer state) will be pursued, using laser and biological methois. 
$\overline{\text { Tointly with Professor Kenneth Sauer }}$

\section{1973 PUBLICATIONS AND REPORTS}

Charles B. Harris and Associates

\section{Joumals}

1. W. G. Breiland and C. B. Harris, Breakdown of the Bom-Oppenheimer Approximation in Radiative Transitions, Chem. Phys. Letteis 18, 309 (1973) (LBL-1411).

2. C. B. Harris, Coherent Exciton Migration: An Experimental and Theoresical View, Proc. of the 6th Molecular Crystal Syriposium, Germany, May 1973 (LBL-1804).

3. D. S. Tinti, G. Kothandaraman, and C. B. Harris, Determination of the Absolute Sign of the Electron Spin Dipolar and Nucleas Quadrupolar Interactions in Nolecular Excited Triplet States, J. Chem. Phys. 59, 190 (1973) (LBL-1461).

4. W. G. Breiland, C. B. Harris, and A. Pines, Optically Detected Electron Spin Echoes and Free Precession in Molecular Excited States. Phys. Rev. Letters 30, 158 (1973) (LBL-1412).

5. C. B. Harris, R. L. Schlupp, and H. Shuch, Optically Detected Electron Spin Locking and Rotary Echo Trains in Bblecular Excited States, Phys. Rev. Letters 30, 1019 (1973) (LBL-1412).

\section{Invited Lectures}

1. Westem Spectroscopy Association, Asilomar, February 1973.

2. American Chemical Society Symposium in Chemical Prysics, Dallas, Texas, April 1973.

3. Sixth Molecular Crystals Symosium, Schloss Elmau, Germany, May 1973.

4. The XIth European Congress on Molecular Spectroscopy, Tallinn, USSR, Jure 1973.
5. Magnetic Resonence Gordon Conference, New Hampshire, June 1973.

6. Nolecular $\mathrm{S}_{\mathrm{r}}$ ectroscopy Gordon Conference, New Hampshire, July 1973.

7. Jan van Guensfonds Lectures, University of Amsterdam, The Netherlands, Novenber and Decenber 1973.

8. American Physical Society Coherent Transients Symposium, Berkeley, California, Decenter 1973.

\section{LBL reports}

1. M. D. Fayer and C. B. Harris, Coherent Energy Migration in Solids. I. Band-Trap Equilibria at Boltzmam and Non-Boltzmann Temperatures, LBL-1808, May 1973.

2. Rodney Nichael Panos, Fhosphorescence Microwave Double Pesonance Sicudies of the Lowest Excited Triplet State of p-

Dichlorobenzene (Ph.D. thesis), LBL-1822, Jure 1973.

3. C. B. Harris, Phosphorescence-NicrowaveDouble-Resonance in Exciton States of Nolecular Crystals and Coherent States of Triplet Spin Ensembles, LBL-1845, June 1973.

4. C. B. Harris and M. D. Fayer, coherent Energy Afigration in Solids. II. Spin Resonence Absorption in Coherent Wave Packet States and the Effects of Phonon-Exciton Scattering, LBL-2210, Aug. 1973.

5. H. C. Brenmer, J. C. Brock, and C. B. Harris, The Use of an "Ordered" Electron Spin State as a Probe in Molecular Spectroscopy: Optically Detected Adiabatic Demagnetization in Excited Triplet States in Zero Field, LBL-2293, OCt. 1973.

6. M. D. Fayer and C. B. Harris, The Lecay of Localized States into Delocalized Band States. I. Theory and Preliminary Experimental Investigations Using Optically Detected Electron Spin Coherence, LBL-2550, Nov. 1973. 
Alexander Pines, Principal Investigator

\section{NUCLEAR MAGNETIC DOUBLE RESONANCE} SPECTROMETER

\section{Alexander Pines and Associates}

A wideband nuclear magnetic doubleresonance spectraneter has been constructed to permit the implementation of novel techniques for high-sensitivit\} jetection of nuclei of low isotopic abundance. The spectroneter was fully operational early in 1973 and was used for the experiments to be described. The main application of the spectrometer to date has been the detection of $13 \mathrm{C}$ in natural isotopic abundance $\left(\sim 1 \frac{1}{5}\right)$; for this purpose it is of unprecedented sensitivity and large signals have been observed from small crystalline sumples. The device has a fast programable pulse unit which controls the radiofrequency modulat:-n. This is interfaced to an online computer making the interchange of modulation sequences and the trial and implementation of new experiments extremr.ly flexible. The computer also serves for online Fourier transformation. The magnet is a wide-bore superconducting solenoid in a
LHe/Liv eryngenic dewar. Fadiofrequency amplifiers are mo-ified radic amateur transmitters operating at 26.7 and $105 \mathrm{MMz}$ and capable of the high porter output which is necessary for the solid state studies.

An inportant component of the spectroneter is the sample probe. This is designed for tine geanetry of the superconducting solenoid and is equipped with home-built variable capacizors to withstand the large $(\sim 30,000 \mathrm{~V})$ radiof requency voltages across the sample coils. A crystal goniameter controllable remotely permits precise orientation and rotation of single crystals in the magnetic field. The crystal holder is designed to transfer directly to an $\mathrm{X}$-ray goniometer, allowing us to orient crystals by $X$-ray precession methods. Part of the probe is shown in Fig. 1, with details in the caption.

The sensitivity enhancenent provided by this spectrometer takes advantage of abindant isotopic nuilear species in the sample. The aburdant nuclear spins, normally $1_{H}$, are polarized in the magnetic field; sirnultaneous ingadiation with carefully seiected phase and amplitude modulated radiofrequency fields at the resonance frequencies of $1_{H}$
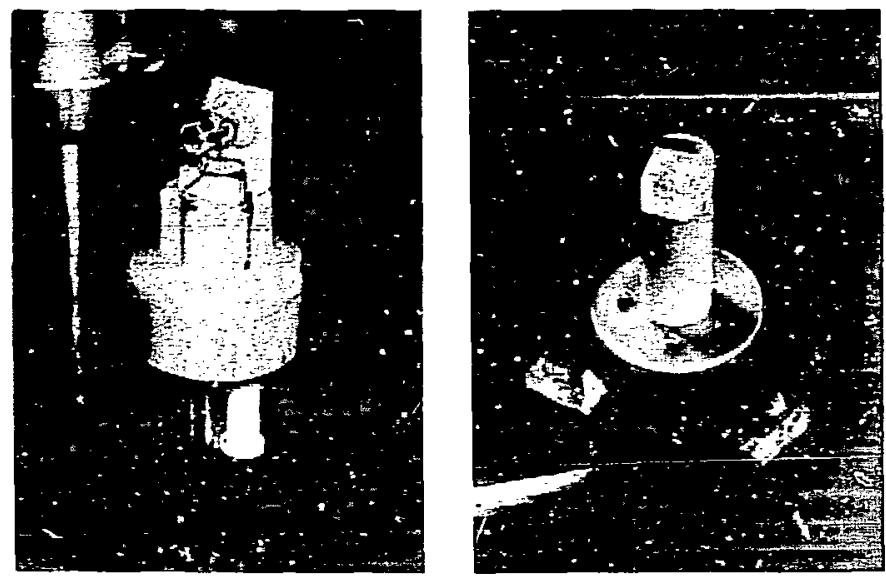

Fig. 1. Double-resonance probe head and crystal holder for X-ray goniometer. The crystals are mounted in the Kel-F cube on the end of the holder; this keys jnto the gear allowing the crystal to be rotated inside the sample coils. The lower part of the probe contains the high-power tuning and matching electronics. 

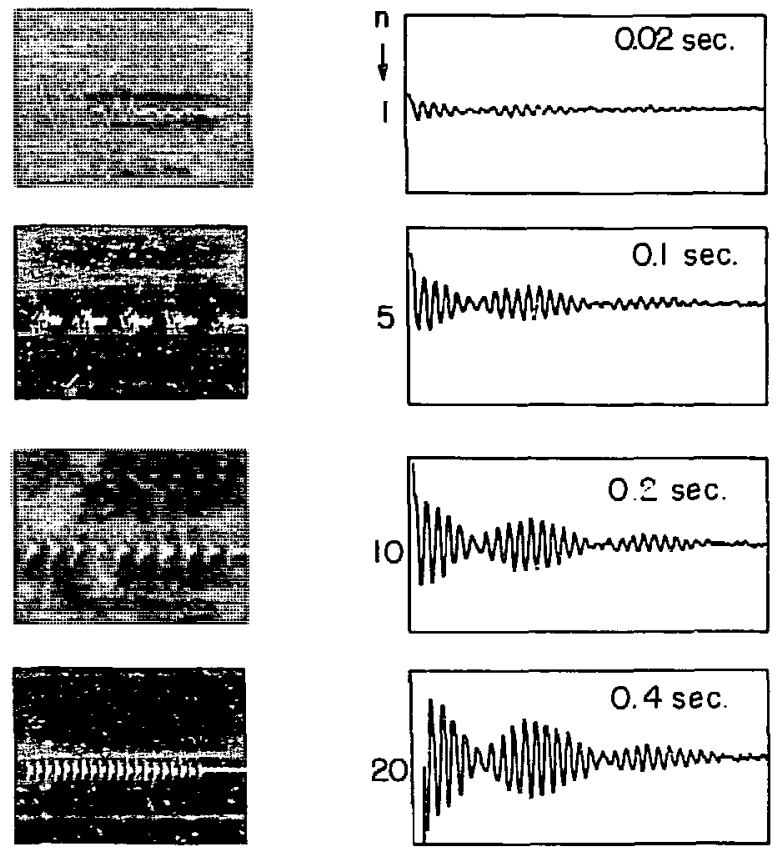

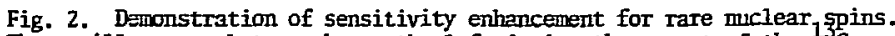
The oscilloscope photographs on the left dipict the output of the ${ }^{13} \mathrm{C}$

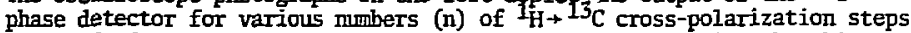
in solid adamantane. The positive pulses are from rf receiver blocking furing the cross-polarization, and they are followed by proton-decoupled ${ }^{13} \mathrm{C}$ free precession signals. It is these which are rapidily transferred and accumblated by the commuter. The cross-polarization pulses are 5 msec long. The traces on the right show the accumilated signais and acqusition times corresponding to the muber of cross-polarizations on the left. These were recorded further off resonance for display purposes.

(XBB 742-900)

and the rare nuclei under stury then effects a transfer of part of the large magnetic polarization to the rare nuclei. This

"cross-polarization" process can then be" repeated many times and the signals from the rare spins accumulated to yield a markedly enhanced sensitivity over conventional detection techniques.

Figure 2 demonstrates this sensitivity enhancement with our spectrometer on a small polycrystalline sample of adanantane $\left(\mathrm{C}_{10} \mathrm{H}_{16}\right)$. The two nuclear species for the double resonance are $1_{H}$ and ${ }^{13} \mathrm{C}$. A strong useful ${ }^{13} \mathrm{C}$ signal is obtained in $<1$ sec in this way, compared to the barely observable signals accumulated over long times by conventional approaches.

\section{MAGIETIC SHIELDING IN SINGIE CRYSTALS*}

Alexander Pines, James J. Chang, and Eric B. Abramson

In magnetic fields, induced electronic currents in molecules set up secondary magnetic fields at nuclei, thus influencing their nuclear magnetic resonance frequency. This phenomenon is termed magnetic shielding (or chemical shielding) and is of crucial importance in the application of nuclear 
magnetism to the stuty of geometrical and electronic structure in molecules and solids. Since the electronic wave functions in most molecules are not isotropic, it is expected that the magnetic shielding should be dependent on the orientation of the molecules in the magnetic field. Indeed, it can be shown that the magnetic shielding should transform under rotations as a symmetric second rank tensor, $\sigma$. Thus, six independent parameters are required to specify the magnetic shielding properties of particular nuclei in a molecule.

Most investigations of magnetic shielding have been performed in isotropic liquid solution. Since, under these conditions, molealles are reorienting rapidly on a time scale defined by the nuclear magnetic precession, only one paraneter, the isotropic shielding $\sigma$,

$$
\sigma=\frac{1}{3} \operatorname{Tr} \sigma,
$$

is extracted from such experiments; thus, to date, only severely linited insight into the nature of magnetic shielding has been available.

We have determined the full shielding tensors for ${ }^{13} \mathrm{C}$ in a number of organic single crystals. The parameters most suitable for describing the tensors are three Euler angles describing the orientation of the principal axes $(1,2,3)$ of $\sigma$ relative to fixed crystallographic or laboratory axes, and the associated three principal values $\sigma_{i i}, i=1-3$. These values describe the magnetic shielding along the principal axes and thus provide a direct measure of the anisotropy of the magnetic shieliting and of the wave function. He find in particular that the tensors are quite characteristic in magnitude and in orientation for various functional groups. Thus they should provide a powerful tool for studies of local structure, conformation, and motion in solids.

To demonstrate the information obtained, Fig. 1 shows part of the two molecules in the unit cell of one of the crystal systems studied, (D) - ammonium tartrate, formila $\left(\mathrm{NH}_{4}{ }^{+}{ }^{-} \mathrm{COO}-\mathrm{CHOH}-\mathrm{CHOH}-\mathrm{COO}^{-}{ }^{+} \mathrm{NH}_{4}\right)$. In isotropic liquid solution, with comventional nuclear metic resonance, only two lines are observed in the ${ }^{13} \mathrm{C}$ nmI spectrum, since the te are clearly only two magnetically inequivalent sites $\left(\mathrm{CHOH}\right.$ and $\mathrm{COO}^{-}$) over the isotropic spatial averaging caused by molecular rotation. In the crystal, with cur technique, we can distinguish eight lines in some orientations, from the eight carbon nuclei in the unit cell, as shorn in Fig. 2.
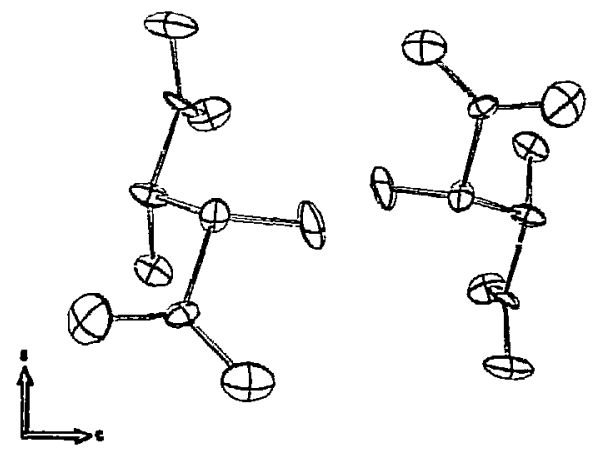

Fig. 1. Perspective view along the crystallegraphic b axis of two tartrate ions (-OOC-OHOH-CHOH-COO') showing the carbon and oxygen atoms in the unit cell of (D)ammoniun tartrate. In general orientations, the carbor nuclei will be in magnetically inequivalent positions. (XBL 742-5592)

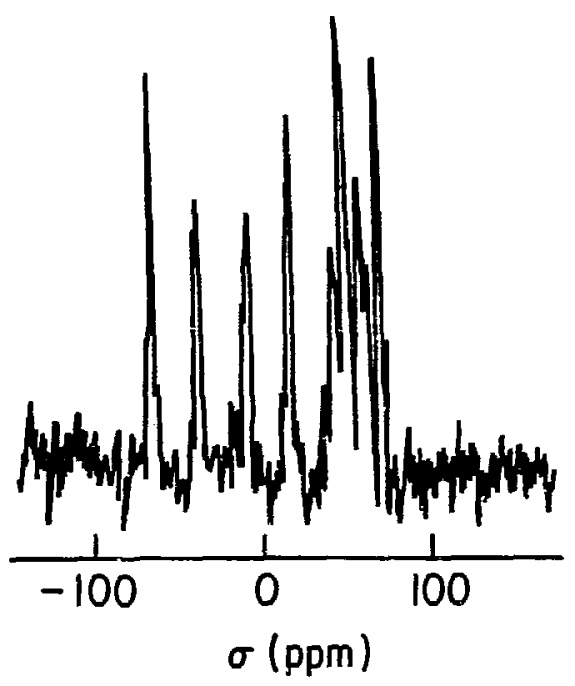

Fig. 2. Fourier transfong ${ }^{13} \mathrm{C}$ nmr spectrum of single-crystal (D)-anmonium tartrate (see Fig. 1), showing separate lines for each of the carbon nuclei. The high-field lines are from the hydroxyl carbons arid the los-field lines from the carboxyl carbons. The horizontal axis is in ppm relative to an extemal reference of liquid benzene. In isotropic solution only two lines are observed.

(XBL 742-5578) 
The crystal can be precisely oriented and rotated as explained in Section 1; the line positions $(\sigma)$ then change as shown in Fig. 3, and the data from three independent rotations are analyzed according to the transformation

$$
\begin{aligned}
\sigma & =\sin ^{2} \theta \cos ^{2} \phi \sigma_{11} \\
& +\sin ^{2} \theta \sin ^{2} \phi \sigma_{22}+\cos ^{2} \theta \sigma_{33},
\end{aligned}
$$

where $\sigma_{i j}$ are the principal $(\theta, \phi, \psi)$ are Euler angles of the transformation from the principal axes $(1,2,3)$ to the laboratory axes. Of particular interest is the orientation of $\sigma(1,2,3)$ ir the molecules, since it is the local structure and synuetIy which we hope to probe. This orientation can be determined using $X$-ray precession data on the same crystals, and Fig. 4 shows the orientation of $\sigma$ for ${ }^{13} \mathrm{C}$ in the carboxyl (COO') groups. Gratifyingly, the axes are related to the local $C_{2 v}$ symmetry at the ${ }^{13} \mathrm{C}$ site. We have fourd this to be true in several other cases.

Table I summarizes, as an example, the principal values of $\sigma$ for ${ }^{13} \mathrm{C}$ in carboxyl groups in several crystals. These are some of the first measurements in what we believe will be a rapidly expanding and important field.

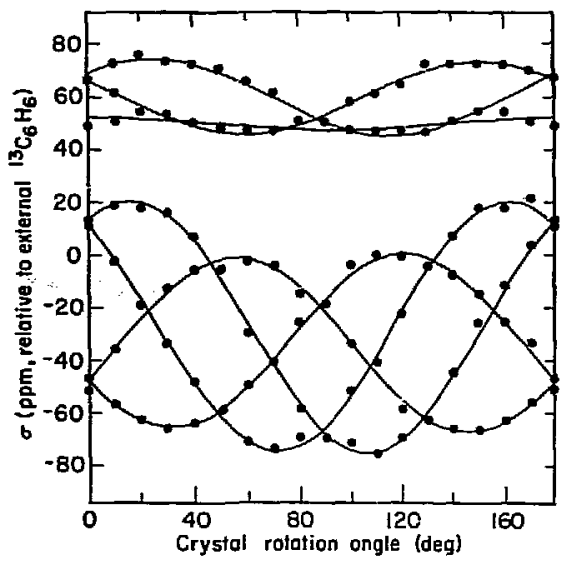

Fig. 3. Dependence of chemical shifts (line positions) of spectra such as that in Fig. 2 on crystal orientation, demonstrating the large riagnetic shielding anisotropy for the carboxyl carbon (lower lines) nuclei. For this plot the crystal was rotated about a fixed axis perpendicular to the magnetic field.

(XBL 741-2161)

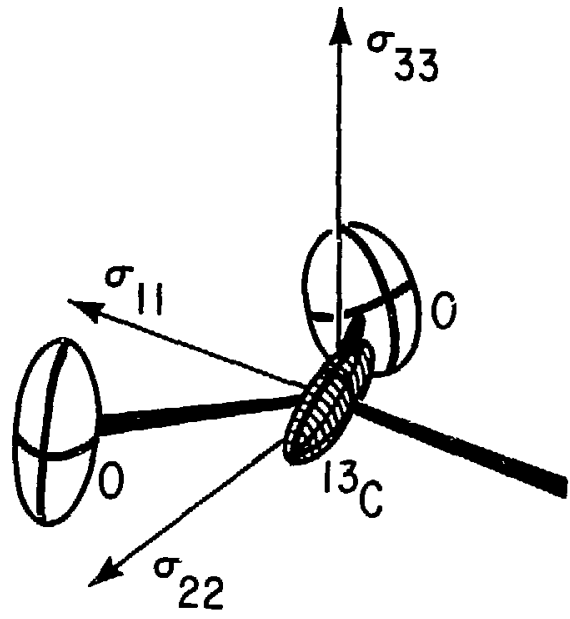

Fig. 4. Orientation of the principal axes of $\sigma$ on the ${ }^{13} \mathrm{C}$ nucleus of the carboxyl group. The heaviest magnetic shielding occurs when the magnetic field is perpendicular to the $\mathrm{COO}^{-}$plane and the lightest shielding when it bisects the co bonds, thus conforming to the local symmetry.

(XBL 742-5591)

Table I. Principal elements of $\sigma$ for ${ }^{13} \mathrm{COO}^{-}$ in selected crystals in ppin $( \pm 4)$ relative to external reference of $13 \mathrm{C}_{6} \mathrm{H}_{6}$.

\begin{tabular}{lrrr}
\hline \multicolumn{1}{c}{ Comqound } & $\sigma_{11}$ & $\sigma_{22}$ & $\sigma_{33}$ \\
\hline Glycine & -119 & -55 & 28 \\
Oxalic acid, anhydrous & -122 & 6 & 17 \\
Oxalic acid, dihydrate & -124 & -8 & 17 \\
Ammonium oxalate & -113 & -32 & 26 \\
Malonic acid & -103 & -47 & 23 \\
Ammonium hydrogen malonate & -113 & -46 & 26 \\
Anmonium tartrate & -109 & -60 & 23 \\
\hline
\end{tabular}

Done partially in collaboration with Robert G. Griffin, visiting IMR from the Francis Bitter National Magnet Laboratory in Cambridge, Massachusetts. 
3. DTNAMICS OF NUCLFAR MAGNETIC DOJBLE RESONANCE

Alexander l'ines and Thomas W. Shattuck

An important consideration in the design and understanding of cross-polarization processes in nuclear magnetic double resonance is that of fluctuation dynamics of the magnetic dipolar coupling between the nuclear spins. To be more specific, consider the ${ }^{H} H$ and ${ }^{13} \mathrm{C}$ nuclei in an organic crystal and imagine, as in Section 2, that we wish to transfer nuclear magnetic polarization fran the ${ }^{H}$ to the ${ }^{13} \mathrm{C}$ spins. In order for this process to occir, energy mist migrate between the nuclear spins, and it is only by fluctuating magnetic fields that this migration can be induced. Such fluctuations occur by modulation of the $\mathrm{I}_{\mathrm{H}}$ - ${ }^{13} \mathrm{C}$ magnetic dipolar coupling due to magnetic dipolar coupling between the ${ }^{1} \mathrm{H}$ spins themselves, Clearly, an understanding of this process is essential to applying it efficiently to various studies of rare nuclei. The quantity of interest is the correlation function:

$f(\tau)=\frac{\left.\operatorname{Tr} \sum_{i} b_{i} I_{i x} \exp \left(i H_{d}^{o} \tau\right) \sum_{i} b_{i} I_{i x}\right) \exp \left(-i H_{d}^{\circ} \tau\right)}{\operatorname{Tr}\left({ }_{i} b_{i} I_{i x}\right)^{2}}$

where $I_{i x}$ is the angular monentum operator for $I_{H}$ nuclear jin $i, b_{i}$ are the coupling terms between a ${ }^{13} \mathrm{C}$ spin and the ${ }^{1} \mathrm{H}$ spins and $\mathrm{H}_{\mathrm{d}}^{\circ}$ is the zero-order component of the magnetic dipolar coupling between the $\mathrm{I}_{\mathrm{H}}$ spins.

It cal be shown that for the case where

$$
\left\|\underset{i}{\Sigma} b_{i} I_{i x}\right\| \ll \| H_{a}^{0} \text {, }
$$

i.e., the coupling between the different. nuclear spins is weaker than that between like spins, that the cross-polarization time $T$ for the migration of energy between unlike spins is related to the Fourier transform of $(1)$ :

$T^{-I}\left(H_{1}\right)=$ Const. $\times \int_{0}^{\infty} f(\tau) \cos \gamma H_{1} \tau d \tau$.

$\mathrm{H}_{1}$ is the intensity of the rotating magnetic field on the $13_{C}$ spins and $\gamma$ is the magnetogyric ratio. Thus, by using a series of $\mathrm{H}_{1}$ values the experimental fom of $\mathrm{T}^{-1}$, the spectral density for the magnetic dipolar fluctuations, Irry be established, This was done by Hahn and co-workers for $19_{F}-43 \mathrm{Ca}$ in $\mathrm{CaF}_{2}$ with the suprising result that $\mathrm{T}^{-1}$ was dependent exponentially on $H_{1}$, thus indicating that $f(\tau)$ is lorentizian. we have foud similar behavior fer $1 \mathrm{H}-13 \mathrm{C}$ double resmance in solids, shrwing that this is not an isolated phenomenon deriving from the ${ }^{43} \mathrm{Ca}$ quadrupole interactions. Figure 1 shows the dependence of $\mathrm{T}^{-1}$ on $\mathrm{H}_{1}$ for admantane, selected because of its high molccular symetry and facile rotation, showing the exponentiol behrvior over three orders of ragnitude. This phenomenon, which indieates long-lived fuctuations, is not yet understood theoretically.

The correlation time $\tau_{c}$ characteristic of the loss of correlation between the spins is given by the slope of the line and is found to be -140 usec. This will be compared with values currently being calallated from the known lattice parameters of the crystal.

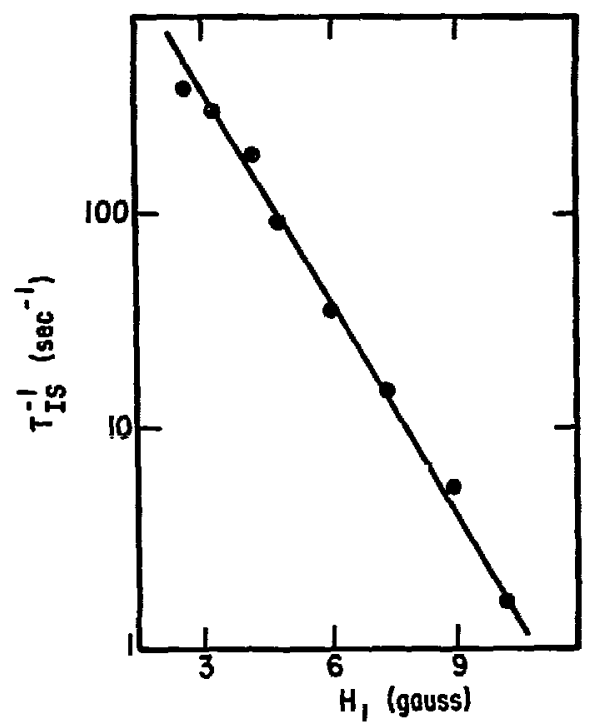

Fig. 1. Dependence of inverse crosspolarization time T IS $^{-1}$ betrieen ${ }_{H}$ ind $13 r$ on the strength of the rotating pagnetic field. For this study, the $\bar{l}_{H}$ muclei in adamantane were polarized and then adiabatically demagnetized in the rotating frame. The $13 \mathrm{C}$ nuclei were then polarized by tuming on a resonant radio frequency field of notating intensity $\mathrm{H}_{1}$.
CBL 742-5579) 
This information has proved extronely useful in implenenting and optinizing our new detection schemes, and has permitted the efficient acquisition of data described in other sections of this report.

\section{LNG-LIVID MUCLEAR SPIN TRALSIENTS IN SOLIDS}

\section{Nexander Pines and thomas iv. Shattuck}

The method of nuclear spin echocs has provided an extremely posierful tool for the direct study of diffusion in liquid-like systens. Intil recently this has not been appljeable to solids, since in these systems the decay of spin coherence is normally dominated by strong magnetic dipolas interactions and is thus not easily reversible. He have reported the first observation of enhanced long-lived nuelear spin echoes for dilute nuelei in solids. These experiments have allowed several novel features of highresolution solid state mur to emerge, e.g., the feasibility of detemining natural lineshapes and linesidths doe to randonly disturbed nuclei (in this case with intemal magnetic dipolar colpling) and the direct messurement of atomic or molecular diffusion in the solid state. The latter extends to solids an approach reserved heretofore for liquids and recently extended to liquid crystals.

The rf modulation schemes employed in these studies, performed initially on $1_{H}$ and $13 \mathrm{C}$ nuclei, consist firstly of crosspolarization from the $\mathrm{I}_{\mathrm{H}}$ to ${ }^{1} \mathrm{C}$ nuclei, as described in Section 1. The accumliated ${ }^{13} \mathrm{C}$ polarization then decays as the initially prepared coherence is destroyed by nommiformaties in the magnetic field and residual magnetic dipolar couplings. Adjitional I3C pulses serve to restore the coherence yielding spin echoes in the manner developed originally by Carr and Purcell. The extension to solids can be made because of the bigh-pon'er spin decoupling performed on the ${ }^{1} \mathrm{H}$ nuclei.

Figure 1 shows an exanple of the response of naturally aburdant ${ }^{13} \mathrm{C}$ nuclei in a polycrystalline sanple of adamantane to this type of excitation with an extemally imposed magnetic field gradient. The trace shows the decay of the $13 \mathrm{C}$ polarization, a pulse and the subsequent refocusing yielding an echo. A train of echoes with closely spaced pulses exhibits a prolonged exporential decay $\left(T^{\dagger},>200\right.$ msec) denonstrating for the first time the high resolution attainable in solids by combining

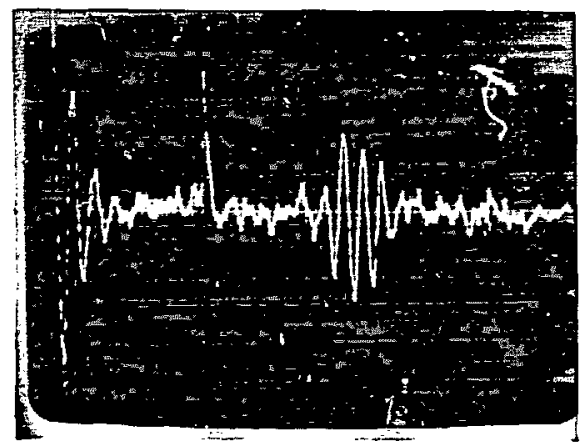

Fig. 1. Spin echo of ${ }^{13} \mathrm{C}$ in solid polycrystalline adanantane. The oscilloscope time scale is $1 \mathrm{msec} / \mathrm{cm}$. The ${ }^{13} \mathrm{C}$ nuclei were polarized and then allowed to precess freely with the $1_{H}$ nuclei strongly irradiated at resonance to effect spin decoupling. The frce precession signal decays away rapidly as shown on the left side of the photograph due to an imposed external magnetic field gradient. A subsequent pulse momentarily restores the coherence of free precession, causing a spin echo. If there is any diffusion of the molecules along the field gradient, the intensity of the echo is reduced.

(XBB 738-4779)

the effective removal of static magnetic field inhomogeneity with the sensitivity and resolution enhancement.

An interesting feature of the echo decay is the exponential shape. This is in agreement with an early prediction of Kittel and Abrahams which indicates that as the distribution of nuclei progresses from periodic to randon, the spectral lineshape should go from Gaussian to Lorentzian. Explicit calculations of the first few moments $\mathrm{M}_{2 \mathrm{n}}$ of the spectral lines:

$$
M_{2 n}=(i)^{n} \operatorname{Tr}\left[H_{d}^{\circ}\left[H_{d}^{\circ} \cdots \cdots \cdot\left[H_{d}^{\circ}, I_{x}\right]\right] \cdots\right]^{2}
$$

verify the theory for simple cases. $H_{d}^{\circ}$ is the zero-order component of the magnetic dipolar interaction and $I_{x}$ is the nuclear spin anglilar momentum operator. our work is the first experimental ranifestation of this phenomenon for randomly distributed ${ }^{13} \mathrm{C}$ nuclei. This should prove useful in determining the degree to which particular nuclei are clustered or ordered in pure solids and doped materials. 
of considerable interest is the possibility, which our techrique introduces, of measuring directly rapid diffusion in the solid and partially ordered systems. This is accomplished by measuring the irreversible loss of coherence with a spin echo decay envelope in pulsed magnetic field gradients of welldefined duration, magnitude, and orientation. In particular, studies are under way on anisotropic diffusion of molecules in solids, on surfaces, and in liquid crystals.

\section{SPIN THEPALDNNAIICS IN TINE-DEPENDENT} FIELDS

\section{Alexander Pines}

The spin tenperature hypothesis has provided an extremely useful tool for the understanding and development of nuclear magnetic resonance in solids. The substance of the hypothesis, as related to our interest, is that a system of nuclear spins corpled by magnetic dipolar interactions in a solid approaches, in a time $T_{2}$, a state of internal equilibrium characterized by a spin temperature. We find that when a strong timedependent perturbation, in the form of a sequence of intense radiofrequency pulses, is applied to such a spin system, the concepts of spin thermodynamies and statistical mechanics may still be employed with respect to a time-independent average Familtonian in a frame of reference defined by the external perturbation. This is an extension of Redfield's hypothesis of spin temperature in the rotating frame to 3 more general periodic and cyclic excitation.

Figme 1 depicts one of the pulse sequences used in the present experiments, performed on the $19_{F}$ spins in a crystal of $\mathrm{CaF}_{2}$. An adiabatic demagnetization in the rotating frame (ADRF) prepares the system in a state of high inverse dipolar spin temperature $B_{0}$,

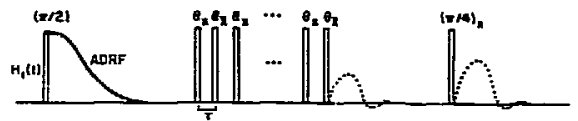

Fig. 1. Radiofrequency pulse sequence used in the experiment. $\theta_{x}$ denotes a pulse of nutation angle $\theta$ of phase such that $i_{1}$ is along the defined $X$ axis in the rotating frame. The dotted lines depict schematically the type of transient signal observed.

(XBL 742-5554) characterized by the density cperator

$$
\rho_{0}=\frac{1}{Z_{0}} \exp \left(-\beta_{0} H_{d}^{\circ}\right)
$$

Where $Z_{0}=\operatorname{Tr}\left\{\exp \left(-B_{0} H_{f}^{\circ}\right)\right\}$ and $H_{d}^{\circ}$ is the usual trincated dipolar interaction anmgst $19 \mathrm{~F}$ spins. The subsequent irradiation $H_{1}(t)$, consists of a series of resonant if pulses of nutation angle $\theta$ with an alternation of phases by $\pi$ every pulse. In general, the treatment of the response of the systen to this excitation would be an intractable probles; horever, we apply the concepts of average Hamiltonian theory, and assume that if $\tau \ll T_{2}$, then, in zero order, we may consider the system to behave as if under the influence of a time-independent average dipolar Hamiltonian $\bar{h}$ in an interaction picture defined by $H_{1}(t)$,

$$
H_{\mathrm{d}}^{\mathrm{P}}=\frac{1}{2 \tau} \int_{0}^{2 \tau} \tilde{H}_{\mathrm{d}}^{\circ}(t) d t \text {, }
$$

where:

$$
\begin{aligned}
& \tilde{H}_{d}^{o}(t)=T \exp \left(\int_{0}^{t}-\frac{i t^{\prime}}{h} H_{1}\left(t^{\prime}\right) d t^{\prime}\right) \\
& \quad x H_{d}^{0} T \exp \left(\int_{0}^{t} \frac{i t^{\prime}}{h} H_{1}\left(t^{\prime}\right) d t !\right)(3)
\end{aligned}
$$

and $T$ is a time-ordering operator. We now assime that after a sufficientiy long time, the system can be described in the new picture by a conmical density operator:

$$
p_{1}=\frac{1}{Z_{1}} \exp \left(-\beta_{1} \dot{H_{d}^{0}}\right) \text {. }
$$

The If irradiation is now teminated. He can inquire into: (a) the short time behavior of the systen and (b) the dipolar spin temperature of the final state. The time-dependent relative magnetization upon termination of the pulse sequence is given

$S_{1}(t)=\frac{\operatorname{Tr}\left\{\exp \left(-\frac{i t}{\hbar} H_{d}^{0}\right) p_{1} \exp \left(\frac{i t}{h} H_{d}^{0}\right) I_{x}\right\}}{\operatorname{Tr}\left\{I_{x}^{2}\right\}}$ (S)

Using the high-temperature approximation for $P_{1}$ in (4) and solving for $H_{d}^{o}$ in the case of ideal " $\delta$-pulses," we find:

$$
S_{1}(t)=-\sin \theta \cos \theta S_{d}(t),
$$


where $S_{d}(t)$ is the normal dipolar free infuction decay atserved from a systen in a state described by (1) after a $(\pi / 4)$ pulse. This is exactly borne out experimentally.

To determine the long-time-behavior, we assume that during the pulse sequence the average dipolar energy ( $\mathrm{h}$ ') is conserved, and that after the irradiation, ( $\mathrm{H}^{\circ}$ ) is conserved. The final state of the system is described by:

$$
p_{2}=\frac{1}{2} \exp \left(-B_{2} H_{d}^{\circ}\right) .
$$

Exploying equations (1)-(4) we obtain with some si ple algebra:

$$
\frac{\beta_{2}}{B_{0}}=\frac{1}{4}\left(1+3 \cos ^{2} \theta\right) \text {. }
$$

These expressions are easily generalized to the case of non-ideal pulses.

Figure 2 depicts the mutation angle dependence of our observed signals. $S_{1}(t) / S_{d}(t)$ is the relative intensity of the transient observed on termination of the sequence, and $B_{2} / B_{0}$ is the final relative inverse dipolar spin temperature. The

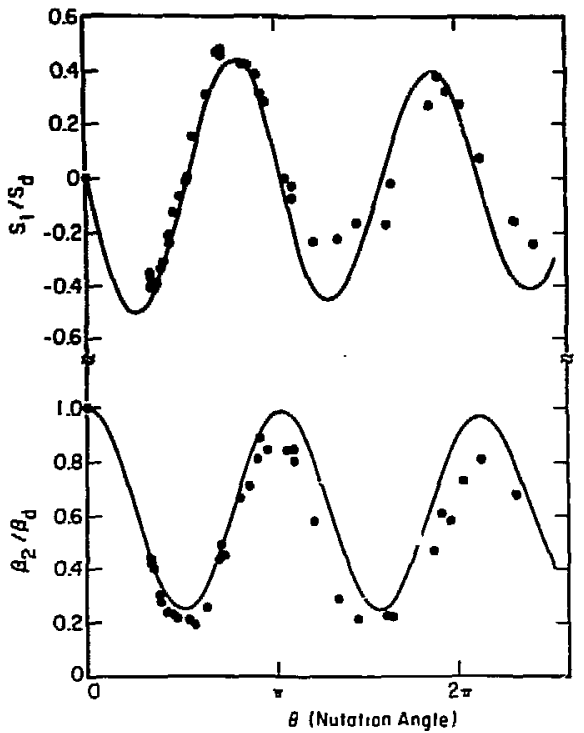

agreement indicates that despite the conplexity of the problem, the assuption of quasi-equilibrium during the strong timedependent excitation is a useful one, and that quantitative predictions may be made. Thus we have denonstrated that spin thermodynanic parameters may actually be modified by the application of selected time-dependent fields. This is being applied to the development of net detection techniques for solid state magnetic resonance and to the production of large nuelear mignetic polarizations.

\section{RESEANCH PLANS FOR CALENDAR YEAR 1974}

\section{Alexander Pines}

Work will continue on magnetic shielding and structure for nuclei of low isotopic abundance. Additional functional groms and inorganic materials will be studied. This will extend to the study of ferroelectric phase transitions in the KDP crystal class by observation of 31 decoupled from $1 \mathrm{H}$. We plan also to study flucturations and quantum mechanical proton tumeling in hydrogen bonds, enploying those same techniques, if the magnetic shielding proves sensitive to proton position. The amplication of magnetic shielding to the study of local electronic structure and comparisons with arrent molecular orbital theories of shielding will be undertaken when sufficient data ete available.

As our preliminary experiments have indicated, nieclear spin transients with extremely long lifetimes can now be produced. This should allow the stiny of anisotropic diffusion in ordered and partially ordered systens. Such studies are being undertaken on liquid crystals and organic molecules adsorbed on solids. The diffusion will be studied along well defined pulsed magnetic field gradients. A new spectrometer and accessories are under construction for these experiments and should be cormleted shortly.

Fig. 2. Relative signal intensity for the two transients compared to the nonmal umpertunbed dipolar free induction decay observed for ${ }^{19} \mathrm{~F}$ spins in $\mathrm{CaF}_{2}$ on application of pulse sequence in Fig. 1. $S_{1} / S_{d}$ is the relative intensity of the first transient and $B_{2} / B_{0}$ is the relative final inverse dipolar temperature, i.e., the relative intensity of the second transient. The solid lines are calculated theoretically.

(XBL 742-5555) 
7. 1973 PUBLICATIONS AND REPORTS

Alexander Pines and Associates

Jounnals

t1. J. H. Leftin, D. Redpath, A. Pines, and

E. Gil-Av, Electrochemlcal Symthesis of Cis-3, 4-Dicarboulethoxycyclobutene, Israel J. Chem. 11, 75 (1973).

*2, A. Pines, M. G. Gibby, and J, S. Waugh, Proton-Enhanced MR of Dilute Spins in Solids, J. Chem. Phys. 59, 569 (1973) .

3. S. Pausak, A. Pines, and J. S. Waugh, Carbon-13 Chemical Shieiding Tensors in Single Crystal Durane, J. Chem. Phys, 59, 591 (1973).

4. W. G. Breiland, C. B. Harris, and A. Pines, Optically Detected Electron Spin Echoes and Free Precession in Molecular Excited States, Phys. Rev. Letters 30, 158 (1973) (LBL-1412).

5. A. Pines and J. D. Ellett, Jr., Pulsed Spin Decoupling in Nuclear Magnetic Resonance, J. Am. Crem. Soc. 95, 4437 (1973) (LBL-1489).

6. A. Pines and T. W. Shattuck, Enhanced Inhomogeneous Nuclear Spin Echoes for Dilute Spins in Solids, Chem. Phys. Lett. 23,614 (1973) (LBL-2235).

\section{LBL reports}

1. J. J. Chang, R. G. Griffin, and A. Pines, Chemical Shielding Tensor of $13 \mathrm{C}$ in a Carboxy1 Group, LBL-2513, Nov. 1973.

2. A. Pines and J. S. Waugh, Dipolar Spin Temperature in a Periodically Pertumed Nuclear Spin System, LBL-2515, Dec. 1973.
3. A. Pines and E. Abramson, Chemical Shielding Tensors of ${ }^{13} \mathrm{C}$ in Dimethyl Oxalate, LBL-2522, Dec. 1973.

4. T. Merrick, S. Smiriga, and A. Pines, A Simle Data Acquisition System for ProtonEnhanced Nuclear Induction Spectroscopy, LBL-2546, Dec. 1973.

5. A. Pines and T, W. Shattuck, Carbon-13 Nuclear Magnetic Polarization from Demagnetized Protons, LBL-2545, Dec. 1973.

\section{Papers presented}

1. A. Pines, "Sensitivity in Fourier Transform MR in Solids," 14th Experimental MR Conference, Boulder, Colorado, April 1973.

2. A. Pines, "Partially Relaxed Fourier Transform AMR Spectroscopy in Solids," 13C MR Symosium, American Chenical Society Meeting, Dallas, Texas, April 1973.

3. A. Pines, 'The Advent of High Resolution NR in Solids," Gordon Research Conference on Magnetic Resunance, Kimball Inion Academy, Merriden, N. H., June 1973.

4. A. Pines, "Sensitivity in High Resolution Nuclear Magnetic Double Resonance," First Specialized Colloque Ampere, Krakow, Poland, Aug. 1973.

5. A. Pines, "Adiabatic Cross-Polarization in Nuclear Magnetic Dowile Resonance," Meeting of the British Radio Spectroscopy Group, Sussex, England, Sept. 1973

Not supported by IMRD funds. 
Ronald R. Herm, Principal Investigator

\section{CROSSED REAMS CHEIISTEY: ALKALINE EARTH ATOH REACTIONS}

Ronald R. Hern, Shen-llay lin, and Charles A. liins

We have now completed our exploratory crossed beans stuilies of the thermal energy reactions of $\mathrm{Ba}, \mathrm{Sr}, \mathrm{Ca}$, and $\mathrm{Mg}$ with various hnloga- and oxygen-containing molecules. Prior to our studies (and other studies initiated concurrently in other beam laboratories), there was practically no information available on the gas phase kinetics of reactions of froup IIA alkaline earth atons despite an active interest on the part of the physical chemist in the gas phase kinetics of alkali atom reactions dating back to the classical Michael Polanyi diffusion flame studies of the 1930's. Our crossed beans stuilies directly provided information on the dynamical behavior (i.e., mechanism) of these reactions, and results for particular reactions have been described in previous IMRD Annyel Reports and have also been published. 1
In closing these studies, however, it seems worthwile to stmmarize the contrasting reactivities which we have observed in the alkaline earth family (estimated from the strength of the alkaline earth halide or oxide product sigral). This sumary is shown in Table I and illustrates two points. First of all, there is often a considerable variation in the total reaction cross section $\left(\mathrm{O}_{\mathrm{N}}\right)$ for reaction of $\mathrm{Ba}, \mathrm{Sr}, \mathrm{Ca}$, and $\mathrm{Mg}$ with a given halide or oxide reactant. Thus, we falled to observe reaction of $\mathrm{Mg}$ with any reagent other thar the diatomic halogen molecules. For $\mathrm{Ba}, \mathrm{Sr}$, and $\mathrm{Ca}$ with any given reactant, we also estimate that $\mathrm{Q}_{\mathrm{R}}(\mathrm{Ba})>\mathrm{Q}_{\mathrm{R}}(\mathrm{Sr})>\mathrm{Q}_{\mathrm{R}}(\mathrm{Ca})$; this behavior is apparent for the $\mathrm{PCl}_{3}, \mathrm{SF}_{6}, \mathrm{CCl}_{4}$, and $\mathrm{C}_{3} \mathrm{H}_{7} \mathrm{NO}_{2}$ entries in Table I. This behavigr may be contrasted with the alkali family where, for a given reactant, $Q_{R}$ shows only a modest decrease (typically about a factor of 2) in the $\mathrm{Cs} \rightarrow \mathrm{Pb}+\mathrm{K}+\mathrm{Na}+\mathrm{Li}$ sequence. The second point illustrated by Table $I$ is that, in terns of reactivity, ga seens to behave like an alkali metal. In abstraction of a halogen atom from an alkyl halide, for exalple, $\mathrm{Q}_{\mathrm{R}}(-\mathrm{I})>\mathrm{Q}_{R}(-\mathrm{Br})>\mathrm{Q}_{R}(-\mathrm{Cl})$, precisely the behavior characteristic of the alkali atom reactions.

Table I. Alkaline earth atom reactions studied. ${ }^{a}$

\begin{tabular}{|c|c|c|c|c|}
\hline & $\mathrm{Ba}$ & $\mathrm{Sr}$ & Ca & $\mathrm{Mg}$ \\
\hline \multicolumn{5}{|c|}{ HALOGEN MOLEOLES } \\
\hline $\mathrm{M}+\mathrm{Cl}_{2}+\mathrm{MCI}+\mathrm{Cl}$ & $\mathbf{R}$ & $\mathbf{R}$ & En & $\mathbf{R}$ \\
\hline $\mathrm{M}+\mathrm{Br}_{2}+\mathrm{MBr}+\mathrm{Br}$ & $\mathbf{R}$ & $\mathbf{R}$ & $\mathbf{R}$ & $R$ \\
\hline $\mathrm{M}+\mathrm{CI} \overline{\mathrm{I}}+\mathrm{MCI}+\mathrm{I}$ & $\mathbf{R}$ & $\mathbf{R}$ & $\mathbf{R}$ & $\mathbf{R}$ \\
\hline $\mathrm{M}+\mathrm{ICI}+\mathrm{MI}+\mathrm{CI}$ & $\mathbf{R}$ & $\mathbf{R}$ & $\mathbf{R}$ & F \\
\hline $\mathrm{M}+\mathrm{NCB}=\rightarrow \mathrm{MON}+\mathrm{Br}$ & $\mathbf{R}$ & - & - & - \\
\hline $\mathrm{M}+\mathrm{BrCN}_{\mathrm{T}} \rightarrow \mathrm{M} \mathbb{E}_{\mathrm{T}}+\mathrm{CN}$ & F & - & - & - \\
\hline \multicolumn{5}{|c|}{ INR JRGANIC HALIDES } \\
\hline $\mathrm{M}+\mathrm{HI}+\mathrm{MI}+\mathrm{H}$ & $\mathbf{R}$ & $R$ & $R$ & NR \\
\hline$M+H F \rightarrow M P+H$ & NR & - & $\cdot$ & - \\
\hline $\mathrm{M}+\mathrm{SnCl}_{4}+\mathrm{MCl}_{\mathrm{n}}+\mathrm{SnCl}_{\mathrm{m}}$ & $\mathbf{R}$ & R & $\mathbf{R}$ & NR \\
\hline $\mathrm{M}+\mathrm{SnCl}_{4}+\mathrm{MSnCl}_{3}+\mathrm{Cl}$ & NR & $\mathrm{NR}$ & NR & NR \\
\hline $\mathrm{M}+\mathrm{PCI}_{3}+\mathrm{MCI}_{n}+\mathrm{PCI}_{\mathrm{m}}$ & R & $\mathbf{R}$ & $\mathbf{F}$ & - \\
\hline $\mathrm{M}+\mathrm{SF}_{6}+\mathrm{MF}_{\mathrm{I}}+\mathrm{SF}_{\mathrm{m}}$ & $\mathbf{R}$ & $I$ & $\mathrm{NR}$ & NR \\
\hline
\end{tabular}


(Table I cont.)

\section{ORGANIC HALIDES}

$$
\begin{aligned}
& \mathrm{Ni}+\mathrm{CH}_{3} \mathrm{I}+\mathrm{HI}+\mathrm{CH}_{3} \\
& \mathrm{~N}+\mathrm{CI}_{2} \mathrm{I}_{2}+\mathrm{MI}_{2}+\mathrm{CH}_{2} \\
& \mathrm{AH}+\mathrm{CF}_{3} \mathrm{I}+\mathrm{AII}(?)+\mathrm{CF}_{3} \\
& \mathrm{AH}+\mathrm{CF}_{3} \mathrm{I}+\mathrm{AF}(?)+\mathrm{CF}_{2} \mathrm{I} \\
& \mathrm{Al}+\mathrm{CH}_{2} \mathrm{Br}_{2}+\mathrm{ABr}_{2}(?)+\mathrm{CH}_{2} \\
& \mathrm{AH}+\mathrm{CCC}_{3} \mathrm{Br}+\mathrm{ABr}\left(? \mathrm{j}+\mathrm{CCl}_{3}\right. \\
& \mathrm{AH}+\mathrm{CCl}_{3} \mathrm{Br}+\mathrm{NCZ}(\mathrm{P})+\mathrm{CCl}_{2} \mathrm{Br} \\
& \mathrm{N}+\mathrm{CH}_{2} \mathrm{CZBr}+\mathrm{NBr}(?)+\mathrm{Cl}_{2} \mathrm{Cl} \\
& \mathrm{Mr}+\mathrm{CH}_{2} \mathrm{ClBr}+\mathrm{MCl}(?)+\mathrm{CH}_{2} \mathrm{Br} \\
& \mathrm{Al}+\mathrm{CCl}_{4}+\mathrm{NCl}_{\mathrm{n}}+\mathrm{CCl}_{\mathrm{m}} \\
& \mathrm{N}+\mathrm{CCl}_{5} \mathrm{NO}_{2}+\mathrm{NC}(?)+\mathrm{CCl}_{2} \mathrm{NO}_{2} \\
& \mathrm{HH}+\mathrm{C}_{4} \mathrm{HOH}_{\mathrm{P}}+\mathrm{BDH}_{4} \mathrm{C}_{4} \mathrm{H}_{9}
\end{aligned}
$$

$\begin{array}{rrrr}R & R & R & \text { NR } \\ R & R & R & - \\ R & - & - & - \\ F & - & - & - \\ - & - & F & - \\ - & - & \mathrm{NR} & - \\ - & - & \mathrm{NR} & - \\ F & - & - & - \\ \mathrm{NR} & - & - & - \\ \mathrm{R} & \mathrm{I} & \mathrm{NR} & - \\ - & - & \mathrm{R} & - \\ \mathrm{NR} & - & - & -\end{array}$

OXIDES

$$
\begin{aligned}
& \mathrm{M}+\mathrm{SO}_{2}+\mathrm{NH}+\mathrm{SO} \\
& \mathrm{NH}+\mathrm{NO}_{2} \rightarrow \mathrm{NO}+\mathrm{NO} \\
& \mathrm{NH}+\mathrm{C}_{3} \mathrm{H}_{7} \mathrm{NO}_{2} \rightarrow \mathrm{NO}_{3}+\mathrm{C}_{3} \mathrm{H}_{7} \mathrm{NO} \\
& \mathrm{BH}+\mathrm{C}_{3} \mathrm{H}_{7} \mathrm{AO}_{2}+\mathrm{MNO}_{2}+\mathrm{C}_{3} \mathrm{H}_{7} \\
& \mathrm{NH}+\mathrm{CCO}_{3} \mathrm{NO}_{2}+\mathrm{NO}^{2} \mathrm{CCO} \mathrm{S}_{3} \mathrm{NO}
\end{aligned}
$$

$\begin{array}{rrrr}R & \text { NR } & \text { NR } & - \\ - & \mathrm{R} & \mathrm{R} & \mathrm{I} \\ \mathrm{R} & \mathrm{R} & \mathrm{NR} & - \\ \mathrm{ND} & \mathrm{NR} & \mathrm{NR} & - \\ - & - & \mathrm{F} & -\end{array}$

${ }^{a}$ I: it proved impossible to study this reaction due to experimental difficulty; NR: no product signal observed, $Q_{R}<\sim 1 A^{2} ;$ F: weak product signai observed, $\sim 1 A^{2}<Q_{R}<-5 A^{2} ; R$ : strong product signal observed, $Q_{R}>\sim 5 A$.

1. R. R. Herm, S. M. Lin, and C. A. Mims, J. Chem. Phys. 57, 3099 (1972); 58, 327, 1983 (1973) ; J. Prys. Chem. 77, 569, 2931 (1973).

2. The alkali atom resuits are reviewed in:

J. L. Kinsey, MrP Intemational Review of Science, edited by J. C. Polanys (Butterworths, London, 1972), Physical Chemistry Series one, vol. 9, Chap. 6.

2. PHOTODISSOCLATION OF NaBr, NaI, AND KI VAPOBS AND OLL,ISIONAL QUENGHING OF $\mathrm{Na}^{\star}\left(3^{2} \mathrm{p}\right)$, $K^{*}\left(4^{2} \mathrm{P}\right), A N D K^{*}\left(3^{2} \mathrm{P}\right)$ BY FOREICN GASES

Boyd I. Earl and Ronald R. Herm

Since the earliest observations by lood, there have been many studies of the gas phase collisional quenching of the first excited 2p configuration of alkali atons by rare gases and simple molecules. However, only a few studies have examined the quenching of these configurations by more complex molecules, and there are very few data available on the quenching of higher energy configurations. In our ofm laboratory, this promipted a program of exanining the quenching of $\mathrm{Na}^{\star}\left(3^{2} \mathrm{P}\right), K^{\star}\left(4^{2} \mathrm{p}\right)$, and $K^{\star}\left(5^{2} \mathrm{P}\right)$ by a variaty of moleziles in order to gain further insight into the mechanism of these quenching collisions.

Experimentally, alkali halide $(M X)$ vapor in a heated quartz cell was photodissociated at a particular ultraviolet wavelength so as to profuce the alkali atom in a particular excited configuration $\left(M^{*}\right)$, and the $M^{*}$ resmance fluorescence emitted at a right angle to the incident ultraviolet flux was measured. Upom admission of a foreign gas at a known pressure to the cel1, the cross 
section $\left(\mathrm{Q}_{\mathrm{q}}\right)$ for collisional quenching of Mt was calculated from the Sterm-Volner relation and the measured foreign gas attenuation of the $\mathrm{N}^{\mathrm{t}}$ fluprescence. Table I lists values of $\mathrm{Q}_{\mathrm{q}}$ which were measured in this work. For a given quenching gas, the

Table I. Measured Quenching Cross Sections."

$\overline{\operatorname{Nan}^{*}\left(3^{2} P\right) \quad K^{*}\left(4^{2} P\right) \quad K^{*}\left(5^{2} P\right)}$

\begin{tabular}{lrrr}
\hline & \multicolumn{3}{c}{ CLASS I } \\
$\mathrm{CH}_{4}$ & $<1$ & $<1$ & 60 \\
$\mathrm{CD}_{4}$ & - & - & 40 \\
$\mathrm{C}_{2} \mathrm{H}_{6}$ & $<1$ & - & 98 \\
$\mathrm{C}_{2} \mathrm{D}_{6}$ & - & - & 70 \\
$\mathrm{CF}_{4}$ & $<1$ & $<1$ & 25 \\
$\mathrm{H}_{2} \mathrm{O}$ & 3 & 2 & 84 \\
$\mathrm{D}_{2} \mathrm{O}$ & $<1$ & - & 91
\end{tabular}

CIASS II

$\begin{array}{lccc}\mathrm{H}_{2} & 8 & 3 & 12 \\ \mathrm{D}_{2} & 8 & 3 & 11 \\ \mathrm{~N}_{2} & - & - & 60 \\ \mathrm{HCI} & - & - & 100^{*} \\ \mathrm{DCI} & - & - & 100^{*} \\ \mathrm{CO}_{2} & 68^{\star} & - & - \\ \mathrm{CH}_{3} \mathrm{OH} & 25 & 24 & 110 \\ \mathrm{CF}_{3} \mathrm{Cl} & 100^{*} & 95^{\star} & 170 \\ \mathrm{CH}_{3} \mathrm{CN} & 110^{\star} & - & - \\ \mathrm{C}_{2} \mathrm{H}_{4} & 69^{*} & 51 & 77 \\ \mathrm{C}_{2} \mathrm{D}_{4} & - & - & 79 \\ \mathrm{C}_{6} \mathrm{H}_{6} & 110^{*} & - & -\end{array}$

CLASS III

\begin{tabular}{|c|c|c|c|}
\hline $\mathrm{SO}_{2}$ & $150^{*}$ & 140 & \\
\hline $\mathrm{Br}_{2}$ & $230^{*}$ & - & - \\
\hline $\mathrm{I}_{2}$ & $290^{\star}$ & $260^{*}$ & $50^{*}$ \\
\hline \multicolumn{4}{|c|}{ 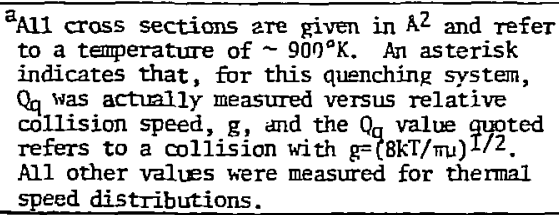 } \\
\hline
\end{tabular}

entries in this table indicate that: (1) $\mathrm{Q}_{\mathrm{q}}\left(\mathrm{N}^{\star} \star 3^{2} \mathrm{P}\right)$ and $\mathrm{Q}_{\mathrm{g}}\left(\mathrm{K}^{\star} \mathrm{4}^{2} \mathrm{P}\right)$ are of comparable magnitude and $(2) \mathrm{Q}\left(\kappa^{\star} 52 \mathrm{P}\right)>\mathrm{Qq}\left(K^{\star} 42 \mathrm{P}\right)$ for Class I and II molecules, the increase being particularly dramatic for Class I.

Collisional quenching of excited alkali atom: has often been discussed in terms of the "llectron transfer model" which pictures the trarsfer of an electron from $M^{*}$ to the quenching molecule at a relatively large reactant separation given, in lowest order, by

$$
R_{c}=e^{2} /\left(\Delta-E^{\star}\right) \text {, }
$$

where $E^{*}$ is the excitation energy of $\mathrm{N}^{*}$ and $\Delta$ is the asymptotic energy of the ion pair (i.e., the ionization potential of $M$ mine the electron affinity of the uenching moleca.e). Although alternate explanations might be devised for any particular phenomenon, this model provides a language whereby the contrasting behaviors exhibited by Classes I, II, and III as well as the observed isotope effects may be rationalized. In particular, the dramatic decrease in $Q_{q}$ which is observed for $\mathrm{I}_{2}$ on proceeding from $K^{*}\left(4^{2} \mathrm{P}\right)$ to $K^{\star}\left(5^{2} \mathrm{P}\right)$ is particularly easily explained. The electron affinity of $\mathrm{I}_{2}$ is quite large so that $R_{C}$ is quite large for the $K^{*}\left(4\right.$ 2P) $+I_{2}$ collision, consistent with the large $\mathrm{Og}$ value which is observed. For $\left.\mathrm{K}^{\star}(5) \mathrm{P}_{\mathrm{P}}\right)+\mathrm{I}_{2}$, however, $E^{*}>\Delta$, so that no quenching should ocair in the lowest order electron transfer picture, consistent with smaller observed $Q_{q}$ value.

\section{ENERGY DEPENDENCE OF SENSITIZED} FLUORESCENCE: $\mathrm{Hg}^{*}+\mathrm{T} 1+\mathrm{Hg}+\mathrm{Tl}^{*}$

Ronald R. Herm and Lambert C. - H. Loh

Cario and Franck ${ }^{1}$ first demoristrated the phenomenon of sensitized fluorescence experimentally when they observed emission from excited TI levels upon irradiation of an $\mathrm{Hg}-\mathrm{T} 1$ vapor mixture by the $2537 \AA \mathrm{Hg}$ resomance line. Despite many studies since then, however, the transfer of excitation from $\mathrm{Hg}^{*}$ to $\mathrm{Ti}$ (or any other aton) is not reliably characterized quantitatively because of uncertainties regarding the presence of metastable mercury species as well as diatomic molecules ( $\mathrm{HgT}_{1}$ and/or $\mathrm{Hg}_{2}{ }^{*}$ ) in the fluorescence cell. This prompted a crossed atomic beans measurement in our Iaboratory of the dependence on relative collision speed, $g$, of the cross section, Q Q of eIectronic excitation fram $\mathrm{Hg}^{*}$ to $\mathrm{Tl}$.

Experimentally, a beam of $\mathrm{Hg}^{\star}\left({ }^{3} \mathrm{P}_{\mathrm{o}}\right)$ and 
Hg* $\left({ }^{3} \mathrm{P}_{2}\right)$ metastable states (produced in an approximate $1: 5$ ratio by electron bombardment excitation of an $\mathrm{Hg}$ beam) was crossed at a right angle by a TI beam which had previousiy passed through a slotted-diskvelocity selector. Since any $\mathrm{Tl}$ levels which might be collisional excited have short $\left(\sim 10^{-7}-10^{-8} \mathrm{sec}\right)$ radiative lifetines, they must radiate before leaving the collision zone defined by the two intersecting beams. Consequently, the cross section for collisional production of the T7 $5350 \mathrm{~A}$ emission line was measured by focusing the emission originating in the bean co11ision zone through an interference filter which isolated the $5350 \mathrm{~A}$ line and onto a photomultiplier tube. Figure 1 indicates that the $5350 \AA \pi$ line corresponds to emission from $T 1^{*}\left(7 \mathrm{~s} 2 \mathrm{~S}_{1 / 2}\right)$ so that the 5350 A emission observed might arise from direct collisional production of $\mathrm{T}^{*}\left(7 \mathrm{~s} 2 \mathrm{~S}_{1 / 2}\right)$ or from collisional production of higher energy $T 7$ level which relaxes to the ground state via a cascade enission process populating $\mathrm{TI}^{ \pm}\left(7 \mathrm{~s} \mathrm{~S}_{1 / 2}\right)$.

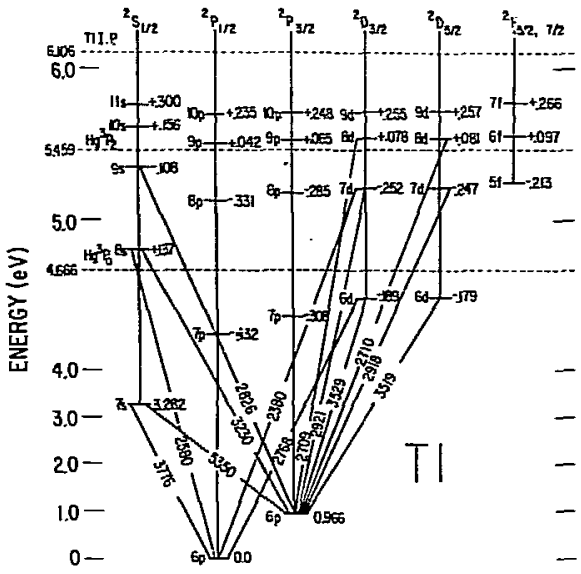

Fig. 1. Thallium energy level diagram. All energies are given in electron volits. For T1 levels below $4 \mathrm{eV}$, the energy above the ground state is indicated; for higher levels, the difference betwicen the $T I$ level and nearest metastable $\mathrm{Hg}$ level is given. The three dashed lines indicate the $\mathrm{Hg}^{*}\left(\mathrm{C}_{0}\right)$ and $\mathrm{Hg} *\left({ }^{3} \mathrm{P}_{2}\right)$ energies and the ionization potential of $\mathrm{T}$. Diagonal lines indicate prominent reported mercum-sensitized emission lines of $\pi$ (in A). (XBI 709-6672)
Figure 2 presents the neasured cross section as a function of relative collision speed. The dotted curve shown in Fig. 2, in conjunction with the energy levels in Fig. 1, illustrates that the measured cross section (at least at sisaller g values) must correspond to production of $\mathrm{a} \mathrm{T}^{*}$ level which is lower in energy than the parent $\mathrm{Hg}^{*}$ level. Moreover, oscillator strengths for the $\mathrm{TI}$ lines indicate a very low probability of production of $\mathrm{T}^{*}\left(7 \mathrm{~s} 2 \mathrm{~S}_{1 / 2}\right)$ intermediat during radiative relaxation of a $2 \mathrm{D}$ or $2 \mathrm{~F}$ level. Thus, the cross section show in Fig. 2 must refer to the collision process:

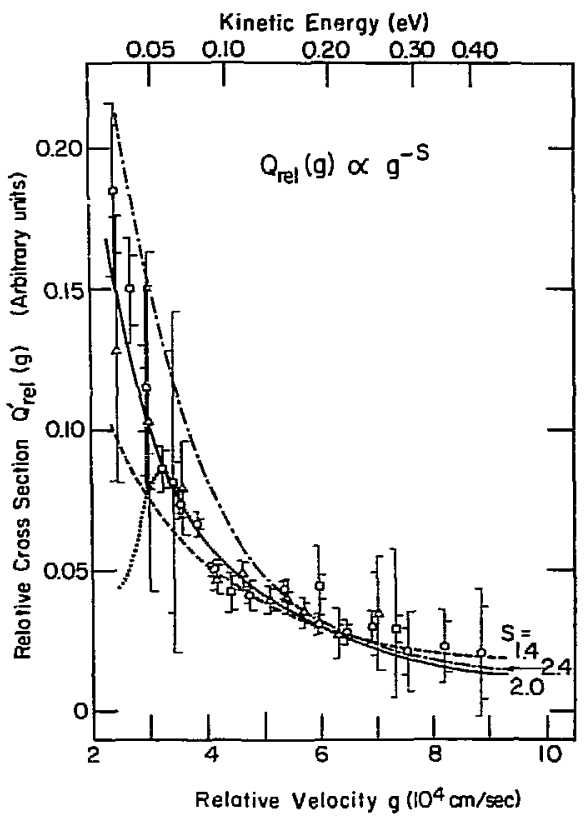

Fig. 2. Data points show measured cross section for 5350 A $\mathrm{T} 1$ enission versus relative collision speed. Solid, dashed, and dotdashed curves show fits to the data obtained by convoluting cross sections of the form $\mathrm{g}^{-s}$ over the experimental distribution in g. The dotted curve (which joins the solid cirve at higher g) shows a similar convoluted result for a cross section which is zero below $0.042 \mathrm{eV}$ [the $\mathrm{Tl} *\left(9 \mathrm{p}{ }^{2} \mathrm{P}_{1 / 2}\right)-\mathrm{Hg}^{*} \cdot\left({ }^{3} \mathrm{P}_{2}\right)$ energy difference] and varies as $\mathrm{g}^{-2}$ at higher kinetic enr rgies. 
$\mathrm{Hg} *\left({ }^{3} \mathrm{p}_{0}\right.$ and $\left./ \mathrm{or}{ }^{3} \mathrm{P}_{2}\right)+\mathrm{T}\left(6 \mathrm{p}^{2} \mathrm{P}_{1 / 2}\right) \rightarrow$

$\lg \left({ }^{1} S_{0}\right)+\mathrm{Tl}^{*}\left(\mathrm{~ns}^{2} \mathrm{~S}_{1 / 2}\right.$ and/or $\left.\mathrm{mp}^{2} \mathrm{P}_{1 / 2,3 / 2}\right)$,

with $n=7,8$, and/or 9 and $m=7$ and/or 8 .

Figure 2 indicates that $\mathrm{G}$ rel $(\mathrm{g})$ varies approximately as $\mathrm{g}^{-2}$ over the range in $\mathrm{g}$ examined, a considerably steeper speed dependence than has been observed in previous measurements of the low-energy behavior of electronically inelastic cross sections. ? This observed $\mathrm{g}^{-2}$ dependence suggests a model wherein reaction (1) may take place if the reactants manage to penetrate to an interatomic separation, $R_{x}$, tnder the influence of a strongly attiactive force (potential energy at $R_{X}$ of about $-0.5 \mathrm{eV}$ ).

1. G. Cario and J. Franck, Z. Phys. 17, 202 (1923).

2. Previous work is referenced in:

M. E. Gersh and E. E. Muschititz, Jr.,

J. Chen. Phys. 59, 3538 (1973).

\section{COLLISION DYNANICS INVOLVING METAL ATOMIS}

Richard Behrens, Jr., Andrew Freednan, Laza A. Gudel, Ronald R. Heru, Lambert C. -H. Loh, Timothy P. Parr, and Charlotte M. Sholeen

In addition to the results of specific projects described above, work contimued during 1973 on the following projects.

(1) A crossed beans measurement of the dependence on relative collision speed of the cross section for the reaction

$$
\mathrm{Hg} *\left({ }^{3} \mathrm{P}_{2}\right)+\mathrm{MX}+\mathrm{HgX}+\mathrm{M}^{*}\left({ }^{2} \mathrm{P}\right)
$$

where

$$
\mathrm{NX}=\mathrm{NaBT} \text { and } \mathrm{NaI} \text {. (LC-HL) }
$$

(2) A study of the mercurous halide electronic chemiluminescence which is observed upon irradiation of a vapor mixture of $\mathrm{Hg}$ and a diatomic halogen at $2537 \bar{\AA}$. (LAG)

(3) Crossed beans studies of the reactions of $\mathrm{Li}$ and $\mathrm{Na}$ with $\mathrm{Br}_{2}$ and other molecules, enploying a combination of magnetic deflection and slotted-disk-velocity analysis to analyze the products. (ONS and LAG)
(4) Crossed beans studies of reactions involving the alkaline earth dihalides $\left(\mathrm{AX}_{2}\right)$. Thus far, these studies have demonstrated that halogen atoms are exchanged under single-collision conditions and with large reactive cross sections (1-100 $\left.\AA^{2}\right)$ for the following collision partners: (1) $\mathrm{BaF}_{2}+\mathrm{BCl}_{3}$ and (2) $\mathrm{BaI}_{2}+$ $\mathrm{Cl}_{2}$ and $\mathrm{HCl}$. (RB, $\mathrm{AF}$, and TPP)

\section{RESEARCH PLANS FOR CALENDAR YEAR 1974}

Ronald R. Herm

Since this research program is to be teminated, the thrust of our 1974 efforts will be the completion of continuing proiects. In addition, however, we plan the following exploratory studies.

(1) The crossed beans apparatus which is being employed to study $\mathrm{Li}$ and $\mathrm{Na}$ reactions provides for simultaneous magnetic deflection and velocity analysis of scattered species. As such, it comprises a mass spectrometer for paramagnetic neutral species. We plan to exploit this feature of the instrument by searching for species such as $\mathrm{Li}_{2} \mathrm{X}$ and $\mathrm{LiX}_{2}(\mathrm{X}$ is a halogen atom) formed as products of chemical reactions or under equilibrium conditions. Although neither type of molecule has been experimentally observed in the gas phase, both species have been predicted to exist.

(2) The crossed beams apparatus which was ellployed to study reactions of alkaline earth dihalides $\left(\mathrm{O} \mathrm{x}_{2}\right.$ ) will be employed to sturly reations of the following species: $\mathrm{AX}_{2}, \mathrm{Ca}, \mathrm{Al}$, and $\mathrm{OH}$.

\section{1973 PUBLICATIONS AND REPORTS}

Ronald R. Herm and As: iiates

\section{Journals}

1. Shen-Maw Lin, Charles A. Mims, and Ronald R. Herm, Crossed Beans Chemistry: Reactions of $\mathrm{Ba}, \mathrm{Sr}, \mathrm{Ca}$, and $\mathrm{Mg}$ with $\mathrm{Cl}_{2}$ and $\mathrm{Br}_{2}, \mathrm{~J}$. Chen. Phys. 58, 327 (1973) (LBL-1126).

2. Charles A. Mims, Shen-Maw Lin, and konald R. Herm, Crossed Beans Product Angular Distributions: $M C 1$ and MI from $\mathrm{Ba}, \mathrm{ST}, \mathrm{Ca}$, and $\mathrm{Mg}_{\mathrm{g}}^{+} \mathrm{ICl}_{\mathrm{Cl}}$ and $\mathrm{BaCN}$ and $\mathrm{BaBr}$ from $\mathrm{Ba}+\mathrm{BrCl}, \mathrm{J}$. Chem. Phys. 58, 1983 (1975) (LRL-1134). 
3. Shen-Maw Lin, Charles A. Mims, and Ronald R. Herm, Crossed-Beams Reactions of Barium, Strontium, and Calcium with Some Halides of Methane, J. Phys. Chem. 77, 569 (1973) (LBL-1175).

4. Boyd L. Earl and Ronald R. Herm, Collisjonal (ruenching of $X^{*}(4 p 2)$ and $\mathrm{K}^{*}(5 \mathrm{p} 2 \mathrm{P})$ by $\mathrm{H}_{2} \mathrm{O}, \mathrm{CF}_{4}$, and $\mathrm{CH}_{4}$, (hem. Phys. Letters 22, 95 (1973) (LBL-1824).

5. Ronald R. Hern, Shen-Maw Lin, and Charles A. Mins, Crossed Beams Chemistry: Reactions of $\mathrm{Ba}, \mathrm{Sr}$, and $\mathrm{Ca}, \mathrm{J}$. Phys. Then. 77, 2931 (1973) (LBL-1884).

\section{LEL reports}

1. Charles A. Mims, Molecular Beam Chemistry of Alkaline Earth Atoms (Ph.D. thesis), LBL-1159, May 1973.

2. Boyd L. Earl, Photochemical Studies of Alkali Halide Vapors (Ph.D. thesis), LBL-1866, Aug. 1973.

3. Boyd L. Earl and Ronald R. Herm, Photodissociation of $\mathrm{NaBr}, \mathrm{NaI}$, and $\mathrm{KI}$ Vapors and Collisional Quenching of $\mathrm{Na}^{\star}\left(3^{2} \mathrm{P}\right)$, $K^{\star}\left(4^{2} \mathrm{P}\right)$, and $K^{\star}\left(5^{2} \mathrm{P}\right)$ by Foreign Gases, LBL-2500, Dec. 1973 (to be sumitted to J. Chem. Phys.). 
Harold S. Johnaton, Frincipal Investigator

1. EXPERTMENTAL STUDIES

a. Visible and U1traviolet Absorption Spectra of Oxides of Nitrogen and $0 x y$-acids of Nitrogen

Richard Graham and Harold S. Johnston

The object of these stities is to obtain quantitative absorption spectra at temperatures and pressures close to stratospheric conditions ( 1 :o 100 TorT, $200-300^{\circ} \mathrm{K}$ ) for the oxides of nutrogen and related species. Spectra have been obtained for $\mathrm{NO}_{2}, \mathrm{~N}_{2} \mathrm{O}_{5}$, $\mathrm{NO}_{3}, \mathrm{HNO}_{2}$, and $\mathrm{HNO}_{3}$. The room temperature spectrum of the nitrate free radical is given as Fig. 1 and that for $\mathrm{NNO}_{2}$ is Fig. 2 .

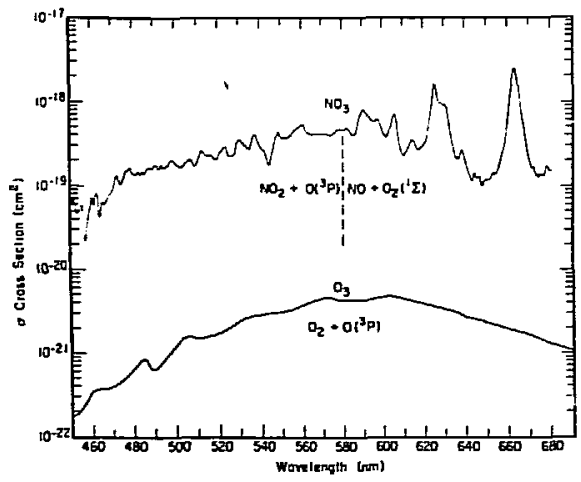

Fig. 1. Light absorption cross section for the $\mathrm{NO}_{3}$ radical and for ozone in the visible regions of the spectrum.

(XBL 738-1683)

b. Quantum Yields for the Photolysis of Nitric Acid Vapor

Shih-ger Chang and Harold S. Johnston

The oxides of nitrogen (NO and $\mathrm{NO}_{2}$ ) are active in the stratosphere in the catalytic destruction of ozone. These active nitrogen oxides are partially tied $\Psi$ as nitric acid vapor. Nitric acid is formed from nitrogen dioxide and hydroxyl radicals:

$$
\mathrm{HO}+\mathrm{NO}_{2} \stackrel{\mathrm{M}}{\rightarrow} \mathrm{HNO}_{3} \text {. }
$$

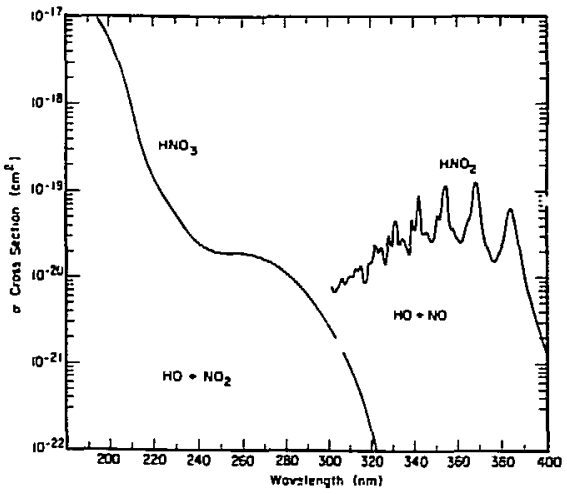

Fig. 2. Ultraviolet absorption cross sections for nitric and nitrous acid. (XBL 738-1786)

It is also destroyeo by hydroxyl radicals:

$$
\mathrm{HO}+\mathrm{HNO}_{3}+\mathrm{H}_{2} \mathrm{O}+\mathrm{NO}_{3},
$$

and it is destroyed by ultraviolet radiation.

In 1973 we detemined the primary products of this photolysis:

$$
\mathrm{HNO}_{3}+\mathrm{hv}+\mathrm{HO}+\mathrm{NO}_{2}
$$

and the primary quantum yield, which is ore from 200 to $3: 0 \mathrm{~mm}$.

The overall photolysis of nitric acid is a very complex reaction. Reaction (3) is typically followed by reaction (2), and then dinitrogen pentoxide is formed from the nitrate radical $\mathrm{NO}_{3}$ and nitrogen dioxide:

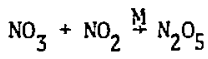

Dinitrogen pentoxide (from Reaction 4) reacts with water (From Reaction 2) on the walls of the vessel to reform nitric acil

$$
\mathrm{N}_{2} \mathrm{O}_{5}+\mathrm{H}_{2} \mathrm{O} \text { walls } 2 \mathrm{HNO}_{3}
$$

The net effect of reactions $2,3,4,5$ is zero; there is no net chemical change. Actually, a small overall quantum yield of about 0.1 is observed because of secondary 
chemical and photochenical reactions of $\mathrm{N}_{2} \mathrm{O}_{5}$ and $\mathrm{NO}_{2}$. To obtain the primary quantum yield we add carbon monoxide as a trap for hydroxyl radicals:

$$
\mathrm{HO}+\mathrm{CO}+\mathrm{\omega}_{2}+\mathrm{H}
$$

and we add oxygen as a trap for the hydrogen atom:

$$
\mathrm{H}+\mathrm{O}_{2}+\mathrm{M} \rightarrow \mathrm{HOO}+\mathrm{M} \text {. }
$$

With proper anounts of $\mathrm{CO}$ and $\mathrm{O}_{2}$ the observed rate of formation of $\mathrm{NO}_{2}$ or $\mathrm{D}_{2}$ gives the primary quantun yield.

When nitric acid is photolyzed in the presence of carbon monoxide and oxygen, about 40 other reactions are possible. Dr. Gary Whitten (see below) has developed a cormuter program for speedy, accurate solution of simultaneous kinetic equations for a large nuber of reactions. This program was designed for study of the complex situation in the stratosphere. It has been modified as a convenient method for analyzing complex laboratory reactions. It was used to model the 40 to 50 reactions that cas be considered for the nitric acid photolysis. The build-up of the product $\mathrm{NO}_{2}$ as observed and as calculated by this method is shown in Fig. 1. Conditions were such that most of the 50 reactions were so slow as to be negligible, but the detailed exanination of the large set of reactions was a very reassuring way to handle the complex system.

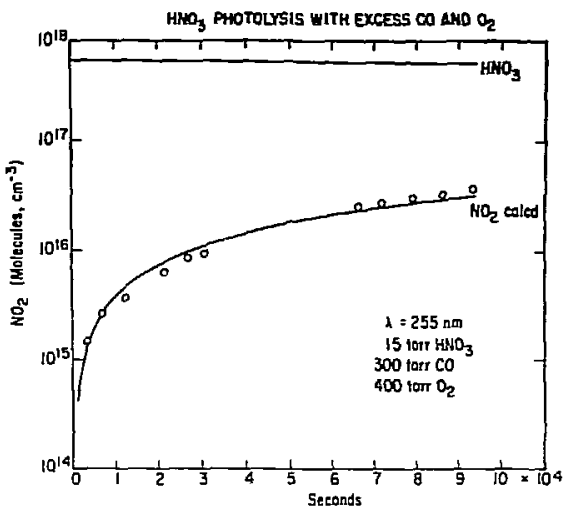

Fig. 1. Oserved production of $\mathrm{NO}_{2}$ in the photolysis of ritric acid in the presence of $\mathrm{CO}$ and $\mathrm{O}_{2}$ and the calculated production of $\mathrm{NO}_{2}$ on the basis of a 40-5tep mechanism. c. The Rate of Reaction of Nitrogen Dioxide and Ozone

Richard Graham and Harold S. Johrston

In the natural stratosphere by far the fastest reaction that destroys ozone is the $\mathrm{NO}_{2}$ catalytic crele

$$
\begin{gathered}
\mathrm{NO}+\mathrm{O}_{3}+\mathrm{NO}_{2}+\mathrm{O}_{2} \\
\text { net: } \frac{\mathrm{NO}_{2}+\mathrm{O}+\mathrm{NO}+\mathrm{O}_{2}}{\mathrm{O}_{3}+\mathrm{O}+\mathrm{O}_{2}+\mathrm{O}_{2}} .
\end{gathered}
$$

There is another process that is inportant in destroying ozme in the lowest stratosphere, the $\mathrm{NO}_{3}$ catalytic cycle

$$
\begin{gathered}
\mathrm{NO}_{2}+\mathrm{O}_{3}+\mathrm{NO}_{3}+\mathrm{O}_{2} \\
\mathrm{NO}_{3}+\mathrm{hv}+\mathrm{NO}+\mathrm{O}_{2} \text { (day) } \\
\frac{\mathrm{NO}+\mathrm{O}_{3}+\mathrm{NO}_{2}+\mathrm{O}_{2}}{\text { net: } 2 \mathrm{O}_{3}+\text { red light }+3 \mathrm{O}_{2}} .
\end{gathered}
$$

We have measured the rate of the $\mathrm{NO}_{2}+\mathrm{O}_{3}$ reaction from 230 to $300^{\circ} \mathrm{K}$; results are given by Table I. The reaction was followed by ultraviolet or visible absorption by czone and by nitrogen dioxide. The overall thernal reaction is (10) followed by (4). The ratio

\begin{tabular}{|c|c|c|}
\hline$\left(\begin{array}{c}\mathrm{T} \\
\left({ }^{\circ} \mathrm{K}\right)\end{array}\right.$ & $\begin{array}{l}\text { No. of } \\
\text { rums }\end{array}$ & $\left(10^{-17} \mathrm{~cm}^{3} \stackrel{k}{k}\right.$ eccule $\left.e^{-1} \mathrm{sec}^{-1}\right)$ \\
\hline $\begin{array}{l}298.0 \\
288.0 \\
278.0 \\
268.0 \\
258.0 \\
248.0 \\
238.0 \\
231.2\end{array}$ & $\begin{array}{r}10 \\
4 \\
8 \\
12 \\
13 \\
12 \\
16 \\
6\end{array}$ & $\begin{array}{l}3.49 \\
2.51 \\
1.80 \\
1.38 \\
0.905 \\
0.621 \\
0.433 \\
0.314\end{array}$ \\
\hline
\end{tabular}
of loss of $\mathrm{NO}_{2}$ to loss of $\mathrm{O}_{3}$ was 1.9 10.1 , indicating some unknown side reaction other than (10) and (4).

Table I. Experimental conditions and rate constants for the reaction $\mathrm{NO}_{2}+\mathrm{O}_{3}+\mathrm{NO}_{3}+\mathrm{O}_{2}$. 
d. The Quantur Yield of Singlet Oxygen from Ozone Photolysis

Douglas Martin, John Girman, and Harold S. Johnston

then ozone absorbs visible or ultraviolet radiation, it dissociates to an oxygen molecule and an oxygen atom. The electronic state of the oxygen atom varies with wavelength:

$$
\begin{aligned}
& \left.\mathrm{O}_{3}+\mathrm{hv} \text { (above } 320 \mathrm{~mm}\right)+\mathrm{O}_{2}+o\left({ }^{3} \mathrm{P}\right), \\
& \left.\mathrm{O}_{3}+\mathrm{hv} \text { (below } 300 \mathrm{~nm}\right)+\mathrm{O}_{2}+o\left({ }^{1} \mathrm{D}\right) .
\end{aligned}
$$

Between 300 and $320 \mathrm{~nm}$ there is a mixture of $O\left({ }^{3} \mathrm{P}\right)$ and $O\left({ }^{1} \mathrm{D}\right)$. Singlet oxygen atoms are the key to both $\mathrm{HO}_{\mathrm{x}}$ and $\mathrm{NO}_{\mathrm{x}}$ chenistry in the stratosphere:

$$
\begin{aligned}
& O\left(^{1} D\right)+\mathrm{H}_{2} \mathrm{O}+2 \mathrm{HO}, \\
& O\left({ }^{1} D\right)+\mathrm{N}_{2} \mathrm{O}+2 \mathrm{NO} .
\end{aligned}
$$

Sunlight is rapidly attenuated by ozone below $310 \mathrm{~mm}$. In order to calculate the rates of reactions (15) and (16), especially in the lower stratosphere and troposphere, one must have the detailed quantum-yield curve for formation of $O\left({ }^{1} D\right)$ as a function of wavelength between 300 and $320 \mathrm{~mm}$.

We have measured the quantum yield for formation of singlet oxygen atcoms by the

Table II. Preliminary results for quantum yield to form $O\left({ }^{1} \mathrm{D}\right)$ from ozone $\left(298^{\circ} \mathrm{K}\right)$.

\begin{tabular}{lcc}
\hline $\begin{array}{c}\lambda \\
(\mathrm{mm})\end{array}$ & $\begin{array}{c}\text { No. of } \\
\text { runs }\end{array}$ & $\begin{array}{c}\$ \\
\left(0^{1} \mathrm{D}\right)\end{array}$ \\
\hline 280 & 7 & 0.99 \\
285 & 4 & 0.99 \\
290 & 8 & 1.00 \\
295 & 4 & 1.04 \\
300 & 11 & 1.00 \\
302 & 4 & $0.90 \pm 0.03$ \\
304 & 4 & $0.97 \pm 0.03$ \\
306 & 4 & $0.91 \pm 0.02$ \\
308 & 4 & $0.78 \pm 0.03$ \\
310 & 8 & $0.48 \pm 0.01$ \\
312 & 4 & $0.34 \pm 0.02$ \\
314 & 4 & $0.29 \pm 0.01$ \\
316 & 6 & $0.18 \pm 0.01$ \\
\hline
\end{tabular}

highly sensitive method of photon counting, based on the following series of reactions:

$$
\begin{aligned}
& \mathrm{O}_{3}+\mathrm{hv}+\mathrm{O}_{2}+\mathrm{O}\left({ }^{1} \mathrm{D}\right), \\
& \mathrm{O}\left(^{1} \mathrm{D}\right)+\mathrm{N}_{2} \mathrm{O}-2 \mathrm{NO}, \\
& \mathrm{NO}+\mathrm{O}_{3}-\mathrm{O}_{2}+\mathrm{NO}_{2}{ }^{*}, \\
& \mathrm{NO}_{2}{ }^{*}+\mathrm{NO}_{2}+\mathrm{hv}(\mathrm{red}) .
\end{aligned}
$$

Preliminary results are given in Table II.

e. Reactivity of Hydroxyl Radicals as a Function of Vibrational Energy State

Jere Streit and Harold S. Johnston

Hydrogen atoms are produced in a microwave discharge and mixed with low-pressure ozone in a large stainless steel tank. The hydrogen atoms react with ozone to produce vibrationally excited hydroxyl radicals:

$$
\mathrm{H}+\mathrm{O}_{3}+\mathrm{O}_{2}+\mathrm{HO}(\mathrm{v}<9) \text {. }
$$

These excited radicals are deactivated to lower vibrational states and they react with ozone:

$$
\begin{aligned}
\mathrm{HO}(\mathrm{v})+\mathrm{O}_{3} & \rightarrow \mathrm{HOO}+\mathrm{O}_{2} \\
& \rightarrow \mathrm{H}+\mathrm{O}_{2}+\mathrm{O}_{2} .
\end{aligned}
$$

The relative concentration of hydroxy 1 radicals is followed by visible-light emission for vibrational transitions where $\Delta v=3$. Fron these data we have obtained information about the rate of deactivation of the highly vibrationally excited molecules and the rate of reaction of $\mathrm{HO}_{\mathrm{O}}$ with $\mathrm{O}_{3}$ as a function of vibrational state of $\mathrm{HO}$.

\section{THEORETICAL STUDIES}

a. Model Calculations of Stratospheric Ozone, Including Atmospheric Kotions

Cary Whitten and Harold S. Johnston

The total problem of air motions and photochemistry in the stratosphere is exceedingly complicated. However, it is not necessary to solve the total problem in order to get definite answers for certain linited questions. We have posed the following limited question: Are the pure air reactions 
and air motions sufficient to account for the global ozone balance? Note the restrictions on this question: it does not ask about the distribution of ozone within the stratosphere, only the global balance; and it asks only if a set of four chemical reactions are

sufficient. These reactions are:

$$
\begin{aligned}
& \mathrm{O}_{2}+\mathrm{hv} \text { (below } 242 \mathrm{~mm} \text { ) } \rightarrow 0+0, \\
& \mathrm{O}+\mathrm{O}_{2}+\mathrm{M} \rightarrow \mathrm{O}_{3}+\mathrm{M}, \\
& \mathrm{O}_{3}+\mathrm{hv} \text { (vis. and u.v.) }+\mathrm{O}_{2}+0, \\
& \mathrm{O}_{3}+0 \rightarrow \mathrm{O}_{2}+\mathrm{O}_{2} \text {. }
\end{aligned}
$$

We take the world as motions and photochemistry prepared it--with respect to temperature, air concentration, and ozone concentration. We consider sunlight above the atmosphere, and we calculate the distribution of radiation as a function of wavelength, elevation ( $1 \mathrm{~km}$ grid), longitude ( $15^{\circ}$ grid), the latitude $\left(5^{\circ}\right.$ grid). With this distribution of radiation we calculate the instantaneous (per second) rates of the four "pure air" reactions listed above at 43,200 volume elements over the glove, automatically including all hours of the day. Reactions (a) and (b) form ozome, reactions (c) and (b) detemine the concentrations of oxygen atoms, and reaction (d) destroys ozone. We integrate these rates of formation and destruction of ozone over the entire stratosphere of the earth. The integral of the transport of ozone over the volume of the stratosphere is simply the rate of transport of ozone across the boundary of the stratosphere, and this transport has been measured by others. A. typical value of global balance of ozone formation and destruction is:

\begin{tabular}{lc}
$\begin{array}{l}\text { Ozone formation } \\
\text { transport to } \\
\text { troposphere } \\
\text { destruction by } \\
0+0_{3}\end{array}$ & $600 \times 10^{29}$ molecules $\mathrm{sec}^{-1}$ \\
$\begin{array}{l}\text { unbalanced ozone } \\
\text { production }\end{array}$ & $80 \times 10^{29}$ molecules $\mathrm{sec}^{-1}$ \\
\hline
\end{tabular}

If this unbalanced production of ozone continued for two weeks, the total ozone of the Earth would double. "Sonething else" besides pure air and atmospheric motions is responsible for $80 \%$ of the natural destruction of stratospheric ozome.

We have examined the proposal that this great discrepancy could be due to experimental error in our kJowledge of the incoming solar radiation, the absorption spectrum of $\mathrm{O}_{2}$ or
$\mathrm{O}_{3}$, or the rate constants for the chemical reactions. We have taken the National Bureau of Standards ' estimate of the standard deviation of each of these five quantities, and we carried out Monte Carlo calculations that randomly deal in various magnitudes of error for each of the five quantities. Two hurdred such calcalations gave a standard error of $83 \times 10^{2}$ molecules $\mathrm{sec}^{-1}$ for the entire calcllation. Thus to the $95 \%$ confidence level, "something else" besides pure air chemistry and air motions accounts for $(408 \pm 186) \times 10^{29}$ molecules $\mathrm{sec}^{-1}$ of natural ozone destruction.

The "water reactions," that is, the reactions of the free radicals $\mathrm{H}$, $\mathrm{HO}_{\mathrm{O}}$ and HoO were found to account for $56 \times 10^{29}$ molecules $\mathrm{sec}^{-1}$. This calculation used 1973 values of the rate constants for these reactions.

The oxides of nitrogen would be sufficient to account for the remaining destruction of ozone if nitric oxide, per se, is present in the stratosphere at about $4 \times 10^{8}$ molecules $\mathrm{Gn}^{-3}$. A recent observation of NO between 17 and 35 kilometers by Ackerman and co-workers formd NO to vary between 2 and $8 \times 10^{8}$ molecules $\mathrm{cm}^{-5}$. (Some other less extensive measurements have found No values higher and lower than these). Thus it appears highly probable that the oxides of nitrogen in the present natural stratosphere destroy between twothirds and three-quarters of the ozone that is produced. Thus the oxides of nitrogen appear to be a major factor in the natural ozone balance.

There are many estimates of the rate of formation of the oxides of nitrogen in the natural stratosphere, and these rates are approximately equal to the rate of injection of oxides of nitrogen into the stratosphere by 500 supersonic transports. Thus, 500 SST promise Iore or less to double on the global scale a very active stratospheric ingredient.

b. The Effect of Nuclear Bomb Tests (1952-62) on Stratospheric $\mathrm{NO}_{x}$ and Ozone

John Birks, Gary Whitten, and Harold S. Johnston

Foley and Rurderman ${ }^{1}$ calaulated the amount of nitric oxide that would be produced by nuclear bombs exploded in the atmosphere. This work was extended by Johnston, Whitten, and Bigks, 2 by GiImore, and by Goldsmith et al. The high tenperature in the nuclear explosion fixes large amounts of nitric oxide from air, and the rising mushroon cloud transports much of it into the stratosphere, 
if the energy of the bomb is one megaton or more. Although nitric oxide from the bombs was not measured, strontium- 00 , excess carbon-14, and other radioactive substances were measured in the stratosphere for many years after the termination of large-scale tests in 1962. From the observed distribution of carbon-14 in the stratosphere, one can infer the $\mathrm{NO}_{2}\left(\mathrm{NO}, \mathrm{NO}_{2}\right.$, and $\left.\mathrm{HNO}_{3}\right)$ distribution (Figs. 1, 2, and 3). Blost of the muclear explosions occurred at the USSR site above the arctic circle. The average $\mathrm{NO}_{\mathrm{X}}$ distribution over the nothem hemisphere was $(2 \pm 1) \times 10^{15}$ molecules $\mathrm{cm}^{-2}$, and less than one-tenth of this in the southern hemisphere. The average natural $\mathrm{NO}_{\mathrm{x}}$ distribution is about $(1 \pm 0.5) \times 10^{16}$ molecules on ${ }^{-2}$. From these distributions of bomb-produced $\mathrm{NO}_{\mathrm{x}}$, we calculated a $5 \pm 2 \frac{2}{3}$ reduction of ozone. Chang and co-workers ${ }^{5}$ calculated the miximum reduction of ozone from the nuclear bonbs to be 49 .

Although the quantity of ozone found in the atmosphere by the nuclear bomb tests of 1961-62 was large, the distribution was not conducive to a large rediction of ozone. At and above the dashed lines in Figs. 1,2, and 3 the photochemical ozone replacement time is 4 months or less; at and below the heavy solid line the photochemical ozone

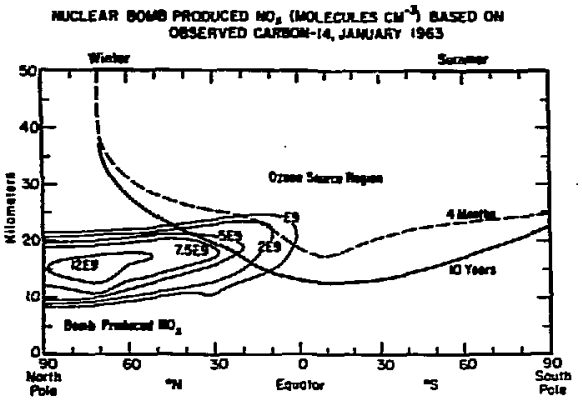

Fig. 1. Distribution of artificial $\mathrm{NO}$ ( $\left.\mathrm{NO}+\mathrm{NO}_{2}+\mathrm{HNO}_{3}\right)$ in the stratosphere at the conclusion of large-scale atmospheric nuclear bomb tests $(1952-62)$ on the bas is of $1.0 \times 10^{32}$ molecuies of No per megaton of boub yield. The distribution is derived from observed carbon-14. The lines show the depth of peretration of ozore-producing sunlight: -.- local ozone replacement time 4 months: local ozone replacement time 10 years. The "ozone source region" is regarded as that where photochenical ozone replacement occurs within 4 months or at a faster rate. replacement time is 10 years or longer. Relatively little $\mathrm{NO}_{\mathrm{x}}$ from the nuclear bombs overlapped the "ozone source region." Thus the percentage reduction of ozone is at most a fer percent, whereas the same quantity of $\mathrm{NO}_{\mathrm{X}}$ spread betrieen 20 and $30 \mathrm{~km}$ in the tropical stratosphere would have had a much greater inquact on the ozone.

Casual inspection of tie historical ozone data (Goldsmith et a1.4) showed no large or conspicuous changes of ozone during or after the large-scale nuclear tests 1952-62. On the other hand it was only in the late 1950's or early 1960's that there were enough ozoneobserving stations to give even an approximate estimate of total global or hemispheric ozone. The history of world-wide ozone before 1957-58 is largely lost for lack of data. The history of ozone during the 1960's,

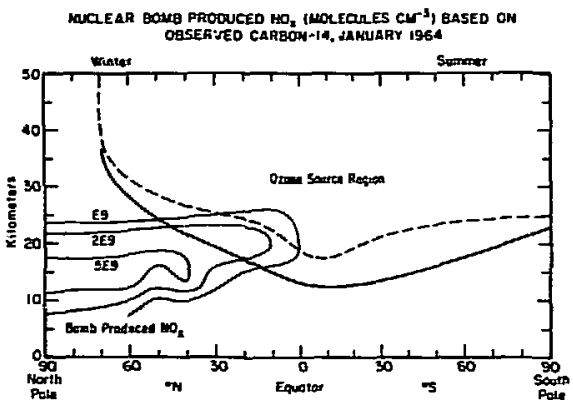

Fig. 2. One year after Fig. 1 .

(XBL 7310-5513)

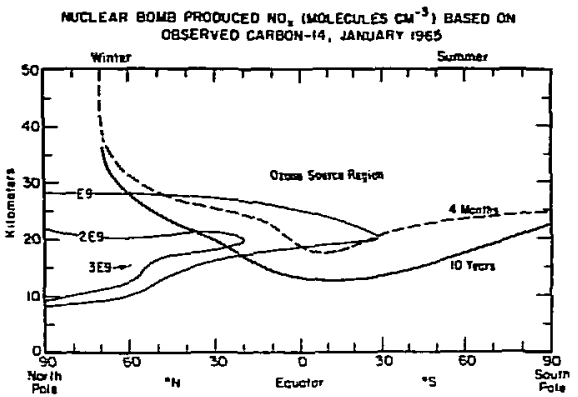

Fig. 3. Two years after Fig. 1.

(XBL 7310-5512) 
however, shows a distinct, statistically significant increase in ozome. Xomhyr et al. 6 analyzed the total ozone data from about a dozen selected stations for the period 1961-70, and they found a statistically significant increase of ozone at most stations, averaging about $5 \%$. Johnston et al. applied Konhyr's method to all of the stations of the world for the period 1960-70, inclusive. No significant trends were found in the southern hemisphere, but a statistically significant increase of ozone of $5 \pm 1.24$ was fornd for the northern hemisphere for the period 1963-70, inclusive. Lor Ion and Kelley analyzed all data for total ozone from 1957 through 1970. They found no significant trend in the southem hemisphere. In the northern hemisphere London and Kelley report a decrease $(-2.4 \pm 0.88)$ over the period $195 \%-61$ and $3 n$ increase of 1112.3t over the decade 1961-70. (The observed minimum was in 1961 although this time is incertain by 2 or 3 years in terms of scatter of the data and the phase of the quasi-biemial cycle.)

Although the reason for the increase of ozone during the 1960's is cebatable, it has been proposed (Johnston et al. 2) that some or all of this increase may be we to the stratosphere returning to normal after the cessation of large-scale bomb tests in 1962. (Ali work partially suported by DOT.)

1. H. H. Foley and M. A. Pudenuan, Stratospheric Nitric Oxide Prohiction from Past Nuclear Explosions and Its Relevance to Projected SST Pollution, J. Geophys. Res. 78,4441 (1973).

2. H. S. Johnston, G. Whitten, and J. Birks, The Effect of Nuclear Explosions on Stratospheric Nitric Oxide and Ozone, J. Geophys. Res. 78, 6107 (1973).

3. F. R. Gilmore; The Production of Nitrogen Oxides by Low Altitude Nuclear Explosions, preprint, Institute for Defense Analysis, July 1973.

4. P. Goldsmith, A. F. Tuck, J. S. Foot, E. L. Simmons, and R. L. Nelson, Nitrogen Oxides, Nuclear Heapons Testing, Concorde, and Stratospheric Ozone, Nature 244, 545 (1973).

5. J. S. Chang, A. C. Hindnarsh, and

N. K. Matsen, Simulation of Chemical Kinetics Transport in the Stratosphere, Lawrence Livermore Report UCRL-74823 (Óct. 1973). 6. W. D. Komhyr, E. W. Barrett, G. Slocurn and $\mathrm{H}$. K. Weicknan, Atmospheric Ozone Increase During the 1960 's, Nature 232, $390-391$ (1971).

7. J. London and J. Kelley, Global Trends in Atmospheric Ozone, preprint, 1973.

\section{RESEARCH PLANS FOR CALENDAR YEAR 1974}

Harold 5. Johnston

We plan to find the quantum yield and primary photochemical products during the photolysis of the $\mathrm{NO}_{3}$ radieal

$$
\begin{aligned}
& \mathrm{NO}_{3}+\mathrm{hv}+\mathrm{NO}+\mathrm{O}_{2} \text { above } 578 \mathrm{~nm} \\
& \mathrm{NO}_{3}+\mathrm{hv}+\mathrm{NO}+\mathrm{O}_{2} \\
& \text { or } \mathrm{NO}_{2}+\mathrm{O} \text { below } 578 \mathrm{~nm} .
\end{aligned}
$$

The role of the reaction, $\mathrm{NO}_{2}+\mathrm{O}_{3} \rightarrow \mathrm{NG}_{3}+\mathrm{O}_{2}$, in reduring ozone depends an the products and quantum yield of the $\mathrm{NO}_{3}$ photolysis. We plan to obtain quantum yields and primary products for the photolysis of $\mathrm{N}_{2} \mathrm{O}_{5}$ and $\mathrm{N}_{2} \mathrm{O}_{4}$. The low-termperature spectra of $\mathrm{N}_{2}$ and $\mathrm{N}_{2} \mathrm{O}_{4}$ should be completed next year.

The production and the photolysis of nitrous acid vapor $\left(\mathrm{HNO}_{2}\right)$ will ba studied. The kinetics of the reaction $\mathrm{NO}+\mathrm{NO}_{2}+\mathrm{H}_{2} \mathrm{O}$ will be followed, and the presumed reaction $\mathrm{HOO}+\mathrm{NO}_{2}+\mathrm{HHO}_{2}+\mathrm{O}_{2}$ will be investigated. These reactions are of possible inportance in the global ozone balance.

We hope soon to finish the study of the quantum yield of $O\left({ }^{1}\right.$ ) from the photolysis of ozone.

Recently it has appeared that other manmade pollutants may have an impact on the global ozone shield. The oxides of chlorine are somewhat more active in destroying ozone than the axides of nitrogen. The oxides of chlorine may reach the stratosphere either directly (perchlorate oxidizers from the space shuttle and other solid rocket fuela) or indirectly (chlorinated hydrocarbons and freons wed at the Earth's surface). We expect to return to consideration of chlorine oxide reactions.

\section{1973 PUBLICATIONS AND REPORTS}

Harold S. Johnston and Associates

\section{Jarmals}

1. H. S. Johnston and R. A. Graham, Gas Phase Utraviolet Spectrum of Nitric Acid Vepor, J. Phys. Chen. 77, 62 (1973) (LBL-1179).

2. H. S. Johnston and G. Whitten, Instantaneous Photochemical Rates in the Global Stratosphere, Pure and Appl. Geophys. 106,1468 (1975). 
3. H. S. Johnston, G. Thitten, and J. Birks, The Effect of Nuclear Explosions on Stratospheric Nitric Oxide and Ozone, J. Ceophys. Res. 78, 6107 (1973) (LBL-1421 Rev.).

4. A. B. Harker and H. S. Johnston, Photolys is of Nitrogen Dioxide to Produce Transient $\mathrm{O}, \mathrm{NO}_{3}$, and $\mathrm{N}_{2} \mathrm{O}_{5}, J$. Phys. Chen. 77, 1153 (1973) (LBL-1425).

\section{Papers presented}

1. H. S. Johnston and G. Whitten, Reactions of Ozone and Nitrogen Oxides at High Altitudes, AGARD Conference on Atmospheric Pollution by Aireraft Engines, Iondon, England (April 1973).
2. H. S. Johnston, Photochemistry in the Stratosphere--with Applications to Sumersonic Transports, National Meeting of American Chemical Society, Chicago, I11. (Aulg. 1973); LBL-2217. Submitted to Astronautica Acta.

3. H. S. Johnston and R. A. Traham, Photochemistry of $\mathrm{NO}_{x}$ and $\mathrm{HNO}_{\mathrm{x}}$ Compounds, The Second General Scientific Assembly of the International Association of Ceomagnetism and Aeronomy, Kyoto, Japan (Sept. 1973); LBL-2249.

\section{LBL reports}

1. Harold S. Jahnston and Shih-Cer Chang, Photolysis of Nitric Acid Vapor, LBL-1865, July 1973. (to be published in J. Phys. Chem.)

2. D. R. Martin, Kinetics of Sulfur Dioxide Forescence (Ph.D. thesis), LBL-1199, !brch 1973. 
Bruce H. Mahan, Principal Investigator

1. DNAMICS OF THE $\mathrm{O}^{+}-\mathrm{H}_{2}$ REACTION: REACTTVE SCATTERING AT RELATIVE ENERGIES ABOVE $15 \mathrm{eV}^{\star}$

Keith T. Gillen, Bruce H. Mahan, and John S. Winn

We have studied the reaction $\mathrm{O}^{+}\left(\mathrm{H}_{2}, \mathrm{H}\right) \mathrm{OH}^{+}$ and its isotopic variants by determining the velocity vector distribution of products for initial relative energies above $15 \mathrm{eV}$. The non-reactive scattering of $\mathrm{O}^{+}$by the various isotopic hydrogen molecules also has been determined. Figure I shows that at the higher relative energies, much of the nonreactive scattering of $\sigma^{*}$ can be explained by a model in which the $0^{+}$makes a collision with a free hydrogen or deuterium atom. That is, the collision is so impulsive that in large measure the effects of molecular binding can be ignored.

He have extended this impulse model to reactive collisions, and have compared its predictions with experiment. In this case, for the general reaction $A(B C, C) A B, A$ hits $B$ inpulsively, B makes an impulsive elastic
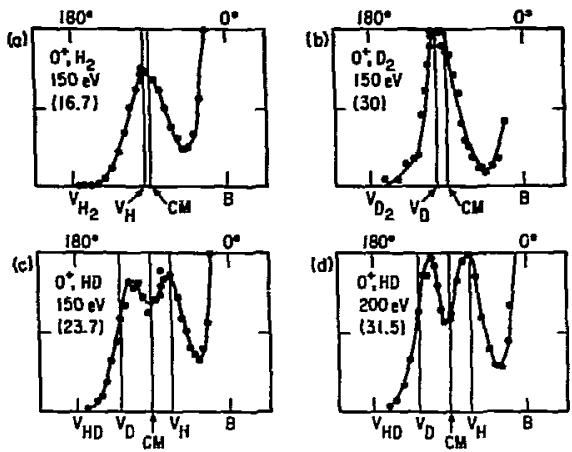

Fig. 1. Profiles of the intensity of $0^{+}$ scattered along the $0^{\circ}-180^{\circ}$ axis in the barycentric system of the atom and diatomic molecule. The label B locates the $0^{+}$beam velocity; $M$, the velocity of the center-ofmass; $V_{H}$, the velocity of $0^{+}$scattered elasticaliy from $\mathrm{H}_{2} ; \mathrm{V}_{\mathrm{H}}$, the velocity of $\mathrm{O}^{+}$ scattered from a free $H$ atom, and similarly for $V_{D}$ and $V_{D}$. (a) $150 \mathrm{eV}$ (lab) $0^{+}$scattered from $\mathrm{H}_{2}$. (b) $150 \mathrm{eV} 0^{+}$scattered Eror $\mathrm{D}_{2}$. (c) $150 \mathrm{eV} \mathrm{O} \mathrm{O}^{+}$scattered from $\mathrm{HD}$. (d) $200 \mathrm{eV}$ $0^{+}$scattered from $\mathrm{HD}$. (XBL 737-6493) collision with $C$, and the molecule $A B$ is formed if, as a result of these impulses, the energy of A relative to B is less than their binding energy. The molecule AC can also be formed from this sequence of collisions.

He have made Monte Carlo calculations of the angular distribution of reaction products predicted by this sequential inpulse mode1. Figure 2 shows a comparison of one of these calculated angular distributions with experimental data. For the reaction $\mathrm{O}^{+}(\mathrm{HD}, \mathrm{D}) \mathrm{OH}^{+}$, product formation can occur by twc sequences. In the first case, $\mathrm{O}^{+}$hits $H, H$ hits $D$, and $\sigma^{*}$ and $H$ conbine to form $\mathrm{OH}^{+}$. As shown in Fig. 2, this sequence is responsible for most of the small angle reactive scattering. In the second type of sequence, or hits $\mathrm{D}, \mathrm{D}$ hits $\mathrm{H}$, and $\mathrm{O}^{+}$and $\mathrm{H}$ combine. 'This sequence is responsible for essentially all of the large angle scattering. The sul of the two processes is in reasunable agreenent with the experimental distribution of prohucts. The deviations between experiment and theory can be rationalized in terms of the very simple hard sphere potential surface used in the calculation. Thus the sequential impulse model provides a reasonably accurate description of the reaction dynamics at these hyperthermal energies.

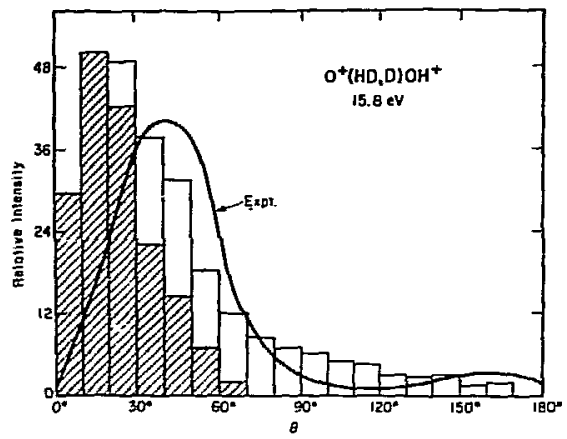

Fig. 2. Experimental and calculated angular distributions for the $\mathrm{O}^{+}(\mathrm{HD}, \mathrm{D}) \mathrm{OH}^{+}$reaction at $15.8 \mathrm{eV}$ initial relative energy. The hrstogram gives the results of a complete 3-dimensional sequential impulse mode1 calculation. The shaded bars represent reaction with the atom first struck by the projectile, and the open bars represent the contribution from reaction with the second or trailing atom. 
Abstracted from a paper to appear in J. Chem. Phys. (LBL-1886).

2. ANALYTICAL TREATMENT OF THE SEQUENTIAL IMPULSE MODEL FOR, CHEMICAL REACTION

Bruce H. Mahan

We have developed an analytical treatment which allows one to predict the energy and angular distribution of reaction products wing the sequential inpulse model for chemical reactions. The treatment makes it clear how the relative masses of the $H$ and $D$ atoms in Such reactions as $\mathrm{O}^{+}(\mathrm{HD}, \mathrm{D}) \mathrm{OH}^{\circ}$, $\mathrm{O}^{+}(\mathrm{HD}, \mathrm{H}) \mathrm{OD}^{+}$control the angular and energy distributions of the isotopic products. It also makes clear the fact that the spectator stripping process which is observed so frequently in high-energy reactions is most likely to occur when a reactant diatamic molecule is ariented perpendicularly to the initial reactive velocity vector. In addition, it shows that stabilization by forward recoil of reaction products after high relative energy collisions will only be observed for excorgic reactions in which the exoergicity is released as product repulsion. In general, the model shows that the most obvious features of high-energy reactions can be deduced from the most rudimentary features of the potential energy surfaces.

\section{DYNAMICS OF THE $\mathrm{C}^{+}-\mathrm{H}_{2}$ REACTION*}

Bruce $H$. Mahan and Thompson M. Sloane

We have investigated the reaction $\mathrm{C}^{+}\left(\mathrm{H}_{2}, \mathrm{H}\right) \mathrm{CH}^{+}$and its isotopic variants at relative energies ranging from 2 to $14 \mathrm{eV}$. The results have proved to be an inportant test of our ability to use the electronic properties of reactants, products, and intermediates to predict reaction dynanics. A representative prosuct velocity vector distribution is shown in Fig. 1. The distribution is nearly symmetric about the $\pm 90^{\circ}$ axis in the barycentric system, which indicates that there is a strong attractive interaction between all three atoms in the collision couplex before the products separate. As the initial relative energy is increased, the symmetry of the distribution about $\pm 90^{\circ}$ diminishes. At relative energies of $5 \mathrm{eV}$ and above, the distributions are distinctly peaked at $0^{\circ}$, the direction of the primary $\mathrm{C}^{+}$beam.

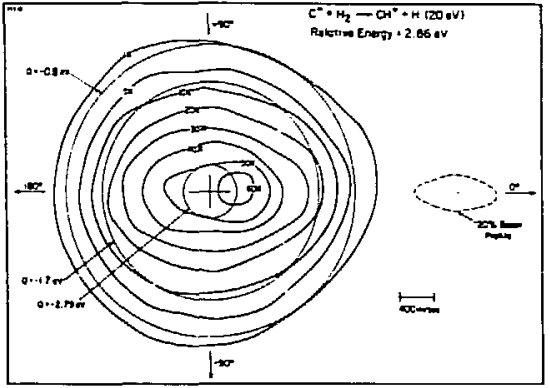

Fig. 1. A contour map of the intensity of $\mathrm{cH}^{+}$as a function of barycentric scattering angle and speed obtained from collisions with an initial relative energy of $2.86 \mathrm{eV}$. Note the synmetry of most of the intensity contours about the $\pm 90^{\circ}$ axis.

(XBL 739-1810)

This general behavior indicates that the potential energy surface for the reaction has a "well" or depression vich is accessible to reactants and products. Figure 2 is an electronic state correlation diagram which was constructed by using only experimental facts and ab initio calculations which pertain to reactants, products, and the symmetric intermediate $\mathrm{CH}_{2}{ }^{+}$. The major

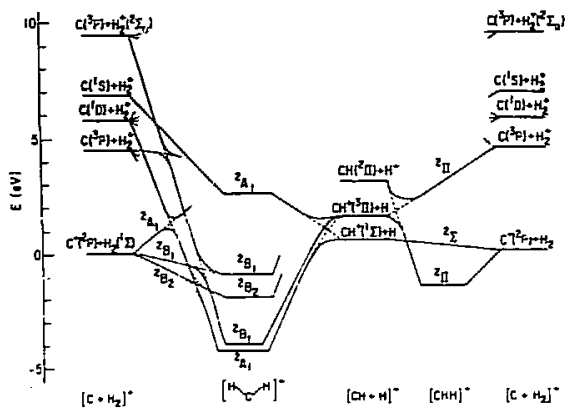

Fig. 2. A correlation diagram for the electronic states of the $\mathrm{CH}_{2}{ }^{+}$system in its linear and isosceles-triangle conformations. At the left, $\mathrm{C}^{+}$approaches $\mathrm{H}_{2}$ along the perpendicular bisector of the bond. At the right, $\mathrm{C}^{+}$approaches $\mathrm{H}_{2}$ collinearly.

Reactant, intermediate, and product electronic states are correlated using the considerations of electronic symatry and molecular orbital configurations. 
qualitative features of this diagram have since been verified by the ab initio selfconsistent field and configiration interaction calculations performed by Schaefer and co-workers. I The correlation diagram shows that the potential energy well which corresponds to symmetric $\mathrm{CH}_{2}^{+}$can be reached from the reactants by collisions in which the $\mathrm{C}^{+}$approaches $\mathrm{H}_{2}$ approximately along the perpendicular bisector of the $\mathrm{H}_{2}$ bond. After strong interaction of all three atoms, the product $\mathrm{CH}^{+}$can be formed either in its ground electronic state $1_{\Sigma}$, or the low-lying in state. Reaction via a path which invulves nearly collinear $\mathrm{CH} \mathrm{H}^{+}$is also possible, and would lead at the higher relative energies to product velocity vector distributions which are asymetric about the $\pm 90^{\circ}$ Iine. Thus the technique of predicting reaction dynamics qualitatively fron correlation diagrams based only on knowr properties of reactants, products, and intermediates is highly successful in this case, and very promising in general.

\section{Abstracted from a paper to appear in J.} Chem. Phys. (LBL-1869).

I. D. H, Liskow, C. F. Bender and H, F. Schaefer, private commication.

4. LARGE ANGLE INEIASTIC SCATTERING OF $\mathrm{Na}^{+}$ $\mathrm{BY} \mathrm{D}_{2}$ *

William L. Drmpfl and Bruce H. Mahan

We have measured the inelasticity of the
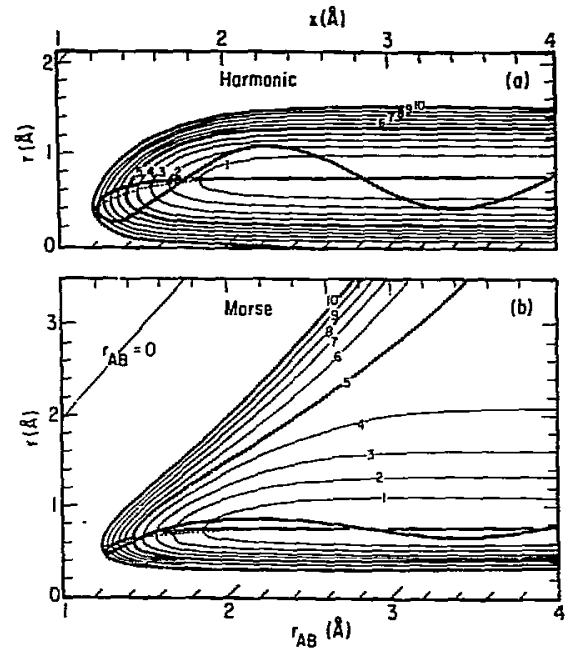
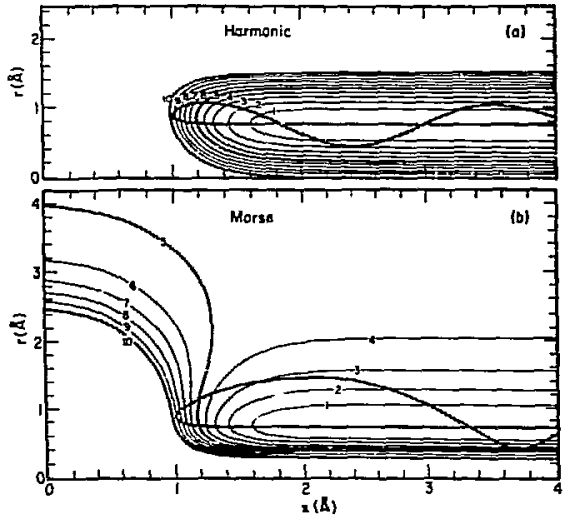

Fig. 2. Exact trajectories for the collisions of $\mathrm{Na}^{+}$with $\mathrm{D}_{2}$ in the $\mathrm{C}_{2 \mathrm{v}}$ conformation at an initial relative energy of $10 \mathrm{eV}$. The ordinate is the $D_{2}$ internuclear separation, and the abscissa is the distance of $\mathrm{Na}^{+}$from the $D_{2}$ ceriter-of-mass. The potential energy contours are labeled in eV. Note that in the Morse oscillator case, the nitial phase of the collision induces an expansion of the oscillator which is not reversed intil the collision partners are well separated. In the harmonic case this contraction occurs sooner, and some of the energy transiently in vibration is transferred back to translation.

(XBL. 7311-5583)

large angle scattering of $\mathrm{Na}^{+}$by $\mathrm{D}_{2}, \mathrm{HD}$, and $\mathrm{H}_{2}$ in the initial relative energy range $0.7-16.9 \mathrm{eV}$. Interpretation of the experimental data and analysis of the mechanics of these collisions using both sirmple models and exact trejectory calculations shows that perpendicular $\left(\mathrm{C}_{2 v}\right)$ rather than collinear conformations of the $\mathrm{Na}^{+}-\mathrm{D}_{2}$ syste. produce the most intense inelastic scattering. Figure 1 shows exalt trajectories for collinear $\mathrm{Na}^{+}-\mathrm{D}_{2}$ collisions calculated assuning an exponential repulsion between

Fig. 1. Exact trajectories for the collinear collisions of $\mathrm{Na}^{+}$with $\mathrm{D}_{2}$ at $10 \mathrm{eV}$ initial relative energy. The potential energy contours are labeled in $\mathrm{eV}$. The ordinate gives the oscillator internuclear separation, while the abscissa gives the separa " $m$ of $\mathrm{Na}^{+}$from the nearest deuterium atoil ${ }_{1 \mathrm{~B}}$ ), or the distance between $\mathrm{Na}^{+}$and the -2 center-of-mass $(x)$.

XBL 7311-5582) 
$\mathrm{Na}^{+}$and the D atoms, and hamonic and Morse potentials for the oscillator. For the more realistic Morse case, the inelasticity $\Delta \mathrm{E}=0.17 \mathrm{eV}$, only a small fraction of the initial relative energy of $10 \mathrm{eV}$. Figure 2 shows that this situation is reversed for collisions in the $C_{2 v}$ conformation. In this case, the inelasticity is $1.6 \mathrm{eV}$ for the hamoric oscillator, and $2.7 \mathrm{eV}$ for the Morse oscillator. Since these perpendicular collisions are both more probable and more inelastic than collinear collisions, it is not surprising that their contribution to the overall energy transfer rate is of greatest inportance.

By fitting the calculated inelastic energy spectrum of $\mathrm{Na}^{+}$to the experimental data at several initial relative energies, we have been able to deduce values for the strength and range parameters of an exponential repulsive potential for the $\mathrm{Na}^{+}-\mathrm{D}_{2}$ system.

Fbstracted from a paper submitted to

J. Chem. Phys. (LBL-2530).

5. DYNAMICS OF THE $\mathrm{N}^{+}-\mathrm{H}_{2}$ REACTION AT LON ENERGIES

James A. Fair and Bruce H. Mahan

We have completed construction of an apparatus which allows us to detemine the velocity vector distributions of the ionic products of ion-molecule reactions carried out with projectile ion energies between 5 and $20 \mathrm{eV}$ in the 1aboratory system. This apparatus thus allows us to extend the range of our collision dynamics experiments to significantly lower energies than has been previously possible in our laboratory.

The initial experiments with this apparatus have been on the reaction $\mathrm{N}^{+}\left(\mathrm{H}_{2}, \mathrm{H}\right) \mathrm{NH}^{+}$. The electronic state correlation diagram for this system shows that there are three potential energy surfaces available to the ground state reactants. One of these surfaces leads via a coniçal intersection to symmetric $\mathrm{NH}_{2}^{+}$in its ${ }_{\mathrm{B}_{1}}$ ground electronic state. This state of $\mathrm{NH}_{2}{ }^{+}$lies $\mathrm{G} \mathrm{eV}$ belov the reactants and products, so one rould expect to observe the symmetric scattering pattem for $\mathrm{NH}^{+}$ which is associated with strongly interacting collision conglex with weak interactions between $\mathrm{NH}^{+}$and the freed $\mathrm{H}$ atom. At relative energies below $1 \mathrm{eV}$, symatric scattering patterns are observed which indicate that at low relative energies, the systen enters the deep potential energy well which corresponds to symmetric $\mathrm{NH}_{2}{ }^{+}$. Attempts are now being made to interpret these results in te the nature of conically intersecting potential energy surfaces.

\section{RESEARCH PLANS FOR CALENDAR YEAR 1974}

Bruce H. Mahan

We will continue to develop our analytical treatment of the sequential inpulse model of chemical reactions in order to be able to apply it to systems with increasingly realistic potential energy surfaces. Our program of relating reaction dynamics to the electronic structure of reactant and products will continue as we complete investigations of the $\mathrm{N}^{+}\left(\mathrm{H}_{2}, \mathrm{H}\right) \mathrm{NH}^{+}$reaction, and undertake studies of the $\mathrm{F}^{+}\left(\mathrm{H}_{2}, \mathrm{H}\right) \mathrm{HF}^{+}$and $\mathrm{Cl}^{+}\left(\mathrm{H}_{2}, \mathrm{H}\right) \mathrm{HCl}^{+}$ reactions. We are also developing a method of obtaining the absorption spectra of polyatomic gaseous ions which, if successful, should greatly expand our understanding of the electronic properties and geometric structure of gaseous ions.

\section{1973 PUBLICATIONS AND REPORTS}

Bruce H. Mahan and Associates

Journals

1. K. T. Gillen, B. H. Mahan, and J. S. Winn, Dymamics of the $\mathrm{O}^{+}-\mathrm{H}_{2}$ Reaction I, Reactive Scattering of $0^{+}\left({ }^{4} \mathrm{~S}_{3 / 2}\right)$ at Relative Energies below $15 \mathrm{eV}, \mathrm{J}$. Chem. Phys. 58, 5373 (1973) (LBL-1429).

2. K. T. Gillen, B. H. Mahan, and J. S. Winn, Impulsive Inelastic Scattering of $\mathrm{O}^{+}\left({ }^{4} \mathrm{~S}\right)$ by Isotopic Hydrogen Molecules, Chem. Phys. Letters 22, 344 (1973) (LBL-1850).

3. B. H. Mahan and T. M. Sioane, Dynamics of the $\mathrm{C}^{+}-\mathrm{H}_{2}$ Reaction, J. Onem. Phys. 59, 5661 (1973) (LBL-1869).

4. K. T. Gillen, B. H. Mahan, and J. S, Winn, Dynamics of the $\mathrm{O}^{+}-\mathrm{H}_{2}$ Reaction. II:

Reactive and Nonreactive Scattering of $\mathrm{O}^{+}\left({ }^{4} \mathrm{~S}_{5 / 2}\right)$ at Relative Energies Above $13 \mathrm{eV}$, $\mathrm{J}$. Chem. Pnys. 59, 6380 (1973) (LBL-1886).

\section{Paper presented}

B. H. Mahan, "Hyperthemel Inelastic Collisions," Gordon Research Conference on Energy Transfer, July 1973. 


\section{LBL reports}

1. John S. Winn, A Beam Study of $\mathrm{Ne}^{+}$and $0^{+}\left({ }^{4} S_{3 / 2}\right)$ Scattering by Molecular Hydrogen Isotopes and Helium (Ph.D. thesis), LBL-1820, June 1973.

2. William Lawrence Dimpfl, The Dynamics of Nonreactive Inelastic Ion-Molecule Collisions (Ph.D. thesis), LBL-1873, Aug. 1973.
3. K. T. Gillen, B. H. Mahan, and J. S. Hinn, Dynamics of the $\mathrm{O}^{+}-\mathrm{H}_{2}$ Reaction. II:

Reactive and Nonreactive Scattering of $0^{+}\left({ }^{4} S_{3 / 2}\right)$ at Relative Energies Above $13 \mathrm{eV}$, J. Chem. Phys., in press (LBL-1886, Sept. 1973). 
Willian B. Miller, Principal Investigator

1. MPROVED CLASSICAL PATH APPROXMNATION FOR THE BOLTZMANN DENSITY MATRIX*

William H. Mfiller

A semiclassical approximation 'for the Boltmarn dersity matrix has been developed which is easily applicable and inclutes a large fraction of quantum effects nonperturbatively. The equilibrium density $p\left(q_{1}\right)$, for example,

$$
\left.\rho\left(q_{1}\right) \equiv\left(q_{1}\right) e^{-8 H_{1}} \mid q_{1}\right),
$$

is given within this model by

$\rho\left(\mathrm{q}_{1}\right)=h^{-N} \int \Phi_{1} \exp \left[-\frac{2}{5} f^{(1 / 2)^{H B}} d \tau H(\tau)\right]$,

where

$$
H(\tau)=H[\underset{\sim}{p}(\tau), \underset{\sim}{q}(\tau)]
$$

is the Hamiltonian for the system of $N$ degree of freedom:

$H[p, q)=\sum_{i=1}^{N} p_{i}^{2} / 2 m_{i}+v(q) ;$

the "trajectory" $\mathrm{g}(\tau), \mathrm{g}(\tau) \equiv \mathrm{q}^{\prime}(\tau) / \mathrm{m}$ is determined by the classical-like equations of motion (note the sign change)

$$
m_{i} \ddot{q}_{i}(\tau)=+\frac{\partial v(q)}{\partial q_{i}},
$$

with intial conditions

$$
\begin{aligned}
& q(0)=q_{1} \\
& q_{i}(0)=p_{i} / m_{i} .
\end{aligned}
$$

In the high-temperature $1 \mathrm{imit}(\beta+\infty)$ it is easy to see that Eq. (1) becomes the standard classical expression

$\rho\left(q_{1}\right)=h^{-N} \int q_{1} \exp \left[-\beta H\left(p_{1}, q_{1}\right)\right]$.

If $\mathrm{Eq}$. (1) is expanded in powers of $h$, one can show that the first quantum correction is given exactly correctly by Eq. (1); in applications, of course, one would not wish to make such an expansion, however, since the classical path approximation contains a large fraction of the quantum effects to infinite order in $h$.

Abstracted from J. Chen. Phys. 58, 1664 (1973).

2. POTENTIAL CURVES AND INEIASTIC CROSS SECTIONS FOR LOW-ENERGY COLIISIONS OF $\mathrm{O}^{+}$ AND He*

Strast D. Augustin, William H. Miller, Peter K. Pearson, and Henry F. Schaefer

Potential curves corresponding to all the valence states of $\mathrm{HeO}^{+}$have been calculated by configuration interaction and are shown in Fig. 1. The principal inelastic process in low-energy collisions of ground state He and $\mathrm{O}^{+}$is seen to be

$$
\mathrm{He}+\mathrm{O}^{+}\left({ }^{4} \mathrm{~S}\right)+\mathrm{He}+\mathrm{O}^{+}\left({ }^{2} \mathrm{D}\right),
$$

the transition arising from a spin-orbit interaction of the lowest ${ }^{4} \mathrm{~L}$ and $\mathrm{Z}$ states of $\mathrm{HeO}^{+}$. Other observations that one can make from Fig. 1 are that (I) the ${ }^{D}$ state of $\mathrm{O}^{+}$will be readily quenched by collisions with $\mathrm{He}$, but not the ${ }_{2} \mathrm{p}$ state; (2) low-energy collisions of $\mathrm{He}^{+}$with ground state oxygen atoms will lead to charge transfer exclusively into the ${ }^{2} \mathrm{P}$ state of $\mathrm{O}^{+}$:

$$
\mathrm{He}^{+}+O\left(^{3} \mathrm{P}\right)+\mathrm{He}+\mathrm{O}^{+}\left(C^{2} \mathrm{P}\right) \text {; }
$$

(3) the ${ }^{1} D$ state of 0 should be readily de-activated by $\mathrm{He}^{+}$:

$$
\mathrm{He}^{+}+\mathrm{O}\left({ }^{1} \mathrm{D}\right)+\mathrm{He}^{+}+\mathrm{O}\left({ }^{3} \mathrm{P}\right) \text {; }
$$

and (4) the ${ }^{1} \mathrm{~S}$ state of 0 should be quenched by $\mathrm{He}^{+}$only via charge transfer into the $4 \mathrm{p}$ state of $0^{+}$(of the valence-excited configuration $2 s_{2} p^{4}$ j:

$$
\left.\mathrm{He}^{+}+\mathrm{O}^{1} \mathrm{~S}\right) \rightarrow \mathrm{He}+\mathrm{O}^{+}(\mathrm{P}) .
$$

The spin-orbit interaction causing the transition in Eq. (1) was determined and tise cross section calculated seniclassically; this is shown in Fig. 2. 


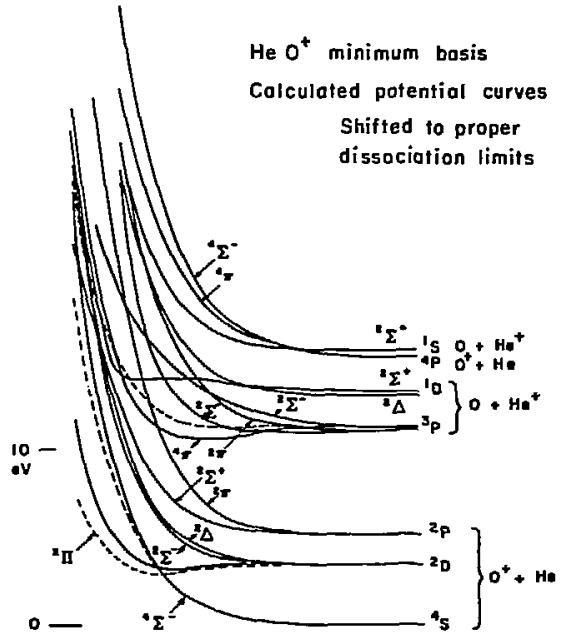

Fig. 1. Potential arres arising from the valence states of $\mathrm{He}$ and $\mathrm{O}^{+}$, and $\mathrm{He}^{+}$and $\mathrm{O}$, shifted vertically to match the known atomic energy levels at infinite separation.

(XBL 7210-4234)

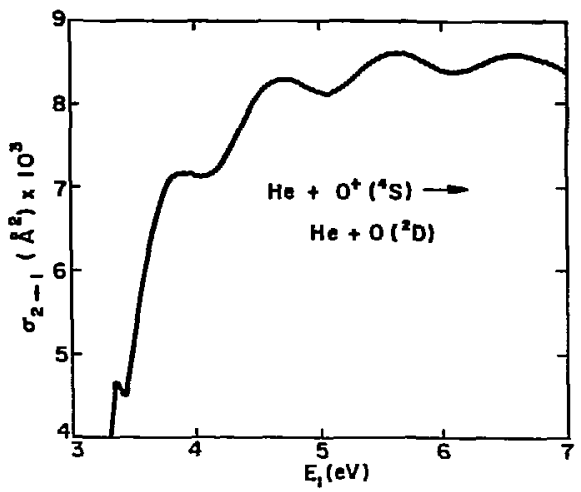

Fig. 2. The inelastic cross section for $\mathrm{He}+\mathrm{O}^{+}\left({ }^{4} \mathrm{~S}\right) \rightarrow \mathrm{He}+\mathrm{O}^{+}\left({ }^{2} \mathrm{D}\right)$, as a function of initial collision energy.

(XBL 7210-4233)
3. PARTLAL AVERAGING IN CIASSICAL S-MATRTX THEORY: VIBRATIONAL EXCITATION OF H, BY He*

\section{William H. Miller and Andrew W. Raczkowski}

Within the framework of a general semiclassical theory that combines exact classical dymanics with the quantum principle of superposition it is shown how a certain averaging procedire allows one to treat some degrees of freedom in a cormletely classical sense while others are quantized semiclassically. This enormously singlifies the application of the theory to threedimensional collision systems and also has an interesting formal structure: the quantum-like degrees of freedom are quantized semiclassically via use of double-ended boundary conditions, while the unquantized classical-like degrees of freedom enter only through a phase space average over their initial coordinates and momenta. Many of the aspects of the theory can thus be carried out in the same manner as standard classical trajectory calculations.

In practice, only the vibrational degrees of freedom need be quantized semiclassically, there typically being enough rotational states involved for their distribution to be treated completely classically. Figure 1 shows our preliminary results for vibrational excitation of $\mathrm{H}_{2}$ by helium:

$\mathrm{He}+\mathrm{H}_{2}\left(\mathrm{n}_{1}=0, j_{1}=0\right)+\mathrm{He}+\mathrm{H}_{2}\left(\mathrm{n}_{2}=1\right.$, all $\left.j_{2}\right)$,

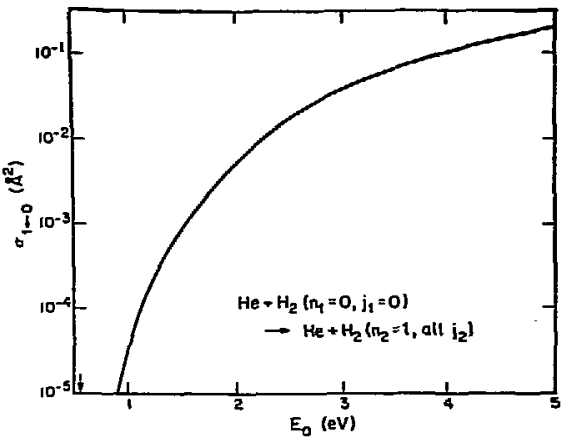

Fig. 1. The cross section for exc ation of $\mathrm{H}_{2}$ (by collision with $\mathrm{He}$ ) from its ground state $\left(n_{1}=j_{1}=0\right)$ to its first excited vibrational state $\left(n_{2}=1\right)$, sumbed over all final rotational states, as a function of initial collision energy. (XBL 7312-7113) 
where $n$ and $j$ denote the vibrational and rotational state of $\mathrm{H}_{2}$. Over this entire energy region the vibrational excitation is "classically forbidden" so that complexvalued classical trajectories ${ }^{2}$ are required to describe it. Figure 2 shows the distribution of final rotational states for the transition at a collision energy of $3 \mathrm{eV}$; although $j_{2}=0$ is the most probable final rotational state, it is seen that there is considerable rotational excitation which accompanies the $0+1$ vibrational transition.

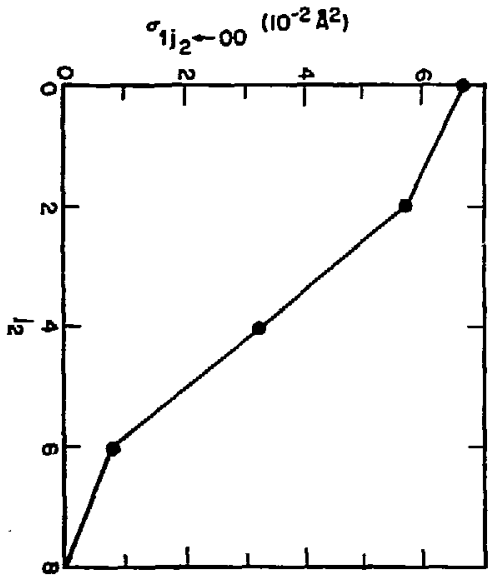

Fig. 2. The distribution of final rotation states $j_{2}$ accompanying the $0+1$ vibrational excitation in $\mathrm{He}+\mathrm{H}_{2}$ collisions, for an initial collision energy of $3 \mathrm{ev}$.

(XBL 7312-7114)

Abstracted from Faraday Disc. Chem. Soc. 55, 45 (1973).

1. W. H. Miller, J. Chenn. Phys, 53, 1949 (1970).

2. W. H. Afiller and T. F. George, J. Chen. Phys. 50, 5668 (1972).

4. PENING AND ASSOCIATIVE IONIZATION OF TRIPLET METASTABLE HELTIM ATOMS ${ }^{\dagger}$

Barbara J. Garrison, William H. Miller, and Henry F. Schaefer

The triplet metastable state of helium,
$1 s 2 s^{3} s$, is an important constituent of the helium afterglow; it is through Penning ionization by helium metastables that ions of other species are produced.

$$
H e^{\star}+X+H e+X^{+}+e^{-} \text {. }
$$

At sufficiently high concentrations the self* destruction of the triplet metastable--

$$
\begin{aligned}
\mathrm{He}^{*}+\mathrm{He}^{*} & +\mathrm{He}+\mathrm{He}^{+}+\mathrm{e}^{-} \\
& -\mathrm{He}_{2}^{+}+\mathrm{e}^{-}
\end{aligned}
$$

--becomes significant and is an important mechanism for loss of metastables as well as source of the atomic and molecular ions $\mathrm{He}^{+}$ and $\mathrm{He}_{2}{ }^{+}$.

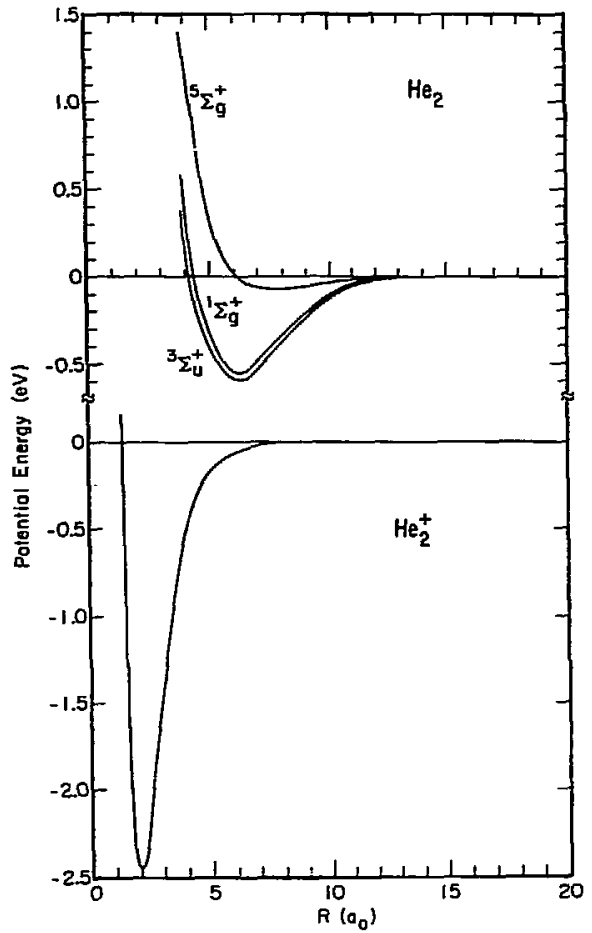

Fig. 1. Potencial energy curves for the ground state of $\mathrm{He}_{2}{ }^{+}$and the states of $\mathrm{Hi}_{2}$ which arise from two $1 \mathrm{szs}^{3} \mathrm{~S}$ atomic states.

[XBL 735-6092] 
Potential energy arres for the $\mathrm{I}_{\mathrm{g}}{ }^{+}$, $3_{\Sigma_{i}}{ }^{+}$, and $5_{\Sigma_{g}}{ }^{+}$states which arise from two triplet metastable helium atoms have been calculated by a large configuration interaction expansion and are shown in Fig. 1. Erom the potential curves for the $\mathrm{I}_{\mathrm{g}}{ }^{+}$and $\mathrm{z}_{\mathrm{u}}{ }^{+}$autoionizing states, cross sections for Penning and associative ionization have been calculated; the results are shown in Fig. 2 .

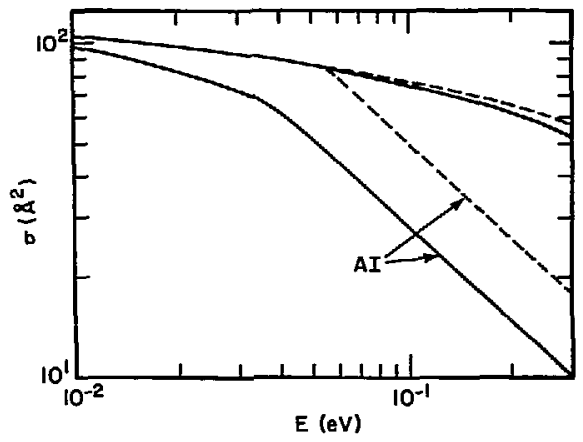

Fig. 2. The total ionization cross section (top curves) for the collision of two triplet metastable helium atoms, and the component of which leads to $\mathrm{He}_{2}^{+}$(lower curves labeled AI), as a function of the relative collision energy. The dashed curves are the results given by the orbiting mode1.

(XBL 735-6081)

In this 10w-energy region the orbiting mode1 is adequate for determining the total ionization cross section but not the partitioning between associated and dissociated product ions.

(A11 work partially funded by NSF.)

\footnotetext{
Abstracted from J. Chem. Phys. 59, 3193 (1973).
}

\section{RESEARCH PLANS FOR CALENDAR YEAR 1974}

William H. Miller

One area for which our semiclassical collision theory makes a particularly significant contribution is the description of vibrational excitation on three-dimensional collision systems. Vibrational transitions are often too weak for a completely classical treatment to be meaningful, but the large number of rotational states which exist precludes an accurate quantum mechanical calculation. The situation is thus ideal for the partial averaging approach (see item No. 3), and we plan to pursue its application to at least a few different physical systems.

Classical S-matrix theory also makes it possible to study--without introducing any dynanical approximations--tumeling in chemical reactions with activation barriers. Since completely classical calculations are wually adequate for reactions without acrivation barriers, the inability to treat reactions with activation barriers is the principal gap in the theory of thermal energy kinetics. In light of these dynamically exact calculations it should also be possible to develop sinmle models which contain the essential features of the exact description.

Another large class of collision phenomena that we are actively engaged in involve electranic transitions in molecular collisions. As a prototype of the finestructure transitions in $F$ atoms which can take place in the reaction

$$
\mathbf{F}+\mathrm{H}_{2} \rightarrow \mathrm{FH}+\mathrm{H},
$$

we are looking at fine-structure transitions in F caused by collisions with rare gas atoms, e.g.,

$$
F\left({ }^{2} P_{1 / 2}\right)+X_{e}+F\left({ }^{2} P_{3 / 2}\right)+X_{e} .
$$

Semiclassical scattering theory provides an excellent description of these processes.

Preliminary work has also begun on unimolecular reactions with the idea of exploring the relation between statistical and dynamical theories of these processes.

\section{1973 PUBLICATIONS AND REPORTS}

Willian H. Miller and Associates

\section{Journals}

1. J. D. Doll, T. F. George, and W. H. Miller, Complex-Valued Classical Trajectories for Reactive Tunneling in Three-Dimensional Collisions of $\mathrm{H}$ and $\mathrm{H}_{2}, J$. Chem. Phys. 58, 1343 (1973) (LBL-1153).

2. W. H. Miller, Improved $\mathrm{Cl}_{2}=5$, 1 Path Approximation for the Boltzmans: D:usity Matrix, J. Chem. Phys. 58, 1664 (1973) (LBL-1122). 
3. S. A. Augustin, W. H. Miller, P. K. Pearson, and H. F. Schaefer, Potential Curves and Inelastic Cross Sections for Low Energy Collisions of $0^{+}$and $\mathrm{He}, \mathrm{J}$. Chem. Phys. 58, 2845 (1973) (LBL-1187).

4. W. H. Miller and A. W. Raczkowski, Partial Averaging in Classical S-Matrix Theory; Vibrational Excitation of $\mathrm{H}_{2}$ by $\mathrm{He}$, Faraday Disc. Chem. Soc. 55, 45 (1973) (LBL-1427) .

5. B. J. Garrison, W. H. Miller, and H. F. Schaefer, Penning and Associative Ionization of Triplet Metastable Helium Atoms, J. Chem. Phys. 59, 3193 (1973) (LBL-1825).

\section{Chapters in books}

1. T. F. Ceorge and W. H. Miller, Classically Forbidden Collision Processes, in Energy, Structure, and Reactivity, edited by D. W. Snith and W. B. Bckae (Hiley, New York, 1973), p. 76 (LBL-2273).

2. W. H. Miller, Semiclassical Methods in Reactive and Non-Reactive Collisions, in The Physics of Electronic and Atomic collisions (onvited papers of the VIIth Intemational Conference on the Physics of Electronic and Atomic Collisions, Belgrade], 1973 (LBL-1839).

\section{Papers presented}

1. W. H. Miller, The Classical S-Matrix for Molecular Collisions, Symposium on Topics in Inelastic and Reactive Molecular Collisions, Weizmam Institute of Science, Rehovot, August 21, 1973.

2. W. H. Miller, lecturer on Seniclassical Scattering Theory, German Sumer School on the Theory of Atomic and Molecular Collisions, Gars am Inn, Federal Republic of Germany, September 2-15, 1973.

LBL reports

1. W. H. Miller, Classical-Limit Quantum Mechanics and the Theory of Molecular Collisions, March 1973 (to appear in Advances in Chemical Physics).

2. W. H. Miller, The Classical S-Matrix in Molecular Coliisicns, IBL-2521 (to appear in Advances in Molecular Beans), December, 1973. 
Rollie J. Myers, Principal Inveatigator

1. MOLECILAR FIEUD EFFECTS IN ELECTRON PARAMAGNETIC RESONANCE SPECTROSOOPY

NA hael R. St. Jolm and Rollie J. Myers

The molecular field nodel has been very successful in explaining the bulk magnetic properties of many solids. In our work we have applied it to the situation of an ion substituted into a host lattice. In this way we have been able to determine values for the electron exchange interaction between the host and substituted ions.

One host lattice has been the tetragonal form of $\mathrm{NiSeO}_{4} \cdot 6 \mathrm{H}_{2} \mathrm{O}$, and we have substituted $\mathrm{Cu}^{2+}, \mathrm{CO}^{2+}$, and $\mathrm{Mn}^{2+}$ into a few of the sites occupied by $\mathrm{Ni}\left(\mathrm{H}_{2} \mathrm{O}\right) 6^{2+}$. At $1 \cdot 3^{\mathrm{a}} \mathrm{K}$ the EPR spectra of the substituted ions are shifted by ${ }_{2}$ the interactions with the surrounding $\mathrm{Ni}^{2}$. The molecular field model allows us to account for most of this shift by exchange interaction with the four nearest neighbor $\mathrm{Ni}^{2+}$. We assime an isotropic exchange interaction of the form

$$
H(\text { exch. })=-2 J \bar{S}(\mathrm{Ni}) \cdot \overline{\mathrm{S}}(\mathbf{X}) \text {. }
$$

The field shifts can be measured in terms of altered $\mathrm{g}$ values. The corrected $\mathrm{g}$ values are expected to be close to those in the di magretic $\mathrm{ZnSeO} \cdot 6 \mathrm{H}_{2} \mathrm{O}$. Table I shows the effect of the corrections and the $J$ value obtained for each in.

One can see that as the substituted ion has more unfilled $t_{2} g$ orbitals the net exchange interaction with $\mathrm{Ni}^{2+}$ decreases. For $\mathrm{Mn}^{2+}$ one has three unfilied $\mathrm{t}_{2 \mathrm{~g}}$ orbitals which exactly cancels the two unfilled $e_{g}$ orbitals. In the host lattice all of these interactions occur through water hydrates.

Experiments have also been done in other hosts. In $\mathrm{Ni}\left(\mathrm{BrO}_{3}\right)_{2} \cdot 6 \mathrm{H}_{2} \mathrm{O}$ the zero-field splittings of the $\mathrm{Ni}\left(\mathrm{H}_{2} \mathrm{O}\right)_{6}{ }^{2+}$ are small and its molecular field would be expected to have large fluctuations even at $1.3^{\circ} \mathrm{K}$. No spectra can be observed for $\mathrm{Cu}^{2+}$ doped into this lattice from 1.3 to $300^{\circ} \mathrm{K}$. For $\mathrm{Co}\left(\mathrm{TrO}_{3}\right)_{2} \cdot 6 \mathrm{H}_{2} \mathrm{O}$ the very short spin-1atifice relaxation times expected for $\mathrm{Co}\left(\mathrm{H}_{2} \mathrm{O}\right)_{6}{ }^{2}$ at higher temperatures could lead to a narrowing of the line width of a substiturted ion. At room temperature a spectrum can be observed for $\mathrm{Cu}^{2+}$ in this lattice, but at $77^{\circ} \mathrm{K}$ it is broadened away. This is in agreement with the expected effect of temperatime on the host $\mathrm{Co}^{2+}$ spin-lattice relaxation.

\section{ELECTRON SPIN RELAXATION FOR Ou(NH3) $6^{2+}$ IN LIQUID AMWONIA}

Richard C. Hilson and Rollie J. Myers

A very careful line width study has been made ${ }^{1}$ for $\mathrm{Cu}\left(\mathrm{H}_{2} \mathrm{O}\right)_{6}{ }^{2+}$ in aqueous solution. Despite unresolved hyperfine splittings from $\mathrm{Cu}$, we were able to make accurate line width measurements for each hyperfine component over a wide range of termeratures.

Table I. Molecular field results.

\begin{tabular}{|c|c|c|c|c|c|c|c|}
\hline \multirow[t]{2}{*}{ In } & \multicolumn{3}{|c|}{$\mathrm{g}_{0}$ values } & \multicolumn{3}{|c|}{$g_{1}$ values } & \multirow{2}{*}{$\frac{\text { Exchange }}{\left(\mathrm{J}-\mathrm{cm}^{-1}\right)}$} \\
\hline & Para. $^{\mathrm{a}}$ & Corr. ${ }^{b}$ & Dia. C & Para. ${ }^{a}$ & Corr. ${ }^{\mathbf{b}}$ & Dia. ${ }^{c}$ & \\
\hline $\mathrm{Cu}^{2+}$ & 2.901 & 2.431 & 2.430 & 2.482 & 2.091 & 2.097 & 0.083 \\
\hline $\mathrm{Co}^{2+}$ & 6.46 & 6.02 & 5.99 & 3.36 & 3.18 & 3.26 & 0.055 \\
\hline $\mathrm{Mr}^{2+}$ & - & - & 2.002 & 2.003 & - & 2.007 & 0.00 \\
\hline \multicolumn{8}{|c|}{$\begin{array}{l}\text { (a) In } \mathrm{NiSeO}_{4} \cdot 6 \mathrm{H}_{2} \mathrm{O} \text { or } \mathrm{NiSO}_{4} \cdot 6 \mathrm{H}_{2} \mathrm{O} \text {. } \\
\text { (b) Corrected for molecular field. } \\
\text { (c) In } 2 \mathrm{nSeO}_{4} \cdot 6 \mathrm{H}_{2} \mathrm{O} \text {. }\end{array}$} \\
\hline
\end{tabular}


However, these data are only approximately fit by the thathing complex theory developed by Kivelson. ${ }^{2}$

An important variable in line width theory is the viscosity of the solvent. Liquid ammonia is much less viscous than water, so that its viscosity near its freezing point is close to water at its boiling point. For this reason we have made a line width stunty of $\mathrm{Cu}^{2+}$ in liquid amonia where the principal species is $\mathrm{Cu}\left(\mathrm{NH}_{3}\right)_{6}{ }^{2+}$.

We have conducted experiments on isotopically pure (99.62t) ${ }^{63} \mathrm{Cu}$ in liquid ammonia from room temperature down to the freezing point $\left(-77.7^{\circ} \mathrm{C}\right)$. The data was digitized and a least squares fit of four lorentz lines to the data yielded the spectral parameters and the lize widths of the hyperfine lines. Spectra were also taken of a frozen glass composed of equal parts of amronia and tetrahydrofuran. The values of the principal values of the $g$ and $A$ tensors obtained from the glass spectrum were $g_{1}=2.23, g_{1}=2.04, A_{0}=170 \times 10^{-4} \mathrm{~cm}^{-1}$, and $A_{1}=5 \times 10^{-4} \frac{1}{c i n}-1$.

A qualitative comparison of the water and of the ammonia line widths shows that the high-temperature broadening mechanism which is coly partly developed in water is fully developed in ammonia. This broadening is shown in Fig. 1, and it becomes a linear function of temperature over viscosity. This is in agreement with spin-rotation interaction. ${ }^{3}$ In water solutions most of the ine width is due to a combination of

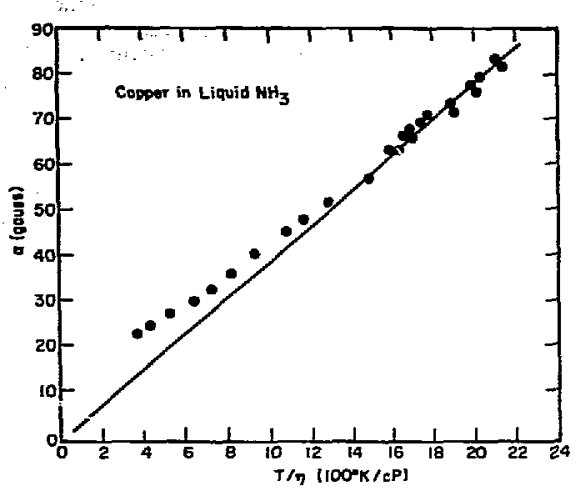

Fig. 1. Shows how the broadening in ammonial appioaches a linear function of termerature/ viscosity.

(XBL 741-5451) at least two terms. The high-temperature term is explained by the ammonia data, but the second term camnot be explained by the usual $^{2}$ theory. The most likely mechanism involves a dynamic Jahn-Teller distortion with a correlation time smaller than that of tumbling. Since an accurate theory has not yet been developed for this mechanism, we shall combine the water and amonia results to establish the inportant parameters.

I. J. J. Chang (Eh.D. thesis) UCRL-19691. 2. R. Wilson and D. Kivelson, J. Chem. Phys. 44,154 (1966).

3. R. Atkins and D. Kivelson, J. Chem. Phys. 44, 169 (7966).

\section{ELECTRON SPIN REIAXATION FOR Ni $\left(\mathrm{H}_{2} \mathrm{O}\right)_{6}{ }^{2+}$ IN SOLUTION}

Thomas $M$. Hynes and Rollie J. Myers

Our work on proton spin relaxation in water solutions of $\mathrm{Ni}^{2+}$ has been extended to include measurements at $220 \mathrm{MHz}$. When these high-field measurements are combined with last year's work at 100 and $60 \mathrm{MHz}$, we have a broad set of data taken over wide ranges of field and temperature. In acidified solutions the principal mechanism for proton spin relaxation in these solutions is die to the spin-1attice relaxation of the $\mathrm{Ni}\left(\mathrm{H}_{2} \mathrm{O}_{6}{ }^{2+}\right.$. In this way we have been able to measure the very short electron spin relaxation time of $\mathrm{Ni}^{2+}$ in aqueous solution. This relaxation is so fast that no electron spin absorption can be directly measured.

The general theory of spin relaxation predicts that spin-1attice relaxation times must pass through a minimum when the Larmor frequency becomes nearly equal to the inverse of the correlation time of the relaxation, or when

$$
w \approx 1 / \tau_{c} .
$$

This is a very general relation which has been found to apply to the previous spin systems yhich have been studied. For $\mathrm{Ni}\left(\mathrm{H}_{2} \mathrm{O}\right)_{6}{ }^{2^{+}}$in solution we find that there is no minimur value in its spin-lattice relaxation, and so this general relation seems to be violated.

This system has the extreme condition in that the electron spin-lattice relaxation time is close to the inverse of the Larmor 
frequency when the correlation time is also this small. This condition seens to fall outside of the assumptions of the usual theory, but it is not clear that it should allow the prediction of a minimum in the spin-lattice relaxation time to disappear $z+$ Another special circinstance for $\mathrm{Ni}\left(\mathrm{H}_{2} \mathrm{O}\right)_{6}{ }^{2+}$ is that the principal mechanism for electron spin-lattice relaxation involves thermal modulation of the zero-field splitting. 1 This modulation may not follow the simple exponential decay associated with randon thermal motions such as that found for rotational diffusion. It seems likely that either the failure of perturbation theory (strong interactions) or of the usual randan fluctuation theory is responsible for the observed absence of a minimm in the spinlattice relaxation time of $\mathrm{Ni}\left(\mathrm{H}_{2} \mathrm{O}_{6}{ }_{6}{ }^{2+}\right.$.

1. N. Bloembergen and L. 0. Korgan, J. Chem. Phys. 34, 842 (1961).

\section{EIECTRON-ELECTRON DOUBLE RESONANCE FOR TWO} RADICAIS IN SOLUTION

\section{Joyce T. Yamel1 and Rollie J. Myers}

In a double resorance experiment a signal is stored in one set of energy levels and its transmission to a second set is analyzed. The first electron-electron double resonance experiments 1 used a single radical species and analyzed the transfer of signal from one set of nuclear hyperfine levels to another. At low concentrations this transfer was purely intrumolecular, and at high concentrations it became daminated by intermolecular exchange interaction betwee molecules.

We have built an electron-electron double resonance apparatus which has been previously described. 2 Two free radicals are placed in a solution and the frequencies of a bimodal cavity and the magnetic field are adjusted so that high microwave power is absotbed by one radical while the spectrum of the other is being observed. Any signal transferred from one radical to the other must be due to interactions between the two in solution. This interaction can either be due to intermolecular dipole-dipole interaction or to electrun-electron exchange. For two identical species the latter is presurned to dominate, but for two different species either could be important. One advantage of the double resonance technique is that the sign of the spectrum change can be used to differentiate between the two interactions.
In Fig. 1 we show a double resonance result. The dotted spectrum is a reference and the solid spectrum shows the effect of 2.5 watts of power at the proper frequency to be absorbed by one radical while the spectrum of the other is being observed. The radical absorbing the high power is a nitroxide radical and the racical whose signal is decreased is called Galvinoxyl free radical. Since power absorbed by ore radical caused a decrease in the signal of the other, the primaiy interaction between the two is electron-electron exchange.

In the near future we would like to examine the concentration dependence of this effect to establish the relative inportance of dipole-dipole and exchange interaction in greater detail.

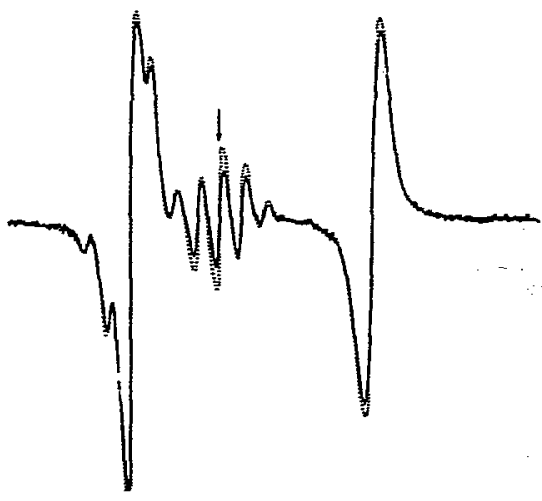

Fig. 1. A double resonance result. Near the arrow in the spectrum there is a large percentage decrease in signal over the dotted reference spectrum. The small percentage decrease shown for the large signals is due to thermal effects caused by the 2.5 watts of additional microwave power used during the solid spectrum. Double resonance can only occur over a narrow region of the sweeping maknetic field, and it is selected by the fixed difference in the two microwave frequencies.

(CBL 741-5450)
1. J. S. Hyde, J. C. W. Chien, and J. H. Freed, J. Chem. Phys. 48, 4211 (1968). 2. J. T. Yamell and R. J. Myers, MPD Anmual Report for 1971, LBL-425, April 1972. 
5. ELECTRON PARAMAGNTIC RESONANCE SPECTRA OF RADICAL ANIONS IN LIQUTD AMADNLA

James H. Hammons and Rollie J. Myers

The special properties of liquid anmonia ${ }^{1}$ make it a unique solvent for a muber of chemical systems. These properties led us a few years ago ${ }^{2}$ to develop a system for the production of anion-radicals in liquid amminia directly in the cavity of an electron paramagnetic resonance spectrometer. At that time our primary attention was drawn to the racical anions of substituted 1,3 butadiene and pyridine.

A preliminary investigation was also made on cyclooctatetraene (COT). We found that it was easily reduced in ammonia and that, uilike other solvents, the dianion had littie stability. A number of substituted COT compounds were available to $u^{3}$ and so we decided to extend our liquid amonia techniques to a sturty of their radical arions. A simple sobstitution on COT radical anion breaks the trofold orbital degeneracy which is associated with nine electrons in the $\pi$-orbitals of a regular eight-membered ring. The ground state of the systen can either correspond to one with-low-odd electron density at the point of substition or to one with high electron density at that point. As a first approximation, the $\pi$-electron density is expected to alternate high and $10 \mathrm{w}$ aromd. the ring. The hyperfine splittings observed in the electron paramagnetic resonance spectrin should always allow us to quantitatively establish the electron distribution. In some cases it might also be pussible to determine the energy of the first excited state from the temperature dependence of the hyperfine splittings.

We.have investigated cor subtituted with: $\mathrm{F}, \mathrm{CH}_{3}, \mathrm{ON}, \mathrm{OCH}_{3}$, cyclopropyl, and with four symmetrical $\mathrm{CH}_{3}$ groups. As expected, the $\mathrm{CN}_{2}$ and $\mathrm{CH}_{3}$ substitutions resulted in groumd states with low and high, respectively, electron densities at the point of substitution. A very careful temperature study was made on several radicals using our accurate least squares fitting method to try to establish the excited-state energy. The data from these experiments are still being reduced and we should be able to determine small deviations from the expected alternation around the ring.

1. H. L. Jolly and C. J. Hallada, UCRL-11254.

2. D. H. Levy and R. J. Myers, J. Chem.

Prys. 41, 1062 (1964).

3.- Supplied by Prof. A. Streitwieser.

\section{RESEARCH PLANS FOR CALENDAR YEAR 1974}

Rollie J. Myers

The molecular field model will continue to be investigated. Since $\mathrm{Mn}^{2+}$ in $\mathrm{NiSeO}_{4} \cdot 6 \mathrm{H}_{2} \mathrm{O}$ has been shown to have so little exchange interaction we will attenpt to utilize an ion such as $\mathrm{V}^{2+}$ which only has half-filled $t_{2 g}$ orbitals. In this way it should be possib1e to map out the exchange interactions between both the $e_{g}$ and $e_{g}$ orbitals and the $e_{g}$ and $t_{2 g}$ orbitalg in this lattice. Eperiments will also be done on interacting pairs of ions. From the interaction parameters of a pair of ions it should be possible to predict the magnetic properties of a bulk sample made up of a regular lattice of interactirig ions.

Our work on electron spin relaxation for $\mathrm{Cu}^{2+}$ in both water and liquid anmonia will be continued. Since it seems likely that a dynanic Jahn-Teller interaction is an important mechanism in both of these solvents, special attention will be paid to experiments which will enable us to determine the rate of Jahn-Teller inversion. Some further work may also be done on spin-1attice relaxation for $\mathrm{Ti}\left(\mathrm{H}_{2} \mathrm{O}\right)_{6}{ }^{2}$. Our previous work has established the inportance of Orbach relaxation for this species, and it is a particularly interesting case for this type of electron spin relaxation.

The electron-electron double resonance data will be analyzed so that the diffusional theory for molecules in solution can be reconciled with the magnitude of the observed double resonance signal. It should be possible to place a lower limit on the size of the exchange interaction between two unlike radicals in solution.

A program will be started on clusters of interacting ions. A mumber of compoumds have been prepared which contain sets of magnetically interacting ions. In solle cases these sets should appear to exhibit what is called superparamagnetism. Work will be done on the small clusters formed in $\mathrm{Fe}^{{ }^{+}}$solutions undergoing hydrolysis. The relation between these clusters and the iron storage protein, ferritin, will be investigated.

\section{1973 PUBLICATION}

Rollie J. Myers and Associates

Book

Rollie J. Myers, Molecular Magnetism and Magnetic Resonance Spectroscopy (Prentice-tail, Inr., Englewood Clifís, N.J., 1973), 244 pp. 
Kerneth S. Fitaer, Prinoipal Invebtigator

\section{SOLUTIONS OF ELECTROLYTES}

Kenneth S. Pitzer, Guillermo D. Mayorga, and Janice J. Kim

The general objective of this program is the prediction of the thermodynamic properties of mixed electrolytes with relatively high accuracy from a minimm number of readily measured parameters. The equations were selected in the light of modem statistical theory in a manner such that each parameter has general physical meaning.

The first paper on this work dealt with the selection of the equations and with tests of their effectiveness for prre solutes and mixtures. In the past year the data on all pure aqueous electrolytes at room temperature were critically reviewed and the constants evaluated by least squares. The results for 227 electrolytes with one or both ions mivalent were presented in Paper II. 1 The equations so determined fit the data substantially within experimental accuracy up to ionic strength of approximately $6 \mathrm{M}$ in most cases. In a few cases the maximm concentration for fill accuracy had to be set lower, and in other cases the data extend only to a lower concentration.

The anomalous behavior of 2-2 electrolytes is discussed in paper II ${ }^{2}$ together with the advantages and disadvantages of treatments assuming association into ion pairs and higher polymers. It is shown that, for thermodynamic purposes, there are many advantages in aroiding the assulption of association, and that by adding one more term to the equations for other types of solutes, one can obtain satisfactory agreement for $2-2$ electrolytes. Parameters are evaluated for the solutes which have been measured and certain special problems are discusssin concerning the accuracy of different calculations.

The principal effort in the las: : months has been directed toward mixed ele: . siytes. The available data haye been evaluaces. We find that it is possibie to predict the properties of dilute solutions of mixed electrolytes with good accuracy from the parameters for the pure electrolytes. In most cases miving terms were found not to be exactly zero (i,e., Bronsted's principle does not hold exactly), but their effect at $I \mathrm{M}$ is only a few percent in either osmotic or activity coeffi ient. At higher concentration the effect of mixing terms is proportionately greater. The mixing parameters measure the difference between the short-range interaction of unlike ions of the same sign from the appropriate average of this interaction for like ions. We are studying these results in the hope of drawing thecretical conclusions and developing means for estivlating mixing parameters in cases where no measurements exist.

1. K. S. Pitzer and G. D. Mayorga, J. Phys. Chem. 77, 2300 (1973).

2. K. ك. Pitzer and G. D. Mayorga, LBL-2282, Oct. 1973.

2. NUCLEAR SPIN SPECIES EFFECTS IN THE HEAT CAPACITY OF $\mathrm{CH}_{4}$

Ŝrald J. Vogt and Kenneth S. Pitzer

The interconversion of maclear spin species in $\mathrm{CH}_{4}$ for $\mathrm{T}<15^{\circ} \mathrm{K}$ will lead to a non-lattice contribution to the heat cepacity, if the rate of interconversion is sufficiently rapid. The rate of interconversion can be experimentally increased by doping a $\mathrm{CH}_{4}$ lattice with a paramagnetic conversion catalyst such as $\mathrm{O}_{2}$. Recent NR meastrements show that the rate of interconversion increases approximately in pioportion to the $\mathrm{O}_{2}$ concentration $(\leqslant 1$ mole $\xi$ ) of the sample.

Measurements of the heat capacity of pure $\mathrm{CH}_{4} \quad \mathrm{O}_{2}$ free) for $\mathrm{T}<30^{\circ} \mathrm{K}$ are being made in search for a possible spin species contribution. Soon, the experiments will begin a new phase by measuring the heat cepacity of $\mathrm{O}_{2}$-doped $\mathrm{OH}_{4}$ in $\mathrm{O}_{2}$ concentrations from 0.1 to 1 mole \&. Hopefully, the series of experiments will shed light on the extent of interconversion in pure $\mathrm{CH}_{4}$ as well as the effects of $\mathrm{O}_{2}$ doping.

\section{ANONALOUS INTERKiAL, MOTIONS IN MOLEOULES}

Lawrenze S. Bermstein and Femeth S. Pitzer

Certain molecules have, in addition to several normal vibrations of small amplitude, one or more modes of motion with smali restoring force and large amplitude.

Intemal rotations about single bonds fall into this categcry but are now well understood. In addition there are other largeamplitude motions which seem anomalous in mlecular structure determinations. 
A general treatment of large anqiitude, multidinensional motion has been developed and applied to the following classes of molecules: $\mathrm{MO}_{3}, \mathrm{MO}_{5}, \mathrm{MX}_{6}, \mathrm{MD}_{7}$, fourmenbered rings, and five-membered rings. The theory predicts both the form of the potential governing the motion and a quantitative estimation of the potential from a knowledge of several experimentally observed paraneters. These parameters are the force constants for the normal mode involved, the geometry of the molecule in the potential minimm, and the separation of the ground electronic state from the particular excited electronic states which are coupled via the inversion coordinates. The availability of these molecular parameters for most molecules lends a large measure of practicality to this approach, since it removes the need for detailed spactroscopic measurement of a large number of inversion levels.

As a test the theory was applied to a well-studied system-- $\mathrm{NH}_{3}$. Energy levels here calculated from the derived potential by a basis set expansion. The results were close to those of a five-parameter potential, fit to fourteen energy levels. Other knowl systems were al o tested and in all cases close quartitat. 'e agreement with the empirical potential was obtained.

This method has been applied to some unusual molecules, the most conspicumus being $\mathrm{XeF}_{6}$. Theory predicts a potential for three coordinates in $X_{e} F_{6}$ hich may be transformed to the equivalent of a vibrating diatomic molecule undergoing a slightly hiidered rotation. This almost free two-dimensional pseudorotation introconverts $\mathrm{XeF}_{6}$ through many different configurations, a situation which parallels the first documented pseudorotator-cyclopentane. The potential is being refined to yield quantitative agreement with the experimental entropy and the electron diffraction radial distribution aurve. Furthermore, the potential accounts for unusual features found in the infrared and Raman experiments and is also in accord with the results of electric field deflection experiments.

\section{RESEARCH PLANS FOR CALENDMR YEAR 1974}

Kenneth S. Pitzer

\section{a. Solutions of Electrolytes}

The work on the osmotic and activity cofficients of nixed electrolytes $3 t$ room teryerame will be completed. Then we will direct our efforts toward the changes of properties with temperature and pressure which are, of course, related to thermal and volumetric properties, respectively. It is expected that some of this work directed particularly toward the hightemperature and high-pressure area will contribute to and be assisted by the geothermal project at LBL.

\section{b. Nuclear Spin Species of Methane}

The heat capacity of solid methare helow $15^{\circ} \mathrm{K}$ shows anomalous properties presumably associated with conversion of nuclear spin species. The heat capacity measurements will continue for pure thethane and for methane with controlied amounts of spin conversion catalysts such as oxygen. This should clarify the situation for pure methane, as well as froviding information on the catalytic properties.

\section{c. Anomalous Intemal Motions in Mblecules}

The theoretical work on the anomalous internal motion of $\mathrm{XeF}_{6}$ should be completed. Somewhat similar anomalies are shown by $\mathrm{IF}_{7}, \mathrm{ReF}_{7}, \mathrm{VF}_{5}$, and possibly certain other pentafluorides, and one or more of these molecules will be studied by appropriate modifications of our present methods.

\section{d. Quantum Chemistry of Heavy Atoms}

We expect to initiate theoretical studies of the energy lerels and other properties of ions and molecules containing very heavy atoms. Methods now established for moiecules with light atoms mist be modified to deal with relativistic effects and with the large number of inmer shell electrons. Several alternative approaches to these problems will be studied before choosing a plan for detailed calculations.

\section{1973 FUBLICATIONS AND REPORTS}

Kenneth S. Pitzer and Assceiates

\section{Journals}

1. K. S. Pitzer, Thermodynamics of Electrolytes. I. Theorftical Basis and General Equations, J. Phys. Chern. 77, 268 (1973) (LBL-846) .

2. K. S. Pitzer and G. D. Mayorga, Thermodynamics of Electrolytes. II. Activity and Osmotic Coefficients for Strong Electrolytes with one or Both Ions Univalent, J. Phys. Chen. 77, 2300 (1973) (LBL-1434). 
LBL report

1. K. S. Pitzer and G. D. Mayorga,

Thermodynanics of Electrolytes. III. Activity and Osmotic Coefficients for 2-2 Electrolytes, LBL-2282, Oct. 1973 (subuitted to J. Solution Chemistryl. 


\section{E. NUCLEAR SCIENCE}

Donatd R. OLonder, Principal Inveatigator

\section{ISOTOPE EXOHANGE OF WATER VAPOR ON} PYROLYIIC GRAPHITE

Rajarama T. Acharya, Alan Z. UIlman, and Donald R. Olander

The mlecular beam apparatus ${ }^{\prime}$ was modified to facilitate isotope exchange studies with $\mathrm{H}_{2} \mathrm{O}$ and $\mathrm{D}_{2} \mathrm{O}$ on pyrolytic graphite. This modification consists of a simple "doser" fabricated from a 1/16-in.-o.d. tubing and positioned in the target chanbar so as to bathe the target with a continuous flux of $\mathrm{D}_{2} \mathrm{O}$ molecules. A modulated nolecular beam of $\mathrm{H}_{3} \mathrm{O}$ is generated in the usual manner. A further modification was the installation of a 10w-frequency chopper, consisting of a beam fllag attached to a rotary vacum feedthrough operated by a rotary solenoid, in the target chamber. The low-frequency chopper is used for modulation frequencies in the range of 0.01 to $1 \mathrm{~Hz}$.

Since the romal lock-in detection technique has a lower modulation frequency linit of $10 \mathrm{~Hz}$, pulse counting and wave form analysis is used in the low-frequency range. The output from the mass spectrometer is processed by a charge-sensitive preamplifier. The pulses are then shaped and amplified by a main amplifier. A lower level discriminator suppresses the if pickop from the mass spectrometer power supply. A pulse divider is used to bring the pulse rate within range of the multiscaler. (i.e., a mutichamel analyzer operated in the moiltiscaler mode). The vave form from the multiscaler is processed to provide amplitude and phase lags of the product signal from the reaction.

Isotope exchunge studies with modulated beam of $\mathrm{H}_{2} \mathrm{O}$ and a continuous flix of $\mathrm{D}_{2} \mathrm{O}$ were canducted in the temperature range of 300 to $1800^{\circ} \mathrm{K}$. The frequency range was extended to about $10,000 \mathrm{~Hz}$ by analysis of the higher harmonics in the beam. The "reaction product" in this stuty was fIDO. The results can be explained by a diffusional process followed by a desorption step. The same mechmism was found to govern the reaction of $\mathrm{O}_{2}$ with the prism plane of pyrolytic graphite. In the isotope exchange reaction, however, the same mertanism occurs on both crystallographic planes.

1. D. R. Olander, K. H. Jones, W. J. Siekhaus, and J. A. Schwarz, J. Vac. Sci.
Tech. 9, 1429 (1972).

2. D. R. Olander, W. J. Siekhaus, J. A. Schwarz, and R. H. Jones, J. Chem. Phys. 57, 421 (1972).

2. THE OXIDATION OF AMADNIA BY $\mathrm{O}_{2}$ ON POLYCRYSTALLINE PLATINLA BY MODULATED MOLFOIUR BEAM MASS SPECTROEETRY

\section{Alan Z. Ulman and Donald R. Olander}

The modulated molecular beam apparatus is being used to study the oxidation of $\mathrm{NH}_{3}$ on $\mathrm{Pt}$. In commercial application, this reaction is catalyzed by platinum wire gauze, but here we use a wafer of polycrystalline metal. The amonia is introduced as a modulated molecular beam. The oxygen may either be mixed with the ammonia or introduced separately as an umodulated bean from a doser (see 1 above).

Prelininary tests with the latter method show competition for adsorption sites between the $\mathrm{NH}_{3}$ and $\mathrm{O}_{2}$ which lead to the odd result of negative apparent reaction probabilities for the production of the products NO and $\mathrm{H}_{2} \mathrm{O}$ when the reactant $\mathrm{NH}_{3}$ is in large excess. This phenamenon, when coipled with the high average reactior probability, leads to a situation in which the modulated reactant $\mathrm{NH}_{3}$ exhibits a reaction phase lag (instead of leading the product emission signal, as is usually the case) while the products NO and $\mathrm{H}_{2} \mathrm{O}$ show phase leads of $180^{\circ}$ at low frequency. In effect, the off-on nature of the modulated $\mathrm{NH}_{3}$ beam effects a chenical titration of adsorbed oxygen, and the results show that the maximm oxygen coverage on the Pt surface is approximately one monolayer. Thus, oxygen adsorption is not restricted to a few specialized reactive sites but can occur on the entire surface.

\section{THE THERMAL ACCOMONATION COEFFICIENTS OF HFILIM AND XENON ON UG 2 AND STAINLESS STEE⿱ *}

Donald R. Olander, Alan Z. Ullman and Rajarama T. Acharya

The thermal accomodation coefficients of helium and xenon on $\mathrm{UO}_{2}$ and stainless steel are of practical importance in the prediction of the temperature distribution in nuclear fuel elements. In the fuel-clad gap, the mean free path of the gas molecules is 
comparable to the dimension of the gas film, so it is necessary to account for the discrete nature of the heat transfer process from the gas to the furl and the cladding. Knowledge of the themal accomnodation coefficients of the gas filling the gap (a mixture of helium and xenon) and the surfaces bounding the gap (the $\mathrm{LO}_{2}$ furel and the stainless steel cladding) is needed in the heat transport analysis.

This paraneter has been measured by use of the modulated molecular bean phase shift technique which has been applied previously to other gas-solid systems. 1 Briefly, the gas temperature following interaction of the gas with the hot solid is determined by the change in the transit phase lag of the modulated bear. The transit phase lag is interpreted in terms of the equivalent Maxwellian tenperature of the reflected gas molecules. Measurements were made for an incident gas temperature of $300^{\circ} \mathrm{K}$ and solid terperatures ranging from 500 to $1200^{\circ} \mathrm{K}$. Two different combinations of incidence and reflection angles were investigated.

The results show that the themal accommodation coefficients on both $\mathrm{UO}_{2}$ and stainless steel are about 0.2 , while for xenon the values are 0.5-0.6. These values are approximately an order of Iragnitude larger than the themal accommodation coefficients currently utilized in codes which compute heat transfer in the fuel-ciad gap, and suggest that application of gap conductance calculations underestimates the resistance of this process by a significant amount.

\footnotetext{
Summary of a paper submitted to J. Nuscl. Mater.

1. D. Olander et al., Surf. Sci. 33, 445 (1972).
}

\section{DIFrUSION OF LANTHANUM IN NDLTEN URANIUN:}

\section{R. Yang and Donald R. Olander}

The measurement of the diffusion coefficient of lanthanum in molten uranium has been corpleted. In order to obtain the lanthanum penetration profile in the uranium phase while diffusion was in progress, the diffusion zone was scanmed by a scintillation $\gamma$-ray detector while the system was in the furnace. Due to the low solubility of lanthanim in uranium, accurate diffusion profiles could only be obtained by measuring the activity far from the interface. The large statistical errors in the count rates at distances far from the interface render such data unreliable. This is believed to be the principal reason for the inaccurate diffusivities obtained in previous experiments (see 1969 and 1972 Arnual Reports):

In order to obtain high count rates at positions far from the interiace, a slagging process was employed. A piece of alumina was inserted in the botton of the crucible to act as a sink for the diffused lanthaman. The La-U interface was separated from the alumina plug by about 5 mm of molten uranium. The diffusion coefficient could be determined by measuring the cumulative comt rate at the uranium-alumina interface as a function of time. A value of $\mathrm{D}=(1.5 \pm 0.2) \times 10^{-5}$ $\mathrm{cm}^{2} / \mathrm{sec}$ at $1250^{\circ} \mathrm{C}$ was determined in this manner. This value is within the range of diffusivities expected in liquid metal systems, and suggests that there is nothing abnormal in the uranium-Ianthanum system. Consequently, the project has been terminated.

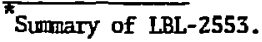

\section{OXYGEN REDISTRIBUTION IN CERAMIC NUCIEAR FUELS*}

Donald R, Olander

The analytical treatment of temperature gradient migration of oxygen in hyperstoidhiometric urania sumarized in last year's Armual Report has been extended to hypostoichiometric mixed oxide $\left[(\mathrm{U}, \mathrm{Pu}) \mathrm{O}_{2-\mathrm{x}}\right]$ which is to be the fuel for the first generation of liquid metal fast breeder reactors. In these ceramics, the oxygen potential is so 10 w that the equilibrium pressures of $\mathrm{H}_{2} \mathrm{O}$ and $\mathrm{CO}_{2}$ (whid are the oxygen carriers) are very low, and other mecharisms of oxygen transport along the tenperature gradient may conmete with the gas phase transport by the oxygen-bearing gases. In particular, the steady state distribution of the oxygen-to-metal ratio along the temperature gradient may be controlled by flow of $\mathrm{H}_{2} \mathrm{O}$ or $\mathrm{CO}_{2}$ in gas-filled cracks balanced by solid diffusion of oxygen ions in the fuel. The influence of solid state diffusion on redistribution depends upon the diffusion coefficionts, densities, and flow areas of the solid and gaseous phases. Hith $\mathrm{H}_{2} \mathrm{O}$ as the carrier gas, oxygen redistribution is practically eliminated with the crack-width-to-solid ratio of $10^{-5}$ but the effect of solid state diffusion is negligible when the solid contains > 18 cracke. 
Transport by $\infty_{2}$ follows the same general behavior as $\mathrm{H}_{2} \mathrm{O}$ except that the maximm pressure of $\mathrm{CO}$ (or $\mathrm{CO}_{2}$ ) is dictated by the requirement that the carbon activity cannot exceed unity. Otherwise, the carton is precipitated according to the reaction: $\mathrm{CO}:=\mathrm{C}+1 / 2 \mathrm{O}$. This assertion assumes that the chemical state of the solid and gaseous phases in the fuel is governed by equilibrium thermodynamies. In actuality, however, the rate of reactions such as the one thich leads to carbon deposition are quite slow, and the carbon potential of the ges may exceed that of pure graphite without loss of gas phase carbon. If this is so, $\mathrm{CO}_{2}$ would still funition as an effective axygen redistributor in cracked, hypostoichiometric, mixed-oxide fuel.

In any case, solid state diffusion acts to reduce oxygen gradients established by other processes (which may be gas phase transport or true thermal diffusion of oxygen in the solid) but cannot by itself cause axygen redistribution. Molecular diffusion in the solid performs an "enrichment limiting" function similar to that of back diffusion in isotope separation by the gas centrifuge or in thermal diffusion columis.

Summary of an article published in J. Nucl. Nater. 47, 113 (1973).

6. THE CONSERVATION EYUATIONS GONERIING POROSITY AND ACTTNIDE REDISTRIBUEION IN MIXFD OXTIE FUELS*

Donald R. O1ander

It has often been stated that the movement of the as-fabricated porosity in a mixed oxide fuel we to the temperature gradient is responsible for actinide redistribution. A calculation has been made to assess the aconracy of this assertion. A temperature gradient is established in a nuclear fuel element as a consequence of the need to remove fission heat. As a result of the temperature gradient, pores originally uniformly distributed throughout the fuel move towards the centerline and form a central void. Just how or if these pores transport plutonium along with them is an inportant question, because plutonium relocation in the fuel affects the allowable power rating of the element. It has been clained that plutoniun redistribution is accomplished by a type of vapor phase zone refining process involving the moving pores. However, correct treatment of the conservation equations for the moving pores and the plutonium in the solid does not support this view. Migration of closed pores cannot contribute to actinide redistribution provided that:

(1) The density of the heavy metal oxides in the vapor contained in the pores is very much smaller than the solid density. If the vapor density were comparable in magnitude to the solid density (as is the case in true zone refining where the noving second phase is a liquid, but not for the rarified vapor in a pore), then the moving phase would have sufficient capsicity to store one component and sweep it along the temperature gradient.

(2) Solid state diffusion of plutonium in the fuel mist be negligible. If this condition is not met, the pores can "push" plutonium ahead of them and so accomplish redistribution (see item 8 of this report for detailed discassion of this effect).

\footnotetext{
Abstract of paper published in J. Nucl. Mater. 47, 251 (1973).
}

7. THE KINETICS OF ACTTNIDE REDISTRIBUTION BY VAPOR MIGRATION IN MIXEDD OXIDE FUEIS (I). BY CRACKS*

\section{Donald R. Ölander}

The kinetics of vapor migration-driven restructuring and actinide redistribution along continuous cracks was studied analytically. The fissured fuel was modeled by a network of rectangular cracks with the temperature gradient along the major axis. Redistribution of fuel constituents was considered to ocaur by molecular diffusion in the gas filling the cracks. Hyperstoichiometric $U / P u$ oxide was treated sa that only a single diffusing species $\left(\mathrm{WO}_{3}\right)$ needed to be considered, at least in the early stages of the process. The dependence of the kinetics upon oxygen-to-metal ratio, temperature gradient, and crack dimensions was investigatel for fuel containing $20 \%$ plutonium.

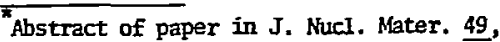
21 (1973).
} 
8. THE KINETICS OF ACTINIDE REDISTRIBITION BY VAPOR MIGRATION IN MIXED OXIDE FUEIS (II). BY PORES*

Donald R. Olander

The migration velocity of a closed lenticular pore in hyperstoichiometric mixed oxid? fuel has beeri calculated, and the U/Pu ratio of the solid near the moving pore has been deternined. Pore migration in mixed oxides differs from the analogous process in pure stoichiometric urria in that the composition as well as the tcuperature of the two faces of the pore are different. It was found that pore migration is not as effective a mechanism of actinide redistribution as vapor transport along cracks. The velocity of the pores in $\left(\mathrm{U}_{0} .{ }_{8} \mathrm{P}^{4} u_{0.2}\right) \mathrm{O}_{2+\mathrm{x}}$ is $\sim 3 \mathrm{l} / 2$ times iaster than that in pure $\mathrm{UO}_{2}$.

"Abstract of paper in J. Nucl. Mater. 49 , 35 (1973).

9. THE SHAPE OF THE DOPPLER-BROADENED SPECIRAL LINES PRODUCED BY LIGHT-ATOM BOMEARIMENT OF METALS*

Donald R. Olander, C. Kerkdijk, and C. Smits

A model for predicting the shapes of Doppler-broadened spectral lines de to de-excitation by photon enission of excited neutral atoms backscattered frcm solids is presented. The distribution of backscattered particles is calculated on the basis of single Rutherford collisions within the solid accampanied by energy loss due to electronic stopping during passage of the particle through the solid. The effect of the energy dependence of the stopping power, radiationless de-excitation of the escaping neutral atom, and the probability of the particle leaving the surface in the desired excited state are incorporated into the calculation. The broadening of the spectral line is determined by combining the Doppler-shift formula with the energy- and angular distribution of the backscattered particles.

\footnotetext{
Abstract of article summitted to Rad. Effects. Hork performed at the FOM Institute of Atomic and Molecular Physics, Austerdam, Holland.
}

\section{RESEARCH PLANS FOR CALENDAR YEAR 1974}

Donald R. Olander

Investigation of the reaction $\mathrm{H}_{2} \mathrm{O}+\mathrm{C}+\mathrm{CO}+\mathrm{H}_{2}$ will be collpleted and a mechanistic model of the reaction proposed.

Amonia oxidation of Pt will be completed and a reaction model proposed.

The reaction of graphite with hydrogen be investigated in the molecular bean apparatus. A high-temperature hylrogen atom furnace is under construction.

The $\mathrm{F}_{2}-\mathrm{LO}_{2}$ reaction, utilizing the newly constructed molecular beam system, will be investigated.

The gas phase radiolysis of oxygen by accelerator protons will be completed.

A thermal gradient furnace is being constructed to study the migration of metallic inclusions in ceramic oxide nuclear fuel materials.

\section{1973 PUBLICATIONS AND REPORTS}

Donald R. Olander and Associates

1. R. T. Acharya and D. R. Olander, The Rate of Jxidation of the Basal and Prismatic Surfaces of Pyrolytic Graphite in the Transition Regime between Chemical and Diffusional Control, Carbon 11, 7 (1973) (LBL-488).

2. D. R, Olander, Oxygen Redistribution in $\left(\mathrm{U}, \mathrm{Pu} \mathrm{O}_{2-x}, \mathrm{~J}\right.$. Nucl. Mater. 47, 113 (1973) (LBL-1469).

3. D. R. Olander, The Conservation Fquations Governing Porosity and Actinide Redistribution in Mixed Oxide Fuels, J. Nucl. Mater. 47, 251 (1973) (LBL-1823).

4. D. R. Olander, The Kinetics of Actinide Redistribution by Vapor Migration in Mixed Oxide Fuels (I. By Cracks), J. Nucl. Mater. 49; 21 (1973) (LBL-1131).

5. D. R. Olander, ibid (II. By Pores), J. Kuc1. Mater. 49, 35 (1973) (LBL-I131).

\section{Papers presented}

1. R. T. Acharya, "Stury of the Reaction of Pyrolytic Graphite with Water by Modulated Nolecular Beam Hess Spectrometry," 33rd Conf. on Physical Electronics, March 26-28, 1973, Berkeley. 
2. D. R. Olander, "Sur face Chemical Reactions by Modulated Molecular Beam Mass Spectrometry," at the Forl Institute of Atomic and Molecular Physics, Ansterdan, Nov. 8, 1972 and at the Technische Hogescholl Twente (Holland), April 11, 1973.

3. D. R. Olander, "Technical Basis of the Gas Centrifuge," CEA, Saclay (Paris), June $7,1973$.

4. D. R. Olander, "Oxygen and P1utonilm Redistribution Kinetics in oxide Fuels for Fast Reactors," CFA, Fontenany-aux-Roses (Paris), June 8, 1973.
5. D: R. Olander, "Plutonim Redistribution in Oxide Fuels," Argonne Vational Laboratory, Aug. 2, 1973.

LBL reports

1. Jack Hovingh, Diffusion of Lanthanum in Molten Uranium (M. S. thesis), LBL-1130, Feb. 1973.

2. Har-Chung Tsat, The Viscosity of Cesiun Metal to Its Critical Temperature (Ph.D. thesis), LBL-1413, July 1973.

3. H. C. Tsai and D. R. Olander, The Viscosity of Liquid Cesium up to $1600^{\circ} \mathrm{C}$, LBL-2201, Aug. 1973. 


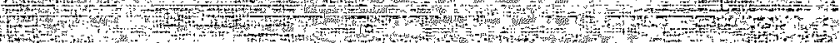

I

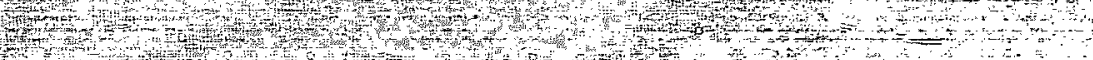

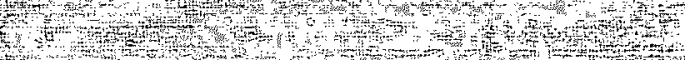

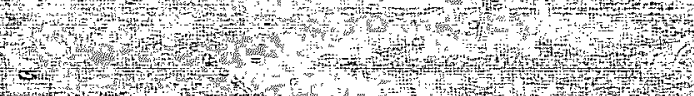

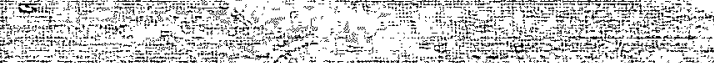

$$
\text { (3) }
$$ (1)

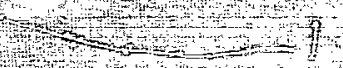

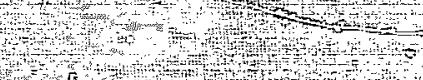

$+$

in s. $+1$ $=0$ 74 ? w $+4$

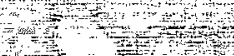

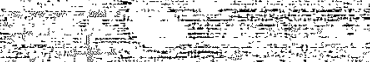
$2 x+1, y=0$

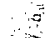

$\Leftrightarrow$

4

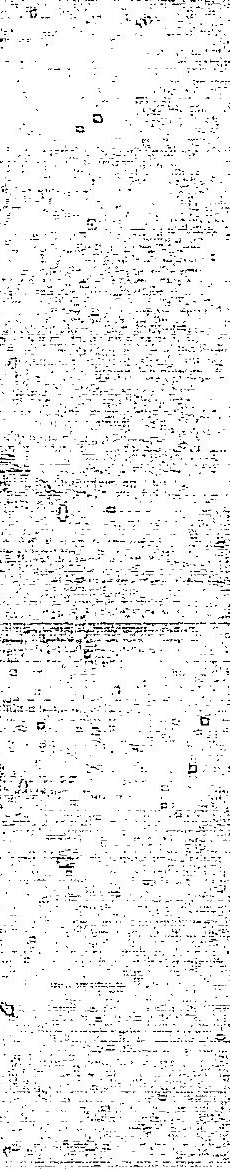




\section{A. CRYSTAL IMPERFECTIONS}

Jack Hashoum, Erincipal Inveatigator

\section{TRANSMISSION ELECTRON MICROSCOPE}

INVESTIGATION OF THE GROVTH OF COPPER PRECIPITATE COLONIES IN SILICON

\section{Erik Nes* and Jack Washburn}

The growth of copper precipitate colonies in high-purity dislocation-free silicen single crystals has been examined by transmission electron microscopy. The colonies, being coplazar arrangemer.ts of copper-silicide particles on either $\{110\}$ or \{100\} planes, nucleate and grow during rapid cooling from higher temperatures. The kinetics of the colony grawth process has been analyzed in terms of a model based on repeated nucleation on $z$ climbing dislocation. The possibility of having the growing coppersilicide particles dragged by the dislocations has been discussed, and a mechanism based on a particle dragging/dislocation climb effect has been suggested in order to explain the developrent of dendritic dislocation difole branches.

Climb of the dislocation is caused by the chemical climb force due to the local vacancy subsaturation near a growing precipitate. Except for this dragging effect, the sequence between consecutive nucleations may still follow the pattern schematically illustrated in Fig. 1.

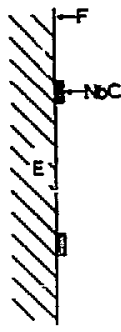

(d)

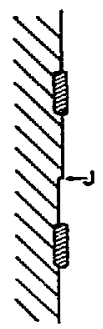

(b)

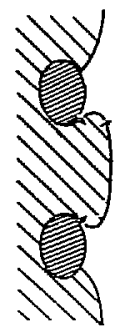

(c)

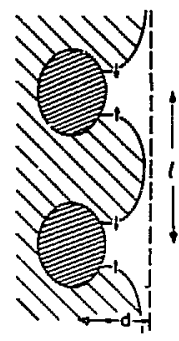

(d)
Fig. 1. Stages in the repeated nucleation process on a climbing edge dislocation.

(XBL 752-5774)

\footnotetext{
"Present address: University of Os10, Institute of Physics, Blindern, 0s10 3 Norway.
}

2. DETEPAINATION OF LOOP TYPE IN As ${ }^{+}$ MMPLANTED SILICON

Wei Kuo Wu

A sirple method for determining loop type in foils near [111] orientation has been described and it has been show to give the same results as previously wed more curbersome methods by applying it to phosphorous and arsenic implanted silicon.

The advantages of this method over others are:

(a) Only sma:l angle tilting is necessary to know the sense of the Kikwhi pattern near \{111\}. No high-angle tilting or dark field top-bottam determinations are needed.

(b) Only plus $\overrightarrow{\mathrm{g}}$ and minus $\overrightarrow{\mathrm{g}}$ bright field photographs are required.

This method is particularly useful in ion implantation studies with orientation near (111), because silicJn usually gives very clear Kikuchi patterns. With this nethod, smali prismatic loops in $\mathrm{As}^{+}$i. silicon have been shom to be of interstitial type.

\section{MENORY SITTCING EFFECTS IN AS-Te-I CHALCOCENILE GLASS}

Robert Jecrnen

The switching process from the memory state to the high resistance state seems to be govemed by a Joule heating and subsequent melting of the crystalline filamentary path. Upon tive cessation of the switching pulse, the filamentary region is quenched into a Te-rich glass of high resistjvity. The switching process is a sensitive function of the heat conduction properties of the surrounding region.

The switching process from the memory state to the high resistance state is tharacterized by a visual disappeararice of the menory state filament. Figrre la shows the memory state filamentary peth connecting the two vapor-deposited metal electrodes on the surface of the glass sample. The formation current magnitude was $0.8 \mathrm{~mA}$, and the pulse rise, iold, and fall times viere 5,20 , and $5 \mathrm{msec}$, respectively. In Fig. 1b. the menory filament is seen to diseppear after a switching pulse $I_{s}=2.0 \mathrm{~mA}$ had been applied. 

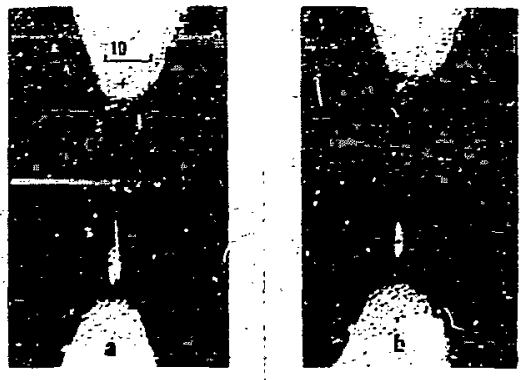

Fig. 1(a) Completed memory state filament. (b) Loss of filament upon switching to tla high resistance state.

(XBB 735-3366)

\section{COMPUER SIILATION OF FRANK LOOP CONTRAST IN FIELD ION INAGES}

\section{Kaj Gimnar Stolt}

The contrast due to small Frark dislocation loups in field ion tips was analyzed by computer simulation. The sinulation of the image was based on the shell model, and the displacement field of the dislocation loops wac computed using the exact displacenent equation for a closed dislocation loop in an isotropically elastic continum (Burgers' formula). A simple method for taking the effect of surface relaxation on the displacement field into account was introduced. The method consists of superposing the displacement field of an image loop located in the mirror position of the real loop relative to the surface. Simulated field evaporation sequances were produced by either increasing the radius of the simulated tip while moving its center of curvature into the tip aleng its axis or by simply shrinking the simulated surface concentrically. The following conclusions were drawn from this investigation:

1) Frank loops will cause image contrast not only when they intersect the tip surface but when they are wholly inside the tip as we11.

2) Frank 1oops of vacancy and interstitial type ciuse qualitatively different contrast, recognizable on inspection, and rather independent of loop plane and position.

3) Taking surface relaxation into account only enhances all analyzed contrast effects but does not alter them qualitatively.

4) Analysis of lattice defects by ion microscopy should be based on extensive and finely stepped evapoiration sequences and absolutely not on single micrographs. This applies both to the characterization of the nature of a defect and to the determination of its size.

5) Determining the size of a Frank loop from its inage contrast is very diffjcult, even using an evaporation sequence, since the contrast is caused by the strain field of the ioop which is larger than the loop.

6) Comparison with experimental observations indicated the plausibility of the simulated contrast.

\section{ON THE ANNEALING OF STACKTNG FAULT} TETRAHEDRA AND FRANK DISLOCATION LOOPS IN SILVER

\section{Thorvald Astrup and Jack Washbunn}

Direct observation of quenched-in stackingfault tetrahedra and Frmik dislocation loops in $99.999+\frac{9}{9}$ silver during annealing was made by hot stage transmission electron microscopy.

The defects produced by quenching from a few degrees nelow the melting point had a range of edge sizes $L$ up to $2000 \mathrm{~A}$ for the SFT and from 650 to $1350 \AA$ for the triangular loops. The smaller SFT, $L=600$, were found either to shrink or to completely anneal out above $600^{\circ} \mathrm{C}$. One large SFT, $\mathrm{L}=2000 \AA$, was observed to collapse into a 100 at $300^{\circ} \mathrm{C}$. Shrinkage of loops taking place from one corner was detected.

The size ranges of faulted defects in gold and silver have been studied along with the different energy barriers involved in the collapse and/or shrinkage of these defects. It setus to be fairly well established that the annealing out of the faulted defects in gold does not pose any problem. For silver, however, the case is a little more complicated.

It is proposed that tie ledge mechanisms are probable mechanisms for shrinkage of SFT, and in the case of collapse, nucleation of a Shockley loop near the corne- instead of in the middle of the face might be onergetically feasible. Escaig's suggestions regarding shrinkage of loops from one coiner seen to be within reasonable ranges energetically.

All the calcilations involve dislocation 
configurations of core dimensions which along with assumption of isotropic elasticity and uncertainties on the value of the stacking fault energy make all attempts to pimpoint exact mechanisms of shrirkage and collapse questionable.

6. ON THE NATURE OF THE LONG-TERM DEGRADATION OF "CADMIUM SULFIDE" SOLAR CELLS

Terry M. Peterson and Jack Washbumn

The spectral response of the $\mathrm{Cu}_{x} \mathrm{~S} / \mathrm{CdS}$ $(x=2,1.95)$ heterojunction is calculated using a simple model, and a comparison with published data is made. This comparison suggests that there is a degradation of the djirleite cell ( $x=1.95$ ) besides that due to thi fact that djurleite has a smaller optica: absorption constant than chalcocite. It is shown that the dislocation array necessary to accommodate the lattice mismatch between the djurleite and the cadmium sulfide could be a contributing factor in this degradation.

\section{ELECTRON MICROSCOPE STUDIES OF MICRO- EROSION IN MgO SINGLE CRYSTALS}

Jagdisi: Narayan and Jack Washbum

The plastic damage introduced in $\mathrm{MgO}$ single crystals by bombarment with $\mathrm{Al}_{2} \mathrm{O}_{3}$ microspheres $(0.3,10,20$ and 27 m diameter) has been studied using optical, transmission, and scaming electron microscopy. Most of the damage is in the form of dislocation dipoles (two closely spaced dislocations of opposite sign) which lie on $\{110\}$ slip planes. The dislocation density increases with the increase in the energy of the impinging particles. Using stereo-microscopy the damage has been shown to be uriformly distributed in thin foils. Studies done on indentations produced by a sharp pin show a very high density of single dislocations.

\section{RESEARCH PLANS FCR CALENDAR YEAR 1974}

Jack Washburn

1. Electron microscope studies of ionimplanted silicon: Effects of annealing treatments and ion-implantation dose on defects in the implanted layer will continue to be investigated for phosphorous, arsenic, and boron-implanted siliccn. Habit planes of interstitial loops will be determined and correlated with the stresses present during nucleation and growth.

2. Field ion microscopy will be applied to a study of the effect of surface layer atoms on work function. $\mathrm{Ni}_{4}{ }^{\mathrm{W}}$ in the ordered state permits surface layers consisting entirely of $\mathrm{Hi}$ atams or of $\mathrm{Ni}+\mathrm{W}$ ic be exposed by field evaporation in certain regions of the field ion microscope tips. Work function measurements will be compared for the two kinds of surfaces.

3. Void growth is a serious problem for the inner wall of a fusion reactor, for electric power generation. It is known that preferential capture of interstitials at dislocations is the root cause of void growth. Radiation damage produced by electron borbardment of copper and copper aluminum ailoys in the $650-\mathrm{kV}$ electron microscope will be used in a continuing stuly of dislocation climb phenomena. In particular, the effect of stacking-fault energy on climb due to capture of interstitial atoms produced by electron irradiation will be investigated. To make these experiments practical it is planned to modify the column of the highvoltage microscope to permit use of side entry stages.

4. The possibility of producing a lowcost photovoltaic cell based on a sputtered thin film of $\mathrm{ZnS}$ will continue to be investigated along with a continuing stuty of the mechanism of operation of the cuprous sulphide/cadnium sulfide heterojunction solar cell.

5. The shape memory effect in NiTi is of potential use in a new kind of heat engine for operation at small $\Delta T$. Electron microscope work will be undertaken to clarify the mechanism of the shape memory effect.

6. The production of silicon solar cells at 10 w enough cost to permit their widespread use for direct conversion of solar energy to electric power probably requires the use of silicon of lower purity and in polycrystalline thin film form. A cooperative program will be undertaken with Professor Gabor Somorjai to investigate the properties of various kinds of grain boundaries in silicon films.

7. Efficient collection of solar heat for heating and cooling of buildings and for preheating water to produce steam for electric power plants requirs a spectrally selective surface of long life and low cost. Various methods of producing thin layers of copper 
oxide on reflective metal surfaces are being investigatad.

\section{1973 FUBLICATIONS AND REPORTS}

Jack Washburn and Associates

\section{Journals}

1. J. Narayan and J. Washburn, Eleretron Microscopic Studies of Micro-Erosion in Brittle Solids, Wear 23, 128 (1973) (LBL-899).

2. J. Narayan and J. Washbum, Self Diffusion in Magnesium Oxide, Acta Met. 21, 533 (1973) (LBL-473) .

3. J. Narayan, On the Interaction of Prismatic and Glissile Dislocations, J. Appl. Phys. 44 (6), 2449 (1973) (LBL-1405).

4. E. Nes and J. Washbum, Transmission Electron Microscope Investigation of the Growth of Copper Precipitate Colonies in Silicon, J. Appl. Phys. 44 (8), 3682 (1973) (LBL-1459) .

5. J. Narayan, Prismatic Dislocation Loops on Impurity Precipitates in Nagnesium Oxide Single Crystals, J. Appl. Phys, 44 (8), 3436 (1973) (LBL-1843).

6. J. Narayan, The Char icterization of the Danage Introduced Dun ing Micro-Erosion of Mgo Single Crystals, Wear 25, 99 (1973) (LBL-887).

7. J. Narayan, Subgrain Boundaries in MgO, J. All. Ceramic Society, Decenber, 1973 issue (LBL-828) .

\section{LBL. reports}

1. $W-k$. Wu, Dctennination of Loop Type in $\mathrm{As}^{+}$Implanted Sil icon (M.S. thesis), LBL-1415, Feb. 1973.

2. J. Narayan, Transmission Electron Microsccpic Studies of Ptismatic Sl ip in Magresium Oxide, LBL-1406, Jan. 1973.

3. Ki-K. K'u, L-J. Cher, J. liashburn, and G. Thomas, On Indexing of Diffracting Planes Us ing the Kikwhi Pattern, LBL-1811, Aug. 1975.

4. Rohert M. Jecnam, Memory Switching Effects in As-Te-I thalcogenide Glass (M. S. thesis), LBL-1817, July 1973.

5. K. Seshan, Contribution of Radiation Damage to the Study of Basic Atomic Motion in Solids, LBL-1450, Feb. 1973.

6. W-K. Wu and J. Washbum, Identification of Interstitial vs. Vancancy Type Dislocation Loops in Ion Implanted Silicon, LB:-1812, Sept. 1973.

7. k. G. Stoli, Computer Simulation of Frank Loop Contrast in Field Ior Images, Ph.D. thesis, LBL-2200, Sept. 1973.

8. H. A. E.-F. Mohamed, Mechanism of Pressure Welding (M.S. thesis), LBL-2510, Dec. 1973.

9. W-K. Ku and J. Washbum, Ot. Detennination of the Burger Vectors and Loop Planes of RodLike Defects in Boron Implanted Silicon, LBL-2287, Nov. 1973. 


\section{B. THEURETICAL METALLURGY}

John H. Morria, Ir., Principa?. Investigator

Introduction. 'the overall objective of this research program is to atvance the tiveory of alloy design. The problem of designing an engineering alloy may be subdivided into four parts: (1) estimation of the themodynamic properties of en alloy of given composition; (2) prediction of the microstructure resulting fram a specified treatment of an alloy of given thermodynamic and kinetic properties; (3) prediction of the engineering properties of an alloy of given microstructure; (4) synthesis of this information in the selection of alloy corposition and processing. Given the synthetic character of alioy design, its study seems best conducted in a program which maintains active research in each of the relevant problem areas.

\section{THEPMODYNAMICS}

\section{a. Phase Stability of Netals and Alloys*}

Charles W. Krause and John W. Morris, Jr.

Despite its central importance in the science of metallurgy, the problen of predicting the preferred structure of a metal alloy remains unsolved. Moreover, the complexity of the problem is such that a viable theory of the crystal structure of alloys is unlikely to emerge for scme time. In the interim the metallurgist will be forced to make do with a mixture of rough approximations and semiempirical rules, and the development of approximate techniques in alloy theory will continue to be important.

The pseudopotential theory of simple metals has yielded several models which promise to be useful in the prediction of structure. The simplest and most general of these follows fram Harrison's development of Cohen's real space formulation of the pseudopotential theory. If a pseudopotential model of a simple metal is developed to second order in perturbation theory, that part of the cohesive energy which depends on the structure may be treated as if the atoms interacted in pairs according to a central, two-body potential. This two-body potential has an asynptotic form which is irdependent of the precise pseudopotential assumed, and which exhibits the Friedel oscillations. Under suitable assumptions one may make a rough estinate of tie relative energies of candidate structures at $0^{\circ} \mathrm{K}$ by simply suming the energy of two-atom interactions according to the asymptotic, or Friedel, potential. This approach has been taken in several studies of the structure of simple metals and alloys and has been followed here, where we supplement prior work with new computations to explore the results of a simple structural model based on the twobaty Friedel potential.

Thile the approximations involved in a structural model based on the Friedel potential are drastic, the model has several attractive features. It leads to equations which are easy to use and which incorporate aspects of the more fundamental theory wille avoiding the recalcitrant problem of choosing proper pseudopotentials. Moreover, the model yields a prediction of alloy structure which is based on the electronatom ratio, in the spirit of the Hme-Rothery and Enge1-Brewer correlations, and which is in general agreement with known structural tendencies in simple metals and alloys.

The central equations of the structural model used here are derived as follows.

Employing the real space formulation of the pseudopotential theory of a simple metal, the cohesive energy per atom may be developed in the perturbation series

$$
E=E_{0}+E_{1}+E_{2}+\cdots
$$

whose successive terms involve perturbations $\therefore:$ increasing order. The zeroth and firstorder terms in this expansion depend on the volume per aton $(\Omega)$, but are independent of stricture, The second-order term, $E_{2}$, is the first to shor the influence of structure. It can be cast in the form

$$
E_{2}=\frac{1}{2 N} \sum_{i, j}^{\prime} v\left(r_{i j}\right),
$$

where $N$ is the number of atoms ${ }^{r_{i j}}$ is the distance between the $i$ 望 and $j$ th atorn cores, and the prime on the sumation indicates that terms having $i=j$ are to be omitted. The function $V\left(r_{i j}\right)$ appearing in the summation acts as a two-body potential in a restricted sense: it governs the change of energy in a relative displacement of atours $i$ and $j$ which leaves the atomic volume, and hence $E_{0}$ and $E_{1}$, constant. If we fix the atomic volume and neglect higher order terns in the perturbation expansion, the relative 
energy of a given structure is mezsured by $E_{2}$; that structure which mirimizes $E_{2}$ wiil be preferred at $0^{\circ} \mathrm{K}$.

Computation of the structural erer $\mathrm{g}, \mathrm{E}_{2}$, requires a specific expression for the effective interatome potential, $V(r)$. This potential is sensitive to the details of the pseudopotential used. Hom over, irrespective of the pseudopotential, $V(r)$ has the asynmtotic form

$$
V(r)+V_{0} \cos \left(2 k_{F} r\right) /\left(2 k_{F} r\right)^{3}
$$

when $\left(k_{F} r\right)$ is large, where $k_{F}$ is the Fermi wave number. The parameter $V_{0}$ depends on fundamental quantities in a rather complicated way, but for our purposes it is sufficient to note that $V_{o}$ is independent of structure. We IIay hence define a dimensionless two-body potential

$$
v(r)=V(r) / V_{0} .
$$

which becomes the Friedel potential

$$
v(r)=\cos \left(2 k_{F} r\right) /\left(2 k_{F} r\right)^{3}
$$

when $k_{F r}$ is large. If we now uniformly approximate $V(r)$ by its asymptotic form, the structural energy, $E_{2}$, may be rewritten in a dimensionless form which is independent of the pseudopotential:

$$
\varepsilon=E_{2} / N_{0}=\frac{1}{2 N} \sum_{i, j}^{i} \cos \left(2 k_{F} r_{i j}\right) /\left(2 k_{F} r_{i j}\right)^{3}
$$

In fact, the dimensionless energy, $\varepsilon=\varepsilon(\mathrm{Z})$, is a function of structure and electron-atom ratio (Z) only; since the separation distances $\left(r_{i j}\right)$ in a given structure scale as $\Omega 1 / 3$, wirere $\Omega$ is atomic volume, and since the Fenmi wave nuber, $\mathrm{k}_{\mathrm{F}}$, is $\mathrm{k}_{\mathrm{F}}=$ $\left(3 \pi^{2} 2 / n\right)^{1 / 3}$, the set of values of the quantity (K/ $\mathrm{Fr}_{i j}$ ) in a given structure, and hence the dimensioniless energy of the structure, is determined by 2 .

Equation (1a.5) may be sumed exactly for given structure, usiring a technique proposed by Shaw. Results for the common metal structures are shown in Fig. 1, where we have plotted the dimensionless energies of the hop and bcc structures relative to that of the fec structure as a function of electron-atom ratio $z$. The result shows intriguing agreement with the phase stabilities of simple metals. At $2=1$ the hcp structure is preferred, as in the simplest monovalent metals, $\mathrm{Na}$ and $\mathrm{Li}$. At
$\mathrm{Z}=2$ the bec and hep structures are almost degenerate; both are observed. At $Z=3$ the fec structure is preferred.

If only close-packed structures are considered, an approximate value for Eq. (1a.5) may be obtained in a very simple way. Blandin, Friedel, and Saada showed how Eq. (1a.5) may be approximately rewritten as a sum over close-packed planes of an interplanar potential which depends on whether the planes are in equivalent (i.e., $A-A)$ or inequivalent $(B,-B$ or $A-C)$ stacking positions. Hodges and Weire suggestea a tecinique for performing the summation for close-packed structures. We modified this technique into a form allowing straightforward computation of the relative energies of arbitrary close-packed polytypes. In Fig. 2 we compare the dimensionless energies of the hop and fcc structures to those of three simple close-packed polytypes: the double hexagonal (dhep) structure, with stacking sequence ....hkhk...; the samarium (5m) strusture, with stacking sequence ...hhkhhk...; and a third structure, denoted A, which is two-thirds cubic in stacking, ...kkhkkh.... . The polytypes intrude over a range of electron-atom ratio $1.24<2<1.34$. This is the range of valence over which Blandin, Friedel, and Saada found that the fec and hcp structures would be simultaneously unstable to faulting, and is a range in which polytypic structures are observed experimentally.

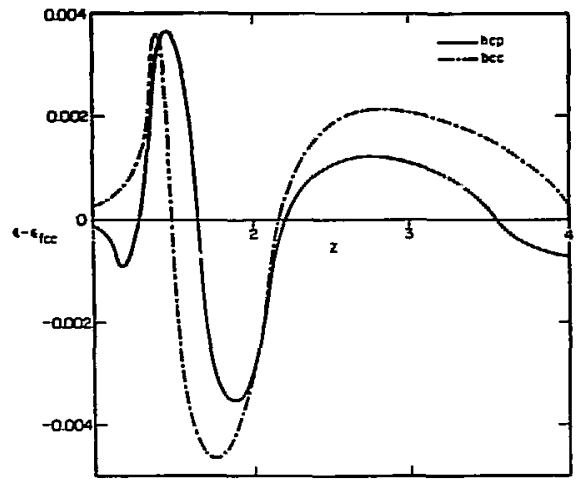

Fig. 1. Results for the dirrensionless relative energies, $\varepsilon_{h p^{-\varepsilon}}$ fcc and $\varepsilon_{h c p^{-}} \varepsilon_{f c c}$, as determined by exact sumbation of the reduced Friedel poteniial as a function of $\mathrm{Z}$.

(XBL 738-1788) 
As is apparent in Fig. 2, the energies of the rlose-packed structures are degenerate at $Z_{c}=1.14$. This degeneracy is evident from the functional form of the interplanar interaction, ard has led to an anticipation of anomalous faulting behavior near $\mathrm{z}_{c}$. As can be seen by comparing Figs. 1 and 2 the degeneracy is spurious: it is introduced with the approximation leading to the interplanar interaction.

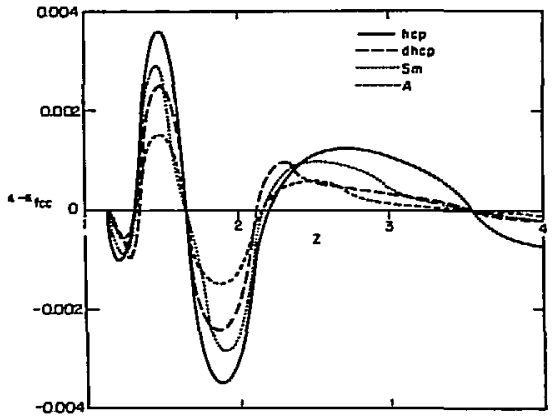

Fig. 2. Results for the dimensionless ener,jies of the polytypic structure hcp, dhcis, Sin and A relative to the foc structure as determined from the BFS interplanar interaction as a function of $\mathrm{Z}$.

(XBL 735-6175)

A shortcoming of the simple Friedel potential is its unique association of preferred structure and electron-aton ratio. To study generalizations we consi. $r$ red a simple extension of the Friedel potential, obtained by adding a phase shift (2反) in Eq. (1a.4) to obtain the modified potential

$$
v(r)=\cos \left(2 k_{F} r+2 \delta\right) /\left(2 k_{F} r\right)^{3}
$$

The inclusion of a phase shift in the potential is not arbitrary. It has been suggested as a device for accounting for sone of the effects of d electrons, and Harrison has argued that a phase shift appears in the asymptotic form of the real space interaction in pseudopotential theory when nonnegligible third-order effects are included.

If the modified potential (1a.6) is substituted in the summation (1a.5) the relative energy of a structire becomes dependent on two parameters: the phase shift $(\delta)$ and the electron-atom ratio $z$. Exact sumation of Eq. (1a.5) then gives the results shown in Fig. 3, where we have plotted the domains of stailitity of the structures fcc, bec, and hep as functions of $Z$ and $2 \delta$. The phases appearing at reasonably stall values of $\delta$ in this plot show interesting agreement with those empirically observed as a function of $\mathrm{Z}$.

To study the stability of close-packed polytypes we recast the potential (1a.6) in the form of an interplanar interaction, and sumed for relative structural energies. The resulting stability fields are shown in Fig. 4. Polytypic phases may i . sabilized

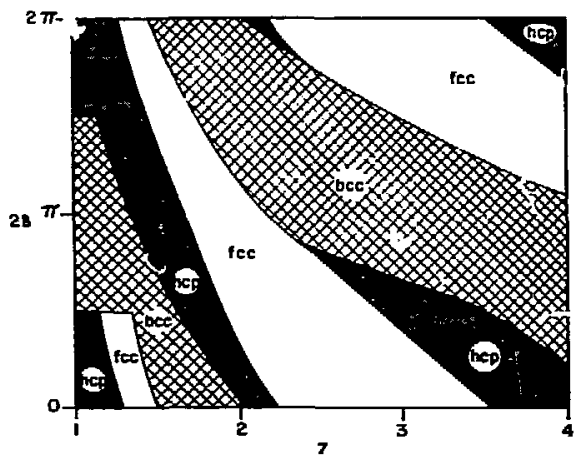

Fig. 3. Results from the determination of the most stable structure among fcc, hcp and bcc from the exact sumation of the Friedel potential as a function of $Z$ and a phase factor, $2 \delta$.

(XBL 735-6178)

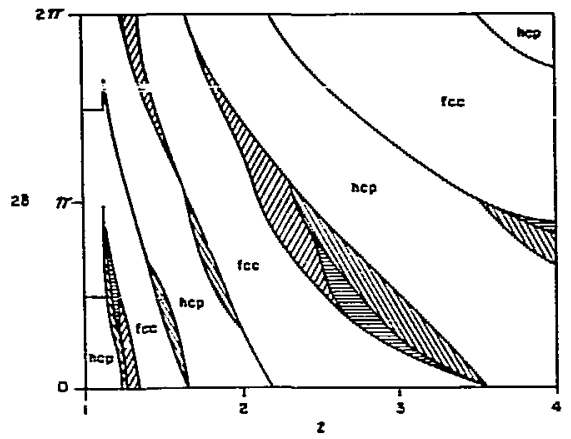

Fig. 4. Results from the determination of the most stable structure from among fec, hcp, dhcp, Sm and $A$ using the interplanar interaction as a function of $Z$ and $2 \delta$.

(XBL 735-6177) 
by a small phase factor when $1.25<Z<1.60$ and when $3.0<z<3.6$. These are the ranges of electron-atom ratio over which closepacked polytypes are commonly found.

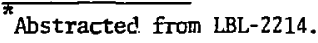

\section{b. Diffusion}

Faysal Hamzeh and Join W. Morris, Jr.

Most problens of diffusion in simple metals and binary alloys at constant temperature and pressure may be solved in a straightforward way through use of Fick's equations, whose utility is well estabiished experimeatally. However, the theoretical treatment of diffusion in multicomponent systems or in more complex situations requires the use of relations in nonequilibritu thermodynamics whose correct forms are not firmly est blished. Since theoretical treatment of transformations in engineering alloys requires an understanding of diffusion in multiconponent systens in the presence of strain or temperature gradients, new research in the theory of diffusion is needed. We began research on this joroblem during the past year. The first prcblem considered was the optimal choice of fluxes and forces for describing diffusion in a mulicamonent system.

It is generally assumed that if a system is reasouably close to equilibrium its regression to equilibrium can be described by a set of linear phenomenological equations of the iorm

$$
J^{\alpha}=\underset{\beta}{\Sigma} L^{\alpha \beta} \cdot \underline{x}^{\beta} .
$$

where $J^{d}$ is the flux of the $\alpha^{\text {th }}$ thermodynamic quantity (heat or mass) measured in a specified reference frame, $x^{\beta}$ is a thermodynamic force appropriate to the $B$ th quantity, and the $L^{\alpha \beta}$ are tensor coefficients which measure the coupling between the ath flux and $B^{\text {th }}$ force. It is then convenient to assume that the coefficients $\mathrm{L}^{\mathrm{c} S}$ are symetric, in the dual sense that $L^{\alpha{ }^{\alpha}}=\tilde{L}^{\alpha \beta}$ and that $\mathcal{L}^{\mathrm{a}}=\mathrm{L}^{\mathrm{Ba}}$. These symetry constraints ne known as the Onsager relations and are generally referred to a theorem by onsager on the regression of fluctuations from equilibrium.

The Onsager symetry relations have been scrongly objected to in theoretical work by Coleman and Truesdell. They point out in particular that the relations are meaningless in the absence of a specific prescription for choosing the fluxes and forces in Fq. (1b.1); if the Onsager relations hold with one choice of the $\tau^{\alpha}$ and $x^{\beta}$, a sinple redefirition of the will lead to a new set of equations of the form (lb.1) in which they do not hold.

In the course of an investigation of the s)mimetry constraints on the coefficients $\mathrm{L}^{\alpha \beta}$ we found th: : it is possible to establish clear rules for the choice of fluxes and forces leading to symmetric coefficients if there in fact is a valid symmetry principle of the Onsager type. Treating the limiting case, suggested by Tresdel1, in which the species exchange monentum in pairs at a rate proportional to the difference in their average velocities, it follows that the s\}minetry relations can be esiablished if the fluxes $J^{\alpha}$ are measured with respect to an average velocity of the cormonents making II the solutions (e.g., the barycentric velocity, the mean molar velocity, the mean volume velocity, or the velocity of one component). Each choice of reference velocity yields a preferred form for the diffusion force in which the symanetry relations hold. Since the limiting case considered is a valid limiting case for important physical processes (e.g., a dilute gas of dilute molecules or diffusion of dilute speries through a solvent matrix) the results hold in general if the Onsager relations do.

\section{CORRELATION OF MLCROSTRUCTURE TO PROCESSING}

\section{a. TTT Curves of Idealized Alloys}

John E. Sanchez and John W. Morris, Jr.

Alloy processing usually depends on the control of solid state reactions to achieve a desired microstructure. The processing times and conditions are chosen to control both the extent of transformation and the mørphological festures of the change of phase, since tilese two factors together determine the ultimate microstructure. In engineering practice, the choice of processing condicions is empirical; there are now virtually no solved problems on the evolution of microstructure during processing.

However, work principally by Cajn showed some years ago that under suitable assumptions it is possible to model many features of the transformation behavior of an idealized alloy on thermal processing. The iderlizations involved treating the alloy as a thermodymamically simple, isotropic, pseudo-onecomponent material having a geometrically simple initial grain structure. Average 
kinetics of the transformation may be computed for selected values of the themodynamic properties of the alloy, and yield time-temperature-transformation curves, the nature of the nuclei dominating transformation, and information on average properties of the microstructure as a function of transformation time.

In our current work we are enploying this model to survey isothennal transfarmation behavior as temperature, grain size, and thermodynamic properties are varied over a realistic range. The extension of the model to treat transformation on contiluous heating or cooling is straightforkard.

\section{b. Computer Simulation of Transformation Behavior}

Kentor: L. Harsion and John W. Morris, Jr.

One of the most important features of alloy microstructure is its heterogeneity. Grains in real alloys are not regular in size or shape, nor are second phases distributed uniformly. This heterogeneity may have critical consequences fo: the mechanics of the alloy. It is, however, difficult to account for in an analytic model of transformation behavior, even in the most simple systems. Non-lmiformities in uicrostructure can, however, be studied through direct conputer simulation of the phase transformation. We hence began work

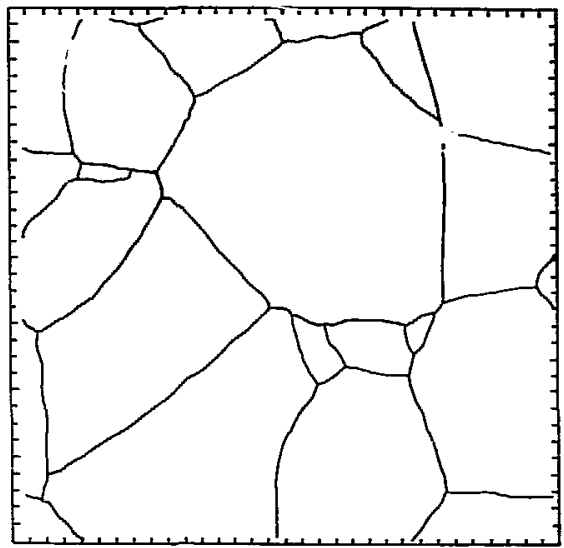

Fig. 1. Example of computer simulated microstructure assuming homogeneous nucleation and isotropic growth.

(XBL 741-5480) cn comuter simulation of phase transformations in simple systens to obtain direct evidence on characteristics of microstructure and to provide gridanas for theoretical work.

Our initial code treats a material in which it is assumed that grains grow isotropically from distributed nuclei, which may be distributed randonly or on pre-selected

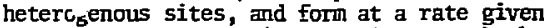
by a selected nucleation function. Both the nucleation and growth rate may be taken as functions of processing conditions. The code treats transformation in a cube with periodic boundary conditions, and yields microstructures obtained by slicing the abe along an arbitrary plane. An example of results obtained with a low, homogeneous nucleation rate is shown in Fig. 1. The code may then compute arbitrary topological properties of the microstructure.

\section{CORRELATION OF MECHANICAL PROPERTIES TO MICNUSTRUCTURE}

\section{a. P1astic Deformation of Idealized Crystals}

Ken'con L. Hanson, Dale H. Klahn and Join W. Morris, Jr.

Despite more then thirty years of research in the dislocation theory of plasticity, the number of solved problems remains small. This lack of solved problems is a serious barrier to alle; design, since a sound theory of plasticity is needed to estimate the effect of possible microstructural changes on the mechanical properties of engineering alloys. We have hence 'een conducting research on the plast $i \cdot$ deformation of idealized crystals.

Our work has focused on what appears to be the simplest realistic problem in the dislocation theory of plasticity: the deformation of a crystal through the planar glide of non-interacting dislocations. The dislocations are idealized as flexible, extensible strings of constant tension. The crystal is assumed to contain microstructural features which are idealized as randamly distributed point barriers to dislocation glide. The deformation rate of the crystal is to be determined as a function of the applied stress, the temperature, and the nature and density of point barricrs. This problem may be reduced to the problem of computing the velocity of thermallyactivated glide oi à dislocation through a field of immobile point obstacles, again as a function of applied stress, temperature, and the nature and density of the obstacles. 
The problem may be described as follows (Fig. 1). Consider a crystal plane which is the glide plane of a dislocation. Let it contain a random distribution of points which act as obstacles to dislocation glide. Let an initially straight dislocation be introduced at one edge of the plane, and let this dislocation glide into the plane under the action of a resolved shear stress. The dislocation glides freely across the empty initial area of the plane. It may also mechanically pass some of the point obstacles, either by cutting through them or folding around them to close on itself. This glide continues until the dislocation finds itself in a configuration in which it is pinned along its whole length by obstacles which it cannot pass mechanically. Such a configuration is illustrated in Fig. 1. If the dislocation is confined to the glide plane and the stress is held constant, the dislocation renains pinned in this stable configuration until themal activation carries it past at least one of the piming obstacles. It then glides until a second mechanically stable configuration is reached and the process of thermal activation must be repeated. The problem is to compute the expected value of the velocity of dislocation
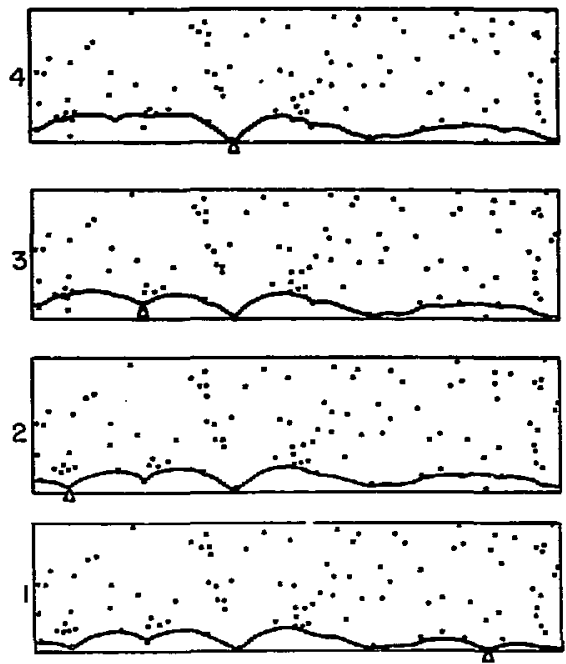

Fig. 1. Sequence of four possible configurations as a dislocation glides into a random array of point obstacles. The activation site is indicated by the symbol $(\Delta)$.

(XBL 732-5722) glide through repeated thermal activation as a function of the applied stress, the temperature, and the nature and density of the point obstacles.

The assumptions and basic equations used maxy be set in a simple dimensionless form. The glide plane of the dislocation is taken to be a square containing a random distribution of point obstacles, whose density is characterized by the area (a) per point or by the chasacteristic len 3th $1_{s}=(a)^{1 / 2}$. The total area of the square array may be written in dimensionless form as the number of points contained: $A^{*}=A / a=n, A$ dislocation in this plane is modelled as a flexible, extensible string of canstant line tension, $\Gamma$, and Burgers vector, $\underline{b}$, of magnitude $b$, taken to lie in the glide plane. Thy resolved shear stress $\tau$ inpeliing glide of this dislocation may be written in dimensionless form

$$
i^{*}=\tau 1_{s} b / 2 \Gamma
$$

Let the dislocati $\pi$, under the applied stress $T^{*}$, encounter a cc. figuration of point obstacles denoted by (i). Between trio adjacent obstacles the dislocation will take the form of a circular arc of dimensionless radius $R^{*}\left(=1 / 2 \tau^{*}\right)$. If the distance between any two adjacent ubstacles along (i) exceeds $2 R^{*}$ or if the dislocation line anywhere intersects itself then the configuration (i) is transparent to the dislocation and will be mechanically bypassed. If (i) is not transparent its mechanical stability is governed by the strength of the dislocation-obstacle interaction.

The obstacles are taken to be identical, circularly symmetric barriers to the dislocation which may be treated as point obstacles. At the $k$ thi po obstacle along $i$ the dislocation line furms the asymptotic angle $\psi_{i}^{k}\left(0 \leqslant \psi_{i}<\pi\right)$. The force, $F_{i}$, which the dislocation exerts on the $k$ th obstacle may be written in dimensionless form

$$
B_{i}{ }^{k}=F_{i}^{k} / 2 \Gamma=\cos \left(\psi_{i}^{k} / 2\right),
$$

where $0 \leqslant B_{i}{ }^{k} \leqslant 1$. The dislocation-obstacle interaction is given by a force-displacenent relation, $B(x / d)$, the effective dimensionless point force on the dislocation as it sweeps tinrough the obstacle, with $d$ the effective range of the interaction $\left(d \ll 1_{s}\right)$. The force $\beta_{c}$ measures the mechanical strength of the obstacle. A non-transparent line configuration of obstacles forms a mechanically stable barrier to the glide of a 
dislucationi under stress $T^{*}$ if $\beta_{i}{ }^{k}<\beta_{C}$ for all obstacles $k$ on $i$. If the $i$ th configuration is mechanically stable, and if we neglect the possibility of thermally activated bow-out between adjacent obstacies, the dislocat_on remains pinned in this configuration mitil one obstacle is passed through themlal activation. If the function $B(x / d)$ is monptonically increasing between the values $B_{i}{ }^{k}$ and $\beta_{c}$ (we assume it is), the activation energy may be written in dimensionless form:

$$
g_{i}^{k}=u\left(B_{c}\right)-u\left(B_{i}^{k}\right),
$$

where $u(\beta)$ is the dimensionless area under both the force dispsacement curve and a horizontal line of height $B$.

Given tlese basic equations, the statistics ot thermally activated glide are as follows: The stochastic probability for the rmal. activation past the $(i, k)$ harrier in one at tempt is

$$
P_{i}^{k}=\exp \left(-a g_{i}^{k}\right)
$$

where $g_{i}{ }^{k}$ is given by Eq. (3a.3) and $\alpha$ is a dimensionless reciprocal temperature

$$
\alpha=2 \Gamma \mathrm{d} / \mathrm{kT} .
$$

Let the dislocation attermt the obstacles with mean frequency $v$, taken to be the same for all obstacles. Then the expected residence time of the dislocation in the $i$ th configuration is

$$
\left(t^{*}\right)=\Lambda_{i}^{-1} \text {, }
$$

where $\Lambda_{i}$ is the activation parameter

$$
n_{i}=\sum_{k=1}^{N_{i}} P_{i}^{k} \text {. }
$$

The expected residence time $\left(t{ }^{*}{ }_{i}\right)$ is the mean time required for the dislocation to pass one obstacle in the 1 th configuration. We may also compute the probability $n(k, i)$ that the $\mathrm{k}^{\mathrm{th}}$ obstacle is the one passed. The result is

$$
n(k, i)=P_{i}^{k} / \Lambda_{i} \text {. }
$$

we assume that glide is controlled by themal activation in the sense that the time required for dislocation glide between successive stahle obstacle configurations is negligible compared with the time required for thermal activation past these configurations. If there are I stable dislocation configurations alcn; a particular glide path $x$ through the arrav, where $x$ is the sequence of obstacle configurations encountered; then the expected transit time of a dislocation along $x$ is

$$
\left\langle t^{*}:_{x}=\sum_{i=1}^{r}\left(n_{i}\right)^{-1} .\right.
$$

The dislocation may, of course, take any one of many available glide paths through the array. We can, however, show that the glide path is chosen through a sequence of Markov processes, and that the set of all possible elenents of the glide path, the set of all mechanically stable obstacle configurations, forms an irreducible Markov chain. It follows from the ergodic property of such chains that the probability, u, that the dislocation will follow the path $x$ is well defined. The expected transit rime is then

$$
\left\langle t^{*}\right\rangle=\sum_{\chi}^{\Sigma} u_{x}\left(t^{*}\right) \chi^{*}
$$

The velocity of glide is defined in a statistical sense only, but has the ergodic average

$$
\left(v^{*}\right)=n^{1 / 2} /\left(t^{*}\right),
$$

where $\mathrm{v}^{*}$ is the dimensimless area swept out by the dislocation per unit time divided by its projected length, the eige length of the array.

The determination of the velocity of glide through a random array of point obstacles is complicated, since the available glide paths change with the applied stress, and the relative proiabilities of chese paths change with temperature. We have, however, identified approximations whicis are useful when either $\alpha$ is large (low temperature) or the applied stress $T^{*}$ is very close to the critical resclved shear stress $\tau^{*} \mathrm{c}$ for athermal g1ide through the array. Given either Iarge $\alpha$ or $\tau^{*} \sim \tau^{*}{ }^{*}$, the dislocation will tend to follow the "minimusn angle" path $x_{0}$ obtained under the conatraint that the dislocation pass each configuration (i) by activating past the point $\mathrm{k}$ at which the angle $\psi_{i} k_{\text {takes }}$ on $i t s$ minimum value. 
These results can be used to model steadystate deformation of an idealized crystal made uf of parallel glide planes. The steady-state strain rate of such a crystal can be computed if characteristics of the mobile dislocation density are known, and if the dislocations are assumed independent of one another. Two limiting distributions of mobile dislocations lead to particularly simple equations, In the first we assume a constant density of non-irteracting, mobile dislocations ergodically distributed through the whole crystal. In this case the average glide velocitv $\left(v^{*}\right)$ is given by

$$
\bar{v}^{\star}=n^{1 / 2} / \bar{t}^{\star}
$$

where

$$
t^{*}=\frac{1}{s} \sum_{1=1}^{S}\left(t^{*}\right)_{1}
$$

is the average of the expected transit timss in a crystal containing $S$ glide planes. As a second limiting case, we assume a distribution of mobile, non-interacting dislocations which is uniform in the sense that the time average of the density of dislocations on each glide plane is the same. In this case the average glide velocity $\left(\tilde{v}^{t}\right)$ is the simple average of the expected glide velocity on the planes composing the crystal:

$$
\tilde{v}^{*}=\frac{1}{S} \sum_{1=1}^{S}\left(v^{\star}\right)_{1}=\frac{n^{1 / 2}}{S} \sum_{1=1}^{S}\left(t^{*} l^{-1} .\right.
$$

It should be apparent that if $\left(v^{*}\right)$ varies from plane to plane these two dislocation distributions will yield different values for the overall average glide velocity. The velocity $\bar{v}^{*}$ is principally influenced by glide on those planes on which the transit time $\left(t^{*}\right)$ is largest, or those on which glide is most difficult. The velocity $\widetilde{\mathbf{v}}^{\text {t }}$ is principally influenced by glide on those planes on which the expected velocity $\left(v^{*}\right)$ is largest, or those on which glide is easiest. Moreover, if $\left(v^{*}\right)$ varies from plane to plane, the two distributions will lead to qualitatively different types of crystal deformation. With ar argodic distribution of mobile dislocations all glide plares will be active and the overall deformation of the crystal will be evenly distributed among them. With a mi form distribution of mobile dislocations the deformation will be concentrated on a few well-defined planes, those on which glide is easiest.
Given the statistical relations goveming rhermally activated glide, the rate of deformation of an idealized crystal can be computed if the mechanical characteristics of the obstacle configurations encountered furing glide are known, given the stress, temperature, and nature of the dislocationobstacle interaction. To stury these characteristics we have construeted and enployed a conputer code which directly. simulates dislocation glide. The code is now in its third-generation form, and allows us to simulate glide through arrays of arbitrary size containing obstacles having an arbitrary distribution of properties at given values of stress and temperature. However, the bulk of research to date has focused on arrays of $-10^{3}$ identical obstacles whose interaction with the dislocation is of a simple "step" form, givirg dimensionless activation energy $g(\beta)=\left(\beta_{c}-\beta\right)$. We have studied in particular, (1) the critical resolved shear stress for athermal glide as a function of obstacle strength and the properties of the strength-determining configurations; (2) the characteristics of the configurations encountered during glide at firite temperat:ure, with particular emphasis on the "minimum angle" path $\chi_{0}$; (3) the velocity of glide as a function of temperature, (a), stress $\left(\tau^{*}\right)$, and obstacle strength $\left(\beta_{c}\right)$; and (4) defornation of a crystal composed of a set of randomly chosen phanes.

The strength-determining configurations in a randon array of obstacles are of central importance, since they not only determine the critical resolved shear stress $\left(\tau^{*}{ }_{c}\right)$ for athermal glide but also have a dominant influence on the velocity of thermally activated glide over a wide range of conditions. We first determined the strengths of these configurations in the following way. By fixing a stress $\left(\mathrm{T}^{*}\right)$, arbitrarily setting $B_{C}$ at 1.0 , letting the dislocation move through the array along the minimm angle path $x_{0}$, and measuring the maximm force $\left(B_{i}\right)$ for each obstacle configuration encountered, we may determine the maximm force $\left(B_{1}\right)$ which the dislocation exerts on the most stable obstacle configuration opposing glide at stress $T^{*}$. This velue $\left(B_{1}\right)$ is the minimm value the obstacle stiength $\left(\beta_{c}\right)$ may have if the obstacle array is to be mechanically stable with respect to glide. Hence if $B_{C}=B_{1}, \tau^{*} c=\tau^{*}$. Since it may be easily shown that $B_{1}$ is a monotonically increasing function of $\tau^{*}$ in a given array, a detemination of $e_{1}$ as a function of $\tau^{*}$ is equivalent to a measure of $T^{*}{ }_{C}$ as a function of $\beta_{c}$. The strength $\left(\beta_{1}\right)$ is plotted as a function of the applied stress $\left(\tau^{*}\right)$ in Fig. 2. The bars indicate the range of values obtained in tests of several arrays. 


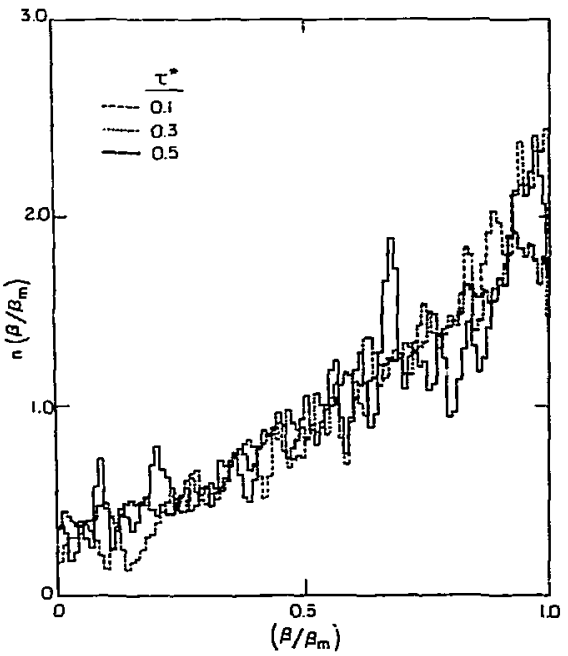

Fig. 2. The dependence of the strength $\left(B_{1}\right)$ of the most stable configuration on the applied stress, $T^{*}$. The solid bars show the range of values for four arrays. The dashed bars show the range of values for twenty arrays. The solid cirve represents the data obtained by Foremen and Makin. The dashed curve is a plot of the Friedel relation. The insert shows normalized histograms of the $B_{1}$ values oi 20 arrays at each of three stresses: $\tau^{\star}=0.1,0.3$, and 0.5 .

(XBL 7310-5464)

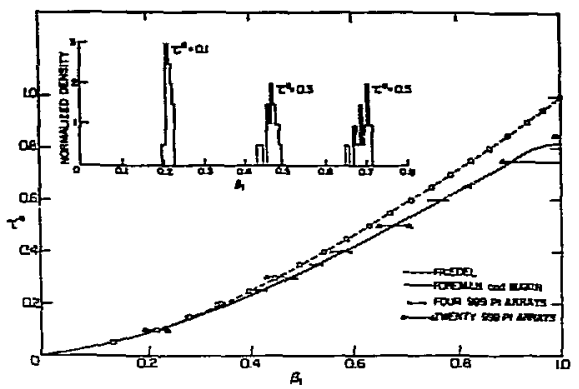

Fig. 3. Nomalized histograms of the density of forces (measured as the ratic $\left(B / B_{T T}\right)$ ) along stakle configurations of strength $B_{m} \sim B_{1}$ at each of three stresses: $\left.\tau^{*}=0.1\left(R_{\text {mI }}=0.2339\right) ; \tau^{*=0}=0 . \mathrm{F}_{\mathrm{m}}=0.5080\right) ;$ and $\tau^{*}=0.5\left(B_{\text {m }}=0.7109\right)$. (XRL 7310-5461)
At low values of $\tau^{*}$ the "Friedel equation" (dashed curve) gives a good approximation. At higher values of $\tau^{*}$ not all arrays contain stable configurations. The limiting stress at which one-half the arrays become transparent is near 0.8 . To indicate the nature of the scatter in data obtained at given stress, the insert in the figure shows normalized histograms of the $B_{1}$ values found in tests of the same arrays at three stress.

To study the distribution of fozces along strong fonfigirations we compiled and compared the $\left\{B_{i}{ }^{k}\right\}$ for strong configurations in several arrays at given values of $\mathrm{T}^{*}$. The results are plotted in Fig. 3, which shows the nommalized density of forces $\left(n\left(B / B_{m}\right)\right)$ at $\tau^{\star}=0.1,0.3$, and 0.5 . The slight drop in $n\left(B / B_{\text {mI }}\right)$ is spurious; the configurations used in the compilations have a distribution of strengths. The nomalized density fumetions nearly coincide. Contrary to a combon

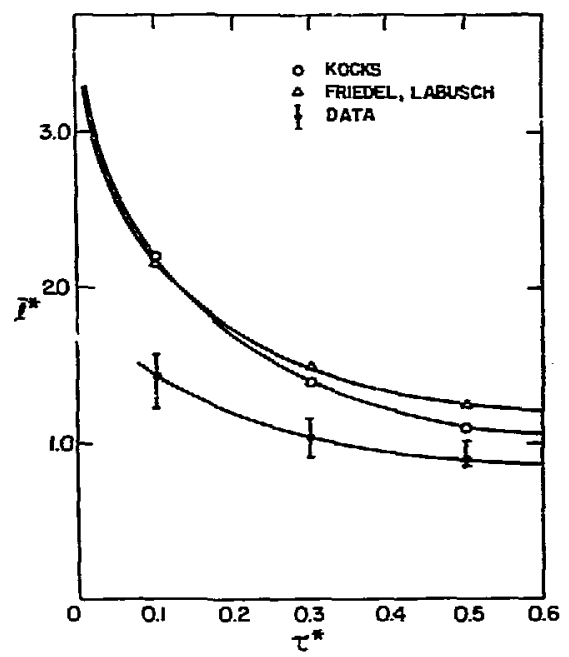

Fig. 4. The variation of the mean obstacle spacing $\left(I^{\mathbf{*}}\right)$ in the strength-determining configurations with the applied stress $\left(\mathrm{T}^{ \pm}\right)$. The solid circles give the mean value obtained using configurations from 100 ramdomily chosen arrays at $\tau^{\star}=0.1$ and 0.3 , and configurations from 20 random arrays at $\tau^{*}=0.5$. The solid bars show the range of $\overline{1}^{\star}$ for the strength-determining configurations in 20 arrays. The comparison corves plot the theoretical relations of Friedel, Labusch, and Kacks.

(XBL 7310-5463) 
speculation, there is no tendency for the distribution to become spiked at $B_{m}$ as $\tau^{*}$ becomes small.

Figure 4 shows the trend with $T^{*}$ of the mean interobstacle segment 1 dngth, $\bar{l}^{\star}$, along the strong configurations. The plot also includes conves obtained from three estimates. Contrary to a frequent assumption, the data do not tend toward the FriedelLabusch curve as $\tau^{\text {t }}$ becones small; they rather diverge from it.

Our studies of the glide path $x$ focused on the minimm angle path, $x_{0}$. We studied the distribution of strengths $\left(\beta_{j}\right)$ of the configurations in $\chi_{0}$ and the distribution of forces $\left(\left[\beta_{i}{ }^{k}\right\}\right)$ as a function of strength. The distribution of the $B_{i}$ along $\chi_{0}$ was found as a function of $\tau^{*}$ by compiling the strengths of all lines encountered along the minimum angle path in 20 arrays each containing $10^{3}$ points. Typical results are shown in Fig. 5, where we have platted the density (per array) of configurations of strength $\beta_{i}$ encountered along $x_{0}$ at stress $\tau^{\star}=0.1$, 0.3 , and 0.5. The area under these curves gives the total number of non-transparent

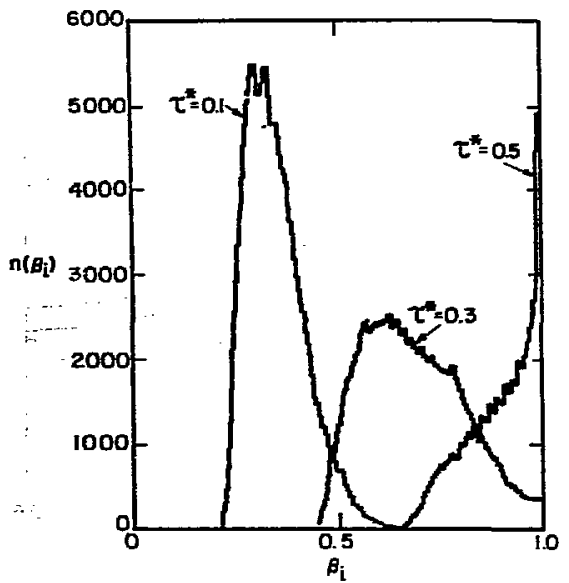

Fig. 5, Historrans showing the distribution of the strengths $\left(B_{i}\right)$ of the configurations encountered along the miniminl angle path $\left(x_{0}\right)$ at each of three stresses, $\tau^{t}=0.1,0.3$, and 0.5 . The histograms were obtained by superimposing data from 20 random arrays. The area under the curves gives the mesn number $r$ of stable configurations on $x_{0}$ per array, and is $r=890$ at $\tau^{*}=0.1,750$ at $\tau^{*}=0.3$, and 470 at $T^{*}=0.5$.

(XBL 7310-5457) configurations ( $r$ per array) along $x_{0}$ at given stress, and is $r=890$ at $\tau^{*}=0.1$, $r=750$ at $\tau^{*}=0.3$, and $r=470$ at $\tau^{*}=0.5$. Given an obstacle strength, $B_{c}$, the expected nuber of mechanically stable configurations at $\mathrm{T}^{*}$ is simply the area under the appropriate anve over the range $B<\beta_{C}$. The distribution of forces, $\left[B_{i}{ }^{k}\right]$, along a configmation in $\chi_{0}$ is, to a reasonable approximation, determined by the strength, $\beta_{i}$. Excepting the first few configurations encountered as the dislocation moves into the array, the distribution of the $\beta_{j}{ }^{k}$ always approximates the strong-line distritution for $B<B_{1}$, and will also include one or a few $B>B_{1}$ scattered over the range $\beta_{1}<\beta<\beta_{i}$. The third property of the path $x_{0}$ studied in this investigation was the spatial distribution of the strong obstacle configurations. The principal observation from this study is the tendency of the strung configurations to bunch so that they share many obstacle points in common.

As the temperature is raised from near zero the parameter $a$ decreases and the path, $x$, followed in gijde becomes a stochastic sequence different from $x_{0}$. It is difficult to characterize these finite temperature paths. However, one can make the general statement that a stochastic path $x$ will tend to contain fewer strong configurations than the minimam angle path $x_{0}$, and hence will permit somewhat faster dislocation glide.

The expected velocity of glide was studied as a function of the parameters governing temperature $(\alpha)$, stress $\left(\tau_{c}\right)$, and obstacle strength $\left(\beta_{c}\right)$. The principal observation from these studies was that, despite the fact that the path followed by the dislocation begins to deviate from $x_{0}$ at rather large values of $\alpha$, an estimate of the glide velocity which assumes $x_{0}$ gives results in reasonable agreenent with the simulation for a greater than about 50 . If we assume the path $x_{0}$ and let $c$ be large, the expected velocity of glide is given by the equation

$$
\left(v^{*}\right)=n^{1 / 2}\left[1-\left(Q-T_{1}\right)\right] \exp \left[-\alpha\left(\beta_{c}-\beta_{1}\right)\right] \text {, }
$$

where $Q$ and $T_{1}$ denote the series:

$$
Q=\sum_{i=2}^{r p} \exp \left[-\alpha\left(B_{i}-\beta_{1}\right)\right]
$$

and

$$
T_{1}=\sum_{k=2}^{N_{1}} \exp \left[-\alpha\left(\beta_{1}-B_{1}^{k}\right)\right],
$$


with $r_{0}$ the number of configurations in $x_{0}$, $B$, the strength of the strongest configuration, and $\mathrm{N}_{1}$ the number of obstacles in the strongest configuration. The series $Q$ is the lead correction term giving the decrement in ( $v^{*}$ ) due to the fact that the dislocation must activate past stable configurations in addition to the strongest along $x_{0}$. The series $T_{1}$ is the lead correction ferm giving the increment to $\left(v^{*}\right)$ from the possibility of thermal activation at a point other than the weakest in a stable configuration. The parameter $\mathrm{T}_{1}$ specifically measures this effect for the strongest configuration ( $i=1)$.

Equation (3a.15) contains only known terms. The strength $B_{1}$ may be estimated for given $\tau^{*}$ from Fig. 2. The forces $B_{i}$ in the series $Q$ may be estimated from his tograms as appear in Fig. 10. The distribution of forces $B_{1} k$ in the series $T_{1}$ may be estimated from histograms such as those in Fig. 3.

The effect of tenperature, stress, and obstacle strength on $\left(v^{*}\right)$ may be easily seen from Equation (3a.15). At large $a$, $(v *)$ obeys an Arrenhius equation with activation energy $\left(B_{c}{ }^{-B_{1}}\right)$. As a decreases ( $v^{*}$ ) will deviate from the Arrenhius equation in a direction which depends on the relative magnitudes of $Q$ and $T_{1}$. When $\tau^{\star}$ is well Delow $\tau^{\star} c, Q$ dominates and the glide velocity falls below its asymptotic curve; when $\tau^{*} \sim T^{*} c, T_{1}$ dominates and $\left(v^{*}\right)$ lies above the asyliptotic cirve.

The deformation of a simple crystal is simulated by letiing the crystal be made up of a set of independently chosen glide planes and assuming a distribution of noninteracting dislocations. The character of the results may be illustrated with a simple example. Let a hypothetical crystal contain four parallel glide planes, which we specify by randomly selecting four arrays of $10^{3}$ points, and let the obstacles impeding glide through these planes have strength $B_{C}=0.63$. The gliue characteristics of these planes are shown in Fig. 6, where we have plotted the glide velocity $\left(v^{\star}\right)$ as a function of the thermal parameter, $\alpha$, for each plane at eaci of the four strisses, $\tau *=0.1$, $0.2,0.3$ and 0.4 . As shown in the figure, at $\tau^{\star}=0.1$ and 0.2 the velocity of glide is essentially the same in the four planes, while at $\tau^{*}=0.3$ and $\tau^{*}=0.4$ the velocities scatter by an amount which increases with $\alpha$. The increasing spread in $\left\langle v^{*}\right\rangle$ as $\tau^{*}$ is raised is in large part attributable to the increasing spread in the $B_{1}$ values as $T^{*}$ is raised. At stresses of $\tau^{*}=0.1$ and 0.2 the velocity $v^{*}$ based on the ergodic distribution (e.g., V.9) is very nearly equal to the velocity $\widetilde{v}^{*}$ based on the uniform distribution. However, at $\tau^{\star}=0.3$ and $0.4, \widetilde{\gamma}^{*}$ is substantially less than $\overrightarrow{\mathrm{v}^{\mathrm{k}}}$. The tro velocities are plotted in Fig. 6. The character of the crystal deformation obtained

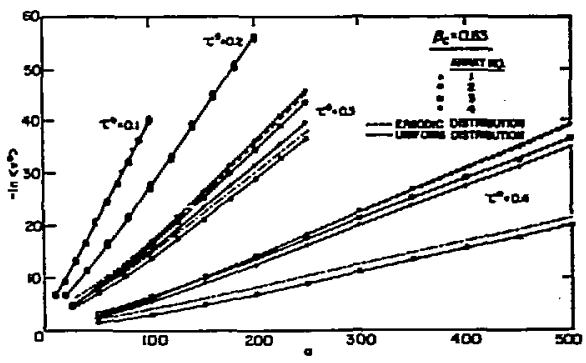

Fig. 6. Comparison of the velocitytemperature relations for four arrays of 999 obstacles having $B_{c}=0.63$ at each of four stresses. Also included are the velocitytemperature curves for a crystal made up of these four arrays under each of two assumptions: an ergodic distribution of dislocations over the planes (-..-) and a mifom distribution of dislocations over the plames $(\cdots \cdot)$.

(XB1. 7310-5467)

is illustrated in Fig. 7. Assme the hypothetical crystal contains a miform distribution of dislocations, and, moreover, that the density of these dislocations is independent of temperature and stress. In this case the strain rate $(\vartheta)$ of the crystal is simply proportional to the average glide velocity $\left(\hat{v}^{*}\right)$. Now imagine an experiment in which the crystal ic strained by a fixed amount (for example, $f=0.2$ ) at a given strain rate (for exarple, let in $\mathbf{v}^{*}=-10$ ). As illustrated in Fig. 7, both the stress required to accomplish this deformation and the final appearance of the crystal depend markelly on the temperature at which the experiment is carried cut. It is particularly interesting that at low temerature (large a) the deformation is concentrated on a unique slip plane. As temperature is raised ( $\alpha$ decreased) the inhomogeneity disappears and dip becomes uniform. This behavior is qualitatively duplicated in the deformation of real crystals.

To complete the solution of the problem of glide through random arrays of point obstacles we require analytic solutions for the properties of obstacle configmations, to 

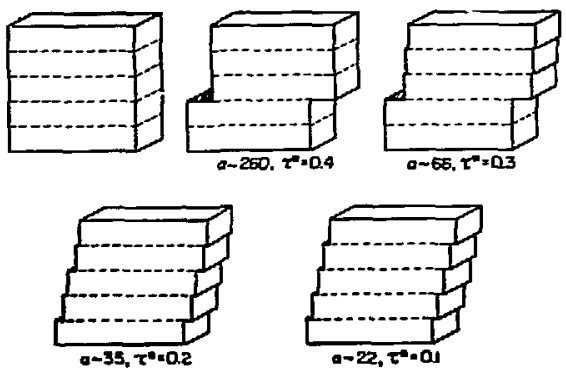

Fig. 7. I1lustration of the deformation of a hypothetical crystal made up of the four glide planes those properties are shown in Fig. 6. This figure shows the change in the appearance of the deformed crystal with temperature, assuming that the crystal contains a uniform distribution of dislocations of fixed density, and is given a total shear strain $\gamma=0.2$ at a fixed strain rate such that $-\ln \widetilde{\mathrm{v}}^{\mathrm{k}}=10$.

(XBL 7310-5468)

relieve our dependence on comouter simulation. We have made progress in Einding analytic approaches, and have recently obtained equations which allow us to estimate the properties of strength-determining configurations with reasonable accuracy.

\section{Abstracted from LBL-1166 and LBL-2276.}

\section{b. Solution lardening*}

Chol K. Syn and John W. Morris, Jr.

Much of the available theoretical work on solution hardening in metals is based on the assumption that the solute atouls may be treated as point barriers to dislocation glide. Similarly, the results of theoretical and computer simulation sturies of the glide of dislocations through fields of point obstacles can only be applied to solution hardening to the extent that a point obstacle approxination can be sustained. It is, however, known that the interaction between a solute atom and a dislocation is of relatively long range, decreasing roughly with the inverse square of the separation distance between the atom and the dislocation. Since general criteria for the validity of point obstacle representations suggest that the range of interaction must be smail (by some measure) compared to the separation of obstacle centers, the point obstacle approximation may only be useful in solution hardening theory when the solute concentration is very small.
Some indication of the applicability of the point obstacle approximation may be obtained from the solution of simple tractable models, such as the interaction of an idealized dislocation with square arrays of solute atoms which act as simple elastic strain centers in the glide plane. Previous solution of this problem have been used to argue that the point obstacle approxination is valid only in the limit of extrene dilution, $c \leq 10^{-5}$ (atom fraction). These results are, however, open to alternate interpretations; the extrene limiting conditions found may have resulted from the specific form of the point obstacle approximation used for comparison rather than from inherent shortcomings of the approximation itself. He have hence reinvestigated the problem.

A tractable problem is phrased under the following assumptions. The material is taken to be a linear elastic continunm containing a dislocation in edge orientation. The glide plane of this dislocation contains a square array of non-interacting solute atoms, modeled as elastic strain centers of magnitude determined by their size mismatch with the host lattice. The dislocationsolute interaction is assumed given by the elastic interaction between the dislocation and solute fields. This interaction is singular at the dislocation core; the singularity is artificially removed, using the DomStefansky modification of the Cottrell core correction. Taking the glide plane of the dislocation to lie midway between atom planes, we consider interaction only with solute atoms in planes inmediately adjacent to the dislocation. The sign of the dislocation-solute interaction is reversed as an atom is displacec vertically through the glioge plane of the dislocation. Hence the dislocation sees two distinct types of solute atoms. To partiy account for this, the square array of harriers may be taken to consist of alternate attractive and repulsive strain centers.

Given these approximations, an edge dislocation of Burgers' vector $b$ and line tension $I\left(-3 / 4 G b^{2}\right.$, where $G$ is the shear modulus $)$ will adopt "an equilibrium configuration under resolved shear stress $\tau$ which is governed by the differential equation

$$
\frac{d^{2} y / d x^{2}}{\left\{1+(d y / d x)^{2}\right]^{3 / 2}}=-\frac{b}{\Gamma}(\tau+\tau y z)
$$

where $\tau_{v}$ is the resolved shear stress on the dislocation due to its interaction with solute atons on the adjacent planes. If the glide plane is a close-packed plane in an fec or hep structure, 


$$
\tau_{y z}=\frac{6 G \varepsilon r_{0}^{3}}{\sqrt{6}} \sum_{m, n=-\infty}^{\infty}(-1)^{m+n} \frac{\left(y-n \ell_{s}\right)\left\{1-e^{-\left(\frac{3}{b^{2}}\right)\left[\left(x-m l_{s}\right)^{2}+\left(y-n l_{s}\right)^{2}+b^{2} / 6\right]}\right\}}{\left[\left(x-m l_{s}\right)^{2}+\left(y-n l_{s}\right)^{2}+b^{2} / 6\right]^{5 / 2}}
$$

for an array of altemate attractive and repulsive obstacles of separation $\&_{S}$, with $r_{0}$ the radius of the solvent atom and $\varepsilon$ the size mismatch parameter of the solute. Equation (36.1) was solved numerically to obtain the dislocation configuration as a function of $\tau$ for given $R_{5}$ and $E$, and to determine the stress $\left(\tau_{y}\right)$ at which the dislocation glides freely through the array of barriers as a finction of $\ell_{s}$ for given $E=0.06$. Computations were carried out for arrays of alternated attractive and repulsive barriers, for arrays of like repulsive barriers [in which case the factor $(-1)^{m+n}$ in E. (30.2) becomes 1], and for arrays of like attractive barriers $\left[(-1)^{\mathrm{m}+\mathrm{n}}\right.$ becomes -1]. Figure 1 shows the computed configurations of the dislocation at the instability point $\left(\tau_{y}\right)$ in the alternate array at five values of $\ell_{s}$.

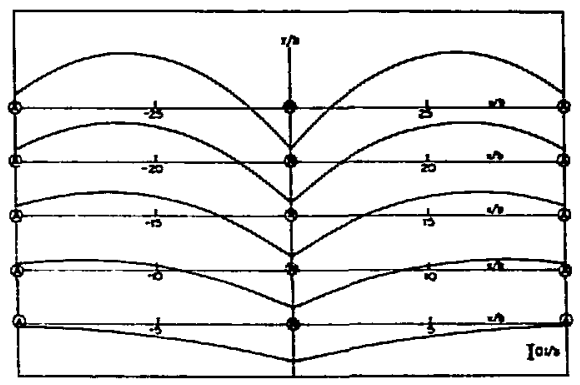

Fig. 1. Variation of equilibzium configurations of dislocation line at the fllow stress level in altemating arrays with $2 \mathrm{~s}=10 \mathrm{~b}$ to $50 \mathrm{~b}$, increasing by $10 \mathrm{~b}$.

(XBL 739-1874)

To compare these results with those obtained from the point obstacle approxination we first found it necessary to phrase the point obstacle approximaticn in precise form. This was done using the Gibbs construction illustrated in Fig. 2. We enclose the obstacle in an imaginary circle (d) of small radius (d) appreciably greater than (d'), the distance over which the dislccation (L) is significantly perturbed by the obstacle. We then extrapolate the ans of $L$ into $D$ until they meet at a point

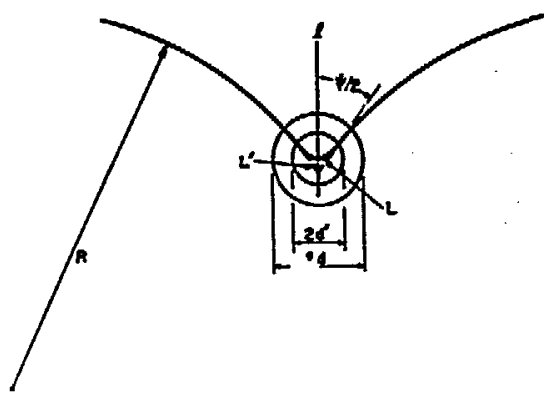

Fig. 2. A geometric construction used to define the point properties of an obstacle having a circularly symetric interaction with a dislocation.

(XBL 732-5723)

\section{$x$, letting the extrapolated lines (L')} represent the dislocation within $D$ and letting the point of intersection represent the obstacle. By equating the energy of the hypothetical configuration (L') to that of the actual configuration (L) we obtain the energy ( $\left.w^{\prime}\right)$ of the dislocation-obstacle interaction in the point obstacle representation. by minimizing this energy we estublish the conditions for equilibrium in the point obstacle representation

$$
\mathrm{tb}=\Gamma / R
$$

everyhihere on $L^{\prime}$, where $R$ is the radius of curvature of the dislocation outside $D$, and

$$
F=2 \Gamma \cos \psi / 2
$$

at $X$, whore $F$ is the equivaient point force exerted by the obstacle and $\psi$ is the asymptotic angle of the arms of the dislocation at $x$. A force-displacenent curve for the fislocation-obstacle interaction is obtained by incrementing $\tau$ so that the dislocation moves through the obstacle at equilibriun.

Force-displacement diagrans for solute ators in at tractive and repulsive orientation were found from solution of $\mathrm{Eq}$. ( $3 \mathrm{~b} .1$ ) for 
arrays of like obstacle;, after first confirming that the dislocation was perturbed only when very close ( $<1 b)$ to the obstacle. The result for a repulsive obstacle is show in Fig. 3. The maximin in the curve is related to the critical cutting angle $\left(y^{z} c\right)$ for the obstacle according to $\mathrm{Eq}$. (3b.4). This maximm is displaced by $-\delta[=0.3 \mathrm{~b})$ toward the dislocation from the physical center of the obstacle, and effectively locates the equivalent point obstacle. The force-displacement curve for the attractive obstacle is nearly the mirror image of that for the repulsive obstacle. It is, however, slightly stronger (with a lower value of $\psi_{c}$ ) and is displaces by $\delta$ from the physical center of the obstacle.

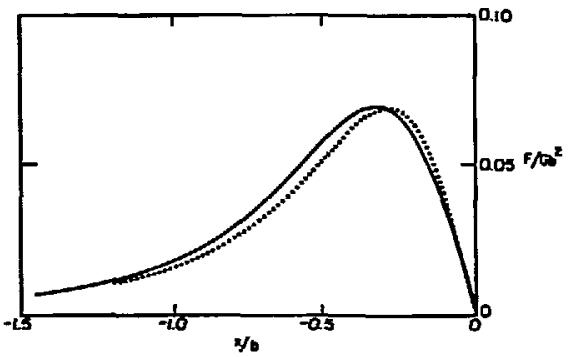

Fig. 3. The force-displacenent relation for the interaction between a dislocation and a repulsive elastic barrier of size mismatch $\varepsilon=0.06$. F is the force exerted by the dislocation on the obstacle at equilibrium as a function of distance from the physical center of the obstacle. The colid curve is couputed from the point obstacle approximation. The dotted comparison curve assumes a rigid dislocation.

(XBL 738-1655)

In the point obstacle approxipation the flow stress for glide through a square array may be written in simple dimensionless form

$$
\tau^{*}{ }_{y}=\cos \left(\psi_{c} / 2\right),
$$

where $\tau^{\star} y=\tau_{\tau^{l}} s^{b} / 2 \Gamma$. The dimensionless flow stress if hence independent of the obstacle separation $\left(l_{s}\right)$. Figure 4 shows that $\tau^{*} y$ is in fact independent of $\ell_{S}$ down to small $2_{5}$ (large solute concentration) in both the attractive and repulsive arrays; hence, the point obstacle approximation accurately : gpresents the properties of these arrays of Iike obstacles.

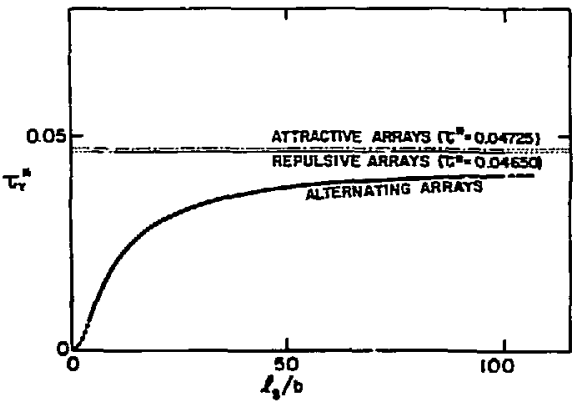

Fig. 4. Variations of the flaw stresses $T y^{*}$ with $\ell_{s} / b$. (XBL 739-1870)

The dimensiomless flow stress, $T^{*} y$, in an array of altemating obstacles is strongly dependent on $\ell_{S}$. However, this does not signify a major breakdown in the point obstacle approximation. Given the displacement of the equivalent point obstacle from the physical center fo the solute atom, and given that the displacenent reverses sign for attractive and repulsive barriers, in the pcint obstacle representation of the alternate array the dislocation "sees" a zig-zag barrier of obstacles offset by $20-0.6$ rather than a linear barrier of equispaced obstacles. In this case $\mathrm{Eq}$. (3b.5) mist be modified to

$$
\tau^{*} \sim \cos \left[\psi_{c} / 2-2 \delta / 2_{s}\right] .
$$

This equation fits the flow stress curve for the altemate array down to values of $\ell_{5}$ corresponding to $c$ near 0.01 , a range of $c$ which includes the winole range over which the assumptions underlying this analysis of solute hardening remain plausible.

We hence conclude that the point obstacle approximation can be applied to physically important cases of hardening by dilute solutes, a result supported by an analysis of experimental data.

A major assumption in our analysis of the point obstacle representation of the dislocation-solute interaction was the elastic isotropy of the Iattice. To estimate the effect of anisotropy we analyzed the dislocation-solute interaction for an edge dislocation in the basal plane of an hexagonal lattice. He specifically treated the problem of $\mathrm{Ag}$ or $\mathrm{Cd}$ ingurities in $\mathrm{Zn}$. Contours of the dislocation-solute interaction for the 
two impurities are shown in Fig. $5 \mathrm{a} \& \mathrm{~b}$, where it is assumed that the interaction is die to the anisotropic size effect only. The two impurities interact in rather different

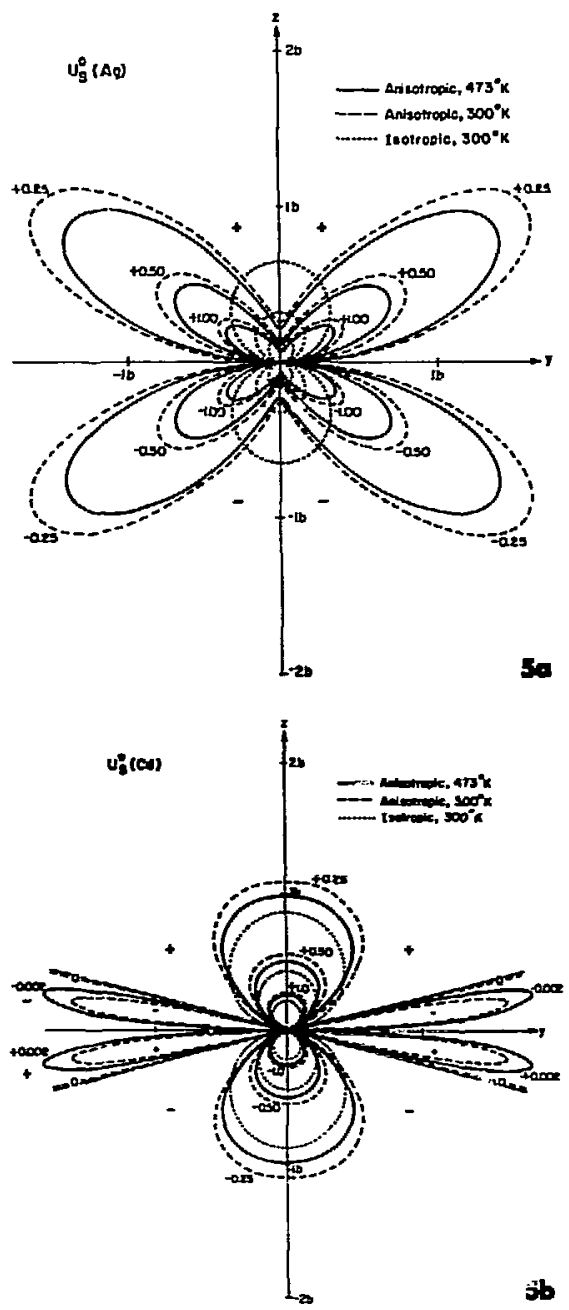

Fig. 5. (a) Anisotropic interaction energy contours for Ag and Cd.

(b) Anisotropic interaction energy contours for Ag solute atoms due to the "size" effect. (XBL 's 7310-5529, 5530 respectivelyj) thays with the dislocation: Cd prefers a site immediately beneath the dislocation, whire Ag prefers sites displaced slightly to either side of it.

The force-displacentent relations for the two impurities, acting as atcractive barriers, are shown in Fig. Ga f $^{\mathrm{b}} \mathrm{b}$ and colmared with relations computed assuming elastic isotropy. The most significant feature of these curves is the pronownced increase in the strength of the barrier when the anisotropic interaction is taken into accolnt. The peak of the cd interaction curve increases by more than a factor of 2; that of Ag rises by almost a factor of 10 . These results indicate that the solute hardening effect way be Iruch more pranominced
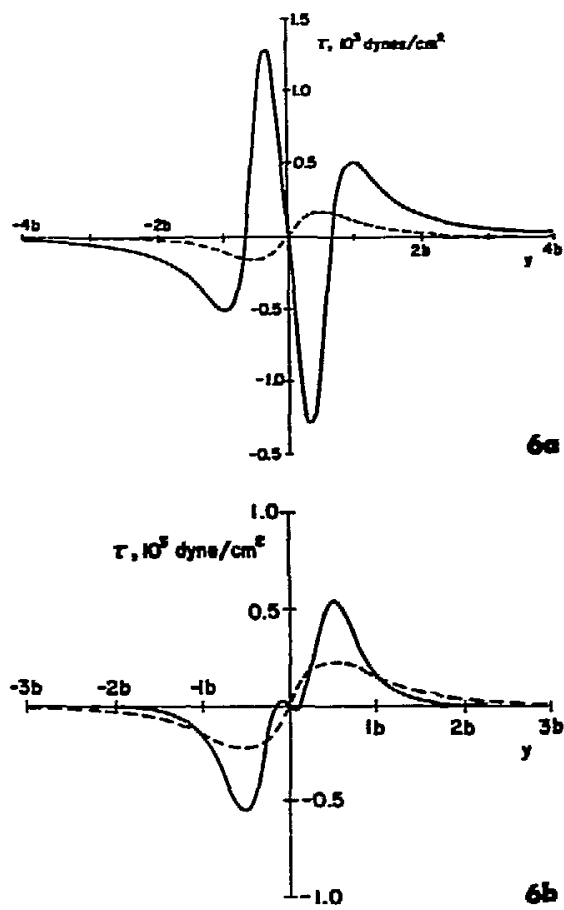

Fig. $6(\mathrm{a} \& \mathrm{~b})$ Force displacement chives for interaction of an edge dislocation in the basal plane of $\mathrm{Zn}$ with (a) an $\mathrm{Ag}$ atom and (b) a Cd atom. The solid curves inclure anisotropy. The dotted curves assune isotropy.

(XBL 's 7312-7147, 7148 respectively) 
than is guessed from isotropic elasticity, a result which may help to explain anomalies in the experimental data on solution hardening.

ॠabstracted from LBL-2270.

\section{c. High-Temperature Creep*}

Dionysics Grivas and John W. Norris, Jr.

A central problem in the study of hightemperature creep is the formulation of reliable constitutive equations to represent the creep data. ithile a precise constitutive equation camot be written down until the mechanisus of creep are fully understood, the senri-empirical relations proposed by Dorn and his associates have been shown to represent the steady-state creep behavior of a number of important systems. The relevant work is summarized in a recent review by Bird, Mukherjee, and Dorn (UCRL19056) who offer a general equation which we may write in the dimensionless form:

$$
\left(\dot{\gamma}^{*}\right)=A\left(\tau^{\star}\right)^{n}\left(\dot{d}^{*}\right)^{-m} \exp \left(-\Delta H^{\star} / R T\right)
$$

The dimensionless shear strain rate $\left(\dot{\gamma}^{*}\right)$ is given by ( $\left(\hat{k T} / \mathrm{D}_{\mathrm{O}} \mathrm{Gb}\right)$, where $\mathrm{G}$ is shear modulus and $D_{0}$ is a jre-exponential

diffusivity; $\tau^{*}$ is the dimensionless stress $(\tau / G)$; $d^{*}$ is the dimensionless grain diameter $(d / b) ; \Delta H^{*}$ is an apparent activation energy for creep; the symbols A, $m$, and $n$ represent constants. Most of the suggested constitutive equations for high-temperature creep can be drawn from Eq. (3c.1) through proper choice of the constants $A, m$, and $n$.

Fird et al. support this equation with an extensive compilation of data on the steady-state creep of metals and simple alloys. They further conclude, on the basis of limited data, that the equation will also represent the steady-state creep of materials which exhibit superplasticity. They specifically suggest that as $\tau=$ is decreased a sumerplastic material will pass through three distinct regions of steady-state creep behavior, in each of which a particular variant of the equation will be obeyed. (I) When $t^{*}$ is sufficiently large they predict a conventional steady-state creep controlled by a dislocation climb mechanisn. They hence anticipate a stress exponent (n) in thr range 4-7, an apparent activation energy $\left(\Delta H^{k}\right)$ near that for bulk diffusion, and a creep rate independent of grain size
(IIF) C). (2) For smaller $q^{*}$ they suggests a region of well-defined "superplastic" creep. On semi-enpirical grounds they anticipate $\pi \sim 2, \Delta H^{*}$ near that for grain boundary diffusion, and an inverse-square grain size dependence ( $I=2)$. (3) For very small $\tau^{*}$ they predict a behavior dominated by the coble mechanism of creep through grain boundary diffusion. They hence anticipate an exponent $n=1$, an activation energy $\Delta H^{*}$ squal to that for grain boundary diffusion, and an inverse-cube dependence on grain size $(\mathrm{m}=3)$.

Bird, Mukherjee, and Dom support their interpretation of creep in superplastic materials by ref. Totting the data of Avery and Backofen on a Pb-Sin eutectic alloy and the data of Ball and Hutchison on a $\mathrm{Zn}-\mathrm{Al}$ eutectoid. They argue that both alloys show clear regions of "conventional" and "superplastic" creep, and find some evidence for coble creep in Zn-Al at low stress. However, the data obtained in these two investigations are limited, and do not permit a full test of the proposed constitutive equations. Recently both Vaidya, Murty, and Dorn (LBL-459) and Misro and Mukherjee have reinvestigated the steady-state creep of In-Al eutectoid. Both sets of investigators claim verification of the Bird-MukherjeeDom representation. There is, however, no comparable data for the Pb-Sn eutectic. While several investigators have studied the steady-state creep of this alloy, no single investigation contains enough information to evaluate all of the ereep parameters. A superposition of data would be of dubious value, since the results of these investigations are inconsistent with one another.

We hence undertook an experimental investigation of the steady-state creep of superplastic $\mathrm{Pb}-\mathrm{Sn}$ eutectoid. The investigation was conducted in two parts. First, we used an Instron machine to measure steadystate creep ratio over a range of $\tau^{\text {th }}$ from $2 \times 10^{-5}$ to $2 \times 10^{-3}$ at temperatures from $0^{\circ} \mathrm{C}-150^{\circ} \mathrm{C}$ for sanples of grain size from 5-10 $\mathrm{wm}$. Second, we used a constant-load creep machine to measure steady-state creep rates over a range of $\tau^{*}$ from $6 \times 10^{-7}$ to $10^{-4}$ at temperatures from 98 to $170^{\circ} \mathrm{C}$ for samples of grain size from 2.8-7 um.

The tests conducted at higher stress generally confirmed the expectations of Bird, Mukherjee, and Dom. Logarithmic plots of measured steady-state strain rate as a function of applied stress divided naturally into two distinct regions: a highstress region of "conventional" creep rith slope $n-7$, and a laver-stress region of "superplastic" creep with slope n-2. These 
regions of creep behavior are apparently associated with different dominant creep mechanisms. Samples tested in the ronventional creep region showed significant primary creep, while semples tested in the superplastic region did not. Creep rates in the superplastic region depended on grain size, while creep rates in the conventional region did not. Hence, assurning that Eq. (3c.I) applies, the two distinct regions of creep behavior should be govemed by different variants of the equation.

An analysis of the creep data showed that Eq. (3c.1) could be used to describe behavior in either region. 'The conventional creep data were fit to the equation with parameters $A=1.5 \times 10^{15}, n=7.1$, $\mathbb{m}=0$, and $\Delta H^{\star}=19.4 \mathrm{kcal} /$ mol. These values were in general agreement with those foumd in conventional creep of pure lead and pure tin (LBL-831). The value of $\Delta H^{\star}$ is of the right order to be interpreted as an activation energy for bulk diffusion. The coalescence of the conventional creep data on a curve characterized by these parameters is illustrated in Fig. 1.

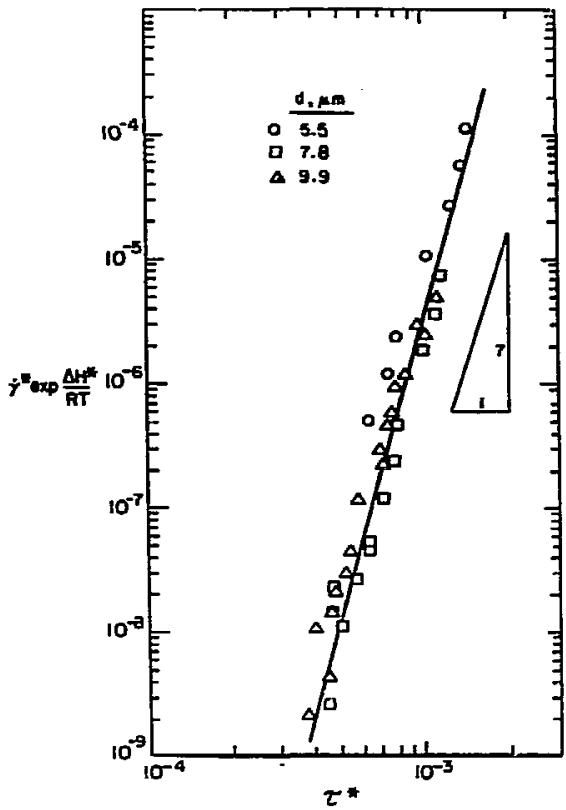

Fig. 1. Plot of $\dot{\gamma}^{ \pm} \exp \left(\Delta H^{*} / R T\right)$ vs $\tau^{*}$ for the conventional creep region revealing no grain size dependence and a slope $\mathfrak{n}=7.1$. (CBL 7211-7188)
Individual determination of the parameters characterizing superplastic creep gave $A=900, \pi-2, m=1.8$, and $\Delta H^{*}=11.5 \mathrm{kcal} / \mathrm{mol}$. These numbers are close to the anticipated values. The activation energy $\mathrm{AH}^{*}$ is of the right order to be interpreted as an activation energy for surface diffusion. The coalescence of the superplastic creep data on a curve detemined by these values of the creep farameters is illustrated in Fig. 2 .

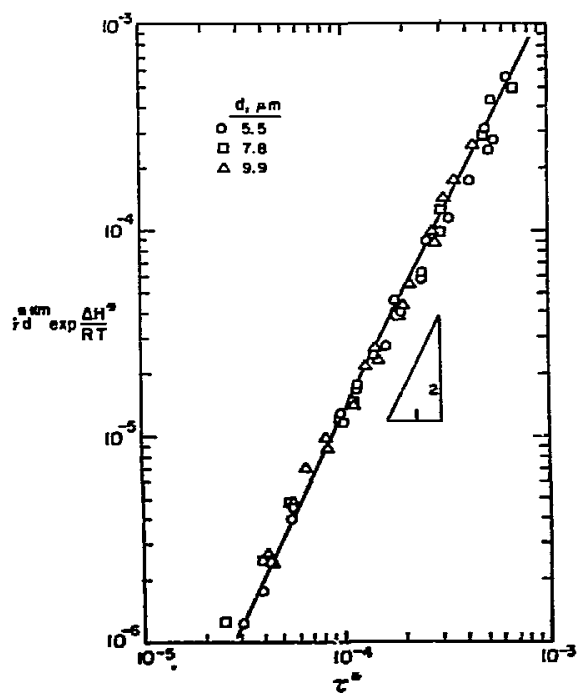

Fig. 2. P1ot of the strain rate compensated for temperature and grain size vs $\tau^{*}$ for all superplastic data.

(XBL 7311-6735)

While the Instron tests tended to support Bird et al., the lower stress tests revealed two surprising results. First, while we did observe a break in the creep curve indicating a change in mechanism at low stress, the low stress creep behavior was not of the Coble type. It was characterized by parameters $A=3.2 \times 10^{12}, n=3$, $n=2.1$, and $\Delta \mathrm{H}^{\star}=18.9 \mathrm{kcal} / \mathrm{mol}$. The coalescence of the creep data on a curve determined by these values of the creep parameters is illustrated in Fig. 3. The value of the activation energy and the concomitant ohservation of primary creep clearly point toward some bulk flow-mechanism in this low-stress region. The value of the stress exponent $n=3$ shows 


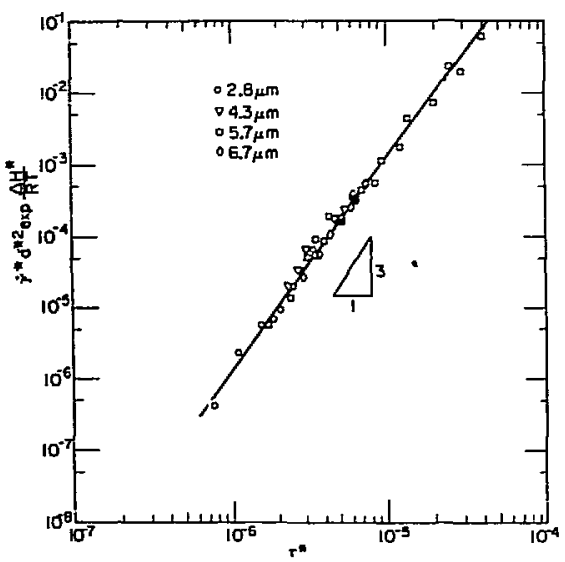

Fig. 3. A logarithmic plot of tire strain rate compensated for temperature and grain size against $\tau^{\star}$.

(XBL 7312-6972)

that superplastivity is lost at low stress in this alioy. While we camot definitively rule out a region of Coble creep at lower values of $\tau^{*}$, tests confucted at $\tau^{*}=6.10^{-7}$ and $\mathrm{j}^{*}=2.8 \mathrm{\mu m}$, well within the range in which coble creep is theoretically anticipated, failed to show any evidence for it.

Second, while tests conducted in the superplastic region in this series of experiments gave values of $n, m$, and $\Delta H^{*}$ in good agreement with those obtained previcursly, the value of A was determined to be $A=5000$, more than an order of magnitude above the value $(A=209)$ obtained in the earlier tests. This large increase in $A$ is difficult to interpret. Given that the consistency of the two test techniques has been established previously, and that errors due to grain growth during testing would go in the opposite direction, the discrepency in A values seens attributable to some difference in the samples. He suspect a difference in microstructural state, since the samples for the two tests were prepared differcnt1y. If this is the case, Eq. (3c.1) is incomplete; the parameter A contains. hidden variabies which relate to the microstructural state. Such an interpretation may explain significant discrepencies between the results previously obtained by other investigators.

"Abstracted from LBL-2519 and LBL-2532.

\section{ALLOY DESIGN*t}

Sungho Jin, John W. Norris, Jr., and Victor F. Zackay

The specific objective of our principal ailoy design activity is the identification of alloy compositions, microstructures, and processing techniques which may lead to new ferritic alloys combining high strength and toughness at very low temperatures. To accomplish this objective, initial alloy criteria were chosen to insure a beneficial combination of strength and ductility at low temperature. These may be summarized as follows:

(1) To ensure ductility the alloy most be structured so that internal stress concentrations are relieved before they lead to failure. This stress relief requires deformation of individual grains and reasunable accormondation of deformation at grain boundaries. Free deformation of the individual grains requires that hese grains be provided with potentially mobile dislocations. The dislocations may cone from a dense initial dislocation distribution or from a dense distribution of active dislocation sources. To insure the mobility of these dislocations, either the lattice concentration of free interstitials mist be very low or the low temperature dislocation-

interstitial interaction must be suppressed. The accommodation of deformation in adjacent grains is facilitated by fine grain size and requires that there be no significant brittle precipitation or film in the grain beundaries. Under aypropriate conditions a ductile grain boundary phase may be beneficial.

(2) To achieve high strength consistent with ducti'ity, available mobile dislocations mist be efficiently pinned until the applied stress becomes large, in a way which does not sactifice mobility once plastic deformation begins. One may devise solutionhardened, dislocation-hardened, or precipitation-hardened microstructures which will, at least in rough theory, function in this way. Our current emphasis is on precipitation-hardening techniques. Since the nature and distribution of precipitate phases may be specified through. a proper choice of camposition and processing, and since the precipitate distribution remains roughly constant during deformation, the precipitation-hardening mechanism has an inherent controllability which makes it appealing in zlloy design. The precipitates enployed must, of course, form in the interior of the grains and must act without poisoning or embrittling the grain boundaries. 
Given these criteria, the iron-nickeltitanium system is a naturel candidate system from which to selert initial compositions. The nickel-titanium couple in iron is known to be a chemically effective agent for reducing the free interstitial content and suppressing the embrittling effect of Free interstitials. The phase diagram of the system contains a broad two-phase ferriteaus tenite region at intermediate tcmperature, allowing use of a yariety of processing and grain refining teckniques. The ternary system also contains a series of $\mathrm{Ni}-\mathrm{Ti}$ and Fe-Ti intemetallics which form preferentially in the ferrite phase and allow the use of precipitation hardening. Moreover, previous engineering experience has shown that highnickel ferrites inherently possess good jowtemperature properties.

Initial research on these alloys for cryogenic use was carried out by $W$. Horwood (LBL-1121), who studied the properties of a low-carbon Fe-12Ni-0.5Ti alloy. By treating forged alloys at temperatures near the thophase $(a+\gamma)$ region he obtained fine-grained alloys which showed a promising combination of yield strength and Charpy impact tough ness at liquid nitrogen temperature $\left(77^{\circ} \mathrm{K}\right)$. Huwever, despite early hopes, these alloys did not prove competitive in properties with available ferritic alloys, in particuler the 9Ni cryogenic steel, at lower temperatures. Given the theoretical promise of these alloys we inaugurated new research with the specific objective of estabiishing superior cryogenic properties. The following alloy processing treatments were identified.
First, by dropping the titanium content from 0.5 to 0.25 weight percent, incorporating a cold working step into the processing sequence, and adding a low-temperature anntal at the end oi the processing sequenc2, we obtained an alloy with en impact toughr. sss exceedirg the capacity of our test $(225 \mathrm{ft}$. 1b) at both 77 and $6^{\circ} \mathrm{K}$, and with a yield itrength competitive with the best available cryogenic alloys $\left(140 \mathrm{ksi}\right.$ at $77^{\circ} \mathrm{K} ; 185 \mathrm{ksi}$ at $6^{\circ} \mathrm{K}$ ). In cooosing these modifications, the decrease in titanium content was motivated by the empirical results of exploratory tests. The cold-working step $(-30 \%$ cold work) was added principally to enharce grais refinement during subsequent anneal; cold work also affects the dislocation substrecture in ways we have not yet fully specified. The low-temperature anneal, at a temperature near $550^{\circ} \mathrm{C}$, was added on the basis of explcratory work which showed that such an anmeal causes a decomposition of the grain boundaries into a fine beaded structure, which, as transmission electron microscofy subsequently showed, consisted principally of equiaxed geains of retained austenite.

Second, we four in through further work that the cold-working step in the alloy processing could be replaced by a thermal cycling treatment. Specifically, by periodically interrupting a $700^{\circ} \mathrm{C}$ anneal with an ice brine quench, and finishing processing with a final anneal at $550^{\circ} \mathrm{C}$ we were able to obtain an alloy having a yield strength of $185 \mathrm{ksi}$ and an impact energy of $205 \mathrm{ft} 1 \mathrm{~b}$ at liquid heliun tenperature. The purpose of the
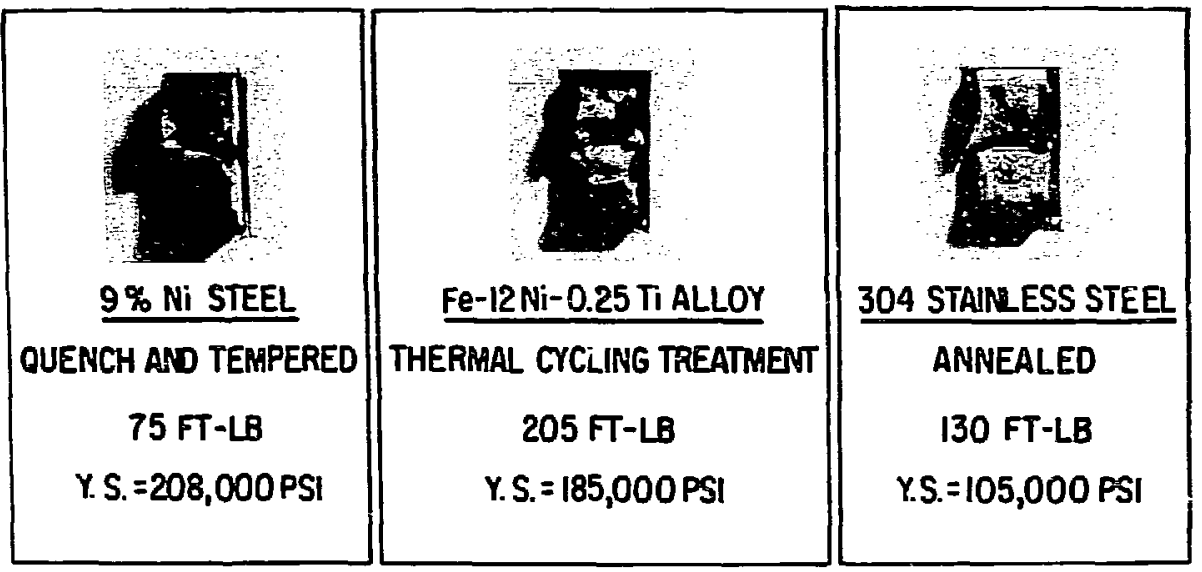

Fig. 1. Charpy specimens tested at $6^{\circ} \mathrm{K}$. 
thermal cycling treatment was grain refinement. Its effect on the substructure is not yc: known. Figure 1 illustrates the results of Charpy impact tests, at $6^{\circ} \mathrm{K}$, in which this alloy was compared with carefully processed 9Ni and 304 stainless steel.

Third, a combination of dilatometric and microstructural studies showed that the Fe-12Ni-0.25Ti alloy undergoes a shear reversion from the $a$ to the $\gamma$ phase on heating. This reversion occurs over a sma1l temperature range near $7100^{\circ} \mathrm{C}$. Given the availability of altemate trans formation paths, a themal cycling about this shear .version temperature should be a particularly -ificient grain refinement technique. We found that six cycles of alternate anneals ai 700 and $660^{\circ} \mathrm{C}$ lead to an alloy with an ultrafine grain structure of essentially equiaxed a phase, and that the $550^{\circ} \mathrm{C}$ final anneal decorated the grain boundaries of this structure with extremely fine grairs, later found to be at least in part retained austenite $(\gamma)$.

Tensile tiots ai 77 and $7^{\circ} \mathrm{K}$ showed that the engineering tensile properties of the ultrafine grained alloy were virtually identical to those previously obtained for this alloy, indicating that the tensile properties of the alloy are controlled by substructure more than grain structure. Charpy irpact tests yielded good results $\left(140 \mathrm{ft} 1 \mathrm{~b}\right.$ at $77^{\circ} \mathrm{K}, 134 \mathrm{ft} \mathrm{lb}$ at $\left.6^{\circ} \mathrm{K}\right)$, though these results are less impressive than those ontained with other processing techniques. However, in fracture toughness test at $77^{\circ} \mathrm{K}$, these ailoys showed renarkable resistance to crack propagation. Using an ASTI standard "compact tension" fracture toughmess specimens for tests at $77^{\circ} \mathrm{K}$, the ultrafine grained alloy proved virtually imsune to unstable crack growth, and subsequent fractography yielded no evidence of brittle or cleavage fracture in the sample. Figure 2 compares the loaddisplacement curves obtained at $77^{\circ} \mathrm{K}$ when $0,70-i n$. compact tension specimens of this alloy (labeled Treatment 4) were tested $i$ :. comparison with the $9 \mathrm{Ni}$ steel and a sample given an altermate treatment. Figure 3

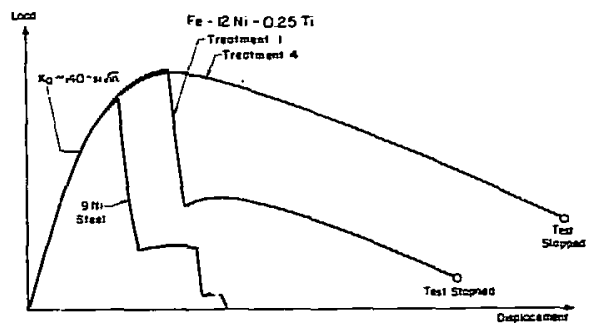

Fig. 2. Load-displacement curves obtained in fractare toughness tests comparing the 9-Nickel steel and tho treatments of the Fe-12Ni-0.25Ti alloy at $77^{\circ} \mathrm{K}$. (XBL 733-5855)

\section{9- Ni Steel}

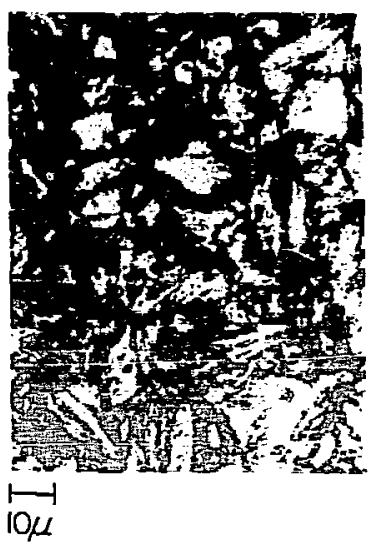

$\mathrm{Fe}-12 \mathrm{Ni}-0.25 \mathrm{Ti}$ Treatment 1

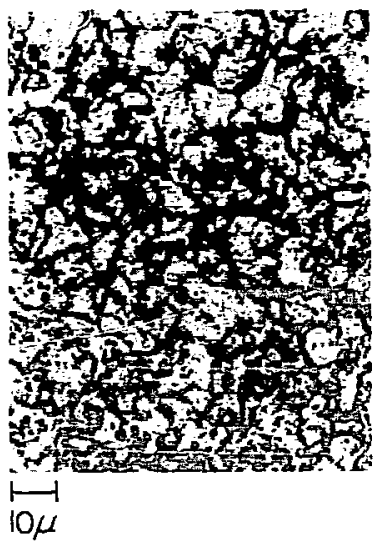

$\mathrm{Fe}-\mathrm{I} 2 \mathrm{Ni}-0.25 \mathrm{Ti}$

Treatment 4

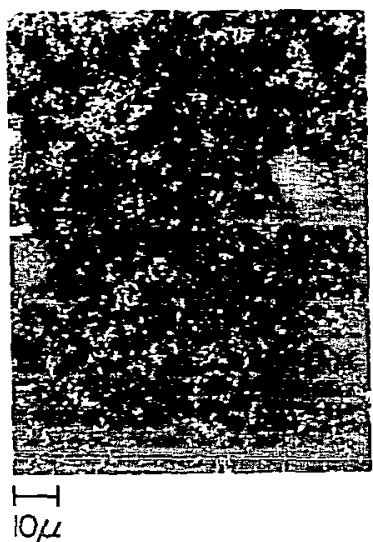

Fig. 3. Microstructures of alloys cited in Fig. 23.

(XBB 737-4458) 


\section{9-Ni Steel}

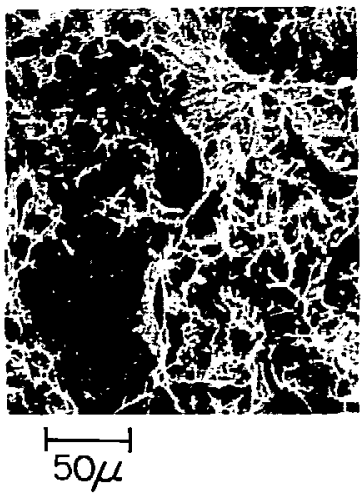

$\mathrm{Fe}-12 \mathrm{Ni}-0.25 \mathrm{Ti}$ Treatment 1

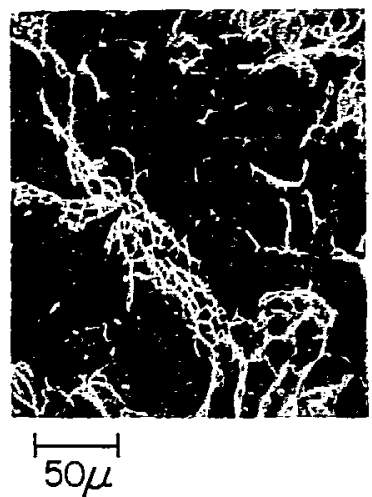

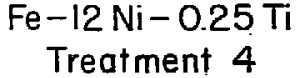

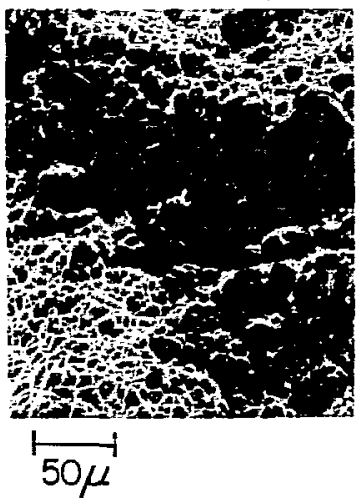

Fig. 4. Post-test fractographs of samples cited in Fig. 22. (XBB 737-4459)

compares the microstructures of the three alloys, and Fig. 4 compares scanning electron fractographs of the fracture surfaces.

Given the good low-tenperature ductility of these ultrafine-grained alloys we began further research to improve their properties while simplifying the rather complex processing sequence initially used. Further dilatometric studies showed that at typical heating rates the shear reversion $\alpha+\gamma$ initiates at a temperature slightly above $650^{\circ} \mathrm{C}$, and is completed at a temperature slightly below $730^{\circ} \mathrm{C}$. An anneai for $\sim 2 \mathrm{hr}$ at $650^{\circ} \mathrm{C}$ yields a fine lath-like mixture of $\alpha$ and $\gamma$ which reverts entirely to $\alpha$ on cooling to room temperature. Subsequent altemate anneals at 730 and $650^{\circ} \mathrm{C}$ suffice to destroy the embrittling preferential orientation of intragranular laths. We therefore selected the processing sequence shown in Fig. 5, which consists of four anneals, alternately at 730 and $650^{\circ} \mathrm{C}$. The successive steps are labelled $1 \mathrm{~A}\left(730^{\circ} \mathrm{C}\right)$, $1 \mathrm{~B}\left(650^{\circ} \mathrm{C}\right), 2 \mathrm{~A}\left(730^{\circ} \mathrm{C}\right)$, and $2 \mathrm{~B}\left(650^{\circ} \mathrm{C}\right)$. The evolution of the microstructure during this cycling is illustrated in Fig. 6. After final cycle $2 B$ the bulk of the microstructure consists of a fine mixture of platelet grains 1-4 $\mu$ m long and a fraction of a micron in the short dimensior. The preferential orientation of these platelets has been largely eliminated.

The available evidence indicates that the structure $2 B$ is virtually $100 \%$ o phase at room temperature; we have been unable to detect $\gamma$. This conclusion was supported by

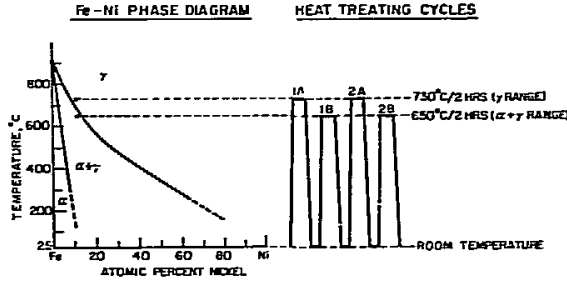

Fig. 5. The Fe-Ni equilibrium phase diagram with heat treating cycles. (XBL 739-1884)

the results of tests run for us by R. L. Miller of U.S. Steel, who enployed aduanced $x$-ray analysis techniques, which permit detection of as little as $0.1 \%$ retained $\gamma$.

We have explored the effect of adding additional $730^{\circ} \mathrm{C} / 650^{\circ} \mathrm{C}$ crcles. These do give an apparent additional refinement of the larger grains remaining in the microstructure, but the effect is small and has no obvious influence on cryogenic mechanical properties.

The change in cryogenic mechanical properties on cycling is documented in Table I and in Fig. 7.

The results of tensile tests are shown in Table I. The yield strength at $77^{\circ} \mathrm{K}$ is in the range 140-150 ksi and is rather insensitive to microstructure. The samples 


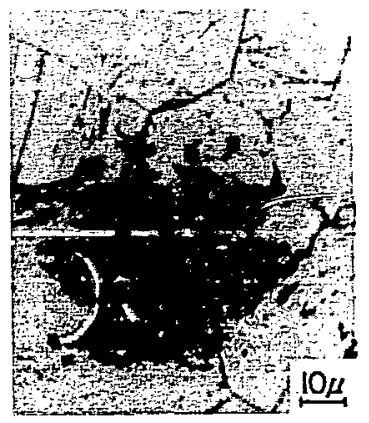

\section{MICROSTRUCTURES}
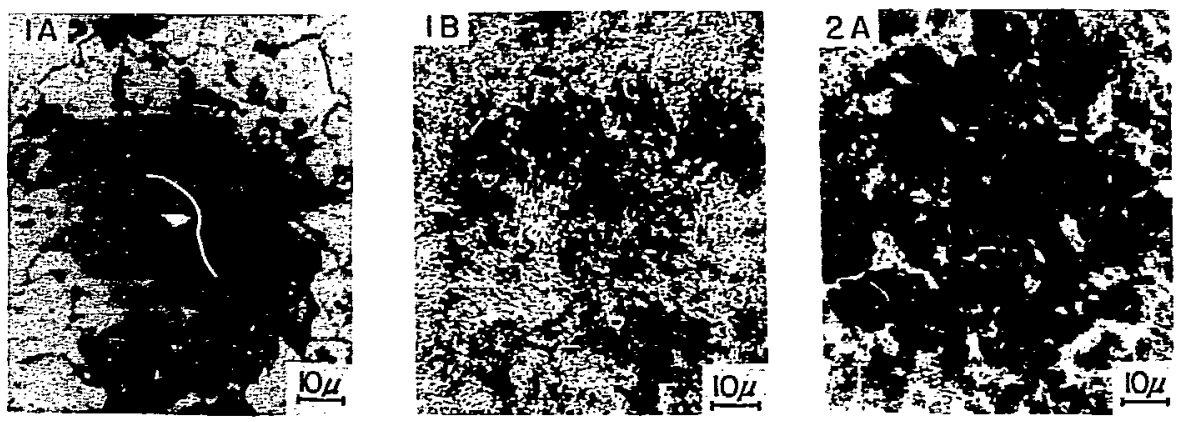

Fig. 6. Evolution of microstructure during thermal cycling.

(XBB 739-5684)

Table I. Results of the tensile tests at $77^{\circ} \mathrm{K}$

\begin{tabular}{|c|c|c|c|c|}
\hline Specimen & $\begin{array}{l}\text { Yield strength } \\
\mathrm{ksi} \text { (newron/m } / \mathrm{m}^{2} \text { ) }\end{array}$ & $\begin{array}{l}\text { Tensile strength } \\
\mathrm{ksi} \text { (newton/m } / \mathrm{m}^{2} \text { ) }\end{array}$ & $\underset{\frac{q}{b}}{\text { Elong. }}$ & R. A. \\
\hline $1 \dot{A}$ & $134\left(9.25 \times 10^{8}\right)$ & $142\left(9.80 \times 10^{8}\right)$ & 31.1 & 73.8 \\
\hline $1 \mathrm{~B}$ & $145\left(10.09 \times 10^{8}\right)$ & $151\left(10.42 \times 10^{8}\right)$ & 24.8 & 70.5 \\
\hline $2 A$ & $141\left(9.73 \times 10^{8}\right)$ & $150\left(10.35 \times 10^{8}\right)$ & 29.3 & 72.9 \\
\hline 2B & $149\left(10.28 \times 10^{8}\right)$ & $154\left(10.63 \times 10^{8}\right)$ & 26.8 & 72.1 \\
\hline
\end{tabular}


treated to stages $1 \mathrm{~B}$ and $2 \mathrm{~B}$ have slightly higher yield strength and lower tensile duetility than truse at states IA and $2 \mathrm{~A}$. These minor effects amnear to be due to the precipitation of $\mathrm{Ni}_{3} \mathrm{Ti}$ in the $\alpha$ phese at $650^{\circ} \mathrm{C}$. Electron microscopic studies indicate that the extent of this precipitation is small.

Fracture toughness tests were conducted at $77^{\circ} \mathrm{K}$ on an MTS machine equipped with a liquid nitrogen cryostat. Compact tension (WOL) specimens of $0.70 \mathrm{in} .(1.78 \mathrm{~cm})$ thickness were used. Two specimens were tested at

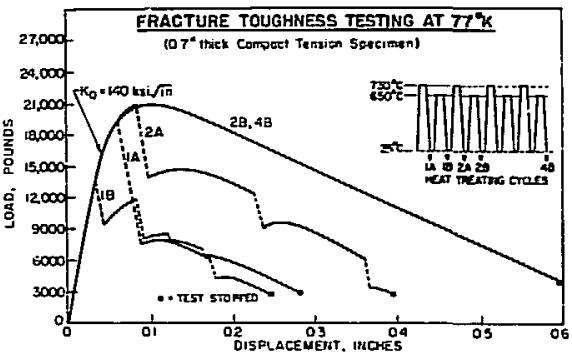

Fig. 7. Load-crack opening displacement curves in fracture toughness testing at $77^{\circ} \mathrm{K}$. (XBL 739-1854) each stage of the thermal cycling treatment.

The results of these tests are shown in Fig. 7. With the possible exception of sample 1B, these specimens were well away from plane strain conjitions; a value of $k_{0} \sim 1.40 \mathrm{ksi} \sqrt{\mathrm{ji}}$. was computed from the $10 \mathrm{ad}$ crack opening displacement (COD) curve. At stages $\mathrm{IA}, \mathrm{IB}$, and $2 \mathrm{~A}$ the alloy exhibited unstable crack propagation as marked by the dotted lines in the load-COD curves. However the fine-grained alloy 2B seened inmune to unstable crack propagation. The specimen was fully plastic, and the preinduced crack grew slowly in a stable manner until the test was stopped. The post-test fracture toughness specimens are compared with one another in Fig. 8. The brittleness of specimens $1 \mathrm{~A}$ and $\mathrm{BB}$, the repeated crack arrest in specimen $2 A$, and the tuctility of specimen 2B are visually apparent. The fracture surfaces were examined by scanning electron microscopy. Figure 9 shows scanning electron fractographs taken slightly ahead of the pre-induced fatigue crack along the center line of the sample. Specimens processed to stages $1 A$ and $I B$ propagated fracture in a quasi-cleavage mode. At stage $2 A$ the fracture mode was a mixture of quasi-cleavage and ductile rupture. Fully grain refined specimens (2B) showed ductile dingle ruture over the whole fracture surface.

Given the success of this grain refining process in imparting cryogenic toughness,

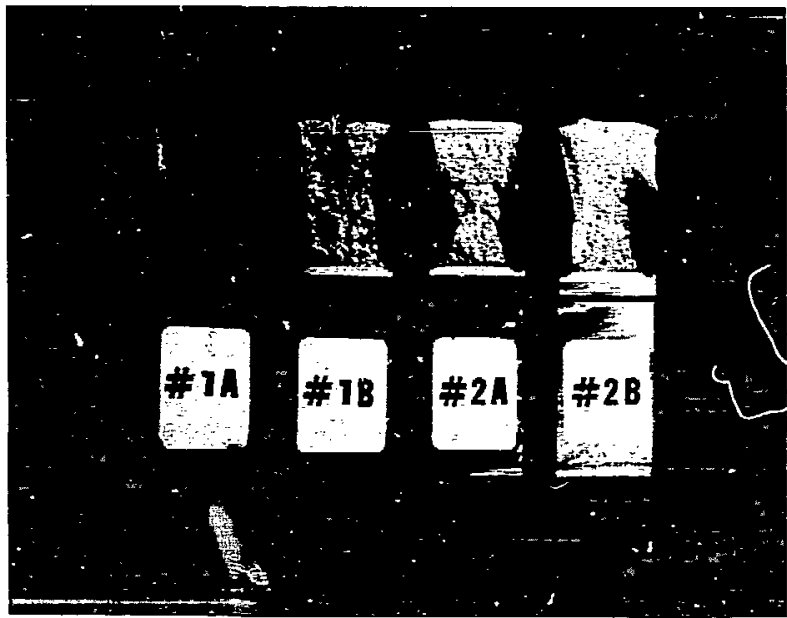

Fig. 8. Post-test fracture toughness specimens. (XBB 739-5644) 

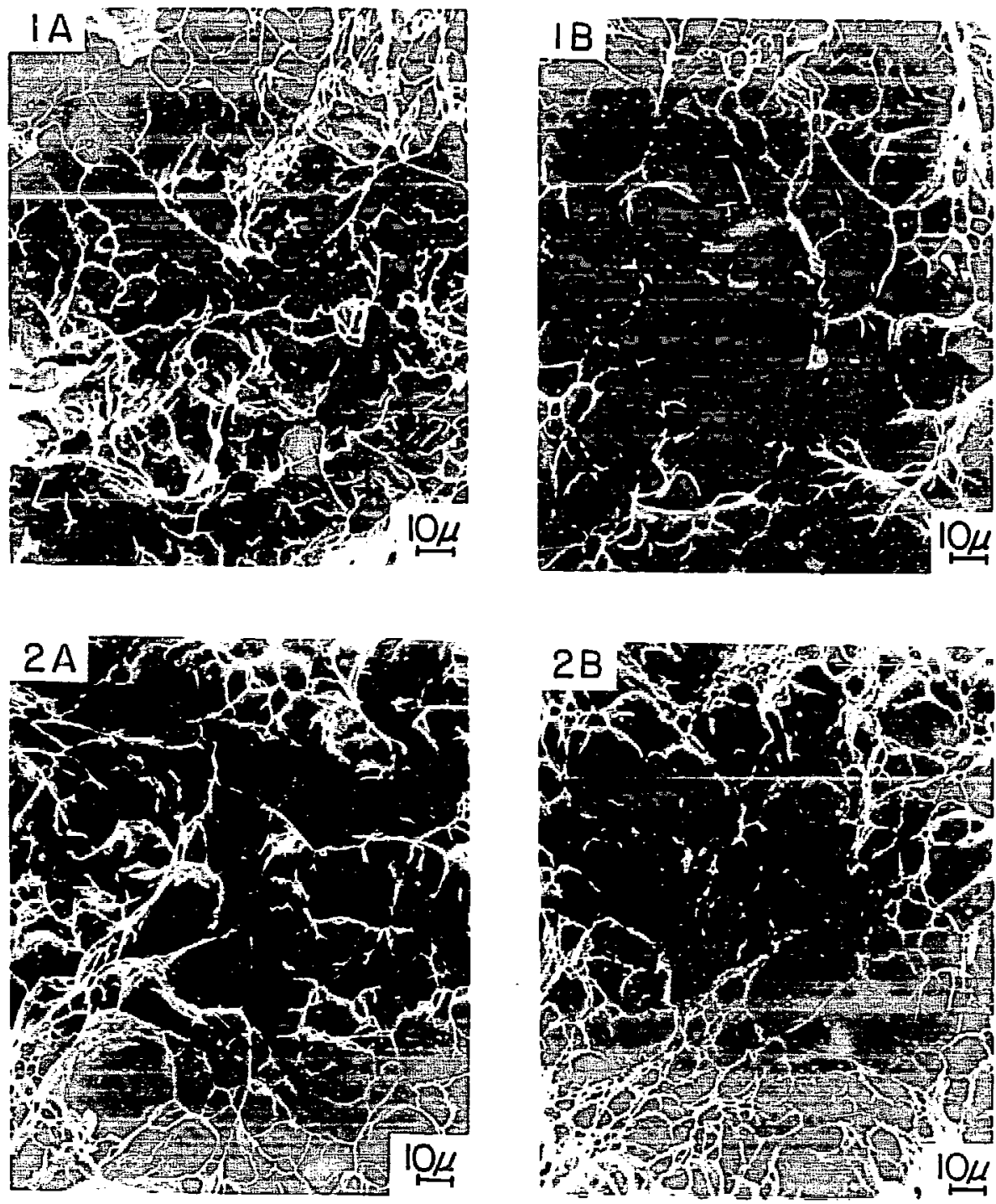

(XBB 739-5678)

Fig. 9. Scanning electron microscope fractographs of the specimens shown in Fig. 29. 
wie have atternted to modify it for alloys of higher titanim cunient to yield tough alleys of higher strength. A grain-refined Fe-12Ni-0.5Ti alloy has been made which has yield strength above $150 \mathrm{ksi}$ at $77^{\circ} \mathrm{K}$ and shows fully plastic behavior in fracture toughness tests at $77^{\circ} \mathrm{K}$ using 0.7-in. k'ol specimens. The alloy exibits a value $k_{n}>150 \mathrm{ksi} \sqrt{2 \pi}$. By increasing the $\mathrm{Ti}$ centent to $1.0 \mathrm{wt}$. I we have obtained alloys having $\sigma_{y}>160 \mathrm{ksi}$ with $k_{0}>160 \mathrm{ksi} \sqrt{\mathrm{In}}$. at $77^{\circ} \mathrm{K}$. To obtain appreciably greater strengths in tough eryogenic alloys we require techniques wich permit sipnificant age hardening without serious loss of ductility. Researth on this problem is in progress.

This research is also stpported by the Office of Naval Research.

$t_{\text {Abstracted from LBL-1483, LBL-1484, and }}$ LBL-2539.

\section{RESEARCH PLANS FOR CALEDAR YEAR 1974}

John W. Mortis, Jr.

Our research objectives during 1974 include the following:

(1) We plan to explore the vibrational properties of idealized structures whose structural energies are detemined by the Friedel potential. It is hoped that this investigation will lead to useful generalizations on the elastic properties and vibrational stabilities of simple structures.

(2) We plan to continue the studies on the theory of diffusion in multicomponent systens begun this year. Our initial goal remains a clear theoretical statement of the optimal choice of fluxes and forces for the treatment of diffusion in multi-component alloys.

(3) We plan to complete the investigation of TTT curres in simple one-component systers. Having done so, wie hope to join the theory and conputer simulation to be able to generate microstructures threugh arbitrary thermal processing. We also plan to expand the theoretical studies to treat more realistic systems.

(4) lic hope to complete an analytic solution of the problem of dislocation glide through point obstacles. Having done so, we plan to attack the next level of sophistication of the problem, in which the obstacles are allowed to have an arbitrary distribution of trechanical properties. Ne also plan to initiate study on deformation through the simultaneous glide of interacting dislocations.

(5) He plan to use the results of our research on thermally activated dislocation glide to whase more realistic mxdels of solution hardening. We hope to obtain theories of solution hardening which can be directly tested against experirental data.

(6) He plan to continue resenrch on the design of tough ferritic alloys for cryogenic use. This research vill take four paths:

(1) application of our previous results in the design of lin-Ni cryogenic alloys; (2) the design of tough alloys at strength levels to $200 \mathrm{ksi}$ at $77^{\circ} \mathrm{K}$, (3) the developmant of simplified grain refinement processes for Fe-Ni alloys; (4) research erphasizing transaission electron microseopy to sort our the evolution of microstructure during the processing of $\mathrm{Fe}-\mathrm{Ni}-\mathrm{Ti}_{\mathrm{i}}$ alloys.

\section{1973 PUBLICATIONS AND REPORTS}

J. W. Morris, Jr. and Associates

Joumals

1. K. E. Amin, K. L. Burry and J. E. Dorn, Parametrization of low-Teuperature Deformation Characteristics in Single Crystals of Mblybdenim, J. Appl. Prys. 44 (2) 615 (1973) (LBL-407 Rev.)

2. F. A. Mbhamed, K. L. Nhrrty, and J. W. Morris, Jr. Harper-Dom Creep in AI, Po, and $\mathrm{Sn}$, Netailurgical Transactions, 4, 935 (1973) (LBL-831) .

3. J. W. Morris, Jr. and P. L. de Bruyn, The Two-Phase Interface in a Simple OneComponent Fluid, J. colloid and Interface Science, 43. (1), 17 (1973) (LBL-454).

4. J. W. Mbrris, Jr. and D. H. Klahn, Statistics of the Themally Activated Gide of a Dislocation Through a Random Array of Point Obstacles, J. Appl. Phys. 44 (11), 4882 (1973) (LBL-1166).

5. E. Kahn, D. Austin, A. Mhikherjee and J. E. DOm, "The Importance of Geometric Statistics to Dislocation Notion," Advances in Applied Probability, Suplenent (2) ,

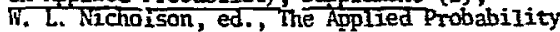
Trust, Sheffield, England (1973), LBL-130.

6. M. L. Vaidya, K. L. Murty and J. E. Dorm, "High Temperature Deformation Mechanisms in Superplastic Zn-22Al Eutestoid," Acta Met., 프, 1616 (1973), LBL-459. 


\section{LBL reports}

1. S. Jin, W. A. Horwood, J. W. Morris, Jr. and V. F. Zackay, A Sinple Method for Charpy Impact Te jting below $6^{\circ} \mathrm{K}$, LBL-1483, March 1973 (Advances in Cryogenic Engineering, in press).

2. S. Jin, J. W. Norris, Jr. and V. F. Zackay, An Iron-Nickel-Titanium Alloy with Outstanding Toughness at Cryngenic Temperature, LBL-1484 Rev., July 1973. (Advances in Cryogenic Engineering, in press)

3. C. W. Krause and J. W. Abrris, Jr., on the Relative Energies of Simple Netallic Structures, LBL-2214, Sept. 1973 (to be piblished in Acta Net.)

4. J. W. Norris, Jr. and C. K. Syn, The Point-Dbstacle Representation of the Dislocation-Dstacle Interaction, IBL-2211, Sept. 1973 (to be published in J. Appl. Phys.)

5. J. N. Norris, Jr. and D. H. Klahn, Thermally Activated Dislocation Gide Through a Random Array of Point Obstacles: Numerical Sinelation, LBL-2276, October 1973.

(to be pubiished in J. Appl. Phys.)

6. V. F. Zackay, E. R. Parker, J. W. Morris, Jr., and G. Thomas, "The Application of Materials Science to the Design of Ensineering Alloys," LaL-2261, 0ct. 1973 (to be piblished in Materials Science and Engineering).

7. Chol K. Syn, The Role of Dislocation Interaction with Solute Atcons in the Strengthening of Metals, Ph.D. thesis, LBL-2270, Novenber 1973.

8. F. M. Hamzeh, On the Destruction of Magnetic Surfaces in Totoidal Systems, LBL-1448, Nov. 1973. (Submitted to Nuclear Fusion)

9. C. W. Krause and J. W. Morris, Jr., "A Correlation between Electronegativity and Electron Density," LBL-2523, Nov. 1973

(submitted to J. Phys. F: Metal Phys.).

10. I. F. Charo, Corrosion Fatigue Properties of Surgical Implant Materials, M. S. thesis, LBLL-2207, Dec. 1973.

11. D. Grivas, K. L. Murty, and J. W. Morris, Jr., "'Steady State Creep of a Superplastic Lead-Tin Eutectic Alloy," LBL-2519, Dec. 1973 (submitted to Metallurgical Transactions)
12. S. Jin, J. W. Morris, Jr., and V. F. Zackay, "Grain Refinement Through Thermal Cycling in an Fe-Ni-Ti Cryogenic Alloy," LBL-2539, Dec. 1973 (submitted to Metailurgical Transactions)

13. D. Grivas and J. W. Morris, Jr, , "Steady State Creep of a Superplastic Lead-Tin Eutectic AIloy at Low Stress," LBL-2532, Dec. 1973 (submitted to Metallurgicai Transactions).

\section{Presentations}

1. D. H. Klahn and J. H, Morris, Jr., "Statistics of Thermaily Activated Gije," TWS Spring Neeting, Philadelphia, Mey 1973.

2. C. W. Krause and J. W. Mbrris, Jr., 'Faulting and Phase Stability in Idealiy Close-Packed Structures," TNS Spring Meeting, Philadelphia, May 1973.

3. S. Jin, W. A. Horwood, J. H. Mbrris, Jr., and V. F. Zackay, "A Ferritic Alloy Combining Strength and Toughness at Cryogenic Temperatures," TMS Spring Neeting, thiladelphia, May, 1973.

4. S. Jin, H. A. Horwood, J. H. Morris, Jr., and V. F. Zackay, "A Simple Method for Chamy Inpact Testing at $6^{\circ} \mathrm{K}, "$ Cryogenic Engineering Conference, Atlanta, Aug. 1973.

5. S. Jin, J. H. Norris, Jr., and V. F. Zackay, "An Iron-Nickel-Titanium Alloy with outstaiding Toughness at Cryogenic Temperature," Cryogenic Engineering Conference, Atlanta, Aug. 1973.

6. J. W. Morris, Jr., "Fe-Ni-Ti Cryogenic Steel," Naval Retearch Laboratory, Aug. 1973.

7. K. L. Hanson and J. W. Norris, Jr., "Stable Looping in Dislocation Gilde,", TIS/ASI Fall Meeting, Chicago, Oct. 1973.

8. C. K. Syn and J. W. Horris, Jr., 'Point Oostacle Representations of the DislacationSolute Atom Interaction," TMS/ASM Fall Meeting, Chicago, Dct. 1973.

9. S. Jin. J. W. Morris, Jr, and V. F. Zackay, 'Grain Refinement through Thermal Cycling in Fe-Ni-Ti ,uloys," TMS-ASM Fall Meeting, Chicago, Oct. 1973. 


\section{MICROSTRUCTURE, PROPERTIES AND ALLOY DESIGN}

Gareth Thomas, Principal Inveatigator

Symopses of Research Programs on Structure, Properties, and Desigl of llaterials. The folloving is a summary of our major research prograns and emphases.

\section{Overz11 Ojectives}

To understand the factors that con $\neq r o l$ the properties, especially strength and toughmess, of materials (metallic and non-metaliic). This involves studies of the effects of composition and processing on microstructure and properties, and includes basic studies of phase transformations and alloy strengthening. From fundamental principles, it is then possible to design microstructures in materials for particular applications. Special attention is paid to economic factors such as eimplicity of composition and processing.

Since commercial alloys are always heat treated to undergo some kind of phase transfomation, it is essential that we understand the mechanisms of transformations, the microstructures that result, and their influence on properties. Nucleation and growth reactions are generally not too satisfactory because of heterogeneities due to heterogeneous nucleation (e.g., at boundaries, dislocations, etc). Thus, our emphasis is on homogeneous reactions [spinodals, ordering] and martensitic reactions.

\section{Synopses of Programs}

Structural steels and duplex austeniticmartensitic alloys. Ihis program is concermed with controling economically the structure and mechanical properties of steels by compositional variables. The martensitic transformation is the most efficient way of prowucing uniformly densely dislocated structures. Such structures provide high strength and toughness often wi thout tempering, provided transformation tivinning is avoided. This means controlling composition. Bainitic transformations appear to be beneficial when compared to strong but brittle high carbon steels and considerable emphasis is now being p?aced on steels to produce $100 \mathrm{~g}$ lower bainite by continuous cooling. New methods of strengthening include dispersion hardening of martensite, e.g., by ausaging, or prior spinodal reactions so as to simulate the benefits of processes such as ausforming, but without complex thermal-mechanical treatments. Mechanisms of martensite transformations in mestastable austenites are being studied using single crystals.

Homogeneous phase transformations. Since these reactions give iniform microstructures, they have great potential for controlling both mechanical and physical properties. The spinodal systens corrently under investigation are Cu-Ni-Fe and Cu-Am-A1. Applications are directed to control of properties through control of structure and design to produco double transformations so as to increase strengthening. The program includes studies of interphase interfaces and the problem of the grain boundary precipitation reaction, which causes serious deterioration in toughness, during aging.

Fundamental studies of short range order (sro) are being dome in $\mathrm{Ni}$ base and other alloys, in order to characterize the physical nature of sro and mechanisms of the transformation. Ordering and spinodal decomposition in ceranic alloys are also under investigation, e.g., Iithium spinels. Phase transitions in ceramic systems can now be more easily studied by electron microscopy with the perfection of ion thiming and the availability of our $650 \mathrm{kV}$ high-voltage instrument. Also the acquisition of the new Phi. tips EM $301100 \mathrm{kV}$ instrument permits us to obtain lattice images. Applications of this technique to ordering sistems are now in progress.

1. DESIG OF EXPERNENTAL STRANG, TOUGH, ECONOSICAL STRICTURAL SIEEIS*

\section{Gareth Thomas}

The orera?l aim of this research program, which was started in 1963, is the development of strong, tough, structural steels utilizing martensitic and bainitic transformations as economically as possible. Thus we are concerned with alloys having sirplicity of composition and heat treatment, and in which careful attention is paid to control of purity and processing. Alloys are designed so as to ensure for martensitic treatments that there is sufficient hardenability so that no prior decomposition of austenite occurs. The objectives are to design from first principles, desirable nicrostructures in steels which provide desirable mechanical properties (strength and toughness]. Thus the experimental teciniques involve detailed metallographic analyses of series of high-purity experimental 
alloys of $1 \mathrm{rm}$, carbon, and one or two substitutional alloying elements such as $\mathrm{Cr}, \mathrm{Mo}, \mathrm{Mn}, \mathrm{Ni}, \mathrm{Co}$, etc. The microstructures are correlated with the tensile properties and fracture toughness values. $1-9$

Desirable microstructures from the point of view of good fracture resistance are: dislocated martensitic/bainitic lath ferrites, autotenpered martensite, interlath films of retained austenite, tompered martensite free from interlath carbides, and lower bainite. These structures are classified in Table I and representative micrographs are shom in Figs. 1-3.

It should be enthasized that the
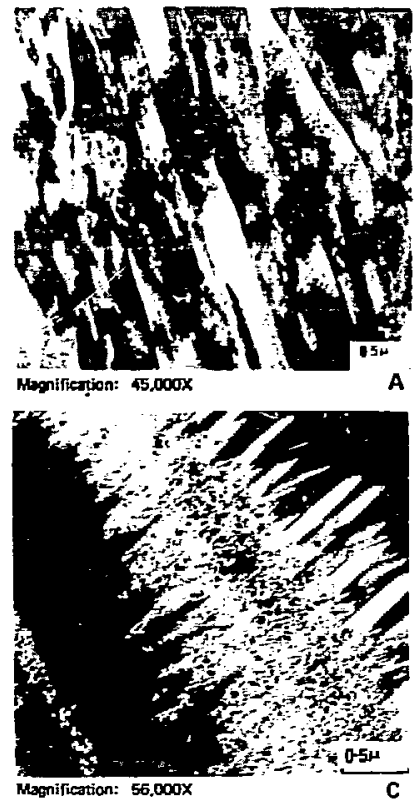

identification of retained austenite at interlath boundaries requires painstaking electron diffraction and dark field analysis as shown in Fig. 4.

One of the novel results of the work to date has been the attainnent of high strength and high toughuess (as measured by $K_{I}$ ) in experimental temary alloys (Table II) in the as-quencied untemered condition.

It is suggested that in order to obtain high strength and toughness, the following basic rules for controlling microstructure apply (assuming inigh-purity starting materials, and vacum melting).

Fig. 1 A) Pright field image of as-quenched martensite in Fe-2jNi-10Co steel. The dislocated lath structure is typical of low carbon martensites and yields high toughmess with moderate to high tensile strength. B) The bright field image of a twinned martensite plate in Fe-28.5Ni-10Co steel. C) A related dark field image of twin reflection. The corresponding selected area diffraction pattern is shown in D), and indicates the dark field image is formed by superimosed twin and matrix reflections. The complexity of the substructure, with matrix dislocations and multiple twinning, is revealed by this technique. Twinned martensite normally occurs when carbon content exceeds approximately $0.3 \%$ or in general when the total solute content increases. Except for cobalt, increasing the solute content also lowers the $M_{5}$ temperature. The presence of a high twin density in a martensitic structural steel has been found to be associated with low fracture toughness and high yieid strength. (XBB 729-4502) 

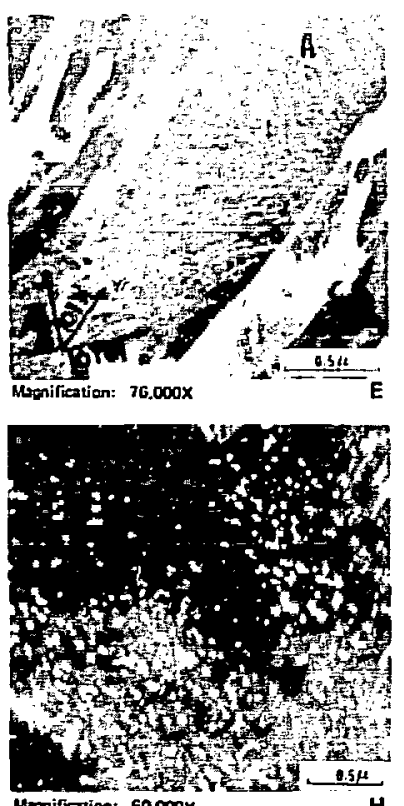

Mrification: 60,000x

H

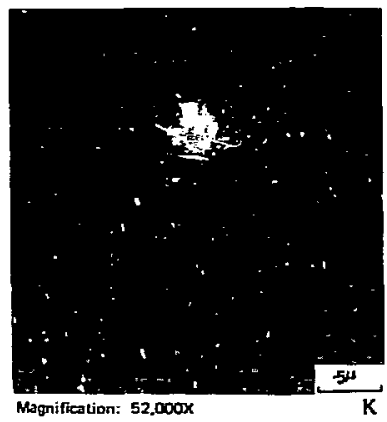

TEMPERED TWINNEO MARTENSITE
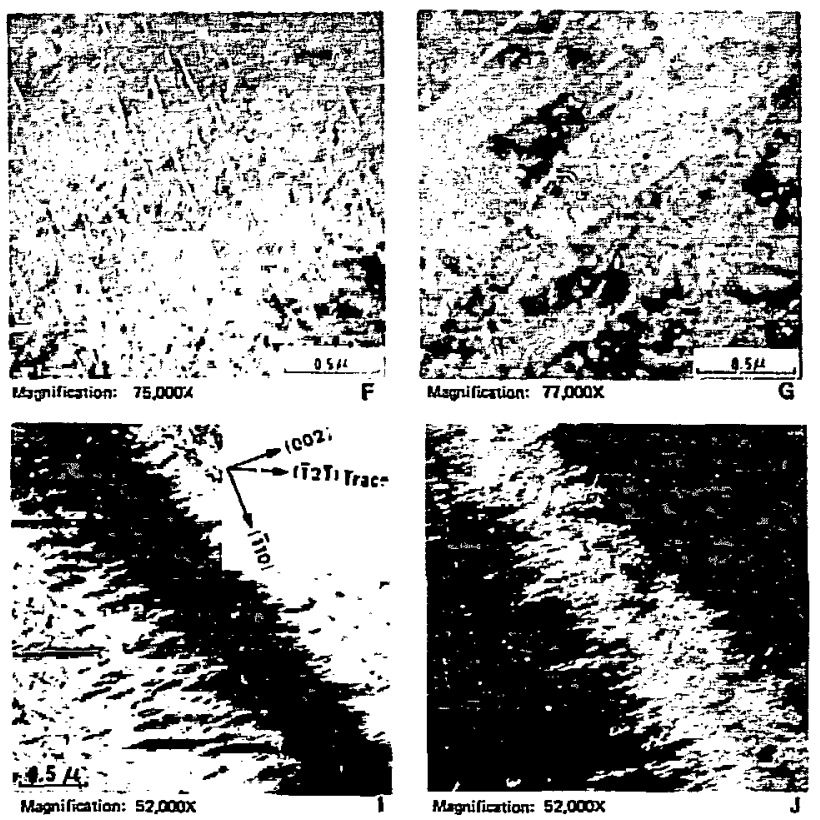

Fig. 2. Dark field imaging is an essential technique for determining the distribution and orientation of carbide precipitates in tempered martensites. (E) is a dark field image of a carbide reflection in Fe-9Ni-4Co-0.45C steel tempered at 500 showing the precipitation of epsilm carbide on $\{100\}$ martensite planes. The initial formation of $\mathrm{Fe}_{3} \mathrm{C}$ on $\{110\}$ martensite planes is seen at A. Essilon carbide will precipitate only at low tempering temperatures and dissolves upon formation of $\mathrm{Fe}_{3} \mathrm{C}$ at higher temperacures. (F) illustrates the dark field inage of a Widmanstatten pattern of $\mathrm{Fe}_{3} \mathrm{C}$ in $\mathrm{Fe}-4 \mathrm{Cr}-5.3 \mathrm{Co}-0.35 \mathrm{C}$ tempered at $400^{\circ} \mathrm{F}$ for 4 hours. This precipitate substructure is found in almost all dislocated martensites tempered at low tamperatures, as well as in as-quenched martensites which undergo autotemering due to their high $M_{5}$ temperatures. The formation of a ifidmanstatten pattern of $\mathrm{Fe}_{3} \mathrm{C}$ is accompanied by "normal" tempering behavior, viz., an increase in fracture toughness and a decrease in yield strength. At higher tempering temparatures, carbides may precipitate along martensite lath boundaries, causing a marked decrease in toughness. (G) shows a dark field image of interlati carbides in the same alloy as in (F) tempered at $800^{\circ} \mathrm{F}$ for 4 hours. At very high tempering tenquratures, the carbides spheroidize, producing an increase in toughness and a further reduction in yield strength. A dark field image of spheroidized carbides is shain in $(\mathrm{H})$, which is the same steel as in (F) tempered at $1000^{\circ} \mathrm{F}$ for 4 hours. When twimed martensites are tempered the caibides precipitate along the twin boundaries. The twin boundary carbides have been associated with a decrease in fracture toughness in structural steels. (I) is a bright field image of a twinned martensite plate in $\mathrm{Fe}-2 \mathrm{NNi}-10 \mathrm{Co}-0.1 \mathrm{C}$ steel, where the twin density is highest at the midrib. The steel was tempered at $200^{\circ} \mathrm{C}$ for 1 hour, and a Widmanstatten pattem of $\mathrm{Fe}_{3} \mathrm{C}$ is seen outside the twinned area. (J) shows a dark field image of the twins, and $(K)$ is a dark field image of the midirectional carbides on the twin boundaries. Note that the particular $\mathrm{Fe}_{3} \mathrm{C}$ reflection used in $(\mathrm{K})$ illuminates only the twin boundary carbides 
(Fig. 2 cont.) and not the Widmanstatten patt:m outside the twimed area. This points out the need for imaging several different carbide reflections in order to determine completely the precipitate morphology. These examples 三llustrate that the tempering behavior depends on the initial martensitic substructure, which can vary within each plate as well as from plate (or latin) to plate.

(XBB 729-4504 E XBB 729-4505)
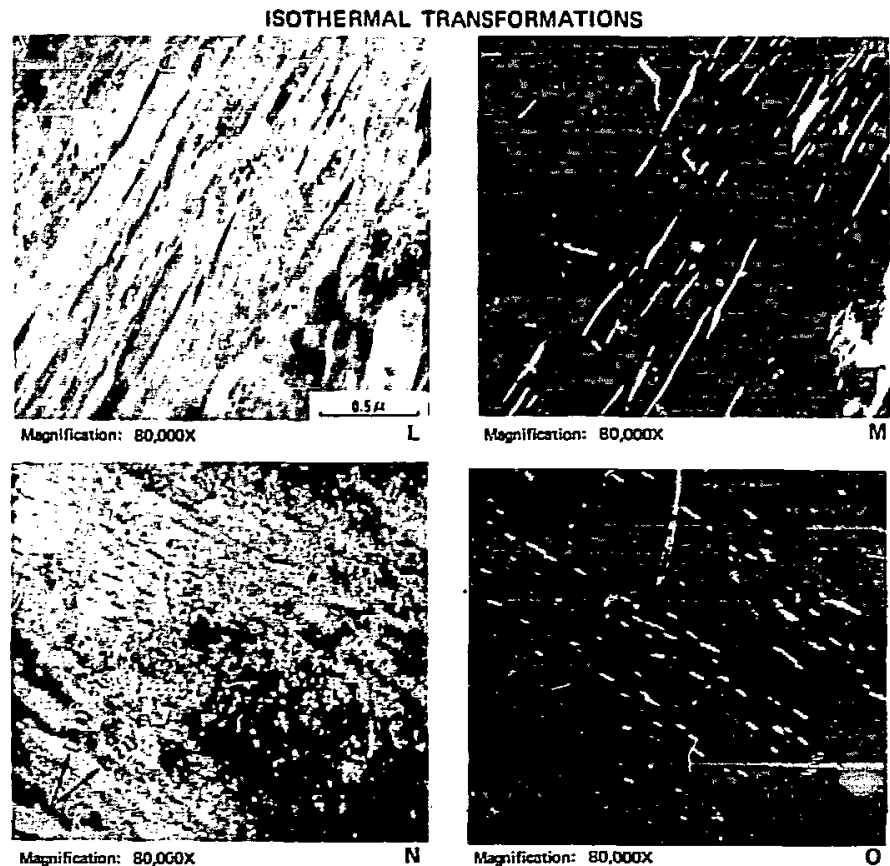

Fig. 3. (L) is the bright field image of upper bainite in $\mathrm{Fe}-4 \mathrm{Cr}-0.34 \mathrm{C}$ steel, and $(M)$ is the dark field image of a carbide reflection, showing the characteristic elongated carbides between the bainitic ferrite laths. Upper bainite, which is formed at high isothermal transformation temmeratures, normaliy has a low fracture toughness. Note the similarity of the carbide morphology in (BD) with that shown in 2(G), a tewpered mitensite which is likewise enbrittled by interlath carbides. At lower transformation temperatures the $\mathrm{Fez}$ C precipitates unidirectionally within the bainite laths. This is seen in (N), the bright field image of lower bainite in $\mathrm{Fe}-4 \mathrm{Cr}-5.3 \mathrm{Co}-$ $0.35 \mathrm{C}$ steel. The dark field image in $(0)$ reverses the contrast of the carbides. Normaily the carbides in lower bainite form at an angle of $55^{\circ}$ to $65^{\circ}$ to the long direction of the bajnite laths. The carbide morfhology of lower bainite in (L) and $(M)$ is similar to that of dislocated martensite tempered at Iow temperatures, as seen in $(2 E, F)$. Both structures also exhibit high toughmess values. It is thus seen that by comparing upper bainite with tempered martensite having interlath carbides, and lower bainite with tenpered martensite having widmanstatten carbides, there is a strong correlation between microstructure and mechanicai properties. In steels having a twinned martensitic substructure and poor toughness, it may be preferable to utilize isothermal transformations to produce dislocated lower bainite having a higher toughness due to the similarity of its structure with that of tempered dislocated martensite. 

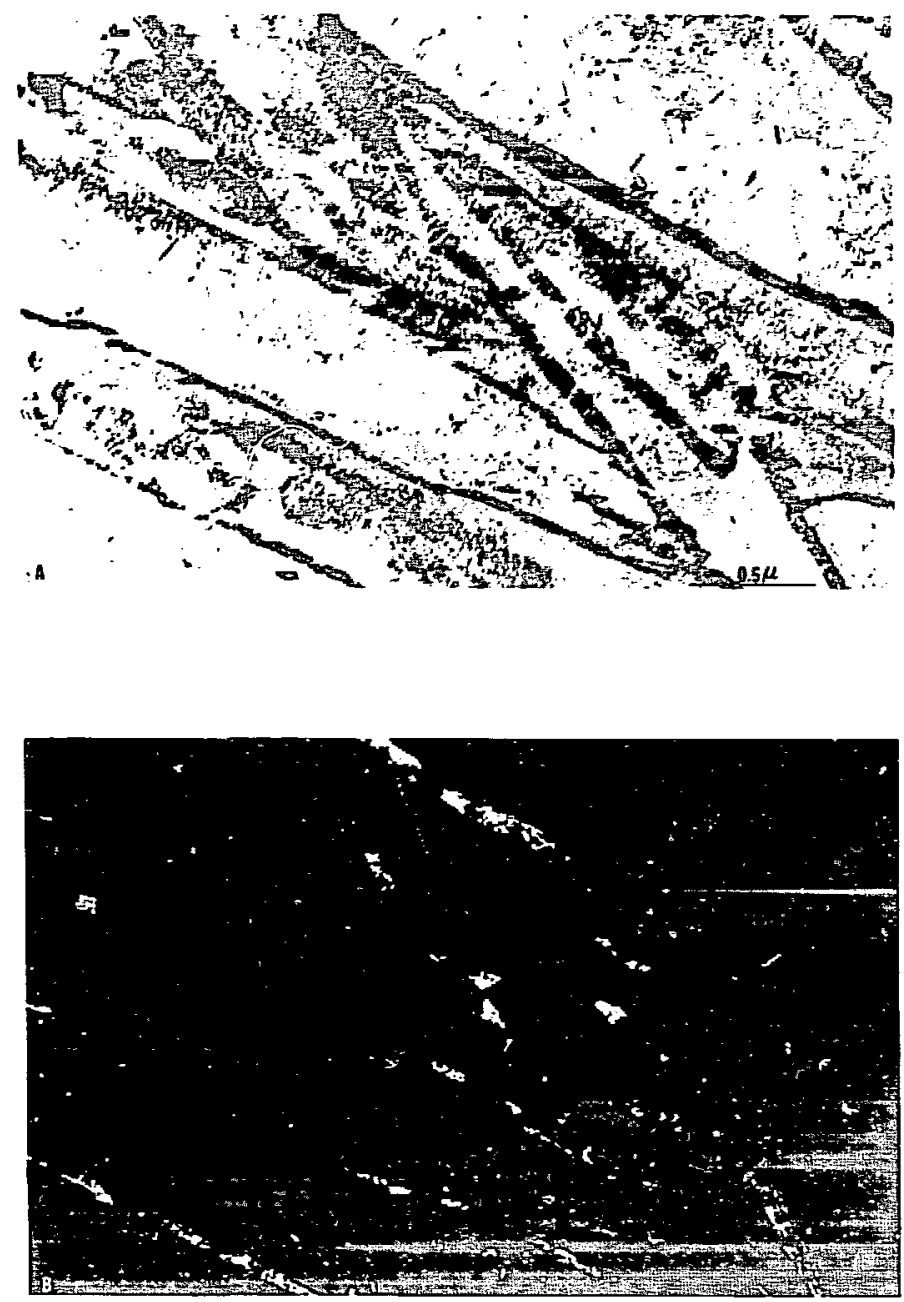

Fig. 4. Bright field inage (a) of as-quenched alloy 0817, showing retained austenite films swrounding each martensite lath. The lath boundary filns are illuminated in the dark fjeld image (b) by using an FCC diffraction spot from the retained austenite. 


\section{a. As-quenched Martensites}

Austenitize at $1100^{\circ} \mathrm{C}$ or higher to take all carbides ints solution; avoid transformation twinning by controlling carbon and keep $\mathrm{M}_{\mathrm{S}}$ above about $300^{\circ} \mathrm{C}$. This determines total alloy content permissable. For dislocated martensites the strength will mainly depend on carbon content: to avoid twinning : $\mathrm{C}<0.4 \%$. Ternary alloying additions provide desired properties, e.g., hardenability, in order to prevent prior austenite decomposition to upper bainjte, examples $\mathrm{Fe}-4 \mathrm{Cr}-0.35 \mathrm{C}$, and $\mathrm{Fe}-2 \mathrm{Mo}-0.4 \mathrm{C}$ and correspond to steels with $\mathrm{M}_{\mathrm{S}} \approx 320^{\circ} \mathrm{C}$. Som? autotenpering during the cooling below $M_{s}$ miy be beneficial to toughness provided no interlath carbides nucleate. Also the presence of interlath retained austenite is beneficial for high toughness.

\section{b. Tempered Martensites}

Toughness drops when interlath carbides precipitate; these may be delayed from forming by allowing fine films of retained austenite to remain around the martensite laths (low additions of $\mathrm{Ni}, \mathrm{Mn}$, or Co may facilitate this).

\section{c. Bainites}

Upper bainite should be avoided at all cost. Loker bainite is sinilar to tenmered martensite but does not usually contain interlath carbides. This structure is desirable for high toughness, and thus lower bainite could give att=active properties in high carbon steels $(\mathrm{C}>0.4 \%)$. This can be achieved economically if $100 \%$ lower bainite can be formed on continuous cooling from the austeritizing temperature. Research along these lines is now in progress.

Table I. Summary of microstructures of martensitic and bainite steels. ${ }^{a}$

\begin{tabular}{|c|c|c|}
\hline Constituent & Notes & Structure \\
\hline \multirow[t]{2}{*}{$\begin{array}{l}\text { Martensite } \\
\text { (as-quenched) }\end{array}$} & $\mathrm{C} \leqslant 0.4 \mathrm{M}_{\mathrm{s}} \geqslant 300^{\circ} \mathrm{C}$ & $\begin{array}{l}\text { Dislocated laths; if autotempered } \\
\text { Widmanstatten }\{110\} \text { cementite. }\end{array}$ \\
\hline & $\mathrm{C} \geqslant 0.4 \mathrm{M}_{\mathrm{s}}<200^{\circ} \mathrm{C}$ & $\begin{array}{l}\{112\} \text { and }\{110\} \text { (high } C) \text { twinned } \\
\text { plates; carbides on twins. }\end{array}$ \\
\hline \multirow[t]{2}{*}{$\begin{array}{l}\text { Tempered } \\
\text { martensite }\end{array}$} & $\begin{array}{l}\text { Dislocated } \\
\text { martensite }\end{array}$ & $\begin{array}{l}\text { Epsilon carbide with }\{100\} \text { habit } \\
\text { precipitates initially and is re- } \\
\text { placed by three variants of }\{110\} \\
\text { Widmanstatten cementite as the } \\
\text { tempering temperature is increased. } \\
\text { Alloy carbides can form at higher } \\
\text { teruperatures, or longer tempering } \\
\text { times. }\end{array}$ \\
\hline & $\begin{array}{l}\text { Twinned } \\
\text { martensite }\end{array}$ & $\begin{array}{l}\text { Single carbide variants on twin } \\
\text { boundaries; as above. }\end{array}$ \\
\hline
\end{tabular}

Lower bainite

Dislocated ferrite with singlevariant $\mathrm{Fe}_{3} \mathrm{C}$ oriented $55-65^{\circ}$ to lath; no interlath carbides; so far some new evidence for twinned ferrite; epsilon carbide possible.

Upper bainite

Dislocated ferrite; interlath carbides. No unique transition temperature for lower to upper bainite transformation--depends on composition.

atixtures of all of these constituents are possible depending on camposition and transformation kinetics. 
Table II. Examples of room temperature mechanical properties of vacum melted experimental steels.

A. Fe-Cr-C series (Ref. 8)

\begin{tabular}{|c|c|c|c|c|c|}
\hline Alloy & Treatment & $\begin{array}{c}0.2 \% \text { offset } \\
\text { yield strength } \\
\text { (psi) }\end{array}$ & $\begin{array}{c}\text { UTS } \\
\text { (psi) }\end{array}$ & el. & $\begin{array}{c}\text { Plane strain } \\
\text { fracture toughjess, } \\
\mathrm{K}_{1 \mathrm{c}}\left(\mathrm{ksi}-\mathrm{in}{ }^{2}\right)\end{array}$ \\
\hline \multirow[t]{4}{*}{$4 \mathrm{Cr}-0.17 \mathrm{C}$} & As-quenched ${ }^{\mathbf{a}}$ & 160,000 & 194,000 & 10 & 83 \\
\hline & Tentp. $200^{\circ} \mathrm{C}, 1 \mathrm{~h}$ & 166,000 & 195,000 & 9.5 & 92 \\
\hline & Tenp. $400^{\circ} \mathrm{C}, 1 \mathrm{~h}$ & 162,000 & 185,000 & 9.7 & 83 \\
\hline & Temp. $600^{\circ} \mathrm{C}, 1 \mathrm{~h}$ & 91,000 & 106,000 & 15.0 & $*$ \\
\hline \multirow[t]{4}{*}{$4 \mathrm{Cr}-0.35 \mathrm{C}$} & As-quenched ${ }^{3}$ & 240,000 & 306,000 & 5 & 70 \\
\hline & Termp. $200^{\circ} \mathrm{C}, 1 \mathrm{~h}$ & 218,000 & 275,000 & 7.5 & 92 \\
\hline & Tertp. $400^{\circ} \mathrm{C}, 1 \mathrm{~h}$ & 201,000 & 237,000 & 9.0 & 77 \\
\hline & Тетр. $600^{\circ} \mathrm{C}, 1 \mathrm{~h}$ & 126,000 & 149,000 & 17.0 & $\star$ \\
\hline
\end{tabular}
* Not determinable--even 1 in. thick specimens gave invalid $K_{1 c}$ data due to very high
toughness (note high elongations).

B. Fe-Mo-C series (Ref. 9)

\begin{tabular}{|c|c|c|c|c|c|}
\hline \multirow[t]{3}{*}{$3.85 \mathrm{MO}-0.18 \mathrm{C}$} & As-quenched ${ }^{\mathbf{a}}$ & 160,000 & 198,000 & 12.6 & 93 \\
\hline & Temp. $400^{\circ} \mathrm{C} z 1 \mathrm{~h}$ & 153,000 & 183,000 & 14 & 89 \\
\hline & Terrp. $600^{\circ} \mathrm{C}, 1 \mathrm{~h}^{\mathrm{b}}$ & 193,000 & 205,000 & 8.5 & 46 \\
\hline \multirow[t]{3}{*}{$2.2 \mathrm{Mo}-0.4 \mathrm{C}$} & As-quenched ${ }^{\mathrm{a}}$ & 258,000 & 311,000 & 2.5 & 54 \\
\hline & Termp. $400^{\circ} \mathrm{C}, 1 \mathrm{~h}$ & 197,000 & 230,000 & 5.8 & 94 \\
\hline & Tenp. $600^{\circ} \mathrm{C}, 1 \mathrm{~h}$ & 206,000 & 223,000 & 10.7 & 73 \\
\hline
\end{tabular}

a 100 m martensite.

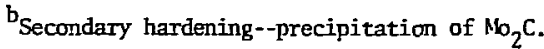

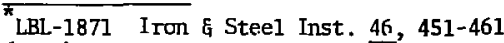
(1973) .

1. S. K. Das and G. Thomas, Structure and Mechanical Properties of Fe-Ni-Co-C Steels, Trans. ASM 62, 659 (1969).

2. D. H, hiuang and G. Thomas, Structure and Mechanical Properties of Tempered Martensite and Lower Bainite in Fe-Ni-NG-C Steels,

Met. Trans. 2, 1587-1598 (1971).

3. G. Thonas, Electron Microscopy Investigations of Ferrous Martensites, Met. Trans, 2, 2373 (1971).

4. G. Thamas and S. K. Das, Multiple
Transfornation Twinning in Ferrous

Martensites, J. Iron Steel Inst. 209, 801 (1971) .

5. M. Raghavan and G. Thomas, Structure and Mechanical Properties of Fe-Cr-C-Co Steels, Met. Trans. 2, 3433-3439 (1971).

6. I-Lin Cheng and G. Thomas, The Enhancement of Strengthening Dislocated Martensite, Met. Trans. 3, 503-516 (1972).

7. D. H. Huang and G. Thomas, Author's Reply to the Discussion of: Structure and Mechanical Properties of Tempered Martensite and Lower Bainite in $\mathrm{Fe}-\mathrm{Ni}-\mathrm{Mn}-\mathrm{C}$ Steels, Met. Trans. 3, No. 1, 343-346 (1972). 
8. J. MoMahom and G. Thomas, Development of Strong, Tough, Economical $\mathrm{Fe}-\mathrm{Cr}-\mathrm{C}$ Steels, Third Int. Conf. on Strength of Metals and Alloys, Microstructure and Design of Alloys, Cambridge, England, 1973, 1, pp. 180-184. See also J. Merlahon, M.S. thesis, LBL-1181 (1972).

9. R. A. Clark and G. Thomas, Met. Trans., to be published; see R. A. Clark, M.S. thesis, LBL-1801 (1973).

\section{THE STRESS-INDUCED MARTENSITE-ALLTTENITE} INTERFACE IN Fe-15Ni-15Cr SINGLE CRYSTALS*

Glen A. Stomet and Garett. Thanas

A single crystal stressed in the [2̄1 $\overline{1}] \mathrm{y}$ direction at $185^{\circ} \mathrm{K}$ was transformed to $5 \%$ a martensite and $28 \mathrm{E}$ martensite by volume. The austenite slip system of maximm shear stress is the (111) $\gamma[011] Y$. Figure 1 shows a two-surface study using the electron and optical microscopes. The a martensite is confined between $E$ martensite plates with the (0001)e \| (i11)y. The size of the acicular martensite crystals is controlled by the spacing of the $E$ martensite plates. These $\varepsilon$ martensite plates are seen in Fig. IA as dark vertical bands. The axes of
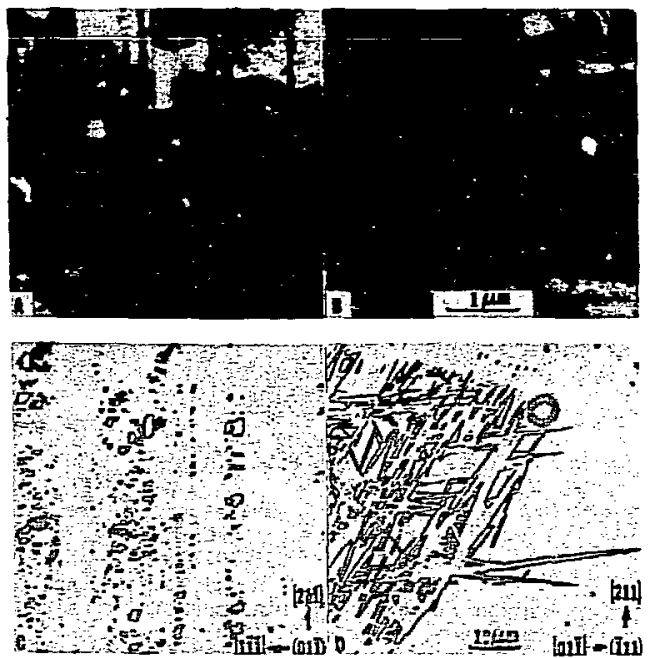

Fig. 1. Two-surface study of the $(01 \overline{1}) \gamma$ and (111) $\alpha$ planes using the electron microscope, $A$ and $B$, and optical microscope, $\mathrm{C}$ and $\mathrm{D}$. (XBB 732-586) the acicular crystals lie in the (iil) $r$ plane. The $E$ martensite habit plane is derined as the plane perpendicular to the (i11) $y$ containing the vector defining the crystal axis.

Measurements of the acicular crystal axis wete made from optical micrographs, using the trace of an $E$ plate on the (1ii) $Y$ plane cutting the (111) $\gamma$ in the $[101] \gamma$ direction as a crystallographic reference. The results that follow are in the form of unit vectors and represent the average of no less than six independent measurements. The experimental error is estimated to be $=0.25^{\circ}$. Typical variation in the axis of $\alpha$ martensite crystals with seemingly the same crystaliographic direction was $\pm 1^{\circ}$. This variation is real and not due to experimental error. Results $0 ;$ the martensite crystal axis and the habit plane normal are given below:

Nartersite Crystal Axis

\begin{tabular}{rrr}
\hline 0.63433004 & -0.12805297 & 0.76238300 \\
0.74554175 & 0.08445573 & 0.66108602 \\
0.10843235 & 0.75505982 & -0.64662748 \\
0.07606209 & -0.66600086 & 0.74206295
\end{tabular}

Habit Plane Normal

\begin{tabular}{llr}
\hline 0.51409345 & 0.80639265 & -0.29229920 \\
0.33291765 & 0.81211692 & -0.47919927 \\
0.80926454 & 0.37072710 & 0.49853744 \\
0.81294602 & 0.47234471 & 0.34060131
\end{tabular}

The physical nature of the interface is being revealed in some detail working with (011) Y foils. Figure $2 \mathrm{~A}$ is a bright field micrograph showing a a martensite crystal cutting the surface with its axis a few degrees out of the plane of the foil. Figure $2 \mathrm{~B}$ is a dark field of the same area using a $(0111) \varepsilon$ reflection. Fine lines light $\Psi$ in the interface defining a sheath surrounding the a martensite. Figure 2C is the $(200) Y$ reflection that lights up the sheath as well, indicating the a martensite crystal is surrounded by alternate regions of faulted austenite and dislocated austenite. Figure 2D is the diffraction pattern from the same area and clearly shows this alloy obeys the Kurdjumov-Sachs orientation relationship. Specifically in this diffraction pattem the $(01 \overline{1})_{Y} \|\left(\right.$ (îl1) ${ }_{Y} \|$ $[\overline{2} 110)_{\varepsilon}$ and $[\overline{1} 11]_{\gamma}\left\|[110]_{\Omega}\right\|[0001]_{E}$.

Ef forts to image interface dislocations have been unsuccessful to date. It appears clear that the interface between the phases in this alloy is a composite of dislocated austenite and faulted austenite giving rise 

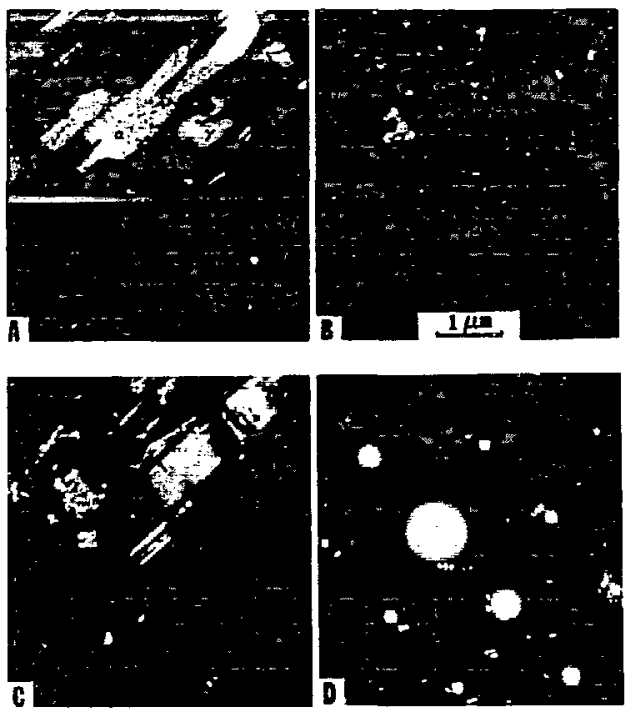

Fig. 2. Structure of the martensite interface. Bright fieid image $A$, (01i1) reflection B, (200)r reflection $C$, and diffraction pattem $D$.

(XBB 734-2477)

to hop reflections. Also the (110) $\alpha$ surface of the crystal is in contact with and parallel to the (0001)e plane. The large very thin e plates appear to control the size of the acicular a crystals and forces the long axis of the crystals to remain parallel to the austenite slip plane which is the (iil) $\gamma$ in this exarple.

WBL-1499, Prac. 31st EMSA Congress 1973, p. 110 (Claitors Publishers, Ba. Rouge)

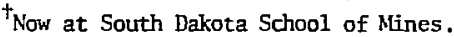

3. ON STRUCTURAL INTERPRETATION OF SHORT RANGE ORDER ${ }^{*}$

Santos K. Das ${ }^{\dagger}$ and 6 . Thomas

The various structural models of short range order in alloys are briefly reviewed. The success and limitations of structural models in interpreting diffuse scattering data are discussed. Particular enphasis is given to the systems for which the diffuse short range ordered maxima in the X-ray and electron diffraction pattems are noncoincident with the position of the superlattice reflections. The recent electron diffraction results on these systems suggest microdomains with different sperstrictures are present in the short range ordered state. The justification for such multiple microdonain configurations is discussed in the light of some recent theoretical developments.

Although evidence has been obtained for microdomains in specimens quenched from above the critical temperature $T_{C}$, so far no convincing direct evidence has been obtained for the existence of domains above $T_{c}$. This is due to difficulties of excessive themal diffuse scattering and possibly small degree of order in restricting contrast in the inages.

Current work emphasizes high-resolution lattice imaging techniques as is discussed in the following abstract.

\footnotetext{
Invited paper presented at International Symposium on Order-Disorder Transformations in Alloys, Tübingen, W. Germany, Sept. 3-6, 1973. To be published by Deutsche Gesellschaft fir Ketallk (LBL-2285).

$t_{\text {Now }}$ at Physics Divisin, Argome National Laboratory.
}

\section{LATTICE IMAGING OF ORDERED ALIOYS}

Robert Sinclair, " Klaus E. Scmeider, "t and Gareth Thomas

The determination of the structural nature of short range order in alloys has been hampered by ambiguities in the interpretation of diffuse scattering in diffraction patterns and high-resolution dark field images in the electron microscope. Since modern electron microscopes are capable of 2 A resolution, the formation of a direct lattice image (lattice fringes) has been applied to this problen. Fringe images were also computed by using many beam dynamical theory to facilitate interpretation of the experimental data. The appearance of the lattice fringe images compares favorably with theory and was foumd to be critically dependent on a number of factors, such as the reflections wed to form the image, the proximity of the specimen orientation to the exact Bragg condition, the specimen thickness, and--for the case of ordered domains in a disordered matrix--the position of the domain within the foil. 
Copper-gold alloys near the compositions CuzAu and CuAu were chosen as model systems. Images of the superlattice planes (e.g., \{100\} for $\mathrm{Cu}_{3} \mathrm{Au},\{110\}$ for $\mathrm{CuAu}$ ) clearly show the structure at antiphase boundaries (as in Fig. 1). In partially ordered alloys, regions of order appear with the pericdicity of the superlattice planes, whilst the disordered matrix shows the fundamental periodicity of the lattice (Fig. 2).

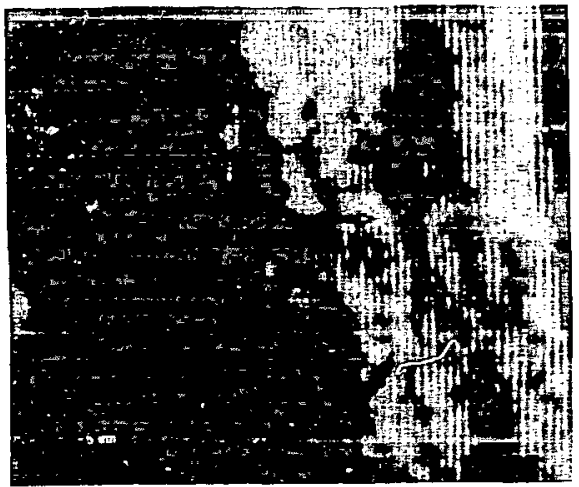

Fig. 1. Lattice inage of the $\{100\}$ planes in ordered $\mathrm{Cuz}_{3} \mathrm{Au}$. The out-of-step nature of the antiphase boundary (arrowed) is revealed in the image.

(XRB 741-285)

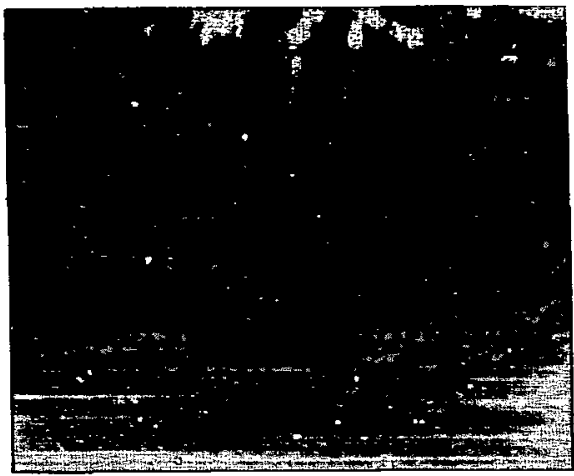

Fig. 2. Lattice image of partially ordered CuzAu. The fringe periodicity in the disordered matrix corresponds to the $\{200\}$ d-spacing of the alloy. The ordered domains, approximately 2.5 min in dianeter, are manifested in the image by alternately wider and narrower white fringes and thus possess the periodicity of the superlattice.

(XBB 741-286) $\overline{\text { Supported by NSF. }}$
${ }_{\text {Deutsche Forschung., Fellowship }}$

5. THE METASTABLE PHASE Ni 2 MO AND THE INITIAL STAGES OF ORUERING IN Ni-No ALUOYS*

Santos K. Das ${ }^{\dagger}$ and Gareth Thomas

The initial stages of ordering in Nisto and $\mathrm{Ni}_{4} \mathrm{Mlo}$ have been investigated by transmission electroll microscopy and diffraction. The development of long-range order in $\mathrm{Ni}$ sto $^{\circ}$ is associated with decomposition into the two metastable phases $\mathrm{Ni}_{2} \mathrm{Mo}$ and $\mathrm{Ni}_{4} \mathrm{Mo}$, wich are eventually replaced by the equilibrium $\mathrm{Ni}$ Mb at a later stage of ordering. Evidence for the presence of the metastable $\mathrm{Ni}_{2}$ lo phase was also found during the early stages of ordering of $\mathrm{Ni}_{4} \mathrm{Mlo}$. Examples of identification are shown in the image and diffraction pattem of Fig. 1. The presence of the metastable phase $\mathrm{Ni} 2^{\mathrm{it}}$

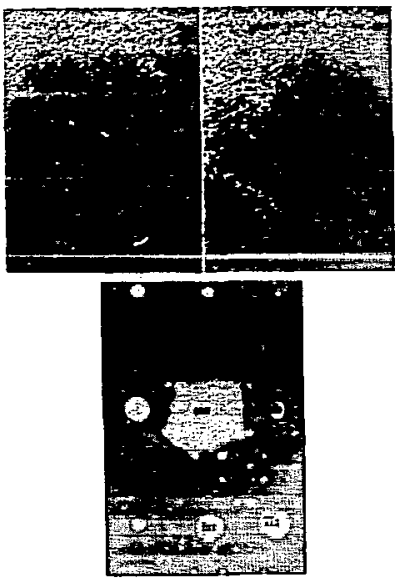

Fig. 1. Micrographs of $\mathrm{Ni}_{4} \mathrm{Hb}$ sample after aging for $8 \mathrm{~h}$ at $650^{\circ}$ : (A) bright fielt micrograph, (B) dark field micrograph of $\mathrm{Ni}$ 4ho superlattice spot marked $t$ in the [121] diffraction pattem shown in (C), which corresponds to the area in Fig. $1(A)$. In (C) the foil has been tilted from that in (A) to obtain a symmetrical diffraction pattern. The single large black-white arrass in (C) point to weak Nizlo superlattice reflections, and the small double arrows are double diffraction spots from $\mathrm{Ni}_{4} \mathrm{Plo}$. 
at $\mathrm{Ni}_{4} \mathrm{Ml}$ composition and that of $\mathrm{Ni}_{2} \mathrm{Ho}$ and $\mathrm{Ni}_{4} \mathrm{Mb}^{\mathrm{Ho}}$ at $\mathrm{Ni}_{3} \mathrm{lla}$ composition can be explained in terns of the recent themodynamic calculations of the ground states of ordered binary alloys by Cahn and his co-workers. Figure 2 shows an example of the good agreement between theory and our results.

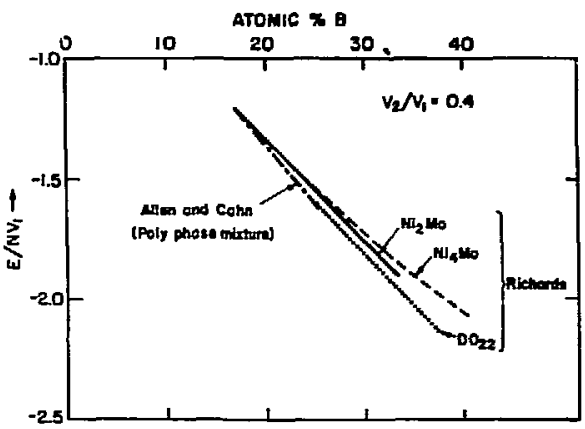

Fig. 2. The theoretical curves for energy of mixing $v$ r:sus composition for $\mathrm{DO}_{22}$, $\mathrm{Ni}_{4} \mathrm{Mo}$, and $\mathrm{Ni}_{2} \mathrm{Mo}$ structures calculated using $\mathrm{v}_{2} / \mathrm{N}_{1}=0.4$.

(XBL 717-7037A)

\footnotetext{
1.BL-1868; Physica Status Solidi, in press 1973. $t_{\text {Now }}$ at Physics Division, Argonne National Laboratory.
}

\section{LOSS OF COEERENCY IN SPINONALLY DEOOMPOSED Cu-Ni-Fe ALLOYS*}

\section{Ronald J. Livakt and Gareth Thomas}

Coarsening of the spinodal microstructure in copper-nickel-iron alloys has been studied in detail using transmission electron microscopy. Loss of coherency in this lamellar microstructure occurs by the capture of slip dislocations and subsequent miltiplication at the interphase interfaces. Based on the observations, it is proposed that the multiplication process providing the misfitaccomodating dislocation loops proceeds by the spiraling of the captured dislocations around the platelets by climb, similarly to the formation of helical dislocations. Because the Burgers vector of the captured dislocation is inclined at $45^{\circ}$ to the $\{100\}$ interface, diffusion-controlled rotation of the initial $[100\}$ coherent interface toward the $\{110\}$ plane containing 6 occurs in order to lower the interfacial energy. This rotation of the semi-coherent interfaces results in a change of the initial platelet morphology to a microstructure containing rod-shaped and more equiaxed particles.

\footnotetext{
Abstract of LBL-1842; Acta Met., in press.

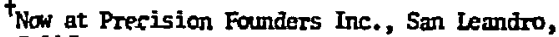
Calif.
}

\section{RESEARCH IN PROGRESS}

a. Bainitic Transformation in Steels*

Der-Hung Huang

Epsilon carbide has been identified in the isothermally transformed bainitic structure of a Si steel by thin-foil transmission electron microscopy and diffrection. The crystallographic relationship between epsilon carbide and bainitic ferrite was found to follow the Jack orientation relationship:

$$
\begin{aligned}
& (0001){ }^{\#(011)_{\mathrm{c}}} \\
& (10 \mathrm{i} 0)_{E} \quad(2 \overline{1} 1)_{q} \\
& (\overline{1} 2 \overline{1} 0)_{E} \rrbracket(11 \bar{i})_{\alpha} \text {. }
\end{aligned}
$$

The calculated lattice misfit between epsilon carbide and ferrite further stbstantiated the fact that the Jack orientation relationship is preferable to the Pitsch-Schrader relationship in bainitic transformation products. The results support the model that supersaturated ferrite is formed initially in lower bainite where epsilon carbide precipitated rapidly and is subsequently replaced by cementite upon further transformation.

The cernentite observed in the bainitic ferrite was in the shape of platelets which were formed on a specific ferrite plane. In many cases the Isaichev orientation relationship was found between the cementite and the ferrite.

Evidence has also been obtained which proves the existence of intemal twinning in bainite. The fact that the observed twins, whether accommodation or transformation, persisted after isothermal holding suggests that the observed midirectional precipitation of carbides camnot be attributed to carbides forming on the transformation twins. 
Substructural imvestigations of a number of steels containing various alloying elements (e.g., $\mathrm{Mn}, \mathrm{Si}, \mathrm{Ni}, \mathrm{Co}, \mathrm{Cr}$, etc.) show that there is no sharp transition tenperature for a lower to an upper bainitic microstructure. It appears that there is a continuous change in the microstructure as the transformation temperature is raised. That is, at lower temperatures internal carbides are seen only inside the laths (typical of lower bainite), and at higher temperatures internal carbides are seen only in between the laths (typical of upper bainite), whereas in the intermediate temperature range both types of carbides are observed. This temperature range is very much composition dependent, and at similar transformation temperatures completely different microstructures were observed in different steels.

Ph.D. thesis in preparation.

b. Precipitation Upon Nitriding Fe-0.3\&Ti Alloy

\section{H. Kirkwood* and Gareth Thomas}

Nitriding increases the hardness of Fe-Ti alloys to 1300 VPN and has been shown to be associated with precipitation of fine coherent platelets on $\{100\}$ having a very large lattice misfit. It is concluded that precipitates have the TiN structure.

Sheffield University, United Kingdom

\section{c. New Programs on Steels}

Gareth Thomas and Asscoiates

1) Effects of boron on structure and properties of martensitic steels; $Y$. L. Chen, Ph.D. thesis initiated 1973/74.

2) Attempts to increase toughness in $\mathrm{Fe} / \mathrm{Cr} / \mathrm{C}$ steels:

a) by bainitic transformations; R. L. Miller, M.S. thesis

b) by nickel, J. Koo, M.S. thesis

c) by variations of processing; B. Rao, M.S. thesis.

d. Phase Transfonmations

1. Grain Boundary Precipitation in Spinodally Decomposed Cu-Ni-Fe Alloys**

Ron Gronsky

The intergranular fracture of relatively ductile Cu-Ni-Fe alloys that have undergone spinodal decamposition has prompted this investigation into the nature of the cellular precipitation reaction originating from grain boundaries. Analysis by optical and transmissien electron microscopy reveals that the cellular constituent grows at a rate of -2 to $4 \times 10^{-9} \mathrm{~cm} / \mathrm{sec}$ and occupies less than 3 volume percent of the alloy after aging for 1000 hours within the spinodal. Evidence of denuded zones and preferential loss of coherency of the spinodal product at grain boundaries has also been obtained.

Aging above the spinodal temperature results in a more rapid growth $\left(\sim 6 \times 10^{-9}\right.$ $\mathrm{cm} / \mathrm{sec}$ ) of the grain boundary precipitates which continues until impingement, followed by a secondary reaction having interlamellar spacings 4 to 6 times larger than those of the initial product. The activation energy of the prinary high-temperature reaction can be identified with the activation energy for grain boumdary diffusion in Cu-Ni-Fe alloys.

Present enfmhasis has been placed on quantative TEM analysis to better establish the orientation relationships and morphological details of the grain boundary constituent, particularly the highly dislocated precipitate interfaces and the nature of the cell boundaries.

M.S. thesis in progress.

2. Structure and Properties of Spinodal Cu-Mn-AI Alloys

Fereshteh H. Mirmirani

Structure and mechanical properties have been studied in the $\mathrm{Cu}-\mathrm{M}$ rn-Al alloy, which is in the center of the miscibility gap in this systen. The results indicate that the alloys undergo order + spinodal + precipitation reaction sequences upon aging. Because of the extensive brittleness of these alloys, tensile mechanical properties could not be measured, and so hardness was used as an indication of the variation in strength with aging.

Vicker's harmesses for as-quenched and aged specimens were measured and correlated to differences in lattice parameter, wavelength, and microstructure of the decomposed phases.

M.S. thesis in progress. 


\section{RESEARCH PLANS FOR CALENDAR YEAR 1974}

Gareth Thomas

\section{a. Alloy Design}

The basic metallographic characteristics suitable for obtaining strong, tough structural martensitic steels are now well understood. The current program includes research on the effects of alloying and heat treatment so as to obtain a fundamental understanding of the possible benefits resulting from retaining interlath aus tenite crystals. Specifically, attention is being focused on our highly pronising $\mathrm{Fe} / 4 \mathrm{Cr} / 0.35 \mathrm{C}$ experimental steel. We will also be concentrating on bainitic steels in the $\mathrm{Fe} / \mathrm{Cr} / \mathrm{C}$ series, bearing in mind the relatively low cost of $\mathrm{Cr}$ compared to other substitutional alloying elements.

We are also continuing to study the role of other interstitial solutes on the structure and properties of low-alloy steels, In particular, nitrogen and boron are under investigation. Potential applications of these projects are towards economic improvements in properties of structural steels. b. Phase Transformations

i) Ordered Alloys

Fundamental studies of phase transformations are essential to the overall alloy design programs in addition to the intrinsic scientific interest of such prograns. Emphasis is being continued on understanding the nature of short range order (possible applications are in high-temperature alloys and reactor vessel alloys). This is being done by high-resolution lattice imaging techniques in the electron microscope and by the special high-voltage E.M. tecliniques of critical voltage. Systens under imvestigation include $\mathrm{Cu}-\mathrm{Au}, \mathrm{Ni}-\mathrm{Ho}, \mathrm{Ni}-\mathrm{H}, \mathrm{Au}-\mathrm{V}$, etc.

\section{ii) Spinodal Alloys}

The spinodal transformation is attractive because it gives rise to uniform microstructures. Infortunately many systems are embrittled as a result of competing precipitation reactions at grain boumdaries. A fimdamental study is being made of this problem in Cu-Ni-Fe. He are also contiming our sturies of the Cu-Mn-AI systen, wich is very canplex but is interesting because one of the phases is ferromagnetic ( $\mathrm{Cu}_{2} \mathrm{~N}$ nAI) and it may be possible to control the dispersion of the ferromagretic phase, and hence the physical properties, of the alloys. 


\section{HIGH VOLTAGE ELECTRON MICROSCOPY}

Gareth Thomas, Ixincipal Investigator

\section{CORRENT RESEARCH PROGRAMS}

Gareth Thomas

This paper abstracts briefly some of the research programs currently being carried out using the $650 \mathrm{kV}$ Hitachi electron microscope. Nany of the programs are interdisciplinary in nature and involve projects in biology, ${ }^{1}$ natural sciences, and engineering, and a recent sumary was given at the Erice School. 2 In the present paper some examples of current work on contrast, resolution, and applications in ceramics and minerals will be outlined.

One of the main advantages of HVBM for crystals is increased penetration and resolution. 3 Except for light elements, the penetration does not inprove mich beyond $1 \mathrm{MeV}$; e.g., Si, 9-14u from 1-2.5 MeV, but no gain was detected for stainless steel. Thus apart from studies of knock-on radiation damage and organic (biological) materials, $1 \mathrm{HeV}$ appears to be optimm for penetration in inorganic materials.

\section{a. Resolution and Contrast}

\section{Lih-Juann Chen*}

We have shown earlier the advantages of bright field and dark field techniques utilizing high-order systematic reflections for improving resolution; e.g., Refs. 4 and 5. Further work using 13 bean systematic computations and experimental observations on several systems has provided some new results at $650 \mathrm{kV}$, as shown by the corresponding Figs. 1a-d. Figures $1 c$, d resolve partials of ahout $75 \mathrm{~A}$ spacing of the pure edge components of a shear $100 p$ ( $\mathrm{t}=\mathrm{a} / 2[011]$ ) in $\mathrm{B}$-doped $\mathrm{Si}$. This spacing is identical to that reported for $100 \mathrm{kV}$ weak beam analys is by Ray and Cockayne ${ }^{6}$ for pure $S i$. Thus the stacking fault energy in the B-doped specimen is also $\sim 55 \mathrm{ergs} / \mathrm{cm}^{2}$. The experimental result, Fig. 1c, shows higher contrast of the weak beam images at high voltage (compare to calculation of Fig. 1a).

For resolving closely spaced dipoles the best conditions for imaging have been shown by calculation ( 9 beam systematic) and experiment to be near $2 \mathrm{~g}$ (outside contrast) in bright field or the corresponding weak beam d.f. in -Ig. These conditions provide maximm image separation, best contrast, and only slightly wider images than if $n>2$.

Bell $^{7}$ first showed that bright field images in $2 \bar{g}$ of stacking faults were contrasty or not depending on the sign of the phase change $\bar{\sigma}=2 \pi \bar{g}_{1} \cdot \overline{\mathrm{R}}$ at the boindary ( $g_{1}$ is the first order of the systematic set). Subsequently, nany more calculations and images have been excmined for faults in $\mathrm{Si}$ which showed this effect depends on thickness (bright fields, Fig. 2) and $w$. However, the dark field image in $g$ when $2 g$
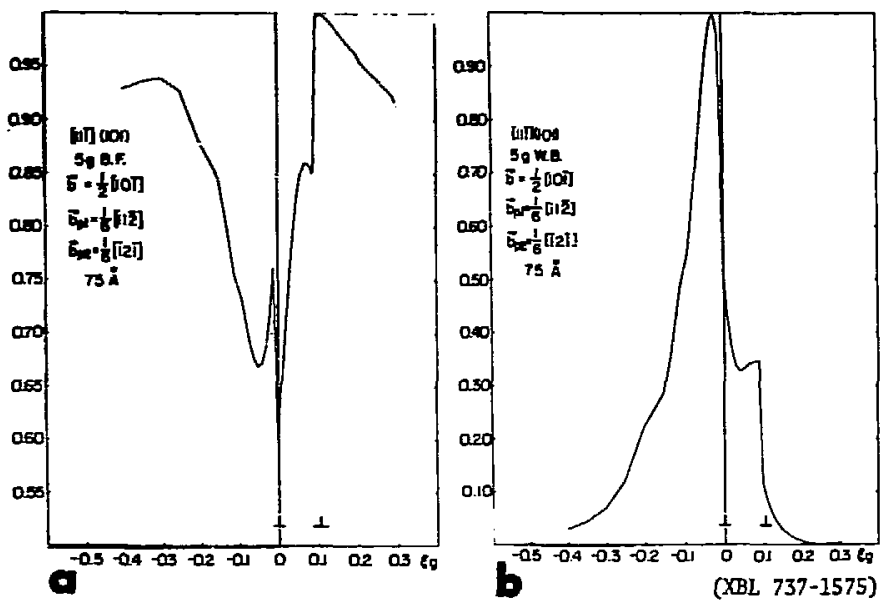

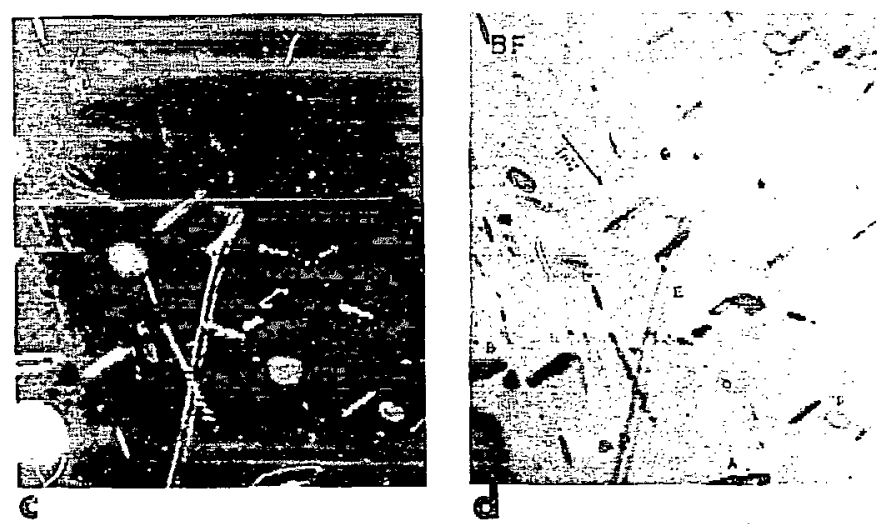

Fig. la,b -- Resolution of partials; depth $2.5 \mathrm{gg} t=6 \mathrm{gg} \mathrm{gg} / \mathrm{gg}=0.06$.

$1 c, d$-C Corresponding example. (XBL 737-1575) \& (XBB 737-4581)
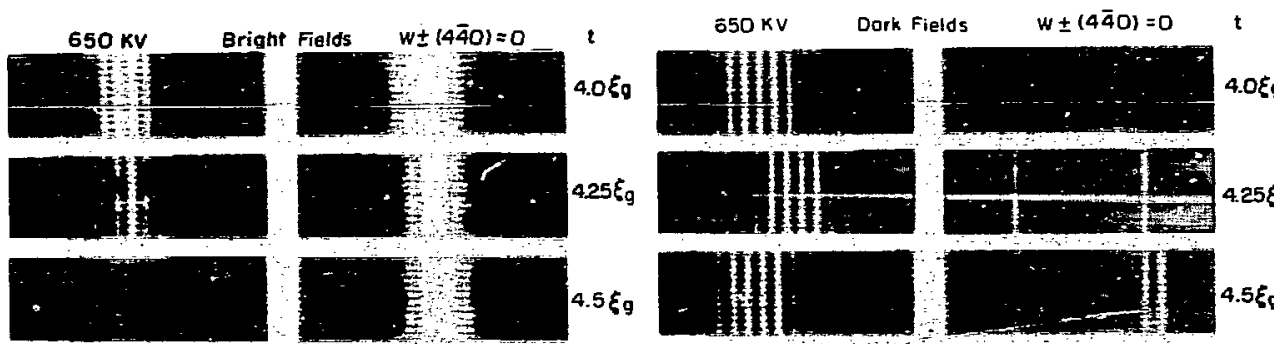

$4.25 \xi \mathrm{g}$
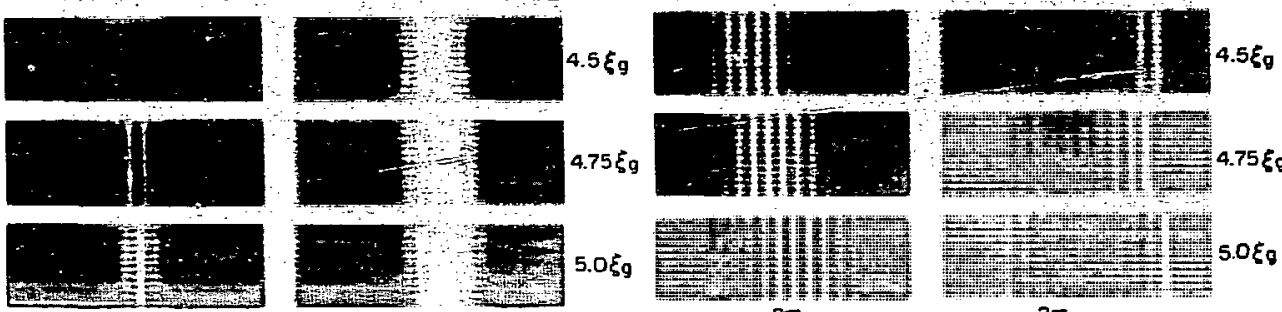

$$
\left.a=-\frac{2 \pi}{3} \quad \text { (Modulus }=2 \pi\right)^{\circ} a=\frac{2 \pi}{3}
$$
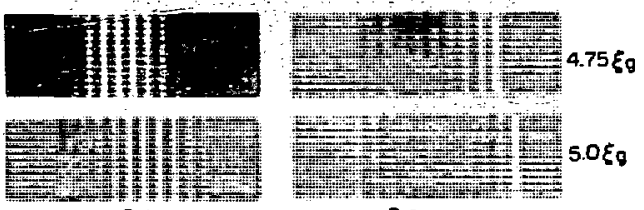

$$
\left.a=-\frac{2 \pi}{3} \quad \text { (Modulus }=2 \pi\right)^{a=\frac{2 \pi}{3}}
$$

Fig. 2. Cormuter-simulated images of stacking faults in silicon. (XBB 737-4385A)

is satisfied (or slightly negative but not positive) is directly indicative of the sign of $\alpha$ independently of thickness (Figs, 2 and 3) being of better contrast when $\alpha=-2 \pi / 3$ (modulus $2 \pi$ ). Thus, this inage gives a rapid method for determining whether faults are intrinsic or extrinsic, especially for loops etc. Within the foil. 

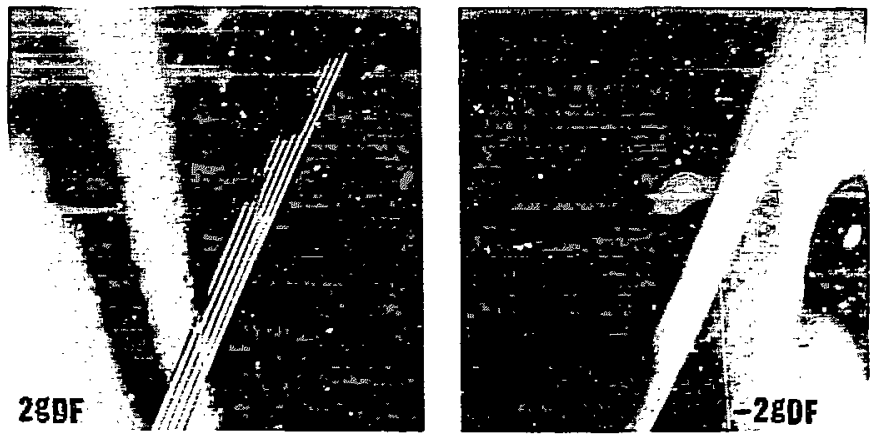

Fig. 3. Determination of the sign of a from a dark-field of $\mathrm{g}$, when $\mathrm{W}_{2} \mathrm{~g}=0$.

(XBB $937-4666)$

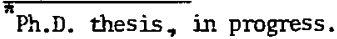

b. Ceranics (Lithium Ferrite)

Omer 0. Van der Biest*

Above $750^{\circ} \mathrm{C}$ lithium ferrite $\left(\mathrm{LiFe}_{5} \mathrm{O}_{8}\right.$ ) has an inverted spinel-structure, i.e., with $\mathrm{Fe}^{3+}$ on tetrahedrally cogrdinated sites and a $3: 1$ mixture of $\mathrm{Fe}^{3+}$ and $\mathrm{Li}^{+}$on the octahedral sites. The latter take on an ordered arrangement below $750^{\circ} \mathrm{C}$. The ordered structure contains antiphase boundaries (APB), with a displacement-vector of $1 / 2(110)$; an example is shown in Fig. 4. The fringes are due to a small-angi: boundary. Figure 5 shows an exanple of $\{110\}$ cation faults. Applications of contrast criteria showed that the faults can be characterized by a displacement vector $\overrightarrow{\mathrm{R}}=1 / 4(110)$, with $\overline{\mathrm{R}}$ always perpendicular to the fault plane. These faults are thus growth faults. As $1 / 4(110)$ is a lattice vector for the oxygen sublattice, the displacement affects only the cations. For spinel reflections, the faults have all the properties of $\pi$ faults.

Figures $6 a, b, c$ show contrast conditions for APBs (a), [101] faults (b), and 1/4[101] partials (c). Weak $\pi$ rontrast occurs in $6(b)$ due to the influence of the superlattice reflections in the systenatic set. This effect can cause difficulties in contrast identification at high voltages. Figure $5(\mathrm{c})$ shows the further advantage of highresolution imaging in $n g(n=6)$ in which the two partials bounding the (101) fault are well resolved. Examples of [111] faulting

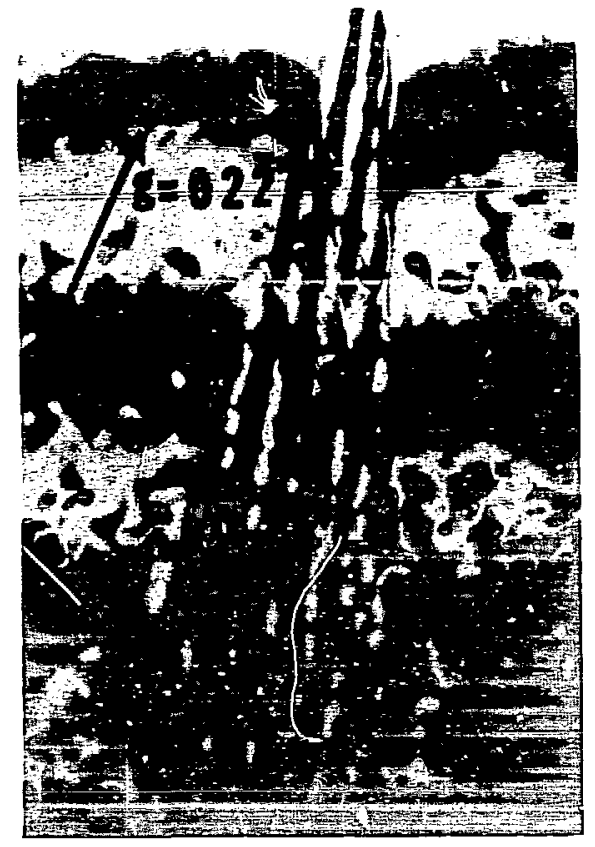

Fig. 4. $\mathrm{LiFe}_{5} \mathrm{O}_{8}$ quenched from $950^{\circ} \mathrm{C}$, aged $16 \mathrm{~min} .650^{\circ} \mathrm{C}$ [111] foil; bright field image $650 \mathrm{kV}$.
(XBB 737-4644, left) 


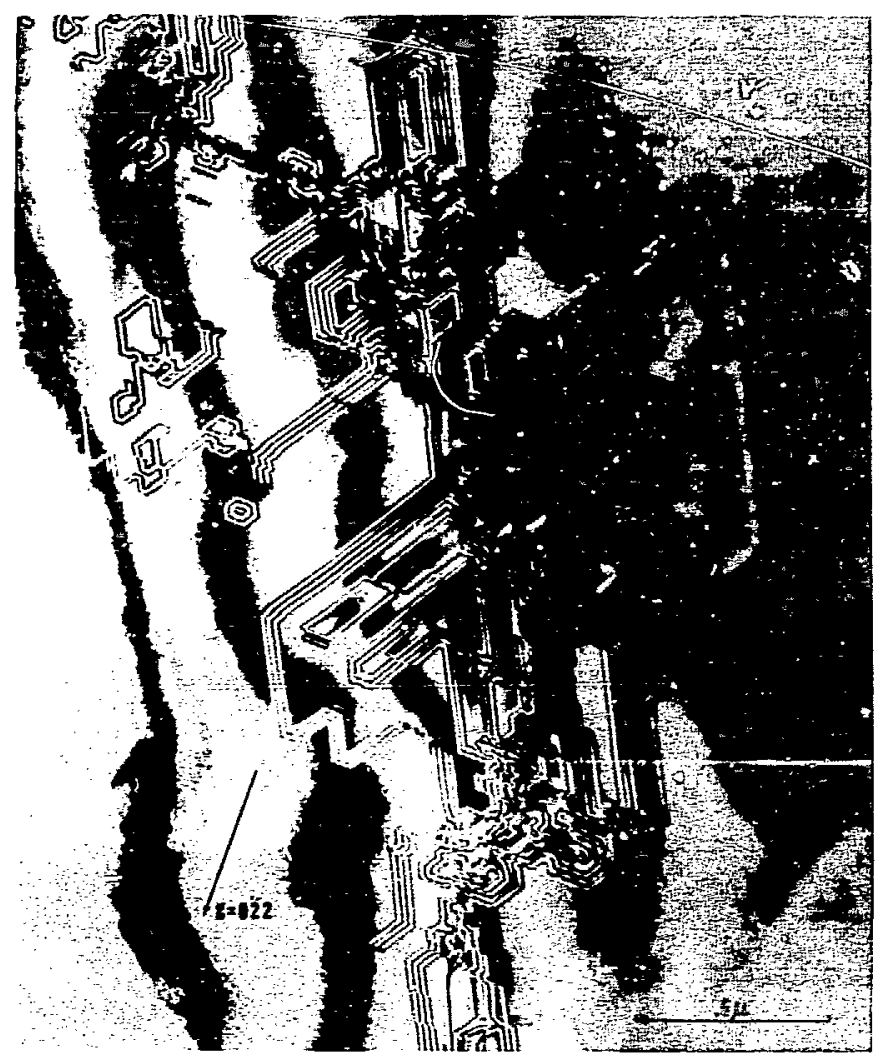

Fig. 5. Disordered LiFes $\mathrm{O}_{8}$ shoring $\{110\}$ cation faults. (XBB 734-2443) 

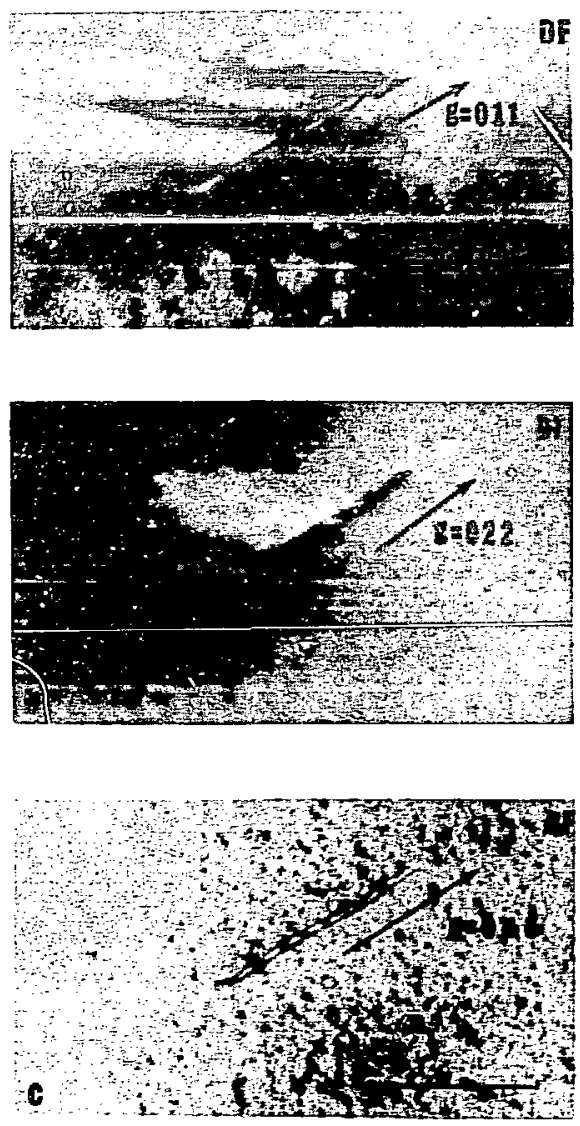

Fig. 6. Contrast examples showing defects in fully ordered Life508: (a) 011 superlattice reflection (b) 0.022 spine1 reflection cation fault visible (c) 066 spinel reflection-partials resolved.

(XBB 734-2815)

associated with a/6 ( 111 ) displacements have also been resolved.

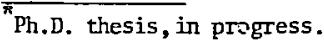
c. Minera15 ${ }^{8}$
W. F. Mbller, * H. R. Wenk and Gareth Thomas

Several investigations of transformations and deformation of minerals (e.g., enstatite and feldspars) have been carried out. Here we summarize the main conclusions conceming the ordered structures of anorthites (Ref. 9). Two different types of APBs have been resolved: viz., type b APBs (b reflections $b_{i}+k$ odd, $l$ odd) and type $c$ APBs (c reflections $h+l$ even, $\ell$ odd). Examples are show in Fig. 7. The displacement vector of b-APBs was determined as $1 / 2[110]$; i.e., the formation of b-APBs is connected with $\mathrm{Si}-\mathrm{Al}$ ordering. The antiphase vector of c-APBs was found to be $1 / 2[111]$.

Mineralogy-Processing. Because of the increasing concem over sources of raw materials, considerable interest exists in searching for metal-producing ores on the ocean floors; e.g., the Pacific Ocean bed is estimated to contain at least $10^{11}$ tons of manganese nodules containing $\mathrm{Ni}, \mathrm{Fe}$, Cu, etc. (e.g., Merolo).

Because of the higher resolution in diffraction and greater penetration, the high voltage electron microscope is useful not only in mineral identification of particles which are too small for X-ray analysis, but also for characterizing particle morphology (important in extractive metallurgy). Details of the present research program will be published elsewhere! 11 but

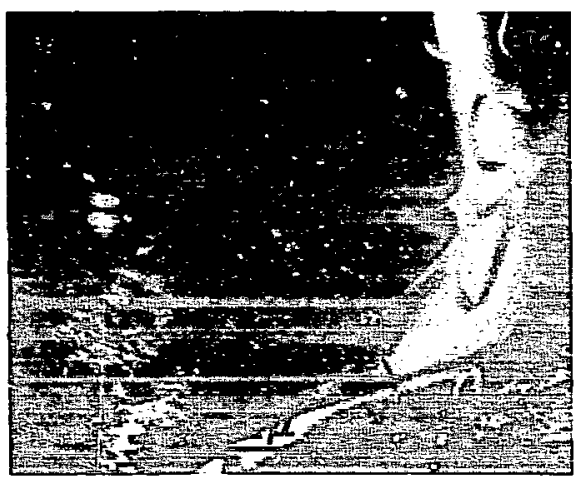

Fig. 7. Simultaneous dark field inages of $b$ reflection (right side) $g=21 \overline{3}$ and $c$ reflection (left side) $g=20 \overline{3}$ show $i \overline{n g}$ the coexistence of both $b$ and $c$ domains in linear breccia 15459.

(XBB 732-865) 

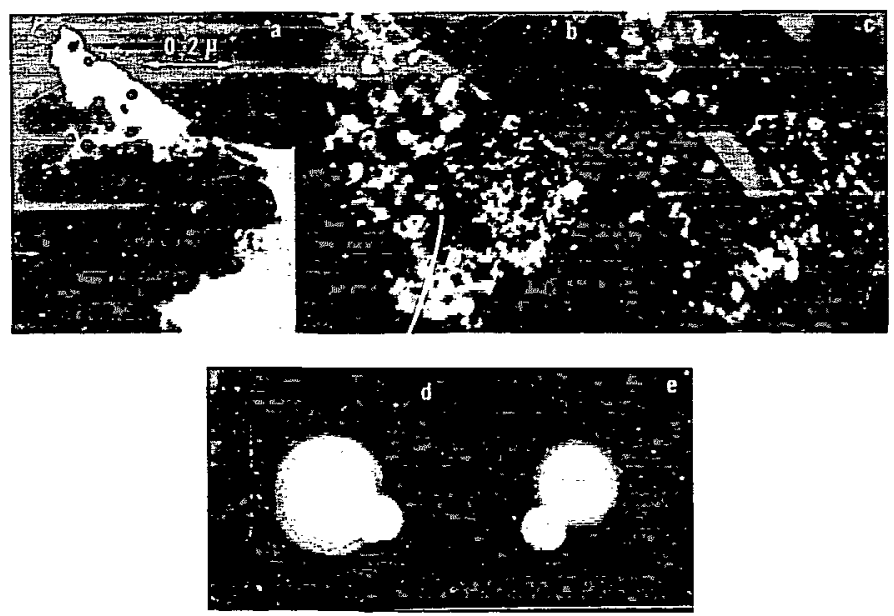

Fig. 8. (a) Bright field and (b), (c) dark field images of Mn nodule showing 100-540 \& particles of $\mathrm{Fe}(\mathrm{OH})_{3}$ identified from rings indicated by doubly exposed image of objective aperture superimposed, nodule from 1270 meters. (XBB 75.3-2367)

one of the main conclusions was that ferric hydroxide is the main iron mineral in the nodules examined. Figure 8 shows an example of particles in the range 100-450 $\mathrm{A}$. Identification is carried out with the aid of computer prograns, which are also used in environmental research; e.g., analysis of asbestos fibers which are too thick $(\sim 2 \mu)$ for identification at $100 \mathrm{kV}$ (e.g., Thoinas ${ }^{12}$ ).

\footnotetext{
Now at Inst. für Krista11., Frankfurt, Germany
}

\section{d. Radiation Damage in Organic Solids ${ }^{1}$}

David G. Howit:*

Examination of microstructure of organic (including biological) materials in the electron microscope is linited by radiation damage. It appears that the damage rate decreases with increasing voltage. Experiments are being carried out using linacs and the $650 \mathrm{kV}$ E.M. to determine the radiation sensitivity over a range of temperature and vostages. The mechanism of damage is also under investigation using high-resolution techriques.

\footnotetext{
i.I.S. thesis; spensored by N.I.H.
}

\section{Joint Program with R. M. Blaeser of} Domer Laboratory.

2. G. Thomas, in Electron Microscopy in Materials Science--New Developments and Prospectives, Edited by U. Valdré (Cormission of European Commmities, 1973), in press.

3. G. Thomeas and J.-C. Lacaze, J. Microscopy, 97, 301 (1973).

4. W. L. Be1l and G. Thomas, Electron Nicroscopy and Structure of Materials, edited by G. Thomas (Wriv. of Calif. Press, Berkeley, 1971), p. 23.

5. H. J. Goringe, E. A. Hewat and C. J. Humphries, Fifth Europ. Electron Nic. Congress (Inst. of Phys., London, 1972), p. 538 .

6. I.L.F. Ray and D. J. H. Cockayne, Phil. Mag. 22, 853 (1970).

7. W. L. Bell, Proc. 7th Int. Elec. Bic. Congress; Soc. Fran. de Nic. Electr. Paris, 1970, p. 81 .

8. Cooperative program with H. R. Wenk, Geology Dept.

9. W. F. Mfiller, H. R. lienk, W. L. Beil, and G. Thomas, Contr. Mineral. \& Petrol. 40,63 (1973); LBL-1457.

10. J. L. Mero, Mineral Resources of the Sea (Elsevier, Ansterdam, 1965).

11. M. von Heinendahi, G. Hubred, D. W. Fuerstenau, and G. Thomas, (submitted to Deep Sea Research); LBL-1496 (1973). 
12. G. Thomas, Proc, 28th EISA Congress (Claitors Publishers, Baton Rouge, La., 1970), p. 2.

\section{FESEARCH PLANS FOR CALENDAR YEAR 1974}

\section{Gareth Thomas}

\section{Electran Microscopy}

\section{i) Contrast}

He will continue to back up the applications of electron diffraction microscopy with basic analyses of contrast phenomena especially for high resolution lattice imaging research, and high-voltage E.M. studies of minerals and ceranics. This approach is essential for quantitative, accurate interpretation of data. (Supported also by N.S.F. funding.)

\section{ii) Radiation Damage}

The basic program on stability of organic crystals to electron irradiation will be continued. Attempts will be made to study mechanisms of damage by using highresolution techniques. The problems involved in measuring electron current density will be evaluated sy comparison of Faraday cage and Li drifted detector techniques on specimens such as valine and adenosine. (Joint project with R. M. Glaeser of Danmer Laboratory; supported also by N.I.H. funding.)

\section{iii) Ceramic Systens}

Little work has been done on microstructureproperty relations in ceramics utilizing high-resolution microscopy. The current program involves a study of the lithium ferrites (ferrimagnetic) identifying ordering reactions and defect chemistry and takes adrantage of the existence of our $650 \mathrm{kV}$ microscope. He will search for a system which undergoes spinodal transformations again in an attempt to control the microstructure and properties.

\section{1973 PUBLICATIONS AND REPORTS}

Gareth Thomas and Associates

\section{Journals}

1. R. D. Garrood and G. Thomas, The Tempering of Martensite in an Fe-1.5 pct
N Allo;, Het. Trans. 4, 225 (1973) (LBL-470)

2. M. Bouchard, W. L. Worthington, D. J. Jurica, and P. R. Strann, A High-Angle Tilting Stage for the $650 \mathrm{kV}$ Hitachi Electron Microscope, Rev. Sci. Instr. 44 (4), 511 (1973) (LBL-1145).

3. W. F. Hïller, H. R. Wenk, W. L. Be1l, and $G$. Thomas, Analysis of the Displacement Vectors of Antiphase Domain Boundaries in Anorthites ( $\mathrm{CaAl}_{2} \mathrm{Si}_{2} \mathrm{O}_{\mathrm{B}}$ ), Contr. Mineral. and Petro1. 40, 63 (1973) (LBL-1457).

4. S. K. Das, P. R. Okamoto, P. M. J. Fisher, and G. Thomas, Short Range Order in $\mathrm{Ni}-\mathrm{H}$, $\mathrm{Au}-\mathrm{Cr}, \mathrm{Au}-\mathrm{V}$ and Au-Non Alloys, Acta Met. 21, 913 (1973) (LBL-441).

5. G. A. Stone and G. Thomas, The Stress Induced Martensite-Austenite Interface in Fe-15Ni-15Cr Single Crystals, in 31st Ann. Proc. Electron Microscopy Soc. Amer., New Orleans, La., 1973, pp. 110-111.' Edited by C. J. Arceneaux. (LBL-1499).

6. W. F. Muller and H. R. Wenk, Changes in the Domain Structure of Anorthites Induced by Heating, N. Jb. Miner. Mh., Jg. H. 1, 17 (1973) (LBL-1882).

7. P. R. Swann, G. Thomas, and N. J. Tighe, In situ Observations of the Nitriding of Tantalum, J. Microscopy 97, 249 (1973) [LRL-1196) .

8. R. Sinclair, High Resolution TBM, Industrial Research, Oct. 1973, p. 62, LBL-2219.

9. G. Thomas and J,-C. Lacaze, Transmission Electron Múcroscopy at $2.5 \mathrm{MeV}$, J. Microscopy 97, 301 (1973) (LBL-II19).

10. S. K. Das and G. Thomas, The Metastable Phase $\mathrm{Ni}_{2} \mathrm{Mo}$ and the Initial Stages of Ordering in Ni-10 Alloys, Physica Status Solidi 20 [2], (1973) (LBL-1868).

11. G. Thomas, Role of Electron Mlicroscopy in Design of Strong, Tough, Econonical Structural Steels, Iron and Steel Internatimal 46, 451 (1973) (LBL-1871).

12. G. Thomas, Current and Future Trends of High Voltage Transmission Electron Microscopy, invited paper, Proc. BISt Congress, 1973 (Claitors Publishers, Batcn Rouge, La., 1973), p.2 (LBL-1802).

13. G. Thomas, Nonequilibrium Defects in Metals, in Science of Materials Used in Advanced Technology, edited by E. R. Parker and U. Colombo (Wiley, New York, 1973), 
Chap. 2, p. 13 (UCRL-19696).

14. G. Thomas, Modern Metallographic

Techniques, ibid., Chap. 3, p. 35 (UCRL-19697).

15. G. Thomas, Nonequilibrium Microstructures, ibid., Chap. 4, p. 71 (UCRL-19698).

I6. J. Molahon and G. Thomas, Development of Economical, Tough, ultra-High-Strength $\mathrm{Fe}-\mathrm{Cr}-\mathrm{C}$ Steels, in The Microstructure and Design of Alloys, Cambridge, England, August 20-25, 1973, Vo1. 1, p. 180.

\section{LBL reports}

1. V. F. Zackay, E. R. Parker, J. W. Morris, Jr. and G. Thomas, The Application of Naterials Science to the Design of Engineering Alloys, LBL-2261, Oct. 1973.

2. W. Wu, L. J. Gen, J. Washburn and G. Thomas, on Indexing of Diffracting Planes lising the Kikuchi Pattem, LBL-1811, Aug. 1973.

3. R. J. Livak and G. Thomas, Loss of Coherency in Spinodally Decoriposed Cu-Ni-Fe Alloys, LBL-1842, July 1973.

4. G. Thomas, Some Applications of High Voltage Electron Nicroscopy to Inorganic Materials, presented as an invited paper for $3 r d$ Intl. Conf. on HVEM at Oxford, U. $K$., August 27-30, 1973, LBL-1899, Aug. 1973.

5. S. K. Das and G. Thomas, on Structural Interpretation of Short Range Order, invited paper for Order-Disorder Conference, Tubingen, Germany, LBL-2285, Sept. 1973.

6. G. Thomas, Some spplications at Berkeley and Possible Future Trends, of High Voltage Transuission Electron Microscopy, Electron Microscopy: Hhysical Aspects, (in press, Jom Wiley \& Sons, Inc.) LBL-2274,
7. G. Thomas, Introduction to Transmission Electron Nicroscopy, Electron licroscopy in Materials Science: New Levelopilients and Perspectives, (in press, Comission of Earropean Comminities) LBL-1471, April 1973.

8. G. Thomas, Introduction to Contrast Analysis, Electron Nicroscopy in Materials Science: ien levelopments and Perspectives (in press, Commission of European Comminities) LBL-1472, April 1973.

9. G. Thonas, Some Applications of Transmission Electron Aficroscopy in Materials Science and Engineering, Electron Mficroscopy in Naterials Science: New Developments and Perspectives, (in press, Commission of European Commanities) LBL-1473, Apri1 1973.

10. Glen Stone and G. Thomas, Deformation Induced Alpha and Epsilon Martensites in Fe-Ni-Cr Single Crystals, IBL-1853, July 1973.

11. H. von Heimendahl, G. Hubred, D. Ḧ. Fuerstenau and G. Thamas, A Transmission Electron Nicroscope Stuty of Deep-Sea Manganese Nodules, LBL-1496, Oct. 1973.

12. Robert A. Clark, Structure and Properties of Fe- $\mathrm{Ho}-\mathrm{C}$ Steels, M. S. thesis, LBL-1801, June 1973 .

13. L. J. Chen and L. M. Falicor, Pseudopotential Calculations of the Stacking Fault Erergy in Silicon, LBL-1864, July 1973.

14. Marcel Bouchard and G. Thanas, Mownlated Structures and Coarsening in Ordered (OH-Mn) 3Al A1loys, LBL-2294, Kov: 1973.

15. M. Bouchard and G. Thomas, Modulated Structures in (Cu-Nn) zAl Alloys II. Fonnation of an L1, Phase within the CuzAl-Side Phase, lBL-2295, Nov. 1973.

16. M. Bouchard and G. Thomas, Modulated Structures in Ordered (Cu-Mn) 3 Al Alloys, III. Formation of the $\gamma$ Phase, LBL-2296, Nov.1973. 


\section{E. ALLOY DESIGN}

Vietor F. Zackoy and Earl R. Parker, Principal Irueatigatora

Introduction. In recent years we have shoin that microstructure of alloys has considerable influence on their mechanical properties. An understanding and application of theories that relate microstructure to mechanical properties can obviate much empiricism in alloy development. The design of new alloys or obtaining considerable, rather than nominal, improvements in the properties of existing alloys, then largely involves achieving microstructural control through variations in chemical composition and heat treatment.

Microstructural influences on mechanical properties depend to a large extent on the specific mechanical property that is under ronsideration. For example, micros tructural changes that affect fracture toughness do not influence fatigue crack growth resistance in the same way, as some of our investigations have indicated. In addition, elements of structure that are considered desirable for good cryogenic mechanical properties may not be the ones that benefit elevated temerature or room temperature properties. Therefore, it is essential that both the applicable tenperature range and the relevant property be given die consideration when microstructural control is utilized in alloy development.

The main objectives of our research program have been a study of microstructural and compositional features that iniluence mechanical properties of alloys at cryogenic, room, and elevated temperatures, and application of the principles we have learned from our own studies and of the information available in the literature to develop new and improved alloys. Examples of present efforts directed toward our goals inclive the following:

1) Studies of the relationship between composition and heat treatment, microstructure, strength, toughness, and fatigue crack growth at temperatures as low as $-196^{\circ} \mathrm{C}$ in interstitial-free $\mathrm{Fe}-\mathrm{Ni}-\mathrm{Ti}$ alloys.

2) Study of those corpositional and microstructural features that control room temperature strength, fracture toughness, and fatigue crack growth properties of low and medium alloy high yield strength steels.

3) Investigation of the relation between microstructure, elevated temperature deformation behavior, and elevated temperature rupture and creep strengths of noncarbon-containing, Laves phase strengthened ferritic alloys.

4) Development and use of a rapid magnetametric technique to determine the time-temperature-transformation. (TTT) curves for austenite decomposition in several lowand medium-alloy steels. Studies of the effect of alloying elements on bainitic hardenability.

\section{DESIGN OF INTERSTITIAL-FREE CRYOGENIC ALWYS}

\section{Michael J. Yokota and Go Sasaki}

\section{a. Introduction}

The mechanical behavior of metals at cryogenic temperatures is of great scientific and technological importance. A detailed discussion of the philosophy behind the design of iron-base interstitial-free alloys for cryogenic applications was presented in the IMRD Annual Report for 1972. Last year we reported on the superior toughness exhibited by one bcc irom alloy containing $128 \mathrm{Ni}$ and $0.58 \mathrm{Ti}$. The high Gharpy impact energy values of well over $100 \mathrm{ft} \mathbf{l b}$, at temperatures down to that of Iiquid nitrogen $\left(-196^{\circ} \mathrm{C}\right)$, were achieved by a simple heat treatment in the lower termerature range of the $\gamma$ phase field. The best evidence available at that time indicated that grain size reduction was of primary importance in improving toughness in the $\mathrm{Fe}-\mathrm{Ni}-\mathrm{Ti}$ system.

During this past year attention was focused on determining the role played by grain size on toughmess, and on characterizing various processing methods which could be used to achieve efficient grain refinement. In addition, the study was expanded to include alloys with nickel contents from 8 to $16 \%$.

b. Improvement in Impact Toughness from Simple Reheating

Figure 1, curve $A$, shows the improvement in impact toughness at $-196^{\circ} \mathrm{C}$ of specimens initially austenitized at $900^{\circ} \mathrm{C}$ and reheated at $50^{\circ} \mathrm{C} / \mathrm{min}$ to temperatures spanning both the equilibrium $\alpha^{+} \gamma$, and the $\gamma$ phase fields $\left(600\right.$ to $\left.800^{\circ} \mathrm{C}\right)$. Al though modest inprovement in toughness was observed when specimens 


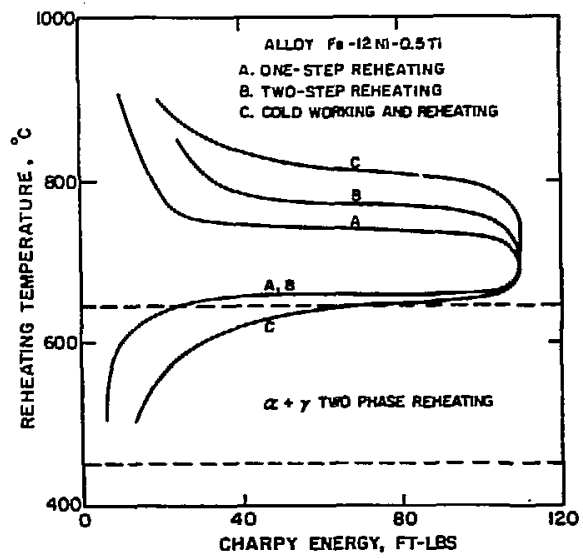

Fig. 1. Plots of Charpy V-notch impact energy at $-196^{\circ} \mathrm{C}$ vs. reheating temperature for alloy Fe-12Ni-0.5Ti. The heat treatments were as indicated.

(XBL 741-5482)

were heated into the two-phase $\alpha+\gamma$ phase field, it is only when they were heat treated to higher temperatures (in the single-phase $\gamma$ field) that appreciable impact toughness resulted. Tre microstructure of specimens exhibiting good toughness showed a single-phase grainrefined structure. But, heat treating at tenperatures we11 within the $Y$ phase field again resulted in poor toughness. Microstructural examination of the latter specimens showed a single-phase structure, but with coarse grain size. Examination of the changes which occurred in the microstructure and in the impact toughmess during heating at $700^{\circ} \mathrm{C}$ (in the midale of the hightoughness. region) confirmed the view that appreciable toughness resulted only when the a+y transformation was essentially completed with a corresponding refinement occurring in the grain structure.

Flectron microscope examination showed that new grains fonied at prior austenite and lath colony boundaries via dissolution of the $a+y$ duplex structure which had formed earlier during heatirg.

c. Improvement in Impact Toughness from Two-Step Reheating

Reheating to temperatures mach above the austenite finish temperature as previously mentioned prohuced progressively larger austenite grains and a drop in the inpact toughness. The $a$ to $\gamma$ transformation during heating and holding at these higher temperatures occurred with little or no formation of $\alpha^{+} \gamma$ dplex structure. In order to test the possible link between the at d fulex structure and the grain refining process, specimens were initially given an internediate treatment at $650^{\circ} \mathrm{C}$ for several hours before heat treating at the higher 750 and $800^{\circ} \mathrm{C}$ temperatures which had previcusly produced poor impact toughness. Reheating via the additional $650^{\circ} \mathrm{C}$ treatment was found to produce finer grain sizes and a corresponding extension of the high toughress reheating range from 725 to $775^{\circ} \mathrm{C}$, as indicated by curve B in Fig: 1. A similar improvement of grain refining was accomplished by an essentially equivalent process of a slower heat-im through the $a+\gamma$ phase region. An examination of the dilatometric response and the resulting microstructures suggested that the presence of the $\alpha+\gamma$ aplex-structure provided a larger muber of $\gamma$ nurleation sites for the formation of new $Y$ grains and also retarded $\gamma$ grain growth through the presence of a at the new grain boundaries.

d. Improvement in Impact Toughness from Cold Working Prior to keheating

The ary transformation, frring $700^{\circ} \mathrm{C}$ reheating, occurred preferentialiy at the prior ustenite and lath colony boundaries. These initially transformed areas in effect dominated the final average grain size achieved unon completion of the ary transformation. It was reasoned that by cold working, the uniqueness of these prior austenite houndaries as high-energy sites for $Y$ nucleation would be lessened sonewhat, and nucleation of new $Y$ grains could occir more uniformly throughout the prior austenite grain. This, in fact, appeared to be the case. A cold working treatment prior to reheating produced a finer grain size at all reheating temperatures and resulted in an extension of the high-toughness temperature range to $800^{\circ} \mathrm{C}$, curve $\mathrm{C}$ of Fig. 1.

The above results showed that considerable inprovement in the inpact toughness of an Fe-124Ni-0.5\%Ti alloy was achieved by reheating to the lower end of the $\gamma$ phase field. A much refined austenite grain size resulted during reheating and, when the alloy was cooled to rocm temperature the $\gamma$ phase completely transformed back to the a (bcc) structure. The simple one-step reheating treatment produced a Charpy energy absorption peak with a $50^{\circ} \mathrm{C}$ wide reheating temperature range. When a thermal or mechanical treatment preceded the reheatiar step, this optimm reheating temperature 
range was extended to nearly $100^{\circ} \mathrm{C}$. The extension of the rehtating temperature range resulted from the higher degree of grain refinement and/or grain boundary stabilization achieved by introducing the prior thermal or mechanical treatments.

The relationship between the refined austenite grain size and the resulting impact toughness is illustrated by Fig. 2 , in which the impact energy at $-196^{\circ} \mathrm{G}$ is plotted versus the grain size for the several grain refining treatments described above. Such a plot shows that whatever the method used to refine the grain size, an austenite grain size less than $15 \mu$ was needed for impact toughmess exceeding $100 \mathrm{ft} 1 \mathrm{~b}$ at $-196^{\circ} \mathrm{C}$. This Is m grain size can be considered a critical grain diameter for ductile behavior at $-196^{\circ} \mathrm{C}$ of the $\mathrm{Fe}-128 \mathrm{Ni}-0.58 \mathrm{Ti}$ alloy investigated in this stury.

Likewise, similar relationships existed for iron alioys containing 8 and $16 \% \mathrm{Ni}$ and $0.5 \% \mathrm{Ti}$. For the 8\%Ni alloy the critical grain size for ductile behavior at liquid nitrogen temperatures was somewhere below $5 \mu \mathrm{m}$. For the 16 ofi alloy the critical grain size was $30 \mathrm{~mm}$.

From such data it was possible to determine a relationship between the nickel content

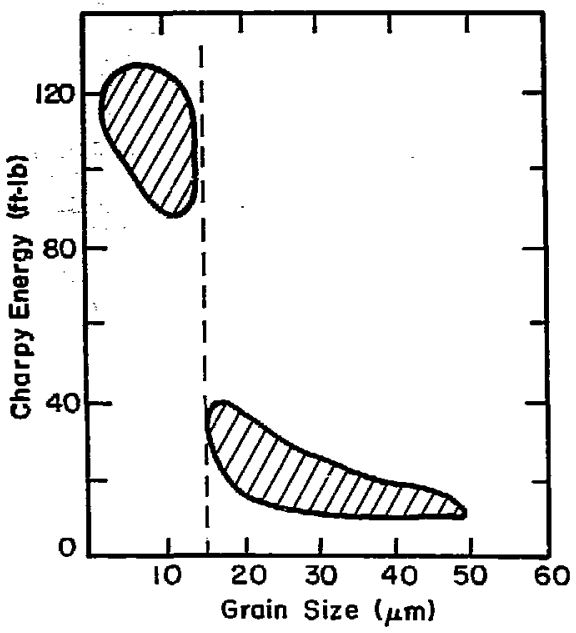

Fig. 2. Plot showing the effect of grain size on Charpy V-notch impact energy, at $-196^{\circ} \mathrm{C}$, in $\mathrm{Fe}-12 \mathrm{Ni}-0.5 \mathrm{Ti}$ alloy.

(XRL 7311-5599) of the alloy and the critical grain diameter for ductile behavior at $-196^{\circ} \mathrm{C}$. From an alloy design point of view it is then necessary to compare the cost of heat treatment to achieve finer and finer grain sizes, and thereby produce increasingly higher toughness in alloys, with the cost of nickel additions which also produce similar toughness but with larger grain sizes.

Completion of such studies as described above should ultimately allow us to design an alloy for a given service temperature by optimization of the strength-toughness properties while mirigizing the economic liabilities such as the number and complexity of heat treatments and the number and amounts of alloy additions.

This research which has been, to a large extent, supported by the U.S. Atomic Energy Commission has in recent months, received additional financial support from the National Aeronautics and Space Administration's iewis Research Center, Cleveland, Ohio.

\section{INFLUENCE OF MICROSTRUICTURE ON FATIGUE CRACK PROPAGATTON IN A CRYOGENIC ALLOY}

\section{Henri Sirot}

Fatigue crack growth rates at room temperature, $-78^{\circ} \mathrm{C}$, and $-196^{\circ} \mathrm{C}$ were determined for a Fe-8tNi-0.15\&Ti-0.1\&A1 alloy in which microstructural variations were achieved through variations in heat treatment.

The alloy after an initial austenitizing treatment at $900^{\circ} \mathrm{C}$ was reheated to $750^{\circ} \mathrm{C}$ in the $Y$ phase field region. Two different microstructures were obtained by changing the mamer in which the alloy was cooled from $750^{\circ} \mathrm{C}$. An ice brine quench from $750^{\circ} \mathrm{C}$ resulted in the formation of massive $a^{\prime}$ martensite (lath type). When the alloy was firmace cooled to $565^{\circ} \mathrm{C}$ (following the $750^{\circ} \mathrm{C}$ treatuent), held at $565^{\circ} \mathrm{C}$, and then furnace cooled to room temperature, a mixed nicrostructure consisting of both equiaxed a and massive $\alpha^{\prime}$ was obtained.

Fatigue crack growth rates were measured at room temperature, $-78^{\circ} \mathrm{C}$, and $-196^{\circ} \mathrm{C}$ for specimens with both the heat treatments described above. Fatigue tests were conducted on standard hOL type specimens. Cyclic loading with a $\mathrm{P}_{\max } / \mathrm{P}_{\min }$ ratio of 10 (leading to a $K_{\max } / K_{\min }$ ratio of 10 ) and at a frequency of 5 cycles per second was used in all tests. At room temperature, crack growth rates were determined from: periodic measurements of crack length using 
a telescope, and also from measurements of fatize striation spacings using the scanning election microscope. The two measurements were in good agreement. In crycgenic tests crack growth rates were obtained only from striation spacings.

ir liminary results indicated that there were 1: ttle differences in crack growth rates betwe $\theta$ : =pecimens with the massive martensite structuis and specimens with the gixed microstru ture; however, additional evidence is needed to draw definite conclusions. There was a threshold $\Delta K\left(\Delta K=K_{\max }-K_{\min }\right)$ below which crack propagation was extremely slow. The reasons for the existence of a threshold, and the influence of microstructure on the threshold are currently under investigation.

\section{MICROSTRUCTURAL, VARIABLES ARD FRACTURE} TOUGFNESS OF HIG STRENGTH C-NO AND C-Mb-NI STEELS

\section{Thomas Tom}

The influence of microstructure on room temperature plane strain fracture toughness was investigated in several high strength $\mathrm{C}-\mathrm{M}_{\mathrm{O}}$ and $\mathrm{C}-\mathrm{MO}-\mathrm{Ni}$ steels. The steels were austenitized at temperatures ranging from 870 to $1200^{\circ} \mathrm{C}$, following which they were ice-brine quenched and refrigerated in liquid nitrogen. The influence of terqering on toughness was studied in steels tempered for 1 hour at terperatures up to $600^{\circ} \mathrm{C}$. The results of room temperature tensile tests, plane strain fracture toughness tests (using conpact tension specimens), and microstructural studies are briefiy discussed below.

\section{a. As-quenched Steels}

The effect of austenitizing temperature on the room temperature plaru strain fracture toughness, yield strength, an i ultimate strength of as-quenched $0.3 \mathrm{C}-5 \mathrm{~N}$ to and $0.41 \mathrm{C}-5 \mathrm{Mo}$ steels is shown in Fig. 1. Both steels exhibited good fracture toughness for austenitizing temperatures above about $980^{\circ} \mathrm{C}$, with about a $100 \%$ increase resulting in the fracture toughness of $0.30 \mathrm{C}-5 \mathrm{~kb}$ steel for increase in austenitizing temperature from 870 to $1200^{\circ} \mathrm{C}$. Three factors were possibly responsible for the increased toughness resulting from austenitizing at high temperatures: 1) increase in prior austenite grain size, 2) minimization or elimination of undissolved carbides, and 3) increase in the degree of autotempering resulting from a raised $\mathrm{M}_{5}$ termerature. Several other $\mathrm{C}-\mathrm{Mb}$ and $\mathrm{C}-\mathrm{Mb}-\mathrm{Ni}$ steels were
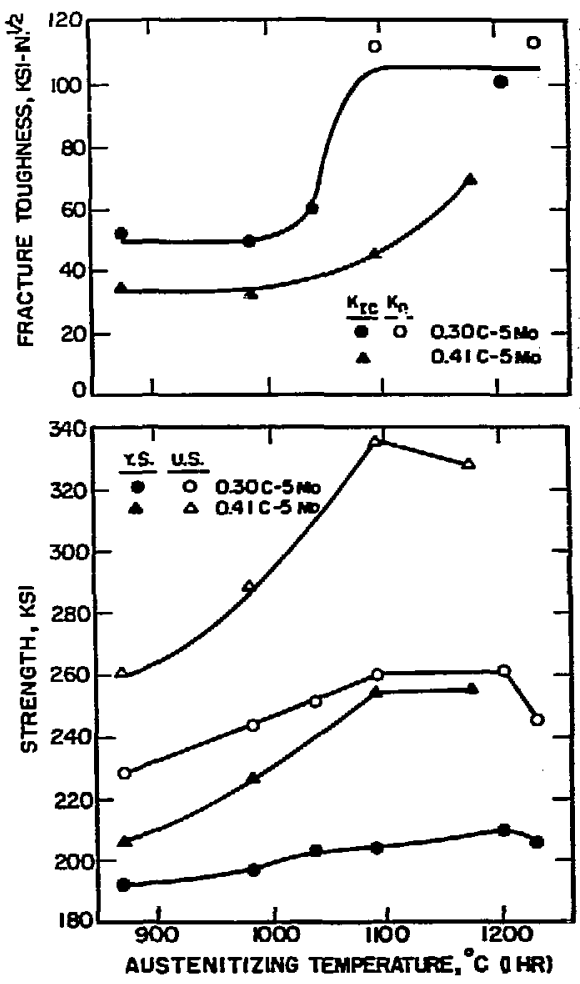

Fig. 1. Plots showing the influence of austenitizing temperature on room temperature fracture toughness $\left(\mathrm{K}_{\mathrm{IC}}\right.$ or $\left.\mathrm{K}_{\mathrm{Q}}\right)$, yield strength $\left(\right.$.S. $_{\text {.) }}$ and vitivate strength (U.S.) of $0.30 \mathrm{C}-5 \mathrm{Mb}$ and $0.41 \mathrm{C}-5 \mathrm{Mb}$ steels.

(CBL 737-6460A)

subsequently prepared in order to isolate the above variables and determine the individual effect of each on fracture toughness.

h Fig. 2 are shown plots of room temperature plane strain fracture toughness vs. grain size for as-quenched $0.34 \mathrm{C}$ - INb and $0.35 \mathrm{C}-1 \mathrm{No}-3 \mathrm{Ni}$ steels, austenitized at 870 and $1200^{\circ} \mathrm{C}$, resulting in austerite grain sizes with ASTM numbers of 6 and 1 respectively. In both steels complete dissolution of carbides was obtained at $870^{\circ} \mathrm{C}$ as well as $1200^{\circ} \mathrm{C}$. It was evident that in the absence of undissolved carbides, 


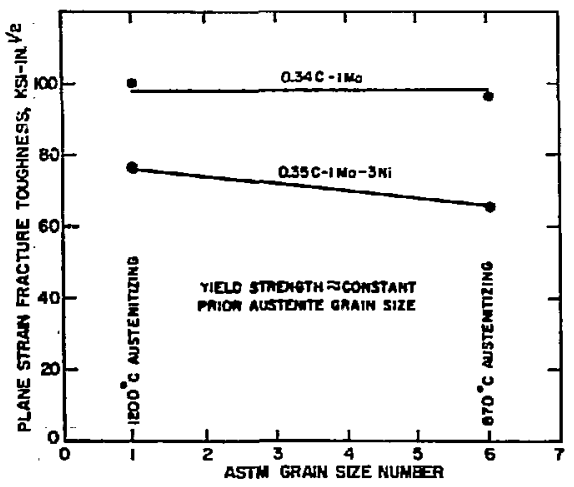

:3g. 2. Plots of room temperature plane s.rain fracture toughness vs prior austenite grain size (indicated by ASTM grain size matiber) for as-quenched $0.34 \mathrm{C}$-1Mo and $0.35 \mathrm{C}-1 \mathrm{Mb}-3 \mathrm{Ni}$ steels.

(XBL 737-6468A)

fracture toughness of the as-quenched steels was independent of prior austenite grain size. The lower fracture tougimess of $0.35 \mathrm{C}-1 \mathrm{Mo}-3 \mathrm{Ali}$ steel compared to that of 0.34C-1Mo stee1 possibly resulted from the lower $M_{S}$ temperature of the former steel $M_{5}$ temperatures were 390 and $464^{\circ} \mathrm{C}$ respectively for the steels in the $1200^{\circ} \mathrm{C}$ austenitized condition). Low $\mathrm{M}_{\mathrm{s}}$ temperatures often cause decrease in the degree of autotempering of martensite, and in some cases canse internal twinning in martensite.

In order to determine the effect of undissolved carbides on fracture toughmess, the results of microstructural examination and the toughness data of $0.30 \mathrm{C}-5 \mathrm{Mo}$ and 0.32C-2Mo steels were compared. Transmission electron microscopy, using carbon replicas extracted from specimens of as-quenched stee1s, indicated that austenitizing treatments at $870^{\circ} \mathrm{C}$ resulted in undissolved carbides of approximate diameter 0.05 microns in $0.32 \mathrm{C}-2 \mathrm{Mo}$ stee1, and carbides of diameter 1-3 microns in $0.30 \mathrm{C}-5 \mathrm{Mo}$ steel. Plane strain fracture toughmess to yield strength $(0.2 \%$ offset) ratios of 0.27 and 0.42 respectively were obtained for as-quenched $0.30 \mathrm{C}-5 \mathrm{M}$ o and $0.32 \mathrm{C}-2 \mathrm{Mo}$ steels (both steels austenitized at $870^{\circ} \mathrm{C}$ prior to testing). In adition, the $\vec{r}^{\prime}$ ine strain fracture tougrness of as-yuenched $0.32-2 \mathrm{Nb}$ steel for the $870^{\circ} \mathrm{C}$ austenitizing treatment was compar.uble to that of as-quenched $0.30 \mathrm{C}-5 \mathrm{Mo}$ sceel sor the $1200^{\circ} \mathrm{C}$ austenitizing treatment. From thase results it was concluded that undissolved carbides of diameter 1-3 microns caused a decrease in plane strain fracture toughness, but carbides of diameter smaller than $\mathbf{0 . 0 5}$ microns did not affect toughness.

\section{b. Tempered Stee1s}

Decreases in roan temperature yield strength and increases in fracture toughness were observed when several $1 \mathrm{Mo}$ and $2 \mathrm{Mo}$ steels of the present inyestiration were tempered at increasing temperatires up to $600^{\circ} \mathrm{C}$. The behavior is illustrated in Fig. 3 for
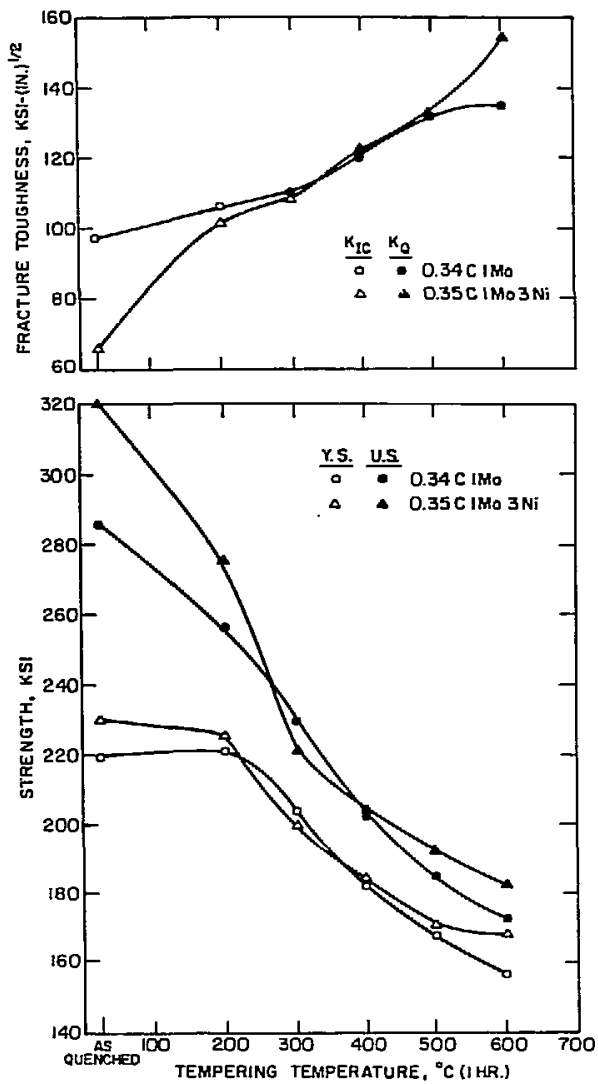

Fig. 3. Plots showing variation, with tempering temperature, of roon temperature yield strength, ultimate strength, and fracture toughress for $\mathrm{C}-\mathrm{Mb}$ and $\mathrm{C}-\mathrm{Mo}-\mathrm{Ni}$ steels. 
$0.34 \mathrm{C}-1 \mathrm{Mo}$ and $0.35 \mathrm{C}-1 \mathrm{Mo}-3 \mathrm{Ni}$ steeis which were austenitized at $870^{\circ} \mathrm{C}$ prior to tempering at several different temperatures and testing at room temperature.

4. INFUIENCE OF HEAT TREATMENT ON TUE FATIQUE CRACK GRONTH RATES IN A SECONDARY HARDENING STEEL

Rona1d M. Horn

Investigations were continued on the relationship between microstructure and fatigue crack growth rates in a $0.3 \mathrm{C}-5 \mathrm{M} \mathrm{b}$ secondary hardening steel. The main objective of the study was to see whether the microstructural features that influenced plane strain fracture toughness influenced fatigue crack growth rates in the same way. Microstructural changes were accomplished by varying austenitizing and tempering treatments. An earlier study 1 had shown that both parameters influenced plane strain fracture toughness. In the present study,

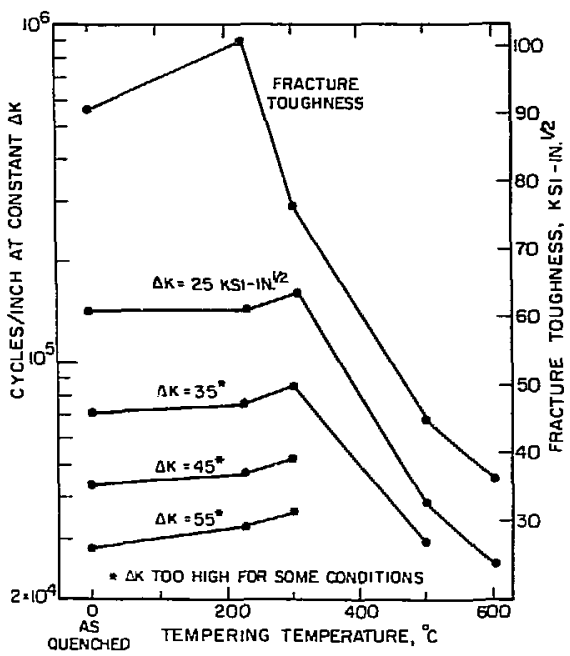

Fig. 1. Comparison of room temperature fatigue crack growth properties and plane strain fracture toughress of $0.3 C-5 \mathrm{~N} b$ stee 1 for the different tempering treatments after austenitization at $1200^{\circ} \mathrm{C}$. The number of cycles for crack growth of 1 in. at a constant stress intensity range was used as a measure of crack growth resistance.

(XBL 739-1860) fatigue tests were carried out in moist air, simulating normal enginecring conditions.

Austenitizing at $1200^{\circ} \mathrm{C}$ resulted in a complete dissolution of carbides. Because of the secondary hardening nature of this steel, tenpering treatments following austenitization and an ice-brine quench led to drastic changes in microstrueture. Figure 1 shows a plot of room temperature fatigue crack growth properties and plane strain fracture toughness vs, tempering temperaure. The number of cycles for crack growth of 1 in. at a given constant $\Delta K$ level was used as a measure of fatigue crack growth resistance. The as-quenched material had both good fracture toughness and gor: fatigue crack growth properties while tempering at $300^{\circ} \mathrm{C}$ led to a deterioration of fracture toughness, but not of fatigue crack growth resistance. Termering at $600^{\circ} \mathrm{C}$ led to deterioration of both fracture toughness and fatigue crack growth resistance.

Scanning electron fractographs of the fatigue fracture surface of the as-quenched steel are shown in Fig. 2. While areas of

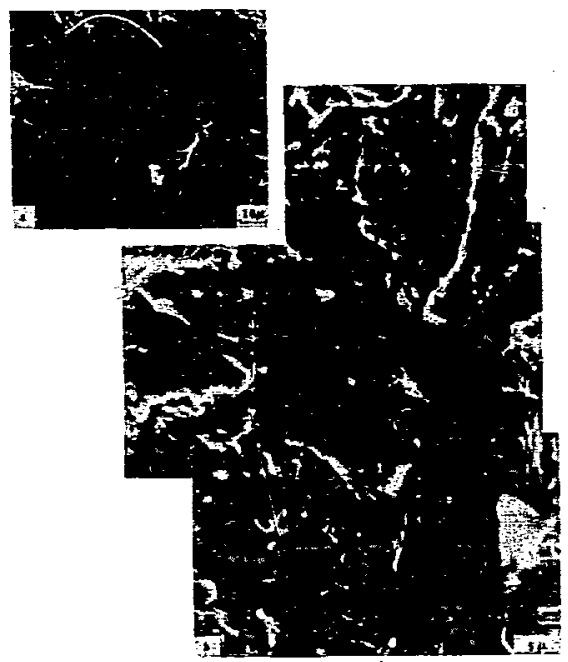

Fig. 2. Scaming electron fractographs of fatigue fracture region in $1200^{\circ} \mathrm{C}$ austenitized as-quenched 0. 3C-5ma. sceel. (a) Overall appearance of surface for $\Delta K=35 \mathrm{ksi}-\mathrm{in} .1 / 2$. (b) conmosite enlargement showing quasicleavage at $A$, fatigue cracking through bulk microstructure at $B$, and local striations at c.

(XBB 739-5579) 
quasi-cleavage were observed at $A$ in Fig. 2, the diffuse striations (as shown at C) were typical of all terpering treatments 4 to $300^{\circ} \mathrm{C}$. The good fracture toughness of the as-quenched steel was attributed to the autotempered martensite free of extensive lath boundary precipitates.] This microstructure also led to good fatigue crack growth resistance.

The deterioration of fracture toughness on tempering at $300^{\circ} \mathrm{C}$, was attributed to the growth of lath boundary precipitates during tempering. The presence of an easy crack path of lath boundary cementite did not, however, affect the fatigue crack growth rates. Fatigue properties, requiring plastic deformation, were insensitive to the microstructural changes that caused deterioration of plme strain fracture toughness.

With tempering in the $500-600^{\circ} \mathrm{C}$ range alloy carbides formed, leading to increased strength. This led to a further decrease in fracture toughness. The fatigue crack growth properties also worsened. Figure 3 shows a scaming electron fractograph of the fatigue surface of a specimen tempered at $600^{\circ} \mathrm{C}$ and tested at $\Delta K=21 \mathrm{ksi}-\mathrm{in} .172$. The appearance of a second failure mode, intergranular failure, as noted in Fig. 3, accounted for the ieterioration of fatigue crack growth resistance.

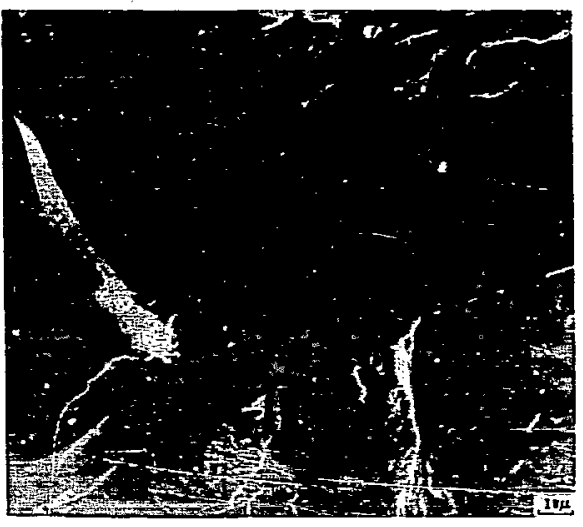

Fig. 3. Cormosite SBI fractograph showing fatigue fracture surface of $1200^{\circ} \mathrm{C}$ austenitized, $600^{\circ} \mathrm{C}$ tempered $0.3 \mathrm{C}-5 \mathrm{k}$ steel. Intergranular mode of failure was evident in fatigue area, $\Delta K=21 \mathrm{ksi}-\mathrm{in} .1 / 2$.

(XBB 759-5585)
Austenitizing at $870^{\circ} \mathrm{C}$ led to a microstructure considerably different from the microstructure resulting from austenitizing at $1200^{\circ} \mathrm{C}$. Alloy carbides were not completely dissolved at the lower austenitizing temperature and this resulted in lower strength and lower plane strain fracture toughness Tempering led to little changes in mechanical properties. Figure 4 compares the fatigue crack growth properties of as-quenched $0.3 \mathrm{C}-5 \mathrm{k}$ s steel for the 870 and $1200^{\circ} \mathrm{C}$ austenitizing termeratures. The $870^{\circ} \mathrm{C}$ austenitizing treatment led to muchimproved fatigue properties. The inprovement could be attributed to ferrite retained during austenitization. Although many undissolved carbide particles were present, leading to lower fracture toughness, the fatigue crack properties were controlled by other microstructural features.

Research in progress is aimed at investigating, in the $0.3 \mathrm{C}$-510 steel, the possible interaction of microstructure, fatıग़ip crack growth, and enviroment. The microstruc.' tre was varied by changing both the austenit $t_{+}$ing and tempering temperatures.

This researc was supported jointly by the U.S. Atomic nergy Commission and the Army Materials and Mecnanics Research Center, Watertown, Massachusetts.

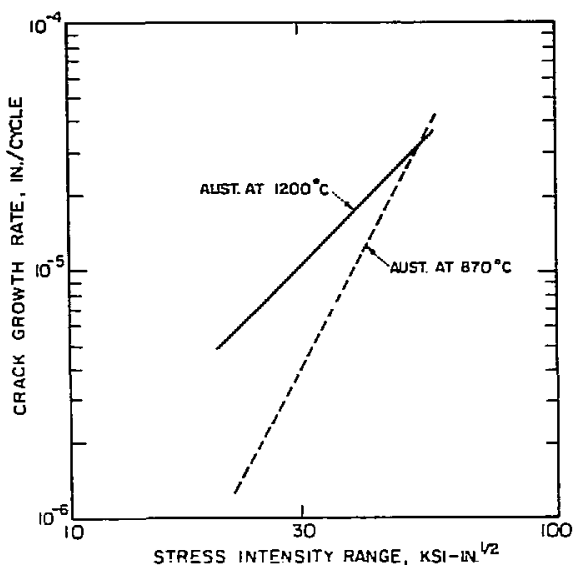

Fig. 4. Comparison of fatigue crack growth rates vs. stress intensity range for asquenched $0.3 \mathrm{C}-5 \mathrm{mo}$ steel.

(XBL 7311-6732)

1. R. D. Goolsby (Ph.D. thesis), LBL-405, Nov. 1971. 
5. STRUCTURE AND ELEVATED TE.PERATURE PROPERTIES OF NON-CARBON-CONTAINING FERRITIC ALLOYS STRENGTHENED BY A LAVES PHASE

Dilip Bhandarkar and Manjeshwar S. Bhat

Recent studies on the use of intermetallic compounds, rather than carbides, for obtaining elevated temperature strength in bcc iron resulted in the development of nun-carboncontaining $\mathrm{Fe}-\mathrm{Ta}-\mathrm{Cr}$ and $\mathrm{Fe}-\mathrm{Ta}-\mathrm{Cr}-\mathrm{Mo}$ alloys which derived their creep resistance from a uniform dispersion of almost spherical particles of the Fe-Ta laves phase (referred to as Fe2Ta hereafter). 1 The heat treatments pertaining to these alloys are described elsewhere.1,2 Preliminary results of stress rupture tests at $1000^{\circ} \mathrm{F}\left(538^{\circ} \mathrm{C}\right)$ and $1100^{\circ} \mathrm{F}\left(593^{\circ} \mathrm{C}\right)$ irdicated that the alloy $\mathrm{Ta} 7 \mathrm{Cr}$ of atonic composition $\mathrm{Fe}-1$ at. $\$ \mathrm{Ta}-7$ at. $8 \mathrm{Cr}$ and the alloy Ta7CrMo of atomic composition $\mathrm{Fe}-1$ at. $8 \mathrm{Ta}-7$ at. $8 \mathrm{C}-0.5$ at. $\mathrm{M}$ Mo had higher ruture strengths than types 403 and 410 stainless steels, but lower ruture strengths than $0.3 \mathrm{C}-1 \mathrm{Cr}-1 \mathrm{Mo}-0.25 \mathrm{~V}$ steel, Greek Ascoloy, and AISI type 422 stainless steel. The results of more extensive structural studies and mechanical testing are described below.

\section{a. Creep and Stress Rupture Properties}

The 1000-hour rupture stress (a measure of rupture strength), and stress for a creep rate of $1 \times 10^{-4} \% / \mathrm{h}$ (a measure of creep strength) were estimated for alloys $\mathrm{Ta7Cr}$ and Ta7CrMo. The results at $1100^{\circ} \mathrm{F}\left(593^{\circ} \mathrm{C}\right)$ are cormared in Table I with those reported in the literature for several common ferritic steels. The spheroidizing heat treatments ${ }^{1}$ used for $\mathrm{Ta7Cr}$ and $\mathrm{Ta} 7 \mathrm{C}$ Ho were, respectively, $10 \mathrm{~min}$ at $1100^{\circ} \mathrm{C}$, and $3 \mathrm{cycles}$ between 22 and $1100^{\circ} \mathrm{C}$ with a $15 \mathrm{~min}$ hold at $1100^{\circ} \mathrm{C}$ during each cycle. It was concluded that the rupture strength of alloy $\mathrm{Ta} 7 \mathrm{Cr}$ was higher than the rupture strengths of ferritic steels containing 5 to $12 \mathrm{wt}$. and strengthened by dispersions of chromium and molybdenum carbides but lower than the rupture strength of ferritic steels containing significant amoumts of vanadium and tungsten. The rupture and creep strengths of alloy Ta7CrMo were even superior to those of alloy Ta7Cr. Among the steels cited above, only the 422 stainless steel had a creep strength higher than that of alloy Ta7Crib ( 3 cycle heat treatment). Additional studies revealed that when the alloy Ta7crilo was given a 2 hour treatmen: at $1100^{\circ} \mathrm{C}$ (instead of the 3 cycle treatine: . the 1000 -hour rupture stress at $1100^{\circ} \mathrm{F}\left(593^{\circ} \mathrm{C}^{\circ}\right)$ was raised and approached that of (in lact, it was slightly higher then that of Greek Ascoloy. The creep strength at $1100^{\circ} \mathrm{F}\left(593^{\circ} \mathrm{C}\right)$ for the 2 hour treatment was higher than that of 422 stainless steel.

b. Structural Investigations of Creep and Fracture in AIloy Ta7Cr

Transmission electron microscopic examination of substructure of crept specimens of alloy Ta7Cr indicated that the initial structure (before creep), which consisted of a lath-1ike substructure with dislocation tangles, subgrains, and a high unpinned dislocation density, underwent partial recovery during creep at $1100^{\circ} \mathrm{F}\left(593^{\circ} \mathrm{C}\right)$ and $1200^{\circ} \mathrm{F}\left(649^{\circ} \mathrm{C}\right)$. A regular subgrain structure with dislocation pile-ups and jogs was observed in crept speciimens. Laves phase particles prevented total recovery by pinning individual dislocations and subgrain boundaries. A typical structure of a specimen which was crept at $1200^{\circ} \mathrm{F}\left(649^{\circ} \mathrm{C}\right)$ and $11,000 \mathrm{psi}$ is shown in Fig. 1, where particle piming of subgrain boundaries, dislocation pile-up (at A), arid pinned dislocation segments (at B) are observed. Structural observations, measured apparent activaticn energy for creep, and the estimated stress sensitivity of steady state creep rate suggested that more than one parallel and independent process was involvet in the creep o? alloy $\mathrm{Ta}$ Cr.

Fracture surface examination, $1 y$ scanning electron microscopy, of specimens broken in stress rupture tests indicated that fracture was initiated by void formation at interfaces between Laves phase particles and the matrix. This resulted in a dimpied

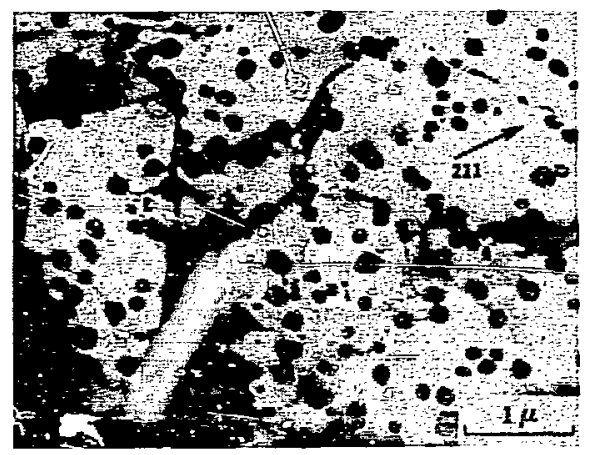

Fig. 1. Transtaission electron micrograph of a thin foil speciiten of alloy Ta7CT (spheroidized for $10 \mathrm{~min}$ at $1100^{\circ} \mathrm{C}$ ), tested in creep at $1200^{\circ} \mathrm{F}\left(649^{\circ} \mathrm{C}\right)$ and 11,000 psi. bright field micrograph with $\bar{g}=[211]$.

(XBB 738-5038, top) 
appearance of fracture surfaces. Void formation sometimes occurred at grain boundaries during long time tests at $110 r^{\circ} \mathrm{F}$ $\left(593^{\circ} \mathrm{C}\right.$, but no intergranular fracture was observed, However, at $1200^{\circ} \mathrm{F}\left(649^{\circ} \mathrm{C}\right)$, extensive grain boundary void formation resulted in mixed intergranular and transgranular fractures.

c. Thase Transformation Characteristics of Alloy Ta7CHh and Their Influence on Microstructiure

Preliminary stidies of the microstructure of alloy Ta7CMo heat treated at $1100^{\circ} \mathrm{C}$ in the $\left(\gamma+\mathrm{Fe}_{2} \mathrm{Ta}\right)$ phase field following solution treating and quenching indicated that the transformation to $Y$ was slow and time dependent at $1100^{\circ} \mathrm{C}$. This feature contrasted with the behavior of Ta7Cr alloy which exhibited a comllete ary transformation in $10 \min$ at $1100^{\circ} \mathrm{C}$. Subsequently, more detailed studies were conducted of the transformation behavior of alloy Ta7Crib, both by cocling the alloy from the solution treating temperatur to each of several temperatures in the $\left(\gamma+\mathrm{Fe}_{2} \mathrm{Ta}\right.$ ) phase field (reaction on cooling), and by quenching the alloy to roon tenterature and then heating it to several temperatures in the $\left(\gamma+\mathrm{Fe}_{2} \mathrm{Ta}\right)$ phase field (reaction on heating). The alloy specimens were held for increasing time intervals at each temperature and icebrine quenched. The microstructure was then examined by optical metallography in order to determine the time at each temperature for the start and completion of the a+y transformation. (The formation of $Y$ phase during hold was easily detected since on brine quench from the holding temperature, $Y$ transfonmed to a by a massive type of reaction resulting in irregular grain boundaries in the transformation product.) The $Y$ formation reaction both on heating and cooling exhibited C-curve kinetics. In Fig. 2 the C-curves are plotted for both the heating (solid curves) and the cooling (broken curves) reactions.

Typical micrographs illustrating the microstructure of partially transformed specimens are shown in Fig. 3 for both the heating and cooling reactions. The micrograpin in Fig. 3(a) was ottained from a specimen cooled to $1020^{\circ} \mathrm{C}$ from the solution treating temperature and held for $10 \mathrm{~min}$ prior to quenching to room temperature. A characteristic lamellar $\gamma+\mathrm{Fe}_{2} \mathrm{Ta}$ structure that is observed in several allogs that undergs a eutectoid reaction formed during holding at $1020^{\circ} \mathrm{C}$. On subsequent quenching $\gamma$ transformed to $\alpha$ while the fraction untransformed at $1060^{\circ} \mathrm{C}$ remained as such. The kinetics of the cooling reaction at

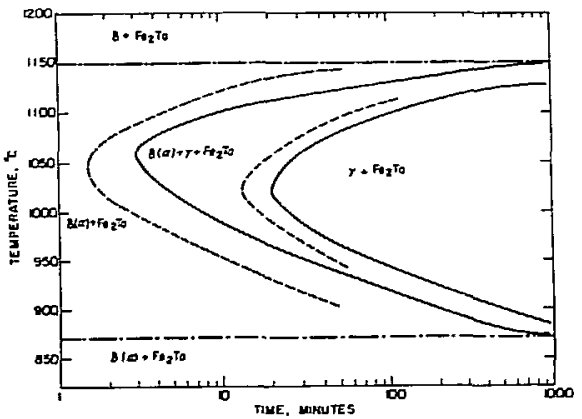

Fig. 2. Time-temperature-trans formation curves for the heating (solid curves) and cooling (broken curves) reactions of alloy Ta7CrMc.

(XBL 741-5483)
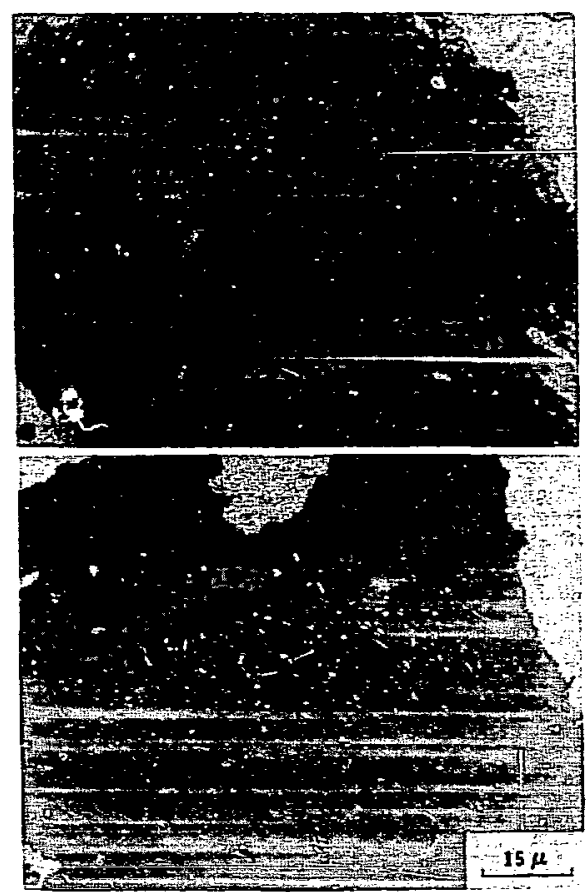

Fig. 3. Microstructures of alloy Ta7Crto partially transformed by holding at $1020^{\circ} \mathrm{C}$ for (a) $10 \mathrm{~min}$ in the cooling reaction, and (b) 15 min in the heating reaction.

(XBB-741-230) 
Table I. Creep and rupture strengths of ferritic alloys at $1100^{\circ} \mathrm{F}\left(593^{\circ} \mathrm{C}\right)$.

\begin{tabular}{|c|c|c|}
\hline Alloy & $\begin{array}{c}\text { 1000-hour } \\
\text { mpture stress } \\
\text { (psi) }\end{array}$ & $\begin{array}{l}\text { Stress for a creep } \\
\text { rate of } 1 \times 10^{-4} \& / h \\
\text { (psi) }\end{array}$ \\
\hline Alloy $\mathrm{Ta} 7 \mathrm{Cr}$ & 16,000 & 9,400 \\
\hline $\begin{array}{l}\text { Alloy Ta7Crilo ( } 3 \text { cycle } \\
\text { heat treatment) }\end{array}$ & 21,600 & 15,000 \\
\hline $0.3 \mathrm{C}-1 \mathrm{Cr}-1 \mathrm{M}-0.25 \mathrm{~V}$ steel & 36,900 & $-^{a}$ \\
\hline $0.15 \mathrm{C}-9 \mathrm{Cr}-1 M_{0}$ stee 1 & 14,100 & 6,300 \\
\hline $0.15 \mathrm{C}-7 \mathrm{Cr}-0.5 \mathrm{Mo}$ stee 1 & $13,30 n$ & 4,000 \\
\hline $\begin{array}{l}403 \text { and } 410 \text { stainless } \\
\text { steels }\end{array}$ & 14,300 & 4,000 \\
\hline Greek Ascoloy & 27,500 & $--^{a}$ \\
\hline 422 stainless steel & 33,800 & 19,000 \\
\hline
\end{tabular}

${ }^{a}$ Creep strength decreases with increasing time at temperature.

several temperatures and the microstructures that resulted were similar in nature to those involved in the pearlite reaction in steels. A typical microstructure that resulted from the heating reaction is illustrated in Fig. 3(b) which shows the optical micrograph of a specinen heated to $1020^{\circ} \mathrm{C}$ (following solution treating and quenching to rocm temperature) and held for $15 \mathrm{~min}$. The Laves phase formed as almost spherical particles in this case. The $\mathrm{C}$-curve kinetics of the heating reaction were explained on the basis of themodynamics, nucleation theory, and diffusion.

It was concluded that in alloy Ta7CHto it was possible to control the heat treating time and temperature, and produce a variety of microstructures with the Laves phase in both spherical and lamellar morphologies. It is well known that creep properties of alloys containing a second phase dispersion are strongly influenced by particle size, morphology, and volume fraction of the second phase. It is proposed to investigace the influence of these and other variables on the creep properties of alloy Ta7Catlo.

1. Y. F. Zackay, E. R. Parker, and

I). Bhandarkar, Proc. John E. Dorn Mern. SyTाp. on Rate Processes in PIastic Deformation, Cleveland, Ohio, Oct. 1972. A1so LBL-1174, Oct. 1972. 2. M. D. Bnandarkar (D. Eng. thesis), LBL-1658, Sept. 1973
6. INVESTIGATION OF BAINITIC HARDERHBILITY IN STEELS BY THE USE OF A RAPID MACONETOMEIRIC IECNIQQUE

\section{B. Naga Prakash Babu}

A rapid magnetic permeability method was developed to conduct a systematic study of the influence of alloying elements and austenitizing temperature on the shape and position of time-tenperature-transformation (TTT) curves of several low and medium alloy steels. The accuracy and reliability of the method were established by plotting the bainitic and martensitic transformation regions of the TTT diagran of commercia] AISI 4340 steel austenitized at $870^{\circ} \mathrm{C}$. The experimentally determined TTT diagram, shown in Fig. 1, was very similar, both in shape and position, to the diagram that has been reported in the literature. 1

From Fig. 1 it is evident that when thick sections of comnercial ALSI 4340 steel are austeritized at $870^{\circ} \mathrm{C}$ and oil quenched, appreciable arounts of upper bainite can result in the mictostructure of the steel. Upper bainite, even when present in small amounts in martensitic and lower bainitic steels, is a detrinental microstructural featire with regard to fracture toughness. In AISI 4340 steel, bainitic hardenability was considerably inproved when austenitizing temperature was raised from 870 to $1200^{\circ} \mathrm{C}$. The TiT diagram of the steel austenitized 


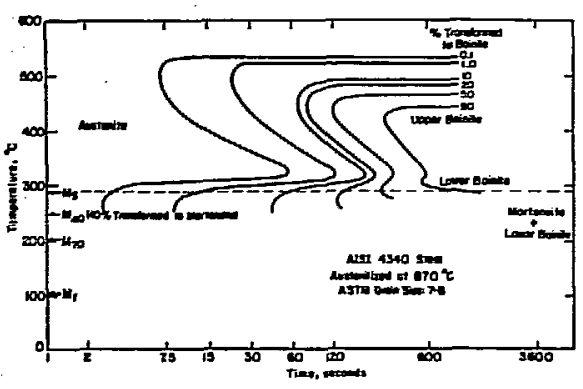

Fig. 1. The TIT curve of commercial AISI 4340 steel austenitized at $870^{\circ} \mathrm{C}$.

(XBL 7311-66́́6)

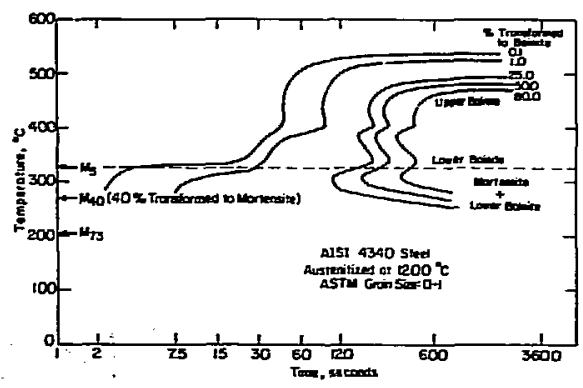

Fig. 2. The TTT curve of commercial AISI 4340 steel austenitized at $1200^{\circ} \mathrm{C}$.

(XBL 741-5484)

at $1200^{\circ} \mathrm{C}$ is shown in Fig. 2. It was evident that in the steel austenitized at $1200^{\circ} \mathrm{C}$ the upper bainitic reaction was shifted to longer times without significantly affecting the lower bainitic reaction. Also evident were separate C curves for the two variants of bainite. The $M_{S}$ temperature was raised by $25^{\circ} \mathrm{C}$ as a result of autenitizing at $1200^{\circ} \mathrm{C}$.

It was believed that improvements in bainitic hardenability, similar to thase achieved by the use of high austenitizing temperatures, could also be achieved by alloying additions. An objective of the present study was to determine quantitatively the relative influences of the common alloying elements such as $\mathrm{Ni}, \mathrm{Cr}, \mathrm{Nh}, \mathrm{Mo}$, and $S i$ on bainitic hardenability. The cormosition of combercial AISI 4340 steel was chosen as the base composition. Systematic variations in composition were achieved by appropriate alloying additions, and the influence of these systematic additions was exanined by experimentally determining the TTT curves for the several steels.

The results indicated that the alloying elements $\mathrm{Ni}, \mathrm{Cr}, \mathrm{Mr}$, Ho, and $\mathrm{Si}$ improved the bainitic hardenability by moving the bainite C-curve to longer times. In general, for the same total alloying addition, the addition of two elements was more effective than the addition of a single elenent. This is illustrated in Fig. 3. where the TTГ arrves of two steels with compositions AISI $4340+2 \mathrm{gNi}$ and AISI $4340+18 \mathrm{Ni}+15 \mathrm{C}$ are compared. In addition, the results of this stury showed that the combined addition of $\mathrm{Cr}$ and $\mathrm{H}$ o was more effective in increasing the bainitic hardenability than the conbined addition of $\mathrm{Ni}$ and $\mathrm{Mo}$.

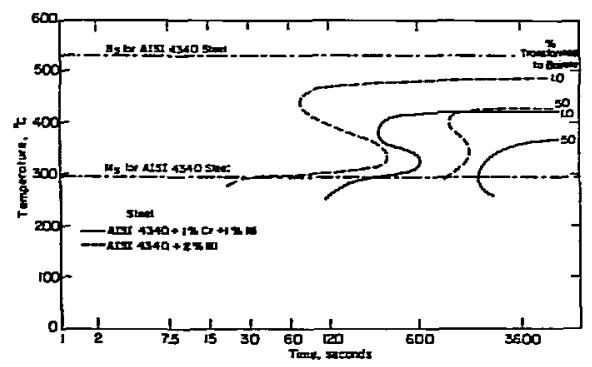

Fig. 3. The TTT curves of steels with compositions AISI $4340+16 \mathrm{Ni}+18 \mathrm{Cr}$ (solid curves) and AISI $4340+28 \mathrm{Ni}$ (broken curves). Both steels were austenitized at $900^{\circ} \mathrm{C}$.

(XBL 741-5485)

The addition of alloying elements $\mathrm{Ni}, \mathrm{Cr}$, $\mathrm{Mn}, \mathrm{Mo}$, and $\mathrm{Si}$ also lowered the $\mathrm{B}_{\mathrm{s}}$ (the teuperature above which no bainite forms on isothermal holding) and the $B_{f}$ (the tenperature below which fully bainitic structures are obtained). The $\mathrm{B}_{5}$ temperature of AISI 4340 was lowered by $25^{\circ} \mathrm{C}$ per wt. addition of either $\mathrm{Ni}$ or $\mathrm{Mn}$, by $55^{\circ} \mathrm{C}$ per wt. addition of $\mathrm{Cr}$, and by $100^{\circ} \mathrm{C}$ per wt. $\&$ addition of Mo. In combined adfitions, the effect of alioying elements in lowering the $B_{S}$ temperature was nearly comulative.

In the non-silicon modified 4340 steels, after the transformation within the $B_{5}-B_{f}$ range, all or nost of the remaining austenite transformed when the steel was 


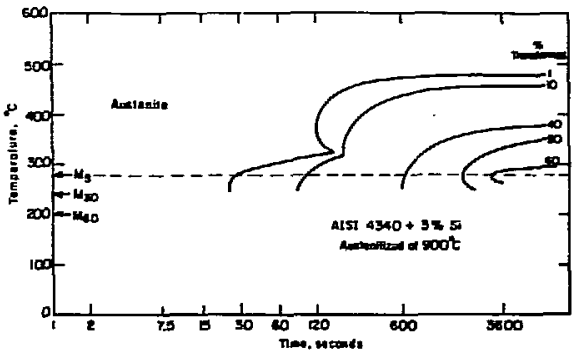

Fig. 4. TTT curves of AISI 4340 stee1 modified by addition of $3 \% \mathrm{Si}$.

(XBL 741-5486)

cooled to rocon temperature. However, in Si modified 4340 steels, the untransformed austenite was retained at room temperature. The TTT diagram for $385 i$ modified 4340 is shown in Fig. 4. In this steel as much as $40 \%$ austenite was retained as part of the bainitic structure. The mechanical properties of steel with the above microstructure have not been studied. There is reason to believe that the retained austenite may enhance toughness by blunting cracks.

1. Isothermal Transformation Diagrams, Inited States Stee1, 1363.

7. AN ISOTHERMAL STUDY OF BAINITIC AND MARTENSITIC TRANSFORMATIONS IN SOME LOW ALLOY STEEIS

\section{Clyde E. Ericsson}

Some low alloy steels have good pearlitic hardenability without good bainitic hardenability. In these steels, significant amounts of proeutectoid ferrite, upper bainite, and lower bainite may form on quenching from the austenitizing temperature. Even smal1 amounts of proeutectoid ferrite and upper bainite have been shown to have detrimental effects on fracture toughmess, while lower bainite and tempered martensite are considered comparable to each other in their effectiveness in enhancing fracture toughness. The objective of the present investigation was to establish both the bainitic and the pearlitic hardenabilities of several commercial low alloy steels, namely, AISI 4130, AISI 4140, D6AC, and AVS $6416(300-M)$. The TTT curves of these steels were determined by a rapid magnetcometric (MPM) technique used in conjunction with computer-aided dat: processing and analysis. All steels were austenitized at $880^{\circ} \mathrm{C}$ prior to isothernal holding at several temperatures. In addition, the strels AISI 4130 and ANS 6416 (300-M) were also studied in the $1200^{\circ} \mathrm{C}$ austenitized condition.

The TTT diagran of AISI 4130 (mustenitized at $880^{\circ} \mathrm{C}$, as determined by the magnetometric technique, is shown in Fig. 1. It is evident that the upper and 1ower bainitic hardenabilities are in good agreement with those reported in the literature for the steel. I Similar good agreement was observed between the TTT curves determined in the present investigation and the curves reported in the literature for AISI 4140 and D6AC steels. I,2 The TTT diagram of the present investigation for ANS 6416 (300-M) steel differed slightly from the diagram reported by other investigators $^{3}$ in two respects. First, the time for the nucleation of the bainite transformation

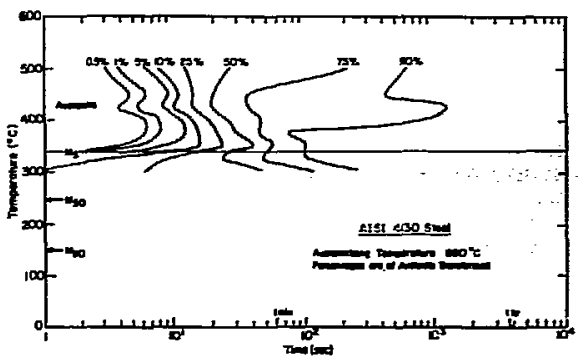

Fig. 1. The TTT diagram of AISI 4130 stee1 (austenitized at $880^{\circ} \mathrm{C}$ ).

(XBL 7311-6654)

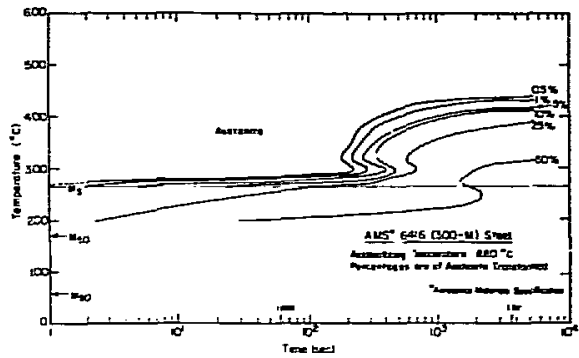

Fig. 2. The TTT diagram of AVS 6416 (300-il) steel (austenized at $880^{\circ} \mathrm{C}$ ) (XBL 7311-6663) 
Table I. Martensite range temperatures of steels.

\begin{tabular}{l|c|c|c|c|c|c}
\hline \multirow{2}{*}{ Material } & \multicolumn{2}{|c|}{$M_{s}$} & \multicolumn{2}{c|}{$M_{50}$} & \multicolumn{2}{c}{$M_{90}$} \\
\cline { 2 - 7 } & $\begin{array}{c}\text { MPM } \\
\text { values }\end{array}$ & $\begin{array}{c}\text { published } \\
\text { values }\end{array}$ & $\begin{array}{c}\text { MPM } \\
\text { values }\end{array}$ & $\begin{array}{c}\text { Published } \\
\text { values }\end{array}$ & $\begin{array}{c}\text { MPM } \\
\text { values }\end{array}$ & $\begin{array}{c}\text { Published } \\
\text { values }\end{array}$ \\
\hline AISI 4140 & & & & & & \\
Aust. at $880^{\circ} \mathrm{C}$ & 295 & 340 & 200 & 300 & 90 & 270 \\
\hline D6AC & & & & & & \\
Aust. at $880^{\circ} \mathrm{C}$ & 290 & 290 & 170 & -- & 50 & -- \\
\hline AISI 4130 & & & & & & \\
Aust. at $880^{\circ} \mathrm{C}$ & 340 & 360 & 250 & 320 & 150 & 300 \\
Aust. at $1200^{\circ} \mathrm{C}$ & 350 & -- & 250 &.- & 150 & -- \\
\hline AMS $6416(300-\mathrm{M})$ & & & & & & \\
Aust. at $880^{\circ} \mathrm{C}$ & 270 & 300 & 170 & -- & 60 & - \\
Aust. at $1200^{\circ} \mathrm{C}$ & 290 & -- & 190 & -- & 60 & - \\
\hline
\end{tabular}

(0.57 transformation) was an order of magnitude greater than the time reported in the literature, and secondly, the austenite decomposition reaction did not proceed to completion above the $\mathrm{M}_{\mathrm{s}}$ temperature. These features are illustrated by the TTT diagram shown in Fig. 2 for AMS 6416 (300-M) steel (austenitized at $880^{\circ} \mathrm{C}$ ).

The TIT curve of AISI 4130 steel austenitized at $1200^{\circ} \mathrm{C}$ is shown in Fig. 3.

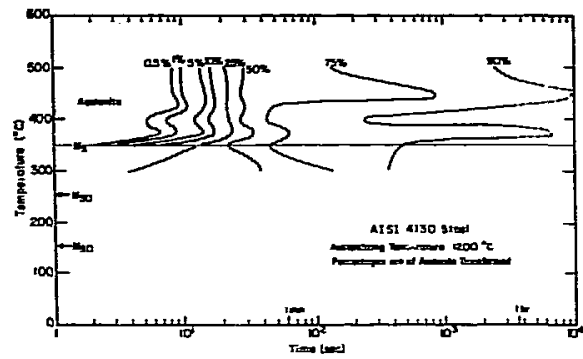

Fig. 3. The ITT diagram of AISI 4130 steel (austenitized at $1200^{\circ} \mathrm{C}$ ).

(XBL 7311-6651)
It was evident from a comparison of Figs. 1 and 3 that austenitizing at the higher temperature resulted in an increase in the time required for nucleation of upper bainite while the lower bainite transformation was virtually unaffected.

The $\mathrm{M}_{\mathrm{s}}, \mathrm{M}_{50}$, and $\mathrm{Mgo}_{90}$ temperatures determined in the present investigation for several steels are listed in Table I. Also listed in the table are the $\mathrm{M}_{5}, \mathrm{M}_{50}$, and $\mathrm{Mog}_{0}$ temperatures reported in the literature for the same steels. In gentral, the temperatures determined in the present study were higher than those reported in the literature. 1-3 In addition, all four steels exhibited an acceleration of austenite decomposition just above the $\mathrm{M}_{5}$.

1. Isothermal Transformation Diagrams, Lnited States Steel, 1963.

2. T. J. Koppenaal, Met. Trans. 1, 3371 (1970).

3. Isothermal Transformation Diagrams of Nickel Alloy Steels, International Nickel Company, Inc., 1965 . 


\section{RESEARCH PLANS FOR CALENDAR YEAR 1974}

Victor F. Zackay and Earl R. Parker

Further studies of the relationship between microstructurn, fracture toughness, and fatigue crack growth of high-yieldstrength steels are planned for the coming year. In particular, the effect of environnent on fatigu crack growth will be investigated in several quenched and tempered steels, Also planned are additional studies on the effect of alloying elements on bainitic hardenability of Iow and edium ailoy steels. The research on elevated temperature properties of ferritic alloys will include the effect of adding alloving elements such as tungsten to $\mathrm{Fe}-\mathrm{Ta}-\mathrm{Cr}_{\mathrm{T}}$ alloys. Studies on optinization of microstructure and creep properties w: 1 te continued in $\mathrm{Fe}-\mathrm{Ta}-\mathrm{Cr}-\mathrm{Mo}$ alloys.

Addi ional inve: ations of phase transformations and resulting microstructures in Fe-Ni-Ti alloys will be aimed at attaining further improvements in toughness at cryogenic tenperatures. The influence of grain refining, and nickel and manganese contents on toughness will be investigated in iron-base alloys containing titanium. New projects will be initiated on using a linear elastic fracture mechanics approach to predict and prevent crack initiation in welded medium strength steels, and on the use of a magnetic technique for rapid determinations of continuous cooling curves for decomposition of anstenite in steels. The theory and background of both these new projects have already been studied.

\section{1973 PUBLICATIONS AND REPORTS}

Victor F, Zackay, Earl R. Parker, and Associates

\section{Journals and books}

1. E. R. Parker and V. F. Zackay, Enhancement of Fracture Toughness in High Strength Steel by Microstructural Control, Engr. Fract. Mech. 5, 147 (1973) (LBL-832).

2. R. A. Mecoy and W. W. Gerberich, Hydrogen Embrittlement Studies of a TRIP Steel, Met. Trans. 4, 539 (1973) (LBL-439).

3. V. F. Zackay, E. R. Parker, and W. E. Wood, Influence of Sone Microstructural Features on the Fracture Toughness of High Strength Steels, in Microstructure and Design of Alloys (Institute of letals, London, 1973), p. 175 (LBL-1833).
4. V. F. Zackay, Enhancement of the Impact Properties of a BCC Cryogenic Alloy by Compositional and Microstructural Control, ibid., p. 591.

5. R. H. Jones, Predicting the Stress-Strain Behavior of Polycrystalline $a$-Iron Containing Hard Spherical Particles, Met. Trans. 4, 2799 (1973) (LBL-I79 Rev.).

6. E. R. Parker, UItra-High Strongth Steels, in The Science of Materials Used in Advanced Technology, edited by E. R. Parker and U. Colombo (Wiley, New York, 1973), p. 355.

\section{Papers presented}

1. R. M. Hom, V. F. Zackay, and E. R. Parker, "Influence of Heat Treatment on the Fatigue Crack Growth Rates of a Secondary Hardening Steel," Materials Engineering Congress, Chicago, Illinois, Oct. 1973 (iBLi-2239) .

2. G. Y. Lai, W. E. Wood, R. A. Clark, V. F. Zackay, and E. R. Parker, "The Effect of Austenitizing Temperature on the Anount of Retained Austenite in AISI Type 4340 Steel," Materials Engineering Congress, Chicago, Illinois, Oct. 1973 (LBL-2250).

3. S. Jin, J. W. Morris, Jr., and V. F. Zackay, "Grain Refinenent Through Thermal Cycling in an Fe-Ni-Ti Cryogenic Alloy," Materials Engineering Congress, Chicago, Illinois, Oct. 1973 (LBL-2539).

\section{LBL reports}

1. W. W. Gerberich and W. E. Wood, The Nechamical Nature of Stress-Corrosion Cracking in AI-Zn-Mg Alloys, LBL-418, Jan. 1973.

2. S. Jin, W. A. Horwood, J. W. Morris, Jr., and V. F. Zackay, A Simple Method for Charpy Impact Testing below $6^{\circ} \mathrm{K}$, LBL-1483, March 1973 (Adtances in Cryogenic Engineering, in press).

3. H. E. Adkins, Jr., Structure and Properties of TRIP Steels Processed by Deformation and Thermal Cycling, LBL-1491, April 1973.

4. W. E. Wood, E. R. Parker, and V. F. Zackay, An Investigation of Metallurgical Factors Which Affect the Fracture Toughness of Ultra High Strength Steels (D. Eng. thesis of W. E. Wood), LBL-1474, May 1973.

5. S. Jin, J. W. Morris, Jr., and

V. F. Zackay, An Iron-Nicke1-Titanium Alloy 
with Outstanding Toughness at Cryogenic Temperature, LBL-1484 Rev., July 1973 (Acivances in Cryogenic Engineering, in press).

6. Go Sasaki, Low Tenperature Toughness of BCC Fe-Ni-Ti Allloys (D. Eng. thesis), LBL-1493, July 1973.

7. T: Tom, Microstructural Variables and Fracture Toughness of High Strength $\mathrm{M}_{6}$ and Mo-Nii :Steels (D. Eng. thesis), L.BL-1856, Sept. 1973.

8. M. D. Bhandarkar, Structure and Elevated Temperature Properties of Ferritic Alloys Strengthened by Intermetallic Compounds (D. Eng. thesis), LBL-1858, Sept. 1973.

9. E. Plaza-Meyer and M. W. Perra, Nuclear Magnetic Resonance Study of Precipitation Aluminum - 48 Copper, LBL-1883, Sept. 1973.

10. G. Y. Lai, W. E. Wood, E. R. Parker, and V. F. Zackay, Influence of Microstructural Features on Fracture Toughness of an U1traHigh Strength Stee1, LBL-2236, Oct. 1973.

11. V. F. Zackay, E. R. Parker, J. W. Morris, $\mathrm{Jr}$. , and $\mathrm{G}$. Thomas, The Application of Materials Science to the Design of Engineering Alloys, LBL-2261, Oct. 1973.

12. M. J. Yokota, G. Sasaki, H. A. Horwood, V. F. Zackay, and E. R. Parker, Developing
High Inpact Toughness in Fe-8 to 16\&Ni-0.58Ti Alloys at Liquid Nitrogen Temperatures, LBL-2278, Oct. 1973.

13. E. R. Parker and V. F. Zackay, Materials Science of Modem Steels, LBL-2286, Oct. 1973.

14. B. N. P. Babu, D. Ott, E. R. Parker, and V. F. Zackay, A Rapid Magnetometric Techrique to Plot Isothermal Transfomation Diagrams, LBL-2502, Oct. 1973.

15. W. E. Hood and W. W. Gerberich, The Mechanical Nature of Stress-Corrosion Cracking in Al-Zn-Mg Alloys: I. Evaluation of the Ductile Rupture Contribution, LBL-2229, Nov. 1973.

16. W. W. Gerberich and W. E. Wood, The Mechanical Nature of Stress-Corrosion Cracking in A1- Zn-Mg A1loys: II. Electrochenical-Nechanical Model, LBL-2230, Nov. 1973.

17. C. E. Ericssor, an Isothermal Study of Bainitic and Marten:-tic Transformations in Some Low Alloy Steels Using a New Magnetic Permeability Technique (M. S. thesis), LBL-2279, Dec. 1973.

18. A. Baghdasarian and S. F. Ravitz, Corrosion Resistance of IRIP Steels, LBL-2506, Dec. 1973. 


\section{F. HIGH FIELD SUPERCONDUCTIVITY}

Milton R. Ficius, Prinoipal Investigaton

Introduction. In the years following 1960 , when the first of the high-fieId superconducting compounds was discovered, progress in understanding their general phenomenolugy isas been much more rapid than the develcpment of appropriate materials for technologica1 applications, most of which for this reasor remain in the conceptual stage.

There are three fundamental and interrelated aspects to be considered in the developinent of suitable materials:

1) The intrinsic superconducting parameters of candidate compounds.

2) The need for special concepts and procedures to obtain these compounds in usable forn, since all of the superior candidates are extremely brittle.

3) The fact that a usable form is one that is capable of incorporation into a conductor design that is compatible with the constraints imposed by the phenomenology of high-field superconductivity.* Perhaps the most basic of these constraints is that required to satisfy the conditions for adiabatic stability. This requirement inplies a composite containing many fine superconducting filaments. The implication of additional constraints will be considered in another part of this report.

Since compounds with excellent superconducting properties are already available, it is with the latter thr aspects relating to materials design and processing that this program is concerned.

\footnotetext{
The subject of appropriate conductor design has been treated extensively by the superconducting Applications Group of the Rutherford Laboratory (a.g., J. Phys. D: Appl. Phys., 1970, vol. 3, pp. 1517-1585).

\section{PRESENT STATUS OF IRD PONDER ROLLED SUPERCONDUCTING TAPE}

Kanithi Henachalam

A new method ias devised for preventing a loss of tin during the cold rolling of a conposite niobium-tin tape that met the two desired criteria of effectiveness and ease of execution. It involved carrying out the tin infiltration of the porous niobim tape under conditions that hardened the tin by a dispersion of intermediate phases of the niobium-tin system. This required simply an increase in infiltrating temperature from 650 to $850^{\circ} \mathrm{C}$. Whereas at the previously used temperature of $650^{\circ} \mathrm{C}$, it is themodynamically possible to have niobium, $\mathrm{Nb}_{3} \mathrm{Sn}, \mathrm{Nb}_{6} \mathrm{Sn}_{5}$, $\mathrm{NbSn}_{2}$ and tin all present in the infiltrated tape, the reaction kinetics for the short immersion times enmloyed ( ane minute) are such that virtually none of the intermediate phases actually form. At $850^{\circ} \mathrm{C}$, however, there is a marked change in reaction kinetics. Figures $1(\mathrm{a})$ and $1(\mathrm{~b})$ sho's the corresponding microstructures. The changes in volume fraction of $\mathrm{Nb}_{3} \mathrm{Sn}$ in tapes processed with different thermo-mechanical histories are
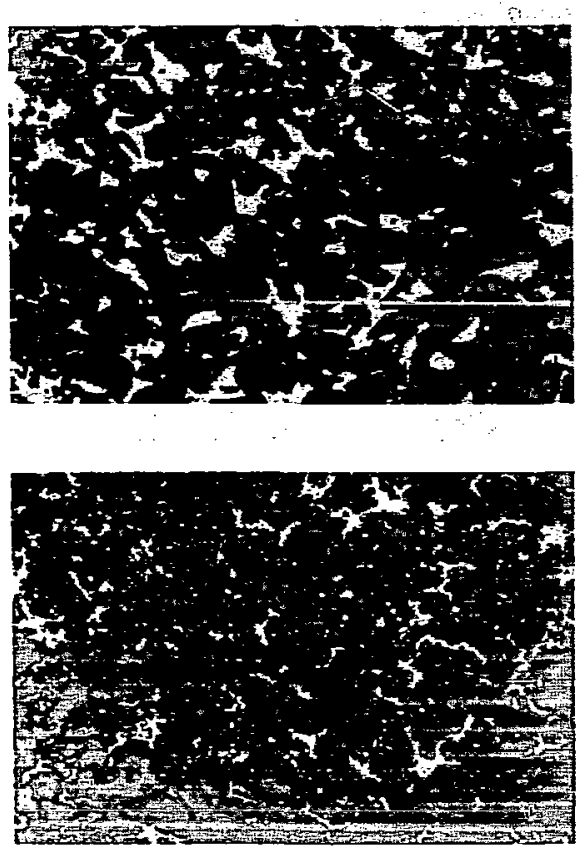

Fig. 1. Porous niobium tape infiltrated with tin. a) Infiltrated at $650^{\circ} \mathrm{C}$, b) infiltrated at $850^{\circ} \mathrm{C}$. thase designations: niobiun, 1 ; tin, $3 ; \mathrm{Nb}_{6} \mathrm{Sn}_{5}, 4$.

(XBB 737-4131) 
shown in Fig. 2, in which (a), (b), and (c) correspond to volume fractions of 30,40 , and $50 \%$, respectively. The current carrying capacity of these tapes at $4.2^{\circ} \mathrm{K}$ in pulsed magnetic fields up to $160 \mathrm{kG}$ is shown in Fig. 3. The (a), (b), and (c) designations of the arrves correspond with the photomicrographs of Fig. 2. Curve (d) shows the effect of doping the niobium powder with 1.58 of zirconium on a tape which contained an $\mathrm{Nb}_{3} \mathrm{Sn}$ volume fraction of $37 \%$. Curve (d') shows the shift in (d) corresponding to an increase in volume fraction to 508 which we are now able to achieve.

The morphological control and superconducting properties have been optimized to a sufficient degree that no further work on the powder rolled tape is presently contemplated. Rather, it will serve as a point of departure in exploring new directions.
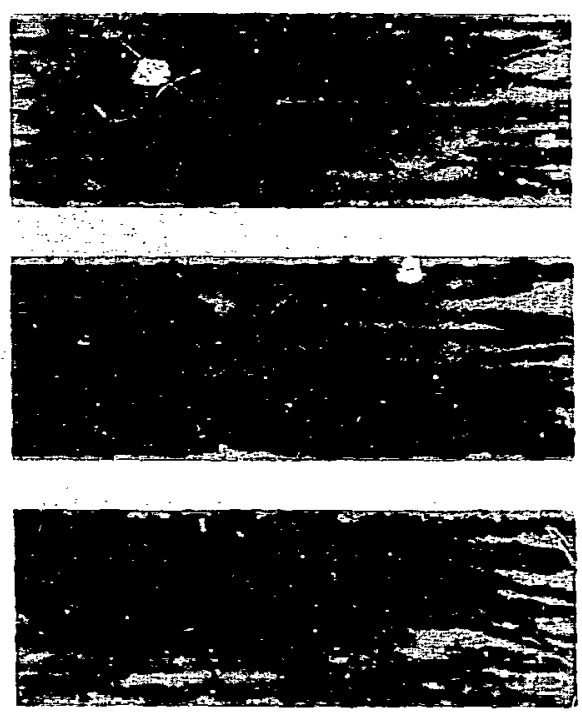

Fig. 2. Thermo-meclianically processed tape. a) Infiltrated at $650^{\circ} \mathrm{C}$, rolled at rocil temperature, and reacted at $970^{\circ} \mathrm{C} ; \mathrm{N}_{3} \mathrm{Sn}$ volume fraction is $30 \%$. b) Infiltrated at $650^{\circ} \mathrm{C}$, rolled at $-72^{\circ} \mathrm{C}$, and reacted at $970^{\circ} \mathrm{C}$; $\mathrm{Nb}_{3} \mathrm{Sn}$ volume fraction is $40 \%$. c) Infiltrated at $850^{\circ} \mathrm{C}$, rolled at rocts temperature, and reacted at $970^{\circ} \mathrm{C} ; \mathrm{Nb}_{3} \mathrm{Sn}$ volume fraction is 505. Phase designations: niobium, 1 ; $\mathrm{Nb}_{3} \mathrm{~S} n, 2$; unreacted tin, 3 .

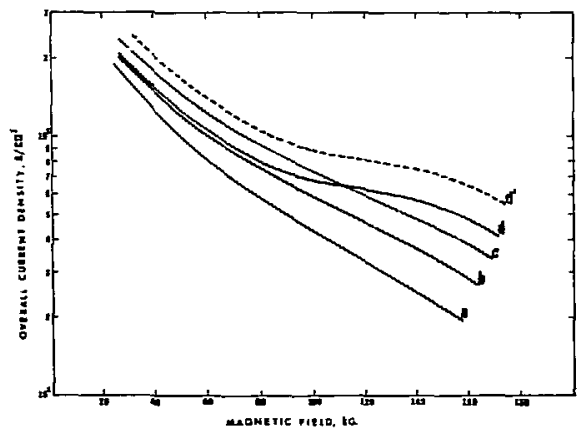

Fig. 3. Pulsed field dependence of current carrying capacity. Curves (a), (b), and (c) correspond to the photomicrographs of Fig. 2 . Curve (d) shows the effect of doping with zirconium for a tape with an $\mathrm{Nb}_{3} \mathrm{Sn}$ volume fraction of $377^{\circ}$; curve (d') represents curve (d) normalized to an $\mathrm{Nb}_{3} \mathrm{Sn}$ volume fraction of $50 \%$.

(XBL 7311-6727)

\section{RESEARCH PLANS FOR CALENDAR YEAR 1974}

\section{Milton R. Pickus}

A critical evaluation of MMR's superconducting tape has been made from the standpoint of the constraints imposed by the theoretically predicted and experimentally verified phenomenology of high-field superconductivity. In combination, these phenomenological constraints determine the essential features of a practical multipurpose superconductor.

The basic element should be a composite, approximately $10 \mathrm{mils}$ in diameter, containing many fine $(\sim 5$ micron diameter) superconducting filaments arrayed in a non-

superconducting matrix. Several of these elements should be tristed together to form a strand. An appropriate nusuer of these strands--to provide the required current carrying capacity--should be woven together in a fully transposed configuration.

When the extreme brittleness of the superior high-field supercunducting compounds is considered in the context of these features, it becomes clear that the key requirement is the design of a material for the basic element. The design and means for producing such a material comprise the objective of the plamed program.

IRD tape has a number of desirable 
features associated with its filamentary morphology. However, the deformation process employed results in an unfavorable aspect ratio between the thickness and width of the filaments. The thickness is of the correct order of magnitude, but the width corresponds to the original average pore size and is too great by a factor of approximately 4 . Even this width must be considered critically: The interconnections between filaments, a characteristic deriving from the original capillary system of pores, could result in an effective width equal to the entire width of the tape.

It is planned therefore to produce the material in the form of a wire. A successful effort in this direction would retain the good features of the tape and provide a material for the basic element of a practical superconductor that could be given the form of either a round or a flat cable. Several methodologies providing axial symetry will be investigated. Among them are pressureless sintering and isostatic compaction. Preliminary results with pressureless sintering already show promise. Additionally, a newly conceivied approach will be explored.

\section{1973 PUBLICATIONS AND REPORTS}

Milton R. Pickus and Associates

\section{IBL report}

1. M. R. Pickus, K. Hemachalam, and B. N. P. Babu, Superconducting Properties of a Powder Rolled Composite Tape Containing $\mathrm{Nb}_{3} \mathrm{Sn}$ Filaments, LBL-1838 preprint. (10 appear in Materials Science and Engineering, Vol. 14, ‥ 3, pp. 265-270.) 


\section{G. POWDER METALLURGY}

\section{Milton R. Pickus, Principal Investigator}

Introduction. Powder metallurgy provides a number of advantages compared with other material-foiming processes. Perhaps the one most commonly used is that based simply on econonics. Contrasted with machining, for example, in the production of simple gears, powder metallurgy is advantageous in two important respects: a sharp reduction in labor and machine costs per part, and no waste corresponding to the generation of chips during machining, which can be as much as $50 \%$ of the starting material. Where optimun mechanical properties see required, however, there is a major problem due io residual porosity. Part of this program is addressed to the investigation of mechanisms for pore elimination.

Additionally there are certain mique capabilities of this process that are of particular value in materials design. Of these, two may be mentioned that are especially germane to another part of the program. One is the combining of nommally incompatible components, such as metals and non-metals, while retaining the desired properties of each. The second is tive ability to produce materials with a controlled porosity, which may be used directly as in the case of filters and metering devices or indirectly as a porous framework to be infiltrated with lower melting point materials, as we are doing in our work on sperconducting materials and as we propose to do in our research on low-friction composites.

\section{SUMSIARY OF ACTIVITIES IN 1973}

Milton R. Pickus, John J. Holthuis, and John A. Jacobsen

Formal research in this program commenced in October 1973 with two graduate students participating. John R. KRein has begun a basic study of the conditions required for the elimination of residual porosity, and Federico J. Reinel has started on the design of low-friction composites of the type needed in advanced technologies. In preparation for this program, swbtantial progress was made in the design, contruttion, and acquisition of needed equipment, and in developing special procedures for evaluating powder metallurgy materials. The construction of a versatile isostatic press with a 2" diameter bore and a capacity of $130,000 \mathrm{psi}$ has just been completed by MRD personnel.
Also ready is a pure, dry hydrogen sintering facility to complement our vacurm sintering capability.

Residual porosity in powder metallurgy materials complicates their metallography and density determination. Surcessful procedures for both have been worked out utilizing a newly constructed vacum impregnating facility.

To provide a reference base for a study of the influence of alloying elements on the sintered microstructures of ferrous systens, the response to different modes of compaction and sintering was investigated for three different types of unalloyed iron powders: carbony1, atomized and sponge. Additionally, to assist in a study of the iron-carbon system, diffusion couples on a macroscopic scale were prepared and studied.

\section{RESEARCH PLANS FOR CALENDAR YEAR 1974}

\section{Milton R. Pickus}

In regard to the basic study of the conditions required for consolidation of powders with a minimm of residual porosity, using only the two-step sequence of compactim and sintering, a selection of approaches that are consistent with contemporary theories of sintering has been made. These include liquid phase sintering and two variations of solid state sintering considered likely to inpede grain growth: the presence of a dispersion of fine particles of a stable phese, or small amounts of certain solutes.

This part of the program will conmence with a study of liquid phase sintering applied first to the iron-carbon system and then to other systems such as irm-boron, ironsilicon, iron-cerium, and iron-titanium. Initially, the effectiveness of various densification mechanisms will be evaluated by means of metallography and mercury porosimetry.

The second part of the program will be concerned with the development of materials that provide a special combination of properties: low coefficient of friction, stability at temperatures to and above $1200^{\circ} \mathrm{F}$, and resistance to corrosion and erosion caused by the flow of hot gases. Materials with these properties are needed for improved energy conversion systens as well as many other applications. As ari 
example, there is an inmediate need in respect to the internal combusion engine. in order to diminish air pollution by automobile emission gases, the use of lead-free gasoline has been attempted. A direct consequence was a ten- to twenty-fold increase in the wear rate of the exhiui valve seats. This causes not only malfunction of the engine, but has the contrary effect of acturily increasing the amount of noxious gases released.

The knowledge and experience gained from our work on superconducting materials involving the infiltration of porous metallic frameworks will be applied to the design of materials for this type of service. Materials to be investigated include those suitabie for the porous $f$. mawork and stable solid lubricants to be infiltrated into the interconnected pnre structure. Solid lubricants such as molybdenum disulfide have too limited a range of temperature stability. New materials must be found. Exploratory work by NASA on solid lubricants for use as surface coatings has indicated one new promising group of candidate materials that will be investigated: these are the lanthanide and alkali fluorides.

Test equipment will be developed to screen and evaluate the composites that are prepared.

\section{1973 PUBLICATIONS}

Milton R. Pickus and Associates

\section{Journal}

1. Translated by J. Holthuis with assistance by L. Brewer: G. V. Samsonov and V. I. Yakovlev, The Influence of Additions of Transition Metals on the Sintering Behavior of Tugsten, Zeitschrift fur Metalilkunde $62,622-626$ (1971).

2. M. R. Pickus, V. F. Zackay, E. R. Parker and J. T. Holthuis, A Puwder Rolled Superconducting Composite with Controlled Norphology, International Jounaz of Powder Metallurgy 9,3 (1973). 


\section{H. ADVANCED MATERIALS}

Robert H. Bragg, Principal Investigator

1. K-EMISSION SPECTRA OF GLASSY CARBOY-ADVANCED MATERIALS

Ram P. Saxena and Robert H. Bragg

The K-emission spectra of glassy carbon (GC) heat treated at 1000,1800 and $2800^{\circ} \mathrm{C}$ were measured along with those from a (111) face of diamond and the "c" face of pyrolytic graphite (PG) using a lead octadeconate crystal ( $2 \mathrm{~d}=100.5 \mathrm{~A}$ ) as an analyzer. The results shown in Figs. I and 2 and sumarized in Tahle I clearly show that the GC spectrum in intermediate between that of digmonu ( $\mathrm{sp}^{3}$ bonding) and PG (essentially $\mathrm{sp}^{2}$ bonding) and moves toward that of PG with increasing heat treatment temperature. These results strongly support the model of CC proposed by Noda and Inagaki ${ }^{1}$ and Kakinoki ${ }^{2}$ that there is a mixture of $\mathrm{sp}^{3}$ and $\mathrm{sp}^{2}$ bmos in bulk GC. While a quantitative determination of the relative proportions of each component has not been made, the precision of these data justify the conclusion that there are significant differences between the bonding in GC and graphite.

A more accurate and detailed investigation of the emission spectrum of GC is not contemlated at this time because these $K$ emission data, colpled with the results reported in Ref. 3 below argue strongly in favor of diamond-like regions in $C C$.

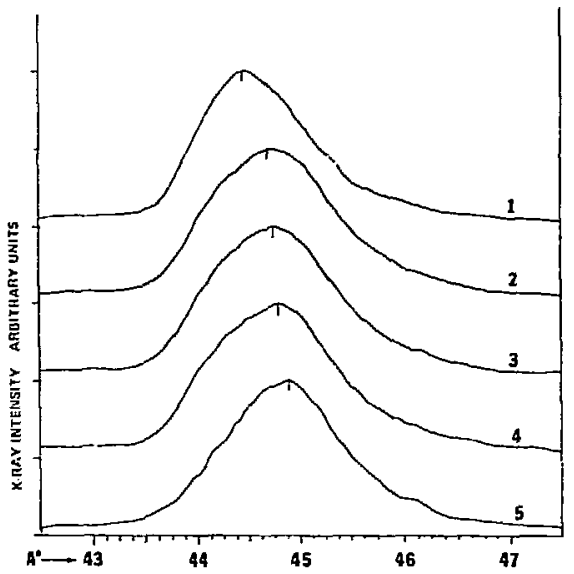

Fig. 1. Carion K-enission band, peaks normalized.

1-Dianond

2-Glassy carion (1000)

3-Glassy carbon (1800;

4-Glassy carbon (2800)

5-Pyrolytic graphite.

(XBL 735-6196)

Table I. Comparison of K-emission band parameters for various forms of carbon.

\begin{tabular}{|c|c|c|c|c|c|}
\hline \multirow{2}{*}{ Material } & \multirow{2}{*}{$\begin{array}{c}\text { Peak } \\
\text { position } \\
\text { (A) }\end{array}$} & \multicolumn{2}{|c|}{ Hal fwidth } & \multirow{2}{*}{$\begin{array}{l}\text { Index of } \\
\text { asymmetrv }\end{array}$} & \multirow{2}{*}{$\begin{array}{c}\text { Shift in peak } \\
\text { position fron } \\
\text { PG, } \Delta(\mathrm{eV})\end{array}$} \\
\hline & & (A) & $(\mathrm{eV})$ & & \\
\hline PG & 44.911 & 1.375 & $(8.8)$ & 0.75 & 0 \\
\hline$G C(2700)$ & 44.80 & 1.5 & $(9.6)$ & 0.75 & 0.64 \\
\hline$G C(1800)$ & 44.75 & 1.5 & $(9.6)$ & 0.95 & 0.96 \\
\hline$G C(1000)$ & 44.70 & 1.5 & $(9.6)$ & 1.00 & 1.28 \\
\hline Diamond & 44.45 & 1.28 & $(8.0)$ & 1.35 & 2.90 \\
\hline Diamond $^{\mathrm{a}}$ & 44.52 & -- & (8.1) & 1.25 & 2.10 \\
\hline
\end{tabular}




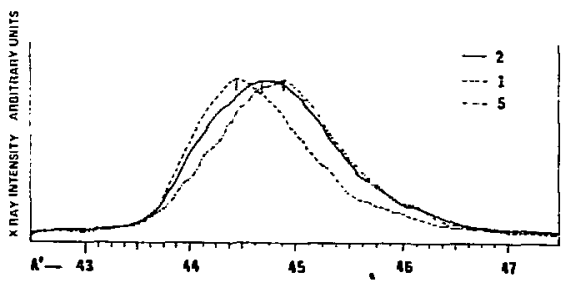

Fig. 2. Diansond, glassy carbon, and pyrolytic graphite K-emission bands superimposed on each other.

(XBL 735-6211)

1. T. Noda and M. Inagaki, Bul1. Chem. Soc. Japarı 37, 1534 (1964).

2. J. Kakinoki, Acta Cryst. 18578 (1963).

3. J. E. Holliday, J. Appl. Phys. 38, 4720 (1967).

\section{VOID STRUCTURE OF GLASSY CARBCOY}

Madar. H. Biswal and Robert H. Bragg

Sinall-angle scattering measurenents were riade from GC heat treated at 1000, 2000, 2500 , and $2800^{\circ} \mathrm{C}$. At $1000^{\circ} \mathrm{C}$ heat treatments u to 8 hnurs produced no changes in void size within experimental error, but as shown in Fig. 1, changes were observed at

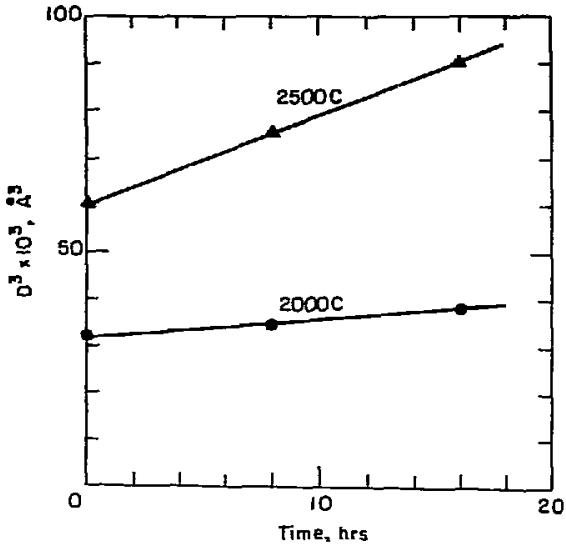

Fig. 1. Void radius versus time for glassy calton.

[XBL 741-5518]
2000 and $2500^{\circ} \mathrm{C}$. The data of $\mathrm{D}^{3}$ versus time is linear at each tenmerature and indicate an activation energy of $1.9 \mathrm{eV}$. This is small compared to the activation energy for self diffusion, $7.8=0.3 \mathrm{eV}$, in graphite but close to $2.2 \mathrm{eV}$ estimated from layer plane ordering. There is ample evidence that at these temperatures the close-1ying lattice defects are he first to be annealed. Thus it is expected that prolonged anneals at the higher temperatures will reveal a second activation energy, i.e., a second mechanism of structural change. From what is known from work on graphitizing carbons it is expected that witimately self-diffusion will be the doninant mechanism. There have been no direct determinations of the activation energy for self-diffusion in $\mathrm{CC}$, but it shoild be the same as that for graphite.

\section{GHARGE TRANSPORT IN GLASSY CARBON}

Ram R. Saxena and Robert H. Bragg

Initial measurements of the conductivity of specimens of GC have been made. As shown in Fig. 1 the conductivity at low temperatures obeys a $\mathrm{T}^{-1 / 4}$ law, suggesting a hopping Inechanism (Fig. 2) analogous to Mott's prediction for amorphous semiconductors. At high temperatures the data follow a $\mathrm{T}^{-1}$ law with a band gap of $1.3 \mathrm{meV}$. From the observed crystallite widths of $120 \mathrm{~A}$ and the total number of localized states, approximately one state per crystailite is indicated. The interpretation in terms of

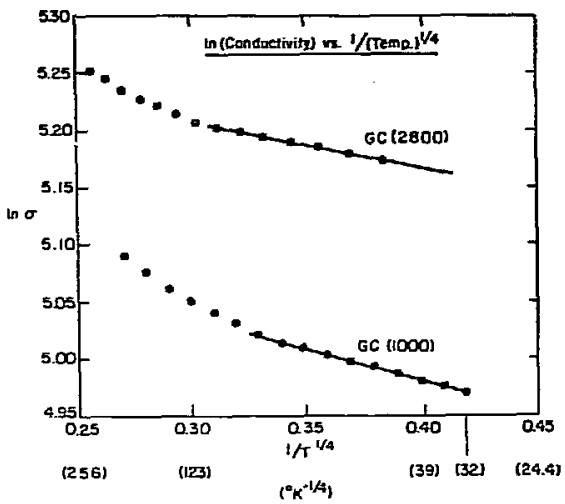

Fig. 1. Conductivity of glassy carbon shoving a $\mathrm{T}^{-1 / 4}$ dependence at Iow temperatures. (XBL 741-5519) 


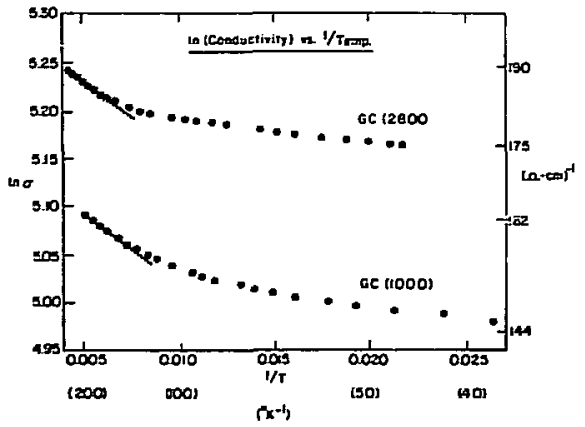

Fig. 2. Conductivity of glassy carbon showing a $\mathrm{T}^{-1}$ dependence at high temperatures. (XBL 741-5520)

an anorphous semiconductor at first glance seens inconsistent with the evidence from high-resolution electron micrographs that $\mathrm{GC}$ consists of highly interwound ribbons of graphite-like layers of carbon atims. However, it is probable that a sufficiently large component of diamond-like bonds between the ribbons can accormt for the observed semiconducting behavior. Evidence for thes is given in section 1 .

\section{EIECTRONIC PROPERTIES OF UNDIRECTIONALLY SOLIDIFIED EUTECTICS}

Louis J. Salmon, Kwaku Danso, and Robert H. Bragg

The parameter affecting the growth of large volumes of the $\mathrm{Cu}-\mathrm{Al}_{2} \mathrm{Cu}$ eutectic having a well aligned lamellar microstructure was studied. While the purpose of this work is to study electronic properties, for which large individal specimens are not required, it is necessary to prepare an adequate supply of standard refererıce material. It was fond that with the furnace and crucible used, temperature gradients greater than $50^{\circ} \mathrm{C} / \mathrm{cm}$ could not be obtained, much smaller than the maximum reported by Ankra in LBL-1182, irs which gradient's op to $206^{\circ} \mathrm{C} / \mathrm{cm}$ were obtained. The difference is due either to crucible size or efficiency of chilling. Cisrent work is concentrated on the latter, and results to date indicate a satisfactory solution will be found. Alloys of the Al-Si eutectic have been prepared from highpurity Al and Si for initial solidification experiments. while it might be expected from the phase diagram that the matrix phase (Al with $\mathrm{Si}$ in solid solution) would be the continuous phase, the opposite has been reported by Day. 1 Thus it is expected that the electronic properties of the grown camposite will reflect the presence of interconnected rods of Si heavily doped with A1. Part of this work was the M.S. thesis of Louis J. Salmon.

1. M. G. Day, "The Solidification of Netals," IS1 P110, The Iron and Steel Institute, London, 1967.

\section{SYALL-ANGLE SCATTERING BY PYROLYTIC GRAPHITE}

l.tıan M. Biswal, Faysel Hamzeh, a.d] Robert H. Bragg

The theory derived for oriented ellipsoids of revolution was applied to data obtained earlier (UCRL-20517) from specimens cut from pyrolytic graphite $(P G)$. They were cut in three orthogonal orientations so that any deviation from a statistically spherical void shape would be reflected in the intensity vs. angle data. A complete analysis of the data using the theory derived from oriented ellipsoids of revolution (LBL-1176) showed that a very detailed determination of void size, shape, and concentration is possible. For the particular material investigated, voids approximated oblate ellipsoids of revolution having axes $2 a, 2 a, 2 b$ of $21 b$, $21 \mathrm{~b}$, and $108 \mathrm{~A}$ respectively with the $\mathrm{b}$ axis normal to the deposition plane. The most stringent test of the theory was obtained from an absolute ditermination of the total void volume, which was found to be $3.1 \%$ compared to $3.5 \%$ obtained from pycnometric measurements, well within experimenta1 error. This work has been concluded.

\section{OTHER WORK IN PROGRSS}

\section{Robert H. Bragg}

Some details of the reports on theoretical and experimental work on oriented ellipsoids of revolution were found to require revision and are now being prepared for publication. A search for stress relief by fine grinding of GC has produced no indication of the expected fecrease in $X$-ray line widths for material which passes a 300 mesh sieve. This is coarse compared to the crystallite sizes 
estimated fram massive material, and the experiments are being extended to material ground in a vibratory tall mill which is capable if producing a sub-micron grain size.

\section{RESEARQI PLANS FOR CALENDAR YEAR 1974}

\section{Rutuert H. Bragg}

Work on the heat treatments and measurements of structure and electronic properties will continue. Since the lav-temperature apparatus is not operational there are no serious experimental difficulties to be overcome in this area. There still remain the problems of obtaining kinetic data expeditiously, and also extending the upper limit of heat treatment temperatures to $3000^{\circ} \mathrm{C}$. Madification in the design of the hot-zone heating element may solve the latter problem but not the former. It is expected that most of the data required for detailed analysis will be obtained in calendar year 1974. The work on the $\mathrm{Al}_{1}-\mathrm{CuAl}_{2}$ eutectic ivill be accelerated, and it is planned to complete a study of the dependence of conductivity on interlamellar spacing and aging at various temperatures during this year. Work on determining the growth parameters of the AI-Si eutectic will be initiated. It is expected that a Guest Scientist, Dr. Stephan Justi, who has done extensive work on the Na modified AI-Si eutectic, will join the group in March 1974.

\section{B. 1973 PUBLICATONS AND REPORTS}

Robert H. Bragg and Assuciates

LBL reports

1. Ram R. Saxena and kobert H. Bragg, K-Emission Syectra of Glassy Carbon, LBL-1860, July $\$ 973$.

2. Louis J. Salmon, Experimental Techniques for Growing Unidirectionally Solidified Oriented Eutectics, LBL-1834, June 1973.

3. F. M. Hamzeh and R. H. Bragg, Small Angle Scattering of $X$-rays fron Groups of Randomly Oriented Ellipsoids of Revolution of Low Concentration, LBL-1874, Aug. 1973.

4. Madan M. Biswal, Faysel M. Hamzeh and Robert H. Bragg, Snall Angle Scattering by Oriented Voids in Pyrolytic Graphite, LBL-812, Dec. 1973. 


\section{A. HIGH TEMPERATURE REACTIONS}

Alan W. Searcy, Erincipal Investigator

1. THE VARIATION WITH TEPERATURE OF THE CONGRUENT VAPORIZATION COPPOSITION OF GALLTIM SESQYUSULFIDE $\left(\mathrm{Ga}_{2} \mathrm{~S}_{3}\right)$

Janes A. Roberts, Ir., and Alan W. Searcy

In studies of congruently vapurizing solids, the fact that the corposition for congruent vaporization may change with temperzturc is generally ignored. In most instances the composition changes are small and their neglect probably has no influence, to within experimental accuracy, on the quantities being determined, such as the heat of vaporization a total vapor

pressure. However reasonable this sumposition may be, it seems desirable to make an explicit test for at least a few solids of relatively narrow conposition linits.

In this study such a test has been : ide for gallium sesquisulfide, which is ks to vaporize congruently to yield $\mathrm{Gaz}_{2} \mathrm{~S}_{\mathrm{g}} \mathrm{g}$ ) $\mathrm{S}_{2}(\mathrm{~g}) .1$ It proved possible not only to observe changes in cauposition for congruent vaporization but also to measure the effect of the composition variation on the partial pressure of each vapor species.

Ion intensity, time, temperature data were used to calculate the congruent vaporization compesitiviui as a function of temperature between $1050^{\circ}$ and $1370^{\circ} \mathrm{K}$ (Fig. 1). The congruent composition remains fairly constant at 60.16 at. 5 from $1050^{\circ}$ to $1190^{\circ} \mathrm{K}$. From $1190^{\circ}$ to $1230^{\circ} \mathrm{K}$ the composition gradually changes to 60.11 at. 5 . At $1230 \pm 5^{\circ} \mathrm{K}$ the congruent composition discontinuously jums to 59.79 at. 8 S. Between $1230^{\circ}$ and $1295^{\circ} \mathrm{K}$ the composition changes linearly to 59.68 at. $\mathrm{S}$, then discontinuousiy jumps to 57.6 at.q $\mathrm{S}$. The composition changes between $1295^{\circ}$ and $1376^{\circ} \mathrm{K}$ to 57.3 at. $\mathrm{S}$. The discontinuities in the congruent compositicn vs. temperature arves found at $1230 \pm 5^{\circ} \mathrm{K}$ and $1295 \pm 5^{\circ} \mathrm{K}$ indicate phase transitions. The $1230^{\circ}$ transition had not previously been reported.

Intersity versus time data obtained when samples moved to new compositions after a temperature change were used to derive plots of partial pressures versus composition at several different constant temeriatures for the two major species, $\mathrm{S}_{2}(\mathrm{~g})$ and $\mathrm{Ga}_{2} \mathrm{~S}(\mathrm{~g})$. A surprising result is th:it when the temperature is lowered to $1230^{\circ} \mathrm{K}$ so that the miscibility gap between phases is traversed, the $\mathrm{G}_{2} \mathrm{~S}(\mathrm{~g})$ partial pressure increases above

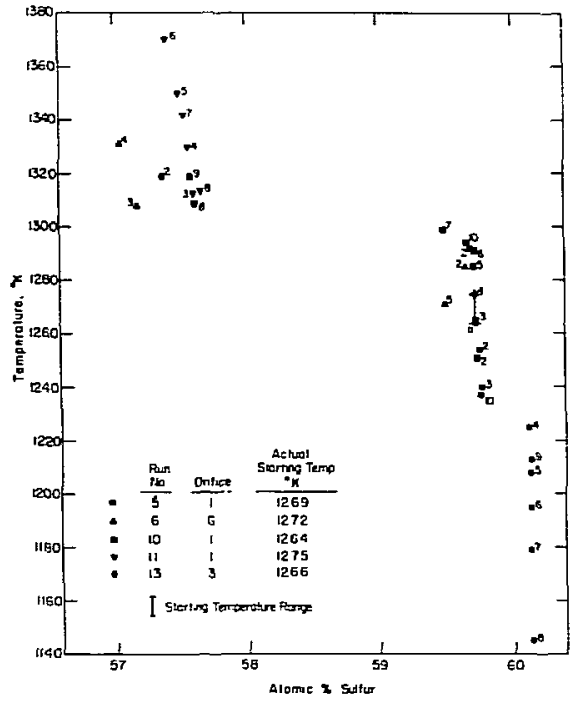

Fig. 1. Congruent vaporization composition vs. temperative for samples passing through the $1295^{\circ} \mathrm{K}$ transition. Run 10 is ircluded for ease in comparing the composition scales.

(XBL 7311-6701)

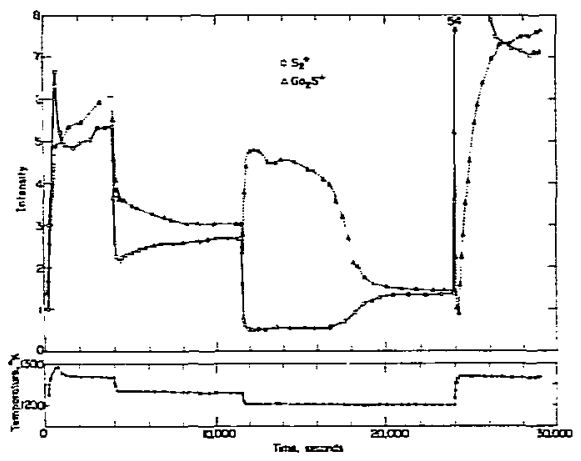

Fig. 2. Ion intensity $\left(\mathrm{Ga}_{2} \mathrm{~S}^{+}\right.$and $\mathrm{S}_{2}^{+}$) vs. time. The intersities are corrected only for isotopic alsmiance.

(XBL 7311-6698) 
its pressure at the higher temperature. This behavior is apparent from the original intensity versus time data (Fig. 2), so there can be no question that the effect is real. An explanation can be found by reference to schematic equilibrium free energy diagrams.

The second law heat of vaporization for tin stoichiometric reaction $\mathrm{Ca}_{2} \mathrm{~S}_{3}(\mathrm{~S})=$ $\mathrm{Ga}_{2} \mathrm{~S}(\mathrm{~g})+\mathrm{S}_{2}(\mathrm{~g})$ should not be significantly affected by the variations observed. For the temperature range $1286^{\circ}$ to $1050^{\circ} \mathrm{K}$, the heat of the dissociative sublimati $m$ to $\mathrm{Ga}_{2} \mathrm{~S}(\mathrm{~g})$ ind $\mathrm{S}_{2}(\mathrm{~g})$ is $157.3 \pm 0.5 \mathrm{kcal} / \mathrm{mol}$ of $\mathrm{Ga}_{2} \mathrm{~S}_{3}$.

1. 0. M. Uy, D. W. Muenow, P. J. Ficalora, and J. L. Margrave, Trans. Far. Soc. 64, 2998 (1968).

\section{KINETICS UF DISSOCIATIVE VAPCRIZATION REACTIONS ${ }^{\mathrm{N}}$}

David J. Meschi and Alan W. Searc.

Experimental data for vaporization and condensation of crystalline solids are in good agreement with the Terrace-Ledge-Kink (TLK) mode1 proposed by Kossel and Stranski. However, most workers in this field tend to concentrate on the mechanics and dynamics of ledge formation and movement ${ }^{2}$ and devote relatively little attention to the significance of experimentally determined apparent activation enthalpies and entropies. Comparison of the experimentally deternined temperature dependence of the evaporation coefficient to that predicted by different theoretical models has not been fully exploited.

In this work, transition state theory for sequential chemical reactions is applied to the TLK model for the vaporization of solids and more specifically to compounds which vaporize according to the reaction

$$
2 A B=2 A(g)+n_{2}(g)
$$

The variation of vaporization rate with temperature depends on the difference in enthalpy between the activated complex of the rate-detemining step and the enthalpy of the bull: solid, and can thus be used as a guide in ascertaining which of the sequential steps is rate determining. Tilis is illustrated with respect to the above vaporization reaction by comparing the case in which kink-pair nucleation is rate determining with that in which desorption is rate limiting.

For a temperature range in which two successive steps both are rate determining, the plot of the logarithm of an "apparent" equilibrium constant $\mathrm{K}^{*}$ versus the inverse of the temperature will usually show a curvature. Experimental evidence of this effect in the vaporization of ice $^{3}$ and sodium chloride ${ }^{4}$ is cited.

Extensive work has been done on the vaporization of II-VI compounds, and the data are consistent with a model in which a single step, probably either dissociation into the adsorption layer from thermally sctivated catalytic sites or desorption, is rate liniting. This is somewhat at variance with the interpretation of Hirth, Muir, and Seacrist ${ }^{5}$ who propose a model based on sunface morphologies in which two successive stens are both considered to be partly rate limi ing.

Accepted for publication in High Temp. Sci.

1. W. Kosse1, Nach. Ges. Wiss. Gottingen

135 (1927); I. N. Stranski, Z. Physik.

Chemie 136, 259 (1928).

2. J. P. Hirth and G. M. Poind, Prog. Met. Phys. 11 (1963).

3. J. G. Davy and G. A. Somorjai, J. Chem. Phys. 55, 3624 (1971).

4. C. T. Ewing and K. H. Stern, J. Phys. Chem. 77, 1442 (1973).

5. Z. A. Munir, L. S. Seacrist, and

J. P. Hirth, Surface Sci. 28, 357 (1971);

Z A. Munir and J. P. Hirth, J. Appl. Phys. 2697 (1970); and L. S. Seactist and

$\overline{2}$.' A. Mtmir, High Tentm. Sci. 3 , 340 (1971).

\section{THERMODYNAMIICS OF DECOMPOSITION OF STRONTIUM SULFATE AND BARIUM SULFATE}

Lloyd Wanabu Fuke, Pirooz Mohazzabi, and Alan 1\%. Searcy

The equilibriun dissociation pressure of strontiun sulfate was measured, for the first time, by the torsion-effusion method in the temperature range $1370^{\circ}$ to $i 540^{\circ} \mathrm{K}$. The total pressure for the reaction

$$
\mathrm{SrSO}_{4}(\mathrm{~s})=\mathrm{SrO}(\mathrm{s})+\mathrm{SO}_{2}(\mathrm{~g})+\frac{1}{2} \mathrm{O}_{2}(\mathrm{~g})
$$

can be represented as

$\log P=-(1.405 \pm 0.009) \times \frac{10^{4}}{I}+(7.167 \pm 0.065)$, 
where the indicated errors are standard deviations from laast-squares analysis. The Second I aw Method yielded for the enthalpy of vaporization $\left(\Delta \mathrm{H}_{v}^{\mathrm{O}}\right) 127.4 \mathrm{kcal} / \mathrm{g}$-atom and for the entropy of vaporization $\left(\Delta S_{\mathrm{v}}^{\circ}\right) 58.5 \mathrm{eu}$. No dependency of vapor pressure upon the orifice area was observed.

Barium sulfate, in contrast, showed a dependence of apparent vapor fressures on orifice area. The total vapor pressure for the reaction $\mathrm{BaSO}_{4}(\mathrm{~s})=\mathrm{BsO}(\mathrm{s})+\mathrm{SO}_{2}(\mathrm{~g})$ क $1 / 2 \mathrm{O}_{2}$ at $1420^{\circ}$ to $1540^{\circ} \mathrm{K}$ is given by extrapolation to zero orifice area as

$\log P=-(2.042 \pm 0.028) \times \frac{10^{4}}{T}+(9.058 \pm 0.189)$.

The second law heat and enthalpy of the reaction are $140.1 \mathrm{kcal}$ and $60.2 \mathrm{eu}$.

\section{MaGNeTIC MaMeNT OF THE Se 2 MULECJIE}

David J. Meschi, Alfred Büchler, J. T. Hougen* and Alan W. Searcy

The magnetic moment of the $\mathrm{Se}_{2}$ molecule has previously been measured in this laboratory by means of a molecular beam technique 1 and found to be less than the one-tenth of a Bohr magneton which was taken as the detection linit for the apparatus then usea. This low magnetic moment for a molecule with two umpaired electrons was attributed to a large splitting between the lower, non-paramagnetic $\mathrm{O}^{+}$component of the ground state and the higher, paramagnetic 1 component. Barrow, Burton, and Callomion have since measured this splitting and found it to be $366.6 \mathrm{~cm}^{-1}$ (Ref. 2), which is too small to explain the low magnetic moment if $\mathrm{Se}_{2}$ has coupling like that of $\mathrm{O}_{2}$ and $\mathrm{S}_{2}$.

It appears probable that the low magnetic moment is caused by a change in the type of coupling between the spin and the molecular rotation from that found in $\mathrm{O}_{2}$ and $\mathrm{S}_{2}$. These lighter members of the chalcogenide family in their diatomic form display Hurds case (b) coupling, but it is expected that as the molecular weight increases there will be a shift towards Honds case (c). 3

The sensitivity of the original apparatus has been inmroved by about a factor of 10 , so that it appeared possible to obtain significant data even at the low coupling with the field to be expected for case (c). Calculations for thrids case (c) have apparently not been made. Accordingly, we undertook a dual progran of redetermination of the deflection of $\mathrm{Se}_{2}$ molecules from a bean by the inhomogeneous magnetir tield and of calc1uation of the predicted magne1.ic mement or its equivalent zeeman effect for $\mathrm{Se}_{2}$.

The method used to calcalate the moment was that outlined by Hougen, 4 using as basis functions thise applicable to thmd's case (a) coupling, and using Barrow's value for the splitting between states.

From the first-order terms, the following magnetic moments were derived:

$$
\mu_{H}=\frac{2 B}{\lambda} M_{J} \mu_{B} \text {, for the } 0^{+} \text {state }
$$

and

$$
\begin{array}{r}
\mu_{H}=\frac{1}{J(J+1)} M_{J^{\mu}}, \\
\mu_{H}=2\left[\frac{1}{J(J+1)}-\frac{B}{\lambda}\right] M_{J^{\mu}}
\end{array}
$$

for the two components of the 1 state. Here $\lambda$ is the splitting constant, equal to half the splicting between the states, $\mathrm{B}$ is the rotational censtant for $\mathrm{Se}_{2}, \mu_{\mathrm{B}}$ is the Bohr magneton, $\mathrm{J}$ is the total argular momentiti quantim number, and $M_{J}$ its projection in the direction of the magnetic field.

At $1000^{\circ} \mathrm{K}$ the madal value of $\mathrm{J}$ is approximately 60 , and the three formilae give moments of the order of 0.01 to 0.06 Bohr magnetons for $\left|\mathrm{M}_{\mathrm{J}}\right|$ equal to $\mathrm{J}$.

The second-order telms also result in appreciable magnetic moments for a field of 5000 gauss, ranging from 0.01 to $0.03 \mathrm{Bohr}$ magnetons for the maximum $M_{J}$.

These moments appear marginally large enough to make possible meaningful experiments with the improved apparatus. But the low signal-to-noise ratio has necessitated a large number of measurements, so the data can ie treated statistically. We are at present workirs out a methad of using a camputer to analyze the data in order either to extract a value for the mean magnetic mament ox place a better upper limit on that value. This analysis should be complete within the next few months.

National Burreau of Standards.

1. D. J. Meschi and A. W. Searcy, J. Chem. Phys. 51, 5134 (1969).

2. R. F. Barrov, W. G. Burton, and J. H. Calloman, Trans. Faraday Soc. 66, 2685 (1970). 3. R. F. Barrow, G, G. Chandler, and C. B. Meyer, phil. Trans. Roy. Sóc. (London) A260, 395 (1966). 
4. J. T. Hougen, The Calculation of

Rotational Energy- Levels and Rotational Line Intensities in Diatomic Molecules, N.B.S. Monograph 115 (National Bureau of Standards, Washington, D. C. , 1970),

\section{THE KINETICS OF DECGPOSITIOF OF RARILM CARBONATE}

Tushar Basu and AIan W. Searcy

The equilibriun vapor pressure of barium carbonate and the vacuum decomposition kinetics of the (001) face of its single crystal were siudied by use of torsioneffusion and torsion-Langmuir techriques respectively. The equilibrium pressures showed a strong dependence on effusion orifice area. The apparent activation entha1py of decomposition for the reaction

$$
\mathrm{BaCO}_{3(\mathrm{~s})}=\mathrm{BaO}_{(\mathrm{s})}+\mathrm{CO}_{2(\mathrm{~g})}
$$

was found to be $34.0 \mathrm{kcal}$, which is less than the enthalpy of the equilibrium reaction, $60.25 \mathrm{kcal}$. The apparent entropy for the reaction was $12.8 \mathrm{eu}$. This entropy is also iess than the entropy of the equilibrium reaction, $35.05 \mathrm{eu}$, in the temperature range studied.

The rate of the free surface decomposition reaction was constant, within the experimental satter in the data, furing the period of the measurements so the effusion of protuct gases through the porous product layer is not rate limiting. The ratio of the free surface decomposition pressure to the equilibrium decomposition pressure decreased in the temperature range $g^{\frac{5}{2}}$ study from $1.9 \times$ $10^{-4}$ at $1200^{\circ} \mathrm{K}$ to $2.4 \times 10^{-4}$ at $1100^{\circ} \mathrm{K}$.

These results constitute the third measurement made of the ratio of the pressure of vapor in a free surface decomposition reaction to the equilibriug decomposition pressure. The rate of dissociation of one of the three substances $\left(\mathrm{CaCO}_{3}\right)$ increases more rapidly with temperature than does the equilibriur dissociation pressure, the rate of dissociation of $\mathrm{BaSO}_{4}$ increases with temperature in direct proportion to the equilibrium pressure, and the rate of dissocirtion of $\mathrm{BaCO}_{3}$ increases more sl.jwly with temperature than does the equilibrium pressure. These three substances thus illustrate the samk three systematically different classes of kinetiz behavior that rere icentified for congment vaporization reactions. I The barium carbonate study is of particular interest in that it appears to be the first to demonstrate that the rate of a decomposition reaction may have a lower temperature dependence than does the equilibrium vapor pressur? .

1. Alan W. Searcy in Chemical and Mechanical Behavior of Inotganic Baterials, ed. A. W. Searcy, D. V. Ragone, and U. Colombo (Wiley-Interscience, New York, 1970) Chap. 6.

\section{RESEARCH FLANG FOP CAIENDAR YEAR 1974}

Alan W. Searcy

Theoretical studies of the thermodynamics of soluticns and of surfaces and interfaces will be continued.

Wie expect to attempt for a second solid, probably $\mathrm{In}_{2} \mathrm{~S}_{3}$, a mass spectrameter study of the variation in composition for congruent vaporization and of the variation in partial pressures with small changes in composition of the kind completed in the 1973 fiscal year with $\mathrm{Ca}_{2} \mathrm{~S}_{3}$. Studies of this type provide data on the variation of partial molar thermodvramic quantities in highly non-ideal sclutions of kinds that have been little investigated and, in consequence, may provide useful tests of solution theories.

We will complete for publication a theoreticai paper that extends transition state theory for vaporization kinetics to endothermic decomposition reactions. The paper will predict the kinetics of decomposition reactions both when equilibrium is maintained at the interface between the reactant and solid reaction product and when equilibrium is not maintained at tie solid-solid interface. It also will predict the influence of a porous product layer on the reaction kinetics. Theoretical work on the kineties of vaporization and decomposition reactions will be continued with probable major emphasis on the role of surface diffusion.

Paranagnetism of transition metal ions in condensed phases has been extensively studied, but little or no direct information on paramagnetism in gas molecules has been available. Preliminary deflection experiments with an inhomogeneous magnetic field acting on a beam of $\mathrm{FeF}_{2}$ gas show an appreciable magnetic moment, consistent with thonds coupling case (b). Similar measurements 
will be made for $\mathrm{NiF}_{2}$ gas with an improved apparatus, and additional measurements are plamed for FeF 2 and $\mathrm{CoF}_{2}$ in order to ascertain trends in paramagnetism with $\mathrm{d}$ oribital occupancy.

To clarify the role of porous product layers as effusion barriers in decomposition reactions, a mass spectrometer stuxy of the effect of porous lids on the amparent partial pressures of sodium chloride monomers and dimers has been initiated. A particular porous elumina lid passes a beam in which the dimer/monomer ratio is reduced about a factor of 100 below the ratio for the saturated vapor. The porous-1id technique will be tested as a method to replace the cumbersame double-oven technique for determining mass spectrometer fragmentation pattems and will then be used to study effusion and surface diffusion transport of high-temperature vapors through porous bodies.

We hope to resume at the University of Genova, in collaboration with Dario Beruto of that institution, a study of the inflience of carbon dioxide pressures on the rate of calcite decomosition. The study should yield both the activation enthalpy for the decamosition reaction to the metastable oxide and the enthalpy of formation of that oxide from stable calcium oxide.

We shall be involved through a consortiln agreement in two research projects funded by NASA at NASA-Ames Research Center:

(1) Sases evolved during the pyrolysis and buming of fabrics designed for wse in aircrafi, such as Durette, a chlorinated aromatic polyamide, have been shown to be toxic. The gas mixtures will be analyzed by gas chromatography and mass spectrometry with the ultimate purpose of identifying the toxic component.

(2) Certain dry chenicals such as sodium bicarbonate act as flame extinguishants. Flames containing amounts of dry chemical just below the extinction dosage will be sampled by means of a time-of-fligint mass spectrometer. It is hoped the data obtained will help to establish the mechanism of flame extinction by dry chemicals.

We will attempt to identify a substance which is available as single crystals and which Jecomposes to a pozous solid product and two or more gas species each of which is at pressures that can be measured with a mass spectrometer. A study of the kinetics of decanposition of such a substance worild complement our stury of vaporization through porous lids and provide a new kind of experimental information bearing on the influence of porous product layers on the kinetics of decomposition reactions.

\section{1973 PUBLICATIONS AND REPORTS}

Alan W. Searcy and Associates

\section{Journals}

1. Z. A. Murir, D. J. Meschi, and G. M. Pound, The Partial Pressures of $\mathrm{Hg}$ gas and $\mathrm{Se}_{\mathrm{m}}$ gases in Equilibrium with Crystalline Mercury Selenide, J. Crystal Growth 15, 263 (1972) (not previously listed).

2. H. B. Skirser and A. W. Searcy, Bass Spectrometric Studies of Gasecus Oxides of Rhenium, J. Phys. Chem. 77, 1578 (1973) (LBL-1139).

3. D. H. Feather and A. Büchler, Gaseous Thallium (I) Netaborate and Thallium (I) Aluminum Flunride, J. Phys. Chem. 77, 1599 (1973) (LBL-1482).

4. R. T. Coyle and A. H. Searcy, The Ancmalous Vaporization Behavior of Magnesium Nitride, High Tenl. Sci. 5, 335: (1973) (LBL-1498) -

\section{LBL reports}

1. A. W. Searcy, A. Büchler, and D. Beruto, The Relationship Between Forward and Reverse Reaction Rates Under Non-equilibrium Conditions, IBL-1460, Jan. 1973.

2. R. T. Coyle and A. W. Searcy, The Anomalous Vaporization Behavior of Nagnesium Nitride, LBL-1498, April 1973.

3. L. M. Fuke, Vaporization Studies of Strontium Sulfate (N.S. thesis), iBL1832, June 1973.

4. D. Meschi and A. W. Searcy, The Kinetics of Dissociative Vaporization Reactions, LBL-I853, July 1973.

5. A. W. Searcy and D. Beruto, Transition State Theory for Vaporization and Condensation, LBL-2215, Nov. 1973.

\footnotetext{
Work done with UC-Davis and CeneraI Electric.

${ }^{\dagger}$ Stanford thiversity
} 


\section{B. MICROSTRUCTURE AND MECHANICAL BEHAVIOR OF CERAMIC MATERIALS: GLASS AND CERAMIC-METAL SYSTEMS}

Joseph A. Pask, Frincipal Investigator

A continuing overall objective of the research program is to contribute to the development of a fundamental understanding of the ractors involved in obtaining ceramic materials with controlled character (which includes microstructure), and of the relationship of character to mechanical behavior at rocm and high temperatures. This objective involves studies on the kinetics and mechanisms of solid state reactions and distribution of phases which in general play a part in the development of microstructure. It also involves studies on the mechanisme responsible for the mechanical behavior of single crystals, and on the application of such knowledge to the understanding of the behavior of polycrystalline ceramic materials.

The compositions under stury--mullite, alumina, forsterite, spinel, megnesia--are basic materials of industrial ceramics and refractories, and sintering is the basic method for their manufacture. The fundamental approach in these studies in terms of physical chemistry, solid state chemistry, and dislocation theory also makes the work relevant in that the determined principles should be applicable to other polycrystalline metal and ceramic materials.

A sccond objective of this program is concerned with structural, thermodynamic, and electrochemical studies of glass-metal and ceramic-metal systems. It involves studies related to wetting, bonding, and the nature of the interfaces between dissimilar phases; to the thermodymamics and kinetics of chenical reactions at such interfaces; and to the lineties and mechanisms of dissolution and diffusion in glasses. A basic understanding of the nature of interfaces and the mechanisms of reactions at interfaces is critical in all materials.

1. DIFFUSION AND PHASE RELATIONSHIP STUDIES IN THE SILICA-AULIINA SYSTEM"

\section{İihan A. Aksay ${ }^{\dagger}$ and Joseph A. Pask}

Sapphire-fused silica diffusion couples, which were amealed in the temperature range of 1678 to $2003^{\circ} \mathrm{C}$ and analyzed by electron beam microprobe, provided data on the stable phase equilibria of the $\mathrm{SiO}_{2}-\mathrm{Al}_{2} \mathrm{O}_{3}$ system. Under stable equilibrium conditions, the intermediate compound of this system, mullite $\left(3 \mathrm{Al}_{2} \mathrm{O}_{3} \cdot 2 \mathrm{SiO}_{2}\right)$ melts incongruently at $1828^{2} 10^{\circ} \mathrm{C}$, ar.d its solid solution field extends from 70.5 to 74.0 wt $\mathrm{Al}_{2} \mathrm{O}_{3}$. The stable phase diagram is a composite of the two binary eutectic diagrams: silica-mullite in the absence of alumina and silica-alumina in the absence of mullite. Under metastable conditions, mullite melts congruently at $1890=10^{\circ} \mathrm{C}$, and its solid solution field extends to $\approx 83$ wt: $\mathrm{Al}_{2} \mathrm{O}_{3}$ (See Figs. 1 and 2).

The activation energy for diffusion in the aluminun silicate melts, above the softening temperature of fused silica, decreased from $211 \mathrm{kcal} /$ mol for pure silica to $42 \mathrm{kcsi} / \mathrm{mol}$ at $63.1 \mathrm{muls}^{\mathrm{s}} \mathrm{Al}_{2} \mathrm{O}_{3}$. This
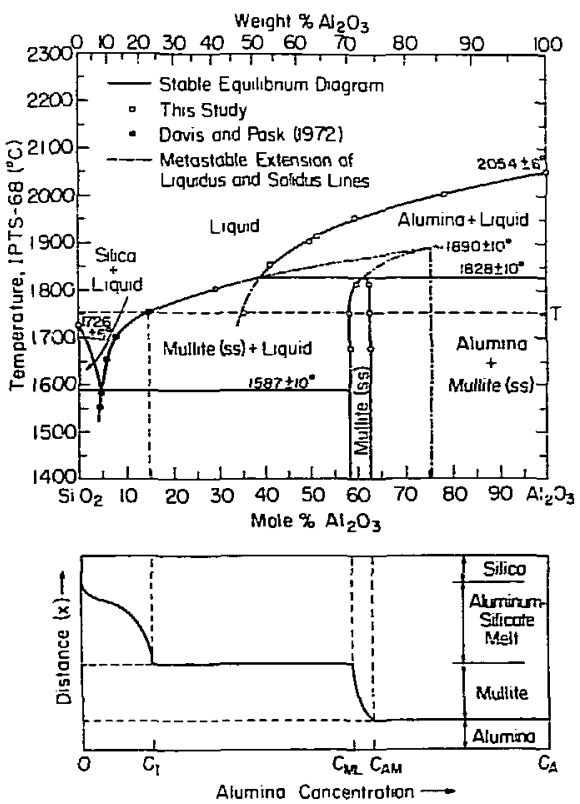

Fig. 1. The relationship between the concentration profile of a semi-infinite $\mathrm{SiO}_{2}-\mathrm{Al}_{2} \mathrm{O}_{3}$ diffusion couple and the stable equilibrium phase diagram is shown at temperature $\mathrm{T}$ below the melting point of mullite. Metastable extensions of the silica-mulite system and the alumina liquidus are superimposed on the stable silica-allmina diagram. $\mathrm{C}_{\mathrm{A}}$ corresponds to $100 \mathrm{Al}_{2} \mathrm{U}_{3}$.

(XBL $936-6222)$ 


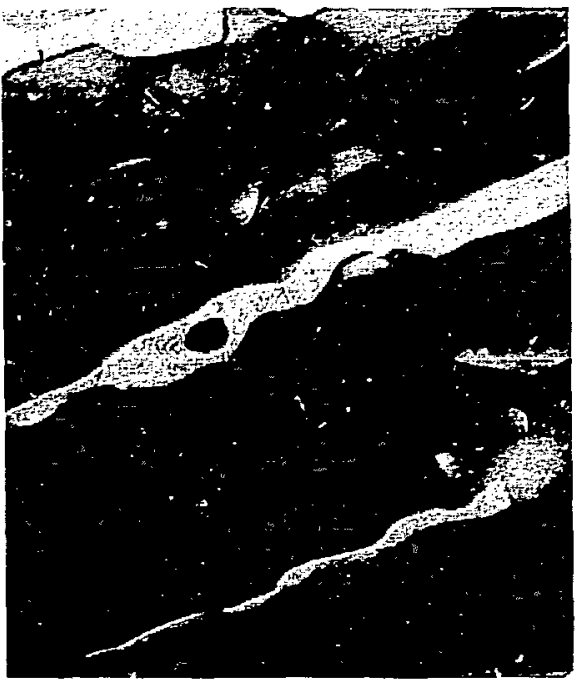

Fig. 2. Nomarski interference-contrast micrograph of a $71.8 \mathrm{wt} \mathrm{Al}_{2} \mathrm{O}_{3}$ and $28.2 \mathrm{wt}$

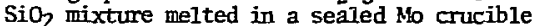
at $1953^{\circ} \mathrm{C}$ for $460 \mathrm{~min}$, cooled to $1753^{\circ} \mathrm{C}$ in $30 \mathrm{~min}$, ammealed at $1753^{\circ} \mathrm{C}$ for 29.4 days, and auenched from $1753^{\circ} \mathrm{C}$ (see Fig. 1). The light gray precipitates are alumina that are completely enveloped with a layer of mullite (gray). The glassy inclusions (dark gray) between the mullite layers also contain fine precipitates of mullite formed during cooling. It is important to note that the overall specimen composition corresponds to that of stoichiometric mullite; and the formation of alumina within a melt of this composition can only be explained by the incongruent growth of millite. However, when the same specimen is heat treated again within the above-mentioned temperature intervals but with rapid cooling from 1953 to $1753^{\circ} \mathrm{C}$, the microstructure shows no alumina precipitates and could easily be misinterpreted as being indicative of the congruency of mullite.

(XBB 7210-5188)

substantial change in activation energy for diffusion is attributed to the gradual increase in the ratio of $\mathrm{AlO}_{6} / \mathrm{AlO}_{4}$ groups with increasing alumina content and thus the formation of non-bridging oxygens. Below the softening point, the activation energy for diffusion in fused silica increases to $338 \mathrm{kcal} / \mathrm{mol}$ due to the tightening of the network structure. At $45 \mathrm{~mol} \mathrm{Al}_{2} \mathrm{O}_{3}$ conrent, the continuous network structure of fuser silica is broken down to form discrete anionic groups. High activation energies in fused silica and high-silica melts are attributed to the rupture of $\mathrm{M}-\mathrm{O}$ bonds of tetrahedrally coordinated silicon and aluninum. Diffusion in high alumina liquids, on the other hand, is by mutual rotation of anionic groups involving only Coulombic interaction and thus requires a 10wer activation energy. The structural model for the $\mathrm{SiO}_{2}-\mathrm{Al}_{2} \mathrm{O}_{3}$ melts is further supported by the viscosity and density data.

An activation energy of $168 \pm 7 \mathrm{kcal} / \mathrm{mol}$ was determined for diffusion in mullite.

\footnotetext{
Ebstractod from LBL-1835 and partially from LBL-1403.

tPresent address: Xerox Corp., Wilson Research Center, Hebster, N.Y.
}

\section{PERMEATION OF SILICATES IN MAGNSIA AND FORSTERTTE COMPACTS*}

Abbaraju P. Raju, ${ }^{\dagger}$ İhan A. Aksay, and
Joseph A. Pask

$\left.\mathrm{CaO}_{2} \mathrm{O}\right)-\mathrm{HgO}-\mathrm{SiO}_{2}$ liquids permeated into magnesia and forsterite compacts at elevated temperatures when continuous or "open" channels were available at the liquid-solid interface. Rearrangement of grain shapes occurred. Solid solution formation at the liquid-forsterite interface resulted in clasing off the open channels. Sessile drop and permeation experiments provided

information used to interpret microstructure development.

\footnotetext{
* Abstracted from Bull. Am. Ceram. Soc. 52 [2], 166-169 (.1973).

†Present address: Bharat Electronics, Ltd., Bangalore, India.

${ }^{\ddagger}$ Present aditress: Xerox Corp., IVilson

Research Center, Hiebster, N.Y.
}

\section{PHASE DISTRIBUTION IN SOLID-LIQUID-VAPOR SYSTEMS*}

IIhan A. Aksay, ${ }^{\dagger}$ Carl E. Hoge, and Joseph A. Pask

The developnent of microstructure in a solid-liquid vapor system is highly dependent 
on the relative interfacial tensions of the phases involved. Inder chemical nonequilibrium conditions, interfaces are in a state of continual change. During this transient stage, the classical Young's and the dihedral angle equations are only valid in terms of the dynamic interfacial tension values of the chemical non-equilibrium confitions. The thermodynamies of nonequilibrium conditions in a solid-1iquidvapor system are discussed. Spreading and subsequent pull-back phenomena, which are often cbserved in wetting studies, are successfully explained by the dymanic interfacial tension. Such phenomena play an important role in the initial particle arrangement and solution-precipitation stages of liquid phase sintering. Sessile drop experiments and perneation studies of iiquids into porous compacts provide a means in understanding the nature of phase distribution in the presence of chenical nonequilibrium conditions.

* Abstracted from LBL-2205.

tPresent address: Xerox Corp., Wilson

Research Center, Webster, N.Y.

\section{THEPAODNAMIICS OF HETTING}

İlhan A. Aksay, ${ }^{\dagger}$ Carl E. Hoge, and Joseph A. Pask

The thermodynamics of a solid-liquidvapor system both under chemical equilibrium and non-equilibrium conditions, based on the model of Gibbs, is discussed. Under chenical equilibrium conditions, the degree of wetting or non-wetting of a flat and non-deformable solid by the liquid is defined by Young's equation in terus of the static interfacial tensions. Under cherical non-equilibrium conditions, wass transfer across an interface results in a transient decrease in the corresponding specific interfacial free energy and the interfacial tension by an amount equal to the free energy of the effective chenical reaction per area at thet interface. hien the reaction is between the solid and the liquid, this transient lowering of the interfacial tension can cause the liquid drop to spread on the solid substrate if the interfacial tension reduction is large enough and if the diffusion rates of the reacting cormonents, and thus the growth rate of the reaction product, are slow enough relative to the flow rate of the liquid.

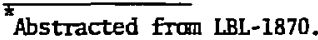 \\ ${ }^{\dagger}$ Present address: Xerox Corp., Wilson \\ Research Center, Webster, N.Y.
}

\section{THERODDNANICS OF SOLID STATE SINTERING*}

Carl E. Hoge and Joseph A. Pask

A thenodynamic analysis of solid state sintering of a single phase isotropic material of uniform particle size indicates that the ratio of the solid/solid and solid/ vapor interfacial energies ( $\left.\gamma_{5 s} / Y_{s v}\right)$ is critical; in order to realize theoretical density the ratio must be smaller for less dense packings of unfired compacts. Another critical requirement is that pores must remain on grain boundaries during sintering. Pores on planar grain boundaries are effectively pinned. Curved grain boundaries can break away from pores when they achieve critical curvatures; this feature is essentially independent of $Y_{s s} / Y_{s v}$ or the corresponding dihedral angle in the normal range of values. Non-uniform particle or grain size distribution thus must be avoided since they lead to grain boundary curvatures.

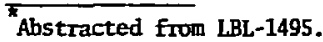

5. KINETICS OF INTERNEDLATE AND FINAL STAGES OF SOLID STATE SINTERING

Boon Wong and Joseph A. Pask

Adequate understanding of the sintering process of oxide ceramics is most critical in the control of their densification and microstructure development. The existing diffusion models for the later stages of sintering polycrystalline refractories have a deficiency in that they do not take into account the grain growth that normally occurs during the process. $1-3$

Pecently, Skorokhod ${ }^{4}$ has developed a viscous flow model for sintering porous viscous solids. Using this model and assumed geometries at several later stages of sintering, associated with Nabarro-Herring type creep models, kinetic equations have been derived for pressureless sintering of a polycrystalline refractory for several conditions.

Experimental sintering studies to verify 
the derived relationships are in progress. $\mathrm{MgO}$, and $\mathrm{CaO}$ doped $\mathrm{MgO}$ powders are being used; it is expacted that $\mathrm{CaO}$ will prevent discontinuous grain growth. Compacts are being made by cold pressing and sinter $n g$ in controlied atmospheres.

1. R. L. Coble, J. Appl. Phys, 32, 787 (1961).

2. R. L. Coble, J. Aqp1. Phys. 32, 793 (1961).

3. P. J. Jorgensen, J. Am. Ceram. Soc. 48,207 (1965).

4. V. V. Skorokhod, Poroshkovaja

Metaliurgiya, No. 12 (72), 18-21, (Dec. 1968).

7. KINETICS AND THERLONNAMICS OF LIQUID PHASE SINTERING

Carl E. Hoge and Joseph A. Pask

The basic driving force in sintering is the reduction in free energy associated with the decrease in interfacial area. At any instance during the sintering process, the differential of the free energy of the system, at constant temperature, pressure, and mole fraction, may be expressed is

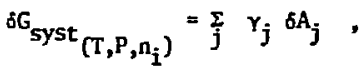

where

$$
\begin{aligned}
Y_{j} & =\begin{array}{l}
\text { interfacial energy of the } j^{\text {th }} \\
\text { interface, }
\end{array} \\
\delta A_{j} & =\text { differential area of the } j^{\text {th }} \\
j & =\text { number of interfaces. }
\end{aligned}
$$

As long as $\delta G_{\text {syst }}$ is negntive, sintering is thermodynamically favored. When $\delta G_{\text {syst }}$ becomes equal to zero, sintering ceases, since the system has attained a minimm free energy configuration. Sintering is usua?ly associated with densification by means of bulk diffusion, grain boundary diffusion, or viscous flow mechanisms. Harever, surface diffusion and vaporizationcondensation, which lead to changes in surface topogranhy but not to densification, also contribute to the sintering process.

Sintering of porder capacts is generally separated into tho classifications; solid phase sintering which is characterized by solid-solid and solid-vapor interfaces, and liquid phase sincering hhich additionally has solid-liquid and liquid-vapor interfaces. In order to fully characterize a sintering compact, one must have a thorough knowledge of interfacial phenomena, diffusion mechanisms, capillary forces, defectinternal surface interactions, gecmetric factors, and reaction kinetics. Although progress has been made in specific areas, no universal sintering theory is availabie at the present time. The mupose of this work is to ingrove the understanding of liquid phase sintering phenomena by investigating thermodynamic and kinetic relationships based on specific idealized geometric models.

Generally, idealized models are formulated to simulate a sintering compact. Relationships are derived for the ideal case and then extended to real compacts. Since no one model can accurately simulate the complete sintering process, several models are needed. When ore model becomes inoperative, a "stage" of sintering is said to be completed. A different model must then be applied to the succeeding stage.

Idealized two-sphere models have been formulated to describe the kinetics of various stages and configurations of liquid phase sintering systens. Using numerical integration techniques, the dependency of densification on time and particle size has been derived.

Additionally, themodynamic anzlyses have been performed for liquid phase sintering of idealized three-dimensional models. Results indicate that critical ratios of

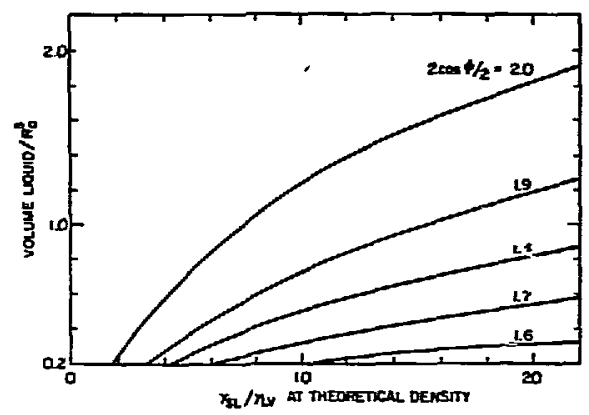

Fig. 1. Combinations of volume fraction of liquid phase and ratio of solid-liquid to liquid-vamor interfacial energies to the left of amy particular curve for dihedral angle yield theoretical densities based on the sintering model; combinations which fall to the right lead to erdpoint densities less than theoretical. 
interfacial energies exist. Above such ratios, endpoint densities less than theoretical are thermodynamically predicted as illustrated in Fig. 1. Figure 1 is a plot of volume fraction liquid phase versus the ratio of the solid-liquid and the liquid-vapor interfacial energies at several dihedral angles formed between tho grains and the liquid.

Experiments are being performed to relate dihadral angles of real sintering conpacts to endooint densities in order to verify the dependency of the degree of densification on the free energy of a sintering system.

8. POLYCRYSTALLINE SPINEL FROM POSNERS PREPARED BY FREEZE DRYING TECHNIQUUE

Chi-Shine Tan and Joseph A. Pask

The nature of the starting powder is extremely critical in realizing microstructures that are uniform and homogeneous on both macroscopic and microscopic scales, especially if the powder is a compound of several oxides. The powders should be of uniform submicron size and free of aggregates. The use of the freeze drying technique is a possible method of abtaining such powders. Work has continued on the preparation of stoichiometric spinel $\left(\mathrm{MgAl}_{2} \mathrm{O}_{4}\right)$ powders by calcining ireeze dried powders formed from an aqueous solution prepared from magnesium sulphate hydrate and aluminum sulphate hydrate in proper proportions.

Hork was dore to understand the relationship between the size and morphology of the calcined spinel powder and the freeze dried powder. The freeze dried powder forms a framework because of the loss of the large amount of water in the solution. The fineness of the framesork is determined by the freezing rate of the aqueous solution as seen in Fig. 1. On cajeination, the freeze dried particles break down into sizes equivalent to the web of the framework; the calcined powders are thus pseudomorphic after the framework of the freeze dried porder.

One of the difficulties, however, is that large aggregates of strong structure frequently form in the calcined spinel powider. Ipon green pressing of such powders, regions of different green density are formed which result in heterogenteous sintered microstructures. Factors leading to the formation of Iarge aggregates were identified as vemelting during drying, melting upon calcination, and partial sintering during calcination. Processing studins here
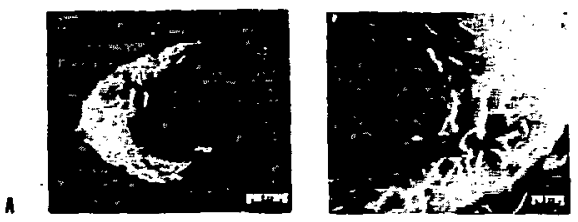

s
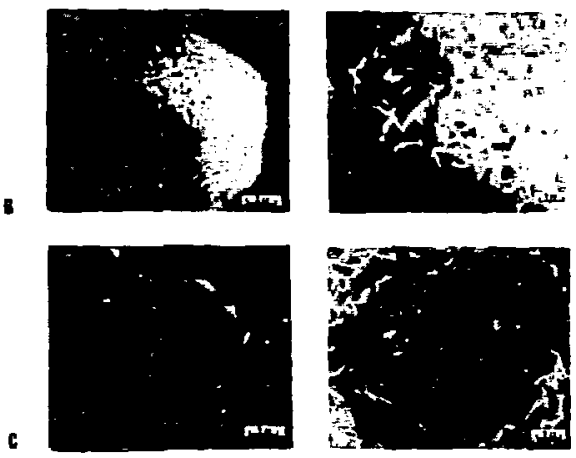

Fig. 1. SBM miciographs of three freeze dried powders at two magnifications:

(A) frozen in freon -12 at $-28^{\circ} \mathrm{C}$, (B) frozen in hexane at $-40^{\circ} \mathrm{C}$, and $(\mathrm{C})$ frozen in heptane at $-60^{\circ} \mathrm{C}$.

(XBB 7310-6098)

undertaken to optimize drying and calcining cunditions in order to reduce aggregation in the prepared spinel porders. Use of such powders resulted in more homogeneous sintered microstructures.

Anion impurities are a major factor that must be considered in the realization of full densification of spinel compracts. For sulfate-derived oxides, a minor residue of sulfate usually stays in the structure ip to an elevated temperature. This residue, although small in quantity, will be present as entrapped gas in the final stage of sintering and prevent full densification. Thermodynamic calculations indicate that the sulfate can be reduced by hydrogen at low temperatures. Such experifients will be performed.

\section{EFFECT OF FABRICATION AN POLYCRYSTALLINE MgO MICROSTRULTURE}

Truett B. Sweeting and Joseph A. Pask

The objective of this study is to determine 
the effect of hot pressing and amealing environments on the character or microstructure of polycrystalline Mgo. A parallel objective is to correlate the resulting microstructures with their stress-strain behavior at elevated temperatures.

A series of experimental hot pressings in vacurm with graphite dies have been made in order to analyze the types of reactions which occur diring the hot pressing and arnealing stages. These reactions are significant to this study since any entrapned reaction product in the bulk, or more likely, on the grain boundaries, can affect the mechanical properties of the specimen. There was evidence of reaction, as shown by the appearance of the samples. The appearance, as characterized by the color and uniformity of the normally white $\mathrm{MgO}$, varied after hot pressing depending on the source of $\mathrm{MgO}$ powder and the nature of the forming conditions. The particular variables found to be significant were the temperature at which pressure was applied, and the final temperature reached drring the run. The subsequent amealing treatment of these pieces also resulted in differences in ampearance for different compacts. Further work is being done to define the exact conditions under which the reactions occur, and then to determine the actual reactions and their products.

A set of specimens for stress-strain analysis is in the process of preparation. A difficulty that has been encountered is powder agglomeration which is resulting in microstructure inhomogenieties.

\section{IMPACT FRACTURE OF BRITTIE TRANSPARETT MATERIALS}

\section{William E. Snowden and Joseph A. Pask}

Study of fracture initiation in brittle transparent materials subjected to transient stresses has continued. Principal objectives of the work are to determine the relation between pulse characteristics and crack growth, and to correlate observed material behavior with predictions arising from a two-dimensional finite-difference computer progran HAP. The experimental system consists of a Schlieren optics s;stem, highspeed cameras, and a magnetic hammer system for generating pulses of varying amplitude and duration on impact.

During the past year an intensive investigation of the motion of various flyer plates, particularly flyers made of alumimm, was coupleted by using high speed photography.
Streaking camera reconds were used to obtain complete time-displacement-velocity histories for each shot. Flyer planarity was examined using a high-speed framing camera. Optimm initial spacing between flyer and target was established from an examination of the records of more than 50 shots, and was found to be approximately $3 \mathrm{~mm}$. At that displacement, flyer velocity was within $15 \%$ of its maximum value for each shot, and the flyer was still planar relative to its thickness across the projected area of impact.

Flyer velocities at $3 \mathrm{~mm}$ displacement for aluminum flyers ranged from $0.022 \mathrm{~mm} / \mathrm{usec}$ to $0.279 \mathrm{mn} / \mathrm{usec}$. For impacts on glass having an acoustic impedance close to that of aluminum, the corresponding range in impact pressure is approximately 2-25 kbars. Flyer velocity was found to be reproducible to within 5 f for constant fire conditions, assuring reasmable reproducibility of impact pressure. In addition, projected impact times were reproducible to within $2.0 \mathrm{sec}$, facilitating synchronization of the impact event and subsequent initiation of fracture with high-speed cameras.

Significant differences between measured flyer velocities and values arising fror theoretical analyses were attributed to difficulties in estimating magnetic field strength. Using oscilloscope traces of current vs. time, however, it was possible to predict flyer velocity to within 15 t of the experimental values. Velocities determined in this manner are usefur in providing a check on flyer velocity during fracture experiments.

Ar estimate of the capabilities of the magnetic hamer systen was made by considering the energy available for flyer acceleration and that required to welt the flyer. A meximum pressure of -55 kbars was estimated for inpacts on gless.

ft present, problems related to precracking thick glass plates are being investigated, and atterpts to exainine pulse characteristics in impacted plates using carbon gauges have been started. Compirter studies to determine the limitations of oneand two-dimensional stress field approximations are also in progress.

\section{CREEP OF LITHIM FUUORIDE SINTLE CRYSTALS AT ELEVATED IEPERATURES*}

Donald R. Cropper ${ }^{\dagger}$ and Joseph A. Pask the creep deformation of lithium fluoride 
single crystals was studied in compression over the termerature range $650-750^{\circ} \mathrm{C}$

(0.8-0.9 $\left.\mathrm{T}_{\mathrm{m}}\right)$. Extended primaty creep was observed for crystals deformed with the compression axis in (100) orientation; strains of 0.20 or more here required for the establishment of steady-state conditions. Crystals with compression axes in the (111) direction reached steady itate quickly, at strains of 0.05 or less. The steady-state strain rate was found to be proportionai to the stress raised to the power $n$, where $n$ ranged from 3.1 for (111) crystals to 4.0 for (100) crystals. The activation energy for creep was determined to be $53 \pm 7 \mathrm{kcal} / \mathrm{mol}$ over the temperature range considered, regardless of crystal orientation or impurity content $џ$ to $300 \mathrm{ppm}$ total impurities; this compares favorably with the activation energy for lattice diffusion of the fluorine ion in LiF. He11-developed substructures were observed in the deformed crystals, the suhgrain diameter varying inversely with the applied stress. These results suggest that the creep deformation of lithium fluoride single crystals may be similar to that for metals and is probably dependent upon the dislocation climb process.

\footnotetext{
Abstracted from Phil. Nag. 27, 1105-1124 (Hay 1973).

fPresent address: The Head Royce Schools, 4315 Lincoln Ave., Oakland, Calif. 94602.
}

12. TIME-DEPENDENCE OF MECHANICAL BEHAVIOR OF MgO SINGLE GRYSTALS

Ching P. Dokko and Joseph A. Pask

An investigation has been undertaken to distermine whether conventional stress-strain behavior can be correlated with creep behavior, using NgO single crystals as the test material. The specimens, both in (100) and ( 111 ) orientations, were deformed at high temperatures $\left( \pm 1 / 2 \mathrm{Tm}_{\mathrm{m}}\right)$ at varicus strain rates and crept at a number of stress levels.

Gradual yielding was observed at low strain rates, conpared with sharper yielding at higher strain rates. When the $0.1 \%$ of fset yield stresses are plotted against strain rates $(\log -\log )$, the slope appears to be close to that of a plot of stress is. steady state creep rate. This relationship suggests a possibility that the defomation mechanisms are the same, whether dislocation motion takes place in the anmealed condition or in the presence of substructures. The yield stress, however, becomes rather insensitive to strain rates in the range where sharp yielding is exhibited. These observations were made for both orientations.

On the other hand, stress-strain curves upon instantaneous increase in the strain rate during a test showed a different response. In (100) crystals, there is little change in flow stress although the strain-hardening rate increases considerably. In contrast, the (111) crystals show a not: ceable increase in flow stress, followed by rapid decay in the strain-hardening rate. It was also found that steary state creep was far more readily achieved in the 1atter orientation.

If it is assumed that the dislocation structure remains the same immediately prior to and immediately after the strain-rate change, then the change in strain-hardening tates should define the dynamic recovery rate that occurs diring deformation. This concept is being evaluated.

The steady-state creep rate shows a stress dependence of $\sim 4.5$ and $\sim 3$ for $(100$ ) and ( 111 ) erystals, respectively. A similar result was reported by Cropper in the case of Lif (see No. 11). However, it is also possible to represent the creep rate of (100) by two exponents, 3 and 6, for lower and higher stress ranges, respectively. The exponent of 3 , which is lower than values predicted by accepted creep theories, warrants further stury.

Another means of looking at short-time (stress-strain) and long-time (creep) behavior on the same basis is the concept of internal and effective stresses which has gained much attention recently. The internal stress represents structural contribution, or the resistance to dislocation motion. Hence, the difference between applied (o) and internal $\left(\sigma_{i}\right)$ stress, which has been termed effective stress $\left(\mathrm{o}_{\mathrm{e}}\right)$ in the literature, should be independent of structure for a given strain rate. This, however, needs to be established before it is applised to both steady and non-steady state conditions for which the structures are different. This aspect is currently being examined. The different transient behavior between (100) and ( 111 ) crystals will be examined from this viewpoint. 
13. INTERFACIAL REACTIONS AND WETTTNG REHAVIOR OF GLASS-IRON SYSTEMS*

Carl E. Hoge, John J. Brennan ${ }^{\dagger}$ and Joseph A. Pask

The $\mathrm{Na}_{2} \mathrm{Fe}_{2} \mathrm{Si}_{2} \mathrm{O}_{5+x}$ and $\mathrm{Na}_{2}-2 \mathrm{Fe}_{x} \mathrm{Si}_{2} \mathrm{O}_{5}$ glasses reacted with substrate iron at $1000^{\circ} \mathrm{C}$ by evalving $\mathrm{Na}$ vapor according to Eq. (I) :

$$
\mathrm{Fe}+\mathrm{Na}_{2} \mathrm{O} \text { (glass) }=\mathrm{FeO}(\text { glass })+2 \mathrm{Na} \text {, }
$$

when the ambient $\mathrm{P}_{\mathrm{Na}}$ was $10 \mathrm{~W}$ and the $\alpha(\mathrm{FeO})_{\mathrm{gl}} / \alpha\left(\mathrm{Na}_{2} \mathrm{O}\right)_{\mathrm{g} 1}$ ratio at the glass-metal interface was relatively small. This reaction occurs more readily as the $\mathrm{O} / \mathrm{Si}$ ratio of the glass increases. Continued reaction results in initial precipitation of $\mathrm{SiO}_{2}$, fayalite $\left(\mathrm{F}_{2} \mathrm{~S}\right)$, or $\mathrm{FeO}$, depending on the value of the $0 / S i$ ratio in the glass.

Maintenance of a $10 \mathrm{~W} \mathrm{P}_{\mathrm{Na}}$ at the interface requires the removal of reduced. $\mathrm{Ya}$ by diffusion and by bubble nucler.tion when the $\mathrm{Na}$ vapor pressure exceeds the total ambient pressure. The time of Na migration by diffusion depends on the jength of the diffusion path, i.e., the thickness of the glass, and the $\mathrm{P}_{\mathrm{Na}}$ of the ambient atmosphere. A lower atmospheric $\mathrm{P}_{\mathrm{O}}$, results in a higher metal surface energy ${ }^{2}\left(\gamma_{S V}\right)$ and a lower $a(\mathrm{FeO})$ at the metal interface, both of which $a-$ favorable for reaction to occur at the i.cierface; under these conditions the sessile drop forms smaller contact angles and may spread, resulting in thimner glass layers.

Armico iron is less reactive than Marz iron because of its higher iron oxide content. The $\alpha(\mathrm{Fe})$ ) at the interface thus remains high for a Ionger time becasse it takes longer for $\alpha(\mathrm{FeO})$ in the interfacial zone to squilibrate with the Iower $\alpha$ (Fen) in the bulk glass.

Quentitative analyses of the glass-metal reactions discussed are complicated by side reactions, i.e., loss of $\mathrm{Na} 2 \mathrm{O}$ at the glass/ vapor interface at low ambient $\mathrm{P}_{\mathrm{Na}}$ and $\mathrm{P}_{2}$, possible decomposition of $\mathrm{FeO}$ ai $10 \mathrm{w} \mathrm{PO}_{2}$, and reaction of any $\mathrm{Fe}^{3+}$ present with the substrate Fe.

Any reactions involving the iron substrate increase the $\mathrm{Fe}^{2+}$, or $\mathrm{FeO}$, content of the glass at the interface. This conposition change is desirable for attaining or maintaining interfacial conpositi ns approaching saturation with iron oxide, i.e. a high $a(\text { Fe } 0)_{\text {int }}$, which is necessary for maximm chemical bonding at the glass/metal interface.

\footnotetext{
Abstracted from J. Am. Ceran. Soc. 56 [2], 51-54 (1973).

'Present address: Research Laboratories, United Aircraft Corp., East Hartford, Conn. 06108.
}

\section{EFFECT OF COMPOSITION ON GIASS-METAL} INTERFACE REACTIONS AND ADRIERENCE*

John J. Bremnan ${ }^{\dagger}$ and Joseph A. Pask

Reduction-oxidation reactions and enhanced wetting or spreading of $\mathrm{Na}_{2} \mathrm{Fe}_{2} \mathrm{Si}_{2} \mathrm{O}_{5+\mathrm{x}}$, $\mathrm{Na}_{2} \mathrm{CO}_{x} \mathrm{Si}_{2} \mathrm{O}_{5}+x$, and $\mathrm{Na}_{2} \mathrm{Ni}_{2} \mathrm{Si}_{2} \mathrm{O}_{5}+x$ giasses an substrates of $\mathrm{Fe}, \mathrm{Co}, \mathrm{Ni}, \mathrm{Ni}-\mathrm{Fe}$, and $\mathrm{Ni}$-Co were observed at $1000^{\circ} \mathrm{C}$ at low partial pressures of $\mathrm{O}_{2}$ and $\mathrm{Na}$ as the $0 / \mathrm{Si}$ ratio of the giass increased. When the substrate had a higher oxidation potential than the metal of one of the cations in the glass, e.g., CoO-containing glass on Fe, metallic precipitates formed by redox reactions under al1 conditions. A redox reaction based on reduction of the valence of a cation in the glass, e.g., $\mathrm{Fe}^{3+}$ to $\mathrm{Fe}^{2+}$, also occirred. Adharence developed between substrates and glasses containing amounts of sibstrate oxide, either in the starting composition or formed by redox reactions, approaching saturation.

Abstracted fron J. Am. Ceram. Soc. 56, [2], 58-62 (1973).

tpresent address: Research Laboratories, United Aircraft Corp., East Hartford, Com. 06108 .

\section{METAL-GLASS INTERFACES}

Glemn A. Holmquist and Joseph A. Pask

Studies on the mechanisms of the reactions that occur at glass-metal interfaces are continuing. Systems being investigated are platinum and gold with fused silica and silica containing small amounts of soda. Sessile drop experiments of molten gold on fused silica in air have shown the appearance of gas bubbles at the interface. The nature of the reaction mechanism is under stuity. 
16. RESEARCH PLANS FOR CALENDAR YEAR 1974

Joseph A. Pask

\section{a. Solid State Reactions}

Studies on the silica-alumina syst.? are continuing. Efforts to wetermine the existence and extent of the spinodal region will be made. Factors playing a role in the nucleation of $\alpha-\mathrm{Al}_{2} \mathrm{O}_{3}$ and mullite on the high- $\mathrm{AI}_{2} \mathrm{O}_{3}$ side of the diagram will be investigeted. The effect of additives on the solid solution range of and diffusion kinetics in mullite will also be determined.

\section{b. Development of Microstructures}

Studies of the factors that play a role in liquid phase sintering and in the development of microstructure are continuing. Experiments will be performed to relate dihedral angles of sintering compacts to degree of densification.

Theoretical equations representing intemediate and final stages of solid state sintering are being developed. Experimental supporting studies will be made using MgO powder and $\mathrm{CaO}$-doped $\mathrm{MgO}$ powder conpacts.

Freeze drying techniques are continuing to be utilized in the preparation of spinel powders for purposes of attaining polycrystalline compacts with controlled microstructure. Particular attention will be paid to the optimization of the process to prevent the formation of aggregates and to eliminate the inclusion of anion impurities.

\section{c. Mechmical Behavior}

An investigation of crack propagation in brittle transparent materials is contimuing. Experiments wiil ie made on precracked thick glass plates and transparent glass-ceramics.

Studies on the correlation of compressive stress-strain behavior with compression creep belavior are continuing. Single crystals of $\mathrm{MgO}$ in (100) and (111) orientations are being wed at high temperatures.

The stress-strain behavior $c \overline{\bar{c}}$ polycrystalline Mgo specimens with different characters or microstructures will be evaluated. Different fabrication techniques are being utilized in the preparation of the specimens.

\section{d. Glass-Metal Interfaces}

Effect of glass composition and experimental conditions on the mechanisms and kinetics of inte-facial reactions and on wetting in gold-glass and platinum-glass systems will be studied. Studies will also be initiated on wetting and reactions in selected molten metal-ceramic systems.

\section{1973 PUBLICATIONS AND REPORTS}

Joseph A. Pask and Associates

Journals and books

1. Equilibria and Kinetics in Modern Ceramic Processing, editor with S. Saito, Y. Kotera, S. Somiya, H. D. Batha, and K. Roy (U.S. - Iapar Seminar Reports on the Basic Science oí Ceramics, Berkeley, Calif.; Niagara Falls, N.Y.; and Inivarsity Pärk, Penna.) 1972.

2. A. P. Raju, i. A. Aksay, and J. A. Pask, Fermeation of Silicates in Magnesia and Forsterite Compacts, Am. Ceram. Soc. Bul1. 52 [2], 166-169 (1973) (LBL-159 Rev.).

3. C. E. Hoge, J. J. Bremnan, and J. A. Pask, Interfacial Reactions and Wetting Behavior of Glass-Iron Systems, J. Am. Ceram. Soc. 56 [2], 51-54 (1973) (L.BL-480).

4. J. J. Bremnan and J. A. Pask, Effect of Composition on Glass-Metal Interface Reactions and Adherence, J. Am. Ceram. Soc. 56 [2], 58-62 (1973) (LBL-481).

5. D. R. Cropper and J. A. Pask, Creep of Lithium Fluc ide Single Crystals at Elevated Temperatures, Phil. Mlag. 27 [5], 1105-1124 (1973) (L.BL-1152).

6. T. Sugita and J. A. Pask, Changes of Freferred Orientation in Hot-Pressed $\mathrm{Al}_{2} \mathrm{O}_{3}$ during Creep, J. Am. Ceram. Soc. 56, [7], 403-404 (1973) (LBL-1147).

Invited talks and participation

1. "Gless-Metal Interfaces," Dept. of Ceramic Engineering, Ohio State University, Columbus, Chio, Feb. 14, 1973.

2. "Glass-Metal Interfaces," Division of Ceramics, Dept. of Metallurgy, Massachusetts Institute of Technology, Canbridge, Mass., Feb. 23, 1973.

3. Chaiman of Session, Symposium on 
"Surfaces and Interfaces of Glass and Ceramics," at N.Y. State College at Alfred Univ., Aug. 27-29, 1973.

4. "Thermodynamics of Solid State Sintering," III, International Round Table Meeting on Sintering, Herceg Novi, Yugoslavia, Sept. 3-8, 2973.

\section{LBL reports}

1. I. A. Aksay, Diffusion and Phase

Relationship Studies in the Alumina-Silica

System (Ph.D. thesis), LBL-ił03, April 1973.
2. C. E. Hoge and J, A. Pask, Thermodynamics of Solid State Sintering, LBL-1495, Marcin 1973.

3. I. A. Aksay and J. A. Pask, The $\mathrm{SiO}_{2} \cdot \mathrm{Al}_{2} \mathrm{O}_{3}$ System: Stable and Metastable Equilibria at 1.0 atm, LBL-I835, Jume 1973.

4. I. A. Aksay, C. E. Hoge, and J. A. Pask, Thermodynamics of Wetting, LBL-1870, July 1973.

5. I. A. Aksay, C. E. Hoge, and J. A. Pask: Phase Distribution in Solid-Liquid-VaporSys tems, LBL-2205, Aug. 1973. 


\section{RELATION OF MICROSTRUCTURE TO PROPERTIES IN CERAMICS}

\section{Richare M. Bulrath, Erincipal I vestigator}

lntroduction. Unlike metals the mechanical, electrical, and magnetic properties of ceramic materials are essentially fixed during the process of foming dense polycrystalline shapes. The processing-property relationship is coupled through the microstructure developed in the processing techniques. For ceramics used in hightemperature structural applications the density and grain size are the primary parameters that control mechanical properties. In electrical and magnetic ceranics the density and grain size not only determine the mechanical properties but influence the electrical and magnetic properties, However, in these materials the dominant factor in developing electrical or magnetic properties is the defect structure.

Defects in ceramics can be developed through compositional control of the atomic species that make up the ceramic $\mathrm{cr}$ by the equilibrium state developed during the hightemperature process (sintering or hot pressing) used to densify a powder conpact.

This research effort is directed toward two primary areas. The first principal area involves developing a better grasp of the sintering process used to densify ceramic powder compacts. This enconpasses sintering studies in materials where only crystalline solid phases are present and in systems where both liquid and crystalline solid phases coexist.

The second research area involves the processing of ferroelectric and ferromagnetic ceranics under conditions where controlled defect structures are produced. The properties of these materials are then reiated to the defect structure.

1. RELATION OF PROCESSING PARAMETERS TO THE PROPERTIES OF LITHIUM FERRITE*

Gautam Bandyopadhyay ${ }^{\dagger}$ and Richard M. Fulrath

Lithium ferrite spinel ( $\mathrm{LiFe}_{5} \mathrm{O}_{8}$ ) has attracted considerable attention because of its square loop properties coupled with swerior temporature stability. Its processing is difficult owing to the loss of lithium and oxygen during the sintering process. In this investigation, lithium ferrite and related compositions were studied to cheracterize the material loss behavior with heat treatment, and also to detemine the influence of sintering parameters, stoichionetry, and selected dopants on the densification, microstructure, and electrical and magnetic properties of the sintered material.

\section{a. Themogravimetry of Spine1 Ferrites}

Extensive thermogravimetric work in air was done with compositions which varied widely from the excess lithia side (anion deficient) to the excess $\mathrm{Fe}_{2} \mathrm{O}$; region (cation deficient). These data are irmortant because the terial loss has a strong influence on the defect structure, which in turn influences the sinterability and nost other properties of the sintered ferrite. It was noted that there was a strong tendency for the copositions to adjust themselves through weight Ioss (lithium or oxygen loss as the case may be), and move into the spinel single-phase region and then equilibrate with the atmospheric oxygen. The schematic representation for this compositional shift for the lithia-rich (Foint a) and $\mathrm{Fe}_{2} \mathrm{O}_{3}$-rich (point b) starting materials and their path of entry (shown by dotted lines with arrows) to the single-phase region is shown in Fig. 1 .

The weight loss behavior of nickel ferrite and zinc ferrite compositions was also

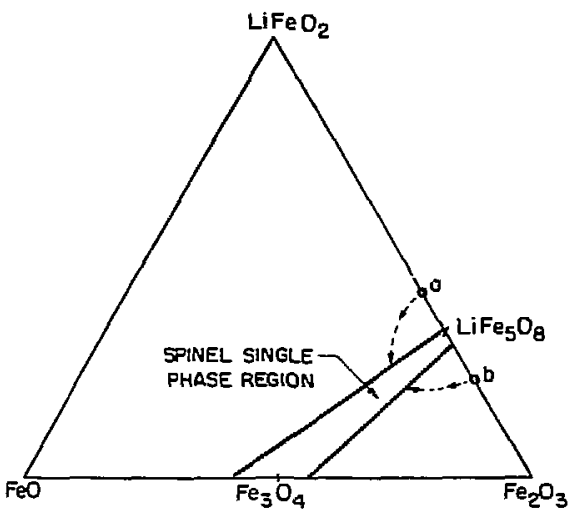

Fig. 1. Schematic representation of the path of entry of the two-phase starting compositions into the single-phase region.

(XBL 737-1594) 
studied for camparison purposes. It was demonstrated that the cation-deficient inverse spinel compositions (e.g., $\mathrm{Fe}_{2} \mathrm{O}_{3}$ excess lithiun ferrite or nicke1 ferrite) exhibit a different behavior than that exhibited by nomml (zinc ferrite) or nearnormal (magnesium ferrite) cation-deficient ferrites. The activation energy for the solid-oxygen equilibria in an inverse composition was found to be $32.75 \mathrm{kcal} / \mathrm{mol}$, whereas the same for the near-normal magnesiun ferrite composition was reported to be $22.8 \mathrm{kcal} / \mathrm{mol}^{1} 1$

b. Lithium Ferrite--Processing and Properties

Polycrystalline compacts were sintered using a packing powder technique where the specimens were buried deep into a packing poider to control the lithium loss. A highoxygen atmosphere was used to control the oxygen loss. The activation energy for the sintering process was found to be $143 \mathrm{kcal} / \mathrm{mol}$. It was observed that the stoichiometry of the starting composition had a pronounced effect on most of the properties that were investigated. Anion-deficient compositions led to denser specimens with higher de resistivity values and square $\mathrm{B}-\mathrm{H}$ loops having low coercive forces. Discontinuous grain growth was favored in these compositions. Also, it was observed that the de resistivity of these polycrystalline specimens was strongly dependent on the microstructure. It is postulated that the grain boundaries acted as the higher conducting path in these systems. The influence of the packing powder conposition on the properties of sintered lithium ferrite was also investigated. The strongest influence was observed on the coercive force value.

\section{c. Effect of Dopants}

Lithium ferrite compacts doped with controlled amounts of $\mathrm{NiO}$ or $\mathrm{NiFe}_{2} \mathrm{O}_{4}$ were sintered using a stoichiometric packing powder under one atmosphere oxygen pressure. Eoth the dopants had only a slight effect on the densification. Nio favored discontinuous grain growth (Fig. 2), whereas $\mathrm{NiFe}_{2} \mathrm{O}_{4}$ suppressed it (Fig. 3). It has been postulated that $\mathrm{NiO}$ reacts with $\mathrm{LiFe}_{5} \mathrm{O}_{8}$ following the reaction

$$
2 \mathrm{NiO}+\mathrm{LiFe}_{5} \mathrm{O}_{8}=2 \mathrm{NiFe}_{2} \mathrm{O}_{4}+\mathrm{LiFeO}_{2},
$$

thereby forming $\mathrm{LiFeO}_{2}$ in the specimen. This reaction was supported by the X-ray analysis and thermogravimetry of the reacted compositions. Experiments were also done relating dc resistivity and $\mathrm{B}-\mathrm{H}$ loop parameters with

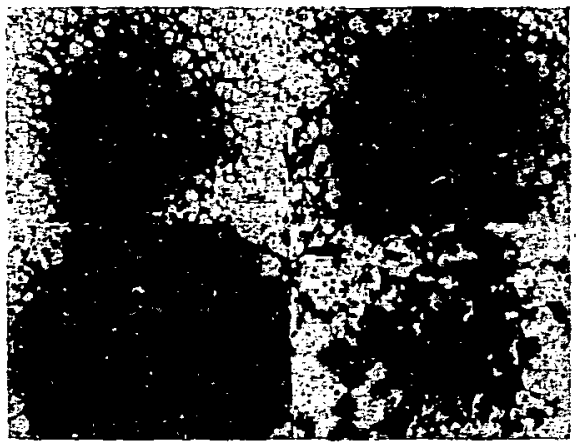

Fig. 2. Influence of NiO dopant on the microstructure of the specimens sintered at $1150^{\circ} \mathrm{C}$ for $2 \mathrm{~h}$ in 1 atm $\mathrm{O}_{2}$ and using stoichiometric packing powder. (A) 1 mols NiO, (B) 3 mols NiO, (C) $5 \mathrm{~mol} \% \mathrm{NiO}$, (D) $10 \mathrm{mols} \mathrm{NiO}$.

(XBB 739-5468)

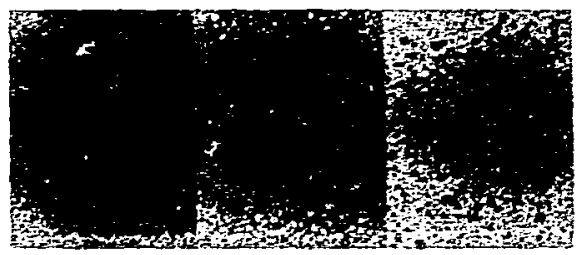

Fig. 3. Influence of $\mathrm{NiFe}_{2} \mathrm{O}_{4}$ dopant on the microstructure of the specimens sintered at $1150^{\circ} \mathrm{C}$ for $2 \mathrm{~h}$ in 1 atm $\mathrm{O}_{2}$ and using stoichiometric packing porder. (A) 1 mo1\% $\mathrm{NiFe}_{2} \mathrm{O}_{4}$, (B) $10 \mathrm{~mol}_{5}^{\circ} \mathrm{NiFe}_{2} \mathrm{O}_{4}$, (C) 20 mols $\mathrm{NiFe}_{2} \mathrm{O}_{4}$.

(XBB 739-5467)

the amount of dopants, and the results were discussed in terms of compositional defect and microstructure.

\footnotetext{
*Abstracted from G. Bandyopadhyay, Relation of Processing Parameters to the Properties of Lithium Ferrite (Ph.D. thesis), LBL-2263, oct. 1973.

tPresent ajdress: Argonne National Lab., Materials Science Dept., Argonne, I11. 60439.
}

1. P. Reinjnen, Reactivity of Solids, edited by G. M. Sctwab ed., (EIsevier, Ansterdam, 1965), pp. 562-5’7i. 
2. A LIQUID PHASE DENSIFICATION TECHNIQUE FOR THE LEAD ZIROONATE TITANATE SYSTEM

Jolm W. Sherohman and Richard M. Fulrati

Because of the ferroelectric nature of the lead zirconate titanate (PZT) system, it has been utilized for many years in the fabrication of piezoelectric devices. Recently, electro-optic device applications have also been realized in the system, since lanthanum-modified lead zirconate titanate (PLZT) has the ability to behave as an electrically controlled light scatterer or retarder.

The densification of the PZT ceramics has been achieved by both hot pressing and normal sintering techniques; yet, both processing schemes require many hours at relatively high temperatures. Consequently, difficulties exist in maintaining controlled stoichimetry due to a high vapor pressure of lead oxide $(\mathrm{PbO})$ in the system and obtaining densities higher than $95 \%$ in the case of umodified PZT. Since sintering with applied pressure (hot pressing) or in the presence of a liquid phase (liquid phase sintering) can lead to enhanced densification, the purpose of this study is to employ a combination of these methods to investigate a unique 1iquid phase densification technique that will develop a highly dense, umodified single phase PZT ceramic with fixed stoichiometry.

The procedure for this technique is essentially a two-step process. The first step makes use of a low-temperature liquid phase that can optimize, with the aid of applied pressure, the rearrangement process on melting of the liquid. The second step involves a subsequent heat treatment without ayplied pressure to allow liquid phase sintering to occur. During this heat treatment, a fixed Fo atmosphere is established that permits the liquid to be removed in a controlled mamner.

The liquid phase is a lead oxyflouride $\left(\mathrm{PbO}-\mathrm{PbF}_{2}\right)$ that has a melting temperature of approximately $500^{\circ} \mathrm{C}$. Various weight percent of the liquid phase compesition is mixed with a $\mathrm{PZ} .5 \mathrm{~T} .5$ powder made from both a mixed oxide 1 and chemically prepared ${ }^{2}$ preparation. The mixed material is cold pressed and placed in a stainless steel hot press die assenbly as shown in Fig. 1. A stainless steel insert is used to provide movement of the zirconia sand into the free volume and give a berter transfer of force to the sample. A typical comparison of displacement versus time at $600^{\circ} \mathrm{C}$ for the mixed oxides and chemically prepared materials is shown in Fig. 2. Original pressings were performed in both $O_{2}$ and in air and it was observed that a black coloration existed in the center of the sanples. X-ray ana"ysis of the center region indicated that metallic lead had formed. From preliminary results it is assumed that this is a pressure-induced reaction in the $\mathrm{PbO} \cdot \mathrm{PbF}_{2}$ liquid. In any case, pressing in helium gives a uriform

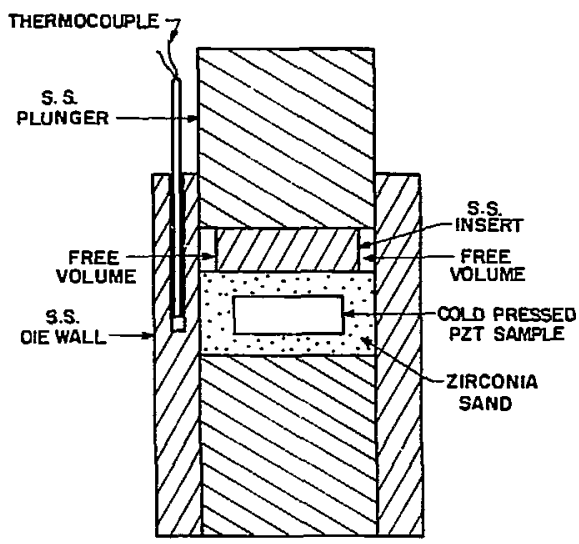

Fig. 1. Stainless steel hot press die assembly.

(XBL 7310-5499)

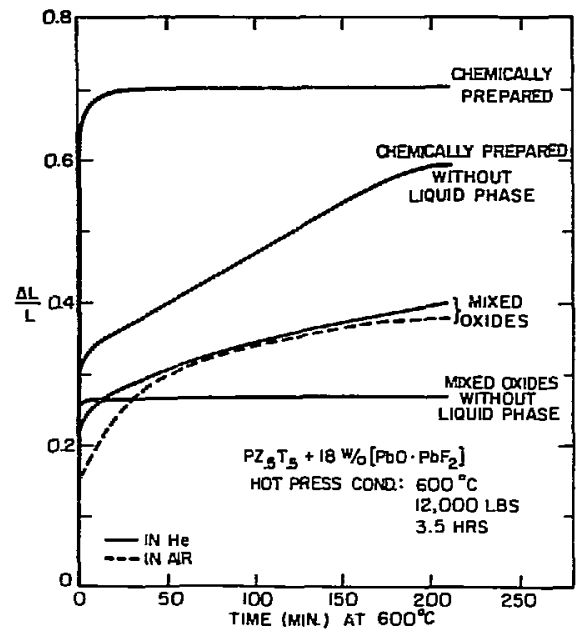

Fig. 2. Displacement versus time for $P Z{ }^{\mathrm{T}} .5$ made from both a mixed oxide and chemically ${ }^{\circ}$ prepared preparation. 
blackness througibut the sample and also a greater displacement as shown in Fig. 2; hence, all hot pressings were performed in helium.

To determine the amount of liquid remaining after the first step in the process, the removal of the liquid phase from the pressed samples was monitored using themogravimetric analysis (TEA). By renoving the Iiquid quickly in an attempt to prevent liquid phase sintering from occurring, the measured density after the TGA indicated the optimm liquid content for hot pressing. Both the amount of liquid remaining and the resulting densities after TGA are shown in Fig. 3. For the chemically prepared $\mathrm{PZ} 5^{\mathrm{T}} 5$, it is observed that a density as high as 98 is obtained for an initial 18 wts liquid phase addition; an initial 22 wt? liquid phase gives a density of $82 \%$ for PZ.5T.5 made froll mixed oxides.

The second step in the process involves removing the liquid phase in a controlled manner by a subsequent heat treatment within
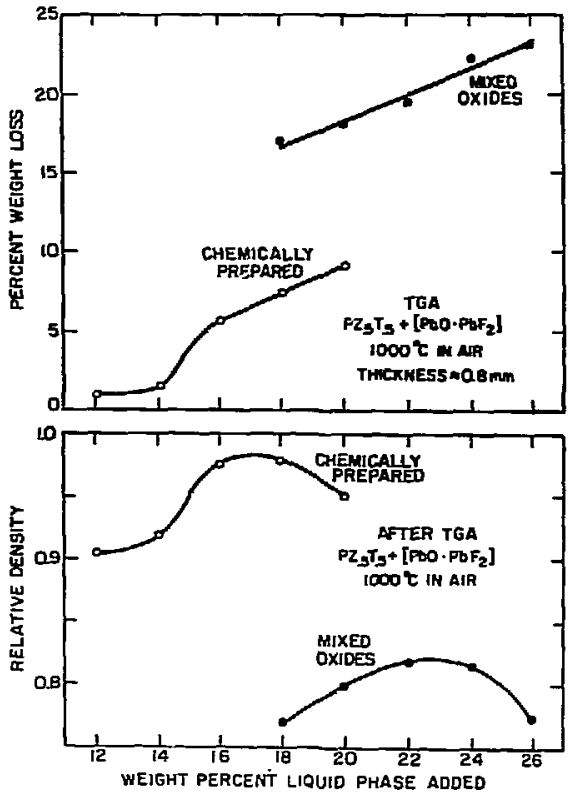

Fig. 3. Ambunt of liquid phase remaining in samples after hot pressing as deteruined by thermogravimetry, and a comparison of the resuitant densities.

(XBL 7310-5495) a fixed PoO atmosphere. A study using three different packing powder conpositions was performed on the mixed axides prepared PZ. 5 T 5 sanple of optimon liquid content as determined in the first step of the process. The packing powder compositions were chosen to estabilst, atmospheres of various $\mathrm{PbO}$ activities that would allow the sample to attenpt to equilibrate by losing lo0, but still mointain the sample in its single-phase region. A "control experiment" packing powder $\left(\mathrm{PZ}_{5} 5^{\mathrm{T}} .5+\mathrm{P}\right)$ of the same Pbo activity as that of the sampie was used to prevent PoO loss but allow only the $\mathrm{PbF}_{2}$ portion of the liquid to evaporate. The resirits of the study are shown in Fig. 4. It was observed that
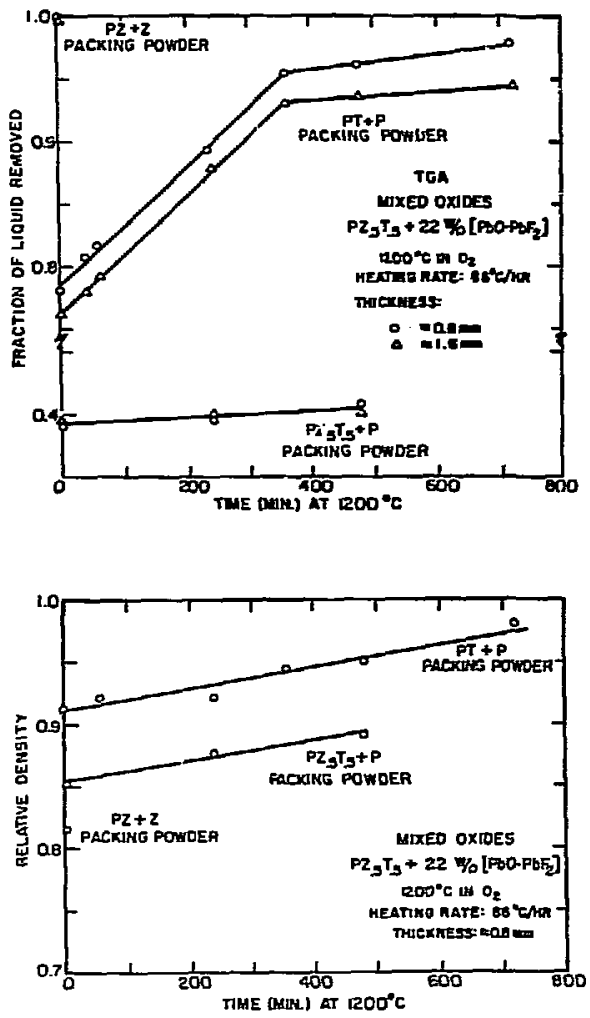

Fig. 4. Removal of the liquid phase from the sample by various packing perider compositions, and a comparison in density after liquid removal.

(XBL 7310-5497) 
for two samples of different thichess the rate of removal of the Pbo portion of the liquid is dependent on the lead oxide activity established by the packing powder compositions. In the case of the lead zirconate plus excess zirconia $(\mathrm{PZ}+2)$ where the Pho activity differcnce from the sample is large, cll the liquid was removed before reaching tenperature. Comparison of the density with that in Fig. 3 indicates very little liquid phase sintering had occurred. For the lead titanate plus excess lead oxide (PT + P) packing powder where the Pto activity difference is swall, it is seen that the rate of $\mathrm{PbO}$ loss is thickness independent until a density of approximately 948 is reached. Above this value a closed-pore situation develops and the loss of PbO becomes thickness dependent. With respect to density, there tends to be a steady increase with the mixed oxides prepared PZ. T. 5 sample reaching as high as 988 in 12 hours.

From the information of Fig. 4, a further study involving the $P Z+Z$ jacking powder would be of interest for various heating rates: since the rate of Pbo loss from the sample is dependent on the PbO activity created by the packing powder and appears to be thickness independent for densities below 94\%, the large activity difference for $P Z+2$ nay allow control liquid phase sintering. Increasing the heating rate will permit the liquid phase to be present in the sample at temperature for longer times. Therefore, a stuty of the density for different heating rates in a $\mathrm{PZ}+\mathrm{Z}$ packing powder may indicate an optimm rate to obtain a density of 948 after removal of the liquid. In this way a high density is acquired by liquid phase sintering that is thickness independent; further densification can be achieved by a normal sintering mechanism without entering a region of thickness dependency. From the data obtained thus far, it appears that by using methods known to enhance sintering, this liquid phase densification technique for the PZT system provides an easy two-step process to develop a dense single-phase material of fixed stoichiometry.

1. The mixing of $\mathrm{PbO}, 2 \mathrm{rO}_{2}$, and $\mathrm{TiO}_{2}$ powders in the correct amounts to give $\mathrm{Pb}\left(\mathrm{Zr} .{ }_{5} \mathrm{Ti} .5\right) \mathrm{O}_{3}$ after calcination.

2. The mixing of $\mathrm{PbO}$ powder and solutions of $\mathrm{Zr}(\mathrm{OBu})_{4}$ and $\mathrm{Ti}\left(\mathrm{OBu}_{4}\right.$ in isopropyl alcohol and water to form a precipitate than can form $\mathrm{Pb}\left(\mathrm{Zr}_{.5} \mathrm{Ti}_{.5}\right) \mathrm{O}_{3}$ upan heating.

\section{LIQUID PHASE SINTERING IN SELECTED} SYSTELS

\section{Leo Froschaver*}

Liquid phase sintering of powdered compacts, i.e., sintering where part of the sample is in the liquid state, is a processing technique that is common to a variety of materials including metal systens (Fe-Cu), cermets ( $\mathrm{HC}-\mathrm{CO})$, and ceramic porcelains. In many of the more refractory systems such as the carbides and borides it is only through liquid phise sintering that the desired densicy of a powder cempact can be achieved.

The technology of liquid thase sintering is much further developed than the theoretical understanding of the process. This is essentially due to two reasans:

1) The existence of at least three phases at the sintering temperature increases the number of process parameters, especially surface energies, solubilities, and volure fraction of phases.

2) Changing surface energies and solubilities with temperature changes the texture of the sarple during cooling and thus makes roon termperature examination difficult to explain the high-temperature behavior.

Thus investigators nearly always determine densification rates and microstructures and attenpt to explain the results by using the known properties of the system. Camparison of sintering kinetics with the results of model calculations leads to a formulation of three possible stages of densification: 1) cearrangement of the solid particles assisted by viscous flor of the liquid, 2) solution of solid material at solid-solid contact points and reprecipitation aided by diffusion in the liquid phase, and 3) densification of a rigid solid skeleton by diffusional processes in the solid. The hetting behavior and the solubility of the solid in the liquid phase should decide wich of these stages should occur in different systems.

It is by comparing the kinetics with model calculations that different micro events in the sintering process have been assumed. The fast iritial and often timeproportional shrinkage is ustally explained as viscous flow with $\equiv$ rearrangement of particles even if there is no experimental evidence. With the hot stage of the scanning electron microscope there is now a tool available to observe the change of microstructure during this stage. Visual evidence 
can clarify which of the assumed mechanisms are actually respi :ssible for densification.

Three systems have been chosen for study of liquid phase sintering based on different characteristics at high temperatures.

1) A system with the solid soluble in the liquid phase and inconplete vetting of the solid by the liquid ( $\mathrm{Fe}-\mathrm{CO}$ ).

2) A systom with no solubility of the solid in the liquid and ineamlete ketting of the solid by the liquiri (î-Cu) .

3) A system with the solid soluble in the liquid and complete wetting of the solid by the liquid $(\mathrm{NC}-\mathrm{CO})$.

Ocher parameters (amoune of liquid phase, particle size of the comontents, green density) con be varied in each system. For all three systcins previous investigators have assumed extensive rearrangcment in the first stage of densification.

The first qualitative examination of sintering of these systems in the scanning electron microscope hot stage showed that in the $\mathrm{kC}-\mathrm{CO}_{\mathrm{C}}$ and $\mathrm{k}-\mathrm{Cu}$ systems extensive rearrangenent ocaurs then the liquid phase first appears. In the Fe-Cu system no viscous flow was observed with up to 40 volume pcrcent liquid phase. This is probably the to the formation of a rigid Fe skeleton during the heating. The nomwetting liquid cannot penetrate the Fe-Fe contact areas and thus the skeleton exists throughour the sintering process. In the $W$-Cu system the diffusion of $W$ is too slaw to form a skeleton diring heating. Figures 1 and 2 show samples of loose powders of iron and tungsten with 40 volupe percent copper before and after melting the copper. The difference in behavior is apparent. A detailed investigation in these systems is now under way. Figure 3 shows an example of the densification of $\mathrm{Fe}$ conbined with different liquid phase volumes. Figure 4 gives the
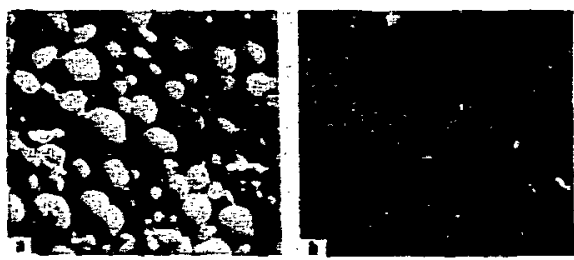

Fig. 1. The same area of view of a loose posider mixture of $60 \% \mathrm{Fe}$ and $40 \% \mathrm{Cu}$ before (a) and after (b) liquid phase formation.
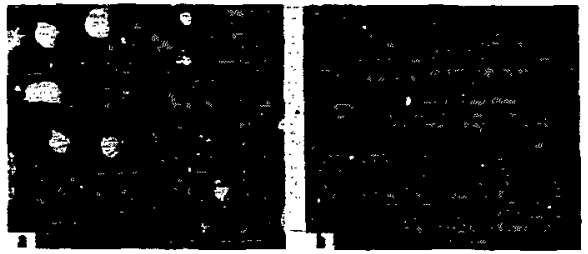

Fig. 2. The same area in a sample of $60 \% \mathrm{H}$ and 403 ou before (a) and after (b) liquid phase fortation.

(XBB 742-812)

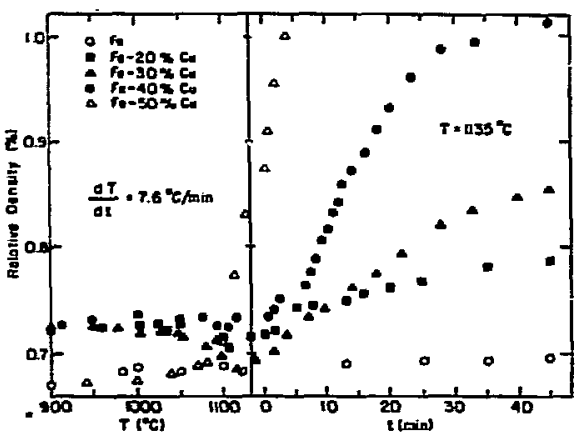

Fig. 3. Densification of Fe-Cu powder compacts with varying anounts of a Cu-rich liquid.

(XBL 7312-6798)

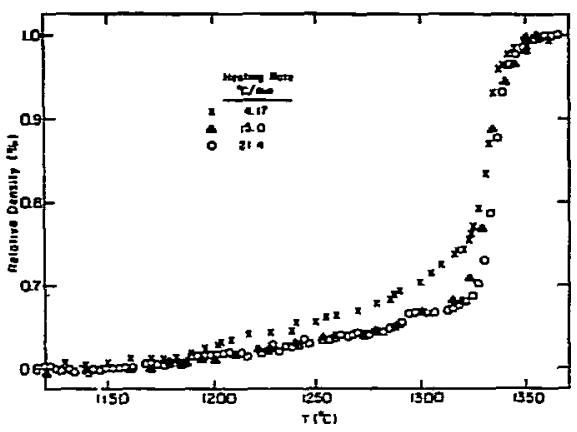

Fig. 4. Densification of $1 \mathrm{CC}-10 \mathrm{~s}$ co as a function of the heating rate of hot stage in the scanning electron microscope.

(XBL 7312-6797) 
Jensification characteristies of $\mathrm{WC}-10 \% \mathrm{Co}$ under three different heating rates.

The importance of the scaming electron rieroscope hot stage-facility is readily apparent in these studies.

Ir. Froschauer is supported on a Post Doctoral Fellowship from the Deutsche Forschungsgemeinschaft.

\section{SOLID STATE SINTERING STUDIES}

David N. K. Wang and Richard N. Fulrath

The densification of ceramic powder compacts without the aid of liquid phases is an important processing step in the production of refractory ceramic materials. The first quantitative studies of the densification process (solid state sintering) of $\mathrm{Al}_{2} \mathrm{O} 3$ were started in 1972 and have been continued in 1973 . The work to date has concentrated on the sintering characteristics of $\mathrm{Al}_{2} \mathrm{O}_{3}+0.1$ wt\& $\mathrm{MgO}$. Powder compacts made by cold pressing subicicron $\mathrm{Al}_{2} \mathrm{O}_{3}$ particles doped with $\mathrm{MgO}$ and containing binders and lubricants are first heated in air to $900^{\circ} \mathrm{C}$ for one hour to remove the organic materials. These compacts containing 60 porosity are heated in the hot stage of the scanning electron microscope under mogramed heating rates to various temperatures to determine the sintering characteristics. The linear shrinkage of the compact is determined by placing $W$ microsphere markers on the sample's surface and recording on $16 \mathrm{Im}$ film the marker's movenent continuously during the sintering run. Using this technique, the sintering of $\mathrm{Al}_{2} \mathrm{O}_{3}$ has been continuously monitered from a green compact density of 403 to nearly $100 \%$ theoretical density.

Figure 1 shows the results of two sintering runs where tive samples were heated at a rate of $4^{\circ} \mathrm{C} / \mathrm{min}$ to isothermal temperatures of 1350 and $1385^{\circ} \mathrm{C}$. After reaching the indicated temperature the temperature was held constant to observe the isothermal sintering behavior. In both cases every datum point is the average of nine individual shrinkage measurements. The statistical scatter in the measurements indicates that sanple $W-7$ was inhanogenous in its shrinkage, with different areas of the sample densifying more than others. Overlaying a magnified picture of the final marker positions on the picture of the original positions points this out dramatically. Sanple W-5 showed honogenous shrinkage with little scatter in the data.

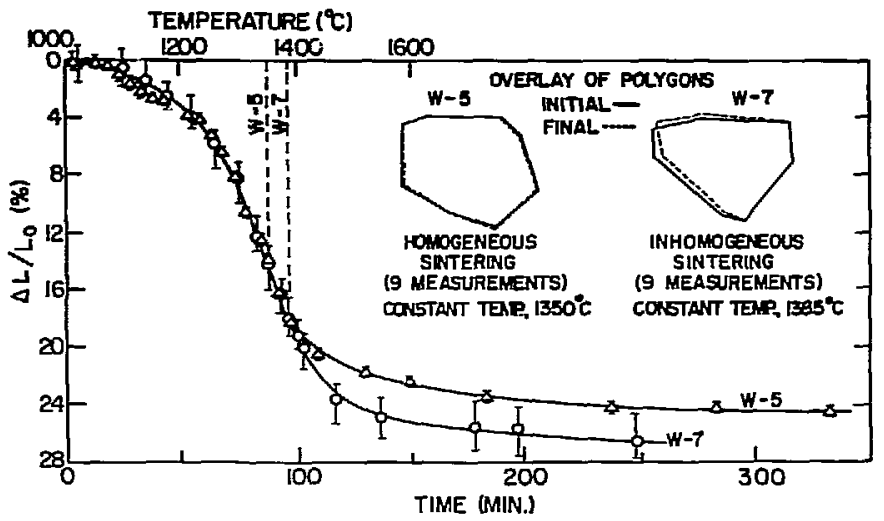

Fig. 1. Linear shrinkage of $\mathrm{Al}_{2} \mathrm{O}_{3}$ compacts heated at $4^{\circ} \mathrm{C} /$ min to the indicated temperature and then held at that temperature for the indicated time. 


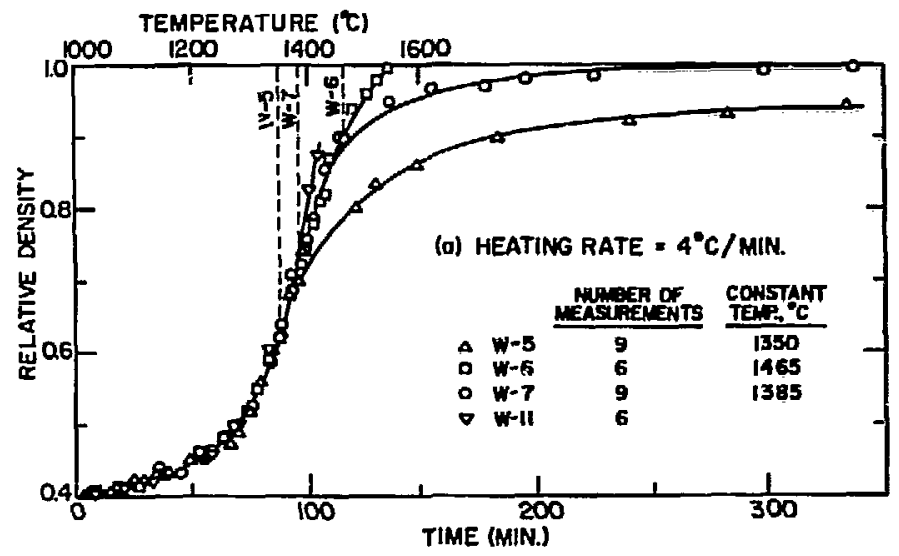

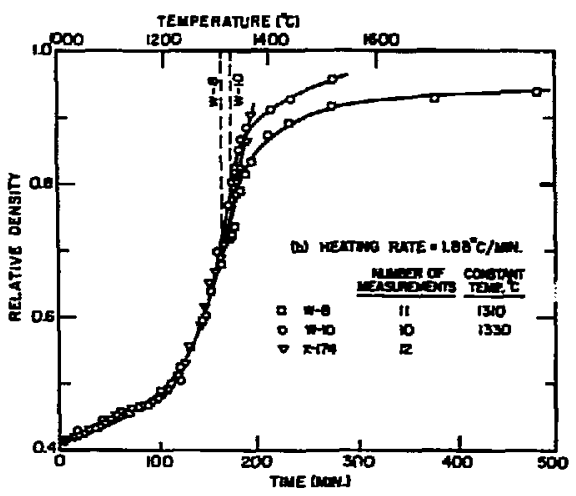

Figure 2 shows the change in relative density as calculated from linear shrinkage data for various heating rates and isothermal temperature holds. As indicated, a higher density is obtained at a given temperature, the slower the heating rate.

Figure 3 gives the densification rates calculated from the data in Fig. 2. The most interesting observatiom is that no matter what the heating rate the densification rate is the same at a given temperature below approximately $1375^{\circ} \mathrm{C}$, ever though the actual density of the specimen may be quite different. For example, at $1330^{\circ} \mathrm{C}$ a sample heated $4^{\circ} \mathrm{C} / \mathrm{min}$ has achieved a density of
Fig. 2. The relative density changes determined from linear shrinkage data as a function of the heating rate and isothermal holding temperature.

(YBL 742-5586 \& 5587)
588 TD (theoretical density) while a sample heated at $1.88^{\circ} \mathrm{C} /$ min at the same tenperature has a density of $76 \mathrm{tD}$, and yet each have the same densification rate. This shows that the densification rate below a given critical terperature is not a function of porosity or heating rates but a function of temperature onIy. This observation and the exponential shape of the densification rate curve are in agreenent with the coble intermediate stage sintering model; however, these data are extended beyond the Coble model and show that on holding at an isothermal temperature below the critical temperature the densification rate decreases with time, which is not predicted by the model. 

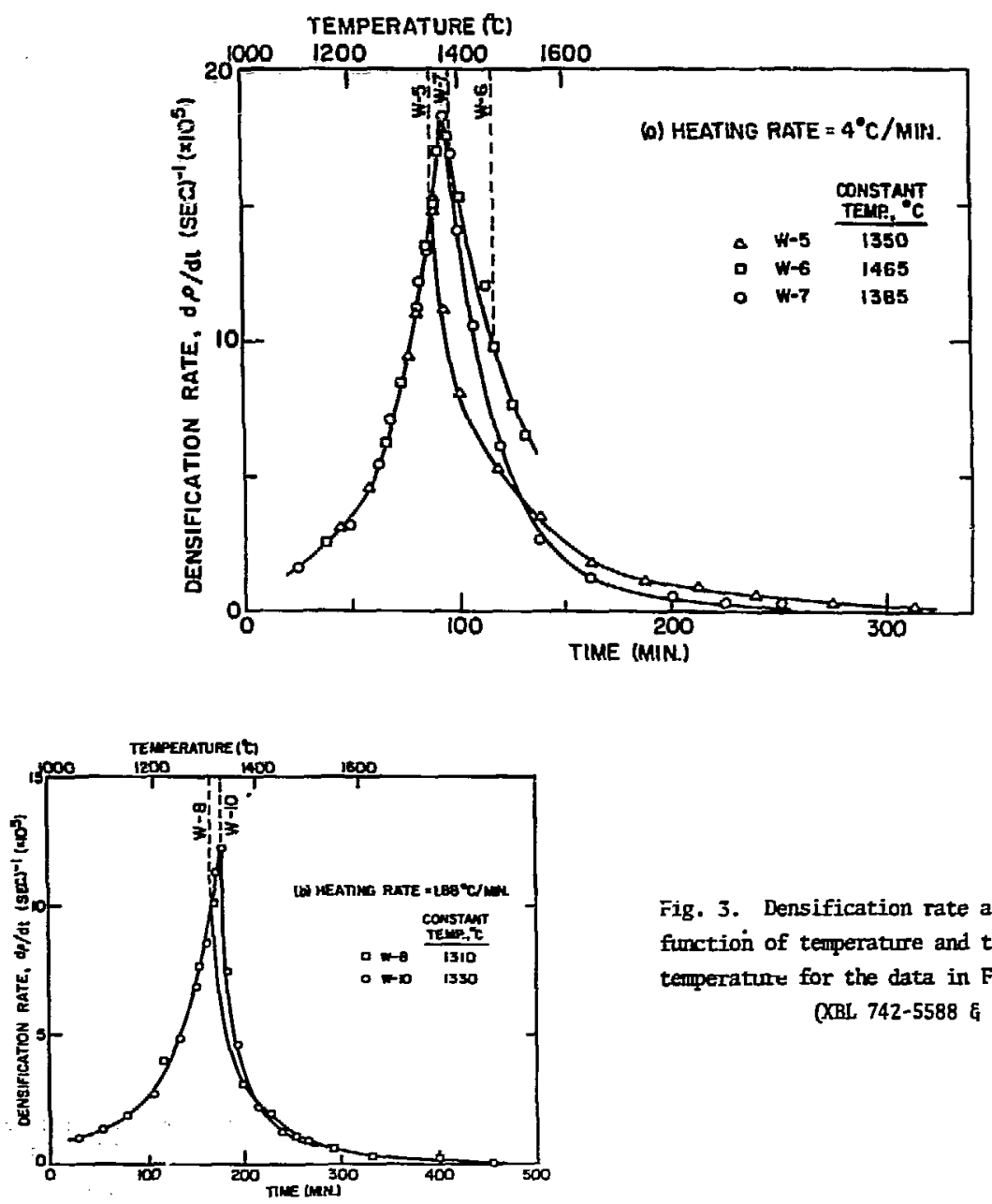

Fig. 3. Densification rate as a function of tenperature and time at termerature for the data in Fig. 2. (XBL 742-5588 \& 5589)

Figure 4 is a plot of the temperaturecompensated densification rate against $1 / T$, from which an activation energy of 50.3 kcal/nol is calculated for the sintering process below the critical temperature of $1375^{\circ} \mathrm{C}$. This value is close to the 57.6 $\mathrm{kcal} /$ mol activation energy experimentally determined for oxygen grain boundary diffusion and much lower than activation energy for sintering calculated by previous investigators.

New modifications made in the hot stage of the scanning electron microscope in 1973 have allowed its use to be extended to $1750^{\circ} \mathrm{C}$. 


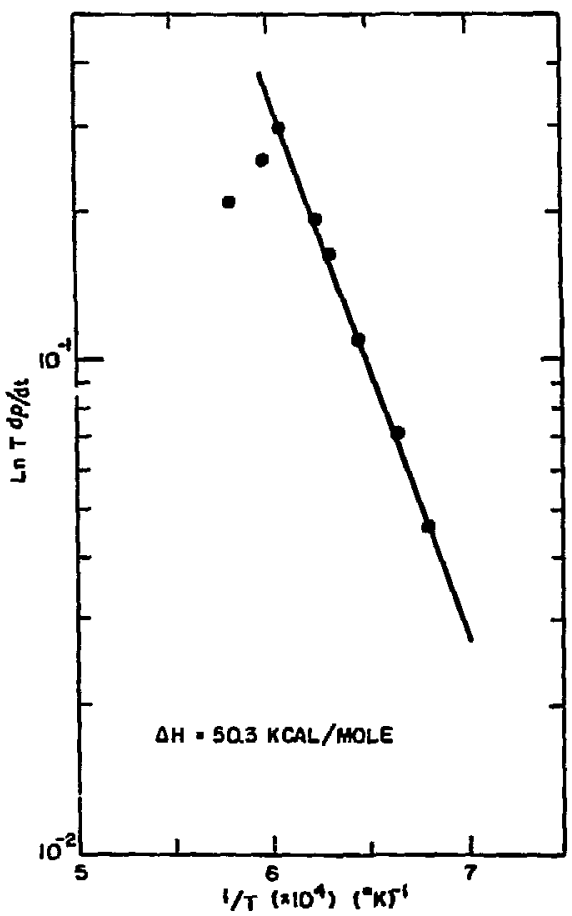

$r_{.}$. 4. Tenperature-compersateo densificaciun as a function of $1 / T$ for the sintering of submicron $\mathrm{MgO}$-doped $\mathrm{Al}_{2} \mathrm{O}_{3}$.

(XBL 742-5590)

5. PERMEATION OF HELIIM IN POLYCRYSTALLINR $\mathrm{Al}_{2} \mathrm{O}_{3}$

Jiunn-Jye Dih and Richard M. Fulrath

Previous work in this laboratory determined that He would permeate through 94 wts and 99.5 wt compercial alumina bulies at tenperatures between 1000 and $1500^{\circ} \mathrm{Z}$ in measurable quantities. The activation energy for permeation of approximately $15 \mathrm{kcal} / \mathrm{mol}$ agreed with that predicted for He permeation through a glass phase. A glass phase was identified in the lowerpurity alumina, but no ontinuouis glass phase could be identified in the higherpurity material. The question of whether He grain boundary permeation would exist in a very-high-purity $\mathrm{Al}_{2} \mathrm{O}_{3}$ and the possibility of determining more information on the nature of the grain boundary through perneation studies resulted in initiatirig a research effort in this area in early 1972 ,

The major problem in permeation stulies is to form spucinens with malytically determined geometries and suitable area-tcthickness ratios to allow measurable quantities of the permeating gas to flow through the specimen. During 1972 alurine shapes of the required geometry were obtained and by a hot prossing technique a few permestion specimens were fabricated. These specimens were vacum tighe to $\mathrm{He}$ at roon tenperature, but on thermal cycling they developed microcracks at aluminaalumina joins which allowed He flow. During 1973 a number of alumina-alumina joining techniques to give He-tight seals at temperatures to $1500^{\circ} \mathrm{C}$ were attermted without success. These processes included active metal seals, direct alumina-alumina joining by hot pressing and sintering, and an experimental high-temperature muxed oxide liquid phase join suggested by an industrial 1aboratory. None of these processes could produce satisfactory specimens. Therefore, in late 1973 a review of the cost and lack of success in fabricating specimens resulted in dropping this zesearch effort.

\section{RESEARCH PLANS FOR CALENDAR YEAR 1974}

\section{Richard M. Fulrath}

Sintering studies both liquid phase sintering and solid state sintering will be emphasized. The systems $\mathrm{Fe}-\mathrm{Cu}$, $\mathrm{W}-\mathrm{Cu}$, and WC-Co will be used for liquid phase sintering studies, and the solid state sintering studies will concentrate on $\mathrm{Al}_{2} \mathrm{U}_{3}$ and $\mathrm{HO}_{2}$. The primary ohjective of these two studies is to obtain the complete densification kinetics fron the initial compact density to nearly theoretical density. These data will assist in developing a better theory to guide the sintering of powder metal products and refractories.

Studies in the defect structure and the processing parameters that control it in electronic and magnetic ceramics will be continued. Primary emphasis will be on the intrinsic and extrinsic defect structures in lead zirconate titanate and their influence on piezoelectric and ferroelectric properties. Electrical resist-vicy will be used to determine semiconductor characteristics and charge carriers.

Fracture in brittle matrix composites 
will be investigated to determine the applicability of either the 'Work to fracture" or the Griffith criteria for the strengthening mechanism.

\section{1973 PUBLICATIONS AND REPORTS}

Richard M. Fulrath and Associates

\section{Joumals}

1. J. S. Reed and R. M. Fulrath, Characterization and Sintering Behavior of Ba and Sr Ferrites, J. Am. Ceram. Soc, 56 [4], 207 (1973) (LBL-815).

2. J. S. Masaryk and R. M. Fulrath, Characterization of the Short Time in Gaseous Diffusion Analysis, J. Am. Ceram. Soc. 56 [6], 342 (1973) (LBL-1454).

3. J. S. Masaryk and R. M. Fulrath, Diffusivity of Helium in Fused Silica, J. Chem. Phys. 59 [3], 1198 (1973) (LBL-B47 Rev.).

4. R. L. Holman and R. M. Fulrath, Intrinsic Non-Stoichiometry in the Lead Zirconate-Lead Titanate System Detemined by Knudsen Effusion, J. Appl. Prys. 44, (1973) (LBL1462).

5. R. M. Fulrath, Let's Test the Mode1, Office of Research Services fighlights,
College of Engineering, University of

Califomia, Berkeley, April 1973 (LBL-1806).

LBL reports

1. R. L. Holman and R. M. Fulrath, Solution Kinetics of La and Sc Ions in PbTi $.5^{2 r} \cdot 5^{\mathrm{O}} \cdot 3$, LBL-1455, Jan. 1973.

2. Joseph S. Masaryk, Diffusion of Gases in Glass (Ph.D. thesis), LBL-1818, May 1973.

3. G. Bandyopadhyay and R. M. Fulrath, Processing Parameters and the Properties of Lithium Ferrite Spine1, LBL-1875, July 1973.

4. G. Bandyopadhydy and R. M. Fulrath, Thermogravimetry of Spinel Ferrites, LBL-2204, Aug. 1973.

5. G. Bandyopadhyay and R. M. Fulrath, Influence of $\mathrm{NiO}$ and $\mathrm{NiFe}_{2} \mathrm{O}_{4}$ Dopants of the Processing and Properties of Lithium Ferrite Spine1, LBL-2255, Oct. 1973.

6. G. Bandyopadryay, A. M. lacy, and R. M. Fulrath, Densification and Grain Growth in Doped Lithium Ferrite Spinel, LBL-2245, Sept. 1973.

7. Gautam Bandyopadhyay, Relation of Processing Parameters to the Properties of Lithium Ferrite (Ph.D. thesis), LBL-2263, Nov. 1973. 


\section{A. THEORETICAL SOLID STATE PHYSICS}

Harvin L. Cohen, Principal Investigator

Introduction. New refinements in the pseudopotential method have led to extremely accurate band structires in well-studied materials and new results for complex and amorphous materials. Theoretical schemes have been developed to take advantage of lattice symetry in complex calculations, making significant reductions in copputer calculations possible, Bonding and superconducting properties of a variety of materials have been analyzed. (AlI work jointly finded with NSF.)

\section{SEMTOONDUCTORS AND INSULATORS*}

Marvin L. Cohen

We have continued our calculations on the electronic structure of seniconductors with emphasis on studies related to electronic band structure and charge density distributions. Narrow gap semiconductors were explored in some detail. These materials are particularly interesting from the device point of view as they are used as generators and detectors of infrared radiation. Our work in this area was related to HgTe-CdTe alloys, IV-VI compounds like PbTe, and InSb. The electronic properties of the narrow gap materials are very rich in umusul physical phenomena. Band edges imvert, temperatume ccefficients of the gaps can be positive or negative, the fermi surfaces are complex, and some of these materials are superconfucting. He have done detailed studies in all of these areas and have fortunately explained many of the observed phenomena, using one-electron theory.

Utraviolet and X-ray photoemission (IPS and XPS) stuxities of semicontuctors have yielded a great deal of detailed information about the valence electron structure of a large number of crystals. These studies have shom that the standard pseudopotential band structure calculations which involve the use of optical data don't necessarily give the correct density of states for the valence bands. We have augnented the usual approach with a non-local scheme. As a preliminary and more or less single step we have wed an effective mass to obtain the corrections at least to first order. This scheme was very successful and paved the way for a more sophisticated approach using a non-local d-well potential. This latter approach has resulted in ultra-accurate band structures for $\mathrm{Ge}$ and haAs and we are presently extending this work to look at other crystals. The above band structures are probably the most accurate band structures ever calculated for any material. For example, in GaAs, the largest discrepancy between theory and Schottky barrier electroreflectance measurements is $0.08 \mathrm{eV}$. The non-local schemes have helped us to interpret photoemission and reflectivity spectra. Structures which were previously unidentified or misinterpreted have been identified in terms of electronic transitions between band states.

Complex materials like temary and layer compounds have been explored success fully, indicating the flexibility of the pseudopotential method. Charge density studies have been particularly useful in these cases. This approach was also used to stucy materials in different crystal structures.

A model potential scheme was developed to attempt to understand the trends in the Group IV materials (C, Si, Ge. Sn, Pb). This appinach involves only two parameters and it illustrated many of the features found in going from $\mathbf{C}$ to $\mathrm{Pb}$. The simplicity of the scheme allowed a detailed variation of the electronic structure and it has lead to a systematic picture of the trends in bonding and electronic structure for this important grom of elements.

A study of the dependence of the energy gaps and band edges on pressure was done. The calculated results were in good agreenent with experiment, but a complete theory is yet to be developed.

Journals 1, 2, 4, 5, 7, 8, 10, 11, 13, 15 and reports $1,5,6,7,8,10,13,14,15$, 16.

\section{AMORPHOUS MATERIALS*}

Marvin L. Cohen

We have had a great deal of success in explorations of the amorphous state of Ge and Si using complex polytypes of these materials. The modifications considered are FC-2 (face-centered cubic with two atoms per cell), 2H-4 (hexagonal with four atoms per cell), BC-8 (body-centered cubic with eight atoms per cell), and ST-12 (simple tetragoial with twelve atons per cell). The long-range order is preserved in our calculations and it is the dianges in the short- 
range order which were studied to discover the important features necessary to give the observed features in cormon with the amorphous materials. Very detailed studies of the band structure, density of states, and dielectric functions of the modifications were made. These studies were extended to explore amorphous III-V semiconductors. The importance of odd versus even number of rings of atoms in the Group IV materials was show previously by our studies. In the III-V case it appears that it is not the rings which are of prime importance, but the existence chains of like or unlike atoms. The relevant feature is the presence of like or unlike bonds; e.g., for GaAs, $\mathrm{Ga}_{2}-\mathrm{Ga}$ and As-As bonds versus GaÁs bonds. Orr calculations make prediction of the features in the density of states which can be measured to illustrate the existence of unlike bonds. At this point these bonds have not been unambiguously discovered. The polytype studies have also yielded an analysis of the observed reflectivity or dielectric function as a function of frequency in general tems. The frequency dependence of the joint density of states and dipole matrix elements can be explored separately using the results of the studies for the $\mathrm{Si}$ and $\mathrm{Ge}$ polytypes. The observed reflectivity for amorphous materials ustally has a characteristic one-hump structure and this can be understood using the above analysis.

$\overline{\text { Journals } 6,12}, 15$ and report 4.

\section{NEN THEORETTCAL MEIHONS FOR SOLID STATE STUDIES*}

Marvin L. Cohen

We have discovered a set of "special points" in the Brillonin zone from which the average over the Brillonin zone of a periodic function of wavevector (e.g., energy, charge density, dipole matrix elements, etc.) can be determined in a simple and accurate way once the function at these points are specified. A specific scheme for increasing the number of points to obtain increased accuracy is also given. The general method and results for some specific lattice structures are given. The special point scheme can save a great dea? of compun er time for many solid state calculations.

We have applied the formalism connected with the special point scheme to the problem of generating Hannier functions. These functions are the real-analogs of the Bloch functions used for $k$-space calculations.
The Hannier functions should be useful in a variety of calculations such as surface studies and studies of amorphous materials.

Analytic expressions for the charge density in Group IV materials were derived. These expressions are useful to study bonding, trends in electronic properties, and other aspects of the electronic properties of these elements.

Joumals $1,7,14$ and reports 2,8 .

\section{CRYSTAL SIRUCTURE*}

Marvin L. Cohen

Despite the vast progress made in solid state theory it is still not possible to make accurate predictions of crystal structure starting with atomic properties. Our studies in these directions have focused on semiconductors, with enphasis on the zincblenderocksalt and zincblende-wutzite transitions. We previously used charge density plots to show the bonding change which is related to the crystal structure change. We have discovered a relationship between the ionicity parameter and the splitting between the first two valence bands in zincblende crystals. This relationship allows a study of ionicity and hence structure through observations of the band gap. This gap can be observed in photoemission data. We have extended this latter study to show the relationship between the gap, the ionicity parameter, and the potential difference between the itoms.

Another study relating the pseudopotential directly to the bonding was done by studying $\mathrm{NaCl}$ and GaAs for both in the zincblende and rocksalt structures. This imvestigation revealed the features of the potential which caused the resultant structure. For example, it is the large core of $\mathrm{Na}$ which appears to he important in fomation of $\mathrm{NaCl}$ in the rocksa1t structure.

ZnS occurs in both the wurtzite (riexagonal) and zincblende (cubic) structures. Detailed charge density studies wert made for both cases. These studies showed that for the wurtzite case the c/a ratio was intimately connected with the overall dipole moment. Hopefully charge density studies will lead to possible predictions of the c/a ratio.

$\overline{\text { Journa1s 4,7, }}, 11$ and reports $3,11$. 
5. METALS, SUPERCONDUCTIVITY AND X-RAY SCATTERING

Slarvin L. Cohen

Our studies of metals include X-ray and charge density calculations for Al. This represents our first charge density calculation for a metal. It illustrates the freeelectron nature with a slight build-up of charge along bonding directions. The $x$-ray form factors are in relatively good agreement with experiment; it is hoped that more detailed experiments or new types of experiments in this area will give more severe tests of the theory. The optical constants were also calculated.

$\mathrm{Nb}, \mathrm{NbC}, \mathrm{NbN}$, and $\mathrm{MbSe}_{2}$ were studied in detail. A non-iocal d-potential was used to allow a pseudopotential study of these materials. Since these materials are superconducting at relatively high temperatures $(\mathrm{Nb}, \mathrm{NbC}-\mathrm{NbN})$ or with unusual superconducting properties (NbSe 2 , part of the emphasis in these studies centered aromd the supercondictivity features. For $\mathrm{NbSe}_{2}$, charge density calculations indicate the bonding features of this material. The layer structure allows many interesting bonding properties.

For $\mathrm{NbC}$ and $\mathrm{NbN}$ charge density, band structure, density of states, and Fermi surface studies appear to give a good picture of the electronic structure for these materials. Some spealations relating Fermi-surface and charge density properties to the superconductivity were made.

Superconductivity studies in addition to the above included a calculation relating superconducting transition tenperatures to the softening of phonons in transition metal compounds. In addition, for the case of PbTe some experimental stuties found some evidence for superconductivity at high temperaturas (e.g., in the $22^{\circ} \mathrm{K}$ range). Orr investigations indicate that the possibility that conventional mechanisms can cause such a high transition temperature are uniikely and the proposed non-conventional excitonic mechanism is also urlikely. Our preliminary investigations seem to indicate that the observations cannot be readily reconciled with existing theory and suggestions that further experimental tests be made to verify the earlier observations are made.

Journals 3,9 and reports $6,9,12$.

\section{RESEARCH PLANS FOR CALENDAR YEAR 1974}

Marvin L. Cohen

We plan to explore XPS data on metals provided by Professor Shirley's groum with the intention of examining the role of llahan singularities in the spectra.

Detailed studies of chalcopyrite semiconductors (e.g., $\mathrm{ZnGeP}$ ) will be made. Reflectivity, bondinB, and XPS speetra will be analyzed. These materials are very nonlinear and may be technologicaliy useful. U1tra-accirate band structures similar to those done for GaAs will be computed for other zincblende, diamond, and rocksalt semiconduxtors. 'In the latter case PbTe, which is a narrow-gap semiconductor, will be analyzed in great detail, particularly for energies and states near the band gap. The role of this material in infrared work makes these states particularly interasting.

Iocal field effects in the dielectric function will be explored. Calculations for Si will atterpt to explain some current scattering measurements. Some general theory will be attempted to explore the relationship between local field effects and electronphonon interactions.

Some work on Cs at varying pressures will be performed. Crystal structure transitions and the change in bonding will be studied with an attempt to inderstand both the oneelectron and superconducting properties of this material.

An attempt to study AgBr will be made. The role of this type of crystal in the photographic process will be analyzed to same extent; i.e., the influence of the electronic band structure will be explored.

Some calculations on the superconducting proximity effect will be attermpted. Measurements by Professor Clarke's group are serving as the motivation for this nork.

We plan to contimue our close association with Professor Shen's group and to perform theoretical calculations relevant to the measurements made by this group.

\section{1973 FIBLICATIONS AND REPORTS}

Marvin L. Cohen and Associates

\section{Journals}

1. D. J. Chadi and M. L. Cohen, Electronic 
Structure of $\mathrm{Hg}_{1-x} \mathrm{CdTe}$ Alloys and Crarge Density Calculations Using Representative k-Points, Phys. Rev. B 7, 692 (1973) (LBL1105).

2. C. Varea de Alvarez, J. P. Walter, R. W. Boyd, and M. L. Cohen, Calculated Band Structures, Optical Constants, and Electronic Charge Densities for InAs and InSb, J. Chem. Phys. Solids 34, 337 (1973) (LBL-482).

3. J. P. Walter, C. Y. Fong, and M. L. Cohen, Electromic Charge Density of Aluminum, Solid State Corm. 12, 303 (1973) (L.BL,-893).

4. W. D. Grobman, D. E. Eastman, and M. L. Cohen, A Relationship Between Photoemission-Determined Valence Band Gaps in Semiconductors and Insulators and Ionicity Parameters, Phys. Letters 43A, 49 (1973).

5. M. L. Cohen, Electronic Charge Densities in Semiconductors, Science 179 , 1189 (1973).

6. J. D. Joamnopoulos and M. L. Cohen, Electronic Properties of Couplex Crystalling and Amorphous Phases of Ge and Si. I. Density of States and Band Structure, Phys. Rev. B 7. 2644 (1973) (LBL-1169).

7. J. D. Joamopoulos and M. L. Cohen, Electronic Charge Densities for $\mathrm{ZnS}$ in the Hurtzite and zincblende Structures, J. Physics C 6, 1572 (1973) (L.BL-1193).

8. C. Varea de Alvarez and M. L. Cohen, Calculated Band Structure and Reflectivity Spectra of $\mathrm{ZnGeP}_{2}$, Phys. Rev. Letters 30, 979 (1973) (LBL-1480).

9. C. Y. Fong and H. L. Cohen, Pseudopotential Calculation of the Electronic Structure of a Transition Netal-Nicbiun, Phys. Letters 44A, 375 (1973).

10. S. E. Kohn, P. Y. Yu, Y. Petroff, $Y$. R. Shen, $Y$. Tsang, and $M$. L. Cohen, Filectronic Band Structure and optical Properties of PbTe, PbSe, and PbS, Phys. Rev. B. $\underline{8}, 1477$ (1973).

11. C. Varea de Alvarez and M. L. Cohen, Model Pseudopotential Calculations of the Electronic and Bonding Properties of Group- $T V$ Elements, Phys. Rev. B $\underline{8}, 1603$ (1973) (LBL1479).

12. J. D. Joamopoulos and M. L. Cohen, Electronic Properties of Conplex Crystalline and imorphous Phases of Ge and Si. II. Band Structure and Oprical Properties, Phys. Rev. B $\underline{8}, 2733$ (1973) (LBL-1826).
13. J. Chelikowsky, D. J. Chadi and M. L. Cohen, Calculated Valence-Band Densities of States and Photoemission Spectra of Diamond and Zincblende semiconductor, Phys. Kev. B 8, 2786 (1973) (LBL-1827).

*14. D. J. Chadi and M. L. Cohen, Approximate Wannier Functions, Solid State Comm. 13, 1007 (1973).

15. J. D. Joamopoulos and M. L. Cohen, New Insight Into the Optical Properties of Amorphous $G e$ and $S i$, Solid State Comm. 13, 1115 (1973) (LBL-1828).

\section{Published abstracts}

I. C. Varea de Alvarez, M. L. Cohen, Y. Petroff, S. Kahn, and Y. R. Shen, Electronic Structure of $2 n G e P_{2}$. Bull. Arl. Phys. Soc. 18,351 (1973).

2. W. D. Grobman, D. E. Easturan, and M. L. Cohen, A Reilationship Between Photoemission-Determined Valence-Band Gaps and Ionicity Parameters, Bul1. Am. Phys, Soc. 18, 384 (1973).

\section{Reports}

1. C. Y. Fong and M. L. Cohen, Electronic Charge Densities for Tho Layer Semiconductors -$\mathrm{SnS}_{2}$ and $\mathrm{SnSe}_{2}$,

*2. D. J. Chadi and M. L. Cohen, Special Points in the Brillowin Zone, (published 1/74)

*3. D. J. Chadi and W. D. Grobman and M. L. Cohen, Atomic Pseudopotentials and the Ionicity Parameter of Phillips and Van Vechten, (to be published Jan. 1974).

4. J. D. Joannopoulos and M. L. Cohen, Electronic Density of States of Antorphous III-V Sericonductors, LBL-2266, Oct. 1973.

5. J. R. Chelikawsky and M. L. Cohen, High Resolution Band Structure and the $E_{2}$ Peak in Ge, LBL-2267, Oct. 1973.

6. M. L. Cohen, Electronic Structure of Narrow Gap Semiconductors, Proceedings of the International Conference on Narrow Gap Seniconductors, Nice, France, Sept. 10-12, 1973 (LBL-2269, Sept. 1973).

7. C. Varea de Alvarez and M. L. Cohen, Pressure Coefficients for Band Gaps in Silicon, LBL-2268, Oct. 1973.

*8. D. J. Chadi and M. L. Cohen, Analytic Expression for Electronic Charge Density Distribution in Dianond Structure Crystals, Dct. 1973. 
9. D. J. Chadi and M. L. Cohen, Electronic Band Structures and Charge Densities of NbC and NbN, LBL-2557, Nov. 1973.

10. J. R. Ghelikowsky and M. L. Cohen, Electronic Structure of GaAs, LBL-2560, Dec. 1973.

11. Y. W. Tsang and M. L. Cohen, Pseudopotential Study of Bonding in the Zincblende and Rock Salt Structures, LBL-2558, Dec. 1973.

12. C. Y. Fong and M. L. Cohen, Band Structure and Charge Densities of $2 \mathrm{H}-\mathrm{NbSe}_{2}$, LBL-2254, Lec. 1973.

13. J. R. Chelikowsky and M. L. Cohen, Calculated Valence Band Density of States and Reflectivity for ZnSe, LBL-2555, Dec.1973.
14. I. Ch. Schlitter and M. Schlüter, Electromic Structure and Optical Properties of PbI 2, LBL-2559, Dec. 1973.

15. Carmen Varea de Alvarez, Electronic Structure of Diamond, zincblende and Chalcopyrite Semiconductors (Ph.D. thesis), LBL-1863, Sept. 1973.

16. C. Varea de Alvarez, M. L. Cohen, L. Ley, S. P. Kowal czyk, F. R. MEFeely, D. A. Shirley and R. W. Grant, Electronic Density of States and Bonding in Chalcopyrite Type Semiconductors, LBL-2330, Dec. 1973.

Not supported by IMRD finds. 


\section{B. FAR INFRARED PROPERTIES OF SOLIDS}

\section{Baul L. Richards, Erincipal Investigator}

\section{FAR IIIFRARED PLUTOCONDUCTTVITY OF ULTRAPURE GERMANRU}

Eugene E. Haller and Paul L. Richards

U1trapure gemanius is prohuced at LBL in substantial quantities for the construction of "germanium intrinsic detectors" of electromagnetic radiation and particles. A continuing problem in the production of this material is the identification of residual imprrities at the level of a few parts in $10^{12}$. Far infrared photoconductivity using the IMRD Fourier spectroscopy facility provides the most sensitive known method for identifying comon acceptors such as B, $\mathrm{Al}, \mathrm{Ga}$, and In.

Isolated acceptor atoms produce a quasihydrogenic series of energy levels within the Ge energy gap. If the sample is Iraintained in the $10-15^{\circ} \mathrm{K}$ temperature range, a far infrared photon can promote a hole from the ground state to one of many empty excited states. There is a substantial probability that the hole will subsequently absorb a phonon and be excited to the valence band. Its presence in the valence band is observed as an increase in the electrical conductivity. Since the first two states involved in this process are sharp, the photoconductivity peaks are narrow (ov $<0.1 \mathrm{~cm}^{-1}$ ). Since there are few thermally excited holes, the photo-excited holes cause a large change in the sanple conductivity. Signals 100 times greater than noise have been obsenved for acceptor concentrations $\sim 10^{10} \mathrm{~cm}^{-3}$.

Because the ground state wave function samples the immediate vicinity of the impurity, the ground state energy varies with the atcmic number. The excited state energies are mich less sensitive to the acceptor species as long as it is neutral. The cluster of photoresponse lines Iooks the same for each acceptor, but the frequency at which the cluster occurs identifies the acceptor responsible. This is shown in Fig. 1 where the frequencies expected from $\mathrm{B}, \mathrm{Al}$, and $\mathrm{Ga}$ are compared with the spectrum observed for a sample containing these impurities.

Photoconfuctivity spectra have been measured on a large number of samples obtained from many different boules. These measurements have proved useful in identifying the inmurities which limit the volume and the performance of "germanium intrinsic

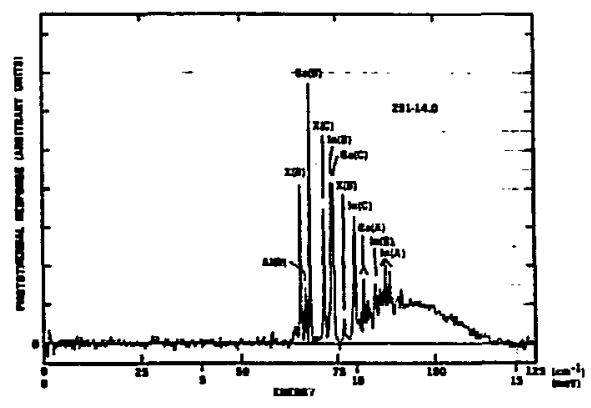

Fig. 1. Far infrared photoconductivity spectrom of ultrapure Ge containing B, Al, $\mathrm{Ga}$, and $X$ (unlown). The positions of the lines agree with lower-resolution results previously obtained for doped samples. Above $75 \mathrm{~cm}^{-1}$ there is a continum spectrum associated with photo excitation into the valence band.

(XBL 7310-1396)

detectors." The sensitivity for shallow acceptors appears to be adequate to identify these impurities even at levels which are no longer important for detector performance.

During the course of these experiments, several new phenomena have been observed which will be investigated to determine their cause. These include two series of lines which correspond to unknown centers with ionization energies between those of $B$ and $A 1$, and those of In and Th.

Attempts will be made to develop noisefree contacts at low temperature so that these measurements can be extended to $\mathrm{N}$-type material.

\section{BALLOON-BASED MEASUREMENTS OF THE COSMIC BACKGROND RADIATION}

John C. Mather, Paul L. Richards, and David P. Woody

Big bang cosmology theory and measurements in the microwave and optical frequency region support the idea that the universe is filled with isotropic blackhody radiation with a characteristic temperature of $2.7^{\circ} \mathrm{K}$. Accurate measurements of this radiation are not available for frequencies above the 
peak of the blackbody spectrum (which occurs at $-6 \mathrm{~cm}^{-1}$ or $\left.\lambda \approx 1.7 \mathrm{~mm}\right)$.

A far infrared spectrometer has been developed that can be flown by balloon to an altitude of $\sim 40 \mathrm{~km}$ to measure this radiation over the frequency range from -3 to $-18 \mathrm{~cm}^{-1}$. The principal features of the system are shown in Fig. 1. These include a cooled

\section{LIQUID HELIUM COOLED \\ FAR INFRARED INTERFEROMETER}

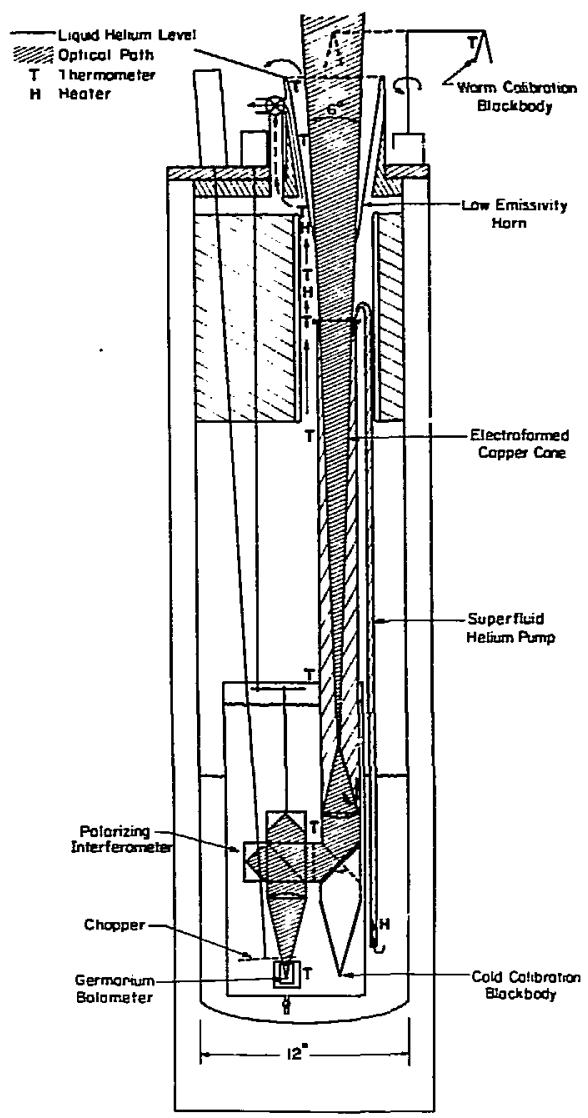

Fig. 1. Scale drawing of radiometerspectrometer for measurements of the cosmic background radiation. The cryostat is $-1.5 \mathrm{~m}$ high and maintains the apparatus at minimu temperature for more than 10 hours.

(XBL 737-6388) two-section horn antenna, a cooled polarizing Michelson interferameter used for Fourier spectroscopy, and a germanium bolcmeter detector. The bolameter is illuminated with immersion optics for improved sensitivity. Blackbody sources are used in flight to calibrate the spectrometer for absolute radicmetry with an anticipated sensitivity of better than $0.02^{\circ} \mathrm{K}$ for a 1 sec observation of a Rayleigh-Jeans source.

One critical feature of this measurement is the avoidance of signals from extraneous wann objects. Kadiation from the apparatus is reduced by cooling to liquid helium temerature all portions of the optical systen winch contact the geometrical bean. The temperature of the warm horn at the top of the antemna (which contacts only diffraction side lobes) is varied in flight to check for resiajual emission. All windows in front of the antenna are removed for the measurement. The antenna has been designed for minimum side lobes at large angles to avoid observing signats from the earth or the balloon hardware. The measured antenna pattern is shown in Fig. 2 .

The most important remaining sources of extraneous radiation are the line enissions from the residual atmosphere above $40 \mathrm{~km}$. The important lines arise from water, ozone, and oxygen. Since the relative line strengths

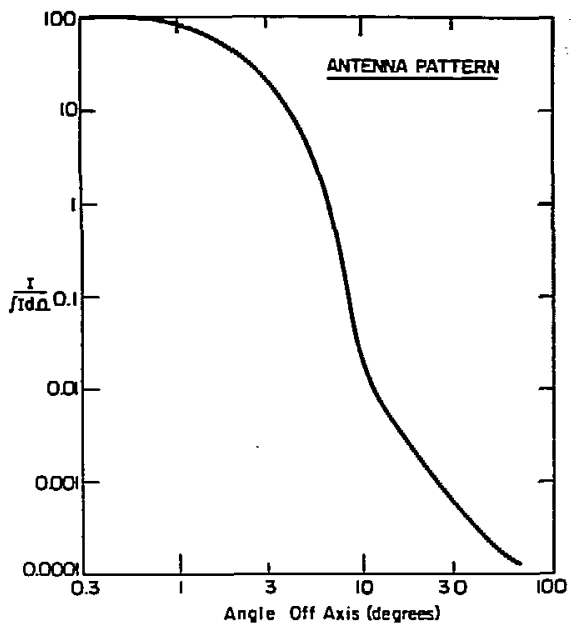

Fig. 2. Response of the radiometer to a point source as a function of the angle of the source from the axis of the antemna.

(XBL 741-5430) 
and positions are accurately known, the observed spectra will be used to determine the anounts of the three gases present. Computer prograns have been written to generate simulated atmospheric emission spectra, which will be subtracted from the observed spectral data to obtain the residual background radiation. An example of such a simulated atmospheric emission spectrm (plotted as an antema temperature) is compared with a $2.7^{\circ} \mathrm{K}$ blackbody curve in Fig. 3 .

The apparatus described here has been constructed and tested in space environment simulators (cold and vacurm) and interfaced to a balloon gondnla developed by Professor $K$. Anderson's group at the Berkeley Space Sciences laboratory. The first flight was launched from Palestine, Texas, on October 26, 1973. Drring the flight the payload temperature dropped to $-60^{\circ} \mathrm{C}$. This was considerably colder than the temperature of $-20^{\circ} \mathrm{C}$

anticipated from the experience of others, and colder than our minimum design temperature

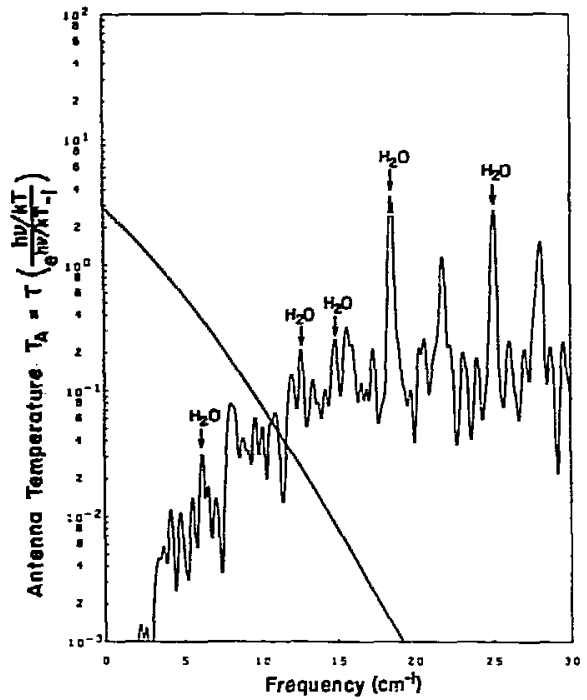

Fig. 3. The antenna temperature of a $2.7^{\circ} \mathrm{K}$ blackbody compared with that of an estimate of the residual atmospheric antenna temperature above $40 \mathrm{~km}$. Antema temperature is defined as the tempereture of a RayleighJeans source with unit emissivity which gives the same emitted power as the actual source. The frequency range of this measurement is from $\sim 3$ to $\sim 18 \mathrm{~cm}^{-1}$.

(XBL 737-1577) of $-50^{\circ} \mathrm{C}$. At this $10 \mathrm{H}$ temperature the mechanical drive to the interferaneter lost power and stopped working. Consequently, although all other electrical and mechanical systems functioned well, very few spectral data were obtained. The payload was recovered undamaged near Anniston, Alabama.

Despite the absence of spectral data much of value was learned from the flight. The reasm for the low temperature is now understood and can be corrected. Preliminary data analysis indicates that another flight with the same apparatus (with a working interferoneter drive) will produce significant new information on the cosmic background radiation. A second flight is planned in early 1974, after minor modifications to the apparatus have been completed.

Another potential application of this apparatus is the stury of the composition of the atmiosphere. If the apparatus is modified to look horizontally and to measure spectra out to $100 \mathrm{~cm}^{-1}$, the sensitivity to minor atmospheric constituents will be greatly increased. A rough estimate suggests that a detection iimit of $\sim 10^{8}$ molecules $/ \mathrm{cm}^{3}$ can be achieved in a 1 sec observation for a gas with an electric dipole moment of 1 debye. (Partially funded by NASA)

\section{SURFACE MAGETIC RESONANCE IN MnF}

Robert B. Bailey, Paul L. Richards, and William E. Tentiant

The far infrared transmission spectrum of a single crystal of the classic antiferrornagnet $\mathrm{MnF}_{2}$ is well known to show a single lowfrequency mode, the antiferromagnetic resonance (AFM) at $8.7 \mathrm{~cm}^{-1}$. In the course of stulying magnetic resonance modes in disordered antiferromagnets, the far infrared spectra of $\mathrm{MnF}_{2}$ powders were measured. The results in Fig. I show either one or two extra modes (marked $S M$ ) in addition to the ARR. The strengths of these SM deperid on the size of the powder particles.

Detailed analysis of the data shows that these extra modes canmot be reasonably attributed to impurities, to strain, or to magnetostatic modes. The most likely explanation is that they arise from the sample surface. We believe these modes to be the first observation of a magnetic surface mode.

The surface mode identification is most convincing for the $S M$ at $8.3 \mathrm{om}^{-1}$ whose strength is observed to vary in proportion 


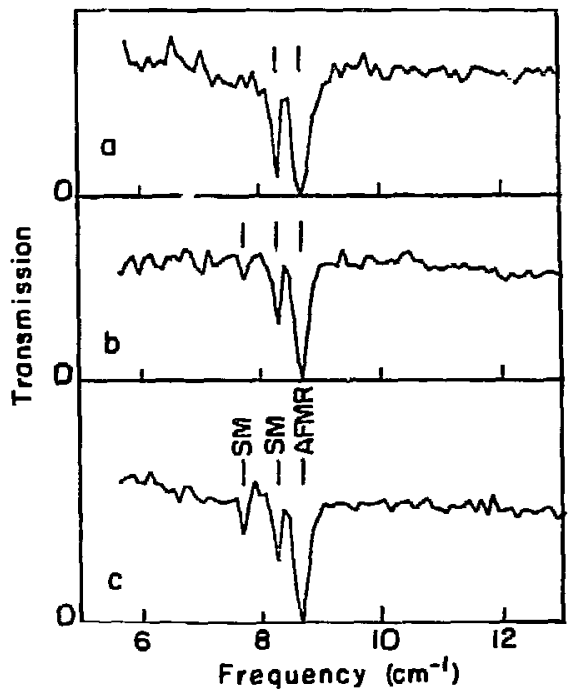

Fig. 1. Far infrared transmission spectra of powder samples of $\mathrm{N}_{\mathrm{n}} \mathrm{F}_{2}$. The powder particle size increases in going from curve a to curve $\mathrm{f}$. These spectra show $\mathrm{M}$ at 7.7 and $8.3 \mathrm{~cm}^{-1}$ in addition to the well-known APMR at $8.7 \mathrm{~cm}^{-1}$. XXL 738-1610)

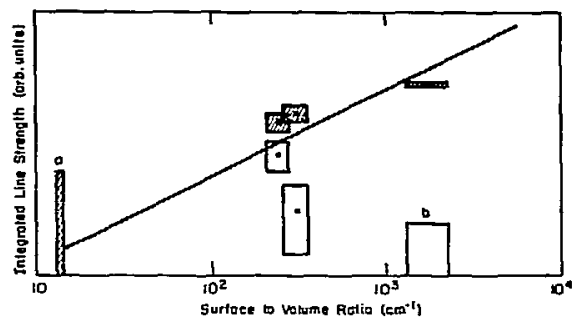

Fig. 2. A $10 \mathrm{~g}-\log$ plot of the integrated line strengths of the $\$ \mathrm{~N}$ at $7.7 \mathrm{~cm}^{-1}$ (open squares) and the $S M$ at $8.3 \mathrm{~cm}^{-1}$ (shaded squares), plotted as a function of the sample surface area normalized to the volume (which was the same for all samples). The shaded squares fit a line with slope $1 / 2$ which is the expected result for saturated umresolved Lorentzian lines whose actual strength is proportional to surface area. (XBI 738-1611) to the surface area of the powder. Its splitting in a magnetic field is the same as that for a buik mode, as would be expected if the surface spins have the same alignment as the bulk spint. The mode at $7.7 \mathrm{~cm}^{-1}$ is strongest for intermediate particle sizes and was not strong enough to observe the magnetic field splitting. The data for the dependence of the strength of both modes m sample surface area are shown in Fig. 2.

The theory of ant: ferromagnetic surface modes predicts that a sharp resonance frequency is associated with a single crystatlographic plane. The surface of our powder particles is expected to be dominated by the (110) cleavage planes of $\mathrm{MnF}_{2}$. Preliminary calculations for this plane, done in collaboration with Dr. T. Wolfram of the Rockwe?1 Science Center, give frequencies in the neighborhood of $8 \mathrm{~cm}^{-1}$, but predict mode strengths $\sim 200$ times smailer than the observed modes.

Microwave apparatus is being constructed to search for these resonances on single crystals of $\mathrm{MLF}_{2}$ with large cleaved 110 surfaces. Higher sensitivity and resolution should be available from the microwave spectrometer than from the infrared techique.

\section{FAR INFRARED NONLTNEAR SPECTROSCOPY IN $\mathrm{LiNbO}_{3}$}

James Morris, Kei-hsiung Yang, Pawl L. Rirhards, and Y. R. Shen

A system for generating continuarusly tunable far infrared radiation by beating two dye lasers in $\mathrm{LiNbO}_{3}$ was described in the annual report last year. The power generated at a number of frequencies using forward collinear phase matching has been measured and the values of the nonlinear coefficient $\chi^{(2)}$ shown in Fig, 1 computed from them. The values of $x^{(2)}$ do not agree with the theoretical values derived from the published inirared and Raman data. However, good agreenent was found, as shown in Fig. 1, when the infrared absorption was remeasimed by observing the width of the phase matching curve. The new resilts for the infrared absorption coefficient of $\mathrm{LiWbO}_{3}$ obtained in this way are shown in Fig. 2. They reveat considerable structure which is believed to arise from frequency-dependent phonon damping. The infrared absorption in the wings of the lowest optical phonon frequency depends on the lifetime of the phonon Created. Since this lifetime is controlled by the decay into two or more phonons, $t$ 
singularities on the joint densities of states of the product phonons will cause stricture on the infrared absorption. This novel method for measuring the frequencydependent phonon damping competes favorably with the more conventional Raman technique.

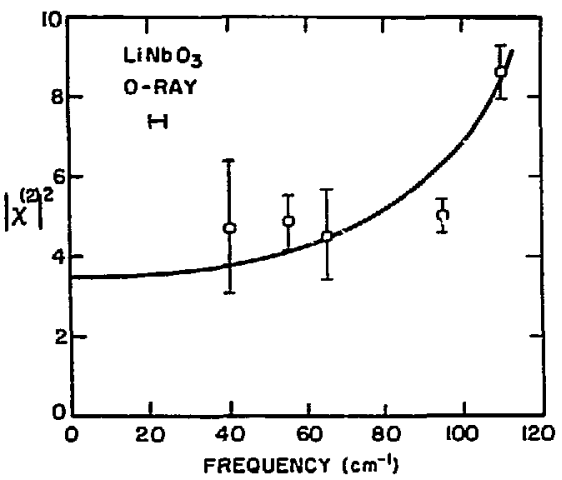

Fig, 1. Square of the nonlinear coefficient $x$ computed from the measured difference frequency power (points) compared with that conputed from the Raman cross section and the intirared absorption coefficient (line).

(XBL 736-6308)

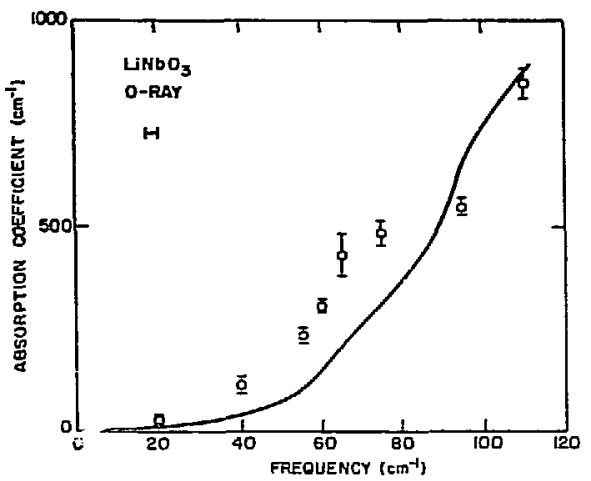

Fig. 2. Infrared absorption coefficient (points) measured from the effective coherence length for difference frequency generation, compared with directly measured infrared data (line) from the literature.

(XBL 736-6397)

\section{INSTRIRIENTATION FOR FOURIER SPECIROSCOPY}

Paul L. Rìchards

The IMRD Fourier spectroscopy facility includes a Michelson interferometer and two polarizing interferometers for far infrared spectroscopy in the frequency range from 2 to $450 \mathrm{~cm}^{-1}$, with a maximum resolution of $0.05 \mathrm{~cm}^{-1}$. "These instruments are coupled on-line to a PDP-11 computer progranmed for fast Fourier transforms and phase corrections.

A new rapid scan Michelson interferometer has been built to cover the frequency range from 400 to $10,000 \mathrm{~cm}^{-1}$ with a resolution of $1 \mathrm{~cm}^{-1}$. This instrument was first operated with an HgCdTe photoconductive detector which limited its range to the 700-4,000 $\mathrm{cm}^{-1}$ region. With this detector the rate of data acquisition was about 100 times faster than for a conventional chemical IR spectrometer with the same resolution. New programs and interfaces are being developed to process the data from this new interfercueter.

\section{FAR INFRARED SPECTRA OF $\mathrm{N}^{3+}$ IN $\mathrm{Al}_{2} \mathrm{O}_{3}$}

Richard L. Aurbach and Paul L. Richards

Fourier transform spectroscopy has been used to measure the transmission of Mh-doped $\mathrm{Al}_{2} \mathrm{O}_{3}$ as a function of frequency, field, orientation, polarization, and temperature. Several resonances have been observed in the frequency range from 3 to $30 \mathrm{~cm}^{-1}$. The splitting of these modes in a magnetic field parallel to the c-axis is shown in Fig. 1. The strengths of several modes increase with magnetic field, possibly indicating admixture of higher lying levels. In the $\mathrm{H} \perp \mathrm{C}$ orientation, the modes show strong polarization dependence. The temperature has been varied from 1.3 to $4.2^{\circ} \mathrm{K}$ in order to idestify ground state trasitions, and a level diagran for the infrared active modes has been assembled. These resonances are attributed to the $\mathrm{mn}^{3+}$ ion, which is expected to show strong dynamic Jahm-Te1ler interactions. The samples for this study were provided by Dr. R. A. Forman of the National Bureau of Standards. A theoretical analysis of $\mathrm{Nn}^{3}$ in $\mathrm{Al}_{2} \mathrm{O}_{3}$ is being carried out by Dr. C. Bates of Nottingham Iniversity concurrently with these measurements. 


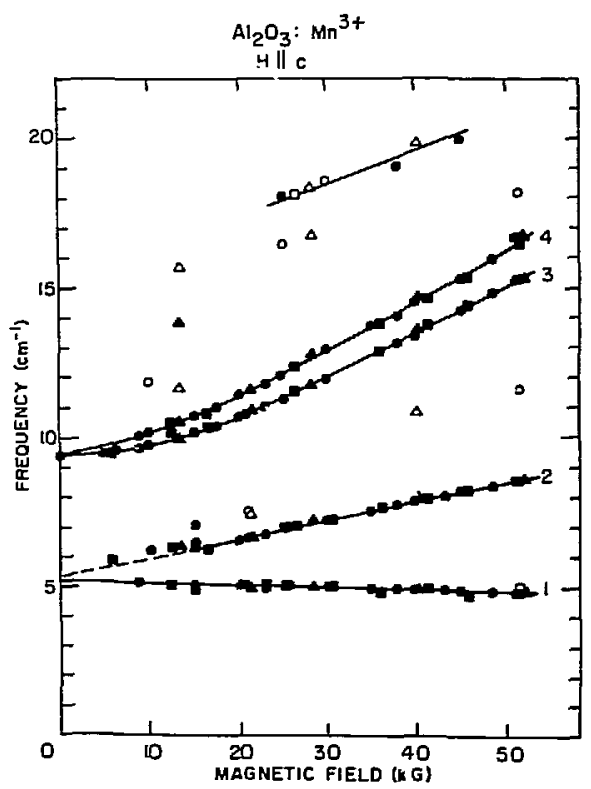

Fig. 1. Transmission minima observed in three samples of $\mathrm{Al}_{2} \mathrm{O}_{3}: \mathrm{Nn}^{3+}$ with magnetic field parallel to the c-axis.

(XBL 7312-7101)

\section{SUPERCONDUCTING TUNNEL JRCTION BOLONEIERS}

John Clarke, Gary I. Hoffer, and Paul L. Richards

In most parts of the infrared spectrum the most sensitive available detector is the He temperature doped $\mathrm{Ge}$ bolometer. The minimum detectable power (NEP) varies with the bolometer area, but is we11 characterized by the figure of merit

$$
\mathrm{D}^{n}=\sqrt{\text { Area }} / \mathrm{NEP} \approx 3 \times 10^{12} \mathrm{a} \cdot \mathrm{W}^{-1} \mathrm{~Hz}^{1 / 2}
$$

for a good bolometer. We are investigating two new types of superconducting infrared boloneter. Both we evaporated film superconducting tunnel jumctions as thermometers. In one, the temperature-dependent Josephson current in a $\mathrm{Pb}-\mathrm{CuA} 1-\mathrm{Pb}$ superconductor-normal metal-superconductor junction is measured with a SQUID galvanometer. In the other, the temperature-dependent quasiparticle tumeling current in a $\mathrm{Pb}-\mathrm{Al}_{2} \mathrm{O}_{3}-\mathrm{Al}$ superconductor-insulator-normal metal junction is measured with a conventional field-effect transistor amplifier. Either type of junction is deposited on a low-heatcapacity sapphire substrate covered on the reverse side with a thin Bi film to absorb infrared radiation. The best performance achieved thus far is for the SNS bolometer which is pictured in Fig. 1. It presently has an electrical

NEP $\approx 5 \times 10^{-15} \mathrm{~W} / \sqrt{\mathrm{Hz}}$ and $\mathrm{D}^{n} \approx 10^{14}$ an $\mathrm{W}^{-1} \mathrm{~Hz}{ }^{1 / 2}$.

Some improvement in these values is anticipated.

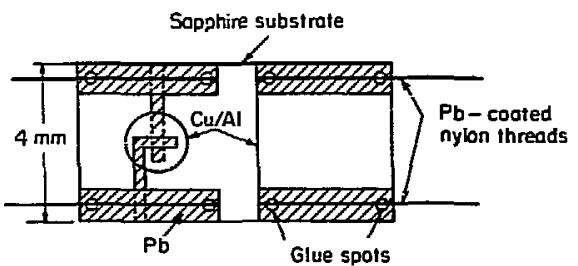

Fig. 1. Configuration of the superconductornorifal metal-superconductor junction bolameter. (XBL 7112-4927A)

\section{RESEARCH PLANS FOR CALENDAR YEAR 1974}

Panl L. Richards

Measurements of the photoconductivity of ultrapure Ge will continue, both as a service to the LBL group producing material for "germanive intrinsic detectors" and in order to explore some of the new physical effects discovered. At least one ballocn flight of the cosmic background apparatus is planned. A single successfur flight should provide significant new data on this important problen. Exploration of the zerofield far infrared resonance modes in the iron group fluorides will continue on the (Fe, Co) $F_{2}$ and $(\mathrm{Zn}, \mathrm{Nm}) \mathrm{F}_{2}$ systems, and Zeeman splittings of the modes already discovered in the ( $\mathrm{Fe}, \mathrm{N} n) \mathrm{F}_{2}$ and $(\mathrm{Co}, \mathrm{Nn}) \mathrm{F}_{2}$ systems will be measured. An attenpt will be made to verify the hypothesis that the observed extra mades in powdered s.t. $F_{2}$ are the first observation of a surface magnon. Interface and software development will be continued so that data can be analyzed on-line from the new near infrared fourier spectrometer. Far infrared studies of the dynamic JahnTeller effects on $\mathrm{Cr}^{2+}$ and $\mathrm{Mn}^{3+}$ will be 
continued. The development of high sensitivity superconducting tumel junction bolometers will be continued. In addition, more conventional superconducting bolometers operating at the resistive transition will be restudied. If sufficient progress is made, a project to study the far infrared absorptivity of metals based on these boloneters may be initiated. In addition, they may be used to improve the sensitivity of the cosmic background apparatus.

In addition to the above, a project to design and construct superconducting Josephson effect min wave mixers and parametric anplifiers is funded by the Office of Naval Research.

\section{1973 PUBLICATIONS AND REPORTS}

Paul L. Richards and Associates

Journals and conference proceedings

1. K. H. Yang, P. L. Riciards, and Y. R. Shen, Coherent Phonon Ceneration by Optical Mixing in a One-Dirensional Superlattice, J. Appl. Phys. 44, 1417 (1973).

*2. P. L. Richards, F. Auracher, and T. Var Duzer, Millimeter and Subillimeter Wave Detection and Mixing with Syercondueting Weak Links, Proc. IEEE 61, 36 (1973).

3. B. Enders, P. L. Richards, W. E. Temnant, and E. Catalano, Antiferronagnetic Resonance Modes in $(\mathrm{Co}, \mathrm{Mn}) \mathrm{F}_{2}$ and $\left(\mathrm{Fe}, \mathrm{Mni}_{2} \mathrm{~F}_{2}\right.$, in Magnetisn and Magnetic Materials 1972, edited by C. 0. Graham, Jr., and J. J. Rhyne (AIP, New York, 1973), Sec. 7, p. 179.

4. P. L. Richards, W. E. Teminant, and E. Catalano, Antiferromagnetic Resonance in Alloys of the Iron-Group Fluorides, Bull. Am. Phys. Soe. (Ser. II) 18, 418 (1973).

5. X. H. Yeng, J. Morris, P. L. Richards, and Y. R. Shen, Phase Matched Ceneration of Tumable Far Infrared Rediation by Mixing Two Dye Lasers, Bull. Am. Phys. Soc. (Ser. II) 18,350 (1973).

$\dagger_{6 .}$ G. I. Rochlin, P. L. Richaris, and F. Auracher, Quasiparticle Interference Current in Superconducting Weak Links, Bull. All. Phys. Soc. (Ser.II) 18, 77 (1973).

\section{LBL and other reports}

¥1. P. L. Richards, Optical Analysis of Solar Energy Collection (1973 Mtaterials Research Council Report).
* 2. P. L. Richards, Microwave Conductivity Measurements on Anisotropic Organic Crystals (1973 Materials Research Council Report).

3. John Clarke, G. I. Hoffer, and P. L. Richards, Superconducting Tunne1 Junction Bolometers, in Proceedings of the International Conference on the Detection and Emission of Electrcmagnetic Radiation with Josephson Junctions, Perros-Guirec, France, 1973 (to be published); LBL-2222, Aug. 1973.

*4. Y. Taur, J. H. Claassen, and P. L. Richards, Conversion Gain and Noise in a Josephson Mixer, in Proceedings of the International Conference on the Detection and Emission of Electromagnetic Radiation with Josephson Junctions., Perros Guirec, France, 1973 (to be published).

5. R. L. Aurbach, P. L. Richards, and R. A. Forman, Far Infrared EPR of $\mathrm{Al}_{2} \mathrm{O}_{3}: \mathrm{An}^{3+}$, LBL-2231 Abs., Oct. 1973.

6. K. H. Yang, J. R. Morris, P. L. Richards, and Y. R. Shen, Phase-Matched Far-Infrared Generation by Optical Mixing of Dye Laser Beans (to be published); LBL-2226, Sept. 1973.

7. William E. Tennant, Low-Temperature Studies: I. New Antiferromagnetic Rescnance Effects in the Iron-Group Fluorides. II. Impedance Hatrhing a Josephson-Effect Gaivanometer by Means of a Superconducting Transformer (Ph.D. thesis), LBL-1844, Nov. 1973.

8. W. L. Hansen and E. E. Haller, A View of the Present Status and Future Prospects of High Purity Germanium, LBL-2435, Nov. 1973.

9. E. E. Haller and W. L. Hansen, Impurities in High-Purity Germanium as Determined by Fourier Transform Spectroscopy, LBL-2436, Nov. 1973.

\footnotetext{
"Sponsoted by the ONR COffice of Naval Research).

tPartly sponsored by the ONR Coffice of Naval Research).

${ }^{\ddagger}$ Sponsored by ARPA (Advanced Research Projects Association).
} 


\section{SUPERCONDUCTIVITY}

Gene I. Rochlin, Rrincipal Investigator

1. PAIR-QUASIPARTICLE INTEPFERENCE CURRENT IN SUPERCONDUCTING TUNNEL DEVICES

Gene I. Rochlin

Previous calculations of the effects of the phase-dependent pair-quasiparticle interference conductance, $G \cos \phi$, on the I-V characteristics of superconducting Josephson-type devices have been extended to treat a wide range of values of $\mathrm{G}_{1} / \mathrm{G}_{0}$ between +1 and -1 . The results have also been parametrized to treat the bias voltage dependence of the normal conductance $G_{0}$. Several effects are noted: for a given value of $G_{1}$, all $I-V$ curves may be reduced to a single family with a uiversal scaling factor $B_{c}$ which depends only on the jurction's measurable $\mathrm{G}_{0}(\mathrm{~N})$ and capacitance; deviations of the $I-V$ curve from the $\beta_{c} \rightarrow 0$ limit persist to very small values of $\beta_{c}$; stable solutions exist even for $\left|G_{1} / G_{0}\right|>1$. The latter effect in particular is most astomishing, since it corresponds to a pendulum whose damping exceeds the driving force over part of the rotation. Theories which assumed that $\left|G_{1} / G_{p}\right|<1$ was the physical limit requirement will have to be re-exmined in this light.

The experimental observations on Sn-I-Sn unshunted thin-film oxide junctions only confirms that $G_{1} / G_{0}<0$, but we have not been able to determine the magnitude of this ratio from our data, which remains a puzzle.

\section{TUNWEL JUNCTIONS WITH FLUOROCARBCN BARRTERS}

\section{Michael D. Jack and Gene I. Rochlin}

The electrical characteristics of In-I-In and In-I-Pb superconducting tunnel junctions have been studied in detail. Since In does not readily form pinhole-free oxide layers, a thin insulating dielectric was formed on freshly deposited In film by passing an electric discharge through an atmosphere of fluorocarbon gas. Junctions were then completed by depositing a thin counter electrode of In or $\mathrm{Fb}$. The same process was used to prepare high-resistance junctions with Aul as the base electrode; these were not, however, studied in detail.

In-I-In and In-I-Pb junctions were produced with resistances in the range
0.01 to $10^{10}$ ohms at liquid helium temperatures. Low-resistance junctions exhibited nonlinear electrical characteristics associated with good quality "oxide" superconducting junctions including (a) the de Josephson effect, (b) quasiparticle tumeling characteristics, (c) phonon structure, and (d) inelastic turneling phenomena. The magnitude of the Josephson current for In-I-In junctions agreed to within a few percent of the value predicted by strangcoupling theory. Current voltage $(\mathrm{I}-\mathrm{V})$ and first- and secund-derivative curves for In-I-In and In-I-Pb were compared with curves for $\mathrm{Al}-\mathrm{I}-\mathrm{In}$ and $\mathrm{Pb}-\mathrm{I}-\mathrm{Pb}$ junctions. Discrepancies between the characteristics can be, for the most part, explained on the basis of existing theories of phonom-mediated superconductivity, using recent data from inelastic neutron scattering stuiies of In. Nonlinear structure at voltages below the phoron spectrum was observed and is most likely associated with Koln singularities. At higher voltages, second-derivative arves exhibited resonances characteristic of $\mathrm{CH}$ and of impurities in the barrier as well as a complex spectrum associated with the vibrational spectrum of the fluorocartom dielectric. To better characterize this dielectric, a variety of surface malytic

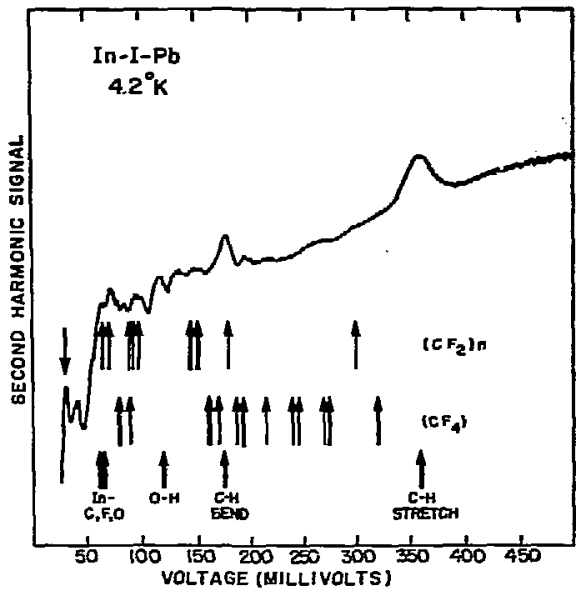

Fig. 1. "Tunneling spectrum" of an In-I-Pb junction at $4.2^{\circ} \mathrm{K}$. The arrows represent prominent peaks in the infrared spectrum of $\left(\mathrm{CF}_{2}\right)_{0}$, poly-tetrafluoroethylene, and $\left(\mathrm{CF}_{4}\right)$, tetrafiuoromethane.

(XEL' 7212-7368) 
techniques were used to determine the complex index of refraction, the chemical composition, and chemical homogeneity of the barrier. I-V curves for high-resistance junctions were used to determine the potential at the metal-insulator interface (see Fig. 1).

\section{METAL OXIDE TUNNEL BARRIERS}

\section{Duncan E. MeBride and Cene I. Rothlin}

he have developed a method of characterizing the barrier in a metal-insulator-metal tumneling junction on the basis of experimental current-voltage curves and a simple theoretical model. We are able to determine unambiguously the barrier height $\phi$ and barrier thickness $s$ by, first, measuring the quantity $S \phi^{3 / 2}$ from the slope of the Fowler-Nordheim

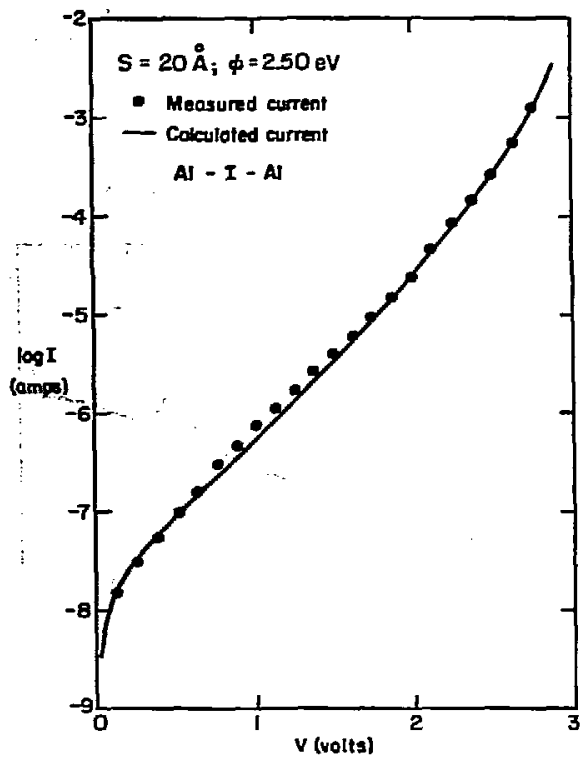

Fig: 1. The curve which gave the best fit for the particular junction with $5 \phi^{3 / 2}=$ $79 \mathrm{~A}(\mathrm{eV}) \mathrm{s}^{3 / 2}$ is plotted on top of the experimental data. The agreement is excellent over five orders of megnitude of current. The slight husp in the data points near $\mathrm{V}=1$ volt is not understood.

(XBL 733-5843) plot. Then experimental data are compared with a family of current-voltage curves calculated for various pairs of $S$ and $\phi$ with $S \phi 3 / 2$ fixed at the measured value, and the pair which gives the best fit is determined. This procedure has been tested on the best-understood tumneling barrier, that is grown thermally on an aluminum film, and is found to give a barrier height of about $2.6 \mathrm{eV}$, in good agreement with independent measurements. (See Fig. I)

Our method also enables us to construct a qualitative description of the tumeling barrier which provides a context for the quantitative meastrements. The barrier seems adequately described by a trapezoidal model, often with mequal sides but of nearly uniform height over the junction area. Although the barrier thickness is not umiform, the variation occurs on a microscopic scale in a well-prepared junction, and the magnitude of the variation is a small fraction of the mean thickness.

We have also used the method to measure parameters of barriers grown thermally on chromium, thin film vanadium, and bulk vanadium, and we obtain barier heights of $0.6,0.1$, and $0.2 \mathrm{eV}$ respectiveiy. The techique is a convenient one for the analysis of data from an experiment, and the results it gives are unambigurous, consistent, and provide a sensitive measurement of the characteristics of the barrier.

\section{RESEARCH PLANS FOR CALENDAR YEAR 1974 \\ Gene I. Rochlin}

The work on the pair-quasiparticle interference term will be completed.

\section{1973 PUBLICATIONS AND REPORTS}

Gene I. Rochlin and Associates

\section{Journals and books}

1. G. I. Rochlin anö P. K. Hensma, Inexpensive Model of a Josephson Weak Link, Am. J. Phys. 41, 878 (1973) (LBL-1185).

2. F. Auracher, P. L. Richards, and G. I. Rochlin, Observability of QuasiparticlePair Interference Current in Superconducting Heak Links, Phys. Rev. B 1, (1973) (LBL-1197 Rev.). 


\section{Papers presented}

1. G. I. Rochlin, P. L. Richards and F. Auracher, "Quasiparticle Interference Current in Superconducting Weak Links," APS meeting, Now York, Jan. 1973.

2. D. E. McBride, G. I. Rochlin, and

P. K. Hansma, "A New Method for Determining

Tumnel Junction Parameters," APS meeting,

San Diego, March 1973.

LBL reports

1. D. E. MeBride, G. I. Rochlin, and

P. K. Hansma, Characterization of Metal-
Oxide Tumnel-Junction Barriers, LBL-1854, June 1973 submitted to J. Appl. Phys.

2. G. I. Rochlin, on Cnmecting the Microscopic and Macroscopic Theories of Type II Superconductivity, LBL-2202, Alu. 1973; swomitted to Am. J. Phys.

3. Dumcan E. McBride, Charucterization of Metal-Oxide Tumneling Barriers (Ph. D. thesis), LBL-1855, Sept. 1973.

4. M. D. Jack, Properties of Tumel Juctions with Fluorocarbon Dielectric Barriers, LBL-1805, Nov. 1973. 
John Clarke, Frinoipal Investigator

\section{1/f NOISE IN DIFFUSIVE SYSTESS}

John Clarke and Richard F. Voss

Noise limits the accuracy of most measurements. Understanding the physical mechanism of the noise and being able to give a quantitative estimate of its frequency spectrum is of primary inportance in optimizing sensitive experiments. Although Johnson noise and shot noise are most frequently quoted as the linits to electrical sensitivity, most low-frequency experiments are, in fact, limited by $1 / f$ noise, whose identifying characteristic is a spectrm varying as $1 / f y$ where $0.7 \leqq Y \leqq 1.5$ over many decades.

By considering Brownian motion of particles in one, two, and three dimensions, we have been able to show theoretically that fluctuations in the number of particles in a given subvolume of a large reservoir have such a 1/f-like spectrom. Some theoretical calculations as well as sample spectra fran a computer simulation are shown in Fig. 1. The theory applies to any quantity obeying a diffusion equation. It implies, for example, that the temperature of an object has 1/f-like fluctuations. Consequent $1 y$, there are a large muber of mechanisms through which $1 / f$ noise may influence most systems. The diffusion mechanism also implies a characteristic length, $\lambda(f) \equiv(D / \pi f)^{1 / 2}$, wich is a measure of the average spatial extent of a fluctuation at frequency $f$. Iow-frequency fluctuations are correlated over large volumes.

We have coserved these effects by shining a bean of light through a colloidal suspension. The frequency spectrom of the fluctuations in the intensity of the transmitted light is shown in Fig. 2 for two different samples. He have also been able to show that $1 / f$ noise in metal films is caused by tenperature fluctuations modulating a temperature-dependent resistivity. The amplitude of the noise in the films is in excellent agreement with our theory. We have alsc demonstrated experimentally that $1 / f$ noise in thin films is correlated over distances on the order of the frequency-dependent correlation length, $\lambda(f)$.

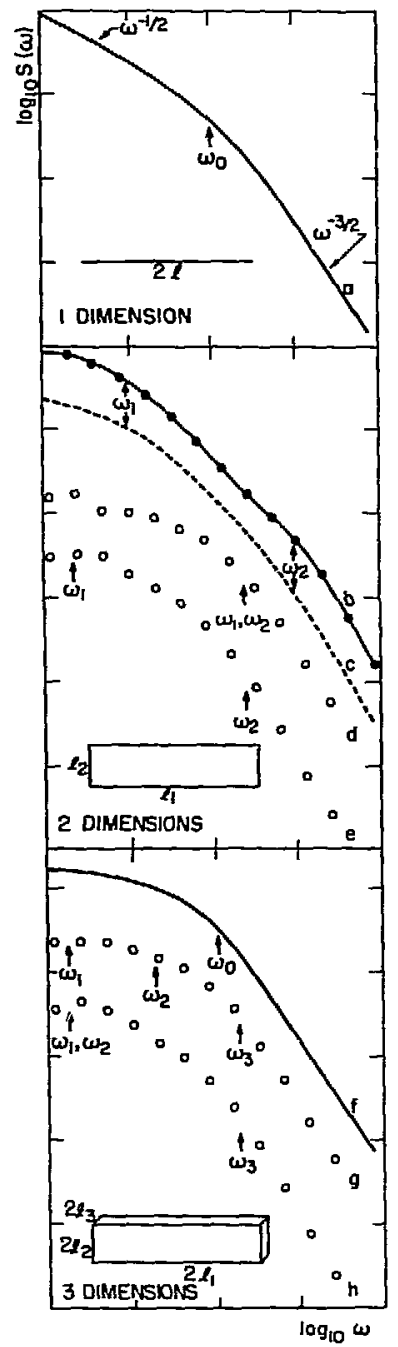

Fig. 1. Fluctuation spectra: (a), (b), (c), and (f) are calculations, while (d), (e), (g) and (h) are computer simulations. Each scale division represents one decade.

(XBL 7312-6764) 


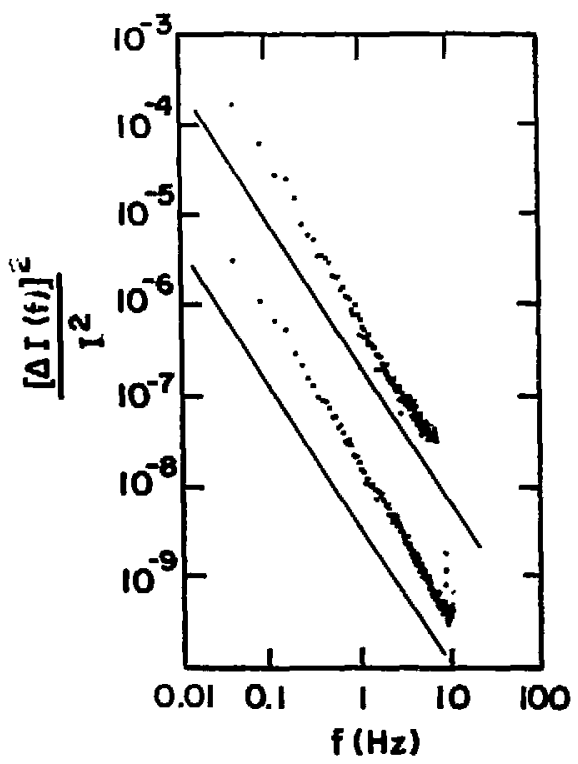

Fig. 2. Fluctuation spectra of light transmitted through tw different colloidal suspensions. The calculated spectra are atso shown.

(XBL 7312-6763)

\section{1/£ NOISE IN CRITICAL SYSTES}

\section{Gilbert Hawkins and John Clarke}

Systems that are close to a critical point undergo large fluctuations in one or more of their thermodynamic properties. For example, the concentration flusituations in a binary mixture are large near the critical point because of the divergtice of the osmotic corpressibility at the second-order phase transition. We have constructed an apparatus to measure the frequency spectrum of these fluctuations. A light beam is passed through a cell containing the mixture, and the spectrum of the fluctuations in the incensity of the transmitted beam is measured. Preliminary measurements indicate that the spectrum is 1/f-Iike. In addition, the amplitude of the noise is strougly temperature dependent. Both of these results are expected on theoretical grounds.

This systen is of interest because the 1/f noise can be measured in an equilibriun system, unlike electrical noise in a resistor. The equations governing the dynamics of fluctuations in equilibrium binary mixtures are well understook, so that the system can be analyzed in detaii theoretically. Furthenore, we expect to be able to deduce the behavior of tine longrange correlation length which characterizes the spatial extent of the concentration fluctuations.

\section{REILAXATION OF QLASIPARTICIE BRANCH IMBALANCE IN SUPERCONDUCTORS}

\section{John Clarke and James L. Paterson}

Under appropriate conditions, a nommal current can propagate in a superconductor. The flow of a normal current inplies an inbalance of the fiasiparticles above and below the Fenmi level. The characteristic time, IO, required for this imbalance to relax to equilibrium governs the dissipation generated by the normal current. Apart from the fumdamental interest in the problem, this imbalance is inportant in various applications; for excomple, the dissipation that occurs when a normal current is converted to a supercurrent at the interface of a normal metal and a siperconductor.

We have generated a branch imbalance by passing a current from a normal metal into a superconducting film via a tumel junction. The-imbalance creates a quasiparticle. voltage $v$ that is measured by means of a second junction grown on top of the superconductor, there

$$
V=I \tau_{Q} / 2 e^{2} \mathrm{~N}(0) g_{N S}(0)
$$

Here, $I$ is the injection current, $\Omega$ the volume of the superconductor, $N(0)$ the density of states at the Fermi surface (for one spin) in the superconductor, and gis $(0)$ the conductance of the second turnel jumction. Figure 1 shows $\zeta=(V / I) g_{N S}(0) \Omega$ versus reduced temperature for $\mathrm{Sn}$. For $\mathrm{Sn}: 3 \mathrm{wt} . \mathrm{s}$ In, only phonon processes are important. The solid curve is a fit using

$$
\tau_{Q}^{p h}=1.0 \times 10^{-10} \Delta(0) / \Delta(T) \sec :
$$

In the clean samples, elastic processes also contribute. The dashed lines are a fit to both inelastic and elastic scattering, with

$$
{ }_{Q}{ }_{Q}^{e l}=\frac{\tau_{1}}{\left(a^{2}\right\}_{0}}\left[1+\left(\frac{h}{2 \tau_{1} \Lambda}\right)^{2}\right] \frac{k_{B} T^{*}}{\Delta}\left[1+\frac{k_{B} T^{*}}{\Delta}\right] \text {. }
$$


In this equation, $\tau_{1}$ is the elastic scattering time, $\left\{a^{2},\right\}_{0}$ the mean square gap anisotropy, and $T^{\text {t }}$ the mean quasiparticle tenperature. At low temperatures, we obtain a good fit with $\mathrm{T}^{*}=2 \mathrm{~T}_{\mathrm{c}}$.

Preliminary results have been obtained for $\mathrm{Pb}$. It appears that recombination may be the major process contribution to branch relaxation in this metal. Further investigation of this result is planned.

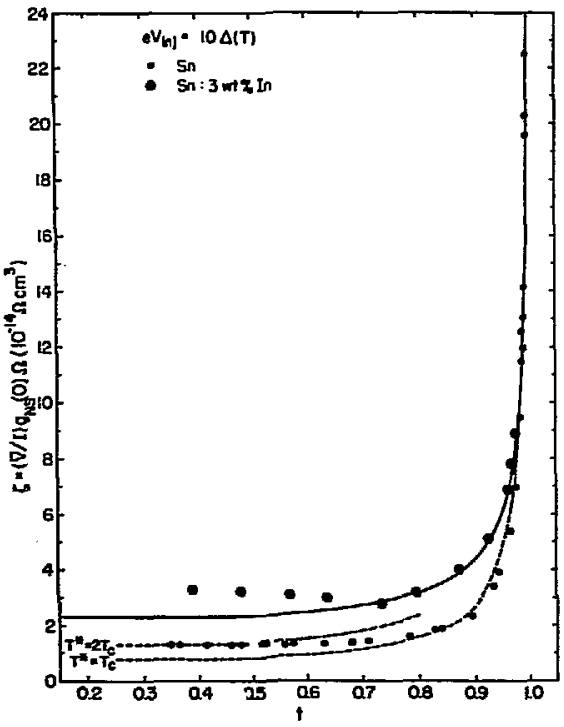

Fig. 1. $\zeta$ versus $t=T / T_{C}$ for $S n$. Solid curve is for phonon processes only. Dashed curves include elastic processes which are irmortant in clean Sn.

(XBL 736-6355)

4. ELECTRON FOCUSING IN BISMIUIH: A NEW METHOD OF MFASIRTNG THE DIAMETER OF A FERMI SUIRFACE

\section{John Clarke and Louis Schwartzkopf}

There are a nusiber of techniques available for measuring various properties of the Fermi sufface of a metal. However, none of these gives a very accurate determination of the diameter of the Ferni surface, except in certain special cases. We have developed a new method for measuring the diameter of any Fermi surface, using electron focasing, and applied it to bismuth.
In Fig. 2 , we sumparize ${ }^{\top} \mathrm{O}, \mathrm{T}_{R}$ (the recombination time) and $t\left(T_{c}\right)^{\prime}$ (the time for injected quasiparticles to cool to $T_{C}$ ) for Sn and $\mathrm{Pb}$.

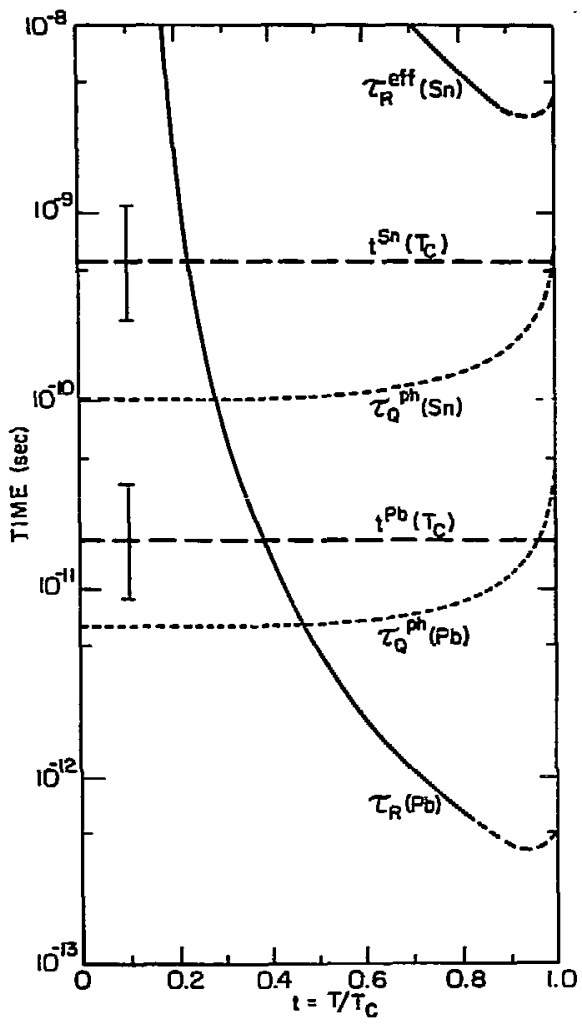

Fig. 2. $\tau_{Q}$, $T_{R}$, and $t\left(T_{c}\right)$ for $S_{n}$ and $P b$.

(XBL 7311-5591)

Tho interlocking superconducting cambs are evaporated onto the surface of the Crystal [Fig. 1(a)]. The resistance $\mathrm{R}(\mathrm{H})$ between the conbs at liquid helium temperatures is measured as a function of a magnetic field parallel to the teeth of the combs. There is a resistance anomaly [Fig. 1(b)] whenever electrons are focused between teeth of different combs or of the same combs.

Single crystals were grown from 99.999+ 
(a)
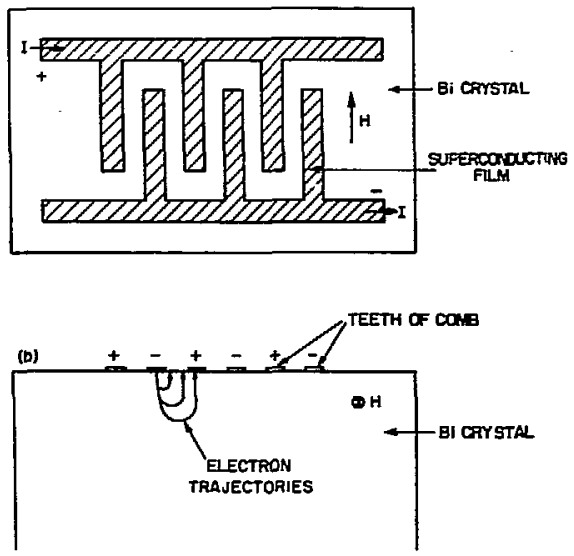

Fig. 1. Comb structure: (a) plan view; (b) side view, showing orbits.

(XBL 738-1727)

prre bismerth, and spark-cut to the desired orientations. The surface was chemically polished, and any contamination removed in a glow discharge. The tin comb : were evaporated onto the cleaned surface.

Figure 2 shows the variation of $\mathrm{R}(\mathrm{H})$ with magnetic field for the binary plare. Measurements of $R(H)$ have been obtained for the other principal crystal orientations. Some of the hole orbits have also been observed.

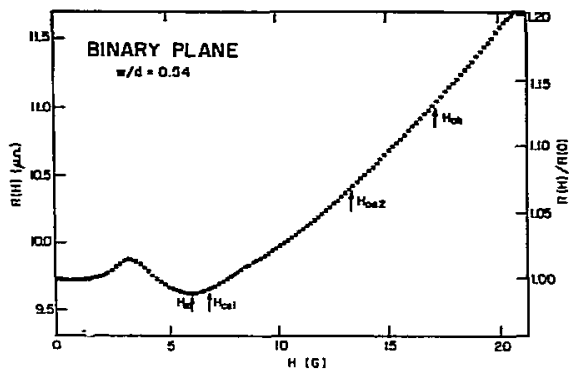

Fig. 2. $R(H)$ versus $H$ for the binary plane of bismuth.

(XBL 736-6254)
At present, our overall accuracy is about $\pm 4 \%$. To within the various experimental errors, our values of the measured diameters are in good agreement with those in the literature. However, we feel that our accuracy could be readily inproved to much better than 1\%; this method would then be the most accurate available for measuring dianeters.

5. DETERMINATION OF BCS PARAMETER N(O)V IN "NORMAL" METALS

John Clarke and Michael L. Rappaport

There are a large number of metals that do not become superconducting at the lowest achievable temperature ( $\leqslant 1$ mK). However, it is of interest to have estimates of the transition temperatures $T_{c}$ of such metals, even though these temperatures are not presently attainable. These estimates can then be compared with theoretical predictions in order to test the reliability of the theory. Our experiment measures the parameter N(0)V $[N(O)$ is the density of states at the Fermi surface for are spin, and $V$ is the electronelectron interaction parameter], which is related to the Debye termerature $\theta_{D}$ and $T_{C}$ by the relation $T_{c}=1.14 \theta_{D} \exp [-1 / N(0) V]$.

The experiment involves the measuremant of the resistance of SNS sandwiches down to very low temperatures in a dilution refrigerator. $S$ is a superconductor, usually $P B$ or $\mathrm{Sn}$, and $\mathrm{N}$ is the metal being studied. From the reduction in resistance as the temperature is lowered, ome can dedice a value of $N(0) V$ in the nomal metal. So far, we have obtained data in which the normal metal is Ir, $\mathrm{Rh}, \mathrm{Cu}$, and $\mathrm{Ag}$.

The transition temperature of $\mathrm{Mg}$ is of particular interest because theoretical predictions place it close to $1 \mathrm{mK}$. Because Mg oxidizes very rapidly, we have designed and built a new high-vacum sputterevaporation systen to prepare samples. Sputter-etching is used to remove surface contamination from a rolled foil, and then $\mathrm{Pb}$ or $\mathrm{Sn}$ is evaporated onto the $\mathrm{Mg}$ without venting the chamber to air. We hope to obtain data on $\mathrm{Mg}$ in the near future.

Theoretical calculations of the tenperature depencence of the resistance of SNSS sandwiches are under way in collaboration with Proressor Cohen's group. 
6. SUPERCONDUCTTNG TIRNEL JLNCTYON BOLOMETERS

\section{John Clarke and Gary I. Hoffer}

There is considerable need for improved boloneters in the submillimeter region. He have developed a new type of bolometer that consists of a superconductor-normal-metal (SNS) Josephson junction evaporated onto a sapphire substrate. The sapphire is suspended on lead-coated nylon treads inside a vacum can (Fig. 1). The critical current, $I_{c}$, of the junction is a rapid function of temperatire. Measurement of $I_{c}$ with a SQUID enables small changes in the temperature of the substrate to be detected. Our best bolometer has an electrical NEP $\approx 5 \times 10^{-15} \mathrm{~W} / \sqrt{\mathrm{Hz}}$, and a detectivity $\mathrm{D}^{*} \mathrm{10}^{16} \mathrm{~cm} \sqrt{\mathrm{Hz}} / \mathrm{W}$. The detectivity is a factor of 30 larger than that of the best bolometers currently avai1able. The reverse side of the sappinire substrate is coated with a thin film of bismuth to absorb the far infrared radiation.

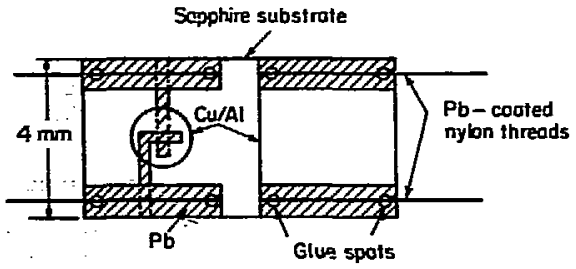

Fig. 1. Configuration of SNS bolameter.

(XBL 7112-4927A)

We have also investigated the use at a superconductor-insulator-normal metal (SIN) quasiparticle tumel junction as a bolometer elenent. The resistance of this junction at voltages below the sperconducting energy gap is a rapid finction of temperature. The sensitivity of this junction should be comparable to that of the SNS junction. However, we have found that onily $\mathrm{Al}-\mathrm{AlO}_{\mathrm{x}}-\mathrm{Pb}$ or Al-AlO $-\mathrm{Sn}$ junctions are of sufficiently high quality to be usable as bolometers. Infortumately, these junctions deteriorate rapidiy when stored at room temperature. Juctions with better storage properties, such as $\mathrm{Nb}-\mathrm{NbO}_{\mathrm{x}}-\mathrm{Cu}$ have leakage currents that make them unusable as bolometer elements. We are therefore concentrating our effort on the SNS bolometer.

\section{STABLE SENSITIVE SUPERCONDUCITNG DEVICES}

John Clarke, Thomas Y. Hsiang, and Myron Fromer

For a number of years, we have used ultrasensitive superconducting devices, SQUIDS, to measure tiny magnetic fields and voltages. He are now working to develop a highly reliable and stable device that can be used in on enviromment outside the laboratory.

He have designed, built, and tested a toroidal de SQUID and its associated electronics. The SQUID has a resolution of $10^{-5}$ flux quanta/ $\sqrt{\mathrm{Hz}}$ at $100 \mathrm{~Hz}$ : this figure represents an order-of-magnitude improvement over the sensitivity of other SQUIDS. The noise spectrums is $1 / f$. The SqUID utilizes point contacts as Josephson jumctions.

He are now developing a thin-film SQUID that we hope will be extremely stable and reliable. The device is made of $\mathrm{Nb}-\mathrm{NbO}-\mathrm{Pb}$ tumel junctions. he have constructed a stainless steel ultra-high vacunm system in which we have mounted a Sputter Gur. The system has been used successfully to fabricate tumel junctions that are of high quality, and that also appear to be very stable with respect to themal cycling and room temperature storage. We hope soon to be able to test a tumel junction Squb. One advantage of turnel junctions is that their critical current is independent of temperature below $4.2^{\circ} \mathrm{K}$. We believe that this will make the devices relatively free from long-term drift, an important consideration in geophysical measurements, and other applications requiring long-term stability.

\section{RESEAROH PLANS FOR CAIENDAR YEAR 1974}

John Clarke

He have developed a theory of $1 / f$ noise that we believe is applicable to a large variety of systems. He plan to considerably expand our work on this project both theoretically and experimentally. The measurements of I/f noise in metal films will be extended to semiconducting films. In tlis way we hope to be able to understand the mechanisms of $1 / \mathrm{f}$ noise in semiconductors, and to apply these ideas to semiconducting devices, such as diodes and transitors. The performance of these devices is severely limited by $1 / f$ noise at low frequencies.

A program has been started to stuoiy l/f noise at low temperatures. We will measure 
the noise at the supercondurting transition of thi? films to test the validity of our theory at low temperatures. These results should enable us to predict the ultinate performance of superconducting bolometers. We plan also to examine the noise in semiconducting bolometers in order to determine their ultimate resolution. The Iow-frequency noise of Josephson jumctions will be measured, and an attenpt made to fit the results to the theory. The lowfrequency noise and long-term drift of these devices is of great importance in certain applications, for example, geophysical measurements. We hope to be able to determine which types of junction have the best long-term stability.

The $1 / f$ spectra of various critical fluids will be measured. We hope to be able to incorporate these fluctuations into our theory. It should also be possible to obtain information about the correlation lengths at or near the critical point from these results.

We now have a good understanding of pairquasiparticle non-equilibriun processes in superconductors. He propose to study the possibility of using these processes in devices.

The measurements of the resistances of superconducting-normal metal superconducting sandwiches at very low temperatures will be continued. In particular, we plan to use $\mathrm{Mg}$ as the normal metal. These experiments should enable us to estimate the values of $\mathrm{N}(0) \mathrm{V}$ and hence of the superconducting transition tenmerature in various metals that are not known suerconductors.

We hope to improve the noise equivalent power of the Josephson junction bolometer to about $10^{-15} \mathrm{~W} / \sqrt{\mathrm{Hz}}$. The response of the bolometer in the millimeter and submillimeter range will be determined. The boloneter - 11 be developed into a hardened device for astrophysical and other applications.

We will continue to develop hights iliable and stable Josephson junctions for use in SQULDS. We hope to be able to use these STUIDS for various measurements outside the laboratory, for example, the measurement of noise and drift in the Earth's magnetic field.
9. 1973 PUBLICATIONS AND REPORTS

John Clarke and Associates

Journats

1. J. Ciarke, low-Frequency Applications of Superconducting Quantum Interference Devices, Proc. IEEE 61, 8 (1973) (LBL-1312).

2. J. Clarke, La Cryoelectronique, La Recherche, No. 38, 845 (1973) (LBL-1810).

3. R. Dalven, Electron and Hale Effective Masses in Lead Polonide (PbP), J. Phys. C6, 671 (1973).

4. R. Dalven, Electronic Structure of PbS, PoSe, and PbTe, in Solid State Physies, Vol. 28, edited by F. Seitz, D. Turntuill, and H. Ghrenrach (Acadenic Press, liew York, 1973), pp. 175-224.

5. R. Dalven, Empirical Relation betreen Energy Gap and Lattice Constant in Cubic Stuicontuctors, Phys. Rev. B, , 6033 (1973) (LBL-2218).

\section{Conferences}

1. J. Clarke and L. Sctivartzkopf, Electron Focusing in Bi: A New Method of Measuring the Caliper of a Fermi Surfece, San Diego Neeting of the APS, Narch 19-22, 1973.

2. J. Clarke, G. I, Hoffer, and P. L. Richards, Superconducting Tumnel Junction Bolometers, Intemational Conference on Detection and Emission of Electromagnetic Radiations with Josephson Junctions, PerrosGuinec, France, Sept. 3-5, 1973 (LBL-2222).

3. R. Dalven, Recent Studies of Lead Folonide (PbPo), Proc. Int. Conf. on Semimetals and Narrow Gap Seniconductors, Nice-Cardiff, 1973 (to be published) (I.BL-2524).

\section{IBL reports}

1. John Claske and James L. Paterson, Measurements of the Relaxation of Quasiparticle Branch Imbaiance in Superconductors, LBL-2289, Nov. 1973.

2. J. Clarke, Josephson Junction Detectors, LBL-2283, Oct. 1973.

3. R. Dalven, Proposed Search for Superconductivity in the Semiconductor Site (to be published) (IBL-2525). 
4. R. Dalven, Comments on the Probabla Electronic Structure of the Group II Polonides (to be published) (LBL-2526).

5. R. Dalven, Proposed Measurement of the kight Shift in Lead Polonide (PbPo), (to be pub1ished) (LBL-2527).

6. James L. Paterson, Pair-Quasiprarticle Potential Differences in Current-carrying Superconductors (Ph.D. thesis), LBL-1840, July 1973.
7. Richard F. Voss and John Clarke, Fluctuation Spectra for Systems Deying a Diffusion Equation, LBL-2534, Dec. 1973.

8. John Clarke and Richard F. Voss, $1 / f$ Noise from the Diffusion of Particles or Heat, LBL-2536, Dec. 1973. 


\section{EXPERIMENTAL SOLID STATE PHYSICS AND QUANTUM ELECTRONICS}

\section{Ron Shen, Principal Investigator}

1. TUNABLE FAR INFRARED GENERATION BY OPTICAL MIXING

James R. Morris, Patrick K. H. Yang,

Paul L. Richards, and Y. Ron Shen

The generation of tunable far infrared (FIR) by optical mixing in nonlinear crystals has attracted much attention recently, 1-7 In this paper we report the generation of continupusly tumable radiation from 20 to $190 \mathrm{~cm}^{-1}$ using a dual-frequency dye laser system. We observed FIR radiation in the 20 to $160 \mathrm{~cm}^{-1}$ frequency range with varions phase matching schemes in $\mathrm{LiNbO}_{3}$ : forward collinear (FCPM), backward collinear (BCPM) , 3,4 and nCn-collinear (NCPM). We have also investigated FCPM in $\mathrm{ZnO}, \mathrm{nSS}, \mathrm{CdS}$, and CdSe at selected frequencies as high as, 70 $\sigma^{-1}$.

Figure 1 shows the basic experimental arrangement for FIR generation with FCPM and BCPM. This single dye cell system was rather simple and very convenient to use. The aIso used two separate dye lasers ${ }^{8}$ purmed with a single ruby beam, especially for the NCPN9 case. The single dye cell system was cormosed of a single dye cell pumped nearly longitudinally by a ruby laser, a GlanThomson prism 10 (GIP) to divide the cavity into two independent anis with orthogmally polarized beams, two echelle gratings to twe independently the frequencies of the two beams, and a single output mirror to insure spatial overlap of the two beams. Temporal overlap of the beams was obtained by equalizing the net gain in the two anms of the cavity. To achieve this, the pump beam was circulariy polarized or linearly polarized at $45^{\circ}$ with

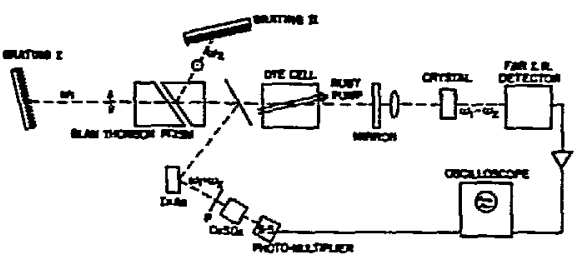

Fig. 1. One of the far infrared generation setups. The wavelength of the two beams can be independently varied from 8100 to 8400 A using a single dye cell.

(XBL 735-6007) respect to the axes of the polarizer. Fine turing of the relative gain of the two arms was obtained with a microscope slide in the cavity. With a 30-kw, 30-nsec ruby laser bean the dye laser (UITC iodide in IMSO) output had a peak power of $600 \mathrm{kH}$ and its two wavelengths could be tumed independently from 8100 to $8400 \mathrm{~A}$. The linear polarizations were pure to within 108.

The FIR output from the nonlinear crystal was detected by an n-type InSb (Putley) detector at $1.4^{\circ} \mathrm{K}$ for the 20-95 $\mathrm{cm}^{-1}$ range and a Ge:Ga detector at $4.2^{\circ} \mathrm{K}$ for the $95-200 \mathrm{~cm}^{-1}$ range. Our results on FCPM and NCPM in $\mathrm{LiNbO}_{3}$ are shown in Fig. 2. The data agree well with the solid theoretical curves.

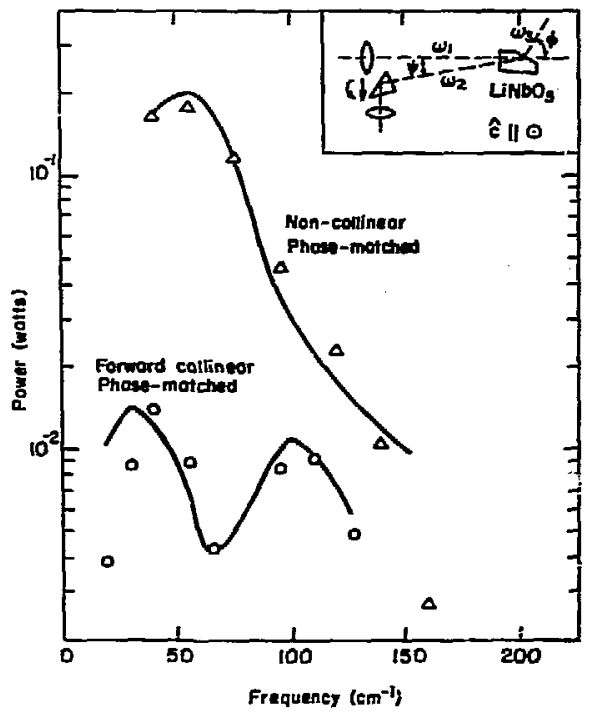

Fig. 2. Far-infrared porer generated vs. frequency for two phase-matching conditions. The far infrared power is nomalized by a sum frequency power. The solid curves are the theoretical calculations based on data of the far infrared absorption and the Ran cross section in $\mathrm{LiNbO}_{3}$. The insert shows the experimental geometry for non-collinear phase-matching which was achieved by a coupled translation and rotation of the prism.

(XBL 738-1787) 
We have also verified that the wral. frequency dye laser system, shown in Fig. I, can be operated with a flashiauly-pumed Fhodamine 6G dye laser, although the dye laser output of our system was insufficient to generate detectable FIR in the mixing experiment. However, a flashlamp-pumped dye laser system of $100 \mathrm{kH}$ peak power and 1 usec pulsewidth would yield the same FIR signal for each pulse as our laser-punged system with $600 \mathrm{~kW}$ peak power and, 30 nsec pulsewidth. Because a repetition rate greater than I pulse/sec is possible with such a dye laser, the dual-frequency single dye cell scheme described here should make a very useful source for FIR spectroscopy. Compared with the other FIR generation experiments using $\mathrm{CO}_{2}$ lasers,, $5-7$ this system has the advantages of a large continuously tumable FIR range and the use of room-temperature mixing crystals.

2. OPTICAL-FIEID INUUCED ORDERING IN THE ISOTROPIC PHASE OF A NIMATIC L,IQUID CRYSTAL

George K. L. Wong and Y. Ron Shen

The linear optical properties of liquid crystalline materials have been the subject of extensive investigation recently. The nonlinear optical properties of the same materials, however, have not yet received much attention. In this paper, we report the first measurements on the optical-fieldinduced refractive index for a nematic sibstance in its isotropic phase. Ordering in the molecular orientation induced by the optical field is essentially responsible for this nonlinear refractive index. Fieldinduced ordering in the isotropic phase of a nenatic system has been previously observed with an applied de electric or magnetic field, but the same effect obtained with an optical field has never been reported before. Using a Q-switched laser pulse, we have also been able to measure directly the relaxation time for the variation of the orientational order. The transient response of the order parameter is governed by the equation

$$
\begin{aligned}
& v a Q_{\alpha \beta} / \partial t+A_{\alpha \beta}=f_{\alpha \beta}(t), \\
& f_{\alpha \beta}=\Delta_{X}\left(3 E_{\alpha} * E_{B}-|E|^{2} \delta_{\alpha \beta}\right) / 9,
\end{aligned}
$$

where $\checkmark$ is a viscosity coefficient. For an input laser pulse with a Gaussian pulse shape,

$$
f_{c B}(t)=C_{a B} \exp \left(-b^{2} t^{2}\right) \text {. }
$$

we have

$$
\begin{aligned}
Q_{a \beta}(t)= & \left(C_{\alpha \beta} / b v\right) \exp (-\tau / \tau) \exp \left(1 / 4 b^{2} \tau^{2}\right) \\
& \times\left\{1+\operatorname{erf}\left[b t-[2 b \tau)^{-1}\right]\right\}
\end{aligned}
$$

which varies as $\exp (-t / \tau)$ when bt $\gg 1$.

We can find $Q_{\alpha \beta}(t)$ by measuring the fieldinduced $\Delta_{\alpha_{\alpha B}}(t)$. Results were obtained for MBBA at various temperatures in the isotropic phase. In every case, we obtained a perfect exponential tail for $Q_{a x}(t)$ from which we caloulated the relaxation time $\tau$. In Fig. 1 , we prosent the experimental data $\tau$ as a function of $T$. They agree very well with

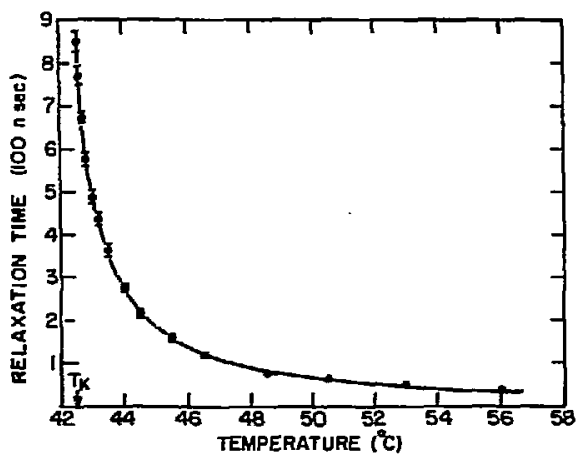

Fig. 1. Relaxation time $\tau$ of the order parameter as a function of temperature. The solid curve is the theoretical curve obtained for $T^{-v} / \mathrm{a}\left(\mathrm{T}-\mathrm{T}^{*}\right)$ with $\mathrm{T}^{\star}=314.7^{\circ} \mathrm{K}$ and $v=v_{0} \exp \left(2800^{\circ} \mathrm{X} / \mathrm{T}\right)$. The dots are the experimental data points.

(XBL 7212-7358)

the theoretical expression $T=v / a\left(T-T^{*}\right)$ of de Gemes 1 if we assume $v=v_{0} \exp (W / T)$ with $\mathrm{W}=2800^{\circ} \mathrm{K}$ as suggested by Stinson and Litster ${ }^{2}$ and $T^{*}=314.7^{\circ} \mathrm{K}$. The clearing temperature of our material is $\mathrm{T}_{\mathrm{K}}=315.5^{\circ} \mathrm{K}$. The relaxation time varies from -40 nsec at temperatures far above the phase transition to $>800$ nsec near the transition. These results are in good agreenent with those obtained from 1 ight scattering by Stinson and litster. ${ }^{2}$ However, we believe our measurements are more straightforward and accurate.

The optical Rerr constant of MBBA is unusually large. In comparison with $\mathrm{CS}_{2}$, the found $\mathrm{B}(\mathrm{MBRA}) / \mathrm{B}\left(\mathrm{CS}_{2}\right)=10$ at $326^{\circ} \mathrm{K}$. Because of the large nullinearity, a liquid 
crystalline material can have potential applications in nonlinear optical devices.

1. P. G. de Gennes, Phys. Lett. 30A, 454 (1969), and Mol. Cryst. Liquid Cryst. 12, 193 (1971).

2. T. W. Stinson, III, and J. D. Litster, Phys. Rev. Lett. 25, 503 (1970).

3. EXPERIMENTAL STUDY OF IRANSIENT SELFFoOUSING

George K. L. Wong and Y. Ron Shen

The liquid crystalline material MBBA in its isotropic phase has a large field-induced refractive index due to molecular reorientation. The orientational effect has a relaxation time which varies with temperature from $\sim 40$ to $>800$ nsec. The system is therefore ideal for study of the transient self-focusing effect using Q-switched laser pulses which have pulsewidths in the range of $10 \mathrm{nsec}$. This is a problem which has been attracting a great deal of attention of research workers in nonlinear optics. There already exist a number of theoretical calculations on the subject. I However, no quantitative experimental results were available, since in ordinary liquids the orientational relaxation time is of the order of psec and it is difficult to obtain quantitative information from picosecond pulse measurements.

We have observed transient self-focusing in NBBA in the isotropic phase. We have studied the dynamics of the effect as a function of tenperature and input power. The results are in semi-quantitatiye agreenent with the theoretical calculations. In this case, the phase modulation of light is relatively slow, and hence no appreciable spectral broadening can be detected. There is evidence that stimulated Raman and Brillouin scattering is initiated by selffocusing of light in the medium, but stimulated Raman and Brillouin scattering is not the mechanism to limit the diameter of the selffocused beam.

1. See, for example, F. Shimizu, IBM J. Res. and Develor. 17, 286 (1973).

\section{LUMINESCENCE AT HIGH EXCITON DENSITIES IN CdSe}

Eric Hanson, Arnold J. Scinmidt, and Y. Ron Shen

High excitation of semiconductors has recently attracted much attention and has been studied in a large nunber of materials. We have investigated the photoluminescence spectrom of case, on which a number of partially conflicting reports exist. $1-3$

The excitation source used was a flashlam purmed dye laser, which was developed in ow group. A peak intensity of $2 \mathrm{MW} / \mathrm{cm}^{2}$ in a 1 usec pulse could be obtained at the sample. All measurements were done at $4: 2$ or $1.8^{\circ} \mathrm{K}$. The excitation frequency could be varied between 5800 and $6100 \AA$. The 1uminescence spectra were recorded via a double monochromator, a photomultiplier, and an oscilloscope. In addition to the well-known luminescence spectrum at $10 \mathrm{w}$ excitation levels, a broad intense new luminescence band appears with increased excitation power. Its intensity grows superlinearly with excitation and its position is shifted to longer wavelength correspondingly. The shift grows with power and is $\sim 40 \mathrm{~A}$ at $1 \mathrm{MN} / \mathrm{cm}$, which is close to the damage threshold. The band is scarcely structural and has a width of $\sim 20 \mathrm{~A}$, All parts of the luminescence spectrum show the same time dependence as the excitation pulse.

Very close to the damage threshold ( $-2 \mathrm{MV} / \mathrm{cm}^{2}$ ) a narrow ( $\mathrm{g} 0$ miec) inherent spike gzows out of the othenwise smooth signal. Its position varies randomly from shot to shot, and its origin is not yet understood.

We also attempted to measure the decay time of the Iuminescence in various parts of the spectrum. For these investigations, the laser pulse was curtailed by a Pöckels cell with a fast risetine. The fall time of the pulse was better than 5 nsec. Some experiments were performed with a nsec excltation pulse. This pulse was obtained by switching a pöckels cell between two crossed polarizers from 0 to $180^{\circ}$ phase shift with a fast pulse and thereby slicing a 3-nsec pulse out of the center of the originally 1-usec-1ong laser pulse. All parts of the luminescence spectrun, which according to various models are due to exciton-exciton collision, exciton molecules, and/or exciton molecule collisions, have decay times smaller than 5 nsec. 
1. J. Bille, H. Liebing, and P. Mengel, Phys. Stat. Sol. 53, 353' (1972).

2. H. Saito, S. Shinoga, and E. Hanamrra, Solid State Commuications 12, 227 (1973):

3. H. Kuroda, S. Shionoya, and E. Hanamira, Solid State Commenications 12, 533 (1973).

\section{DISPERSION OF NONLINEAR OPTICAL SUSCEPTIBILITIES $\chi^{(2)}(2 \omega)$ OF III-V SEMCONDUCTORS}

Don Bethune, Arnold J. Schmidt, and Y. Ron Shen

Nonlinear optical susceptibilities have always been the most important subject in nonlinear optics. They are essential for the design of modern optical devices. Most of the theories and experiments on nonlinear susceptibilities deal with frequencies in the transparent region. Only a few of them cover a narrow region in the abscrption band. No work has yet been reported on nonlinear susceptibilities over a wide frequency range.

He are presently making measurements or the nonlinear optical susceptibilities $x^{(2)}(20)$ of Gas, InAs, and InSs at 80 mo $300^{\circ} \mathrm{K}$ using a flash-pumed dye laser. The findamental frequency varies fram 1.8 to $2.8 \mathrm{eV}$. Our results therefore complenent those earlier results of Parsons and Changl using a ruby-1aser-pumped dye laser. In this region, either $\omega$ or $2 \omega$ appear in resonance with a muber of known critical points There is also possible enhancement of $x^{[2]}(2 \omega)$ due to similtameous resonances of $\psi$ and $2 u$ with some critical points. We shall compare our experimental results with the theoretical calculations which are being carried out in cooperation with Prof. C. $Y$. Fong of U. C. Davis, using the pseudopotential method with the available band structures of these ccupounds.

I. F. G. Parsons and R. K. Chang, Optics Colm. ‥ 173 (7971).

\section{RESONANT RAMAN SCATTERING IN ClizO}

Peter Y. Yu, Yves Petroff, and Y. Ron Shen

Resonant Rantor scattering (RRS) close to free or bound excitons has been the subject of a number of reports, but the same effect involving a "fortidden" exciton has received little attention. We have found strong resonant enhancement in the $220-\mathrm{cm}^{-1}$ Raman. mode of $\mathrm{Cu}_{2} \mathrm{O}$ at the $\mathrm{F}_{12}$-phonon-assisted atsorption edge of the forbidden 1s yellow exciton. The results are shown in Fig. 1 together with a theoretical curve which yields good agreement with the experimental data. It shows that the $220-\mathrm{cm}^{-1}$ mode is due to scattering of two $\mathrm{I}_{12}$ phonons and the resonant enhancement is strongly affected by the exciton lifetime. The latter effect has never been considered or observed before in RRS.

We have also observed sharp resonant enhancersents in sore other two-phonon Raman III. Ies of $\mathrm{Cu}_{2} \mathrm{O}$ around the $\mathrm{n}=2$ to 6 peaks of the yellow exciton series. An example is

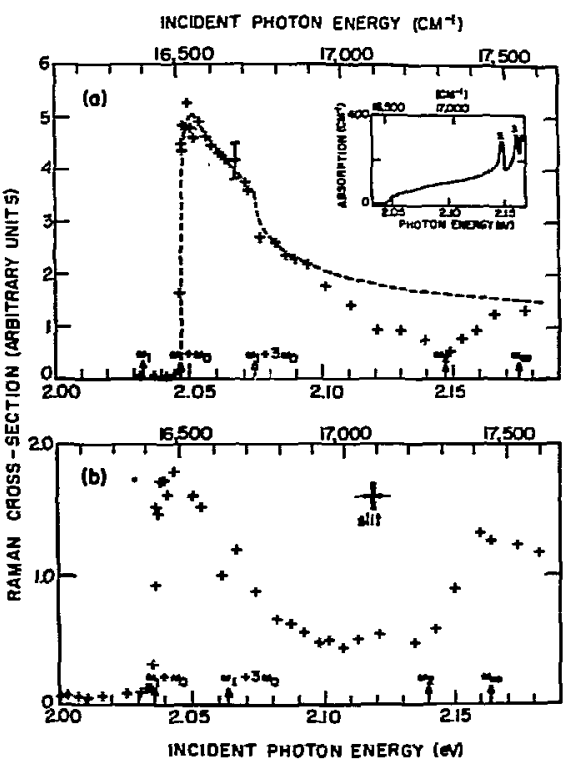

Fig. 1. Rarten cross section of the $220-\mathrm{cm}^{-1}$ line of $\mathrm{Cu}_{2} \mathrm{O}$ at two different temperatures: (a) $\sim 16^{\circ} \mathrm{K}$ and (o) $\sim 80^{\circ} \mathrm{K}$. [These temperatures represent those of the lattice obtained in (a) from the lineshape of the phononassisted free-exciton recombination spectra and in (b) from the position of the is yellow excitor in the Iuminescence.] Inset in (a), absorption spectra of $\mathrm{Cu}_{2} \mathrm{O}$ at $4.2^{\circ} \mathrm{K}$. Dashed curve in (a) is the theoretical curve.

(XBL 7210-7111) 
shown in Fig. 2. We are able to explain the results quentitatively by a theory which allows for multiple resonances in the scattering process. The calculated curve is seen to be in good agreement with the experimental data in Fig. 2.

We have also measured the resonant enhancement of five one-phonom Raman nodes of $\mathrm{Cu}_{2} \mathrm{O}$ in the vicinity of the blue and indigo excitons. The experimental results show qualitative agreement with the theoretical predictions.

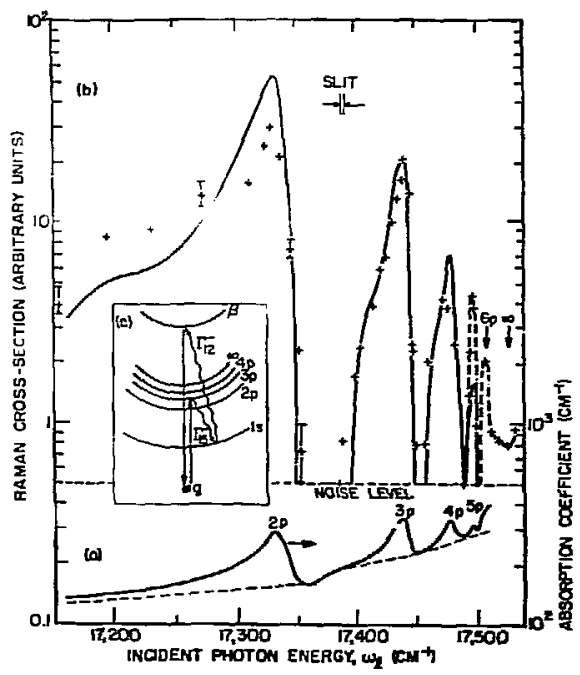

Fig. 2. (a) The absorption spectrim of $\mathrm{Cu}_{2} \mathrm{O}$ measured at $\sim 5^{\circ} \mathrm{K}$. The dotted curve represents the background absorption die to phonon-assisted transitigns. (b) The Raman cross section of the $\Gamma_{15} \overline{5}^{(2)}(\omega)+$ $\Gamma_{12}^{-}\left(770 \mathrm{~cm}^{-1}\right)$ mode of $\mathrm{Ch}_{2} \mathrm{O}$ obtained at $\sim 10^{\circ} \mathrm{K}$ as a function of incident photon energies. The solid curve is the theoretical anve. (c) A schematic diagram of the dominant resonant Ramen process at $\omega_{2} \sim \omega_{30}$. g stands for the ground state and $\beta$ an allowed exciton. (XRL 7311-5575)

7. ABSORPIION, PHOTOLUNINESCENCE, AND RESONANT RANAN SCATTERIIT IN BiI 3 --THE NOHEXISTENCE OF BIEIECTRONS IN BîI

Yves Petroff, Peter Y. Yu and Y. Ron Srien

Recently Gross and coworkers ${ }^{1}$ have reported observing a series of lines in the absorption and luminescence spectra of $\mathrm{BiI}_{3}$. The frequencies of these lines seem to obey the equation

$$
v_{n}=v_{\infty}+\frac{\mathrm{R}}{\mathrm{n}^{2}}=15,978+\frac{1995}{\mathrm{n}^{2}} \mathrm{~cm}^{-1} \cdots
$$

with $n=3,4,5,6$, and 7 . This series converges towards the $10 \mathrm{w}$-frequency side and therefore has the form of an "inverted" hydrogenic series. Gross et al. suggested that this series is due to the formation of "bielectrons" or "biholes" in the crystal. A bielectron (or bihole) is forred by two electrons (or holes) with a negative reduced mass and coupled to each other by Courlomb interaction to form a hydrogen-like boind state with energies given by an inverted hydrogenic series.

The question whether such bielectrons or biholes can exist or not is an interesting one. So far, there has been no direct experimental, evidence of their existence. Although the bielectron model can account for the energy of certain absorption and luminescence lines observed by Gross et al., there are difficulties in reconciling this model with other optical properties of $\mathrm{BiI}_{3}$. We have therefore repeated the experiments of Gross et al. and, in addition; we have measumed the luminescence excitation spectirim and the resonance Ranian scattering in BiI using a $C w$ tumable dye laser. The results on absorption and photoliminescence are shom in Fig. 1. We found that oir results

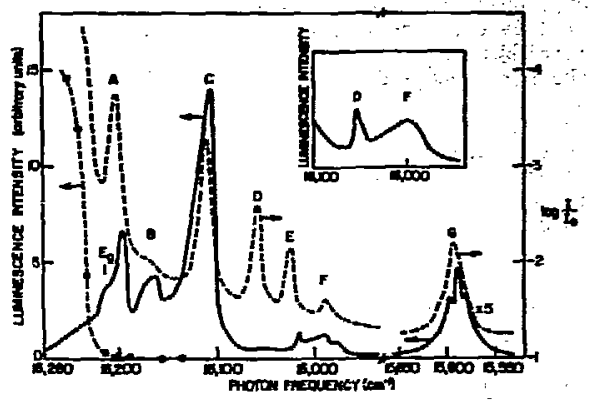

Fig. 1. Absorption, luminescence, and luminescence excitation spectra of $\mathrm{BiI}_{3}$. Solid line is the luminescence spectrin of sample $A$ at $4.2^{\circ} \mathrm{K}$. Datted line is the absorption spectrm of sample $A$ at $1.8^{\circ} \mathrm{K}$. The insert shows the luminescence of sample $C$ in the region where it differs from sanmle $A$. .... . .... . ... is the luminescence excitation spectrun for peak $C$ in sample $C$ at $4.2^{\circ} \mathrm{K}$. 
cammot be explained by the bielectron model. We are led to corclure that the line spectra observed by Gross et al. in $\mathrm{BiI}_{3}$ is probably due to inpurities or defects, as suggested by Timofeev and Vashcherko.

1. E. F. Gross, V. I. Perel, and R. I. Skekhmamet'ev, Zhetf Pis. Red. 13, 320 (1971);

[English Translation: JETP Lett. 13, 229 (1971] ; E. F: Gross, N. V. Starostin, and R. I. Skekhmamet'ev, Fizika Tverdogo Tela 13, 3393 (1971); [English Translation:

Soviet Physies--solid State 13, 2850 (1973)].

2. V. B. Timofeev and V. I. Vashchenko, Opt. Spektr. 24, 740 (1968); [English

Translation: Opt. and Spect. 24, 396 (1968)].

\section{RESONANT RAMAN SCATTERING IN CPYSTALLTINE \\ Se}

Peter Y. Yu, Nabil Amer, Yves Petroff, and Y. Ron Shen

The optical spectra of trigonal Se at $10 \mathrm{w}$ temperatures show a strong polarizationdependent excitanic peak in the region aramd $2 \mathrm{eV}, 1,2$. We have measured the resonant Raman scattering (RRS) in trigonal Se at liquid helium temperatures betreen 1.9 and $2.2 \mathrm{eV}$ using a ch tumable dye laser. The Raman active modes of symmetry $A_{1}\left(235 \mathrm{~cm}^{-1}\right)$ and $E\left(147 \mathrm{~cm}^{-1}\right)$ were found to exhibit differeit resonance enhancements. The $A_{1}$ mode showed broad structures near the absorption edge wille the Enode has a sharp resonance at $1.99 \mathrm{eV}$. The infrared active (Raman forbidden) $-A_{2}$-mode $\left(112 \mathrm{~cm}^{-1}\right)$ also showed sharp resonance due to the exciton labeled as a-exciton. 1" We are presently doing resoniant Riangm measurements on many other modes. They all seer to show interesting resonant enhancenent behavior. We shall try to cimpare the RRS lineshapes with existing theories.

$$
=--\rightarrow !
$$

1. S. Tutihasi and I. Chem, Phys. Rer. $158,623(1967)$.

2. W. Henrian, in The Physics of Selenium and Tellurium, edited by W. C. Cooper (Pergamon Press, Oxford, 1969).

\section{HSVEIENGIH-MOTULATION SPECTROSCOPY OF SOLIDS}

Stanley Kohn, Yves Petroff, and $Y$. Ron Shen

We have used our wavelength-modulation spectrometer to study a muber of solids. He discuss the various cases separately in the following.

\section{a. $\mathrm{PbS}, \mathrm{PbSe}$, and $\mathrm{PbTe}$}

The narrow-gap IV-VI semiconductors have been the object of extensive research over the past few years. Particular enphasis has been placed on st ties of band-edge properties and the fundamental gap, but few experiments have been done at higher energies. We have mersured the wavelength-modulated reflectance of PbTe, PbSe, and PbS from 1.5 to $6 \mathrm{eV}$ at temperatures ranging from 5 to $300^{\circ} \mathrm{K}$. We have also made empirical pseudopotential calculations of the band structures, the $\varepsilon_{2}(\omega)$ spectra, and $(1 / R) d R / d \omega$ for these compoumds and compared with the experimental results. They confin the critical-point assignment for the spectrom of PbTe made previously by cohen and Tsang. 1

1. M. L. Cohen and Y. W. Tsang, Proc. of the Conference on the Physics of Semimetals and Narrow Gap Semiconductors, 1970, edited by D. L. Carter and R. T. Bates (Pergamon Press, New York, 1971), p. 303.

b. GaSe, GaS, and Alloys

The interest in the properties of layer materials has grown considerably in the last fes years. In particular the optical properties of Gase have been widely investigated.

The first reflectivity spectra were reported by Bassani et a1. 1 and Gasanova et al.2. More recently electroreflectance, electroabsorption, and thermoreflectance measurements have been reported. There is sone disagreement about the position of the electronic transitions and also their assigment.

To help a new pseudopotential band structure calculation of GaSe, we have measured the wave-modulation spectra in the energy range 2 to $6 \mathrm{eV}$ at 300,77 , and $5^{\circ} \mathrm{K}$, of Gase, $\mathrm{GaS}, \mathrm{GaSe}_{0.8} \mathrm{~S}_{0.2}$, and $\mathrm{GaSe}_{0.2} \mathrm{~S}_{0.8}$ - A large number of new structures has been observed.

1. F. Bassani, D. L. Greenaway, and G. Fischer, in Proc. Intem. Conf, on the Physics of Semticonductors (1964), p. 51.

2. N. Gasanora and G. A. Akhundov, Opt. Spectry. 20 193 (1966). 
c. SbSI and $\mathrm{ZnCeP} 2$

We report here the sturty of the normal reflectivity spectra $R$ and the corresponding derivative spectra $(1 / R) d R / d E$ of SbSI between 2 and $6 \mathrm{eV}$. The spectra show very strong anisotropy. We have also tried to use the change of the wavelength modulation spectrum to monitor the change in the band structure of SbSI due to the phase transition at $292^{\circ} \mathrm{C}$ $\left(D_{2 h}{ }^{16}+C_{2 v}\right)^{9}$. Careful exmination of the spectra at various temperatures around $\mathrm{T}_{\mathrm{c}}$ shows no observable change. We report aIso the wavelength-modulated reflectivity spectra of the chalcopyrite crystal $\mathrm{ZnCeP}_{2}$ at $5^{\circ} \mathrm{K}$ between 2 and $6 \mathrm{eV}$, for $\mathrm{E} \mathrm{II} \mathrm{C}$ and E 1 C. The experimental results are compared with the theoretical band structure calculation by de Alvarez and Cohen. 1

1. C. de Alvarez and M. L. Cohen, Phys, Rev. Lett. 30, 979 (1973).

d. Effect of Carrier Concentration on Reflectivity Spectra of Ge and Ins5

We have measured at $5^{\circ} \mathrm{K}$ the derivative spectra $(1 / R) \mathrm{dR} / \mathrm{dE}$ around the $E_{1}$ and $E_{1}+\Delta_{1}$ structures, of $\mathrm{Ge}$ and InSb with different inpurity concentrations. In the more highly doped samples, the peaks are broadened and shifted slightly to lower frequencies. The change in the value of $(1 / \mathrm{RdR} / \mathrm{dE}$ is mich larger than recently predicted by Seraphin and Aspmes, based on the surface field effect. Different possibilities for the effect are discussed. Havelength modulation measurements on sanples with an applied surface electric field have shown no difference.

\section{RAYLIGH-WLNG SCATIERTNG IN A LIQUID CRYSTALLTNE MATERIAL}

David Y. S. Lin, Nabil M. Amer, and Y. Ron Shen

Light scattering as a means to probe the various dynamic properties of liquid crystalline materials has become increasingly popular recently. While most of the published work deals with scattering from low-frequency thermal flucturtions, little effort goes into studies of high-frequency fluctuations. In particular, the depolarized Rayleigh-wing scattering has received practicaliy no attention. This latter effect, which presumably arises from orientational fluctuations of individual molecules in media camposed of anisotropic molecules, has, however, Iong been the subject of extensive investigation on ordinary liquids. We have done what we believe to be the first investigation of Rayleigh-wing scattering in liquid crystalline materiais. We are particularly interested in the change of the Rayleigh-wing spectrm as the temperature varies near the isotropic-nematic phasetransition. We found that, as in ordinary: liquids, the spectrum can be decomposed into two Lorentzians, one having a half width of a few $\mathrm{cm}^{-1}$ and the other one order of magnitude broader. Both Lorentzians narrowed-

appreciably as the temperature was. lowered, but there was a sudden increase in the linewidths at the isotropic-to-nematic transition. The results are interpreted with the usial model for orientation fluctiations of individual molecules, incorporated with the sudden charge of the order parameter at the phase transition.

\section{THEORETICAL PROBLEMS}

\section{Y. Ron Shen}

a. Far Infrared Generation by Optical Mixing and Stimulated Raman Scattering via Spin-FIip Transitions in inso

Far infrared generation by optical mixing and by stimulated scattering via spin-flip transitions is treated, using the general formalism of coherent excitations of

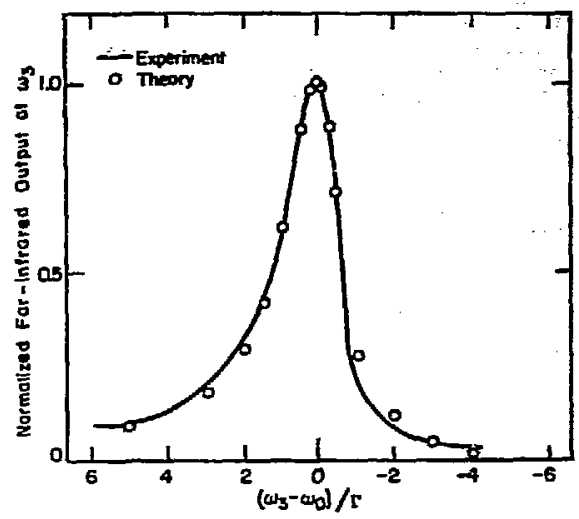

Fig. 1. Theoretical results (crosses) of normalized far infrared power output in optical mixing as a function of $\left(\omega_{3}-\omega_{n}\right) / \Gamma$ in contarison with the experimental results (arve of Ref. 1). 
polaritons. Practical numerical examples for InSb are given. The result for the case of optical mixing agrees well with the experimental result of Nguren and Bridges I (see' Fig. 1). The calculation also suggests that the infrared output from a spin-flip Raman laser should be easiiy obserubile.

1. V. T. Nguryen and T. J. Bridges, Phys. Rev. Lett. 29, 359 (1972).

b. Distinction Between Resonant Raman Scattering and tot Luminescence

With the advance of tunable lasers, resonance Raman scattering has become a subject of much imrestigation. There is, however, apparent confusion in the literature on the difference between resonance Raman scattering (RRS) and hot luminescence (HL). Recently, klein 1 showed that in some cases the resonance Raman scattering efficiency could be written as the product of the absorption coefficient and the quantun yield for hot Iuminescence. He then concluded that RRS was often equivalent to $H L$. In the literature, usually either one or the other was used to interpret the observed resonamt Raman data. 1-5. We have derived expressions for the cross-sections of RRS and ill using the density-matrix formalism wich takes into account relaxation toe to rartdom processes more properly than the golden-rule approach. We show that RRS and HL are in fact two distinct physical-processes, although they are simultaneously present in ordinary RRS experiments.

The physical differences between the two processes are quite obvious. RRS is a twophotom direct process, wile Hl is a two-step process. HL arises from radiative decay of the excess popolation pumed into the intermediate state by the exciting field, but RRS does not. The two processes have in general different lineshapes. If the exciting field is abrupty shut off, tLL should have an exponential decay corresponding to the decay of the excess population in the intermediate state, aside from the usual infuction decay. These differences can be seen more clearly in the following derivation.

1. M. V. Klein, Prys, Rev. B8, 919 (1973).

\section{RESEAROH PLANS FOR CALENDAR YEAR 1974}

Y. Ron Shen

We shall continue our research on resonant Raman scattering and luminescence in various types of semiconductors wing the $\mathrm{cw}$ tunable dye laser. We shall try to set up a pulsed dye laser system for the resonant Raman work in order to cover a larger spectral range. We plan to investigate other norlinear optical effects in liquid crystals and to measure the optical effects in a homologous series of liquid crystals. We shall start new experiments on high-intensity excitations in solids. We shall try to extend the range of wavelength-modulation spectroscopy into vacunm in. We shall also continue the measurements of nonlinear optical susceptibilities in various crystals.

\section{1973 PUBLICATIONS AND REPORTS}

Y. Ron Shen and Associates Journals

1. R, Zucca and $Y$. R. Shen, Wide-Range Wavelength Modulation Spectrometer, Appl. Opties 12, 1293 (1973) (LBL-1184).

2. S. Kohn, Y. Petroff, P. Y. Yu, and Y. R. Shen, Wavelength Modulation Spectra of PbS, PbSe, PbTe, and SnSe, J. Noninetals I, 147 (1973) (LBL-456).

3. S. Kohin, Y. Petroff, and Y. R. Shen, Wavelength Madulation Spectra of GaSe, GaS, and Alloys, S'irface Science 37, 205 (1973) (LBL-1407).

4. D. Y. Yu, Y. R. Shen, and Y. Petroff, Resonance Raman Scattering in $\mathrm{Cu}_{2} \mathrm{O}$ at the Blue and Indigo Excitons, Solid State Commications 12, 973 (1973) (LBL-1441).

5. P. Y. Yu, Y. R. Shen, and Y. Petroff, Resonance Raman Scattering at the Forbidden Yellon Exciton in $\mathrm{Cu}_{2} \mathrm{O}$, Phys. Rev. Letters 30, 283 (1973) (LBL-1192).

6. Y. R. Shen, Optical Wavelength-Modulation Spectroscopy, Surface Science 37, 522 (1973) (LBL-1402).

7. Y. Petroff, S. Kohn, and Y. R. Shen, Optical Spectra of CsI, CsBr, ZnGeP 2 , and SbSI, Surface Science 37, 540 (1973)

(LBL-1409). 
8. Geotge K. L. Wong and Y. R. Shen, OpticalField-Induced Ordering in the Isotropic

Phase of a Nematic Liquid Crystal, Phys. Rev. Letters 30, 895 (1973) (LBL-1433).

9. S. E. Kohn, P. Y. Yu, Y Petroff,

Y. R. Shen, Y. Tsang, and M. L. Cohen,

Electronic Band Structure and Optical

Properties of PoTe, PbSe, and PbS, Phys. Rev.

B ㅇ, 1477 (1973) (LBL-1132).

10. Y. Petroff, S. Kohn, and Y. R. Shen, Effect of Carriet Concentration on the

Reflectivity Spectrum of $\mathrm{Ge}$ and InSb,

Surface Science 37, 591 (1973) (LBL-1410).

11. K. H. Yang, P. L. Richards, and Y. R. Shen, Coherent Phonon Generation by Optical Mixing in a One-Dimensional Superlattice, J. App1. Phys, 44, 1417 (1973) (LBL-1889).

12. N. M. Amer and Y. R. Shen, Low-Frequency Ramen Mode in Snectic Liquid Crystals Near the Phase Transitions, Solid State Commuications 12, 263 (1973) (LBL-1156).

13. Y. R. Shen, Theory of Far Infrared Generation by Optical Mixing and Stimulated Raman Scattering via Spin-Flip Transitions in In.56, App1. Phys. Lett. 23, 516 (1973).

14. M. M. T. Loy and $Y, R$. Shen, Study of Self-Focusing and Small-Scale Filaments of Light in Nonlinear Kedia, IEEEE J. Quantum Electron. QE-9, 409 (1973) (LBL-431).

15. K. H. Yang, J. Morris, P. L. Richards and $Y$. R. Shen, Phase-Matched Generation of Tunable Far Infrared Radiation by Mixing of Tho Dye Lasers, Bull. Am. Phys. Soc. 18, 350 (1973)

16. C. Varea de Alvarez, M. L. Cohen, S. Kohn, Y. Petroff and Y. R. Shen, Electronic Structure of $\mathrm{ZnGeP}_{2}$, Bull. Am. Phys. Soc. 18, 351 (1973),

17. P. Y. Yu, Y. Petroff and Y. R. Shen, Resonance Raman Scattering in $\mathrm{Cu}_{2} \mathrm{O}$ at the Blue and Indigo Excitons, Bull. Am. Phys. Soc. 18, 411 (1973) (LBL-1446 Abs.).

18. Y. Petroff, P. Y. Yu, and Y, R. Shen, Optical Properties of BiI 3 , Bull. Am. Phys. Soc. 18, 412 (1973) (LBL-1444 Abs.).

19. P. Y. Yu and Y. R. Shen, Free Carrier Effects on the Resonance Raman Scattering of
InSb at the E1 Transition. Bull. Arr. Phys. Soc. 18, 413 (1973) (LBL-1442 Abs.) .

20. P. Y. Yu and Y. R. Shen, have Vector Dependence in the Resonance Raman Scattering of InSb Near the $E_{1}$ Transition, Bull. An. Phys. Soc. 18, 413 (1973) (LBL-1447 Abs.).

21. Y. Petroff, P. Y. Yu, and Y. R. Shen, Resonance Raman Scattering in $\mathrm{BiI}_{3}$, Bull. Am. Plys. Soc. 18, 413 (1973) (LBL-1445 Abs.).

22. G. K, L. Wong and Y. R. Shen, LaserField-Inauced Ordering in the Isotropic MBEA, Bulz. Am. Phys. Soc. 18, 437 (1973)

(LBL-1443 Ahs.).

23. D. Bethume, A. J. Schmidt, and Y. R. Shen, Dispersion of Nonlinear Optical Susceptibility $\chi^{(2)}$ (2w) of III-V Semiconductors, Bull, Am. Phys. Soc. 18, 1577 (1973) (LBL-2271 Abs.).

24. G. K. L. Wong and Y. R. Shen, Transient Self-Focusing of Iight in MBBA, Bull. Am. Phys. Soc. 18, 1588 (1973) (LBL-2262 Abs.).

25. P. Y. Yu, N. M. Amer, and Y. R. Shen, Resonant Raman Scattering in Selenium, Buli, An. Phys. Soc. 18, 1589 (1973) (LBL-2272 Abs.).

26. K. H. Yang, J. R. Mbrris, P. L. Richards, and $Y$. R. Shen, Phase-Matched Far Infrared Generation by Optical Mixing of Dye Laser Beams, Appl. Phys. Lett. 23, 669 (1973) (LBL-2226).

\section{LBL reports}

1. Y. Petroff, P. Y. Yu, and Y. R. Shen, Absorption, Photoluninescence, and Resonance Raman Scattering in BiI $I_{3}, L_{B L}-1890$, Aug. 1973.

2. Y. R. Shen, Distinction between Resonance Ramar Scattering and tot Luminescence, Jure 1973.

3. C. Y. Fong, Y. Petroff, S. Kohn, and Y. R. Shen, Wavelength-Nodulation Spectra of SbSI and Its Electronic Structure, LBL-2225, Aug. 1973.

4. P. Y. Yu and Y. R. Shen, Multiple Resonance Effects in Ranan Scattering, LBL-2290, Nov. 1973

"Hork dor 3 while on Sabbatical leave at Laboratoire d' Optique Quantique, Univ. of Paris, 1972. 

IMRD STAFF FOR 1973

Principal

Investigators

Neil Bartlett

Robert Bragg

Leo Brewer

John Clarke

Mrvin Cohen

Robert Comnick

Lee Donaghey

Ricinard Fulrath
Postdoctoral Fellows

and Other Scientists

C. Adams

D. McKee

*W. Roland

*B. Zemrva
Graduate Students

K. Leary

D. McKee

T. Richardson
K. Ankra
M. Biswal
ny. Chen
K. Danso
F. Hamzeh
R. Mishra
L. Salmon
R. Saxena
G. Bullard
J. Stiga

*C. Chang

*. Duley

*w. Smeltzer

${ }^{*} \mathrm{R}$. Dalven

M. Frommer

*G. Hawkins

J. Kruger

*G. Martinez

*. Schluter

*J. Wans

G. Hoffer

T. Hsiang

M. Ketchen

J. Paterson

M. Rappaport

L. Schwartzkopf

R. Voss

*D. Gariti

\#J. Gelikowsky

*J. Joannopolous

C. Varea de AIvarez

W. Ear1

T. Rowland

C. nright

*T. Anderson

R. Bissinger

*p. Chen

K. Geraghty

C. Manke

P. Mundkur

R. Pong

*S. Styer

G. Bandyopadhyay

*T. Basu

D. Biswas

K. Crabtree

J. Dih

J. Masaryk

J. Sherohman

D. Wang 
Principal

Investigator

Charles Harris

Ronald Herm

Ralph Hultgren

Harold Johnston

William Jolly

George Jura

Bruce Mahan
Postdoctoral Fellows

and Other Scientists

H. Brenner

*T. Gough

A. Nishimra

R. Schlupp

*H. Schuch
Graduate Students

W. Breiland

J. Brock

AA. Burrs

M. Fayer

J. Koert

4. Lewellyn

R. Panos

R. Shelby

M. Tarrasch

P. Wilday

R. Behrens

B. Earl

A. Freedman

L. Gundel

L. Loh

T. Part

c. Sholten
S. Chang
D. Fielder
E. Kamaratos
D. Martin
T. Pawkert
R. Watson
G. Whitten

J. Howdeshell

M. Lazaruts

tT. Schaaf

K. Strom
J. Birks

P. Connel1

E. Franzblau

J. Giman

R. Graham

D. Martin

औ. Nordstram

G. Streit

T. Briggs

J. Illige

W. Perry

L. Pont

J. Reed

D. Yang

T. Chen

R. Glienna

B. Jurado

W. Dimpfl

J. Fair

W. Ruska

P. Schubart

R. Terkowitz

J. IYim 
Principal

Investj gators

William Miller

J. W. Morris, Jr.

Rolf Muller

Rollie Myers

John Newinan

Donald Olander

Earl Parker

Victor Zackay

Mílton Pickus
Pastdoctoral Fellows and Other Scientists

*. Hunt

*R. Preston

*C. Sloane

*o. Weres

D. Klahn

:Y. Ohtakara

*C. Syn

J. Mathieu

A. UIIman

M. Yokota
Graduate Students

S. Augustin

B. Garrison

S. Homstein

A. Raczkowski

tP. Whitlock

"G. Zahr

I. Charo

W. Gourdin

D. Grivas

F. Hamzeh

K. Hanson

H. Hang

S. Jin

C. Kraulse

J. Sanchez

C. $5 y n$

S. Wen

B. thitaker

C. Brown

C. Ches

J. Cooper

F. McLarmon

M. Sand

T. Hynes

D. Lindiner

M. St. John

R. Hilson

J. Yarnell
P. Appel
R. Homsy
J. Miksis
C. Mohr
K. Nisancioglu

R. Acharya

*. Kruger

A. Machiels

*F. Nuh

R. Yang

B. Babu

B. Francis

K. Henachalam

L. Niwa

G. Shiflett

T. Tom 
Pr:ncipal
Investigators

Earl larker

Victor Zackay

Josepin Pask

Norman Phillips

Niilton Pickus

Paul Pichards
Postdoctoral Fellows

and Other Scientists

D. Ehandarkar

*S. Bush

*J. Evans

"G. Lai

*F. Ravitz

M. Yokota

I. Aksay

R. Langston

*C. Marumo

*G. Brodale

E. Hormung

S. Buckner

*J. Claassen
Graduate Students
*4. Adkins
B. Babu
D. Bhandarkar
M. Bhat
R. Clark
C. Ericsson
B. Francis
W. Garris on
R. Horn
S. Ivy
G. Kohn
*A. Llopis
R. Lott
H. Offer
E. Plaza
P. Puff
*J. Sanchez
G. Sasaki
E. Saur
M. Schanfein
H. Sirot
L. Thompson
T. Tom
*J. Wert
H. Wood
J. Yuen
P. Zajchowski

I. Aksay

P. Dokko

C. Hoge

G. Holmquist

*S. Risbud

iv. Snarden

T. Sweeting

C. Tao

B. Wong

S. Bader

iv. Fogle

T. Hall

*B. Krusor

G. Schwartz

M. Mn

K. Hemachalem

J. Klein

F. Reinel

R. Aurbach

R. Bailey

*J. Mather

V. Taur

W. Tenrant

D. Woody

K. Yang 
Principal

Imvestiptors

Gene Rochlin

Alan Searcy

Y. Ron Shen

Gabor Somorjai

Gareth Thomas

Charles Tobias
Postdoctoral Fellows

and Other Scientists

Graduate Students

M. Jack

D. McBride
"D. Beruto
A. Buchler
- Coyle
D. Meschi

*A. Mysyrowicz
A. Schmidt
P. Yu

k. Baron

S. Brumbach

*C. Clang

M. Chesters

*J. Deville

*J. Do11

D. Hagen

*L. Kesmodel

*. Martin

*H. Siekhaus

T. Taylor

*Y. Tsang

D. Kirkwood

*K. Schneider

$\star R$. Sinclair

๓.. Von Heimendahl
T. Basu

L. Fuke

S. Lim

P. Mohazzabi

J. Roberts

K. S::ah

D. Bethujét

14. Garrison

E. Hanson

S. Koin

Y. Lin

J. Morris

J. Stokes

K. Wong

S. Bernasek

D. Blakely

*J. Crumip

L. Firment

J. Glane

*R. Johnson

D. Kahn

C. Megerle

S. Overbury

np. Stair

J. Wasilczyk

L. Chen

*I. Chen

R. Clark

R. Gronsky

R. Hall

D. Howitt

D. Huang

J. Koo

J. Mcllahon

R. Mfiller

F. Mimirani

B. Narasimha Rao

M. Okada

G. Stone

0 . Van der Biest

R. Acosta

E. Car1son

to. Chacon

U. Landau

J. Riggs 
Principal Investigators

Jack Washburn
Postdoctoral Fellows and Other Scientists
Graduate Students

S. Alavi

T. Astrum

R. Drosd

T. Huo

R. Jecmen

T. ḱosel

J. Lira-Olivares

H. Mhaned

i. Peterson

J. Roberts

K. Seshan

A. Srivastava

K. Stolt

W. Wu 


\section{VISITING SCIENTISTS/SEMINAR SPEAKERS}

Dr. Anthany Francis, Department of Chemistry, University of I11inois Gicago, Illinois

Professor Heinz Gerischer, Institute for Physical Chemistry, Munich, Germany

Professor Oskar Glemser, Director of the Institute for Inorganic Chemistry, University of Gottingen, Gottingen, Germany

Professor Paul Hagemmuller, Structural Inorganic Ghemistry Laboratories, University of Bordealx, Bordealx, France

Professor Pudolph Hoppe, Director of the Inorganic Chemistry Institute, Justus Liebig University, Giessen, Germany

Dr. M. Jaksic, Instiute of Chemical Technology and Metallurgy, Belgrade, Yugoslavia

Dr. F. A. Kuzneisov, Deputy itirector, Institute of Inorganic Chemistry, Siberian Division of the Academy of Sciences, U.S.S.R.

Dr. Rudiger Mews, Inorganic Chemistry Institute, University of Gottingen, Gottingen, Germany

Dr. Dieter Namman, Institute fur Anorganische Chemie, Iniversitat of Dortmind, ivi cmind, West Germany

Dr. Josik Portier, Structural Inorganic Chemistry Laboratories, Iniversity of Bordealix, Bordeaux, France

Dr. Peter Robertson, Swiss Federal Institute of Technologv, Zurich, Switzerland

Professor Peter Sartori, Inorganic Chemistry Institute, The University, Aachen, Germany

Professor Martin Schmeisser, Rector of the University of Dortmund, Dortmund, Germany

Professor Fritz Seel, Director of the Inorganic Chemistry Institute, The University of the Saarland, Saarbrucken, Genmany

Dr. Friedrich 0. Sladky, Institute for Inorganic Chenistry, University of Innsbruck, Innsbruck, Austria

Dr. Alain Tressaud, Structural Inorganic Chenistry Laboratories, University of Bordeanx, Bordealux, France

Dr. Don Webster, Research Scientist, Lackheed, Palo Alto Research Laboratory, Palo Alto, California 


\section{Ph.D. Degrees}

1. IIhan A. Aksay, Diffusion and Phase Relationship Studies in the Alumina-Silica System (LBL-1403, Apri1).

2. Gautam Bandyopadhyay, Relation of Processing Parameters to the Properties of Lithium Ferrite (LBL-2263, Nov.).

3. William Lawrence Limpfl, The Dynamics of Nonreactivs Inelastic Ion-Molecule Collisions (LBL-1873, Aug.).

4. Boyd Lore1 Earl, Photochemical Studies of Alkali Halide Vapors (LBL-1866, Aug.).

5. John Louis Gland, Low Erergy Electron Diffraction and Work Function Studies of Adsorbed Organic Layers on the (100) and (111) Crystal Surface of Platinum, (LBL-1816, Sept.) .

6. Donald D. Gibler, Perfluoro Cations of the Non-Metallic Elements (LBL-1157, Apri1) .

7. Michael David Jack, Properties of Tumel Junctions with Fluorocarbon Dielectric Barriers, [I.BL-1805, Nov.].

8. Daniel Rny Kahn, The Hydrogenolysis of Cyclopropane on Platinum Stepped Single Crystals at Atmosphoyir Pzessure (LBL-1891, Sept.) .

9. Douglas R. Martin, Kinetics of Fluorescence of Sulfur Dioxide (LBL-1199, March).

10. Joseph S. Masaryk, Diffusion of Gases in (Iass (LBL-1818, May).

11. Duncan Eldridge McBride, Jr., Characterization of Metal Oxide Tumneling Barriers (LBL-1855, Sept.).

12. Douglas Edward McKee, Preparative and Structu. I Studies Involving Noble-Gas and Related Compounds (L.BL-1814, May).

13. Charles Arthur Mims, Moleculer Beam Chemistry of Alkaline Earth Atous (LBL-1159, May) .

14. Kemal Mustafa Nisancioglu, Current Distribution and Mass Transfer in Rotating Electrode Systers (LBL-1880, Sept.) .

15. Per-Erik Nordal, Nucles: Double Resonance Stuty of $\mathrm{KH}_{2} \mathrm{PO}_{4}$ (LBL-117, May).

16. Rodney M. Panos, Phosphorescence Microwave Double Resonance Studies of the Lowest Excited Triplet State of p-Dichlorobenzene (LBL-1822, Jume).

17. James L. Paterson, Pair-Quasiparticle Potential Differences in Curren-Carrying

Superconductors (LBL-1840, July).

18. Jeffrey Andrew Stokes, Havelength Modulation Spectroscopy of Some Semiconductors and Metals (LDL-1125, March).

19. Kaj Gunnar Sto1t, Computer Simulation of Frank Loop Contrast in Field Ion Images (LBL-2200, Sept.).

20. Chol Kyl Syn, The Role of Dislocation Interaction with Solute Atoms in the Strengthening of Metals (LBL-2270, Nov.).

21. Frederick John Szalkowski, Auger Electron Snectroscopy Analysis of Vanadium and Vanadium Compound Surfaces (LBL-888, Det.).

22. Han-Chumg Tsai, The Viscosity of Cesium Melal' to its Critical Temperature (LBL-1413, July). 23. Carmen Varea De Alvarez, Electronic Structure of Diamand, Zincblende and Chalcopyrite Semiconiuctors (LBL-1853, Sept.).

24. Jom S. Wimn, A Beam Study of $\mathrm{Ne}^{+}$and $\mathrm{O}^{+}\left({ }^{4} \mathrm{~S}_{3 / 2}\right)$ Scattering by Molecular Hydrogen Isotopes and Helium (LBL-1820, Jume).

\section{D.Eng. Degrees}

1. Mangalore Dilip Bhandarkar, Structure and Elevated Temperature Properties of Ferritic Alloys Strengthened by Intenmetallic Compounds (LAL-1858, Sept.).

2. Go Sasaki, Low-Tenperature Toughness of BCC Fe-Ni-Ti A1loys (LBL-1493, July).

3. Thamas Tom, Microstructural Variables and Fracture Toughness of High Strength Mo and Mo-Ni Steels (LBL-1856, Sept.).

4. Hillizan Edwin Wood, An Investigation of hetallurgical Factors which Affect whe Fracture Toughness of Ultra High Strength Steels (LBL-1474, May). 
M.S. Degrees

1. Howard E. Adkins, Structure and Properties of TRIP Steels Processed by Deformatian and Thermal Cycling (LBL-I491, April).

2. Charles Ray Brown, Interferometry of Solid Thisl Fiims (LBL-2264, Dec.).

3. Israel Frederic Charo, Corrosion Fatigue Properties of Surgical Inplant Materials

(LBL-2207, DeC.).

4. Robert Allan Clark, Structure and Properties of Fo-Mo-C Steels (LBL-1801, Jine).

5. Clyde Emest Ericsson, An Isothemal Study of Bainitic and Martensitic Transformations in

Some Low Alloy Steels Using a New Magnetic Permeability Technique (LBL-2279, Dec.).

6. Lloyd Manabu Fuke, Vaporization Studies of Strontiun Sulfate, (LBL-1832, Jima).

7. Ronald M. Horn, Influence of Heat Treatment on the Fatigue Crack Growth RAtes of a

Secondary Hardening Stee1 (LBL-2292, Dec.).

B. Jack Hovingh, Diffusion of Lantharum in Molten Uranirnn (LBL-1130, Feb.).

9. Robert $M$. Jecmen, Memory Switching Effects in As-Te-I Chalcogenide Glass (LBL-1817, July).

10. Roy Neal Lott, Evaluation of the End Quench Test as a Design Criterion (LBL-1476, June).

11. Hani Abo E1-Fotoh Mohamed, Mechanism of Pressure Welding (LBL-2510, Dec.).

12. Les1le Oga Pont, X-Ray Photoelectron Spectroscopy of Some NickeI and Iron Conpounds (LBI-1829, June).

13. Lovis Jean Salmon, Experimental Techniques for Growing Unidirectionally Solidified Oriented Eutectics (LBL-1834, June).

14. John J. Wasilczyk, Measunement of Intensities of Low Energy Electron Diffraction Beams

from Platinum Surfaces and Fran Absorbed Overlayeis (LBL-1807, Jume).

15. Wei-Kuo Wu, Determination of Loop Type in As ${ }^{+}$Implanted Silicon (LBL-1415, Feb.).

16. Harry Hung-Kwan Yip, Mass Transfer Coefficient in Packed Bed at Low Reynolds Numbers (LBL-1831, June). 